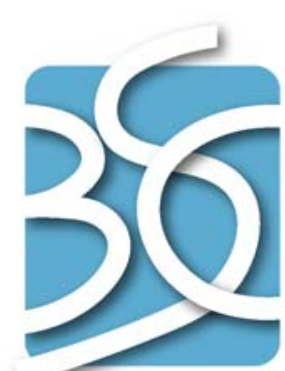

BECHTEL SAIC COMPANYLC

QA: QA

ANL-MGR-MD-000006 REV 02

September 2004

\title{
Agricultural and Environmental Input Parameters for the Biosphere Model
}

Prepared for:

U.S. Department of Energy

Office of Civilian Radioactive Waste Management

Office of Repository Development

1551 Hillshire Drive

Las Vegas, Nevada 89134-6321

Prepared by:

Bechtel SAIC Company, LLC

1180 Town Center Drive

Las Vegas, Nevada 89144

Under Contract Number

DE-AC28-01RW12101 


\section{DISCLAIMER}

This report was prepared as an account of work sponsored by an agency of the United States Government. Neither the United States Government nor any agency thereof, nor any of their employees, nor any of their contractors, subcontractors or their employees, makes any warranty, express or implied, or assumes any legal liability or responsibility for the accuracy, completeness, or any third party's use or the results of such use of any information, apparatus, product, or process disclosed, or represents that its use would not infringe privately owned rights. Reference herein to any specific commercial product, process, or service by trade name, trademark, manufacturer, or otherwise, does not necessarily constitute or imply its endorsement, recommendation, or favoring by the United States Government or any agency thereof or its contractors or subcontractors. The views and opinions of authors expressed herein do not necessarily state or reflect those of the United States Government or any agency thereof. 
Agricultural and Environmental Input Parameters for the Biosphere Model ANL-MGR-MD-000006 REV 02

September 2004 


\begin{tabular}{|c|c|l|}
\hline \multirow{2}{*}{ OCRWM } & $\begin{array}{c}\text { SCIENTIFIC ANALYSIS SIGNATURE PAGE/ } \\
\text { CHANGE HISTORY }\end{array}$ & Page iii \\
\cline { 3 - 3 } & & 1. Total Pages: 208 \\
\hline
\end{tabular}

2. Scientific Analysis Title

Agricultural and Environmental Input Parameters for the Biosphere Model

3. DI (including Revision Number)

ANL-MGR-MD-000006 Rev 02

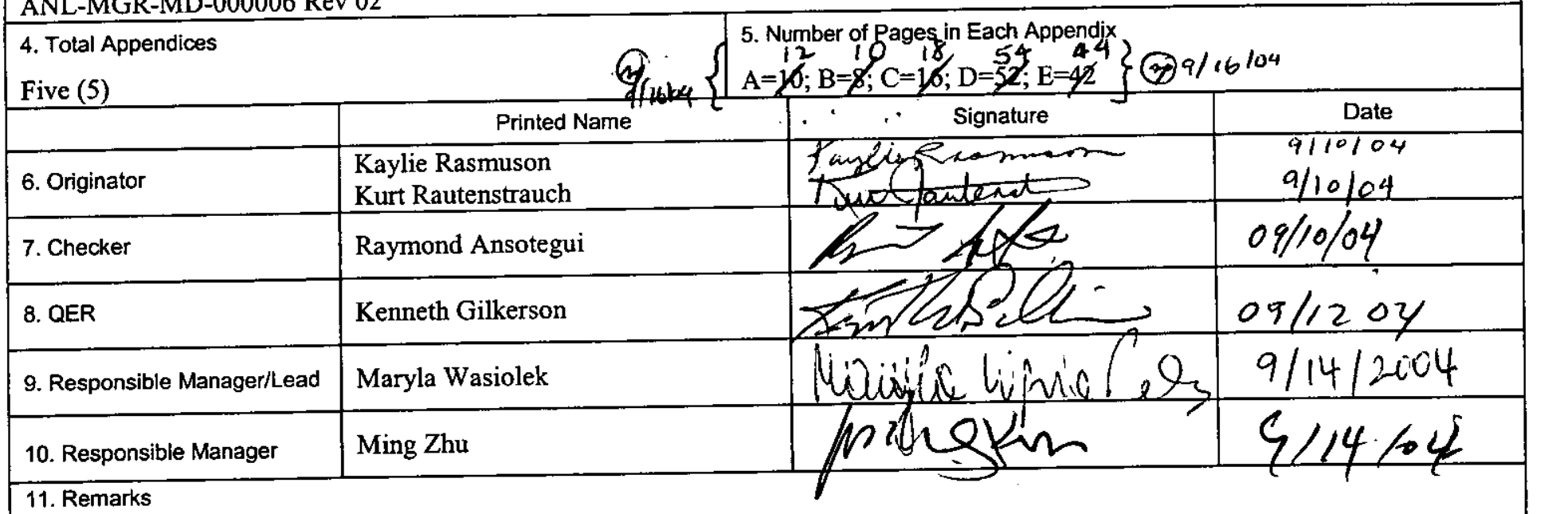

11. Remarks

\section{Change History}

\begin{tabular}{|l|l|}
\hline \multicolumn{1}{|c|}{ 12. Revision/ICN No. } & \multicolumn{1}{|c|}{ 13. Description of Change } \\
\hline REV 00 & Initial Issue. \\
\hline REV 01 ICN 00 & $\begin{array}{l}\text { Complete revision to develop parameter values for new biosphere model being used for license } \\
\text { application. Title of analysis report was changed from "Identification of Ingestion Exposure } \\
\text { Parameters" to "Agricultural and Environmental Input Parameters for the Biosphere Model." }\end{array}$ \\
\hline REV 02 & $\begin{array}{l}\text { Entire document revised to address RIT evaluation comments. Reference evapotranspiration (ET), } \\
\text { crop ET, and irrigation parameters for present-day climate were recalculated based on changes in } \\
\text { weather data for present-day climate. Updated references. Added qualification for use within } \\
\text { technical product to Section 4 for growing season data from local farmers. Added Section 7.2, } \\
\text { Satisfaction of Acceptance Criteria. Added DIRS numbers to references in text and Section 8. Added } \\
\text { justification for use of data and agricultural practices outside of the Yucca Mountain Region. } \\
\text { Incorporated changes suggested in RIT review. }\end{array}$ \\
\hline
\end{tabular}




\section{CONTENTS}

Page

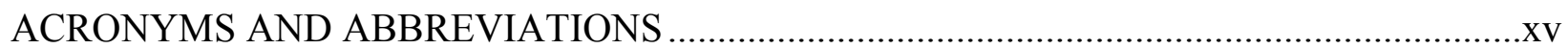

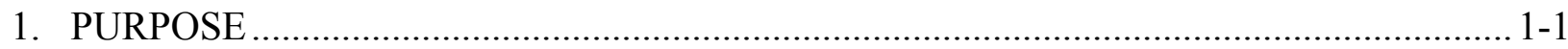

2. QUALITY ASSURANCE ..........................................................................................

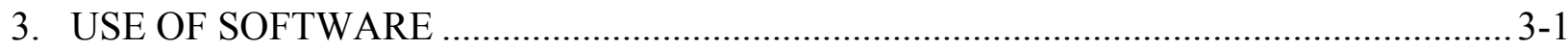

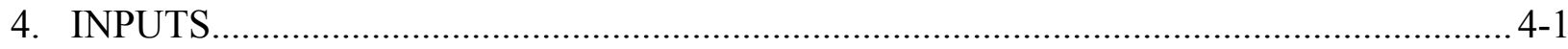

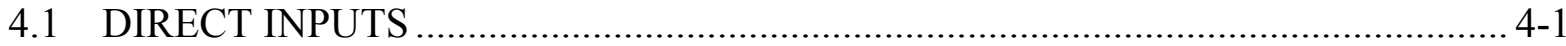

4.1.1 Water Content of Foods ..................................................................... 4-4

4.1.2 Dry-to-Wet-Weight Ratios for Cattle Forage ............................................ 4-5

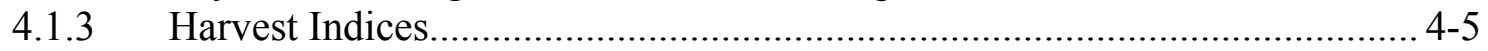

4.1.4 Growing Season .....................................................................................

4.1.4.1 Growing Season - Present-Day Climate.......................................... 4-6

4.1.4.2 Growing Season - Upper Bound Glacial Transition Climate......... 4-10

4.1.5 Climate Information............................................................................. 4-12

4.1.5.1 Present-Day Climate....................................................................... 4-12

4.1.5.2 Upper Bound Monsoon Climate................................................... 4-13

4.1.5.3 Lower Bound Glacial Transition Climate ...................................... 4-14

4.1.5.4 Upper Bound Glacial Transition Climate..................................... 4-15

4.1.6 Soil Infiltration Rate .................................................................... 4-16

4.1.7 Salinity of Irrigation Water................................................................... 4-16

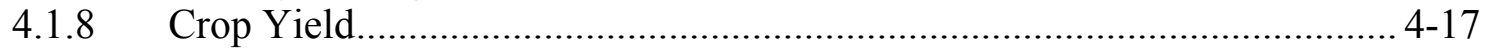

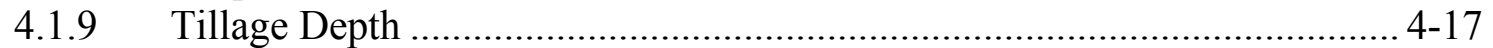

4.1.10 Irrigation Methods …………............................................................ 4-18

4.1.11 Rooting Depth..................................................................................... 4-19

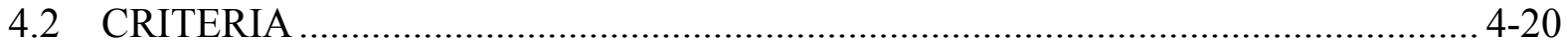

4.3 CODES, STANDARDS, AND REGULATIONS .................................................. 4-23

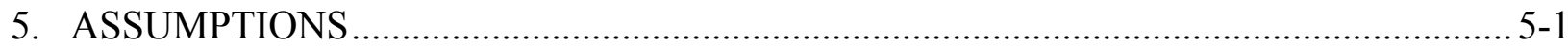

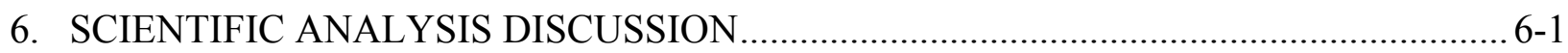

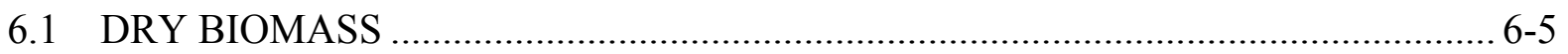

6.1.1 Use in Biosphere Model.................................................................... 6-5

6.1.2 Parameter Development...................................................................... 6-7

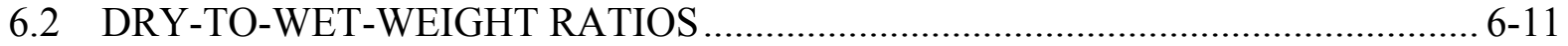

6.2.1 Use in Biosphere Model.................................................................... 6-11

6.2.2 Parameter Development............................................................................ 6-11

6.3 FRACTION OF OVERHEAD IRRIGATION ……............................................ 6-14

6.3.1 Use in Biosphere Model................................................................. 6-14

6.3.2 Parameter Development.................................................................. 6-14

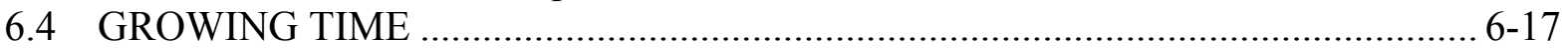




\section{CONTENTS (Continued)}

6.4.1 Use in Biosphere Model.................................................................... 6-17

6.4.2 Parameter Development................................................................... 6-17

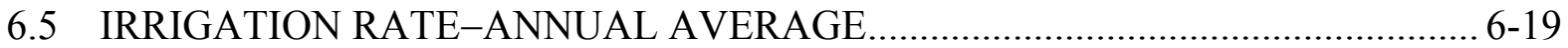

6.5.1 Use in Biosphere Model................................................................... 6-19

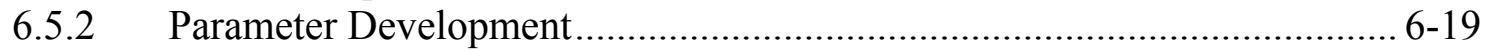

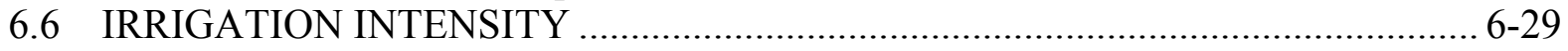

6.6.1 Use in Biosphere Model................................................................. 6-29

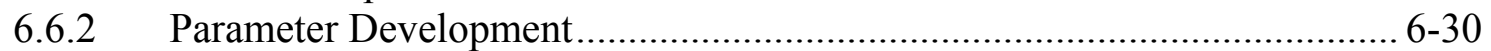

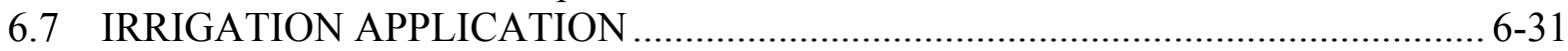

6.7.1 Use in Biosphere Model.......................................................................... 6-31

6.7.2 Parameter Development................................................................ 6-32

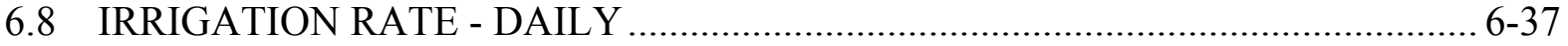

6.8.1 Use in Biosphere Model......................................................................... 6-37

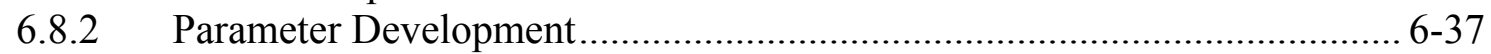

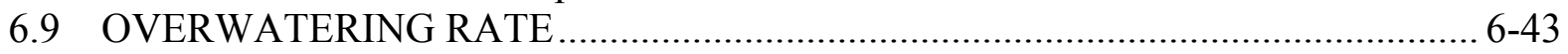

6.9.1 Use in Biosphere Model..................................................................... 6-43

6.9.2 Parameter Development.................................................................. 6-43

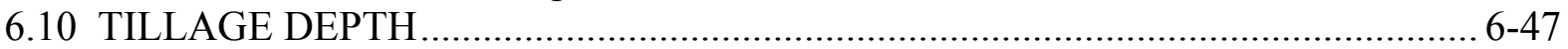

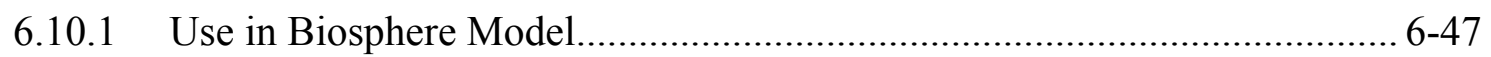

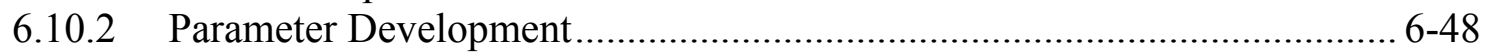

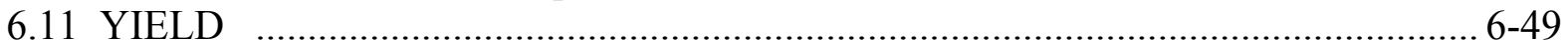

6.11.1 Use in Biosphere Model................................................................... 6-49

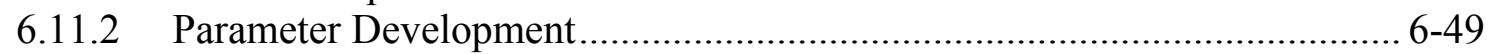

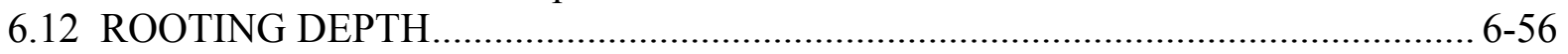

6.12.1 Use in Biosphere Model....................................................................... 6-56

6.12.2 Parameter Development.................................................................... 6-57

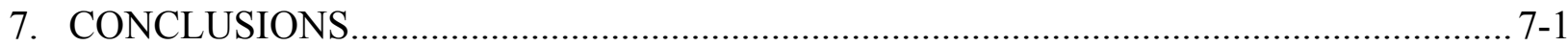

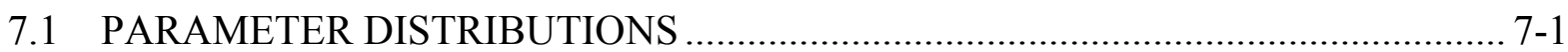

7.2 HOW THE APPLICABLE ACCEPTANCE CRITERIA ARE ADDRESSED ............. 7-5

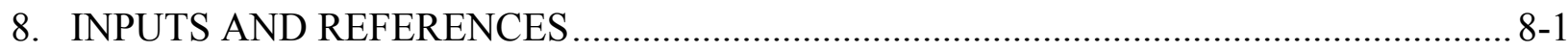

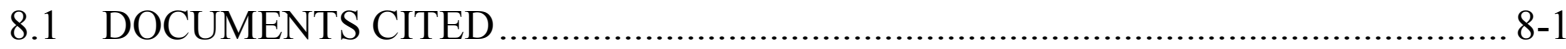

8.2 CODES, STANDARDS, REGULATIONS, AND PROCEDURES .......................... 8-11

8.3 SOURCE DATA, LISTED BY DATA TRACKING NUMBER …........................... 8-12

8.4 OUTPUT DATA, LISTED BY DATA TRACKING NUMBER ……..................... 8-12

APPENDIX A - SELECTION OF REPRESENTATIVE PLANTS ……………………........ A-1

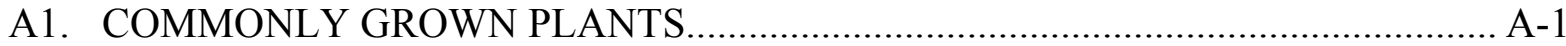

A1.1 Amargosa Valley …………………............................................... A-1

A1.2 Eastern Washington ......................................................................... A-3

A2. FOOD CONSUMPTION ………………………............................................ A-5

A3. REPRESENTATIVE CROP VALUE PARAMETERS .......................................... A-6

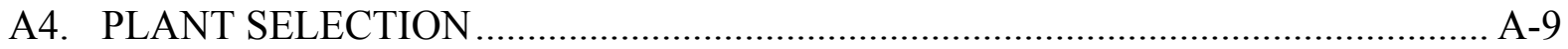




\section{CONTENTS (Continued)}

Page

APPENDIX B - JUSTIFICATION OF METHODS USED FOR CALCULATING IRRIGATION PARAMETERS …......................................................... B-1

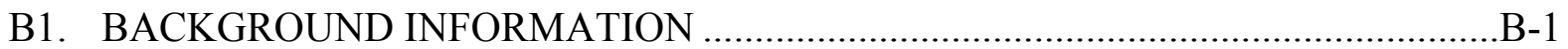

B2. JUSTIFICATION FOR USE OF FAO METHODS ..................................................

B2.1 Thornthwaite Formula ........................................................................

B2.2 Blaney-Criddle ..........................................................................

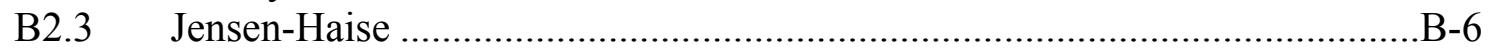

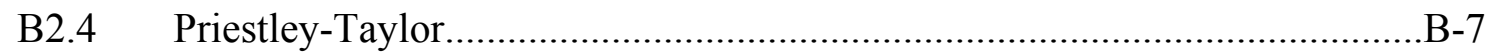

B2.5 FAO Corrected Penman....................................................................

APPENDIX C - METHODS FOR CALCULATING REFERENCE

EVAPOTRANSPIRATION …........................................................... C-1

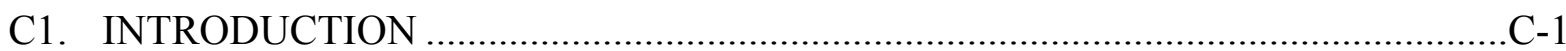

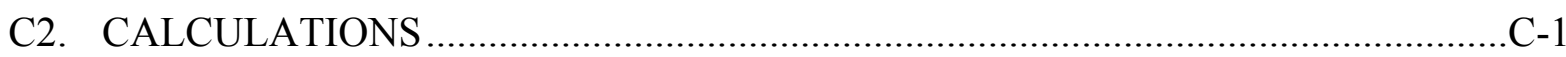

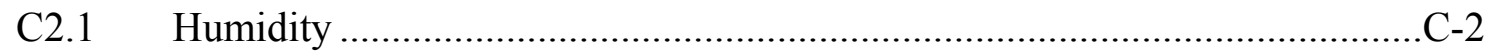

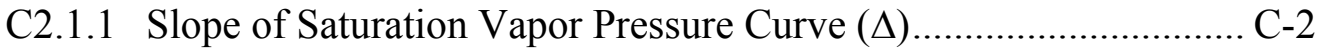

C2.1.2 Psychrometric Constant $(\gamma)$................................................ C-5

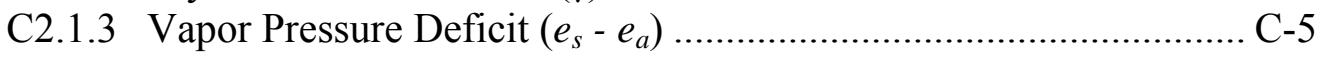

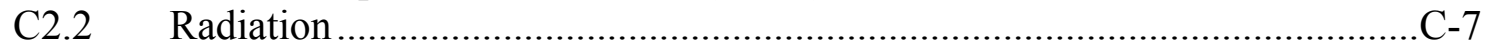

C2.2.1 Extraterrestrial Radiation $(\mathrm{Ra})$............................................... C-8

C2.2.2 Solar Radiation (Rs) ........................................................... C-11

C 2.2.3 Clear Sky Radiation (Rso) .................................................... C-12

C2.2.4 Net Solar (shortwave) Radiation (Rns) ................................... C-12

C2.2.5 Net Longwave Radiation (Rnl) .............................................. C-13

C2.2.6 Net Radiation $(\mathrm{Rn})$................................................................ C-14

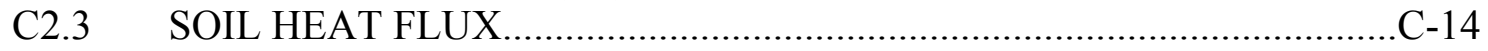

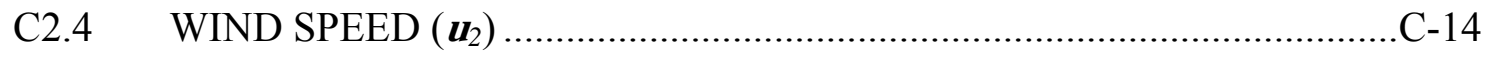

C2.5 REFERENCE EVAPOTRANSPIRATION ...........................................

APPENDIX D - METHODS FOR DERIVING CROP COEFFICIENTS AND CROP

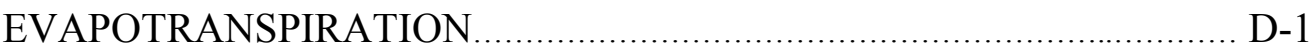

D1. INTRODUCTION …….................................................................................... D-1

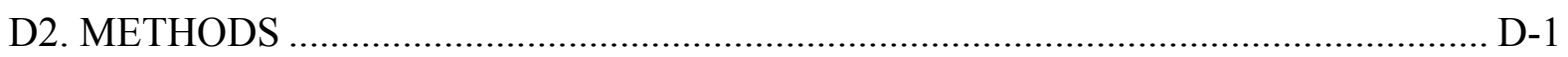

D2.1 Growing Season Lengths .............................................................. D-1

D2.1.1 Present-Day Climate.................................................................. D-1

D2.1.2 Upper Bound Glacial Transition Climate..................................... D-4

D2.2 Growth Stage Lengths.................................................................. D-7

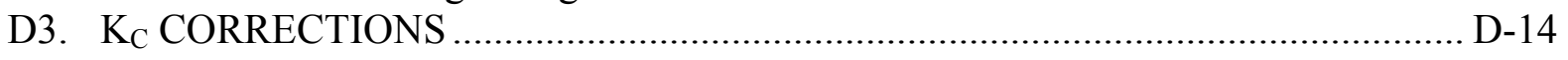

D4. AVERAGE MONTHLY K $\mathrm{K}_{\mathrm{C}}$ VALUES …........................................................ D-23

D5. CALCULATION OF CROP EVAPOTRANSPIRATION …............................... D-25 


\section{CONTENTS (Continued)}

Page

APPENDIX E - METHODS FOR DERIVING SEASONAL WATER REQUIREMENTS, LEACHING REQUIREMENTS, DEEP PERCOLATION, AND IRRIGATION APPLICATION AMOUNTS ............................ E-1

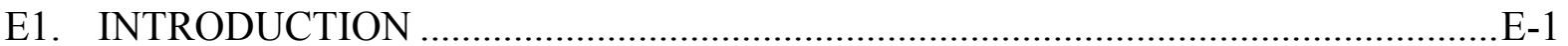

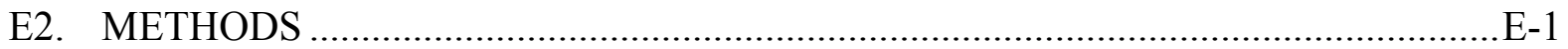

E2.1 Effective Precipitation .......................................................................... E-1

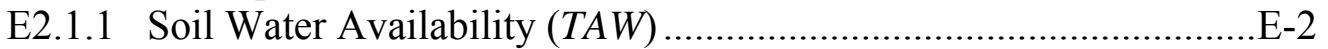

E2.1.2 Evapotranspiration/Precipitation Ratio Method for Estimating

Effective Precipitation ...................................................................16

E2.2 Stored Soil Moisture (Wb), Leaching Requirement (LR), and Deep

Percolation (DP) ........................................................................E-26

E2.2.1 Stored Soil Moisture and Deep Percolation ................................E-26

E2.3 Leaching Requirement (LR) ...............................................................

E2.4 Seasonal Water Requirements $\left(\mathrm{W}_{\mathrm{s}}\right)$, Net Irrigation Requirements

(In), Leaching Fraction (LF), and Overwatering Rate (OW) .......................

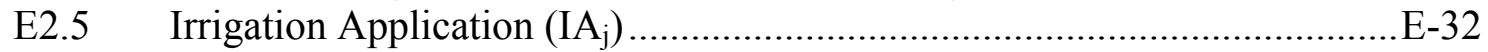

E2.5.1 Readily Available Water (RAW) .............................................

E2.5.2 Soil Water Balance Approach ......................................................E-34

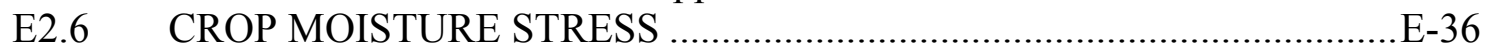

E2.6.1 Under-Watering ............................................................. 


\section{FIGURES}

Page

1-1. Documentation Hierarchy for the ERMYN ........................................................ 1-3

6.1-1. Sensitivity of Dust Interception Fraction to Dry Biomass ....................................... 6-6

6.6-1. Sensitivity of Water Interception Fraction to Irrigation Intensity ............................. 6-30

A-1. Growing Season Lengths for Representative Crops under Present-Day Climate

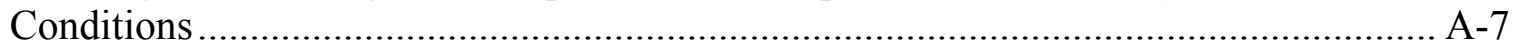

A-2. Growing Season Lengths for Representative Crops under Upper Bound Glacial Transition Climate Conditions ...................................................................................... A-8

B-1. Leaf Cross Section Showing Diffusional Pathway for Carbon Dioxide $\left(\mathrm{CO}_{2}\right)$ and

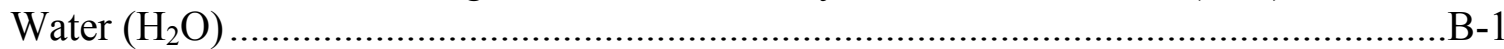

B-2. Water Potential (MPa) In Various Components of the Soil-Plant-Atmosphere System

B-3. Water Balance of a Cropped Field .............................................................................

D-1. Crop Coefficient Curve for Early Lettuce under Present-Day Climate Conditions ..... D-24 


\section{INTENTIONALLY LEFT BLANK}




\section{TABLES}

Page

1-1. Parameters and Related FEPs ............................................................................ 1-4

4.1-1. Direct Inputs Used in Analysis ................................................................................ 4-1

4.1-2. Average Monthly Weather Data for Present-Day Climate ...................................... 4-13

4.1-3. Average Monthly Weather Data for Upper Bound Monsoon Climate ......................... 4-14

4.1-4. Average Monthly Weather Data for Lower Bound Glacial Transition Climate........... 4-15

4.1-5. Average Monthly Weather Data for Upper Bound Glacial Transition Climate ........... 4-16

4.1-6. Acres Irrigated in Amargosa Valley .......................................................................... 4-18

4.1-7. Maximum Effective Rooting Depths (m) ................................................................. 4-19

4.2-1. Requirements Applicable to this Analysis ................................................................. 4-20

6-1. Representative Crops ….................................................................................. 6-2

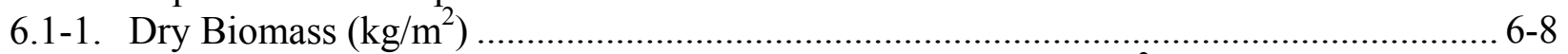

6.1-2. Averages and Cumulative Distributions for Dry Biomass $\left(\mathrm{kg} / \mathrm{m}^{2}\right)$........................... 6-9

6.2-1. Dry-to-Wet-Weight Ratios.............................................................................. 6-12

6.2-2. Averages and Cumulative Distribution Functions for Dry-to-Wet-Weight Ratios ....... 6-13

6.3-1. Recommended Distributions for Fraction of Overhead Irrigation............................... 6-15

6.4-1. Growing Time (days) ................................................................................... 6-17

6.5-1. Average Annual Irrigation Rates (IR, m/year) for 26 Crops and Turf Grass for Upper Bound Monsoon and Lower Bound Glacial Transition Climates..................... 6-22

6.5-2. Average Annual Irrigation Rates (IR, m/year) for 26 Crops and Turf Grass for Present-Day and Upper Bound Glacial Transition Climates ..................................... 6-23

6.5-3. Averages and Normal Distributions for Long-Term Average Annual Irrigation

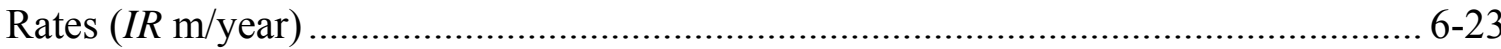

6.5-4. Averages and Cumulative Distributions for Annual Average Irrigation Rates (IR $\mathrm{m} /$ year) for Present-Day and Upper Bound Glacial Transition Climates ..................... 6-24

6.5-5. Monthly Mean Air Temperatures $\left({ }^{\circ} \mathrm{F}\right)$ for Amargosa, Nevada .................................. 6-27

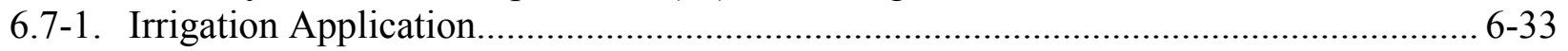

6.7-2. Averages and Cumulative Distributions for Irrigation Application $\left(I A_{j} \mathrm{~mm}\right)$ for Present-Day Climate

6.7-3. Averages and Cumulative Distributions for Irrigation Application $\left(I A_{j} \mathrm{~mm}\right)$ for Upper Bound Glacial Transition Climate ........................................................... 6-35

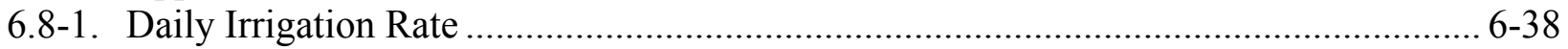

6.8-2. Recommended Cumulative Distributions for Daily Irrigation Rate $\left(I R D_{j} \mathrm{~mm} /\right.$ day $)$ for Present-Day Climate ................................................................................ 6-39

6.8-3. Averages and Cumulative Distributions for Daily Irrigation Rate $\left(I R D_{j} \mathrm{~mm} /\right.$ day $)$ for Upper Bound Glacial Transition Climate........................................................ 6-40

6.9-1. Average Overwatering Rates for 26 Crops and Turf Grass for Present-Day and Upper Bound Glacial Transition Climates.

6.9-2. Averages and Cumulative Distributions for Overwatering Rates ( $O W \mathrm{~m} /$ year) for Present-Day and Upper Bound Glacial Transition Climates 


\section{TABLES (Continued)}

6.11-1. Commercial Yield of Leafy Vegetables .................................................................. 6-51

6.11-2. Commercial Yield of Other Vegetables...................................................................... 6-52

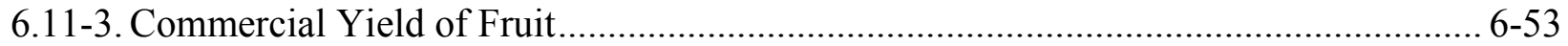

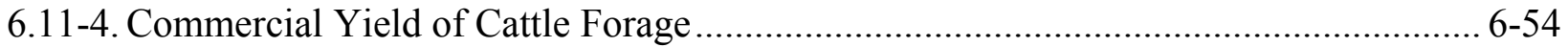

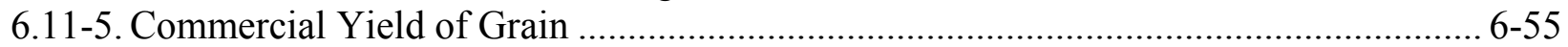

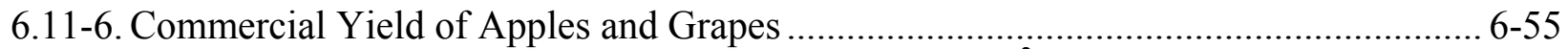

6.11-7. Averages and Cumulative Distributions for Yield $\left(\mathrm{kg} / \mathrm{m}^{2}\right)$......................................... 6-56

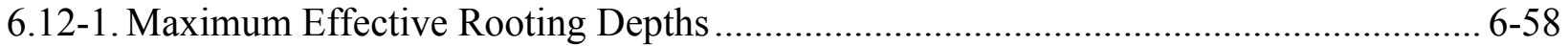

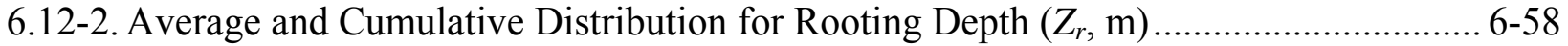

7.1-1. Recommended Distributions and Averages for Agricultural and Environmental

Parameters for the Biosphere Model...................................................................... 7-2

A-1. Acres Planted in Amargosa Valley ………………….............................................. A-1

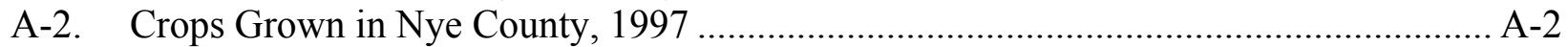

A-3. Crops grown in Spokane and Whitman Counties, Washington, 1997 ............................ A-4

A-4. Per-Capita Food Consumption................................................................................... A-5

C-1. Atmospheric Parameters for Present-Day Climate Conditions ..........................................

C-2. Atmospheric Parameters for Upper Bound Monsoon Climate Conditions ........................ -3

C-3. Atmospheric Parameters for Lower Bound Glacial Transition Climate Conditions ........C-4

C-4. Atmospheric Parameters for Upper Bound Glacial Transition Climate Conditions.........C-4

C-5. Radiation Parameters, Soil Heat Flux, and Wind Speed for Present-Day Climate

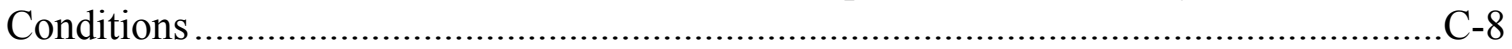

C-6. Radiation Parameters, Soil Heat Flux, and Wind Speed for Upper Bound Monsoon Climate Conditions .........................................................................................

C-7. Radiation Parameters, Soil Heat Flux, and Wind Speed for Lower Bound Glacial Transition Climate Conditions .........................................................................................

C-8. Radiation Parameters, Soil Heat Flux, and Wind Speed for Upper Bound Glacial Transition Climate Conditions.......................................................................................

C-9. Mean Monthly Reference Evapotranspiration for Present-Day, Upper Bound Monsoon, Lower Bound Glacial Transition, and Upper Bound Glacial Transition

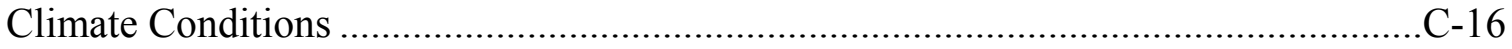

D-1. Growing Season - Present-Day and Upper Bound Monsoon Climates .......................... D-3

D-2. Growing Season - Upper and Lower Bound Glacial Transition Climates...................... D-5

D-3. Length (days) of Four Crop Growth Stages and Total Growing Season for Present-Day and Upper Bound Monsoon Climate Conditions ....................................... D-8

D-4. Length (days) of Crop Growth Stages and Total Growing Season for Lower and Upper Bound Glacial Transition Climate Conditions.................................................... D-11

D-5. Estimated Minimum Relative Humidity for Upper Bound Monsoon and Lower Bound Glacial Transition Climates..... 


\section{TABLES (Continued)}

D-6. Adjusted Crop Coefficients $\left(\mathrm{K}_{\mathrm{c}}\right)$ and Maximum Crop Height for Early and Late Season Crops for Present-Day Climate Conditions

D-7. Adjusted Crop Coefficients $\left(K_{c}\right)$ and Maximum Crop Height for Early and Late Season Crops for Upper Bound Monsoon Climate Conditions

D-8. Adjusted Crop Coefficients $\left(K_{c}\right)$ and Maximum Crop Height for Early and Late Season Crops for Lower Bound Glacial Transition Climate Conditions.

D-9. Adjusted Crop Coefficients $\left(K_{c}\right)$ and Maximum Crop Height for Early and Late Season Crops for Upper Bound Glacial Transition Climate Conditions .

D-10. Mean Monthly Crop Coefficients $\left(K_{c}\right)$, Reference Evapotranspiration $\left(E T_{o}\right)$, and Crop Evapotranspiration $\left(E T_{c}\right)$ for Present-Day Climate Conditions.

D-11. Mean Monthly Crop Coefficients $\left(K_{c}\right)$, Reference Evapotranspiration $\left(E T_{o}\right)$, and Crop Evapotranspiration $\left(E T_{c}\right)$ for Upper Bound Monsoon Climate Conditions.

D-12. Mean Monthly Crop Coefficients $\left(K_{c}\right)$, Reference Evapotranspiration $\left(E T_{o}\right)$, and Crop Evapotranspiration $\left(E T_{c}\right)$ for Lower Bound Glacial Climate Conditions

D-13. Mean Monthly Crop Coefficients $\left(K_{c}\right)$, Reference Evapotranspiration $\left(E T_{o}\right)$, and Crop Evapotranspiration $\left(E T_{c}\right)$ for Upper Bound Glacial Transition Climate Conditions......

E-1. Minimum and Maximum Rooting Depths for 26 Crops and Turf.

E-2. Mean Monthly Rooting Depths (m), Effective Storage Depths (mm), and Effective Precipitation (mm) for 26 Crops and Turf for Present-Day and Upper Bound Monsoon Climate Conditions.

E-3. Mean Monthly Rooting Depths, Effective Storage Depths, and Effective

Precipitation for 26 Crops and Turf for Upper and Lower Bound Glacial Transition Climate Conditions

E-4. Average Monthly Effective Precipitation Determined From Mean Monthly

Precipitation and Average Monthly Crop Evapotranspiration

E-5. Seasonal Water Inputs and Requirements for 26 Crops and Turf for Present-Day Climate Conditions .....

E-6. Seasonal Water Inputs and Requirements for 26 Crops and Turf for Upper Bound Monsoon Climate Conditions

E-7. Seasonal Water Inputs and Requirements for 26 Crops and Turf for Lower Bound Glacial Transition Climate Conditions

E-8. Seasonal Water Inputs and Requirements for 26 Crops and Turf for Upper Bound Glacial Transition Climate Conditions

E-9. Monthly Stored Water and Deep Percolation Totals $(\mathrm{mm})$.........................................E-28

E-10. Crop Salt Tolerance Levels $\left(E C_{e}, \mathrm{mmhos} / \mathrm{cm}\right)$ that Result in No Yield Reduction for 26 Crops and Turf.

E-11. Maximum Rooting Depths and Soil Moisture Parameters for 26 Crops and Turf........E-33

E-12. Water Balance Calculations Over the Thirty-Day Time Period Prior to Harvest for Early Season Lettuce and Present-Day Climate Conditions.

E-13. Irrigation Application for Crops under Present-Day Climate Conditions ......................E-37

E-14. Irrigation Application for Crops under Upper Bound Glacial Transition Climate Conditions...... 


\section{TABLES (Continued)}

Page

E-15. Water Balance Calculations Over the Thirty-Day Time Period Prior to Harvest with Water Witheld to Cause Crop Water-Stress …………………………….......... E-40

E-16. Reduction in Irrigation Requirement with Crop Stress for Present-Day Climate

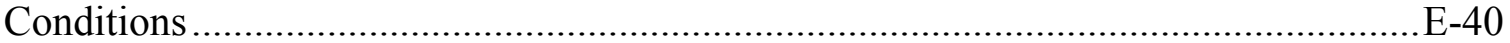

E-17. Reduction in Irrigation Requirement with Crop Stress for Upper Bound Glacial Transition Climate Conditions................................................................................... 


\section{ACRONYMS AND ABBREVIATIONS}

ARS Agricultural Research Service

BDCF biosphere dose conversion factor

ERMYN Environmental Radiation Model for Yucca Mountain Nevada

FAO Food and Agriculture Organization of the United Nations

FEPs features, events, and processes

LA license application

NASS National Agricultural Statistics Service

NOAA National Oceanic and Atmospheric Administration

NRC Nuclear Regulatory Commission

NRCS Natural Resources Conservation Service

RMEI reasonably maximally exposed individual

TSPA total system performance assessment

TWP technical work plan

USDA U.S. Department of Agriculture

USGS U.S. Geological Survey

YMP Yucca Mountain Project

YMRP Yucca Mountain Review Plan 


\section{INTENTIONALLY LEFT BLANK}




\section{PURPOSE}

This analysis is one of 10 technical reports that support the Environmental Radiation Model for Yucca Mountain Nevada (ERMYN) (i.e., the biosphere model. It documents development of agricultural and environmental input parameters for the biosphere model, and supports the use of the model to develop biosphere dose conversion factors (BDCFs). The biosphere model is one of a series of process models supporting the total system performance assessment (TSPA) for the repository at Yucca Mountain. The ERMYN provides the TSPA with the capability to perform dose assessments. A graphical representation of the documentation hierarchy for the ERMYN is presented in Figure 1-1. This figure shows the interrelationships between the major activities and their products (the analysis and model reports) that were planned in Technical Work Plan for Biosphere Modeling and Expert Support (BSC 2004 [DIRS 169573]). The Biosphere Model Report (BSC 2004 [DIRS 169460]) describes the ERMYN and its input parameters.

This analysis was conducted according to AP-SIII.9Q, Scientific Analyses, and the biosphere Technical Work Plan (BSC 2004 [DIRS 169573]). It is one of the five reports that develop input parameters for the biosphere model. This report defines and justifies values for twelve parameters required in the biosphere model that are related to the use of contaminated groundwater to irrigate crops. Values for the twelve parameters developed in this analysis are used for input to the calculations for the BDCFs for the biosphere groundwater exposure scenario (Nominal Performance Biosphere Dose Conversion Factor Analysis, BSC (2004 [DIRS 169674]), and values for five of the parameters are used for input to the calculations for the BDCFs for the volcanic ash exposure scenario (Disruptive Event Biosphere Dose Conversion Factor Analysis, BSC 2004 [DIRS 167287]) as described in Figure 1-1. The parameters support development of BDCFs for the three climate states considered in TSPA. The parameter values recommended in this report are used in the soil, plant, and carbon-14 submodels of the ERMYN (Table 1-1). The twelve parameters addressed are:

Dry Biomass $\left(\mathrm{kg} / \mathrm{m}^{2}\right), D B_{j}-$ Total, aboveground standing dry biomass for each crop type $j$.

Dry-to-Wet-Weight Ratio ( $\mathrm{kg}_{\text {dry-plant }} / \mathrm{kg}_{\text {wet-plant)}}$, $D W_{j}$-Ratio of dry to wet biomass for edible parts of plants for each crop type $j$.

Fraction of Overhead Irrigation (dimensionless), $f_{o j}$-Fraction of irrigation applied to crop type $j$ using overhead (o) methods, such as sprinklers and spray.

Growing Time (days), $t_{g, j}-$ Length of growing season(s) for crop type $j$.

Irrigation Rate-Annual Average (m/year), IR-Average amount of groundwater applied per year to irrigated lands, including cropland, gardens, and landscapes.

Irrigation Intensity (cm/hour), $I_{j}$-Rate at which groundwater is applied during sprinkler irrigation to crop type $j$.

Irrigation Application (mm), $I A_{j}-$ Amount of irrigation per application event for crop type $j$.

Irrigation Rate-Daily (mm/day), $I R D_{j}$-Daily average irrigation rate for crop type $j$ applied over all seasons. 
Overwatering Rate (m/year), $O W$-Average amount of precipitation or groundwater applied by irrigation that percolates beyond the root zone and leaches salts and radionuclides out of that zone, for all crop types.

Rooting Depth (m), $Z_{r}$ - Mean maximum effective rooting depth for all crops.

Tillage Depth (m), $T_{d}$-The depth to which soil is tilled or plowed prior to planting.

Yield $\left(\mathrm{kg}_{\mathrm{wet}} / \mathrm{m}^{2}\right), Y_{j}-$ Crop biomass or wet yield per crop type $j$.

The parameters developed in this report support treatment of twelve features, events, and processes (FEPs) addressed in the biosphere model (Table 1-1). Inclusion and treatment of FEPs in the biosphere model is described in the Biosphere Model Report (BSC 2004 [DIRS 169460], Section 6.2). Consideration of the LA FEPs List (DTN: MO0407SEPFEPLA.000 [DIRS 170760] constitutes a deviation from the Technical Work Plan for Biosphere Modeling and Expert Support (TWP) (BSC 2004 [DIRS 169573]), which referred to an earlier revision of the FEPs list (DTN: MO0307SEPFEPS4.000 [DIRS 164527]). 


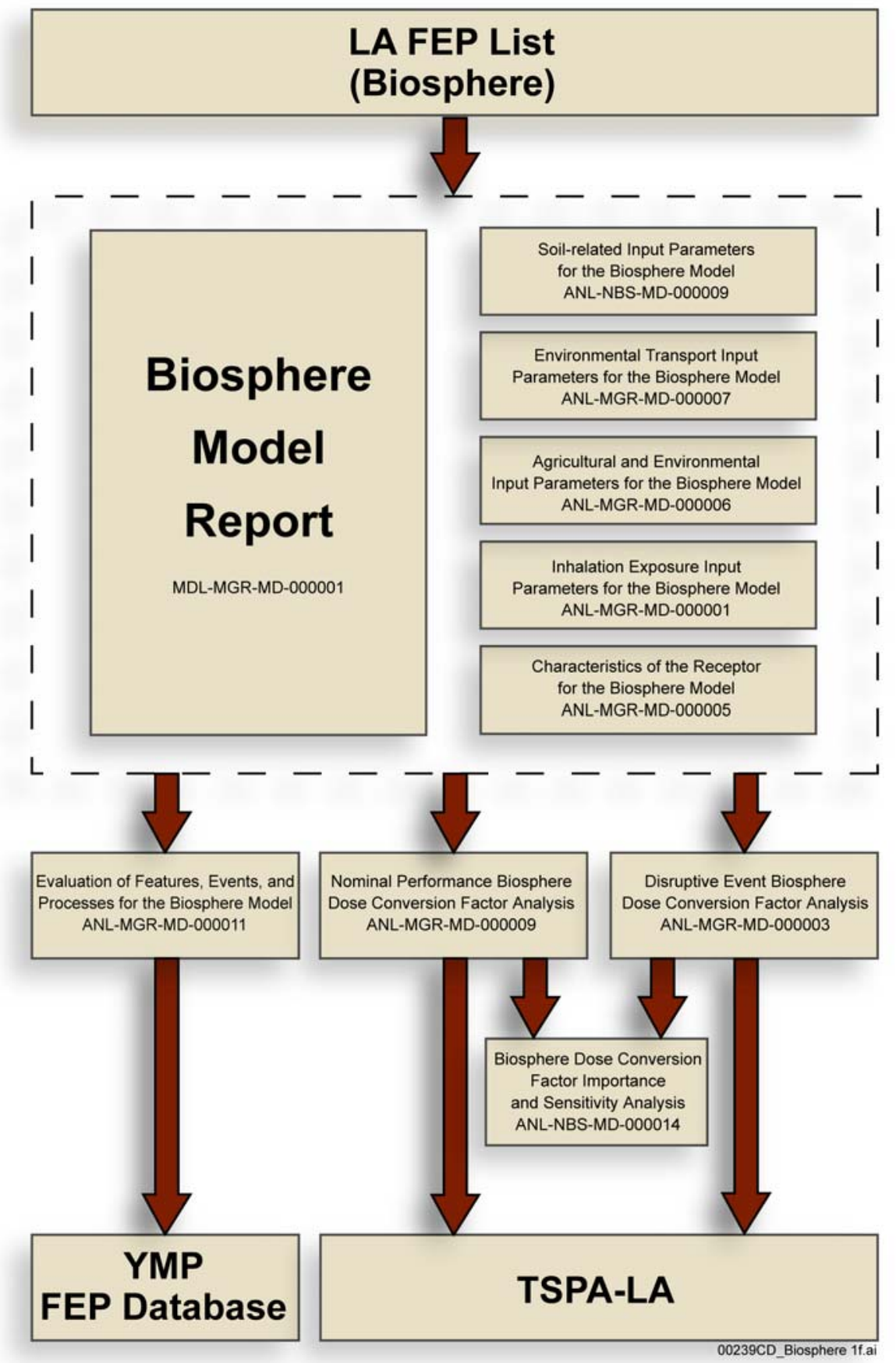

Figure 1-1. Documentation Hierarchy for the Environmental Radiation Model for Yucca Mountain Nevada 
Table 1-1. Parameters and Related FEPs

\begin{tabular}{|c|c|c|c|c|}
\hline Parameter & Related FEP & $\begin{array}{l}\text { LA FEP } \\
\text { Number }\end{array}$ & $\begin{array}{l}\text { Biosphere } \\
\text { Submodel }\end{array}$ & $\begin{array}{c}\text { Report Section } \\
\text { Summarizing } \\
\text { Disposition in } \\
\text { TSPA }^{\mathrm{a}} \\
\end{array}$ \\
\hline Dry Biomass & Plant uptake & 3.3.02.01.0A & Plant & Section 6.1 \\
\hline $\begin{array}{l}\text { Dry-to-Wet-Weight } \\
\text { Ratio }\end{array}$ & Plant uptake & 3.3.02.01.0A & Plant & Section 6.2 \\
\hline \multirow{3}{*}{$\begin{array}{l}\text { Fraction of Overhead } \\
\text { Irrigation }\end{array}$} & Water management activities & 1.4.07.01.0A & \multirow{3}{*}{ Plant } & \multirow{3}{*}{ Section 6.3} \\
\hline & Agricultural land use and irrigation & 2.4.09.01.0B & & \\
\hline & Plant uptake & 3.3.02.01.0A & & \\
\hline \multirow{4}{*}{ Growing Time } & Biosphere characteristics & 2.3.13.01.0A & \multirow{4}{*}{ Plant } & \multirow{4}{*}{ Section 6.4} \\
\hline & Agricultural land use and irrigation & 2.4.09.01.0B & & \\
\hline & Climate change & 1.3.01.00.0A & & \\
\hline & Plant uptake & 3.3.02.01.0A & & \\
\hline \multirow{6}{*}{$\begin{array}{l}\text { Irrigation Rate-Annual } \\
\text { Average }\end{array}$} & Biosphere characteristics & 2.3.13.01.0A & \multirow{6}{*}{$\begin{array}{c}\text { Soil, } \\
\text { Carbon-14 }\end{array}$} & \multirow{6}{*}{ Section 6.5} \\
\hline & Agricultural land use and irrigation & 2.4.09.01.0B & & \\
\hline & Climate change & 1.3.01.00.0A & & \\
\hline & Precipitation & 2.3.11.01.0A & & \\
\hline & Radionuclide accumulation in soils & 2.3.02.02.0A & & \\
\hline & Urban and industrial land/water use & 2.4.10.00.0A & & \\
\hline \multirow{5}{*}{ Irrigation Intensity } & Water management activities & 1.4.07.01.0A & \multirow{5}{*}{ Plant } & \multirow{5}{*}{ Section 6.6} \\
\hline & Biosphere characteristics & 2.3.13.01.0A & & \\
\hline & Agricultural land use and irrigation & 2.4.09.01.0B & & \\
\hline & Plant uptake & 3.3.02.01.0A & & \\
\hline & Soil type & 2.3.02.01.0A & & \\
\hline \multirow{5}{*}{ Irrigation Application } & Biosphere characteristics & 2.3.13.01.0A & \multirow{5}{*}{ Plant } & \multirow{5}{*}{ Section 6.7} \\
\hline & Agricultural land use and irrigation & 2.4.09.01.0B & & \\
\hline & Climate change & 1.3.01.00.0A & & \\
\hline & Precipitation & 2.3.11.01.0A & & \\
\hline & Plant uptake & 3.3.02.01.0A & & \\
\hline \multirow{5}{*}{ Irrigation Rate-Daily } & Biosphere characteristics & 2.3.13.01.0A & \multirow{5}{*}{$\begin{array}{l}\text { Plant, } \\
\text { Carbon-14 }\end{array}$} & \multirow{5}{*}{ Section 6.8} \\
\hline & Agricultural land use and irrigation & 2.4.09.01.0B & & \\
\hline & Climate change & 1.3.01.00.0A & & \\
\hline & Plant uptake & 3.3.02.01.0A & & \\
\hline & Precipitation & 2.3.11.01.0A & & \\
\hline \multirow{5}{*}{ Overwatering Rate } & Biosphere characteristics & 2.3.13.01.0A & \multirow{5}{*}{ Soil } & \multirow{5}{*}{ Section 6.9} \\
\hline & Agricultural land use and irrigation & 2.4.09.01.0B & & \\
\hline & Climate change & 1.3.01.00.0A & & \\
\hline & Precipitation & 2.3.11.01.0A & & \\
\hline & Radionuclide accumulation in soils & 2.3.02.02.0A & & \\
\hline
\end{tabular}


Table 1-1. Parameters and Related FEPs (Continued)

\begin{tabular}{|c|c|c|c|c|}
\hline Parameter & Related FEP & $\begin{array}{l}\text { LA FEP } \\
\text { Number }\end{array}$ & $\begin{array}{l}\text { Biosphere } \\
\text { Submodel }\end{array}$ & $\begin{array}{c}\text { Location of } \\
\text { Summary of } \\
\text { Disposition in } \\
\text { TSPA }^{\mathrm{a}}\end{array}$ \\
\hline \multirow{7}{*}{$\begin{array}{l}\text { Tillage Depth (surface } \\
\text { soil depth) }\end{array}$} & Radionuclide accumulation in soils & 2.3.02.02.0A & \multirow{7}{*}{$\begin{array}{c}\text { Soil, Air, } \\
\text { Carbon-14, } \\
\text { External } \\
\text { Exposure }\end{array}$} & \multirow{7}{*}{ Section 6.10} \\
\hline & Soil type & 2.3.02.01.0A & & \\
\hline & $\begin{array}{l}\text { Soil and sediment transport in the } \\
\text { biosphere }\end{array}$ & 2.3.02.03.0A & & \\
\hline & Agricultural land use and irrigation & 2.4.09.01.0B & & \\
\hline & $\begin{array}{l}\text { Atmospheric transport of } \\
\text { contaminants }\end{array}$ & 3.2.10.00.0A & & \\
\hline & Plant uptake & 3.3.02.01.0A & & \\
\hline & External exposure & 3.3.04.03.0A & & \\
\hline Yield & Plant uptake & 3.3.02.01.0A & Plant & Section 6.11 \\
\hline \multirow{6}{*}{$\begin{array}{l}\text { Rooting Depth (surface } \\
\text { soil depth) }\end{array}$} & Radionuclide accumulation in soils & 2.3.02.02.0A & \multirow{6}{*}{$\begin{array}{c}\text { Soil, Air, } \\
\text { Carbon-14, } \\
\text { External } \\
\text { Exposure }\end{array}$} & \multirow{6}{*}{ Section 6.12} \\
\hline & Soil type & 2.3.02.01.0A & & \\
\hline & $\begin{array}{l}\text { Soil and sediment transport in the } \\
\text { biosphere }\end{array}$ & 2.3.02.03.0A & & \\
\hline & $\begin{array}{l}\text { Atmospheric transport of } \\
\text { contaminants }\end{array}$ & 3.2.10.00.0A & & \\
\hline & Plant uptake & 3.3.02.01.0A & & \\
\hline & External exposure & 3.3.04.03.0A & & \\
\hline
\end{tabular}

Source: FEPs are listed in MO0407SEPFEPLA.000 [DIRS 170760].

${ }^{a}$ The effects of the related FEPs are included in the Total System Performance Assessment through the biosphere dose conversion factors. See BSC (2004 [DIRS 169460], Section 6.2), for a complete description of the inclusion and treatment of FEPs in the biosphere model. The treatment of each parameter is described in the listed sections of this report and summarized in Section 7.

$\mathrm{BDCF}=$ biosphere dose conversion factor; FEPs=features, events and processes; LA=License Application; TSPA=Total System Performance Assessment 


\section{INTENTIONALLY LEFT BLANK}




\section{QUALITY ASSURANCE}

Development of this report involves analysis of data to support performance assessment, as described in the TWP (BSC 2004 [DIRS 169573]), and thus is a quality affecting activity in accordance with AP-2.27Q, Planning for Science Activities. Approved quality assurance procedures identified in the TWP (BSC 2004 [DIRS 169573], Section 4) have been used to conduct and document the activities described in this report. Electronic data used in this analysis were controlled in accordance with the methods specified in the TWP (BSC 2004 [DIRS 169573], Section 8).

The natural barriers and items identified in the Q List (BSC 2004 [DIRS 168361]) are not pertinent to this analysis and a Safety Category per AP-2.22Q, Classification Analyses and Maintenance of the Q-List, is not applicable. 


\section{INTENTIONALLY LEFT BLANK}




\section{USE OF SOFTWARE}

The only software used to analyze data was the commercial off-the-shelf product Microsoft ${ }^{\circledR}$ Excel 97 SR-2. Standard functions of that software were used to calculate means and standard deviations for distribution development in Section 6, to develop graphs used in sensitivity analyses (Figures 6.1-1 and 6.6-1), and to manipulate data for calculation of irrigation parameters (Appendices $\mathrm{C}$ through $\mathrm{E}$ ). Uses of those functions, including formulas, algorithms, inputs, and outputs are described in the tables, figures, or associated text. 


\section{INTENTIONALLY LEFT BLANK}




\section{INPUTS}

\subsection{DIRECT INPUTS}

The technical product inputs for each parameter are described with justification below and summarized in Table 4.1-1. See the document input reference system for the status of all inputs and references.

Table 4.1-1. Direct Inputs Used in Analysis

\begin{tabular}{|c|c|c|c|}
\hline Input Data & Source & Parameter & Presented In \\
\hline Water Content of Food & USDA (2002 [DIRS 159272]) & Dry-to-Wet-Weight Ratios & Table 6.2-1 \\
\hline $\begin{array}{l}\text { Dry-to-Wet-Weight } \\
\text { Ratios (alfalfa, corn } \\
\text { silage, and oat hay) }\end{array}$ & $\begin{array}{l}\text { Till and Meyer (1983 [DIRS 101895] } \\
\text { Table 5.16, with oat hay=forage) }\end{array}$ & Dry-to-Wet-Weight Ratios & $\begin{array}{l}\text { Section } 4.1 .2 \\
\text { Table } 6.2-1\end{array}$ \\
\hline Harvest Indices & $\begin{array}{l}\text { Neitsch et al. (2002 [DIRS 163122], } \\
\text { Table A-8, pp. } 381 \text { to } 384 \text { ) }\end{array}$ & Dry Biomass & Table 6.1-1 \\
\hline $\begin{array}{l}\text { Present-Day Climate } \\
\text { Growing Seasons }\end{array}$ & $\begin{array}{l}\text { Mills et al. (no date [DIRS 124338]); } \\
\text { Call (1999 [DIRS 158672]); } \\
\text { Morris and Johnson (1991 [DIRS 103034], } \\
\text { pp. } 3 \text { and 4); } \\
\text { USDA (2002 [DIRS 159273], pp. } 16 \text { and 17); } \\
\text { Allen et al. (1998 [DIRS 157311] Table 11, } \\
\text { pp.104 to 108); } \\
\text { LeStrange (1997 [DIRS 125452] and } \\
\text { [DIRS 125429]). }\end{array}$ & $\begin{array}{l}\text { Irrigation Application } \\
\text { Irrigation Rate - Annual } \\
\text { Average } \\
\text { Irrigation Rate - Daily } \\
\text { Overwatering Rate } \\
\text { TDMS }{ }^{\text {a Parameter: }} \\
\text { Grow Time }\end{array}$ & $\begin{array}{l}\text { Section } 4.1 .4 \\
\text { Appendix } D \\
\text { Section } 2.1 .1\end{array}$ \\
\hline $\begin{array}{l}\text { Upper Bound Glacial } \\
\text { Transition Climate } \\
\text { Growing Seasons }\end{array}$ & $\begin{array}{l}\text { Washington State University Cooperative } \\
\text { Extension (2002 [DIRS 159256], p. 2); } \\
\text { Antonelli et al. (1998 [DIRS 158654], } \\
\text { Table 2); } \\
\text { Washington Agricultural Statistics Service } \\
\text { (1999 [DIRS 152232]); } \\
\text { Painter et al. (1995 [DIRS 158674], } \\
\text { Tables A1 and A4); } \\
\text { Schmierer et al. (1997 [DIRS 160479], } \\
\text { pp. } 9 \text { to 18); } \\
\text { Orloff and Marble (1997 [DIRS 158655], } \\
\text { pp. } 106 \text { to 107). }\end{array}$ & $\begin{array}{l}\text { Irrigation Application } \\
\text { Irrigation Rate - Annual } \\
\text { Average } \\
\text { Irrigation Rate - Daily } \\
\text { Overwatering Rate }\end{array}$ & Table D-2 \\
\hline $\begin{array}{l}\text { Weather - Present-Day } \\
\text { Climate Conditions }\end{array}$ & MO04019SUM9397.000 [DIRS 167054] & $\begin{array}{l}\text { Irrigation Application } \\
\text { Irrigation Rate - Annual } \\
\text { Average } \\
\text { Irrigation Rate - Daily } \\
\text { Overwatering Rate } \\
\text { TDMS }^{\text {a Parameters: }} \\
\text { Precipitation quantity } \\
\text { Relative humidity } \\
\text { Solar Flux } \\
\text { Temperature } \\
\text { Wind Speed }\end{array}$ & Table 4.1-2 \\
\hline $\begin{array}{l}\text { Weather - Upper } \\
\text { Bound Monsoon } \\
\text { Climate Conditions }\end{array}$ & $\begin{array}{l}\text { Western Regional Climate Center (2003 } \\
\text { [DIRS 162307]), (2003 [DIRS 162301]), (2003 } \\
\text { [DIRS 162302]) }\end{array}$ & $\begin{array}{l}\text { Irrigation Rate - Annual } \\
\text { Average }\end{array}$ & Table 4.1-3 \\
\hline
\end{tabular}


Table 4.1-1. Direct Inputs Used in Analysis (Continued)

\begin{tabular}{|c|c|c|c|}
\hline Input Data & Source & Parameter & Presented In \\
\hline $\begin{array}{l}\text { Weather - Lower } \\
\text { Bound Glacial } \\
\text { Transition Climate } \\
\text { Conditions }\end{array}$ & $\begin{array}{l}\text { National Weather Service (2003 } \\
\text { [DIRS 162299]); } \\
\text { Western Regional Climate Center (2003 } \\
\text { [DIRS 162302]); } \\
\text { Western Regional Climate Center (2003 } \\
\text { [DIRS 162300]). }\end{array}$ & $\begin{array}{l}\text { Irrigation Rate - Annual } \\
\text { Average }\end{array}$ & Table 4.1-4 \\
\hline $\begin{array}{l}\text { Weather - Upper } \\
\text { Bound Glacial } \\
\text { Transition Climate } \\
\text { Conditions }\end{array}$ & $\begin{array}{l}\text { Western Regional Climate Center (1997 } \\
\text { [DIRS 152233]) }\end{array}$ & $\begin{array}{l}\text { Irrigation Application } \\
\text { Irrigation Rate - Annual } \\
\text { Average } \\
\text { Irrigation Rate - Daily } \\
\text { Overwatering Rate }\end{array}$ & Table 4.1-5 \\
\hline Soil Infiltration Rate & Dollarhide (1999 [DIRS 159253]) & Irrigation Intensity & Section 6.6 \\
\hline Well Water Salinity & LA0206AM831234.001 [DIRS 160051] & $\begin{array}{l}\text { Irrigation Application } \\
\text { Irrigation Rate - Annual } \\
\text { Average } \\
\text { Irrigation Rate - Daily } \\
\text { Overwatering Rate } \\
\text { TDMS }^{\text {a Parameter: }} \\
\text { Electrical Conductivity } \\
\end{array}$ & Section 4.1 .7 \\
\hline $\begin{array}{l}\text { Crop Yield - Leafy } \\
\text { Vegetables }\end{array}$ & $\begin{array}{l}\text { USDA (1998 [DIRS 158648], Tables 4-14, } \\
\text { 4-15, 4-21, 4-22, 4-33, 4-35, and 4-54); } \\
\text { USDA (1999 [DIRS 158647], Tables 4-14, } \\
\text { 4-15, 4-21, 4-22, 4-33, 4-35, and 4-54); } \\
\text { USDA (2000 [DIRS 158646], Tables 4-14, } \\
\text { 4-15, 4-21, 4-22, 4-33, 4-35, and 4-54); } \\
\text { USDA (2001 [DIRS 158645], Tables 4-14, } \\
\text { 4-15, 4-21, 4-22, 4-34, 4-36, and 4-55). }\end{array}$ & Yield & Table $6.11-1$ \\
\hline $\begin{array}{l}\text { Crop Yield - Other } \\
\text { Vegetables }\end{array}$ & $\begin{array}{l}\text { USDA (1998 [DIRS 158648], Tables 4-18, } \\
\text { 4-26, 4-40, 4-43, and 4-47); } \\
\text { USDA (1999 [DIRS 158647], Tables 4-18, } \\
\text { 4-26, 4-40, 4-43, and 4-47); } \\
\text { USDA (2000 [DIRS 158646], Tables 4-18, } \\
\text { 4-26, 4-40, 4-43, and 4-47); } \\
\text { USDA (2001 [DIRS 158645], Tables 4-18, } \\
\text { 4-26, 4-41, 4-44, and 4-48). }\end{array}$ & Yield & Table 6.11-2 \\
\hline Crop Yield - Fruits & $\begin{array}{l}\text { USDA (1998 [DIRS 158648], Tables 4-17, } \\
\text { 4-32, 4-61, 4-73, and 5-70); } \\
\text { USDA (1999 [DIRS 158647], Tables 4-17, } \\
\text { 4-32, 4-61, 4-72, and 5-72); } \\
\text { USDA (2000 [DIRS 158646], Tables 4-17, } \\
\text { 4-32, 4-61, 4-72, and 5-72); } \\
\text { USDA (2001 [DIRS 158645], Tables 4-17, } \\
\text { 4-33, 4-62, 4-71, and 5-76). }\end{array}$ & Yield & Table 6.11-3 \\
\hline $\begin{array}{l}\text { Crop Yield - Apples } \\
\text { and Grapes }\end{array}$ & $\begin{array}{l}\text { USDA (1998 [DIRS 158649], Tables "Apples, } \\
\text { Commercial: Bearing Acreage and Yield by } \\
\text { State and United States, 1995-97" and } \\
\text { "Grapes: Bearing Acreage and Yield by Type, } \\
\text { State, and United States, 1995-97"); } \\
\text { USDA (1999 [DIRS 158650], Tables on pp. } 8 \\
\text { and 40); }\end{array}$ & Yield & Table 6.11-6 \\
\hline
\end{tabular}


Table 4.1-1. Direct Inputs Used in Analysis (Continued)

\begin{tabular}{|c|c|c|c|}
\hline Input Data & Source & Parameter & Presented In \\
\hline $\begin{array}{l}\text { Crop Yield - Apples } \\
\text { and Grapes } \\
\text { (Continued) }\end{array}$ & $\begin{array}{l}\text { USDA } 2000 \text { (DIRS 158653), Tables on pp. } 8 \\
\text { and 40; } \\
\text { USDA } 2001 \text { (DIRS 158651), Tables on pp. } 10 \\
\text { and 44; } \\
\text { USDA } 2002 \text { (DIRS 158652), Tables on pp. } 10 \\
\text { and 46. For all years, grapes = all types. }\end{array}$ & & \\
\hline $\begin{array}{l}\text { Crop Yield - Cattle } \\
\text { Forage }\end{array}$ & $\begin{array}{l}\text { USDA } 1998 \text { (DIRS 158648), Tables 1-41, 6-3, } \\
\text { and 6-4; } \\
\text { USDA } 1999 \text { (DIRS 158647), Tables 1-41, 6-3, } \\
\text { and 6-4; } \\
\text { USDA } 2000 \text { (DIRS 158646), Tables 1-41, 6-3, } \\
\text { and 6-4; } \\
\text { USDA } 2001 \text { (DIRS 158645), Tables 1-39, 6-3, } \\
\text { and 6-4. }\end{array}$ & Yield & Table 6.11-4 \\
\hline Crop Yield - Grain & $\begin{array}{l}\text { USDA } 1998 \text { (DIRS 158648), Tables 1-8, 1-40, } \\
\text { 1-50, and 1-56; } \\
\text { USDA } 1999 \text { (DIRS 158647), Tables 1-8, 1-40, } \\
\text { 1-51, and 1-57; } \\
\text { USDA } 2000 \text { (DIRS 158646), Tables 1-8, 1-39, } \\
\text { 1-51, and 1-57; } \\
\text { USDA } 2001 \text { (DIRS 158645) Tables 1-8, 1-37, } \\
\text { 1-49, and 1-55. }\end{array}$ & Yield & Table $6.11-5$ \\
\hline Tillage Depth & $\begin{array}{l}\text { Lang et al. } 1999 \text { (DIRS 160031), p. 3; } \\
\text { Granberry et al. } 2000 \text { (DIRS 160033), p. 8; } \\
\text { Johnson } 1999 \text { (DIRS 160029), Chapter 8, p. } 1 .\end{array}$ & Tillage Depth & Section 6.10 \\
\hline Irrigation Methods & $\begin{array}{l}\text { Martin et al. 1999 (DIRS 159383), 1999 } \\
\text { (DIRS 159384), } 1999 \text { (DIRS 159382); } \\
\text { Mayberry 2000 (DIRS 159386), 2000 } \\
\text { (DIRS 159388), } 2000 \text { (DIRS 159389), } 2000 \\
\text { (DIRS 160005); } \\
\text { Teegerstrom and Umeda } 2001 \text { (DIRS 159392); } \\
\text { Teegerstrom et al. } 2001 \text { (DIRS 159391); } \\
\text { Hinman et al. } 1997 \text { (DIRS 159376); } \\
\text { Klonsky and De Moura } 2001 \text { (DIRS 159381); } \\
\text { Uriu and Magness } 1967 \text { (DIRS 159169), } \\
\text { pp. } 697 \text { to 698; } \\
\text { Wolf and Johnson } 1999 \text { (DIRS 159393), p. 5; } \\
\text { MO0208SPAMETHO.004 (DIRS 159565) }\end{array}$ & $\begin{array}{l}\text { Fraction of Overhead } \\
\text { Irrigation } \\
\text { TDMS }^{\text {a }} \text { Parameter: } \\
\text { Agricultural Statistics }\end{array}$ & $\begin{array}{l}\text { Section } 6.3 \\
\text { Table } 4.1-6\end{array}$ \\
\hline Rooting Depth & $\begin{array}{l}\text { Allen et al. } 1998 \text { (DIRS 157311), Table 22, } \\
\text { pp. } 163 \text { to } 165\end{array}$ & $\begin{array}{l}\text { Rooting Depth } \\
\text { Irrigation Application } \\
\text { Irrigation Rate - Annual } \\
\text { Average } \\
\text { Irrigation Rate - Daily } \\
\text { Overwatering Rate }\end{array}$ & Table 4.1-7 \\
\hline
\end{tabular}

a TDMS=Technical Data Management System; USDA=U.S. Department of Agriculture. 
For some parameters, data and agricultural practices outside the Yucca Mountain region were selected for use. This is justified in Section 6 and Appendix A. To ensure that distributions developed from these data are consistent with conditions in the Yucca Mountain region, appropriate analogue sites were chosen or uncertainties were considered as described in Section 6 and Appendix A. All references cited in this document and listed in Section 8, other than those identified as inputs in this section, were included to support or corroborate the methods and conclusion of the analyses.

\subsubsection{Water Content of Foods}

Information on water content of foodstuffs from the USDA Nutrient Database for Standard Reference, Release 14, prepared by the U.S. Department of Agriculture (USDA) Agricultural Research Service (ARS) (USDA 2002 [DIRS 159272]) was used to calculate dry biomass and dry-to-wet-weight ratios of vegetables, fruits, and grains, as described in Sections 6.1.2 and 6.2.2, respectively. The USDA ARS is a federal government organization and considered a source of established fact data. The inputs from this established fact source are technically defensible and appropriate for this analysis for the following reasons:

- As the principal in-house research component of USDA, ARS provides the scientific expertise needed to support the work of most of the Department's action and regulatory agencies and other Federal agencies, such as the Food and Drug Administration, the U.S. Environmental Protection Agency, some components within the U.S. Department of Defense, and the U.S. Department of the Interior. For example, the Food and Nutrition Service, which administers the nutrition assistance programs of the USDA, uses data from the ARS' Continuing Survey of Food Intakes by Individuals and Diet and Health Knowledge Survey to update the thrifty food plan that, in turn, is used to monitor the effectiveness of food assistance programs by measuring the dietary status of low-income Americans, analyze the nutrient content of foods commonly eaten by low-income individuals, and develop improved methods to assess the absorption and bioavailability of key nutrients in the diets of important population subgroups.

- The ARS information is documented and substantiated in electronic databases and publications and is considered factual and suitable for quality-affecting work.

The information in USDA (2002 [DIRS 159272]) is appropriate for this analysis because it comes from a comprehensive dataset that summarizes percent water content of most representative crops, and these values can be used directly to calculate dry-to-wet-weight ratios. According to the USDA, this dataset is the major source of food composition data in the United States and provides the foundation for most food composition databases in the public and private sectors (USDA (2002 [DIRS 159272], p. 2). The data were compiled from numerous sources and the water content of most representative crops was derived from 10 to more than 200 "data points" or sources of information. The percent water contents used in parameter development are presented in Table 6.2-1. An additional external source was required for dry-to-wet-weight ratios of cattle forage because the USDA Nutrient Database for Standard Reference, Release 14 (USDA 2002 [DIRS 159272]) does not include animal forage. 


\subsubsection{Dry-to-Wet-Weight Ratios for Cattle Forage}

The reciprocal values of fresh to dry ratios for alfalfa (0.227), corn silage (0.238), and oat hay (0.182) were selected from NUREG/CR-3332, Radiological Assessment, A Textbook on Environmental Dose Analysis (Till and Meyer 1983 [DIRS 101895], Table 5.16, with oat hay $=$ grass forage). This source was published by the Nuclear Regulatory Commission (NRC). The resulting dry-to-wet-weight ratios from this source were used to develop the distribution for dry-to-wet-weight ratios for cattle forage as described in Section 6.2.2.

The NUREG/CR-3332 authored by Till and Meyer (1983 [DIRS 101895]) constitutes one of the premier textbooks used for environmental dose analysis for radionuclides. The fresh-to-dry weight ratios for cattle forage were compiled from an Agricultural Handbook from 1963 published by the USDA ARS, which is considered an established fact source (see Section 4.1.1 for source justification). The fresh-to-dry weight data for cattle forage in Till and Meyer (1983 [DIRS 101895]) have been used routinely in other radiological assessments for dose analysis (e.g., IAEA 1994 [DIRS 100458], Table 5); Kennedy and Strenge (1992 [DIRS 103776], Table 6.17); Napier et al. (1988 [DIRS 157927], Table 4.25). This additional source is necessary because the primary source for dry-to-wet-weight ratios (USDA 2002 [DIRS 159272]) does not include values for cattle forage. Use of these values, and discussions of uncertainty associated with their use, is further described in Section 6.2.2.

\subsubsection{Harvest Indices}

Aboveground dry biomass for grains, other vegetables, and fruits cannot be determined directly from yield and dry-to-wet-weight ratios because not all of the aboveground plant parts are considered edible. The non-edible parts are not included in yield and dry-to-wet-weight ratio measurements. Therefore, harvest indices were used with yield and dry-to-wet-weight ratios to calculate total above ground dry biomass for these crop types. Harvest indices are a measure of the ratio of seed, fruit, or tuber dry biomass to total aboveground dry biomass. Dividing the product of yield and dry-to-wet-weight ratio by the harvest index gives the total above ground dry biomass (i.e., biomass of fruits, leaves, and stems) for a representative crop.

Harvest index values for grains, other vegetables, and fruits reported in Neitsch et al. (2002 [DIRS 163122], Table A-8, pp. 381 through 384) were used in Section 6.1.2 to calculate total aboveground dry biomass. The methods for determining harvest indices in this source resulted in values that were appropriate for calculation of dry biomass from USDA measurements of commercial crop yield. The document contains a comprehensive list of harvest indices for the representative crops within each crop type. It is a joint publication between the USDA ARS (see source justification in Section 4.1.1) and the Texas Agricultural Experimental Station, which are considered sources of established fact data. The Texas Agricultural Experimental Station is the research extension of the land-grant system in agriculture. It is committed to basic and applied research in the areas of agriculture, life sciences, and natural resources. The agency is a leader in agricultural research nationwide and is therefore an appropriate source for this analysis. The selected harvest indices are reported in Table 6.1-1.

Harvest indices tend to be conservative unless crops are grown under extreme stress conditions, and have changed little in recent years (Prince et al. 2001 [DIRS 159323], pp. 1196 to 1197). 
Most published measurements of harvest indices for grains reviewed by Prince et al. (2001 [DIRS 159323], p. 1197) varied by no more than \pm 0.06 from the values selected for this analysis. Additionally, the distribution of dry biomass is more sensitive to variation in yield than variation in harvest indices (see Section 6.1.2). Therefore, changes in the accuracy of harvest indices has little influence on the bounds for the distributions of dry biomass for crop types. Therefore, the selected harvest indices are appropriate for this analysis. Use of these harvest indices, and discussions of uncertainty associated with their use, is further described in Section 6.1.2.

\subsubsection{Growing Season}

The following sources were used to determine the start of the growing season (i.e., planting time for annuals, initiation of growth and start of irrigation for perennials) and season length for representative crops. This information was used in Section 6.4 to determine growing time distributions. Planting period and season length were also used in the development of growth stages (initial, development, mid-season, and late-season), which define the period of time that a crop coefficient $\left(K_{c}\right)$ is used in the calculation of crop evapotranspiration (ET Mean monthly $E T_{c}$ is used to calculate the four irrigation parameters (Sections 6.5, 6.7, 6.8, and 6.9). Growing season length is also used to identify total number of growing days per month and the thirty-day period prior to harvest for each crop. This information is required for calculation of annual average irrigation rate (Section 6.5 and Appendix E), irrigation application (Section 6.7), daily average irrigation rate (Section 6.8 and Appendix E), and overwatering rate (Section 6.9 and Appendix E).

\subsubsection{Growing Season - Present-Day Climate}

Garden Crops and Turf-Information on agricultural and horticultural practices compiled by state Cooperative Extension Services was used to establish planting periods, harvest periods, and growing seasons for garden crops and turf for present-day climate conditions. Use of data from Cooperative Extension Services is technically defensible and appropriate for this analysis for the following reasons:

- Cooperative Extension Services are partnerships between state land-grant colleges and the U.S. Department of Agriculture Cooperative State Research, Education, and Extension Service, and are considered sources of established fact data. They serve as the outreach branches of state universities and the Department of Agriculture. The mission of the Cooperative Extension Services is to develop and disseminate information on agriculture, horticulture, health, environment, economics, and other topics of importance developed by the USDA and universities.

- Cooperative Extension Services are one of the most comprehensive sources of agricultural and horticultural information. No other organization summarizes and presents a wide range of site-specific information on how to grow crops and garden plants. For many garden crops, Cooperative Extension Services are the only source of site-specific information. 
- Information distributed by Cooperative Extension Services is widely used by farmers, gardeners, and homeowners. For example, in southern Nevada, pamphlets and publications are available from Nevada Cooperative Extension offices, over the internet, and from other outlets such as gardening supply stores.

- Personnel working for Cooperative Extension Services are recognized experts in agriculture, gardening, and horticulture.

The planting dates of garden crops under present-day climatic conditions at Yucca Mountain were obtained from Beginning Gardening in the Desert (Mills et al., no date [DIRS 124338]), published by the Southern Nye County Cooperative Extension. The document includes ranges of suggested planting dates for garden crops in southern Nye County, which includes Amargosa Valley. This source is appropriate because it contains information for a large selection of crops and is specific to the present-day climatic conditions in southern Nye County. These, and all other data described in this subsection, are presented in Table D-1.

Growing season lengths of garden crops for the present-day climate are derived from the Arizona Master Gardener Manual (Call 1999 [DIRS 158672]), published by the University of Arizona Cooperative Extension. Crop-specific information on pages 71 through 125 of Chapter 10 was used if available; otherwise, data from Table 10.10 was used. This source is appropriate because it contains a comprehensive list of season lengths for garden crops grown under arid to semi-arid conditions. There is no similar, comprehensive source of season lengths for garden crops in southern Nevada. This source does not include information on growing season lengths for apples, strawberries, or grapes.

Duration of home irrigation (which is only used to calculate annual average irrigation rate in Section 6.5) is from Maintaining Hybrid Bermudagrass for Urban Mojave Desert Landscapes (Morris and Johnson 1991 [DIRS 103034], pp. 3 and 4), published by the University of Nevada Cooperative Extension. This site-specific pamphlet recommends irrigating bermudagrass year-round in southern Nevada.

Feed Corn and Corn Silage-Growing seasons for feed corn and corn silage are from Nevada Agricultural Statistics 2000-2001 (USDA 2002 [DIRS 159273], pp. 16 and 17), a state office of the USDA National Agricultural Statistics Service (NASS). Use of data from this source is technically defensible, and appropriate for this analysis for the following reasons:

- The NASS is the statistical agency for the USDA, which is considered a source of established fact data. The mission of the NASS is to serve the United States, agriculture, and its rural communities by providing meaningful, accurate, and objective statistical information and services. They are responsible for conducting surveys of agricultural production and practices and reporting the results of those surveys.

- The NASS is the only organization in the United States that compiles nationwide information on commercial crop production and agricultural trends. Therefore, they are the most consistent and comprehensive, and for many topics the only source of this information. 
- USDA quality-assurance processes developed specifically for the types of surveys conducted by NASS are followed to control the accuracy of released information. Information provided by this organization therefore is suitable for quality-affecting work related to characterization of agricultural production and practices.

According to this source, corn is planted during May and June, silage is harvested in August through October, and grain corn is harvested in October and November. Because this source describes growing seasons for all of Nevada, much of which has later and longer planting times than southern Nevada, the first months listed for planting and harvest were chosen.

Apples and Strawberries-Planting date and growing season lengths for several crops, planting periods, and climatic regions are reported in Crop Evapotranspiration (Allen et al. 1998 [DIRS 157311], Table 11, p.107), a publication by the Food and Agriculture Organization of the United Nations (FAO). The growing season information for fruit orchard trees and berries from this source was used in Appendix D to establish planting dates and season lengths for apples and strawberries, respectively. The information is presented in Table D-1. This source was required because the information for apples and strawberries was not included in the primary information sources for growing season lengths used in this analysis (i.e., state Cooperative Extension Services and NASS). Information from this source is technically defensible, and appropriate for this analysis for the following reasons:

- The FAO is one of the largest specialized agencies in the United Nations system and the lead agency for agriculture and rural development, and it is considered a source of established fact data. Included in its many functions are collection, analysis, interpretation, and dissemination of information relating to nutrition, food, agriculture, forestry, and fisheries. The Organization serves as a clearing-house, providing farmers, scientists, government planners, traders and non-governmental organizations with the information they need to make rational decisions on planning, investment, marketing, research, and training.

- A series of Irrigation and Drainage Papers were written by experts in the various related fields of study and published by the FAO. Crop Evapotranspiration (Allen et al. 1998 [DIRS 157311], FAO Irrigation and Drainage Paper 56) describes comprehensive guidelines for determining crop water requirements. Planting dates and growing season lengths for several crops and several climatic zones are found in Table 11, pp. 104 to 108. Information was selected for orchard fruit trees and berries in arid climatic zones that are consistent with the current arid conditions in Amargosa Valley. This information is appropriate because the growing season information includes the appropriate climate zones, and the growing season information is reasonable for an arid climate.

Use of this growing season information and discussions of uncertainty associated with its use, is further described in Appendix D and Section 6.4. 
Grapes, Grains, and Cattle Forage-Information regarding planting and harvesting dates for grapes, barley, winter wheat, oat hay, and alfalfa in southern Nye County, Nevada are from interviews with farmers in southern Nye County (LeStrange 1997 [DIRS 125452] and 1997 [DIRS 125429]). These data were used in Appendix D to establish growing season lengths for grapes, barley, winter wheat, oat hay, and alfalfa and are presented below and in Appendix D, Section 2.1.1. This information is appropriate for this analysis because it is specific to the Yucca Mountain region. The data were obtained from sources not associated with the Yucca Mountain Project (YMP) and require qualification for use in this analysis per AP-SIII.9Q, Scientific Analysis. The following information was considered to evaluate whether the data sources were reliable and to confirm through corroboration that the data are suitable for use in this analysis.

- Reliability of Data Sources-Information on alfalfa, barley, winter wheat, and oat hay was obtained from a farmer in southern Nye County with forty years of farming experience (LeStrange 1997 [DIRS 125429]). Information on bloom and harvest dates for grapes were provided by the founder of the Pahrump Valley Vineyards in southern Nye County (LeStrange 1997 [DIRS 125452]). Grapes for several wine varieties have been successfully produced at this vineyard since 1990. The number of years that both of these sources have been farming in southern Nye County is long enough to have gained experience under a variety of conditions that might occur in the area, including drought, normal, and above average precipitation years. Their success in southern Nye County and experience are such that it is concluded that the data sources are reliable for use in this analysis.

- Availability of Corroborating Data-Because variation in planting and harvest periods among years is common for arid to semi-arid environments, ranges for average planting and harvest times are generally reported in 20 to 60 day intervals (see Table D-1 for examples). Therefore, planting and harvest dates from arid to semi-arid environments were considered to corroborate the planting and harvest dates from the local farmers if they differed by one month or less.

Alfalfa-According to the southern Nye County farmer, alfalfa irrigation begins in early February. The first cutting occurs around mid-April with six to seven cuttings per year. According to Schmierer et al. (1997 [DIRS 160479], pp. 9 through 18), and Allen et al. (1998 [DIRS 157311], Table 11, p. 107), initiation of spring growth or planting of alfalfa in semi-arid climates is recommended when temperatures are $-3{ }^{\circ} \mathrm{C}$ to $-4{ }^{\circ} \mathrm{C}$. The last harvest of the growing season should occur four to six weeks before the first killing frost (Schmierer et al. 1997 [DIRS 160479], pp. 9 through 18). Using mean monthly temperature data from Yucca Mountain meteorological monitoring Site 9 (see Section 4.1.5.1) the lowest minimum temperatures occur in January (mean minimum temperature $1.1{ }^{\circ} \mathrm{C}$ ) and December (mean minimum temperature $=0.8$ ). Because the mean minimum temperatures are not low enough for killing frosts to occur, the potential growing period for alfalfa in Amargosa Valley is January through December. Additionally, Allen et al. (1998 [DIRS 157311], Table 11, p. 107), lists January as the planting month for alfalfa in California, with an approximate time between cuttings of 60 days. This corresponds to about six cuttings per year. Therefore, the growing season information for alfalfa given by the local farmer in LeStrange (1997 [DIRS 125429]) is reasonable for an arid climate. 
Barley, winter wheat, and oats-According to the southern Nye County farmer, one crop of barley, winter wheat, and oats can be produced per year in southern Nye County. Winter wheat and barley are planted in October and harvested in June, and oats are planted in March or April and harvested in June. Usual planting and harvesting periods for field crops are provided for most states in USDA NASS (1997 [DIRS 169307]). Because the arid climates of Arizona and California are similar to that of Amargosa Valley, these two states are used as analogues to corroborate growing season information for barley, winter wheat, and oats from the local farmer. For barley, the beginning of the planting season is September 5, November 10, and September 15 for Nevada, Arizona, and California, respectively (USDA NASS 1997 [DIRS 169307], Table: Barley, Fall: Usual Planting and Harvest Dates, by State, no page). The beginning of the harvest period is July 10 for Nevada, and May 15 for Arizona and California. The dates are the same for winter wheat with the exception of California where the beginning of the planting and harvest seasons are October 20 and June 15, respectively (USDA NASS 1997 [DIRS 169307], Table: Wheat, Winter: Usual Planting and Harvest Dates, by State, no page). These planting and harvest periods are within the same month or within one month of the October planting and June harvest for barley and winter wheat provided by the local farmer. There was no information on oats for Nevada, Arizona, or California, so information provided for "other hay" is used. Only harvest information was provided for other hay. The beginning of the harvest period was June 15 for Nevada, February 15 for Arizona, and May 15 for California (USDA NASS 1997 [DIRS 169307], Table: Hay, Other: Usual Planting and Harvest Dates, by State, no page). Harvest periods beginning in June and May for Nevada and California corroborate the harvest period for oats provided by the local farmer. The harvest period beginning in February for Arizona might be due to a wider variety of other hay grown in that state. Based on the above information, the growing season data for barley, winter wheat, and oats provided by the local farmer are reasonable for an arid climate

Grapes-According to the founder of the winery, grapes bloom in March to early April and are harvested late August to early September in southern Nye County. This is corroborated by the planting period (March) and growing season length (205 days) suggested for grapes grown in California by Allen et al. (1998 [DIRS 157311], Table 11, p. 107). Therefore, the growing season information for grapes provided by the owner of the local vineyard is reasonable for an arid climate.

The data sources have several years of experience farming under conditions in southern Nye County and are considered reliable, and the data are corroborated by published, reliable sources. Therefore, it is concluded that the data are considered suitable and qualified for the specific application in this analysis.

\subsubsection{Growing Season - Upper Bound Glacial Transition Climate}

Planting season of most garden crops for upper bound glacial transition climate conditions were obtained from Vegetable Gardening (Washington State University Cooperative Extension 2002 [DIRS 159256], p. 2). This document was published by Washington State University Cooperative Extension in Spokane County, which is considered a source of established fact data (see source justification in Section 4.1.4.1). It lists ranges of suggested planting dates for garden crops in eastern Washington. This source is appropriate because it contains information for a 
large selection of garden crops and is specific to eastern Washington. These, and all other data described in this subsection, are presented in Table D-2.

Growing season length of most garden crops for future climatic conditions are from Home Gardens (Antonelli et al. 1998 [DIRS 158654], Table 2), a guide to gardening in Washington published by Washington State University Cooperative Extension, which is considered a source of established fact data. This source was selected because it contains a comprehensive list of season lengths for most garden crops grown in Washington.

Planting dates for apples, grapes, and strawberries are derived from the midpoint of the "Usual Planting Dates" in the 1999 Annual Bulletin: Usual Planting \& Harvesting Dates, Washington (Washington Agricultural Statistics Service 1999 [DIRS 152232]). This document was published by the USDA NASS, which is considered a source of established fact data (see Section 4.1.4.1 for source justification). This information was selected because it is representative of agricultural practices in Washington.

Growing season for winter wheat and spring barley are from the 1995 Crop Rotation Budgets for Eastern Whitman County, Washington (Painter et al. 1995 [DIRS 158674], Tables A1 and A4). This document was published by Washington State University Cooperative Extension, which is considered a source of established fact data. Season length was calculated as the length of time between the midpoints of planting and harvesting months. This source was selected because it provides crop- and site-specific information for the county where two future-climate analogue weather stations (Rosalia and St. Johns) are located.

Growing season for apples, grapes, strawberries, feed corn, oats, and oat hay are from the 1999 Annual Bulletin: Usual Planting \& Harvesting Dates, Washington (Washington Agricultural Statistics Service 1999 [DIRS 152232]), published by the USDA NASS. The midpoints of "Usual Planting Dates" and "Most Active Usual Harvesting Dates" are used to define planting and harvest dates, respectively. These data were selected because they are representative of agricultural practices in Washington.

Alfalfa-Growth initiation dates, final harvest dates, and cutting schedules that are typical for alfalfa grown in the Intermountain West are reported in Intermountain Alfalfa Management (Schmierer et al. 1997 [DIRS 160479], pp. 9 to 18; Orloff and Marble 1997 [DIRS 158655], pp. 106 to 107). This manual was published by the University of California Division of Agriculture and Natural Resources, which is considered a source of, established fact data. The intent of the manual was to provide a comprehensive guide to alfalfa production and management that could be used by growers, advisors, and consultants. The growing season information for alfalfa from this source was used in Appendix D to establish cut schedules and growing season lengths for alfalfa and in Section 6.4 to develop the growing time distribution for cattle forage. This source was required because information on alfalfa was not included in the primary data sources for growing season lengths used in this analysis (i.e., state Cooperative Extension Services and the USDA NASS).

Initiation of growth and cutting schedules for alfalfa from Intermountain Alfalfa Management (Schmierer et al. 1997 [DIRS 160479], pp. 9 to 18; Orloff and Marble 1997 [DIRS 158655], pp.106 to 107) are for conditions that are similar to those in eastern Washington (upper bound 
glacial transition climate analogue). Recommendations for initiation of spring growth or planting, and the last harvest of the growing season are based on temperatures (Schmierer et al. 1997 [DIRS 160479] pp. 9 to 18) and are corroborated by Allen et al. (1998 [DIRS 157311], Table 11, p. 107). This allows the use of future climate information (Section 4.1.5) to determine appropriate dates for initiation of spring growth and the date of the last harvest. This is an appropriate source because it provides information that can be used with site specific data to determine initiation of growth and harvest dates, and it is corroborated by another published and technically defensible source (Allen et al. 1998 [DIRS 157311]), see Section 4.1.4.1 for source justification). Use of this information, and discussions of uncertainty associated its use, is further described in Appendix D and Section 6.4.

\subsubsection{Climate Information}

The primary source for climate information for future climate states (see introduction to Section 6 for descriptions of future climate analogues [upper bound monsoon, lower bound of the glacial transition, and upper bound of the glacial transition]) is the National Oceanic and Atmospheric Administration (NOAA) and its agencies (e.g., National Climatic Data Center and the Western Regional Climate Center). This source is appropriate because the National Climatic Data Center serves as the repository for all NOAA meteorological information collected routinely from governmental agencies (e.g., Department for Commerce and Department of Defense) and private sources (e.g., National Cooperative Observer Program) and is considered a source of established fact data. The meteorological information undergoes quality control processing before being made available for public, private, or commercial use. This organization is recognized as the best source of national meteorological data by all agencies of the United States Government, and the data are accepted in the United States courts as interpreted by qualified experts. Weather data are used in Appendices $\mathrm{C}$ and $\mathrm{E}$.

\subsubsection{Present-Day Climate}

Climate data collected at Yucca Mountain meteorological monitoring Site 9, were used to calculate reference evapotranspiration $\left(E T_{o}\right.$, see Appendix $\left.C\right)$ for present-day climatic conditions (i.e., present-day) at Yucca Mountain. This site is at an elevation of $838 \mathrm{~m}$ (2,750 feet) (CRWMS M\&O 1999 [DIRS 102877], Table 1-1 on p. 6), near the southwestern corner of the Nevada Test Site at the approximate boundary of the accessible environment defined in 10 CFR 63.302 [DIRS 156605]. Measurements of annual precipitation used in the biosphere model for the present-day climate were lower than those considered in the modeling of infiltration rates at Yucca Mountain (e.g., BSC 2004 [DIRS 170007], Table 6-8) because the location of the reasonably maximally exposed individual (RMEI) required by 10 CFR 63.312(a) [DIRS 156605] is at a lower elevation than the area of water infiltration above the repository. The location of the RMEI was used as the point of measurement for precipitation data to satisfy 10 CFR 63.102(i) [DIRS 156605] which states in part that "The environment inhabited by the RMEI, along with associated human exposure pathways and parameters, make up the reference biosphere, as described in section 63.305." The following data were used: mean, minimum, and maximum temperature; minimum and maximum relative humidity; solar radiation; mean precipitation; and mean wind speed (DTN: MO04019SUM9397.000 [DIRS 167054]). Average monthly values were based on five years (1993-1997) of data with the following exceptions: For June, mean temperatures, average minimum temperatures, average maximum relative humidity, and average 
wind speed were based on four years of data (1994 - 1997). For July, mean temperatures and average minimum temperatures were based on four years of data (1994-1997). The data collection and analysis methods are described in BSC (2004 [DIRS 167055]). These data are appropriate because they were collected at the southernmost Yucca Mountain meteorological site, located in the valley bottom in northern Amargosa Valley and therefore are consistent with the current arid conditions of the Yucca Mountain region. The data are presented in Table 4.1-2.

Table 4.1-2. Average Monthly Weather Data for Present-Day Climate

\begin{tabular}{|c|c|c|c|c|c|c|c|c|}
\hline \multirow[b]{2}{*}{ Month } & \multicolumn{3}{|c|}{$\begin{array}{c}\text { Temperature }^{\mathrm{a}} \\
\left({ }^{\circ} \mathrm{C}\right)\end{array}$} & \multicolumn{2}{|c|}{$\begin{array}{c}\text { Relative Humidity }{ }^{\mathrm{a}} \\
(\%)\end{array}$} & \multirow{2}{*}{$\begin{array}{c}\text { Solar } \\
\text { Radiation }^{\mathrm{a}} \\
\text { (MJ/m } / \mathrm{day})^{\text {(MJay }}\end{array}$} & \multirow{2}{*}{$\begin{array}{l}\text { Wind } \\
\text { Speed }^{a} \\
(\mathrm{~m} / \mathrm{s})\end{array}$} & \multirow{2}{*}{$\begin{array}{c}\text { Precipitation } \\
(\mathrm{mm})\end{array}$} \\
\hline & Mean & Max & Min & Max & Min & & & \\
\hline January & 7.0 & 13.5 & 1.1 & 62.2 & 39.1 & 9.6 & 3.9 & 23.4 \\
\hline February & 9.6 & 16.5 & 3.0 & 55.2 & 27.6 & 13.9 & 4.3 & 17.1 \\
\hline March & 13.6 & 21.5 & 5.8 & 48.3 & 19.9 & 19.5 & 4.4 & 11.7 \\
\hline April & 16.7 & 24.6 & 8.0 & 37.9 & 13.7 & 24.6 & 4.7 & 3.0 \\
\hline May & 22.1 & 30.1 & 12.9 & 38.7 & 14.1 & 27.5 & 4.6 & 5.6 \\
\hline June & 27.3 & 35.3 & 16.8 & 27.2 & 8.7 & 30.0 & 4.9 & 7.6 \\
\hline July & 31.2 & 39.2 & 21.1 & 23.9 & 7.3 & 29.6 & 4.5 & 0.5 \\
\hline August & 30.5 & 38.9 & 21.0 & 24.2 & 8.0 & 27.0 & 4.7 & 0.3 \\
\hline September & 25.4 & 33.8 & 16.8 & 30.5 & 11.3 & 22.8 & 4.4 & 9.1 \\
\hline October & 17.7 & 25.9 & 9.7 & 33.3 & 13.8 & 17.4 & 4.2 & 5.4 \\
\hline November & 10.6 & 18.3 & 3.7 & 47.6 & 23.4 & 11.9 & 4.0 & 7.1 \\
\hline December & 6.9 & 13.9 & 0.8 & 54.4 & 28.0 & 9.6 & 4.0 & 11.7 \\
\hline
\end{tabular}

Source DTN: MO04019SUM9397.000 [DIRS 167054]. Weather data collection and summary methods are in BSC (2004 [DIRS 167055]).

a Data were collected at Yucca Mountain Meteorological Monitoring Site 9.

\subsubsection{Upper Bound Monsoon Climate}

Information from Nogales and Tucson, Arizona weather stations were used to calculate $E T_{o}$ for the upper bound monsoon climate. Average monthly values were based on eight (wind speed) and 29 (remaining variables) years of information for Nogales, and 48 years of information for Tucson. Mean, minimum, and maximum temperature, mean precipitation, and mean wind speed were used from Nogales. Mean sunshine duration was used from Tucson. This information is appropriate because it is from the upper bound monsoon climate analogue weather station having the longest and most complete record (BSC 2004 [DIRS 170002], Table 6-1 and Section 6.6.2) and from a nearby weather station. The information for both sites was obtained from the Western Regional Climate Center (2003 [DIRS 162307]), (2003 [DIRS 162301]), and (2003 [DIRS 162302]), which is cooperatively run by the Desert Research Institute of the University of Nevada, Reno, and the National Climatic Data Center of the NOAA. The information is presented in Table 4.1-3. 
Table 4.1-3. Average Monthly Weather Data for Upper Bound Monsoon Climate

\begin{tabular}{|c|c|c|c|c|c|c|}
\hline \multirow[b]{2}{*}{ Month } & \multicolumn{3}{|c|}{$\begin{array}{c}\text { Temperature }^{\mathrm{a}} \\
\left({ }^{\circ} \mathrm{C}\right)\end{array}$} & \multirow{2}{*}{$\begin{array}{c}\text { Percent of } \\
\text { Possible } \\
\text { Sunshine }\end{array}$} & \multirow{2}{*}{$\begin{array}{c}\text { Wind Speed }^{b} \\
(\mathrm{~m} / \mathrm{s})\end{array}$} & \multirow{2}{*}{$\begin{array}{c}\text { Precipitation }^{\mathrm{c}} \\
(\mathrm{mm})\end{array}$} \\
\hline & Mean & $\operatorname{Max}$ & Min & & & \\
\hline January & 7.5 & 17.7 & -2.7 & 80 & 2.01 & 33.3 \\
\hline February & 9.2 & 19.5 & -1.2 & 82 & 2.95 & 27.7 \\
\hline March & 11.5 & 21.8 & 1.1 & 86 & 3.00 & 25.4 \\
\hline April & 14.7 & 25.7 & 3.6 & 92 & 2.95 & 12.4 \\
\hline May & 18.7 & 30.1 & 7.3 & 93 & 3.04 & 8.1 \\
\hline June & 23.9 & 35.4 & 12.4 & 93 & 2.95 & 13.7 \\
\hline July & 26.1 & 34.6 & 17.5 & 78 & 2.32 & 108.5 \\
\hline August & 25.3 & 33.4 & 17.2 & 80 & 2.06 & 107.7 \\
\hline September & 22.8 & 32.3 & 13.2 & 87 & 2.24 & 42.7 \\
\hline October & 17.1 & 27.8 & 6.4 & 88 & 2.46 & 46.7 \\
\hline November & 11.2 & 22.0 & 0.3 & 85 & 1.92 & 19.8 \\
\hline December & 7.8 & 18.1 & -2.4 & 79 & 2.24 & 37.3 \\
\hline
\end{tabular}

Sources: Western Regional Climate Center (2003 [DIRS 162307] [temperature and precipitation from Nogales, Arizona]), (2003 [DIRS 162301] [percent of possible sunshine from Tucson, Arizona]), and (2003 [DIRS 162302] [wind speed from Nogales, Arizona]).

a Temperature was converted from ${ }^{\circ} \mathrm{F}$ to ${ }^{\circ} \mathrm{C}\left({ }^{\circ} \mathrm{C}=\left[{ }^{\circ} \mathrm{F}-32\right] / 1.8\right)$.

b Wind speed was converted from $\mathrm{mph}$ to $\mathrm{m} / \mathrm{s}(\mathrm{m} / \mathrm{s}=0.447 \mathrm{mph})$.

${ }^{c}$ Precipitation was converted from inches to millimeters $(\mathrm{mm}=$ inches $\times 2.54 \times 10)$.

\subsubsection{Lower Bound Glacial Transition Climate}

Information from Delta, Utah and Milford, Utah weather stations was used to calculate $E T_{o}$ for the lower bound glacial transition climate. Average monthly values based on 30 years of information for Delta and eight years of information for Milford were used. Mean minimum, and maximum temperature, mean dewpoint temperature, and mean precipitation were used from Delta. Mean temperature was calculated from the mean minimum and mean maximum temperatures. Mean sunshine duration and mean wind speed were used from Milford. This information is appropriate because it is from the future-climate analogue weather station having the longest and most complete record (BSC 2004 [DIRS 170002], Table 6-1 and Section 6.6.2) and from a nearby weather station. The information for Delta was obtained from the National Weather Service (2003 [DIRS 162299]) and the Western Regional Climate Center (2003 [DIRS 162302]). The information for Milford was obtained from the Western Regional Climate Center (2003 [DIRS 162300]). The information is presented in Table 4.1-4. 
Table 4.1-4. Average Monthly Weather Data for Lower Bound Glacial Transition Climate

\begin{tabular}{|c|c|c|c|c|c|c|c|}
\hline \multirow[b]{2}{*}{ Month } & \multicolumn{3}{|c|}{$\begin{array}{c}\text { Temperature }^{\mathrm{a}} \\
\left({ }^{\circ} \mathrm{C}\right)\end{array}$} & \multirow{2}{*}{$\begin{array}{l}\text { Monthly Dew } \\
\text { Point } \\
\text { Temperature }^{\mathrm{a}} \\
\left({ }^{\circ} \mathrm{C}\right)\end{array}$} & \multirow{2}{*}{$\begin{array}{l}\text { Percent of } \\
\text { Possible } \\
\text { Sunshine }\end{array}$} & \multirow{2}{*}{$\begin{array}{c}\text { Wind Speed } \\
\text { (m/s) }\end{array}$} & \multirow{2}{*}{$\begin{array}{c}\text { Precipitation } \\
(\mathrm{mm})\end{array}$} \\
\hline & Mean $^{b}$ & Max & Min & & & & \\
\hline January & -3.1 & 3.9 & -10.0 & -8.3 & 58 & 4.87 & 15.7 \\
\hline February & -0.3 & 6.7 & -7.2 & -6.7 & 64 & 4.74 & 14.5 \\
\hline March & 4.2 & 11.7 & -3.3 & -5.6 & 63 & 5.10 & 20.8 \\
\hline April & 9.7 & 17.8 & 1.7 & -1.7 & 69 & 5.05 & 20.1 \\
\hline May & 14.7 & 23.3 & 6.1 & 1.1 & 73 & 5.45 & 21.3 \\
\hline June & 19.4 & 28.9 & 10.0 & 1.7 & 82 & 5.54 & 12.7 \\
\hline July & 24.7 & 34.4 & 15.0 & 7.8 & 77 & 5.36 & 6.6 \\
\hline August & 23.6 & 33.3 & 13.9 & 5.6 & 79 & 4.92 & 10.7 \\
\hline September & 18.3 & 28.3 & 8.3 & 2.8 & 80 & 4.43 & 10.4 \\
\hline October & 11.1 & 20.0 & 2.2 & -0.6 & 76 & 4.65 & 20.8 \\
\hline November & 2.8 & 10.6 & -5.0 & -3.9 & 62 & 4.20 & 11.4 \\
\hline December & -1.4 & 5.6 & -8.3 & -6.7 & 60 & 4.38 & 16.8 \\
\hline
\end{tabular}

Sources: National Weather Service (2003 [DIRS 162299] [temperatures and precipitation from Delta, Utah]); Western Regional Climate Center (2003 [DIRS 162302] [wind speed from Milford, Utah]); Western Regional Climate Center (2003 [DIRS 162300] [percent of possible sunshine from Milford, Utah]).

a Temperature was converted from ${ }^{\circ} \mathrm{F}$ to ${ }^{\circ} \mathrm{C}\left({ }^{\circ} \mathrm{C}=\left[{ }^{\circ} \mathrm{F}-32\right] / 1.8\right)$.

b Mean temperature was calculated from the maximum and minimum temperatures.

${ }^{c}$ Wind speed was converted from $\mathrm{mph}$ to $\mathrm{m} / \mathrm{s}(\mathrm{m} / \mathrm{s}=0.447 \mathrm{mph})$.

${ }^{d}$ Precipitation was converted from inches to millimeters $(\mathrm{mm}=$ inches $\times 2.54 \times 10)$.

\subsubsection{Upper Bound Glacial Transition Climate}

Average monthly values based on 36 to 48 years of weather information collected at the Spokane International Airport were used to calculate $E T_{o}$ for the upper bound of the glacial transition climate (see Appendix C). The following information was used: mean, minimum, and maximum temperature; mean, minimum, and maximum relative humidity; mean sunshine duration; mean wind speed; and mean precipitation. This information is appropriate because it is from the future-climate analogue weather station having the longest and most complete record (BSC 2004 [DIRS 170002], Table 6-1 and Section 6.6.2). The information was obtained from the Western Regional Climate Center (1997 [DIRS 152233]), which is cooperatively run by the Desert Research Institute of the University of Nevada, Reno, and the National Climatic Data Center of the NOAA. The weather information is presented in Table 4.1-5. 
Table 4.1-5. Average Monthly Weather Data for Upper Bound Glacial Transition Climate

\begin{tabular}{|c|c|c|c|c|c|c|c|c|}
\hline \multirow[b]{2}{*}{ Month } & \multicolumn{3}{|c|}{$\begin{array}{c}\text { Temperature }^{\mathrm{a}} \\
\left({ }^{\circ} \mathrm{C}\right)\end{array}$} & \multicolumn{2}{|c|}{$\begin{array}{c}\text { Relative } \\
\text { Humidity (\%) } \\
\end{array}$} & \multirow{2}{*}{$\begin{array}{c}\text { Percent of } \\
\text { Possible } \\
\text { Sunshine }\end{array}$} & \multirow{2}{*}{$\begin{array}{l}\text { Wind } \\
\text { Speed }^{b} \\
(\mathrm{~m} / \mathrm{s})\end{array}$} & \multirow{2}{*}{$\begin{array}{c}\text { Precipitation } \\
(\mathrm{mm})\end{array}$} \\
\hline & Mean & $\operatorname{Max}$ & Min & Max & Min & & & \\
\hline January & -2.7 & 0.7 & -6.2 & 86 & 79 & 28 & 3.93 & 50.3 \\
\hline February & 0.7 & 4.8 & -3.4 & 85 & 69 & 41 & 4.11 & 37.8 \\
\hline March & 3.7 & 8.7 & -1.3 & 81 & 54 & 55 & 4.29 & 37.8 \\
\hline April & 7.7 & 13.9 & 1.5 & 77 & 44 & 61 & 4.47 & 30.0 \\
\hline May & 12.2 & 18.8 & 5.5 & 77 & 40 & 65 & 4.11 & 35.8 \\
\hline June & 16.7 & 23.7 & 9.6 & 75 & 36 & 67 & 4.16 & 32.0 \\
\hline July & 20.4 & 28.4 & 12.4 & 65 & 28 & 80 & 3.84 & 17.0 \\
\hline August & 20.2 & 28.1 & 12.4 & 63 & 28 & 78 & 3.71 & 18.3 \\
\hline September & 14.9 & 22.2 & 7.7 & 71 & 34 & 72 & 3.66 & 18.5 \\
\hline October & 8.5 & 14.8 & 2.2 & 79 & 49 & 55 & 3.66 & 25.2 \\
\hline November & 1.7 & 5.2 & -1.8 & 87 & 76 & 29 & 3.89 & 54.6 \\
\hline December & -2.3 & 1.0 & -5.7 & 88 & 83 & 23 & 3.89 & 61.5 \\
\hline
\end{tabular}

Source: Western Regional Climate Center (1997 [DIRS 152233]).

${ }^{\text {a }}$ Temperature was converted from ${ }^{\circ} \mathrm{F}$ to ${ }^{\circ} \mathrm{C}\left({ }^{\circ} \mathrm{C}=\left[{ }^{\circ} \mathrm{F}-32\right] / 1.8\right)$.

${ }^{b}$ Wind speed was converted from $\mathrm{mph}$ to $\mathrm{m} / \mathrm{s}(\mathrm{m} / \mathrm{s}=0.447 \mathrm{mph})$.

${ }^{c}$ Precipitation was converted from inches to millimeters $(\mathrm{mm}=$ inches $\times 2.54 \times 10)$.

\subsubsection{Soil Infiltration Rate}

Information from the USDA Natural Resources Conservation Service (NRCS) on permeability rate of soil surface layers $(0-15 \mathrm{~cm})$ of soils in Amargosa Valley was used in Section 6.6 to develop a distribution of irrigation intensity. Permeability rate of the soil surface layers (measured in $\mathrm{cm}$ per hour) was used as a measure of infiltration, which is defined as "the downward entry of water into the soil" (Brady and Weil 1999 [DIRS 160019], p. 844). The permeability rates are from an unpublished soil survey of Amargosa Valley and were obtained directly from the Nevada Office of the NRCS (Dollarhide 1999 [DIRS 159253]). The NRCS is considered a source of established fact data. The permeability rates are appropriate measures of infiltration rates because they are specific to surface soils in northern Amargosa Valley and because they were collected by the federal agency with expertise in evaluating and describing soils. These rates are used to determine the feasible range of sprinkler output rates for soils in Amargosa Valley and are presented in Section 6.6.

\subsubsection{Salinity of Irrigation Water}

Electrical conductivity (EC) is commonly used to estimate water and soil salinity. Wells in the Amargosa and Yucca Mountain areas were drilled and monitored for salinity levels (among other variables) for the Nye County Early Warning Drilling Program (DTN: LA0206AM831234.001 [DIRS 160051]). Electrical conductivity was sampled on three dates from three well zones at Well number NC-EWDP-19D, located in the southwest corner of the Nevada Test Site (within the region being evaluated for the receptor population). Average well water salinity, as reflected by the mean measurement of $E C$ from these samples $(E C=0.44 \mathrm{dS} / \mathrm{m}$, DTN: LA0206AM831234.001 [DIRS 160051]) rounded up to the nearest tenth 
$(E C=0.50 \mathrm{dS} / \mathrm{m})$ was used in the calculations of crop leaching requirements (Appendix E). The values of $E C$ were converted from units of $\mu \mathrm{S} / \mathrm{cm}$ to $\mathrm{dS} / \mathrm{m}$ by multiplying the values in $\mu \mathrm{S} / \mathrm{cm}$ by $10^{-3}\left(1 \mathrm{dS} / \mathrm{m}=10^{3} \mu \mathrm{S} / \mathrm{cm}\right)$. The leaching requirement uses the salinity of irrigation water and crop tolerance to salts to calculate the amount of water needed to flush salts below the rooting zone. It is used as the overwatering rate when precipitation does not meet leaching requirements (Section 6.9 and Appendix E). It is also added to the annual average and daily average irrigation rates when precipitation does not meet leaching requirements (Sections 6.5, 6.8, and Appendix E).

The EC data from this source are corroborated by salinity measurements from 31 irrigation or domestic wells located in the town of Amargosa Valley (formerly Lathrop Wells) or west of State Route 373 and south of Highway 95 in Amargosa Valley (McKinley et al. 1991 [DIRS 116222], pp. 9 to 17). Average well water salinity for these 31 wells was $0.51 \mathrm{dS} / \mathrm{m}$ (converted from $\mu \mathrm{S} / \mathrm{m}$ ). Thus, the data from the Nye County Early Warning Drilling Program are representative of local conditions. Additionally, irrigation calculations are relatively insensitive to salinity values that are below the tolerance levels of the crops under consideration. Salinity tolerances for the crops used in this analysis ranged from $1.0 \mathrm{dS} / \mathrm{m}$ for carrots and strawberries to $8.0 \mathrm{dS} / \mathrm{m}$ for barley (Allen et al. 1998 [DIRS 157311], Table 23, pp. 178 to 180). Therefore, the mean well water salinity value was lower than the salinity tolerances for the crops under consideration, making leaching requirements minimal.

\subsubsection{Crop Yield}

Information from the USDA NASS (USDA 1998 [DIRS 158648], 1998 [DIRS 158649], 1999 [DIRS 158650], 1999 [DIRS 158647], 2000 [DIRS 158646], 2000 [DIRS 158653], 2001 [DIRS 158645], 2001 [DIRS 158651], 2002 [DIRS 158652] [see Section 4.1.4.1 for source justification]) was used to develop distributions of yield (wet edible biomass), as described in Section 6.11. The USDA NASS is considered a source of established fact data. Yields of commercially produced crops during five years (1995 - 1999) from up to four states (Arizona, California, Nevada, and Washington) with arid to semi-arid conditions were selected. These yield values are appropriate because they were developed from a large dataset of information on crop production (yield) over a wide range of semi-arid to arid conditions and therefore include variation due to changes in weather and agricultural practices. Information from Arizona and California were used in addition to that from Nevada and Washington because sufficient information for many crops was not available from Nevada and Washington. Information from gardens was not used because the methods used to develop the limited available information generally were not defined and the yield values therefore were of unknown quality. The yield values and the USDA sources are presented in Tables 6.11-1 through 6.11-6.

\subsubsection{Tillage Depth}

Information from the University of Georgia, the University of Ohio, and Washington State University Cooperative Extension Services was used to develop the distribution for tillage depth, as described in Section 6.10. University Cooperative Extension Services are considered sources of established fact data (see Section 4.1.4.1 for source justification). Conventional tillage depth is cited as 25 to $30 \mathrm{~cm}$ (Lang et al. 1999 [DIRS 160031], p. 3; Granberry et al. 2000 [DIRS 160033], p. 8; Johnson 1999 [DIRS 160029], Chapter 8, p. 1). This information is 
appropriate because it shows that there is little variation in conventional tillage depths, and that common tillage or plowing implements are designed to mix the soil to depths of 25 to $30 \mathrm{~cm}$. Additionally, information on tillage depths from these non-site specific sources is appropriate because the use of irrigation and fertilizer in the Amargosa Valley would tend to make the site less distinguishable from other, more temperate areas.

\subsubsection{Irrigation Methods}

Information from University Cooperative Extension Service State Extension Offices was used in Section 6.3 to determine methods commonly used to irrigate commercial and garden crops (see Section 4.1.4.1 for source justification). Information on irrigation methods for leafy vegetables and other vegetables was selected from Martin et al. 1999 ([DIRS 159383], 1999 [DIRS 159384], 1999 [DIRS 159382]), Mayberry 2000 ([DIRS 159386], 2000 [DIRS 159388]), Teegerstrom and Umeda 2001 ([DIRS 159392]), Teegerstrom et al. 2001 ([DIRS 159391]), and Hinman et al. 1997 ([DIRS 159376]). Information on irrigation methods for fruits was selected from Klonsky and De Moura 2001 ([DIRS 159381]), Mayberry 2000 ([DIRS 159389], 2000 [DIRS 160005]), Teegerstrom and Umeda 2001 ([DIRS 159392]), Teegerstrom et al. 2001 ([DIRS 159391]), Uriu and Magness 1967 ([DIRS 159169], pp. 697 to 698), and Wolf and Johnson 1999 ([DIRS 159393], p. 5). This information was selected because it comes from a variety of arid and semi-arid conditions, was prepared by agriculture professionals, and the Cooperative Extension Services are considered sources of established fact data. The irrigation methods are described in Section 6.3.

Data collected on irrigation methods in Amargosa Valley during surveys conducted for the Radiological Monitoring Program (DTN: MO0208SPAMETHO.004 [DIRS 159565]) were used in Section 6.3 to determine methods commonly used to irrigate grains and cattle forage. This information was selected because it is site specific for the Amargosa farming community. The data are presented in Table 4.1-6.

Table 4.1-6. Acres Irrigated in Amargosa Valley

\begin{tabular}{|l|r|r|r|r|r|}
\hline & \multicolumn{5}{c|}{ Irrigation Method } \\
\hline \multicolumn{1}{|c|}{ Crop Type } & \multicolumn{1}{c|}{ Sprinkler } & \multicolumn{1}{c|}{ Drip } & \multicolumn{1}{c|}{ Surface } & \multicolumn{1}{c|}{ No Data } & \multicolumn{1}{c|}{ Total } \\
\hline Grains and Forage & $1,697.5$ & & 225.5 & 43.1 & $1,966.1$ \\
\hline Fruits and Nuts & & 37.0 & 2.0 & 83.9 & 122.9 \\
\hline Leafy and other Vegetables & & & & & 0.3 \\
\hline To be Planted & 58.0 & & & & 0.3 \\
\hline Fallow & 420.3 & & & 204.5 & 145.1 \\
\hline Sod & 126.2 & & & 69.2 & 195.4 \\
\hline Total & $2,302.0$ & 37.0 & 314.6 & 401.0 & $3,054.5$ \\
\hline
\end{tabular}

DTN: MO0208SPAMETHO.004 [DIRS 159565]. 


\subsubsection{Rooting Depth}

Ranges for maximum effective rooting depths $(\mathrm{m})$ for crops used in this analysis were taken from Allen et al. 1998 ([DIRS 157311], Table 22, pp. 163 to 165). The low end of each range was selected for each crop. The ranges are presented in Table 4.1-7. Maximum effective rooting depths were used to develop the distribution for rooting depth in Section 6.12, and in Appendix E to calculate effective precipitation, available water in the root zone, irrigation application, and overwatering rates.

Table 4.1-7. Maximum Effective Rooting Depths (m)

\begin{tabular}{|l|c|l|c|}
\hline \multicolumn{1}{|c|}{ Crop } & Depth (Range) & \multicolumn{1}{c|}{ Crop } & Depth (Range) \\
\hline Alfalfa & $1.0-2.0$ & Grapes & $1.0-2.0$ \\
\hline Apples & $1.0-2.0$ & Lettuce $^{\text {a }}$ & $0.3-0.5$ \\
\hline Barley & $1.0-1.5$ & Melons & $0.8-1.5$ \\
\hline Bell peppers & $0.5-1.0$ & Oats & $1.0-1.5$ \\
\hline Bermuda grass & $0.5-1.0$ & Onions & $0.3-0.6$ \\
\hline Broccoli & $0.4-0.7$ & Potatoes & $0.4-0.6$ \\
\hline Cabbage & $0.5-0.8$ & Spinach & $0.3-0.5$ \\
\hline Carrots & $0.5-1.0$ & Squash & $0.6-1.0$ \\
\hline Cauliflower & $0.4-0.7$ & Strawberries & $0.2-0.3$ \\
\hline Celery & $0.3-0.5$ & Sweet corn & $0.8-1.2$ \\
\hline Field corn & $1.0-1.7$ & Tomatoes & $0.7-1.5$ \\
\hline Corn silage & $1.0-1.7$ & Winter wheat & $1.5-1.8$ \\
\hline Cucumbers & $0.7-1.2$ & & \\
\hline Fescue & $0.5-1.0$ & & \\
\hline
\end{tabular}

Source: Allen et al. 1998 ([DIRS 157311], Table 22, pp. 163 to 165).

${ }^{a}$ Head lettuce or leaf lettuce not specified.

Crop Evapotranspiration, Guidelines for Computing Crop Water Requirements (Allen et al. 1998 [DIRS 157311], FAO Irrigation and Drainage Paper 56, see Section 4.1.4.1 for source justification) describes comprehensive guidelines for determining crop water requirements. Ranges of maximum effective rooting depths for most of the representative crops and turf used in this analysis are provided in Allen et al. (1998 [DIRS 157311], Table 22, pp. 163 to165). Allen et al. (1998 [DIRS 157311]) recommended using the smaller range values for irrigation scheduling because a large percentage of root biomass and activity occurs in the upper portion of the rooting zone. Therefore, the smaller values for rooting depth were selected for this analysis. This source is appropriate for use in this analysis because it is one of several Irrigation and Drainage Papers published by the FAO, a leading agency for agriculture in the United Nations system, and it is considered a source of established fact data. Additionally, similar rooting depths to those reported in Allen et al. (1998 [DIRS 157311]) are described as "typical" by the American Society of Civil Engineers (Jensen et al. 1990 [DIRS 160001], Table 2.7, pp. 22 to 23), and are supported by Bishop and Beetham (1989 [DIRS 160038], Table 20, no page number), and Hagan et al. (1967 [DIRS 160037], various chapters). 


\subsection{CRITERIA}

Table 4.2-1 lists the requirements from the Project Requirements Document (Canori and Leitner 2003 [DIRS 166275]) that are applicable to this analysis. These requirements are for compliance with applicable portions of 10 CFR Part 63 [DIRS 156605].

Table 4.2-1. Requirements Applicable to this Analysis

\begin{tabular}{|l|l|l|}
\hline \multicolumn{1}{|c|}{ Requirement Number } & \multicolumn{1}{|c|}{ Requirement Title } & \multicolumn{1}{|c|}{ Related Regulation } \\
\hline PRD-002/T-015 & Requirements for Performance Assessment & 10 CFR 63.114 \\
\hline PRD-002/T-026 & Required Characteristics of the Reference Biosphere & 10 CFR 63.305 \\
\hline PRD-002/T-028 & $\begin{array}{l}\text { Required Characteristics of the Reasonably Maximally } \\
\text { Exposed Individual }\end{array}$ & 10 CFR 63.312 \\
\hline
\end{tabular}

Source: Canori and Leitner 2003 ([DIRS 166275], Table 2-3).

In addition to the requirements listed in Table 4.2-1, definition of terms in 10 CFR 63.2 and description of concepts in 10 CFR 63.102 (DIRS 156605) that are relevant to biosphere modeling are also applicable to this analysis.

The acceptance criteria from Sections 2.2.1.3.13 (Redistribution of Radionuclides in Soil) and 2.2.1.3.14 (Biosphere Characteristics) of the Yucca Mountain Review Plan, Final Report (YMRP) (NRC 2003 [DIRS 163274]) are based on meeting the requirements of 10 CFR 63.114, 63.305, and 63.312 [DIRS 156605] as they relate to biosphere characteristics modeling. These criteria are listed to further describe how the requirements referenced in Table 4.2-1 should be met. Only those bulleted items from Sections 2.2.1.3.13 and 2.2.1.3.14 of the YMRP (NRC 2003 [DIRS 163274]) that apply to this analysis are included here. Where a subcriterion includes several components, only some of those components may be addressed. How these components are addressed is summarized in Section 7.2 of this report. Section 2.3.1.3.11 of the YMRP (NRC 2003 [DIRS 163274]) (Airborne Transport of Radionuclides) is interpreted to apply only to airborne transport of radionuclides to the biosphere following a volcanic eruption; airborne transport of radionuclides within the biosphere is evaluated in the context of the review criteria in Section 2.3.1.3.14. Only those acceptance criteria and related explanations that apply to this analysis are listed.

Section 2.2.1.3.13.3, Redistribution of Radionuclides in Soil

\section{Acceptance Criterion 1 - System Description and Model Integration Are Adequate}

Subcriterion 2. The total system performance assessment model abstraction identifies and describes aspects of redistribution of radionuclides in soil that are important to repository performance, including the technical bases for these descriptions. For example the abstraction should include modeling of the deposition of contaminated material in the soil and determination of the depth distribution of the deposited radionuclides. 


\section{Acceptance Criterion 2 - Data are Sufficient for Model Justification}

Subcriterion 1. Behavioral, hydrological, and geochemical values used in the license application are adequately justified (e.g., irrigation and precipitation rates, erosion rates, radionuclide solubility values, etc.). Adequate descriptions of how the data were used, interpreted, and appropriately synthesized into the parameters are provided.

Subcriterion 2. Sufficient data (e.g., field, laboratory, and natural analogue data) are available to adequately define relevant parameters and conceptual models necessary for developing the abstraction of redistribution of radionuclides in soil in the total system performance assessment.

\section{Acceptance Criterion 3 - Data Uncertainty in Characterized and Propagated Through the Model Abstraction}

Subcriterion 1. Models use parameter values, assumed ranges, probability distributions, and bounding assumptions that are technically defensible, reasonably account for uncertainties and variabilities, do not result in an underrepresentation of the risk estimate, and are consistent with the characteristics of the reasonably maximally exposed individual in 10 CFR Part 63.

Subcriterion 2. The technical bases for the parameter values and ranges in the total system performance assessment abstraction are consistent with data from the Yucca Mountain region [e.g., Amargosa Valley survey (Cannon Center for Survey Research 1997), studies of surface processes in the Fortymile Wash drainage basin; applicable laboratory testings; natural analogues; or other valid sources of data. For example, soil types, crop types, plow depths, and irrigation rates should be consistent with current farming practices, and data on the airborne particulate concentration should be based on the resuspension of appropriate material in a climate and level of disturbance similar to that which is expected to be found at the location of the reasonably maximally exposed individual, during the compliance time period.

Subcriterion 3. Uncertainty is adequately represented in parameters for conceptual models, process models, and alternative conceptual models considered in developing the total system performance assessment abstraction of redistribution of radionuclides in soil, either through sensitivity analyses, conservative limits, or bounding values supported by data, as necessary. Correlations between input values are appropriately established in the total system performance assessment. 
Section 2.2.1.3.14.3, Biosphere Characteristics

\section{Acceptance Criterion 1 - System Description and Model Integration are Adequate}

Subcriterion 3. Assumptions are consistent between the biosphere characteristics modeling and other abstractions. For example, the U.S. Department of Energy should ensure that the modeling of features, events, and processes, such as climate change, soil types, sorption coefficients, volcanic ash properties, and the physical and chemical properties of radionuclides are consistent with assumption in other total system performance assessment abstractions.

\section{Acceptance Criterion 2 - Data are Sufficient for Model Justification}

Subcriterion 1. The parameter values used in the license application are adequately justified (e.g., behaviors and characteristics of the residents of the Town of Amargosa Valley, Nevada, characteristics of the reference biosphere, etc.) and consistent with the definition of the reasonably maximally exposed individual in 10 CFR Part 63. Adequate descriptions of how the data were used, interpreted, and appropriately synthesized into the parameters are provided.

Subcriterion 2. Data are sufficient to assess the degree to which features, events, and processes related to biosphere characteristics modeling have been characterized and incorporated in the abstraction. As specified in 10 CFR Part 63, the U.S. Department of Energy should demonstrate that features, events, and processes, which describe the biosphere, are consistent with present knowledge of conditions in the region, surrounding Yucca Mountain. As appropriate, the U.S. Department of Energy sensitivity and uncertainty analyses (including consideration of alternative conceptual models) are adequate for determining additional data needs, and evaluating whether additional data would provide new information that could invalidate prior modeling results and affect the sensitivity of the performance of the system to the parameter value or model.

\section{Acceptance Criterion 3 - Data Uncertainty Is Characterized and Propagated Through the Model Abstraction}

Subcriterion 1. Models use parameter values, assumed ranges, probability distributions, and bounding assumptions that are technically defensible, reasonably account for uncertainties and variabilities, do not result in an underrepresentation of the risk estimate, and are consistent with the definition of the reasonably maximally exposed individual in 10 CFR Part 63.

Subcriterion 2. The technical bases for the parameter values and ranges in the abstraction, such as consumption rates, plant and animal uptake factors, massloading factors, and biosphere dose conversion factors, are consistent with site characterization data, and are technically defensible. 
Subcriterion 4. Uncertainty is adequately represented in parameter development for conceptual models and process-level models considered in developing the biosphere characteristics modeling, either through sensitivity analyses, conservative limits, or bounding values supported by data, as necessary. Correlations between input values are appropriately established in the total system performance assessment, and the implementation of the abstraction does not inappropriately bias results to a significant degree.

\subsection{CODES, STANDARDS, AND REGULATIONS}

No codes, standards, or regulations other than those identified in the Project Requirements Document (Canori and Leitner 2003 [DIRS 166275], Table 2-3) and determined to be applicable (Table 4-3) were used in this analysis. 


\section{INTENTIONALLY LEFT BLANK}




\section{ASSUMPTIONS}

No assumptions were made in the absence of direct confirming data or evidence to develop the distributions of parameter values in this analysis. Other scientific analysis assumptions are described in Section 6 and Appendices C through E. 


\section{INTENTIONALLY LEFT BLANK}




\section{SCIENTIFIC ANALYSIS DISCUSSION}

This section describes the analyses conducted to develop average values and distributions for the twelve parameters considered in this report. The recommended parameter values are intended for use as inputs in the ERMYN biosphere model to support calculation of BDCFs for three climate states and for both the biosphere groundwater exposure scenario and volcanic ash exposure scenario.

Seven of the parameters (dry biomass, dry-to-wet-weight ratios, fraction of overhead irrigation, growing time, irrigation application, daily irrigation rate, and yield) require separate distributions for the five crop types used in the biosphere model (leafy vegetables, root and other vegetables [hereafter called other vegetables], fruits, grain, and cattle forage). Five of the parameters (annual irrigation, irrigation intensity, overwatering rate, tillage depth, and rooting depth) are composite values with a single distribution representative of all crop types and turf.

Much of the variation in these parameters is from differences among crops and much of the uncertainty is due to lack of knowledge about the specific crops a farmer or gardener will choose to grow (for example, see Section 6.5.2). To ensure that this variation and uncertainty is adequately addressed, the first step in this analysis was to select a set of crops for each crop type that is representative of the variation in types of plants likely to be grown under present-day and future climatic conditions. To ensure that parameters developed in this analysis are consistent with arid to semi-arid conditions of the present-day and predicted future climates, selection of these representative crops was based on an evaluation of crops grown in southern Nye County, Nevada and eastern Washington (upper bound glacial transition climate analogue), variation in the growing season in arid to semi-arid environments for commonly grown crops, and plant growth form. National patterns of food consumption were evaluated to support the selection. This analysis is described in Appendix A and the recommended crops are listed in Table 6-1. Average parameter values were calculated using these representative crops throughout the analysis.

Development of the parameter distributions was based on values calculated for the representative crops, which resulted in the use of uniform, normal, and cumulative probability distributions, or fixed values. Minimum and maximum values were required for most of the parameter distributions to preserve biological meaning and avoid selection of nonsensical values. For example, minimum and maximum values were necessary for irrigation parameters so that values likely to result in yield reduction or crop mortality would not be selected. For irrigation parameters, minimum values tended to be closer to the distribution mean than maximum values because of crop sensitivity to water stress. Under these circumstances, non-symmetrical truncation of normal distributions and shifts in the calculated mean were avoided by using cumulative distribution functions to better represent the available data. Cumulative distribution functions were also used when it was suspected that the data did not meet the assumptions of the normal distribution.

To calculate means and develop probabilities for cumulative distribution intervals for cattle forage, a 3 to 1 weighting process was used, where alfalfa was assigned a value of 3 , and oat hay and corn silage were each assigned a value of 1. In Amargosa Valley, alfalfa totaled 67 to 97 percent of the acreage planted in hay for 1996 through 1999 (Table A-1) and 2004 
(Appendix A). In Whitman and Spokane County, Washington (upper bound glacial transition climate analogues) alfalfa totaled 59 and 69 percent (respectively) of the acreage planted in hay, with very low percentages planted in oat hay and corn silage (Table A-3). Inclusion of values for oat hay and corn silage were necessary to account for uncertainties associated with crop selection and crop differences in parameter values. In some cases (e.g., yield), corn silage had very different parameter values compared to alfalfa. Because of this and the importance of alfalfa compared to corn silage and oat hay, weighting of means and probabilities was necessary to calculate averages and generate distributions for cattle forage. Weighting was not necessary for other crop types or for parameters developed from all 26 crops and turf because there was no information indicating that some crops were more common than others, or values within a crop type were similar, making weighting unnecessary.

Table 6-1. Representative Crops

\begin{tabular}{|l|l|}
\multicolumn{1}{|c|}{$\begin{array}{c}\text { Crop Type } \\
\text { Representative Crops }\end{array}$} & \multicolumn{1}{c|}{$\begin{array}{c}\text { Crop Type } \\
\text { Representative Crops }\end{array}$} \\
\hline Leafy Vegetables & Fruits \\
\hline Broccoli & Apples \\
\hline Cabbage & Grapes \\
\hline Cauliflower & Melons \\
\hline Celery & Strawberries \\
\hline Head Lettuce & Tomatoes \\
\hline Leaf Lettuce & Grains \\
\hline Spinach & Barley \\
\hline Other Vegetables & Feed Corn \\
\hline Bell Peppers & Oats \\
\hline Carrots & Wheat \\
\hline Cucumbers & Cattle Forage \\
\hline Onions & Alfalfa \\
\hline Potatoes & Corn silage \\
\hline Squash & Oat hay \\
\hline Sweet Corn & Home Irrigation \\
\hline & Present-Day - Bermudagrass \\
\hline & Future - Fescue \\
\hline
\end{tabular}

${ }^{a}$ See Appendix A for information on selection of representative crops.

Information from literature and field surveys was used to determine appropriate and reasonable values that are consistent with arid to semi-arid environments for each crop for dry biomass, dry-to-wet-weight ratios, growing time, tillage depth, rooting depth, and yield. The methods outlined in the FAO Irrigation and Drainage Papers 56 (Allen et al. 1998 [DIRS 157311]) and 24 (Doorenbos and Pruitt 1977 [DIRS 103062]) were used to calculate crop water and irrigation supply requirements, respectively. Allen et al. 1998 ([DIRS 157311]) provides energy balance and mass transfer equations to calculate reference evapotranspiration $\left(\mathrm{ET}_{\mathrm{o}}\right)$ and lists crop coefficients $\left(\mathrm{K}_{\mathrm{c}}\right)$, which are used to determine crop water requirements. These equations were recommended as the international standard for calculating $\mathrm{ET}_{\mathrm{o}}$ (Allen et al. 1998 [DIRS 157311]) following an evaluation of several methods used to calculate evapotranspiration across a variety of climatic conditions (Jensen et al. 1990 [DIRS 160001]). Members of the 
International Commission for Irrigation and Drainage and the World Meteorological Organization were among the panel of experts that made the recommendations for revisions and improvements for calculation of $\mathrm{ET}_{\mathrm{o}}$. The methods for calculating net irrigation and seasonal irrigation requirements in Doorenbos and Pruitt 1977 ([DIRS 103062]) are widely accepted and were used to complete the analysis to determine irrigation rates. Alternate technical methods and justification for use of the methods in Allen et al. 1998 ([DIRS 157311]) and Doorenbos and Pruitt 1977 ([DIRS 103062]) are in Appendix B. Variation and uncertainty associated with $\mathrm{K}_{\mathrm{c}}$ are discussed in Section 6.5.2. Variation and uncertainty associated with $\mathrm{ET}_{\mathrm{o}}$ are discussed in Sections 6.5.2, 6.7.2, 6.8.2, and 6.9.2.

Climate States-To ensure assumptions are consistent between biosphere modeling and other abstractions as described in the Yucca Mountain Review Plan, Final Report (NRC 2003 [DIRS 163274], Section 2.2.1.3.14.3) parameters in this analysis were developed to support BDCF calculations for the three climate states used in TSPA (present-day interglacial, monsoon, and glacial transition (BSC 2003 [DIRS 166296], p. 79)). These climates and their predicted occurrence at Yucca Mountain in the future are described in Future Climate Analysis (BSC 2004 [DIRS 170002], Section 6.6.2). Analogue weather stations for the climates used in this analysis are identified in BSC 2004 ([DIRS 170002], Table 6-1 and Section 6.6.2).

The present-day interglacial climate includes current conditions (BSC 2004 [DIRS 170002], Section 6.6.2) and is referred to as present-day climate in this report. Current conditions are characterized by hot, dry summers, warm winters, and have lower annual precipitation and higher annual temperatures than glacial transition climate states. Conditions for the present-day climate state were characterized using weather measurements taken at or near Yucca Mountain, and agricultural practices in southern Nevada and other arid southwestern regions that are consistent with the climate of Amargosa Valley (e.g., Imperial Valley California, Maricopa County Arizona).

The lower bound monsoon climate state predicted to occur after the present-day interglacial climate state is also characterized by current conditions (BSC 2004 [DIRS 170002], Section 6.6.2). Therefore, parameter distributions that are developed for present-day climate are also applicable to the lower bound monsoon climate.

The upper bound monsoon climate is characterized by strong summer monsoons and warmer winter seasons with increased precipitation compared to the present-day climate (BSC 2004 [DIRS 170002], Section 6.6.2). Recommended analogue weather stations for the upper bound monsoon climate are Nogales, Arizona and Hobbs, New Mexico. Temperature, precipitation, and wind speed data from the Nogales weather station were used in the analysis. Solar radiation data were not available from either the Nogales or Hobbs weather stations. Therefore, these data were obtained from the Tucson, Arizona weather station, which was the closest station to Nogales that had the required information. Agricultural practices in southern Nevada and other arid southwestern regions (e.g., Imperial Valley California, Maricopa County Arizona) that were used to characterize the conditions (i.e., crop selection and season lengths) for present-day climate were also used to characterize conditions for the upper bound monsoon climate.

The lower bound glacial transition climate is semi-arid and characterized by predominantly winter precipitation. Precipitation for this climate state is higher and temperatures are cooler 
than for present-day climate (BSC 2004 [DIRS 170002], Section 6.6.2). The recommended weather stations for the lower bound glacial transition climate are Delta, Utah and Beowawe, Nevada. Temperature, precipitation, and dewpoint temperature from Delta were used in the analysis. Wind speed and solar radiation data were not available from either the Delta or Beowawe weather stations. Therefore, these data were obtained from the Milford, Utah weather station, which was the closest station to Delta that had the required information. Cold limiting temperatures (see Tables 4.1-4 and 4.1-5) that affect crop growth and season length occur during March through April in the spring and October in the fall for both Delta and Spokane (location of analogue weather station for the upper bound glacial transition climate, see below). Therefore, the agricultural practices (i.e., crop selection and season lengths) in east central Washington that were used in this analysis to characterize conditions for the upper bound glacial transition climate state were also used for the lower bound.

The upper bound glacial transition climate is semi-arid and characterized by cool, wet winters, and warm to cool dry summers relative to present-day conditions (BSC 2004 [DIRS 170002], Section 6.6.2). Recommended analogue weather stations for the upper bound glacial transition climate (i.e., cooler and wetter) are Spokane, St. John, and Rosalia, Washington (BSC 2004 [DIRS 170002], Table 6-1 and Section 6.6.2). Data from the Spokane weather station and agricultural practices in east central Washington were used in this analysis to characterize conditions for the upper bound glacial transition climate state.

Biosphere dose conversion factors are developed for the three climate states used in TSPA (BSC 2004 [DIRS 169674], Section 6.1.3; BSC 2003 [DIRS 166296], p. 79). Distributions of parameters in this analysis that are affected by climate (growing time, irrigation application, annual irrigation rate, daily irrigation rate, and overwatering rate) were developed for the present-day climate and the upper bound of the glacial transition climate. In addition, means of annual average irrigation rate (which has a strong influence on BDCFs) were developed for the upper bound of the monsoon and lower bound of the glacial transition climates. These means, and the distributions for annual average irrigation rate for the present-day and upper bound glacial transition climates were used to develop BDCFs for the three climate states, as described in BSC 2004 ([DIRS 169674], Section 6.1.3).

Biosphere Groundwater Exposure Scenario and Volcanic Ash Exposure Scenario-Five of the parameters in this analysis report (dry biomass, dry-to-wet-weight ratios, growing time, tillage depth, and yield) are used in both the biosphere groundwater exposure scenario and the biosphere volcanic ash exposure scenario (BSC 2004 [DIRS 169460], Section 6.4, note that tillage depth and rooting depth are treated as one parameter [surface soil depth] in the biosphere model). Ash depths $18 \mathrm{~km}$ downwind from Yucca Mountain were predicted to range from 0.07 to $55 \mathrm{~cm}$ (based on 100 realizations of the ASHPLUME model). About 35 percent of predicted depths were less than $1 \mathrm{~cm}, 75$ percent were less than $5 \mathrm{~cm}$, and 90 percent were less than $15 \mathrm{~cm}$ (BSC 2004 [DIRS 170026], Table 6-4). Ash depths at the location of the RMEI (18 km south of Yucca Mountain) would be about 2 orders of magnitude or more lower under normal, variable wind conditions (CRWMS M\&O 2000 [DIRS 153246], Section 3.10.5.1 and Figure 3.10-14) because the wind at Yucca Mountain blows to the south infrequently (BSC 2004 [DIRS 170026], Figure 8-1). The use of tillage, irrigation, and fertilizers with agricultural and garden crops would result in rapid mixing of the thin ash layer with little effect on soils or crop characteristics considered in this analysis (i.e., tillage depth or dry-to-wet-weight 
ratios). Therefore, separate distributions for five of the parameters in this analysis are not necessary for the two biosphere exposure scenarios.

\subsection{DRY BIOMASS}

\subsubsection{Use in Biosphere Model}

Dry biomass $\left(D B_{j}, \mathrm{~kg} / \mathrm{m}^{2}\right)$ is a measure of the total, above-ground standing crop biomass per unit area, for each crop type. It is used in the plant submodel in the calculations of water and dust interception fractions. In both calculations, it represents the amount of plant material available to intercept contaminated water or dust.

Water Interception Fraction-Dry biomass is one of three parameter inputs to the calculation of the water interception fraction $\left(R w_{j}\right)$ (Equation 6.1-1; BSC 2004 [DIRS 169460], Section 6.4.3), which is based on experiments of Beryllium-7 $\left({ }^{7} \mathrm{Be}\right)$ and Iodine-131 $\left({ }^{131} \mathrm{I}\right)$. This fraction, which can vary from zero to one, represents the percentage of radionuclides in irrigation water sprayed on plants that is intercepted and deposited on plant leaves.

$$
R w_{j}=K_{1} D B_{j}{ }^{K_{2}} I A_{j}{ }^{K_{3}} I_{j}{ }^{K_{4}}
$$

where

$R w_{j}=$ water interception fraction for crop type $j$ (dimensionless)

$K_{1}, K_{2}, K_{3}$, and $K_{4}=$ empirical constants that depend on the plant-type and contaminant form. $K_{1}$ is in units of $\left(\mathrm{kg} / \mathrm{m}^{2}\right)^{-K 2}(\mathrm{~mm})^{-K 3}(\mathrm{~cm} / \mathrm{hr})^{-K 4}$ and $K_{2}, K_{3}$, and $K_{4}$ are dimensionless. $D B_{j}=$ standing biomass of crop type $j\left(\mathrm{~kg}_{\text {dry weight }} / \mathrm{m}^{2}\right)$

$I A_{j}=$ amount of irrigation per application event for crop type $j(\mathrm{~mm})$

$I=$ irrigation intensity $(\mathrm{cm} / \mathrm{hr})$

$j=$ crop type

Values for constants cited in the Biosphere Model Report (BSC 2004 [DIRS 169460], Section 6.4.3) are as follows:

$$
\begin{aligned}
& K_{1}=2.29 \text { for beryllium }\left(\mathrm{Be}^{+}\right), 1.54 \text { for iodine }\left(\mathrm{I}^{-}\right), \\
& K_{2}=0.695 \text { for beryllium }\left(\mathrm{Be}^{+}\right), 0.697 \text { for iodine }\left(\mathrm{I}^{-}\right), \\
& K_{3}=-0.29 \text { for beryllium }\left(\mathrm{Be}^{+}\right),-0.909 \text { for iodine }\left(\mathrm{I}^{-}\right), \\
& K_{4}=-0.341 \text { for beryllium }\left(\mathrm{Be}^{+}\right),-0.049 \text { for iodine }\left(\mathrm{I}^{-}\right) .
\end{aligned}
$$

The interception fraction is obtained from a regression equation derived from experimental data with recommended values for the empirical constants which depend on contaminant form, and were developed based on given values for standing biomass $\left(D B_{j}\right)$, irrigation amount per application $\left(I A_{j}\right)$, and irrigation intensity $\left(I_{j}\right)$ (BSC 2004 [DIRS 169460], Section 6.4.3). Because biomass is raised to the power of approximately 0.7 in this equation, there is a positive relationship between biomass and water interception. For example, for dry biomass values ranging from 0.1 to $1.5 \mathrm{~kg} / \mathrm{m}^{2}$, the water interception fraction for $\mathrm{Be}^{+}$changes from about 0.1 to 
about 0.7 (with $I A_{j}=30 \mathrm{~mm}$ and $I_{j}=4 \mathrm{~cm} /$ hour). The interception values for $I^{-}$only changes from about 0.01 to 0.08 over that range. Thus, interception for the cationic $\mathrm{Be}^{+}$is sensitive to changes in biomass, but interception for the anionic $\mathrm{I}^{-}$is insensitive to those changes.

Dust Interception Fraction-Dry biomass is one of two variables in the calculation of dust interception, $R a_{j}$ (Equation 6.1-2; BSC 2004 [DIRS 169460], Section 6.4.3), which represents the percentage (expressed as a number from zero to one) of suspended dust that is intercepted by the leaves of a plant.

$$
R a_{j}=1.0-e^{-a_{j} D B_{j}}
$$

where

$a_{j}=$ an empirical factor in units of square meter per kilogram of dry plant biomass (2.9 for leafy vegetables, fresh forage feed and grain, 3.6 for other vegetables and fruit).

Changes in biomass ranging from 0.15 to $0.7 \mathrm{~kg} / \mathrm{m}^{2}$ result in changes in the dust interception fraction from about 0.4 to 0.9 (Figure 6.1-1). Values of dry biomass greater than about 0.8 cause little change in the interception fraction, as the fraction asymptotes toward 1.0 at high values of dry biomass. Thus, the dust interception fraction is sensitive to changes in dry biomass ranging from 0.1 to 0.8 , but insensitive to higher values.

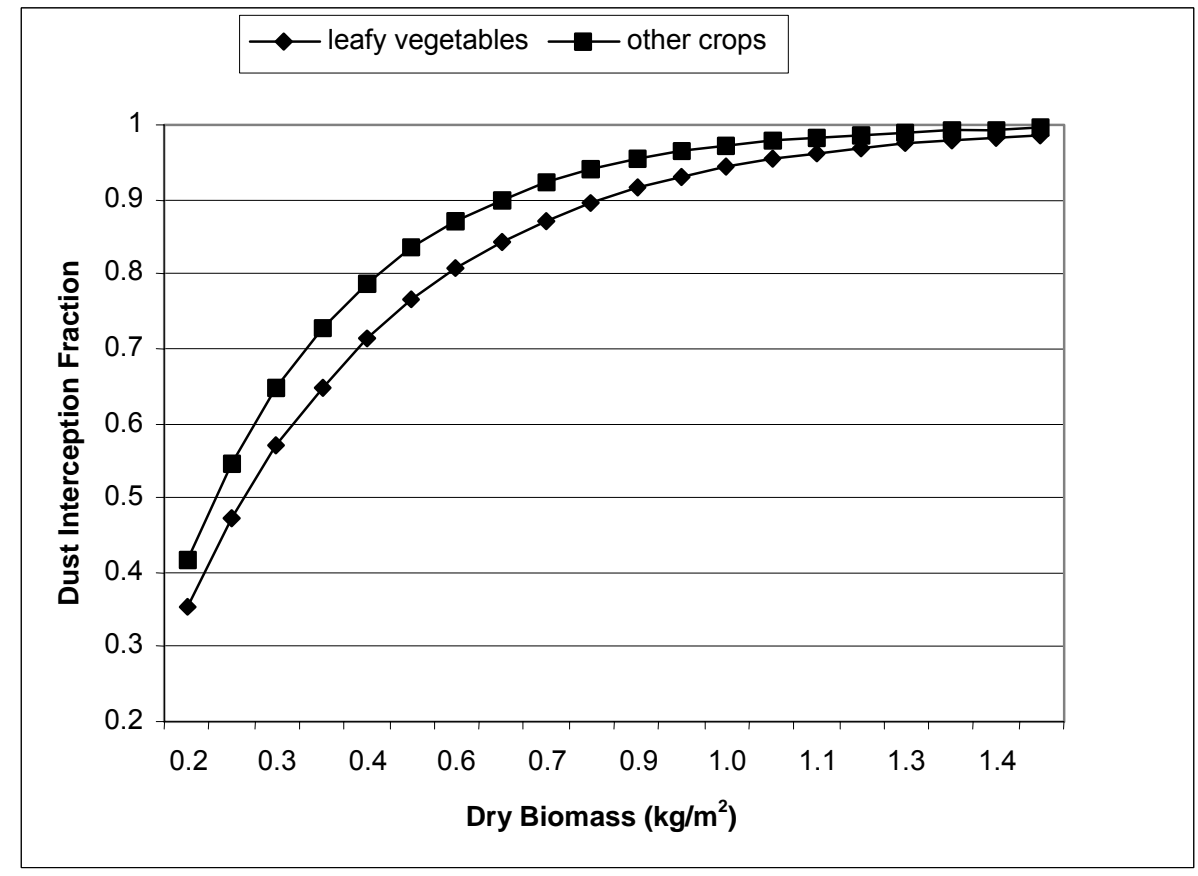

NOTE: Calculated as $R a_{j}=1.0-e_{j}^{-a D B}$, where $a_{j}=2.9$ for leafy vegetables and 3.6 for other crops.

Figure 6.1-1. Sensitivity of Dust Interception Fraction to Dry Biomass 


\subsubsection{Parameter Development}

Dry biomass of leafy vegetables and cattle forage was calculated by multiplying yield of each representative crop (Section 6.11) by the dry-to-wet-weight ratio for that crop (Section 6.2). Because the total aboveground portions of leafy vegetables and cattle forage are edible and weighed fresh (i.e., wet weight) to determine yield, the resulting values are valid estimates of total aboveground dry biomass (Table 6.1-1).

Dry biomass for grains, other vegetables, and fruits were calculated by multiplying edible yield of each representative crop (Section 6.11) by the dry-to-wet-weight ratio for that crop (Section 6.2) and dividing the resulting value by a harvest index (Table 6.1-1).

A harvest index is a measure of the ratio of seed, fruit, or tuber dry biomass to total aboveground dry biomass. The harvest index was first used in plant breeding studies to identify cultivars and select for desirable traits that would improve crop yield (Hay 1995 [DIRS 160540], p. 198; Prince et al. 2001 [DIRS 159323], p. 1196). More recently it has been used to estimate net primary production for cropped land (Prince et al. 2001 [DIRS 159323]), assess dry matter partitioning responses of horticultural crops to fertilizer or irrigation treatments (Scholberg et al. 2000 [DIRS 160434]; van Delden 2001 [DIRS 160433]), and estimate aboveground biomass from published yield values (Prince et al. 2001 [DIRS 159323], p. 1196).

Harvest index inputs are described in Section 4.1.3 and presented in Table 6.1-1. Harvest indices for grains, other vegetables, and fruits were selected from Neitsch et al. 2002 ([DIRS 163122], Table A-8, pp. 381 to 384) because they are appropriate for use with USDA measurements of yield and dry-to-wet-weight ratios to estimate total aboveground dry biomass. The harvest indices from Neitsch et al. 2002 ([DIRS 163122], Table A-8, pp. 381 to 384) were established for non-stressed crops. Values for the optimal harvest index were selected from Table A-8 (Neitsch et al. 2002 [DIRS 163122], Table A-8, pp. 381 to 384). For crops with aboveground yield (e.g., bell peppers and strawberries) the harvest index is less than 1.0 (Neitsch et al. 2002 [DIRS 163122], p. 381). For crops with below ground yield (e.g., onions and carrots) the harvest index may be greater than 1.0 (Neitsch et al. 2002 [DIRS 163122], p. 381).

Squash and corn were not included in the dry biomass distribution for other vegetables because yield data were not available (see Section 6.11). Apples were not included in the dry biomass distribution for fruits because trees are usually drip irrigated and so are not used in calculation of the Water Interception Fraction, and the equation for the Dust Interception Fraction has not been validated for trees (IAEA 1996 [DIRS 160402], pp. 7 to 13). 
Table 6.1-1. Dry Biomass $\left(\mathrm{kg} / \mathrm{m}^{2}\right)$

\begin{tabular}{|c|c|c|c|c|c|c|c|c|c|}
\hline $\begin{array}{c}\text { Crop Type } \\
\text { Crop }\end{array}$ & Yield $^{a}$ & Ratio $^{\text {b }}$ & $\mathrm{HI}^{\mathrm{c}}$ & Biomass $^{\mathrm{d}}$ & $\begin{array}{c}\text { Crop Type } \\
\text { Crop }\end{array}$ & Yield $^{a}$ & Ratio $^{\text {b }}$ & $\mathrm{HI}^{\mathrm{c}}$ & Biomass $^{d}$ \\
\hline Leafy Vegetables & & & & & Fruits & & & & \\
\hline Broccoli & 1.46 & 0.093 & - & 0.14 & Grapes $^{\mathrm{e}}$ & 1.51 & 0.194 & 0.45 & 0.65 \\
\hline Cabbage & 3.83 & 0.078 & - & 0.30 & Melons & 2.92 & 0.102 & 0.50 & 0.60 \\
\hline Cauliflower & 2.01 & 0.081 & - & 0.16 & Strawberries & 3.63 & 0.084 & 0.45 & 0.68 \\
\hline Celery & 7.79 & 0.054 & - & 0.42 & Tomatoes & 3.0 & 0.062 & 0.33 & 0.56 \\
\hline Head Lettuce & 3.25 & 0.041 & - & 0.13 & Average & & & & 0.62 \\
\hline Leaf Lettuce & 2.98 & 0.060 & - & 0.18 & $S D^{f}$ & & & & 0.05 \\
\hline Spinach & 1.78 & 0.084 & - & 0.15 & & & & & \\
\hline Average & & & & 0.21 & Grains & & & & \\
\hline \multirow[t]{2}{*}{$S^{f}$} & & & & 0.11 & Barley & 0.44 & 0.906 & 0.54 & 0.74 \\
\hline & & & & & Corn & 1.10 & 0.896 & 0.50 & 1.97 \\
\hline Other Vegetables & & & & & Oats & 0.28 & 0.918 & 0.42 & 0.61 \\
\hline Bell Peppers & 3.37 & 0.078 & 0.60 & 0.44 & Winter wheat & 0.54 & 0.891 & 0.40 & 1.20 \\
\hline Carrots & 3.64 & 0.122 & 1.12 & 0.40 & Average & & & & 1.13 \\
\hline Cucumbers & 3.56 & 0.035 & 0.27 & 0.46 & $S D^{f}$ & & & & 0.61 \\
\hline Onions & 4.92 & 0.103 & 1.25 & 0.41 & & & & & \\
\hline Potatoes & 5.15 & 0.08 & 0.95 & 0.43 & Cattle Forage & & & & \\
\hline Average & & & & 0.43 & Alfalfa hay & 1.02 & 0.227 & - & 0.23 \\
\hline \multirow[t]{4}{*}{$S D^{f}$} & & & & 0.02 & Corn silage & 5.78 & 0.238 & - & 1.38 \\
\hline & & & & & Oat hay & 1.87 & 0.182 & - & 0.34 \\
\hline & & & & & Average & & & & 0.65 \\
\hline & & & & & $S D^{f}$ & & & & 0.63 \\
\hline
\end{tabular}

Source: USDA 2002 ([DIRS 159272]).

a Wet yield $\left(\mathrm{kg} / \mathrm{m}^{2}\right)$, See Tables 6.11-1 to 6.11-6 .

b Dry-wet-weight ratio, See Table 6.2-1.

c Harvest Index (ratio of edible dry biomass to total above ground dry biomass, see Section 4.1.3. A dash means no index was required, optimal harvest index values from Neitsch et al. 2002 ([DIRS 163122], Table A-8, pp. 381 to 384).

${ }^{\mathrm{d}} \mathrm{kg} / \mathrm{m}^{2}$, calculated as (yield $\mathrm{x}$ dry-to-wet-weight ratio) $\div$ harvest index.

e $\mathrm{HI}$ for strawberries was used for grapes.

$\mathrm{f}$ Standard deviation calculated using the STDEV function of Excel.

The average for each crop type is the mean biomass of representative crops, with the exception of the weighted mean used for cattle forage (Table 6.1-2). 
Table 6.1-2. Averages and Cumulative Distributions for Dry Biomass $\left(\mathrm{kg} / \mathrm{m}^{2}\right)$

\begin{tabular}{|c|c|c|c|c|c|c|c|}
\hline Crop Type & Average $^{\mathrm{a}}$ & $\begin{array}{c}\text { Upper } \\
\text { Limit of } \\
\text { Interval }^{\mathrm{b}}\end{array}$ & $\begin{array}{l}\text { Cumulative } \\
\text { Probability }\end{array}$ & Crop Type & Average $^{a}$ & $\begin{array}{l}\text { Upper Limit } \\
\text { of Interval }^{b}\end{array}$ & $\begin{array}{l}\text { Cumulative } \\
\text { Probability }\end{array}$ \\
\hline \multirow{10}{*}{$\begin{array}{l}\text { Leafy } \\
\text { Vegetables }\end{array}$} & 0.21 & 0.10 & 0.00 & \multirow[t]{7}{*}{ Fruits } & 0.62 & 0.10 & 0.00 \\
\hline & & 0.13 & 0.05 & & & 0.56 & 0.05 \\
\hline & & 0.14 & 0.20 & & & 0.60 & 0.35 \\
\hline & & 0.15 & 0.35 & & & 0.65 & 0.65 \\
\hline & & 0.16 & 0.50 & & & 0.68 & 0.95 \\
\hline & & 0.18 & 0.65 & & & 1.30 & 1.00 \\
\hline & & 0.30 & 0.80 & & & & \\
\hline & & 0.42 & 0.95 & \multirow[t]{7}{*}{ Grains } & 1.13 & 0.50 & 0.00 \\
\hline & & 0.50 & 1.00 & & & 0.61 & 0.05 \\
\hline & & & & & & 0.74 & 0.35 \\
\hline \multirow{9}{*}{$\begin{array}{l}\text { Other } \\
\text { Vegetables }\end{array}$} & 0.43 & 0.30 & 0.00 & & & 1.20 & 0.65 \\
\hline & & 0.40 & 0.05 & & & 1.97 & 0.95 \\
\hline & & 0.41 & 0.28 & & & 2.20 & 1.00 \\
\hline & & 0.43 & 0.51 & & & & \\
\hline & & 0.44 & 0.73 & \multirow{5}{*}{$\begin{array}{l}\text { Cattle } \\
\text { Forage }^{c}\end{array}$} & 0.48 & 0.10 & 0.00 \\
\hline & & 0.46 & 0.95 & & & 0.23 & 0.05 \\
\hline & & 0.60 & 1.00 & & & 0.34 & 0.73 \\
\hline & & & & & & 1.38 & 0.95 \\
\hline & & & & & & 1.50 & 1.00 \\
\hline
\end{tabular}

a Mean dry biomass for a crop type from Table 6.1-1, with the exception of the weighted mean calculated for cattle forage. The weighted mean was calculated as $(3 \times 0.23$ [dry biomass for alfalfa] $+1 \times 1.38$ [dry biomass for corn silage] $+1 \times 0.34$ [dry biomass for oat hay]) $/ 5=0.48$.

${ }^{b}$ Limits determined from crop specific biomass (see Table 6.1-1).

${ }^{c}$ For 90 percent of the distribution between the minimum and maximum crop biomass, the probabilities for the two cattle forage intervals were weighted $3: 1$ for the range between oat hay to alfalfa $(p=0.68)$ and alfalfa to corn silage $(p=0.22)$.

A cumulative distribution function is recommended for each crop type (Table 6.1-2). Ninety percent of the probability distribution is between the minimum and maximum biomass of representative crops within a crop type (e.g., biomass for leafy vegetables ranges from 0.13 [head lettuce] to $0.42 \mathrm{~kg} / \mathrm{m}^{2}$ [celery], Table 6.1-1). The distribution between the minimum and maximum crop dry biomass is divided into intervals of virtually equal probability (summing to 90 percent), with the exception of cattle forage (see below). The number of intervals is one less than the number of representative crops considered and the upper limits are crop-specific values of biomass. The probabilities for the two intervals for cattle forage were weighted 3:1 for the range between oat hay and alfalfa $(\mathrm{p}=0.675)$ versus the range between alfalfa and corn silage $(\mathrm{p}=0.225)$ (see Section 6 for justification). This results in a higher probability for selection of values that are similar to alfalfa. To account for variation and uncertainty that could result in values beyond the range of crop specific values, intervals of five percent probability each were added to the lower and upper ends of the distribution. Yield (Section 6.11) was evaluated for crops within a crop type having low and high dry biomass values to determine appropriate bounds for the distributions. The lowest yield value reported for crops with relatively low dry biomass was used with dry-to-wet-weight ratios and harvest indices (when appropriate) to recalculate dry biomass. The resulting value was rounded down to the nearest tenth and used as 
the lower bound. For example, broccoli and head lettuce had the lowest reported dry biomass for leafy vegetables; however, broccoli had a lower yield value and was selected to calculate the lower bound. Using the minimum yield reported for broccoli $\left(1.08 \mathrm{~kg} / \mathrm{m}^{2}\right.$, Table $\left.6.11-1\right)$ and the dry-to-wet-weight ratio reported for broccoli (0.093, Table 6.2-1) the lower bound for leafy vegetables is $1.08 \times 0.093=0.10$. Carrots, strawberries, oats, and alfalfa were used to calculate the lower bounds for other vegetables, fruits, grains, and cattle forage, respectively. The upper bounds were determined with the same method using the highest yield value reported for crops with high biomass. The resulting values were rounded up to the nearest tenth (Table 6.1-2). Celery, onions, strawberries, corn, and corn silage were used to calculate the upper bounds for leafy vegetables, other vegetables, fruits, grains, and cattle forage, respectively. It should be noted that potatoes had a higher yield than onions for other vegetables $\left(6.61 \mathrm{~kg} / \mathrm{m}^{2}\right.$ versus $6.50 \mathrm{~kg} / \mathrm{m}^{2}$ ). However, the low dry-to-wet-weight ratios for potatoes resulted in a lower dry biomass than that calculated for the highest yield of onions. Therefore, the yield for onions was more appropriate for calculating the upper bound. The wide range in yield values for strawberries made their use appropriate for calculation of both lower and upper bounds for fruits (see Table 6.11-3)

Much of the variation in this parameter is due to variation in yield (i.e., wet biomass of harvest). As discussed in Section 6.11, the distributions of yield adequately incorporate variation and uncertainty due to climate or farming conditions, farming and gardening practices, and selection of crops and crop types. There is little uncertainty in the measurements of dry-to-wet-weight ratios (Section 6.2); thus, they contribute little to the uncertainty in dry biomass. Harvest indices tend to be conservative unless crops are grown under extreme stress conditions (Prince et al. 2001 [DIRS 159323], p. 1196). Most published measurements of harvest indices reviewed by Prince et al. 2001 ([DIRS 159323], p. 1197) varied by no more than \pm 0.06 from the values used in this analysis. Increasing or decreasing the values of harvest indices of grain by 0.06 would result in mean dry biomass values of about 1.0 and 1.3, respectively, well within the bounds of the recommended distribution (range $=0.50$ to $2.20 \mathrm{~kg} / \mathrm{m}^{2}$ ). Thus, there is little variation or uncertainty associated with harvest indices for grains. Uncertainty in harvest index values for other vegetables and fruits was accounted for by selection of four to five crops per crop type. The distributions for dry biomass are more sensitive to variation in yield than harvest indices (see selection of distribution bounding values above). Therefore, changes in the accuracy of harvest index for representative crops has little influence on the distribution bounds of dry biomass for each crop type.

The same distributions are recommended for both climate scenarios and for use in both the biosphere groundwater and volcanic ash exposure scenarios (see introduction to Section 6). Distributions for yield and dry-to-wet-weight ratios were developed from a variety of crops and arid to semi-arid climate conditions representative of present-day and future climates (see Sections 6.2 and 6.11). Therefore, yield, dry-to-wet-weight ratios, or other physical characteristics of crops that influence dry biomass account for influences that climate change or a volcanic eruption at Yucca Mountain would have. Uncertainty associated with differences that might occur in dry biomass between crops grown in Amargosa Valley and other locations is accounted for through use of locally grown crops and incorporation of variation in the distributions. 


\subsection{DRY-TO-WET-WEIGHT RATIOS}

\subsubsection{Use in Biosphere Model}

The dry-to-wet-weight ratio $\left(D W_{j}, \mathrm{~kg}\right.$ dry plant $/ \mathrm{kg}$ wet plant $)$ is a measure of the ratio of dry mass to wet mass of edible foodstuffs per crop type. It is used in the plant submodel in the calculation of radionuclide concentrations in plant foodstuffs contributed from plant root uptake ( $C p_{\text {root } i, j}$, $\mathrm{Bq} / \mathrm{kg}_{\text {wet plant }}$ ) (Equation 6.2-1; BSC 2004 [DIRS 169460], Section 6.4.3). The dry-to-wet-weight ratio is included in this equation because the transfer factors are based on the dry weight of food.

$$
C p_{\text {root } i, j}=C s_{m, i} F_{s \rightarrow p i, j} D W_{j}
$$

where

$$
\begin{aligned}
& C s_{m, i}=\text { activity concentration of radionuclide } i \text { in surface soil }(\mathrm{Bq} / \mathrm{kg} \text { dry soil }), \\
& F_{s \rightarrow p i, j}=\text { soil-to-plant transfer factor for radionuclide } i \text { and crop type } j\left(\mathrm{~Bq} / \mathrm{kg}_{\text {dry plant }} /\right. \\
& \left.\mathrm{Bq} / \mathrm{kg}_{\text {dry soil }}\right) \text {, } \\
& D W_{j}=\text { dry-to-wet weight ratio for edible part of plant }(\mathrm{kg} \text { dry plant } / \mathrm{kg} \text { wet plant })
\end{aligned}
$$

In this equation, the dry-to-wet-weight ratio has a positive, linear effect on radionuclide concentrations. Thus, plant root uptake will be greater for drier foodstuffs within a crop type (i.e., those with a larger ratio) than it will be for wetter plants.

\subsubsection{Parameter Development}

Information on the water content of food products compiled by the USDA 2002 ([DIRS 159272]; see Section 4.1.1) and dry-to-wet-weight ratios for alfalfa, corn silage, and oat hay from Till and Meyer 1983 ([DIRS 101895], Table 5.16, p. 5-48; see Section 4.1.2) are in Table 6.2-1. These data were used to develop distributions of dry-to-wet-weight ratios (Table 6.2-2).

The average for each crop type is the mean dry-to-wet-weight ratio of representative crops, with the exception of the weighted mean used for cattle forage (Table 6.2-2).

A cumulative distribution function is recommended for each crop type (Table 6.2-2). The probability distribution ranges between the minimum and maximum dry-to-wet-weight ratios of representative crops within a crop type (e.g., dry-to-wet-weight ratios for leafy vegetables range from 0.041 [head lettuce] to 0.093 [broccoli], Table 6.2-1). The distribution between the minimum and maximum crop dry-to-wet-weight ratios is divided into intervals of virtually equal probability, with the exception of cattle forage. The number of intervals is one less than the number of representative crops and the upper bounds are crop-specific values of dry-to-wet-weight ratios (Table 6.2-2). The probabilities for the two cattle forage intervals were weighted $3: 1$ for the range between oat hay and alfalfa $(p=0.75)$ versus the range between alfalfa and corn silage $(\mathrm{p}=0.25)$ (see introduction to Section 6 for justification). This results in a higher probability of selection of values that are similar to alfalfa. 
The number of samples used by USDA to calculate water content per crop generally is large (10 to more than 200 measurements for all but cucumbers [3 measurements], leaf lettuce [estimated], potatoes [9], and barley [7]). The standard errors of their estimates of average percent water content per crop are very small (range $=0.06$ to 1.0 percent). Because dry-to-wet-weight ratios are a simple conversion of crop water content $(1-[\%$ water $/ 100])$ the variation per crop in dry-to-wet-weight ratios is also very small. Thus, there is so little variation or uncertainty about the dry-to-wet-weight ratio per crop that it was not necessary to extend the distribution beyond crop specific values. Additionally, because very little within crop variation in moisture content occurred across climatic zones that were included in the USDA database, it is reasonable to expect that published values of dry-to-wet-weight ratios would be consistent with those of crops grown in Amargosa Valley.

Table 6.2-1. Dry-to-Wet-Weight Ratios

\begin{tabular}{|c|c|c|c|c|c|c|c|}
\hline $\begin{array}{c}\text { Crop Type } \\
\text { Crop }\end{array}$ & NDB No. ${ }^{b}$ & \% Water & $\begin{array}{l}\text { Dry:Wet } \\
\text { Ratio }^{c}\end{array}$ & $\begin{array}{c}\text { Crop Type } \\
\text { Crop }\end{array}$ & NDB No. ${ }^{b}$ & \% Water & $\begin{array}{c}\text { Dry:Wet } \\
\text { Ratio }^{c}\end{array}$ \\
\hline Leafy Vegetables & & & & Fruits & & & \\
\hline Broccoli & 11090 & 90.69 & 0.093 & Apples & 09004 & 84.46 & 0.155 \\
\hline Cabbage & 11109 & 92.15 & 0.078 & Grapes & 09132 & 80.56 & 0.194 \\
\hline Cauliflower & 11135 & 91.91 & 0.081 & Melons & 09181 & 89.78 & 0.102 \\
\hline Celery & 11143 & 94.64 & 0.054 & Strawberries & 09316 & 91.57 & 0.084 \\
\hline Head Lettuce & 11252 & 95.89 & 0.041 & Tomatoes & 11529 & 93.76 & 0.062 \\
\hline Leaf Lettuce & 11253 & 94.00 & 0.060 & Average & & & 0.120 \\
\hline Spinach & 11457 & 91.58 & 0.084 & $S^{d}$ & & & 0.054 \\
\hline Average & & & 0.070 & & & & \\
\hline \multirow[t]{2}{*}{$S D^{d}$} & & & 0.019 & Grains & & & \\
\hline & & & & Barley & 20004 & 9.44 & 0.906 \\
\hline \multicolumn{2}{|l|}{ Other Vegetables } & & & Corn & 20014 & 10.37 & 0.896 \\
\hline Bell peppers & 11333 & 92.19 & 0.078 & Oats & 20038 & 8.22 & 0.918 \\
\hline Carrots & 11124 & 87.79 & 0.122 & Wheat flour & 20076 & 10.94 & 0.891 \\
\hline Cucumbers & 11206 & 96.49 & 0.035 & Average & & & 0.903 \\
\hline Onions & 11282 & 89.68 & 0.103 & $S D^{d}$ & & & 0.012 \\
\hline Potatoes & 11352 & 92.02 & 0.080 & & & & \\
\hline Squash & 11641 & 93.68 & 0.063 & Cattle Forage & & & \\
\hline Corn & 11167 & 75.96 & 0.240 & Alfalfa hay ${ }^{\mathrm{e}}$ & & & 0.227 \\
\hline Average & & & 0.103 & Corn silage ${ }^{\mathrm{e}}$ & & & 0.238 \\
\hline \multirow[t]{3}{*}{$S D^{d}$} & & & 0.067 & Oat hay ${ }^{\mathrm{e}}$ & & & 0.182 \\
\hline & & & & Average & & & 0.216 \\
\hline & & & & $S D^{d}$ & & & 0.030 \\
\hline
\end{tabular}

${ }^{\text {a }}$ Source for vegetables, fruits, and grains: USDA 2002 ([DIRS 159272]).

b USDA 2002 ([DIRS 159272]) nutrient database number (NDB No.) for a foodstuff.

c Calculated as 1 - $(\%$ water $\div 100)$ for most vegetables, fruits, and grains.

${ }^{d}$ Standard deviation calculated using the STDEV function of Excel.

e Source: Till and Meyer 1983 ([DIRS 101895], Table 5.16 p. 5-48, with grass considered representative of oat hay). 
Table 6.2-2. Averages and Cumulative Distribution Functions for Dry-to-Wet-Weight Ratios

\begin{tabular}{|c|c|c|c|c|c|c|c|}
\hline Crop Type & Average $^{a}$ & $\begin{array}{c}\text { Upper } \\
\text { Limit of } \\
\text { Interval }^{\mathbf{b}}\end{array}$ & $\begin{array}{l}\text { Cumulative } \\
\text { Probability }\end{array}$ & Crop Type & Average $^{\mathrm{a}}$ & $\begin{array}{c}\text { Upper } \\
\text { Limit of } \\
\text { Interval }^{\text {b }} \\
\end{array}$ & $\begin{array}{l}\text { Cumulative } \\
\text { Probability }\end{array}$ \\
\hline \multirow{8}{*}{$\begin{array}{l}\text { Leafy } \\
\text { Vegetables }\end{array}$} & 0.070 & 0.041 & 0.00 & Fruits & 0.120 & 0.062 & 0.00 \\
\hline & & 0.054 & 0.17 & & & 0.084 & 0.25 \\
\hline & & 0.060 & 0.33 & & & 0.102 & 0.50 \\
\hline & & 0.078 & 0.50 & & & 0.155 & 0.75 \\
\hline & & 0.081 & 0.67 & & & 0.194 & 1.00 \\
\hline & & 0.084 & 0.83 & & & & \\
\hline & & 0.093 & 1.00 & Grains & 0.903 & 0.891 & 0.00 \\
\hline & & & & & & 0.896 & 0.33 \\
\hline \multirow{7}{*}{$\begin{array}{l}\text { Other } \\
\text { Vegetables }\end{array}$} & 0.103 & 0.035 & 0.00 & & & 0.906 & 0.67 \\
\hline & & 0.063 & 0.17 & & & 0.918 & 1.00 \\
\hline & & 0.078 & 0.33 & & & & \\
\hline & & 0.080 & 0.50 & \begin{tabular}{|l|} 
Cattle \\
Forage $^{\mathrm{c}}$
\end{tabular} & 0.220 & 0.182 & 0.00 \\
\hline & & 0.103 & 0.67 & & & 0.227 & 0.75 \\
\hline & & 0.122 & 0.83 & & & 0.238 & 1.00 \\
\hline & & 0.240 & 1.00 & & & & \\
\hline
\end{tabular}

${ }^{a}$ Mean dry-to-wet-weight ratio for a crop type from Table 6.2-1, with the exception of the weighted mean calculated for cattle forage. The weighted mean was calculated as $(3 \times 0.227$ [dry-to-wet-weight ratio for alfalfa] $+1 \times 0.238$ [dry-to-wet-weight ratio for corn silage] $+1 \times 0.182$ [dry-to-wet-weight ratio for oat hay]) $/ 5=0.220$.

${ }^{\mathrm{b}}$ Limits determined from crop specific dry-to-wet-weight ratios (see Table 6.2-1).

${ }^{c}$ The probabilities for the two cattle forage intervals were weighted $3: 1$ for the range between oat hay and alfalfa $(p=0.75)$ versus the range between alfalfa and corn silage $(p=0.25)$.

The important sources of variation and uncertainty for dry-to-wet-weight ratios are related to variation among crops within a crop type and uncertainty in the types of locally grown crops planted and consumed. These are adequately accounted for through the use of three or more representative crops within a crop type.

Values of the dry-to-wet-weight ratios for alfalfa (0.227), corn silage (0.238), and oat hay (0.182) were selected for this analysis (see Section 4.1.2). Comparable values used in radiological assessments include 0.19 for alfalfa (IAEA 1994 [DIRS 100458], Table 5), 0.22 for fresh forage (Kennedy and Strenge 1992 [DIRS 103776], Table 6.17), 0.20 for fresh forage (Napier et al. 1988 [DIRS 157927], Table 4.25 on p. 4.71), and 0.22 for beef cattle fresh forage (LaPlante and Poor 1997 [DIRS 101079], Table B-1 on p. B-9). In addition, Orloff 1997 ([DIRS 158788], p. 109) states that the moisture content of alfalfa is generally between 75 and 80 percent, the midpoint of which equals a dry-to-wet-weight ratio of 0.225 . These values are within the range of those selected, indicating that there is little uncertainty about the dry-towet-weight ratios of forage. Therefore, the recommended distributions are adequate for each crop-type.

The same distributions are recommended for both climate scenarios and for use in both the biosphere groundwater and volcanic ash exposure scenarios (see introduction to Section 6) 
because climate change and a volcanic eruption at Yucca Mountain will not result in a change in the moisture content of foods or forage.

\subsection{FRACTION OF OVERHEAD IRRIGATION}

\subsubsection{Use in Biosphere Model}

The fraction of a crop type that is irrigated using sprinkler or spray irrigation $\left(f_{o, j}\right.$, dimensionless) is used in the plant submodel in the calculation of uptake into foodstuffs of radionuclides deposited on the plant surface via water (Equation 6.3-1; BSC 2004 [DIRS 169460], Section 6.4.3). This equation, without $f_{o, j}$, is also used to calculate the interception of soil on the surface of plants.

$$
C p_{\text {water } i, j}=\frac{D w_{i, j} f_{o j} R w_{j} T_{j}}{\lambda_{w} Y_{j}}\left(1-e^{-\lambda_{w} t_{g, j}}\right)
$$

where

$$
\begin{aligned}
& C p_{\text {water } i, j}=\text { activity concentration of radionuclide } i \text { in crop type } j \text { contributed from the } \\
& D w_{i, j} \quad=\text { the deposition rate of radionuclide } i \text { due to application of irrigation water } \\
& \left(D w_{i, j}\right) \text { or resuspended dust }\left(D a_{i, j}\right) \text { onto crop type } j\left(\mathrm{~Bq} / \mathrm{m}^{2} \mathrm{~d}\right) \text {, } \\
& f_{o j} \quad=\text { fraction of irrigation applied using overhead methods for crop type } j \\
& \text { (dimensionless); this parameter only applies to uptake from irrigation water } \\
& \text { and does not appear in the equation for deposition via dust, } \\
& R w_{j} \quad=\text { the interception fraction for irrigation water for crop type } j \text {; or } R a_{j} \\
& \text { interception fraction of resuspended dust for crop type } j \text { (dimensionless), } \\
& T_{j} \quad=\text { the translocation factor for crop type } j \text {, (dimensionless), } \\
& \lambda_{w} \quad=\text { the weathering constant (per d), which can be calculated from weathering } \\
& \text { half-life ( } \mathrm{T}_{\mathrm{w}} \text { in units of day) by } \lambda_{w}=\ln (2) / \mathrm{T}_{\mathrm{w}} \text {, } \\
& Y_{j} \quad=\text { crop yield or wet biomass for crop type } j\left(\mathrm{~kg} \text { wet weight } / \mathrm{m}^{2}\right) \text {, } \\
& t_{g, j} \quad=\text { crop growing time for crop type } j(\mathrm{~d}) \text {. }
\end{aligned}
$$

The fraction of overhead irrigation is included in the model to account for the portion of crops that are not watered using overhead sprinklers and to propagate uncertainty in irrigation methods. A change in this fraction results in a proportional change in the numerator of Equation 6.3-1.

\subsubsection{Parameter Development}

There are three basic methods used to irrigate field crops, orchards, and gardens: surface irrigation, drip systems, and sprinkler systems. Surface irrigation includes ditch and furrow irrigation and other flood methods that saturate part, or all, of the soil surface. Drip irrigation 
includes the use of bubblers, drip emitters, drip tubing, micro sprays, or other methods that deliver water to the soil surface at or near the base of plants. Sprinkler systems include stationary and mobile sprinklers (e.g., center pivot, side roll sprinklers) that spray water over plants, and lawn-type sprinklers and garden hoses sprayed over gardens. Overhead spraying is the only method that will result in groundwater contaminated with radionuclides being applied to the leaf surfaces (i.e., uptake by foliar interception of irrigation water). Because the rate of removal of radionuclides from the surface of plants (i.e., the weathering factor) is relatively fast (see Section 6.4.1), the method of irrigation used during the month prior to harvesting is more important than that used during germination or early growth stages.

Distributions of the probability of leafy vegetables, other vegetables, and fruits being irrigated with overhead spray or sprinkler irrigation were developed from descriptions of irrigation methods commonly used to grow the representative crops in arid and semi-arid environments from USDA Cooperative Extension Service State Extension Offices. Distributions of the probability of grains and cattle forage being irrigated with overhead spray or sprinkler irrigation were developed from observations of irrigation methods in Amargosa Valley. These observations were recorded in 1998 during surveys conducted for the Radiological Monitoring Program (DTN: MO0208SPAMETHO.004 [DIRS 159565], Section 4.1.10, Table 4.1-6). Most (86 percent of grains and forage and at least 75 percent of all acreage) agricultural fields in Amargosa Valley during 1998 were irrigated with overhead sprinklers (Table 4.1-6). Because few fruits and vegetables are commercially grown in Amargosa Valley, and because there is little irrigation of crops in eastern Washington (Table A-3), much of the following information on irrigation practices for fruits and vegetables comes from Arizona and California. Information from Arizona and California was chosen because the arid climates of these southwestern states are consistent with the current arid conditions in Amargosa Valley, and it is reasonable to expect that irrigation methods would be similar in Amargosa Valley. There is no information available on the prevalence of irrigation methods used in gardens, although recommended methods are described in publications such as Antonelli et al. (1998 [DIRS 158654], p. 11) and Call (1999 [DIRS 158672], Chapter 18).

Because there is much variation and uncertainty associated with this parameter for most crop types, recommended distributions, which are summarized in Table 6.3-1, have relatively large standard deviations.

Table 6.3-1. Recommended Distributions for Fraction of Overhead Irrigation

\begin{tabular}{|l|c|c|c|c|c|}
\hline \multicolumn{1}{|c|}{ Crop Type } & $\begin{array}{c}\text { Type of } \\
\text { Distribution }\end{array}$ & Average & $\begin{array}{c}\text { Standard } \\
\text { Deviation }\end{array}$ & Minimum & Maximum \\
\hline Leafy Vegetables & Normal & 0.75 & 0.1 & 0.49 & 1.0 \\
\hline Other Vegetables & Normal & 0.75 & 0.1 & 0.49 & 1.0 \\
\hline Fruits & Normal & 0.50 & 0.1 & 0.24 & 1.0 \\
\hline Grains & Normal & 0.90 & 0.05 & 0.77 & 1.0 \\
\hline Cattle Forage & Normal & 0.90 & 0.05 & 0.77 & 1.0 \\
\hline
\end{tabular}

The same distributions are recommended for present-day and upper bound glacial transition climates because irrigation methods would not change appreciably due to changes in climate (in part because irrigation methods are substantially influenced by water availability, economics, 
and crop selection) and because increases or decreases of human knowledge and technology over time are not to be considered in this analysis, per 10 CFR 63.305(b) [DIRS 156605]. This parameter is not used in the biosphere volcanic ash exposure scenario; therefore, changes resulting from a volcanic eruption at Yucca Mountain are not considered in this analysis.

Leafy Vegetables and Other Vegetables-Surface irrigation (flood, ditch, and furrow) is commonly used for commercial production of most leafy vegetables and other vegetables, such as lettuce, carrots, and onions in Arizona (Martin et al. 1999 [DIRS 159383], 1999 [DIRS 159384], 1999 [DIRS 159382]; lettuce in California (Mayberry 2000 [DIRS 159386]); numerous vegetables in central and western Arizona (Teegerstrom and Umeda 2001 [DIRS 159392]; Teegerstrom et al. 2001 [DIRS 159391]), although some vegetables, such as bell peppers in California, may be grown using drip irrigation (Mayberry 2000 [DIRS 159388]). Use of overhead sprinkler irrigation for vegetables is uncommon in the southwestern United States, but is used at least some in semiarid regions of the Pacific Northwest (e.g., potatoes and sweet corn in south central Washington [Hinman et al. 1997 (DIRS 159376)]. Surface, drip, or sprinkler irrigation may be used in gardens.

To ensure that leaf interception of radionuclides is not underestimated, a normal distribution with a mean of 0.75 is recommended for leafy vegetables and other vegetables. To account for the large amount of uncertainty in this parameter, a standard deviation of 0.1 is recommended, with a minimum of 0.49 and a maximum of 1.0 (Table 6.3-1). The minimum value was based on the ninety-ninth percentile of the low end of the distribution (calculated as $0.75-[2.58 \times 0.1]$ ).

Fruits-Surface irrigation (melons in central and southwestern Arizona-Teegerstrom and Umeda 2001 [DIRS 159392]; Teegerstrom et al. 2001 [DIRS 159391]; cantaloupe in California-Mayberry 2000 [DIRS 159389]) and drip irrigation (watermelons in California-Mayberry 2000 [DIRS 160005]; strawberries in California-Klonsky and De Moura 2001 [DIRS 159381]) are commonly used for commercial production of melons and berries. Grapes are grown using drip or flood irrigation, in part because wetting leaves with overhead spraying causes leaf diseases (Wolf and Johnson 1999 [DIRS 159393], p. 5). Fruit and nut trees may be irrigated using stationary sprays on risers (Uriu and Magness 1967 [DIRS 159169], pp. 697 to 698); however, the water is sprayed under the canopy, and fruits do not get wet. Therefore, spray irrigation that would contaminate fruits is uncommon for commercial production of fruits. Surface, drip, or sprinkler irrigation may be used in gardens for melons, berries, and other low-growing fruits.

A normal distribution with a mean of 0.5 , a standard deviation of 0.1 , a minimum of 0.24 , and a maximum of 1.0 is recommended for fruits (Table 6.3-1). The minimum value was based on the ninety ninth percentile of the low end of the distribution (calculated as $0.5-[2.58 \times 0.1]$ ). The mean of this distribution is lower than that recommended for vegetables because leaf interception is not an important process for fruit and nut trees and because spray irrigation is uncommon for commercial production of other fruits.

Grains and Cattle Forage-At least 86 percent of 1,966 acres of grains and forage grown in Amargosa Valley during 1998 was irrigated using center pivot, side roll, or other types of sprinklers. About 12 percent was surface irrigated, and the method used to irrigate the remainder was not recorded (Table 4.1-6). Surface and sprinkler irrigation also are used elsewhere to 
irrigate grains and forage (Hinman et al. 1997 [DIRS 159376]; Orloff et al. 1997 [DIRS 158774], pp. 36 to 37; Teegerstrom and Clay 1999 [DIRS 159390]).

Because overhead sprinkler irrigation is used most often, but not exclusively, in Amargosa Valley for commercial crops, a normal distribution with a mean of 0.9 , a minimum of 0.77 , and a maximum of 1.0 is recommended for grains and cattle forage. Because there is less uncertainty about the type of irrigation used for these crops in Amargosa Valley than for other crops, a smaller standard deviation of 0.05 is recommended. The minimum value was based on the ninety ninth percentile of the low end of the distribution (calculated as $0.9-[2.58 \times 0.05]$ ).

\subsection{GROWING TIME}

\subsubsection{Use in Biosphere Model}

Growing time for crop type $j$ ( $t_{g j}$, days/growing season) is a measure of the amount of time crops are growing and exposed to contaminated water and dust. It is used in the biosphere model in the calculation of the uptake into foodstuffs of radionuclides deposited on the plant surface via water and dust interception (Equation 6.3-1).

Growing time is part of a negative exponent in the last term of Equation 6.3-1 that accounts for the weathering of radionuclides on plant surfaces. This term approaches one (i.e., no effect on radionuclide concentration as weathering of radionuclides on the leaf approach equilibrium conditions) as growing time increases. For a weathering half life of 14 days $\left(\lambda_{w}=0.05\right.$, calculated as $\ln _{2}$ /weathering half life), the weathering decay term equals 0.92 when $t_{g, j}=50$ days, 0.98 when $t_{g, j}=75$ days, and 0.99 when $t_{g, j}=90$ days. Therefore, weathering approaches equilibrium at 50 to 100 days, and leaf uptake is not sensitive to values of growing time greater than about 50 to 75 days.

\subsubsection{Parameter Development}

Selection of values for growing season length of representative crops is described in Section D2.1 of Appendix D and summarized in Table 6.4-1. The data from which these values were derived are described in Section 4.1.4.

Table 6.4-1. Growing Time (days)

\begin{tabular}{|c|c|c|c|c|c|}
\hline $\begin{array}{c}\text { Crop Type } \\
\text { Crop }\end{array}$ & $\begin{array}{l}\text { Present- } \\
\text { Day } \\
\text { Climate }^{a}\end{array}$ & $\begin{array}{c}\text { Upper } \\
\text { Bound } \\
\text { Glacial } \\
\text { Transition }^{\text {Climate }^{\mathrm{a}}}\end{array}$ & $\begin{array}{c}\text { Crop Type } \\
\text { Crop }\end{array}$ & $\begin{array}{l}\text { Present- } \\
\text { Day } \\
\text { Climate }^{\mathrm{a}}\end{array}$ & $\begin{array}{l}\text { Upper } \\
\text { Bound } \\
\text { Glacial } \\
\text { Transition }^{\text {Climate }}\end{array}$ \\
\hline Leafy Vegetables & & & Fruits & & \\
\hline Broccoli & 80 & 83 & Apples & 240 & 166 \\
\hline Cabbage & 85 & 75 & Grapes & 183 & 105 \\
\hline Cauliflower & 80 & 63 & Melons & 100 & 103 \\
\hline Celery & 125 & 110 & Strawberries & 205 & 64 \\
\hline Head Lettuce & 60 & 78 & Tomatoes & 80 & 88 \\
\hline Leaf Lettuce & 60 & 58 & Average & 161 & 105 \\
\hline Spinach & 50 & 55 & Recommended $^{\mathrm{b}}$ & 160 & 105 \\
\hline
\end{tabular}


Table 6.4-1. Growing Time (days) (Continued)

\begin{tabular}{|c|c|c|c|c|c|}
\hline Average & 77 & 75 & & & \\
\hline \multirow[t]{2}{*}{ Recommended $^{\mathrm{b}}$} & 75 & 75 & Grains & & \\
\hline & & & \begin{tabular}{|r} 
Barley \\
\end{tabular} & 243 & 91 \\
\hline \multicolumn{3}{|l|}{ Other Vegetables } & Corn & 154 & 178 \\
\hline Bell peppers & 78 & 100 & Oats & 160 & 141 \\
\hline Carrots & 75 & 80 & Winter wheat & 243 & 334 \\
\hline Cucumbers & 60 & 68 & Average & 200 & 186 \\
\hline Onions & 110 & 155 & Recommended $^{\mathrm{b}}$ & 200 & 185 \\
\hline Potatoes & 110 & 115 & & & \\
\hline Squash & 58 & 65 & Cattle Forage & & \\
\hline Sweet corn & 82 & 105 & \begin{tabular}{|c|} 
Alfalfa hay \\
\end{tabular} & 56 & 70 \\
\hline Average & 82 & 98 & Corn silage & 93 & 137 \\
\hline \multirow[t]{3}{*}{ Recommended $^{\mathrm{b}}$} & 80 & 100 & Oat hay & 75 & 57 \\
\hline & & & Average & 75 & 88 \\
\hline & & & Recommended $^{\mathrm{b}}$ & 75 & 90 \\
\hline
\end{tabular}

Different values are presented for each climate because differences in temperature, planting season, and selection of varieties adapted to those climates result in differences in season length for some crops. For example, barley is always grown as a winter/spring crop in southern Nevada and therefore has a long growing season, but can be grown in a much shorter time during spring and summer in eastern Washington (Appendix A, Figures A-1 and A-2).

The values in Table 6.4-1 represent the typical number of days that the representative crops must be irrigated (because they were selected primarily for calculations of irrigation rates). Thus, they are valid measurements of growing time for water interception calculations. They are also valid measurements of soil exposure time for annual crops (i.e., all representative vegetables and grains), cattle forage, and perennial fruits in southern Nevada, because these crops are irrigated throughout the entire growing season. Similarly, annual crops and cattle forage in eastern Washington are irrigated throughout the entire growing season making irrigation time equal to soil exposure time for the upper bound glacial transition climate analogue. However, irrigation time is not equal to soil exposure time for perennial fruits in eastern Washington (grapes, apples, and strawberries) because these crops are only irrigated until fruit harvest, but the leaves of these plants remain and are exposed to dust throughout the entire growing season. Because the average value of growing time for fruits for the upper bound glacial transition climate is greater than 100 days (and the model is insensitive to higher values, see Section 6.4.1) separate values for the soil interception calculation are not required.

Because leaf uptake is insensitive to changes in growing times greater than about 75 days, fixed values are recommended for this parameter, and recommended values were selected by rounding the average growing time per crop type to the nearest value divisible by five (Table 6.4-1). Rounding to the nearest value divisible by five was done to simplify presentation of data and because a higher level of accuracy was not necessary. 
Deposition and redistribution of a thin layer of ash expected from a volcanic eruption at Yucca Mountain would not cause long-term changes in climate or soil that would result in substantial changes in crop growing time (see Section 6.); therefore, the same distribution is recommended for both the biosphere groundwater and volcanic ash exposure scenarios.

\subsection{IRRIGATION RATE-ANNUAL AVERAGE}

\subsubsection{Use in Biosphere Model}

Irrigation rate $(I R, \mathrm{~m} /$ year $)$ is a measure of the average rate at which contaminated groundwater is applied to soils to irrigate plants. It is used in the soil submodel to calculate radionuclide concentrations in soil (Equation 6.5-1; BSC 2004 [DIRS 169460], Section 6.4.1), and in a very similar equation in the carbon-14 submodel. Changes in land use and crop rotation practices make it possible that a variety of plants, including garden crops, commercial crops, and horticultural plants could be grown on a plot of land over a long period. Because of this, the distribution for annual irrigation rate is based on all 26 representative crops and turf (Table 6.1). Using several plant types to develop the distribution for annual irrigation rate accounts for uncertainty in crop selection and rotation.

The equation used to calculate radionuclide concentrations in soil is (BSC 2004 [DIRS 169460], Equation 6.4.1-4):

$$
C s_{i}=\frac{C w_{i} I R}{\lambda_{e f f, i}}
$$

where

$$
\begin{aligned}
C s_{i}= & \text { activity concentration of radionuclide } i \text { in surface soil per unit area }\left(\mathrm{Bq} / \mathrm{m}^{2}\right), \\
i & =\text { index of primary radionuclide, } \\
C w_{i}= & \text { activity concentration of radionuclide } i \text { in the groundwater }\left(\mathrm{Bq} / \mathrm{m}^{3}\right), \\
I R & =\text { annual average irrigation rate on land }(\mathrm{m} / \mathrm{yr}), \\
\lambda_{e f f, i}= & \lambda_{d, i}+\lambda_{l, i}+\lambda_{e} \\
\lambda_{d, i}= & \text { radioactive decay constant for radionuclide } i(1 / \mathrm{yr}) ; \text { this can be calculated from } \\
& \text { radionuclide half-life using the conversion } \ln (2) / \mathrm{T}_{\mathrm{d}, \mathrm{i}}, \text { where } \mathrm{T}_{\mathrm{d}, \mathrm{i}} \text { is half-life of } \\
& \text { radionuclide } i(\mathrm{yr}), \\
= & \text { average annual leaching removal constant for radionuclide } i(1 / \mathrm{yr}), \\
\lambda_{l, i}= & \text { annual average surface soil erosion removal constant }(1 / \mathrm{yr}) .
\end{aligned}
$$

Changes in annual average irrigation rate have a linear effect on soil concentrations and therefore may be an important parameter in calculating BDCFs.

\subsubsection{Parameter Development}

Methods in Allen et al. (1998 [DIRS 157311]) and Doorenbos and Pruitt (1977 [DIRS 103062]) published by the FAO were used to calculate $I R$ and are justified in Appendix B (Section 2). Background information on plant water use is also included in Appendix B (Section 1). The methodology is based on determination of crop water requirements, which are calculated from 
evapotranspiration of a grass reference surface and adjusted with a crop-specific coefficient (Appendices $\mathrm{C}$ and D).

Parameter inputs were growing season lengths (Section 4.1.4), average monthly weather data for present-day, upper bound monsoon, lower bound and upper bound glacial transition climates (Section 4.1.5), and salinity of irrigation water (Section 4.1.7). Growing season lengths were used in Appendices D and E to adjust growth stage lengths and calculate seasonal water requirements, respectively. Average monthly weather data were used in Appendix C to calculate reference evapotranspiration $\left(E T_{o}\right)$ and in Appendix $\mathrm{E}$ to calculate effective precipitation. Salinity of irrigation water (Section 4.1.7) was used in Appendix E to determine the leaching requirement used to calculate seasonal water requirements.

Reference evapotranspiration was calculated for a grass reference surface and represents the effects of climate on crop evapotranspiration $\left(E T_{c}\right)$. The reference surface as defined by Allen et al. (1998 [DIRS 157311], p. 15) is a "hypothetical grass reference crop with an assumed crop height of $0.12 \mathrm{~m}$, a fixed surface resistance of $70 \mathrm{~s} \mathrm{~m}^{-1}$ and an albedo of 0.23 ". It is assumed to be of uniform height, actively growing, completely shading the ground, with an adequate water supply. Climatic variables that drive $E T_{o}$ include air temperature, humidity, radiation, and wind speed. The FAO Penman-Monteith equation (Allen et al. 1998 [DIRS 157311], Equation 6, p. 24) was used to calculate $E T_{o}$ (calculations and examples are in Appendix C). Mean monthly $E T_{o}$ was calculated for present-day, upper bound monsoon, lower bound future, and upper bound glacial transition climates (Appendix C, Table C-5). Variation and uncertainty in $E T_{o}$ that could affect irrigation parameter values are discussed in Sections 6.5.2, 6.7.2, 6.8.2, and 6.9.2.

The crop coefficient $\left(K_{c}\right)$ integrates the effects of four primary crop characteristics that differ from the reference grass surface (crop height, albedo, canopy resistance, and evaporation from soil). Changes in crop characteristics (i.e., leaf area, stomatal conductance, developmental stages) over the growing season also affect $K_{c}$; therefore, growth stage information was used to derive crop specific values (calculations and examples are in Appendix D). Locally determined values for $K_{c}$ were not available for this analysis and so values published in Allen et al. (1998 [DIRS 157311], Table 12, pp. 104 to 108) were used for the 26 representative crops and turf. To reduce uncertainty associated with published $K_{c}$, and to ensure consistency with present knowledge of the conditions in the Yucca Mountain region, these values were adjusted to local conditions using relative humidity and wind speed for the four climate states (Appendix D, Tables D-5 and D-6). A monthly mean $K_{c}$ was calculated to correspond with monthly mean $E T_{o}$ (Appendix D).

Variation in $K_{c}$ is primarily influenced by differences in crop specific characteristics (Allen et al. 1998 [DIRS 157311], p. 90). This allows standard $K_{c}$ values to be used across geographical locations and different climates, which has resulted in general acceptance and usefulness of the $K_{c}$ methodology. There is little variation in $K_{c}$ values among crops within a crop type (Allen et al. 1998 [DIRS 157311], p. 109). Use of a variety of representative crops and crop types that are grown in Amargosa Valley and eastern Washington adequately accounts for variation and uncertainty in $K_{c}$ for this analysis, and ensures consistency with present knowledge of the conditions in the Yucca Mountain region and future climate states. 
Crop evapotranspiration was used with information on timing of growing seasons to determine average monthly crop water requirements. Average daily $E T_{c}$ ( $E T_{c}$ daily $)$ for each month (Appendix D, Section 5, Tables D-7 and D-8) was calculated according to Allen et al. (1998 [DIRS 157311], Equation 58 on p. 103):

$$
E T_{c \text { daily }}=K_{c} \times E T_{o}
$$

Where $E T_{c}$ daily and $E T_{o}$ are in units of $\mathrm{mm} /$ day, and $K_{c}$ is dimensionless. The resulting value was multiplied by the number of growing season days per month to get mean monthly $E T_{c}$ ( $E T_{C}$ monthly, $\mathrm{mm} / \mathrm{month}$ ) needed to estimate seasonal water requirements.

Seasonal crop water requirements ( $W_{s}$, Appendix E, Section 2.4) were calculated using the following equation from Doorenbos and Pruitt (1977 [DIRS 103062], p. 79):

$$
W_{s}=\frac{\sum_{i=1}^{n}\left(E T_{c \text { monthly }}-P e\right)}{1-L R}
$$

where

$$
\begin{array}{ll}
E T_{c \text { monthly }}= & \text { monthly mean crop evapotranspiration }(\mathrm{mm}), \\
P e & =\text { monthly mean effective precipitation ( } \mathrm{mm}[\mathrm{see} \text { Appendix E for calculation } \\
& \text { methods }]) \\
L R & =\text { leaching requirement (dimensionless), } \\
n & =\text { months in growing season. }
\end{array}
$$

Seasonal irrigation requirements $(I n)$ were calculated from one of the following equations from Doorenbos and Pruitt (1977 [DIRS 103062], p. 70). The first equation was used if precipitation met the seasonal LR (Appendix E, Section 2.4). The second equation was used if irrigation was required to meet the seasonal LR (Appendix E, Section 2.4).

$$
\begin{gathered}
\text { In }=\sum_{i=1}^{n} E T_{c \text { monthly }}-\left(\sum_{i=1}^{n} P e+G e+W b\right) \\
\text { In }=W_{s}-(G e+W b)
\end{gathered}
$$

where

$$
\begin{aligned}
& E T_{c \text { monthly }}=\text { monthly mean crop evapotranspiration }(\mathrm{mm}), \\
& \mathrm{Pe} \quad=\text { monthly mean effective precipitation }(\mathrm{mm}) \text {, } \\
& \mathrm{Ge} \quad=\text { groundwater contribution to the water requirement ( } \mathrm{mm} \text { [see Appendix E } \\
& \text { for calculation methods]), } \\
& \mathrm{Wb} \quad=\text { stored soil moisture in the root system (mm [see Appendix E for calculation } \\
& \text { methods]), } \\
& W_{s} \quad=\text { seasonal crop water requirement }(\mathrm{mm}) \\
& n \quad=\text { months in growing season. }
\end{aligned}
$$


For each crop and turf, annual average irrigation rate $(I R)$ was equal to In (Appendix E, Sections 1 though 2.4 and Table 6.5-1) and used to calculate means and develop distributions. For two season crops and alfalfa, average values of $I R$ were summed across growing seasons to get a total for the year (Tables 6.5-1 and 6.5-2).

Values of $I R$ were determined for the 26 crops and turf to calculate average $I R$ for the upper bound monsoon and lower bound glacial transition climates (Table 6.5-1). This was done to support development of BDCFs for the three climate states used in TSPA. See Section 6 [Climate States] and BSC (2004 [DIRS 169674], Section 6.1.3) for description of use of these means in development of BDCFs for the three climate states used in TSPA. The averages for IR were $0.52 \mathrm{~m} /$ year and $0.88 \mathrm{~m} /$ year for upper bound monsoon and lower bound glacial transition climate conditions, respectively (Table 6.5-1).

Table 6.5-1. Average Annual Irrigation Rates (IR, m/year) for 26 Crops and Turf Grass for Upper Bound Monsoon and Lower Bound Glacial Transition Climates

\begin{tabular}{|c|c|c|c|c|c|}
\hline Crop & $\begin{array}{l}\text { Upper Bound } \\
\text { Monsoon } \\
\text { Climate }^{\mathrm{a}}\end{array}$ & $\begin{array}{l}\text { Lower Bound } \\
\text { Glacial } \\
\text { Transition } \\
\text { Climate }^{\mathrm{a}} \\
\end{array}$ & Crop & $\begin{array}{l}\text { Upper Bound } \\
\text { Monsoon } \\
\text { Climate }^{\mathrm{a}}\end{array}$ & $\begin{array}{l}\text { Lower Bound } \\
\text { Glacial } \\
\text { Transition } \\
\text { Climate }^{\mathrm{a}}\end{array}$ \\
\hline Alfalfa & 1.07 & 1.36 & Head lettuce & 0.36 & 1.09 \\
\hline Apples & 1.00 & 1.18 & Lettuce & 0.37 & 0.80 \\
\hline Barley & 0.54 & 0.56 & Melons & 0.29 & 0.76 \\
\hline Bell Peppers & 0.35 & 0.80 & Oat feed & 0.34 & 0.92 \\
\hline Broccoli & 0.48 & 1.11 & Oat hay & 0.26 & 0.39 \\
\hline Cabbage & 0.52 & 1.05 & Onions & 0.90 & 1.05 \\
\hline Carrots & 0.55 & 1.29 & Potatoes & 0.51 & 0.90 \\
\hline Cauliflower & 0.47 & 0.80 & Spinach & 0.27 & 0.66 \\
\hline Celery & 0.85 & 0.86 & Squash & 0.15 & 0.43 \\
\hline Feed Corn & 0.44 & 1.15 & Strawberries & 0.81 & 0.39 \\
\hline Corn silage & 0.31 & 1.08 & Sweet corn & 0.46 & 0.88 \\
\hline Cucumbers & 0.16 & 0.51 & Tomatoes & 0.32 & 0.74 \\
\hline \multirow[t]{5}{*}{ Grapes } & 0.52 & 0.58 & Turf Grass & 1.05 & 1.26 \\
\hline & & & Winter Wheat & 0.57 & 1.22 \\
\hline & & & Average & 0.52 & 0.88 \\
\hline & & & $\mathrm{SD}^{\mathrm{b}}$ & 0.26 & 0.29 \\
\hline & & & $\mathrm{CV}^{\mathrm{C}}$ & 0.51 & 0.32 \\
\hline
\end{tabular}

a Irrigation rates from Tables E-6 and E-7 for upper bound monsoon and lower bound glacial transition climates, respectively. See Appendix $E$ for calculation methods and examples.

${ }^{\mathrm{b}}$ Standard deviation calculated using the STDEV function of Excel.

${ }^{c}$ Coefficient of variation (SD/mean).

Averages and two types of distributions (cumulative and normal) were developed for $I R$ using the 26 crops and turf for present-day and upper bound glacial transition climates. See Section 6 [Climate States] and BSC (2004 [DIRS 169674], Section 6.1.3) for description of use of these distributions in development of BDCFs for the three climate states used in TSPA.

The averages for $I R$ for present-day and upper bound glacial transition climate conditions were $0.95 \mathrm{~m} /$ year and $0.50 \mathrm{~m} /$ year, respectively (Table 6.5-2). Two distributions for $I R$ are included in 
this analysis for present-day and upper bound glacial transition climates so that the more appropriate distribution can be selected for use in the biosphere model. IR differs from other parameters in this analysis because it is used for long-term radionuclide accumulation in soil. Because of this, the biosphere model could require $I R$ values that are representative of long-term averages, which do not include the entire range of possible variation. In this case, normal distributions with the calculated means and standard errors are recommended for both climates (Table 6.5-3). To avoid extreme values that are not representative of long-term averages, the ninety-ninth percentiles are recommended as the minimum and maximum values for the distributions. For present-day climate, this results in a distribution with values that range from 0.74 to $1.16 \mathrm{~m} /$ year (Table $6.5-3$ ). For upper bound glacial transition climate, the distribution values range from 0.40 to $0.60 \mathrm{~m} /$ year (Table $6.5-3$ ).

Table 6.5-2. Average Annual Irrigation Rates (IR, m/year) for 26 Crops and Turf Grass for Present-Day and Upper Bound Glacial Transition Climates

\begin{tabular}{|c|c|c|c|c|c|}
\hline Crop & $\begin{array}{l}\text { Present-Day } \\
\text { Climate }^{\mathrm{a}}\end{array}$ & $\begin{array}{c}\text { Upper Bound } \\
\text { Glacial } \\
\text { Transition } \\
\text { Climate }^{\mathrm{a}} \\
\end{array}$ & Crop & $\begin{array}{c}\text { Present-Day } \\
\text { Climate }^{\mathrm{a}}\end{array}$ & $\begin{array}{l}\text { Upper Bound } \\
\text { Glacial } \\
\text { Transition } \\
\text { Climate }^{\mathrm{a}} \\
\end{array}$ \\
\hline Alfalfa & 1.94 & 0.83 & Head lettuce & 0.66 & 0.63 \\
\hline Apples & 1.82 & 0.73 & Lettuce & 0.66 & 0.46 \\
\hline Barley & 0.84 & 0.31 & Melons & 0.84 & 0.49 \\
\hline Bell Peppers & 0.72 & 0.42 & Oat feed & 0.57 & 0.55 \\
\hline Broccoli & 0.83 & 0.64 & Oat hay & 0.46 & 0.21 \\
\hline Cabbage & 0.91 & 0.58 & Onions & 1.34 & 0.54 \\
\hline Carrots & 1.00 & 0.71 & Potatoes & 0.84 & 0.47 \\
\hline Cauliflower & 0.83 & 0.44 & Spinach & 0.51 & 0.37 \\
\hline Celery & 1.50 & 0.46 & Squash & 0.40 & 0.18 \\
\hline Feed Corn & 1.18 & 0.73 & Strawberries & 1.44 & 0.16 \\
\hline Corn silage & 0.83 & 0.69 & Sweet corn & 0.74 & 0.52 \\
\hline Cucumbers & 0.50 & 0.21 & Tomatoes & 0.69 & 0.38 \\
\hline \multirow[t]{5}{*}{ Grapes } & 0.99 & 0.36 & Turf Grass & 1.62 & 0.83 \\
\hline & & & Winter Wheat & 0.94 & 0.67 \\
\hline & & & Average & 0.95 & 0.50 \\
\hline & & & $S D^{b}$ & 0.41 & 0.19 \\
\hline & & & $\mathrm{CV}^{\mathrm{c}}$ & 0.43 & 0.38 \\
\hline
\end{tabular}

${ }^{a}$ Irrigation rates from Tables E-5 and E-8 for present-day and upper bound glacial transition climates, respectively. See Appendix $E$ for calculation methods and examples.

b Standard deviation calculated using the STDEV function of Excel.

${ }^{c}$ Coefficient of variation (SD/mean).

Table 6.5-3. Averages and Normal Distributions for Long-Term Average Annual Irrigation Rates (IR m/year)

\begin{tabular}{|c|c|c|c|c|}
\hline & Average $^{\mathbf{a}}$ & $\begin{array}{c}\text { Standard } \\
\text { Error }\end{array}$ & Minimum & Maximum \\
\hline Present-Day Climate & 0.95 & 0.08 & 0.74 & 1.16 \\
\hline $\begin{array}{c}\text { Upper Bound Glacial } \\
\text { Transition Climate }\end{array}$ & 0.50 & 0.04 & 0.40 & 0.60 \\
\hline
\end{tabular}

${ }^{a}$ Mean IR of 26 representative crops and turf calculated from Table 6.5-2. 
If the biosphere model requires an $I R$ distribution that includes yearly variation and a wider range of uncertainty, then cumulative distribution functions are recommended for present-day and upper bound glacial transition climates (Table 6.5-4). Ninety percent of the probability distribution is between the minimum and maximum $I R$ of representative crops (e.g., range $=0.40$ [squash] to 1.94 [alfalfa] $\mathrm{m} /$ year for present-day climate). The distribution between the minimum and maximum crop $I R$ is divided into five intervals of equal probability (summing to 90 percent, Table 6.5-4), with 5 or 6 crops per interval. To account for variation and uncertainty beyond the range of crop specific values, intervals of five-percent probability each were added to the lower and upper ends of the distribution. To avoid $I R$ values that could result in yield reduction or plant mortality due to water stress, recommended minimum bounds for present-day and upper bound glacial transition climate distributions are $0.33 \mathrm{~m} / \mathrm{year}$ and $0.14 \mathrm{~m} / \mathrm{year}$, respectively (Table 6.5-4). To include variation and uncertainties associated with season length and excessive irrigation, maximum bounds of $2.29 \mathrm{~m} /$ year and $0.98 \mathrm{~m} /$ year are recommended for present-day and upper bound glacial transition climates, respectively (Table 6.5-4). Minimum and maximum bounds are justified in the analysis below.

Table 6.5-4. Averages and Cumulative Distributions for Annual Average Irrigation Rates (IR m/year) for Present-Day and Upper Bound Glacial Transition Climates

\begin{tabular}{|c|c|c|c|c|c|}
\hline \multicolumn{3}{|c|}{ Present-Day Climate } & \multicolumn{3}{|c|}{$\begin{array}{c}\text { Upper Bound Glacial Transition } \\
\text { Climate }\end{array}$} \\
\hline Average $^{\mathrm{a}}$ & $\begin{array}{l}\text { Upper } \\
\text { Limit of } \\
\text { Interval }\end{array}$ & $\begin{array}{l}\text { Cumulative } \\
\text { Probability }\end{array}$ & Average $^{a}$ & $\begin{array}{l}\text { Upper } \\
\text { Limit of } \\
\text { Interval }\end{array}$ & $\begin{array}{l}\text { Cumulative } \\
\text { Probability }\end{array}$ \\
\hline \multirow[t]{8}{*}{0.95} & 0.33 & 0.00 & 0.50 & 0.14 & 0.00 \\
\hline & 0.40 & 0.05 & & 0.16 & 0.05 \\
\hline & 0.66 & 0.23 & & 0.36 & 0.23 \\
\hline & 0.83 & 0.41 & & 0.46 & 0.41 \\
\hline & 0.91 & 0.59 & & 0.54 & 0.59 \\
\hline & 1.34 & 0.77 & & 0.69 & 0.77 \\
\hline & 1.94 & 0.95 & & 0.83 & 0.95 \\
\hline & 2.29 & 1.00 & & 0.98 & 1.00 \\
\hline
\end{tabular}

${ }^{a}$ Mean IR of 26 representative crops and turf calculated from Table 6.5-2.

This parameter is not used in the biosphere volcanic ash exposure scenario; therefore, changes resulting from a volcanic eruption at Yucca Mountain are not considered in this analysis.

Variation and Uncertainty-Variation in $I R$ is primarily from differences in water use among crops, variation in growing season length among crops, differences between minimum and maximum season lengths for each crop, and yearly variation in climate variables that drive $E T_{o}$. Uncertainty in the distribution of $I R$ is due to lack of knowledge about which crops a farmer will choose to grow and about water management practices (i.e., excessive watering or under watering during a growing season).

Variation among crops and uncertainty about which crops a farmer will grow are adequately accounted for through use of 26 crops and turf. Selection was based on an evaluation of crops currently grown in southern Nye County, Nevada and eastern Washington, national patterns of 
food consumption, and variation in the growing season under arid to semi-arid climate conditions for commonly grown and consumed crops (see Appendix A).

Within Crop Variation in Season Length-Generally, the midpoint of minimum and maximum season lengths gathered from several sources was selected as a representative and reasonable growing season length for each crop (Appendix D, Tables D-1 and D-2). For the present-day climate, within crop differences between the minimum and maximum season lengths ranged from 10 to 60 days with a mean difference of 32 days $(S D=15.2$, calculated from Table D-1). For the upper bound glacial transition climate, within crop differences between the minimum and maximum season lengths ranged from 5 to 70 days with a mean difference of 24 days $(S D=15.2$, calculated from Table D-2). Even though the ranges in minimum and maximum season lengths appear to be considerable, in most cases, season lengths were constrained by mean monthly temperatures for the two climates (i.e., temperatures below crop tolerance levels) or by growing two-season crops. These constraints resulted in relatively little variation in IR due to within crop differences in potential growing season lengths compared to variation in $I R$ among crops. Examples are illustrated below.

Crops with the lowest IRs were evaluated to establish low bounds for the distributions that would encompass the potential variation caused by minimum season lengths for a crop. Squash and strawberries had the lowest $I R$ for present-day and upper bound glacial transition climates, respectively (Table 6.5-2). However, there was no information on minimum and maximum ranges for season length for strawberries. Therefore, squash was used to evaluate the low end of the distributions for both climate conditions. Squash season length for present-day climate was 58 days, and the minimum season length was 50 days (Appendix D, Table D-1). Re-calculation of $I R$ based on the minimum season length showed a reduction from $0.40 \mathrm{~m} /$ year to $0.33 \mathrm{~m} /$ year. This value was selected as the minimum for the recommended distribution because it included variation in $I R$ due to season length for a single-season, low water-use crop, and also encompassed uncertainties regarding under-watering (discussed below).

Squash season length for upper bound glacial transition climate was 58 days, and the minimum season length was 50 days (Appendix D, Table D-2). Re-calculation of $I R$ based on the minimum season length showed a reduction from $0.18 \mathrm{~m} /$ year to $0.14 \mathrm{~m} / \mathrm{year}$. This value was selected as the minimum for the recommended distribution because it included variation in $I R$ due to season length for a low water-use crop, and also encompassed uncertainties regarding under-watering (discussed below).

Bounds for the high end of the distributions were evaluated using crops with high water-use, or a wide range between minimum and maximum growing season lengths. Alfalfa, apples, bermudagrass, and celery were considered for present-day climate, and alfalfa, fescue, carrots, and feed corn were considered for upper bound glacial transition climate.

Alfalfa had the highest $I R$ for present-day climate (1.94 m/year, Table 6.5-2) compared to other crops. Additionally, six cuttings were used, making the total growing time 336 days. Because of the time required for each cutting, and the short winter dormant period, additional cuttings or a longer time between cuttings were not possible. Thus, $1.94 \mathrm{~m} /$ year is the maximum amount of water that alfalfa can use based on maximum growing season length. Apples also had relatively high water requirements $(1.82 \mathrm{~m} /$ year$)$; however, apples are usually drip irrigated making the $I R$ 
less important to the distribution than alfalfa, which is sprinkler, irrigated. Bermudagrass (turf) also had a relatively high $I R(1.62 \mathrm{~m} /$ year $)$; however, its growing season was 365 days and could not be increased. The mean difference between minimum and maximum growing season lengths of 32 days for present-day climate was added to early celery because a range specific to celery was not available (Appendix D, Table D-1). A 32-day increase is similar to the ranges in growing season length for other leafy vegetables (Appendix D, Table D-1), and does not overlap the planting time for late season celery. Addition of days to the late season celery crop would do little to increase the irrigation requirement because of the very low evaporative demand in January and February. The resulting irrigation requirement for celery (early and late season) was $1.82 \mathrm{~m} /$ year, an increase of $0.32 \mathrm{~m} /$ year. This is similar to $I R$ for alfalfa $(1.94 \mathrm{~m} /$ year). Therefore, variation due to season length for two-season and multi-season high water-use crops is accounted for in the range of crop specific $I R$ for present-day climate conditions.

Tall fescue (turf grass) and alfalfa had the highest $I R(0.83 \mathrm{~m} /$ year $)$ for upper bound glacial transition climate compared to the remaining 25 crops. Growing season length was constrained by dormancy and occurrence of killing frost from November through the end of March, making it unreasonable to extend the growing seasons. Based on maximum growing season lengths, it is reasonable to conclude that $0.83 \mathrm{~m} / \mathrm{year}$ is the maximum amount of water that fescue or alfalfa would normally use. Maximum season lengths for carrots and feed corn were examined to determine whether variable growing season length or variable onset of growth (with no increase in season length) should be used to establish upper bounds for the upper bound glacial transition climate distribution of $I R$. These crops were chosen because they have relatively high $I R$ (carrots $=0.71 \mathrm{~m} /$ year and feed corn $=0.73 \mathrm{~m} /$ year).

Moving the planting date for carrots from April 23 to April 15 (Appendix D, Table D-2) resulted in an eight-day extension at the beginning of the growing season. Extension of the harvest date was not possible because of constraints imposed by the planting date for the late season crop (July 13 for carrots). Because of low evaporative demands in April, the 8-day extension of the growing season resulted in an $I R$ increase of only $0.02 \mathrm{~m} /$ year for carrots. This illustrates that use of two season crops encompasses the variation that might occur from within crop variation in growing season length at the high end of the distribution.

The planting and harvest dates for feed corn were moved forward 26 days to illustrate the impact of a change in timing of growth for a relatively high water-use crop $(0.73 \mathrm{~m} / \mathrm{year})$. The change in timing changed several parameters, including precipitation and evaporative demands, and resulted in an $I R$ of $0.85 \mathrm{~m} / \mathrm{year}$. This value is similar to those for fescue and alfalfa. Therefore, potential variation in $I R$ due to within-crop variation in timing of growth is encompassed by variation in $I R$ among crops for upper bound glacial transition climate conditions.

Yearly Variation in Climate-Variation in $I R$ from yearly variation in mean monthly climate variables that drive $E T_{o}$ was not directly calculated because the dataset that was used did not include this information. While hourly or daily variations in $E T_{o}$ can be large, $E T_{o}$ averaged for monthly time periods tend to be conservative from year to year (Tanner 1967 [DIRS 159950], Chapter 29, p. 557). Error in estimates of $E T_{o}$ using empirical formulas have been shown to decrease by two to three times as the period of estimation increased from one week to one month (Tanner 1967 [DIRS 159950], Chapter 29, p. 557). Variation from the expected monthly average in $E T_{o}$ was estimated using air temperature data as a meteorological index representing 
variation in evaporative demands. Monthly mean, average maximum, and average minimum air temperatures with standard deviations for 26 to 29 years in Amargosa Valley, Nevada (Table 6.5-5) were obtained from the Western Regional Climate Center (2002 [DIRS 161250], 2002 [DIRS 161251], 2002 [DIRS 160537]). The coefficient of variation (CV=SD/mean) showed little yearly variation occurred in the three temperature parameters each month (Table 6.5-5). Yearly variation ranged from 3.0 percent to 10.0 percent depending on the temperature parameter and month (Table 6.5-5). It should be noted that the input data used to calculate $I R$ for present-day climate were averaged over 5 years and the $C V$ would be higher than that for data averaged over 26 to 29 years. More variation in $I R$ occurred due to variation among crops (43 percent and 38 percent for present-day and upper bound glacial transition climates, respectively, Table 6-5.2) than would occur due to yearly variation in monthly mean $E T_{o}$. Therefore, it is reasonable to conclude that the recommended distributions encompass the variation in $I R$ that could be caused by yearly variation in mean monthly climate variables that drive $E T_{o}$.

Table 6.5-5. Monthly Mean Air Temperatures $\left({ }^{\circ} \mathrm{F}\right)$ for Amargosa, Nevada

\begin{tabular}{|c|c|c|c|c|c|c|c|c|c|c|c|c|}
\hline & Jan & Feb & March & April & May & June & July & Aug & Sept & Oct & Nov & Dec \\
\hline Mean Temperature & 45.9 & 50.2 & 55.5 & 62.3 & 71.7 & 80.0 & 85.9 & 84.9 & 77.2 & 66.0 & 52.9 & 45.4 \\
\hline$S D^{a}$ & 2.6 & 3.3 & 3.0 & 3.9 & 3.4 & 3.0 & 2.3 & 2.2 & 2.7 & 3.6 & 3.1 & 3.0 \\
\hline $\mathrm{CV}^{\mathrm{b}}$ & 0.06 & 0.07 & 0.05 & 0.06 & 0.05 & 0.04 & 0.03 & 0.03 & 0.03 & 0.05 & 0.06 & 0.07 \\
\hline Years $^{c}$ & 27.0 & 29.0 & 29.0 & 29.0 & 28.0 & 28.0 & 28.0 & 27.0 & 27.0 & 26.0 & 26.0 & 28.0 \\
\hline $\begin{array}{l}\text { Maximum } \\
\text { Temperature }\end{array}$ & 60.5 & 65.4 & 71.3 & 79.3 & 88.8 & 97.5 & 103.2 & 102.0 & 95.0 & 83.8 & 69.3 & 60.9 \\
\hline$S D^{a}$ & 3.9 & 4.8 & 4.8 & 4.0 & 4.8 & 4.0 & 3.2 & 2.6 & 2.9 & 3.4 & 4.4 & 4.4 \\
\hline $\mathrm{CV}^{\mathrm{b}}$ & 0.06 & 0.07 & 0.07 & 0.05 & 0.05 & 0.04 & 0.03 & 0.03 & 0.03 & 0.04 & 0.06 & 0.07 \\
\hline Years $^{c}$ & 27.0 & 29.0 & 29.0 & 29.0 & 29.0 & 28.0 & 28.0 & 28.0 & 27.0 & 27.0 & 26.0 & 28.0 \\
\hline $\begin{array}{l}\text { Minimum } \\
\text { Temperature }\end{array}$ & 31.4 & 35.0 & 39.6 & 45.3 & 54.6 & 62.4 & 68.6 & 67.8 & 59.4 & 48.2 & 36.5 & 30.0 \\
\hline$S D^{a}$ & 2.8 & 3.1 & 2.7 & 3.5 & 3.4 & 3.2 & 2.6 & 2.5 & 3.2 & 3.6 & 3.0 & 2.9 \\
\hline $\mathrm{CV}^{\mathrm{b}}$ & 0.09 & 0.09 & 0.07 & 0.08 & 0.06 & 0.05 & 0.04 & 0.04 & 0.05 & 0.07 & 0.08 & 0.10 \\
\hline Years $^{c}$ & 27.0 & 29.0 & 29.0 & 29.0 & 28.0 & 28.0 & 28.0 & 27.0 & 27.0 & 26.0 & 26.0 & 28.0 \\
\hline
\end{tabular}

Source: Western Regional Climate Center 2002 ([DIRS 161250], 2002 [DIRS 161251], 2002 [DIRS 160537]).

a Standard deviation.

${ }^{\mathrm{b}}$ Coefficient of variation $=\mathrm{SD} /$ mean).

${ }^{\mathrm{c}}$ Number of years that data were collected.

Uncertainty in Water Management Practices-Uncertainty in the distribution of IR due to lack of knowledge about water management practices (i.e., excessive irrigation or under-watering during a growing season) can be bounded by assessing practices that would result in reductions in crop yield.

Excessive irrigation-When irrigation exceeds the storage capacity of soil in the root zone, water percolates past the root zone, or runs off site and is unavailable for use by the plant, or will accumulate and waterlog poorly drained soils (Viets 1967 [DIRS 159952], Chapter 24, p. 466). Such situations affect nutrient availability and therefore crop yield. Excessive percolation 
leaches nitrates and other mineral nutrients that are essential to plant growth (Viets 1967 [DIRS 159952], Chapter 24, p. 466). In poorly drained soils, or if water is ponded at the surface for an extended period, water will replace oxygen in soil pores resulting in oxygen deficiencies for root growth and microbial activity (Viets 1967 [DIRS 159952], Chapter 24, pp. 466 and 478). Microbes compete with plant roots for oxygen, and reduce available nitrate through denitrification (nitrate converted to unusable gaseous nitrogen) in wet soils (Viets 1967 [DIRS 159952], Chapter 24, p. 478). Excessive irrigation can also increase annual weeds and perennial grasses which causes reduction in yield for most crops. Overwatering increases pumping costs and is limited by water permits. A farmer or gardener would probably respond to signs of excessive irrigation and modify their water management practices to avoid losses in yield or increases in pumping costs.

To determine reasonable upper bounds for IR distributions, impacts of overwatering alfalfa were evaluated. Overwatering alfalfa causes root and shoot diseases, nutrient losses through leaching, weed encroachment, and does not increase yield (Orloff et al. 1997 [DIRS 158774], p. 25). Environmental problems such as stream, river, or groundwater pollution can be a direct result of leaching fertilizers due to excessive irrigation of alfalfa (or other crops). Values for yield reduction caused by overwatering suggest that an approximate 18 percent increase in irrigation over crop requirements can result in yield reduction of about 0.4 tons per acre (Keller and Carlson 1967 [DIRS 159951], Figure 31-2, p. 612). Orloff et al. 1997 ([DIRS 158774]) suggest that alfalfa does not tolerate wet soils during periods of active growth, and wet soils have the potential to shorten stand life. Therefore, it is reasonable to suggest that farmers would not over irrigate alfalfa by more than about 18 percent of the crop water requirement. This percent increase results in $I R$ values of $2.29 \mathrm{~m} /$ year and $0.98 \mathrm{~m} /$ year for alfalfa under present-day and upper bound glacial transition climate conditions, respectively. To include uncertainty associated with excessive watering practices, these values were used as the upper bounds for the distributions of $I R$ for present-day and upper bound glacial transition climates.

Under-watering-Moisture stress occurs if precipitation and/or irrigation do not meet crop water requirements (see Appendix B). The level of moisture stress can vary from minor, where crop leaves wilt during the day but recover at night, to severe, where recovery is not possible and leaf desiccation occurs. Reductions in crop yield and quality can occur at various levels of water stress depending on the sensitivity of the crop. For example, grain crops tend to be more tolerant of water stress than potatoes or leafy vegetables (Robins et al. 1967 [DIRS 159939], pp. 635 and 636; Vittum and Flocker 1967 [DIRS 159941], pp. 676 and 677). As with excessive irrigation, it is likely that a farmer or gardener would respond to signs of under-watering by modifying their water management practices to avoid losses in quality and yield.

To evaluate the impacts that under-watering might have on the distribution of $I R$, soil moisture storage capacity of the root zone and crop sensitivity to soil moisture stress were considered for crops at the low end of the recommended distributions (Appendix E, Section 2.6). The methods used to calculate irrigation application (Section 6.7 and Appendix E, Section 2.5) were modified to reflect under-watering conditions that would likely cause stress. Soil moisture was allowed to stay at a level that would impose stress for two days prior to each scheduled irrigation event over a 30-day time period (scheduling of irrigation events differed according to crop requirements). Two days was chosen as a likely time interval that would cause some level of crop stress without causing mortality. The resulting number of days the crop would experience stress and the 
percent reduction in applied water was determined (Appendix E, Section 2.6). The results of this exercise showed that small percent decreases in irrigation could cause several (non-consecutive) days of water stress in the 30 day time period (Appendix E, Table E-14). Based on this analysis, a 10 percent reduction in irrigation parameters was selected to determine whether under-watering should be used to determine lower bounds for the distributions, and to avoid selection of a lower bound that would cause yield reduction or crop mortality. Squash was chosen for the IR analysis for present-day climate and strawberries were chosen for upper bound glacial transition climate. These two crops had the lowest $I R$ values for the two climate conditions (Table 6.5-1).

Using a 10 percent reduction in $I R$ for squash resulted in a decrease from $0.40 \mathrm{~m} / \mathrm{year}$ to $0.36 \mathrm{~m} /$ year. $0.36 \mathrm{~m} /$ year was only slightly higher than the recommended minimum value for the distribution based on variation in season length $(0.33 \mathrm{~m} / \mathrm{year})$. Thus, the recommended distribution accounts for uncertainty in water management practices without including values that would result in crop mortality.

For upper bound glacial transition climate conditions, a 10 percent reduction in $I R$ for strawberries resulted in a decrease from $0.16 \mathrm{~m} /$ year to $0.14 \mathrm{~m} / \mathrm{year}$. This value was equal to the recommended minimum for the distribution of $I R$ based on variation in season length. Therefore, the recommended distribution for upper bound glacial transition climate also accounts for uncertainty in water management practices without including values that would result in crop mortality.

\subsection{IRRIGATION INTENSITY}

\subsubsection{Use in Biosphere Model}

Irrigation intensity $\left(I_{j}, \mathrm{~cm} /\right.$ hour $)$ is a measure of the rate at which contaminated groundwater is applied to a crop type each time a crop is irrigated. It is used in the plant submodel in the calculation of the water interception fraction (Equation 6.1-1). In that equation, irrigation intensity is raised to the power of a negative fraction; thus, increasing the rate at which water is applied decreases the interception fraction (because the plant surface becomes saturated more rapidly and more contaminated water runs off of the leaves). Changing irrigation intensity from 0.5 to $10 \mathrm{~cm} /$ hour results in a decrease in the interception fraction of beryllium from 0.57 to 0.21 (Figure 6.6-1, with biomass $=0.4 \mathrm{~kg} / \mathrm{m}^{2}$ and irrigation application $=40 \mathrm{~mm}$ ). The interception fraction is much more sensitive to values of irrigation intensity less than about $4.0 \mathrm{~cm} /$ hour because the fraction asymptotes at higher intensities (Figure 6.6-1). Irrigation intensity has no effect on the interception fraction for iodine because the parameter is raised to the power of -0.05 for that anion and so the outcome of this product is relatively insensitive to any significant change that may be made in the value of irrigation intensity. 


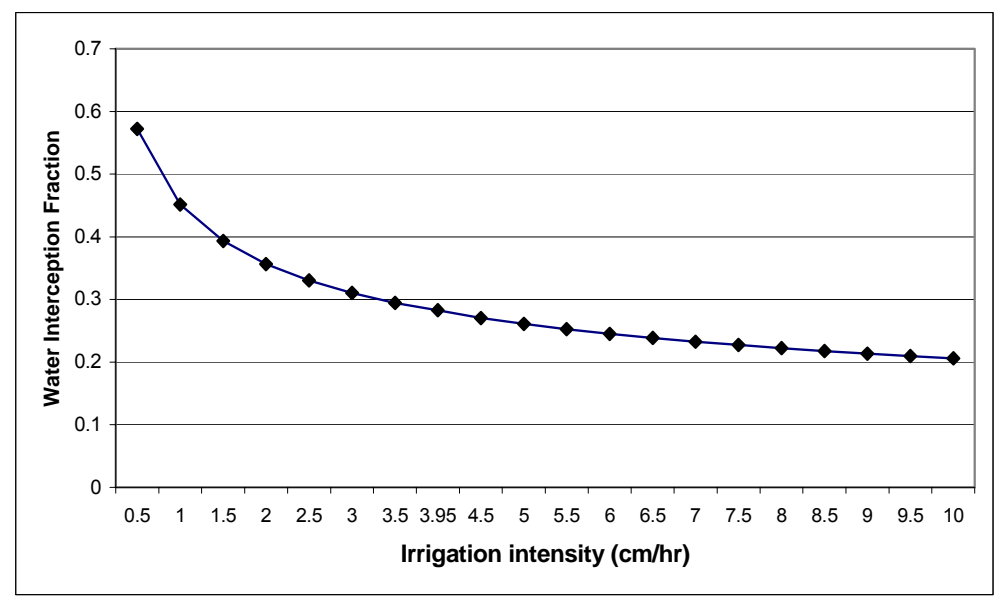

NOTE: Calculated as fraction $=2.29 \times$ dry biomass ${ }^{0.695} \mathrm{x}$ irrigation application ${ }^{-0.29} \mathrm{x}$ irrigation intensity ${ }^{-0.341}$, with dry biomass $=0.4 \mathrm{~kg} / \mathrm{m} 2$ and irrigation application $=40 \mathrm{~mm}$.

Figure 6.6-1. Sensitivity of Water Interception Fraction to Irrigation Intensity

\subsubsection{Parameter Development}

Irrigation intensity can vary substantially depending on the method of irrigation used. High irrigation intensity is achieved in gardens using hoses and lawn sprinklers and in agricultural fields using large gun sprayers. Low rates can be achieved on garden and commercial sprinkler systems (e.g., center pivot, side roll, or stationary spray systems) by selecting nozzles with low flow rates and increasing the spacing between nozzles. Irrigation intensity for sprinkler types and typical spacing used in commercial agriculture can range from less than $0.5 \mathrm{~cm}$ per hour to more than $10 \mathrm{~cm}$ per hour (Doorenbos and Pruitt 1977 [DIRS 103062], Table 44, p. 77; Ley 1992 [DIRS 159380], Table 2; Hansen and Trimmer 1997 [DIRS 159373], Figures 1 and 2; Kranz 2002 [DIRS 159377], Figure 2).

One of the most important factors considered when determining the rate at which water can be applied using agricultural sprinkler systems is the soil texture and associated infiltration rate (Christiansen and Davis 1967 [DIRS 159263], pp. 896 and 897; Hansen and Trimmer 1997 [DIRS 159373]; Kranz 2002 [DIRS 159377]). On clay soils, which have infiltration rates of about 0.1 to $1.5 \mathrm{~cm} /$ hour (Doorenbos and Pruitt 1977 [DIRS 103062], Table 40, p. 91), water must be applied slowly to avoid ponding, runoff, and erosion. In contrast, sandy and sandy loam soils have high infiltration rates $(1.5$ to $7.5 \mathrm{~cm} /$ hour for sandy loam and 2.5 to $25 \mathrm{~cm} /$ hour for sandy soils (Doorenbos and Pruitt 1977 [DIRS 103062], Table 40, p. 91)) and can be irrigated at relatively high rates.

Information on the permeability rates of soils in northern Amargosa Valley was obtained from the USDA NRCS (Dollarhide 1999 [DIRS 159253], Table: Physical Properties of Soils, Column: Permeability, see Section 4.1.6) and examined to determine the feasible range of Irrigation intensity for soils in that area. The common soils in northern Amargosa Valley (Arizo, Corbilt, Sanwell, Shamock, Yermo) are sandy to sandy loam, well drained, and have a moderate to rapid permeability (CRWMS M\&O 1999 [DIRS 107736], Figure 1 and pp. C-1, C-2, C-25, C-27, C-39, and C-40). The infiltration rate of the upper layers of these soils is about 
5 to $15 \mathrm{~cm}$ per hour (Dollarhide 1999 [DIRS 159253], Table: Physical Properties of Soils, Column: Permeability).

Because of the high infiltration rate of soils in northern Amargosa Valley, systems with low irrigation intensity would not be required and likely would be avoided because they are more expensive to operate. For example, evaporation is higher when using low spray rates, which decreases irrigation efficiency and increases costs, especially in hot, dry, windy conditions such as those experienced in Amargosa Valley during summer. Also, it takes a long time to deliver sufficient water at low application rates, which increases labor and pumping costs. At an irrigation efficiency of 70 percent, it takes almost 18 hours to apply $3 \mathrm{~cm}$ of water at an irrigation intensity of $0.25 \mathrm{~cm}$ per hour, and about 9 hours to apply that amount at an intensity of $0.5 \mathrm{~cm}$ per hour (Ley 1992 [DIRS 159380], Table 3).

Based on this information, $4.3 \mathrm{~cm}$ per hour (midpoint of the distribution), and a uniform distribution of irrigation intensity with a minimum of $1.0 \mathrm{~cm}$ per hour and a maximum of $7.5 \mathrm{~cm}$ per hour are recommended. A minimum value less than the minimum infiltration rate of soils in Amargosa Valley ( 2 to $15 \mathrm{~cm} /$ hour) is recommended to account for uncertainty about irrigation methods used and irrigation efficiency in Amargosa Valley. Although application rates higher than the maximum recommended value are possible for most soils in Amargosa Valley (and are quite likely for some irrigation methods such as gardens irrigated with a hose), a higher maximum is not recommended because higher values have little influence on the calculation of leaf interception fraction (see Section 6.6.1). A uniform distribution is recommend because there is no information to indicate which rates within this range are more likely.

The same distribution is recommended for all crop types because sprinklers producing a wide range of application rates are available for both garden and commercial crops, and soil conditions would not differ substantially for garden and commercial crops. Likewise, the same distribution is recommended for present-day and upper bound glacial transition climates, because soil infiltration rates would not change and available sprinkler equipment do not differ between arid and semiarid regions.

There is uncertainty in the development of a distribution for irrigation intensity because there is limited information on irrigation methods used in Amargosa Valley, there is a wide range of irrigation methods available, and irrigation systems can be modified easily to change irrigation intensity. The bounds of the distribution recommended in this analysis were selected to ensure that these uncertainties are propagated in the biosphere model.

This parameter is not used in the biosphere volcanic ash exposure scenario; therefore, changes resulting from a volcanic eruption at Yucca Mountain are not considered in this analysis.

\subsection{IRRIGATION APPLICATION}

\subsubsection{Use in Biosphere Model}

Irrigation application $\left(I A_{j}, \mathrm{~mm}\right)$ is a measure of the amount of contaminated water applied to a crop type each time crops are irrigated during the last 30 days of growth. It is used in the plant submodel in the calculation of the water interception fraction (Equation 6.1-1). In that equation, irrigation application is raised to the power of a negative fraction (see Section 6.1.1); thus, 
increasing the amount of water applied during each application decreases the interception fraction (because the plant surface becomes saturated and more contaminated water runs off of the leaves). Changing the irrigation amount from 15 to $65 \mathrm{~mm}$ results in a change in the interception fraction of beryllium from about 0.34 to 0.23 (with biomass $=0.4 \mathrm{~kg} / \mathrm{m}^{2}$ and irrigation intensity $=4 \mathrm{~cm} /$ hour). The interception fraction for iodine changes from about 0.06 to about 0.02 . Thus, the water interception fraction is relatively insensitive to changes in irrigation application.

\subsubsection{Parameter Development}

Methods for calculating crop water requirements that were published by FAO (Allen et al. 1998 [DIRS 157311]) were used to calculate $E T_{o}$ (Appendix C), $K_{c}$ (Appendix D), and $E T_{c}$ (Appendix D). Methods are justified in Appendix B (Section 2). Background information on plant water use is also in Appendix B (Section 1). Mean daily $E T_{C}$ averaged for one-month time periods and soil moisture balance over a 30 day period prior to harvest were used to calculate IA for each crop (see Appendix E, Section 2.5.2 for methods and example calculations). Several irrigation events were required during the last 30 days of growth for most crops. The average application amount for all irrigation events (per crop) was determined and these values were used to calculate the average $I A_{j}$ per crop type (Table 6.7-1). The average application amount for two seasons was used where applicable. Additionally, $I A_{j}$ values for alfalfa were averaged across cuttings.

Parameter inputs were rooting depth (Section 6.12), growing season lengths (Section 4.1.4) and average monthly weather data (Section 4.1.5) for present-day and upper bound glacial transition climates. Rooting depth was used in soil water balance calculations in Appendix E. Growing season lengths were used in Appendix D to calculate mean monthly $K_{c}$ and in Appendix E to determine when the last 30 days of growth occurred for each crop. Average monthly weather data were used in Appendix $\mathrm{C}$ to calculate $E T_{o}$. Average monthly precipitation was used in Appendix $\mathrm{E}$ to calculate effective precipitation. Effective precipitation for 30 days prior to harvest was used in the calculations of IA (Appendix E, Section 2.5.2).

The average for each crop type is the mean $I A_{j}$ of the representative crops, with the exception of the weighted mean used for cattle forage (Tables 6.7-2 and 6.7-3). 
Table 6.7-1. Irrigation Application

\begin{tabular}{|c|c|c|c|c|c|}
\hline $\begin{array}{c}\text { Crop Type } \\
\text { Crop }\end{array}$ & $\begin{array}{l}\text { Present- } \\
\text { Day } \\
\text { Climate } \\
I A_{j}(\mathrm{~mm})^{a}\end{array}$ & $\begin{array}{c}\text { Upper } \\
\text { Bound } \\
\text { Glacial } \\
\text { Transition } \\
\text { Climate } \\
I_{j}(\mathrm{~mm})^{a}\end{array}$ & $\begin{array}{c}\text { Crop Type } \\
\text { Crop }\end{array}$ & $\begin{array}{l}\text { Present- } \\
\text { Day } \\
\text { Climate } \\
I_{A_{j}(\mathrm{~mm})^{\mathrm{a}}}\end{array}$ & $\begin{array}{c}\text { Upper } \\
\text { Bound } \\
\text { Glacial } \\
\text { Transition } \\
\text { Climate } \\
I_{j}(\mathrm{~mm})^{a}\end{array}$ \\
\hline Leafy Vegetables & & & Fruits & & \\
\hline Broccoli & 22.0 & 19.3 & Apples & 49.4 & 54.4 \\
\hline Cabbage & 23.5 & 26.1 & Grapes & 48.4 & 43.2 \\
\hline Cauliflower & 20.8 & 22.0 & Melons & 35.4 & 34.6 \\
\hline Celery & 8.4 & 8.0 & Strawberries & 6.0 & 7.3 \\
\hline Head Lettuce & 10.9 & 9.0 & Tomatoes & 30.3 & 31.4 \\
\hline Leaf Lettuce & 10.0 & 10.1 & Average & 33.9 & 34.2 \\
\hline Spinach & 7.5 & 7.8 & $\mathrm{SD}^{\mathrm{b}}$ & 17.6 & 17.5 \\
\hline Average & 14.7 & 14.6 & $\mathrm{CV}^{\mathrm{C}}$ & 0.52 & 0.51 \\
\hline$S D^{b}$ & 7.0 & 7.6 & & & \\
\hline $\mathrm{CV}^{\mathrm{C}}$ & 0.48 & 0.5 & Grains & & \\
\hline & & & Barley & 48.6 & 66.7 \\
\hline Other Vegetables & & & Corn & 50.4 & 32.2 \\
\hline Bell peppers & 19.8 & 17.7 & Oats & 50.0 & 46.2 \\
\hline Carrots & 21.2 & 20.1 & Winter wheat & 77.9 & 59.9 \\
\hline Cucumbers & 34.8 & 37.2 & Average & 56.7 & 51.3 \\
\hline Onions & 9.1 & 11.3 & $S D^{b}$ & 14.1 & 15.3 \\
\hline Potatoes & 18.9 & 14.4 & $\mathrm{CV}^{\mathrm{C}}$ & 0.25 & 0.30 \\
\hline Squash & 33.3 & 34.1 & & & \\
\hline Sweet corn & 44.7 & 40.3 & Cattle Forage & & \\
\hline Average & 26.0 & 25.0 & Alfalfa hay & 57.6 & 52.5 \\
\hline$S D^{b}$ & 12.1 & 11.8 & Corn silage & 60.0 & 61.9 \\
\hline \multirow[t]{4}{*}{$\mathrm{CV}^{\mathrm{C}}$} & 0.46 & 0.5 & Oat hay & 56.3 & 48.3 \\
\hline & & & Average & 58.0 & 54.2 \\
\hline & & & $S D^{b}$ & 1.9 & 7.0 \\
\hline & & & $\mathrm{CV}^{\mathrm{C}}$ & 0.03 & 0.1 \\
\hline
\end{tabular}

a Irrigation application amounts from Tables E-13 and E-14 for present-day and upper bound glacial transition climates, respectively. See Appendix E for calculation methods and examples.

b Standard deviation calculated using the STDEV function of Excel.

${ }^{c}$ Coefficient of variation (SD/mean). 
Table 6.7-2. Averages and Cumulative Distributions for Irrigation Application ( $\left.I A_{j} \mathrm{~mm}\right)$ for Present-Day Climate

\begin{tabular}{|c|c|c|c|c|c|c|c|}
\hline Crop Type & Average $^{\mathrm{a}}$ & $\begin{array}{c}\text { Upper } \\
\text { Limit of } \\
\text { Interval }^{\mathbf{b}}\end{array}$ & $\begin{array}{l}\text { Cumulative } \\
\text { Probability }\end{array}$ & Crop Type & Average $^{\mathrm{a}}$ & $\begin{array}{c}\text { Upper } \\
\text { Limit of } \\
\text { Interval }^{\mathbf{b}}\end{array}$ & $\begin{array}{l}\text { Cumulative } \\
\text { Probability }\end{array}$ \\
\hline \multirow{9}{*}{$\begin{array}{l}\text { Leafy } \\
\text { Vegetables }\end{array}$} & 14.7 & 6.0 & 0.00 & \multirow[t]{8}{*}{ Fruits } & 33.9 & 5.0 & 0.00 \\
\hline & & 7.5 & 0.05 & & & 6.0 & 0.05 \\
\hline & & 8.4 & 0.20 & & & 30.3 & 0.28 \\
\hline & & 10.0 & 0.35 & & & 35.4 & 0.51 \\
\hline & & 10.9 & 0.50 & & & 48.4 & 0.72 \\
\hline & & 20.8 & 0.65 & & & 49.4 & 0.95 \\
\hline & & 22.0 & 0.80 & & & 58.3 & 1.00 \\
\hline & & 23.5 & 0.95 & & & & \\
\hline & & 27.7 & 1.00 & \multirow[t]{7}{*}{ Grains } & 56.7 & 43.0 & 0.00 \\
\hline \multirow{11}{*}{$\begin{array}{l}\text { Other } \\
\text { Vegetables }\end{array}$} & 26.0 & & & & & 48.6 & 0.05 \\
\hline & & 8.0 & 0.00 & & & 50.1 & 0.35 \\
\hline & & 9.1 & 0.05 & & & 50.4 & 0.65 \\
\hline & & 18.9 & 0.20 & & & 77.9 & 0.95 \\
\hline & & 19.8 & 0.35 & & & 91.9 & 1.00 \\
\hline & & 21.2 & 0.50 & & & & \\
\hline & & 33.3 & 0.65 & \multirow{5}{*}{$\begin{array}{l}\text { Cattle } \\
\text { Forage }^{c}\end{array}$} & 57.8 & 50.0 & 0.00 \\
\hline & & 34.8 & 0.80 & & & 56.3 & 0.05 \\
\hline & & 44.7 & 0.95 & & & 57.6 & 0.72 \\
\hline & & 52.7 & 1.00 & & & 60.0 & 0.95 \\
\hline & & & & & & 71.0 & 1.00 \\
\hline
\end{tabular}

${ }^{a}$ Mean $I A_{j}$ for a crop type from Table 6.7-1, with the exception of the weighted mean calculated for cattle forage. The weighted mean was calculated as $(3 \times 57.5[I A$ for alfalfa $]+1 \times 60.2[I / A$ for corn silage $]+1 \times 56.5[I A$ for oat hay]) $/ 5=57.8$.

${ }^{b}$ Limits determined from crop specific IA (see Table 6.7-1).

${ }^{c}$ For 90 percent of the distribution between the minimum and maximum crop specific $I A_{j}$, the probabilities for the two cattle forage intervals were weighted $3: 1$ for the range between oat hay to alfalfa $(p=0.68)$ and alfalfa to corn silage $(p=0.22)$.

A cumulative distribution function is recommended for each crop type for both present-day and upper bound glacial transition climates (Tables 6.7-2 and 6.7-3). Ninety percent of the probability distribution is between the minimum and maximum IA of representative crops within a crop type (e.g., IA for leafy vegetables ranges from 7.5 [spinach] to $23.5 \mathrm{~mm}$ [cabbage] for present-day climate, Table 6.7-1). The distribution between the minimum and maximum crop $I A_{j}$ is divided into intervals of equal probability (summing to 90 percent), with the exception of cattle forage (see below). The number of intervals is one less than the number of representative crops and the upper limits are crop-specific values of IA (Table 6.7-2). The probabilities for the two intervals for the distribution of cattle forage were weighted 3:1 for the range between oat hay and alfalfa $(p=0.675)$ versus the range between alfalfa and corn silage $(p=0.225)$ (see Section 6 for justification). This results in a higher probability for selection of values that are similar to alfalfa. To account for variation and uncertainty that could result in values beyond the range of crop specific values, intervals of five percent probability each were added to the lower and upper ends of the distribution. The bounds are based on crop water stress calculations and overwatering potentials and are justified in the analysis below. 
This parameter is not used in the biosphere volcanic ash exposure scenario; therefore, changes resulting from a volcanic eruption at Yucca Mountain are not considered in this analysis.

Table 6.7-3. Averages and Cumulative Distributions for Irrigation Application $\left(I A_{j} \mathrm{~mm}\right)$ for Upper Bound Glacial Transition Climate

\begin{tabular}{|c|c|c|c|c|c|c|c|}
\hline Crop Type & Average $^{\mathrm{a}}$ & $\begin{array}{c}\text { Upper } \\
\text { Limit of } \\
\text { Interval }^{\text {b }}\end{array}$ & $\begin{array}{l}\text { Cumulative } \\
\text { Probability }\end{array}$ & Crop Type & Average $^{\mathrm{a}}$ & $\begin{array}{c}\text { Upper } \\
\text { Limit of } \\
\text { Interval }^{\text {b }}\end{array}$ & $\begin{array}{l}\text { Cumulative } \\
\text { Probability }\end{array}$ \\
\hline \multirow[t]{10}{*}{ Leafy Vegetables } & 14.6 & 7.0 & 0.00 & \multirow{8}{*}{ Fruits } & 34.2 & 6.0 & 0.00 \\
\hline & & 7.8 & 0.05 & & & 7.3 & 0.05 \\
\hline & & 8.0 & 0.20 & & & 31.4 & 0.28 \\
\hline & & 9.0 & 0.35 & & & 34.6 & 0.51 \\
\hline & & 10.1 & 0.50 & & & 43.2 & 0.72 \\
\hline & & 19.3 & 0.65 & & & 54.4 & 0.95 \\
\hline & & 22.0 & 0.80 & & & 64.2 & 1.00 \\
\hline & & 26.1 & 0.95 & & & & \\
\hline & & 30.8 & 1.00 & \multirow[t]{7}{*}{ Grains } & 51.3 & 28.0 & 0.00 \\
\hline & & & & & & 32.2 & 0.05 \\
\hline \multirow{10}{*}{$\begin{array}{l}\text { Other } \\
\text { Vegetables }\end{array}$} & 25.0 & 10.0 & 0.00 & & & 46.2 & 0.35 \\
\hline & & 11.3 & 0.05 & & & 59.9 & 0.65 \\
\hline & & 14.4 & 0.20 & & & 66.7 & 0.95 \\
\hline & & 17.7 & 0.35 & & & 78.7 & 1.00 \\
\hline & & 20.1 & 0.50 & & & & \\
\hline & & 34.1 & 0.65 & \multirow{5}{*}{$\begin{array}{l}\text { Cattle } \\
\text { Forage }^{c}\end{array}$} & 53.5 & 43.0 & 0.00 \\
\hline & & 37.2 & 0.80 & & & 48.3 & 0.05 \\
\hline & & 40.3 & 0.95 & & & 52.5 & 0.73 \\
\hline & & 47.6 & 1.00 & & & 61.9 & 0.95 \\
\hline & & & & & & 73.0 & 1.00 \\
\hline
\end{tabular}

${ }^{a}$ Mean $I A_{j}$ for a crop type from Table 6.7-1, with the exception of the weighted mean calculated for cattle forage. The weighted mean was calculated as $(3 \times 52.5$ [IA for alfalfa] $+1 \times 61.9$ [IA for corn silage] $+1 \times 48.3$ [IA for oat hay]) / $5=53.5$.

${ }^{b}$ Limits determined from crop specific IA (see Table 6.7-1).

${ }^{c}$ For 90 percent of the distribution between the minimum and maximum crop specific $I A$, the probabilities for the two cattle forage intervals were weighted $3: 1$ for the range between corn silage to oat hay $(p=0.22)$ and oat hay to alfalfa $(p=0.68)$.

Variation and Uncertainty-Much of the variation and uncertainty associated with the distributions of $I A_{j}$ were accounted for through selection of three or more representative crops per crop type (see Section 6.5 and Appendix A). Variation that was not accounted for includes year to year variation in monthly climate variables. Uncertainty not accounted for is due to lack of knowledge about water management practices (i.e., excessive irrigation or under-watering during the 30 days prior to harvest).

Yearly Variation in Climate-Year to year variation in mean monthly climatic variables affect $I A_{j}$ through calculation of $E T_{o}$ (Appendix $\mathrm{C}$ ). Variation in $I A_{j}$ from yearly variation in mean monthly climate variables was not directly calculated because the data were not available. While daily or hourly fluctuations in $E T_{o}$ can be large, monthly means tend to be conservative from year to year (see Section 6.5.2.1). Variation from the expected monthly average $E T_{o}$ was calculated using air temperature data as a meteorological index representing variation in 
evaporative demands (Section 6.5.2). Monthly mean, monthly average maximum, and monthly average minimum air temperatures with standard deviations for 26 to 29 years in Amargosa Valley, Nevada (Table 6.5-5) were obtained from the Western Regional Climate Center 2002 ([DIRS 161250], 2002 [DIRS 161251], 2002 [DIRS 160537]). Small coefficients of variation $(C V=S D /$ mean $)$ indicate little yearly variation in the average monthly temperature parameters (Table 6.5-5). Yearly variation ranged from 3.0 percent to 10.0 percent depending on the temperature parameter and month (Table 6.5-5). Variation in $I A_{j}$ among crops within a crop type ranged from 3 percent to 52 percent for present-day climate and from 10 percent to 51 percent for upper bound glacial transition climate (Table 6.7-1). Therefore, variation in $I A_{j}$ among crops within a crop type is generally greater than the variation in $I A_{j}$ expected from yearly changes in mean monthly climate variables. It is reasonable to conclude that the recommended distributions sufficiently account for yearly variations in monthly mean climate.

Uncertainty in Water Management Practices-Uncertainty in the distribution of $I A_{j}$ due to lack of knowledge about water management practices (i.e., excessive irrigation or under watering during a growing season) can be bounded similarly to $I R$, by assessing practices that would result in crop stress.

Excessive Irrigation-Problems caused by excessive irrigation are discussed in Section 6.5.2. These include nutrient loss from the root zone through leaching, water loss through percolation below the root zone or runoff, oxygen deficiencies for root growth and microbial activity, denitrification, and infestation by weeds (Section 6.5.2). These processes can result in loss of yield, reduced crop quality, pollution, and increased water pumping costs. In Section 6.5.2 it was concluded that overwatering alfalfa by about 18 percent would result in yield reduction through a variety of mechanisms, including those mentioned above. It is reasonable to conclude that an 18 percent increase in $I A_{j}$ would have similar effects on other representative crops and pumping costs. To establish appropriate upper bounds for the distributions of $I A_{j}$ that would encompass uncertainties associated with excessive irrigation, maximum values (within a crop type) were increased by 18 percent (Tables 6.7-2 and 6.7-3). Cabbage, sweet corn, apples, winter wheat, and corn silage were used to establish upper bounds in the present-day climate analysis. Cabbage, sweet corn, apples, barley, and corn silage were used in the upper bound glacial transition climate analysis.

Under watering-Moisture stress occurs if irrigation water does not meet crop water requirements (see Appendix B). The level of moisture stress can vary from minor, where crop leaves wilt during the day but recover at night, to severe where recovery is not possible and leaf desiccation occurs. Reductions in both crop yield and quality can occur at various levels of water stress depending on the sensitivity of the crop. For example, grain crops tend to be more tolerant of water stress than potatoes or leafy vegetables (Robins et al. 1967 [DIRS 159939], pp. 635 and 636; Vittum and Flocker 1967 [DIRS 159941], pp. 676 and 677). It is likely that a farmer or gardener would respond to signs of under watering by modifying their water management practices to avoid losses in crop quality and yield.

The methods used to determine percent reduction in the total amount of irrigation applied for other irrigation parameters (see Appendix E for example) were not applicable to $I A_{j}$. This is because stress was imposed by withholding water for 2 days after scheduled irrigation events, then enough water was added to bring the volume in the root zone to the level where stress would be alleviated. This often resulted in fewer applications but increased application amounts. 
However, the results of the exercise indicated that a 10 percent reduction in irrigation would likely cause water stress. Therefore, it is reasonable to use the 10 percent reduction recommended for other irrigation parameters to determine lower bounds for the distributions of $I A_{j}$

Spinach, onions, strawberries, barley, and oat hay were chosen for the present-day climate analysis because these crops had the lowest IA within their crop type (Table 6.7-1). IA was reduced by 10 percent for each of these crops and used as minimum bounds for the distributions for crop types (Table 6.7-2). The recommended minimum values were rounded down to the nearest $\mathrm{mm}$.

Spinach, onions, strawberries, feed corn, and oat hay were chosen for the upper bound glacial transition climate analysis because these crops had the lowest IA within their crop type (Table 6.7-1). IA was reduced by 10 percent for each of these crops and used as minimum bounds for the distributions for crop types (Table 6.7-3). The recommended minimum values were rounded down to the nearest $\mathrm{mm}$.

\subsection{IRRIGATION RATE - DAILY}

\subsubsection{Use in Biosphere Model}

Daily irrigation rate $\left(I R D_{j}, \mathrm{~mm} \mathrm{day}^{-1}\right)$ is a measure of the average amount of contaminated groundwater applied per day over the growing season (over all growing seasons for multiple season crops) for a crop type. It is used in the plant uptake submodel to calculate the rate of deposition of radionuclides onto the surface of plants for crop type $j$ ( $\mathrm{Dw}_{i j}$, BSC 2004 [DIRS 169460], Section 6.4.3):

$$
D w_{i, j}=C w_{i} I R D_{j}
$$

where $C w_{i}$ is the concentration of radionuclide $i$ in the groundwater $\left(\mathrm{Bq} / \mathrm{m}^{2}\right)$. The deposition rate is then used in the calculation of leaf uptake of radionuclides, as shown in Equation 6.3-1. Because values of daily irrigation rate directly influence the concentration of radionuclides in leaves, this parameter may have an important influence on BDCFs. It is also used in a similar equation in the carbon-14 submodel to calculate the concentration of carbon-14 $\left({ }^{14} \mathrm{C}\right)$ in surface soils (by multiplying irrigation rate by ${ }^{14} \mathrm{C}$ concentration in water and dividing by decay and removal constants).

\subsubsection{Parameter Development}

Distributions for $I R D_{j}$ were developed for each of the five crop types for present-day and upper bound glacial transition climates. Daily irrigation rates for each crop were determined by dividing $I R$ by growing season days (Table 6.8-1). Therefore, $I R D_{j}$ is directly related to $I R$ making inputs and calculation methods the same as those described in Section 6.5 and Appendix E.

$I R D_{j}$ for each crop and averages per crop type are in Table 6.8-1 for present-day and upper bound glacial transition climates. The average for each crop type is the mean $I R D_{j}$ of the representative crops, with the exception of the weighted mean used for cattle forage (Tables 6.82 and 6.8-3). 
Table 6.8-1. Daily Irrigation Rate

\begin{tabular}{|c|c|c|c|c|c|}
\hline $\begin{array}{c}\text { Crop Type } \\
\text { Crop }\end{array}$ & $\begin{array}{l}\text { Present-Day } \\
\text { Climate } \\
I R D_{j,}{ }^{a}(\mathrm{~mm} / \\
\text { day })\end{array}$ & $\begin{array}{l}\text { Upper Bound } \\
\text { Glacial } \\
\text { Transition } \\
\text { Climate } \\
\text { IR }{ }_{j,}{ }^{\text {a }} \\
\text { (mm/day) }\end{array}$ & $\begin{array}{c}\text { Crop Type } \\
\text { Crop } \\
\end{array}$ & $\begin{array}{c}\text { Present-Day } \\
\text { Climate } \\
I_{R D_{j},}{ }^{a} \\
(\mathrm{~mm} / \mathrm{day})\end{array}$ & $\begin{array}{l}\text { Upper Bound } \\
\text { Glacial } \\
\text { Transition } \\
\text { Climate } \\
\text { IRD }{ }_{j,}^{\text {a }} \\
\text { (mm/day) }\end{array}$ \\
\hline Leafy Vegetables & & & Fruits & & \\
\hline Broccoli & 5.19 & 3.86 & Apples & 7.59 & 4.38 \\
\hline Cabbage & 5.38 & 3.86 & Grapes & 5.40 & 3.48 \\
\hline Cauliflower & 5.21 & 3.51 & Melons & 8.38 & 4.79 \\
\hline Celery & 6.00 & 4.18 & Strawberries & 7.02 & 2.51 \\
\hline Head Lettuce & 5.48 & 4.02 & Tomatoes & 8.67 & 4.33 \\
\hline Leaf Lettuce & 5.48 & 3.92 & Average & 7.41 & 3.90 \\
\hline Spinach & 5.11 & 3.34 & $S D^{b}$ & 1.30 & 0.91 \\
\hline Average & 5.41 & 3.81 & $\mathrm{CV}^{\mathrm{c}}$ & 0.18 & 0.23 \\
\hline$S D^{b}$ & 0.30 & 0.29 & & & \\
\hline \multirow[t]{2}{*}{$\mathrm{CV}^{\mathrm{C}}$} & 0.06 & 0.08 & Grains & & \\
\hline & & & Barley & 3.44 & 3.42 \\
\hline Other Vegetables & & & Corn & 7.69 & 4.11 \\
\hline Bell peppers & 9.26 & 4.16 & Oats & 3.58 & 3.93 \\
\hline Carrots & 6.65 & 4.43 & Winter wheat & 3.87 & 1.99 \\
\hline Cucumbers & 8.36 & 3.08 & Average & 4.64 & 3.36 \\
\hline Onions & 6.07 & 3.48 & $S D^{b}$ & 2.04 & 0.96 \\
\hline Potatoes & 7.67 & 4.08 & $\mathrm{CV}^{\mathrm{c}}$ & 0.44 & 0.28 \\
\hline Squash & 6.93 & 2.73 & & & \\
\hline Sweet corn & 9.03 & 4.95 & Cattle Forage & & \\
\hline Average & 7.71 & 3.84 & Alfalfa hay & 5.85 & 4.01 \\
\hline$S D^{b}$ & 1.22 & 0.78 & Corn silage & 9.02 & 5.03 \\
\hline \multirow[t]{4}{*}{$\mathrm{CV}^{\mathrm{c}}$} & 0.16 & 0.20 & Oat hay & 6.18 & 3.64 \\
\hline & & & Average & 7.02 & 4.23 \\
\hline & & & $S D^{b}$ & 1.74 & 0.59 \\
\hline & & & $\mathrm{CV}^{\mathrm{c}}$ & 0.25 & 0.14 \\
\hline
\end{tabular}

${ }^{a}$ Daily irrigation rates derived from seasonal net irrigation requirements (Tables E-5 and E-8) divided by the number of days in the growing season (mid season length in Tables D-1 and D-2).

b Standard deviation.

${ }^{c}$ Coefficient of variation $=\mathrm{SD} /$ mean .

A cumulative distribution function is recommended for each crop type for both climate conditions (Tables 6.8-2 and 6.8-3). Ninety percent of the probability distribution is between the minimum and maximum IRD of representative crops within a crop type (e.g., IRD for leafy vegetables ranges from 5.11 [spinach] to $6.00 \mathrm{~mm} /$ day [celery] for present-day climate Table 6.8-1). The distribution between the minimum and maximum crop IRD is divided into intervals of virtually equal probability (summing to 90 percent), with the exception of cattle forage (see below). The number of intervals is one less than the number of representative crops and the upper bound glacial transition climate have equal IRD values (Table 6.8-1). Therefore, 
probabilities were doubled for those intervals with upper limits of 5.48 and 3.86 for present-day and upper bound glacial transition climates, respectively. This resulted in two less intervals than the number of representative crops for leafy vegetables for both climates. The probabilities for the two intervals for the distribution of cattle forage were weighted 3:1 for the range between alfalfa and oat hay $(p=0.675)$ versus the range between oat hay and corn silage $(p=0.225)$ (see Section 6 for justification). This results in a higher probability for selection of values that are similar to alfalfa. To account for variation and uncertainty that could result in values beyond the range of crop specific values, intervals of five percent probability each were added to the lower and upper ends of the distributions (Tables 6.8-2 and 6.8-3). The bounds are based on crop water stress calculations and overwatering potentials and are justified in the analysis below.

This parameter is not used in the biosphere volcanic ash exposure scenario; therefore, changes resulting from a volcanic eruption at Yucca Mountain are not considered in this analysis.

Table 6.8-2. Recommended Cumulative Distributions for Daily Irrigation Rate $\left(I R D_{j} \mathrm{~mm} /\right.$ day $)$ for Present-Day Climate

\begin{tabular}{|c|c|c|c|c|c|c|c|}
\hline Crop Type & Average $^{a}$ & $\begin{array}{l}\text { Upper Limit } \\
\text { of Interval }\end{array}$ & $\begin{array}{l}\text { Cumulative } \\
\text { Probability }\end{array}$ & Crop Type & Average $^{\mathrm{a}}$ & $\begin{array}{c}\text { Upper } \\
\text { Limit of } \\
\text { Interval }^{\mathbf{b}}\end{array}$ & $\begin{array}{l}\text { Cumulative } \\
\text { Probability }\end{array}$ \\
\hline \multirow{10}{*}{$\begin{array}{l}\text { Leafy } \\
\text { Vegetables }\end{array}$} & 5.41 & 4.00 & 0.00 & \multirow{8}{*}{ Fruits } & 7.41 & 4.00 & 0.00 \\
\hline & & 5.11 & 0.05 & & & 5.40 & 0.05 \\
\hline & & 5.19 & 0.20 & & & 7.02 & 0.28 \\
\hline & & 5.21 & 0.35 & & & 7.59 & 0.51 \\
\hline & & 5.38 & 0.50 & & & 8.38 & 0.72 \\
\hline & & 5.48 & 0.80 & & & 8.67 & 0.95 \\
\hline & & 6.00 & 0.95 & & & 10.23 & 1.00 \\
\hline & & 7.08 & 1.00 & & & & \\
\hline & & & & \multirow[t]{7}{*}{ Grains } & 4.64 & 3.00 & 0.00 \\
\hline & & & & & & 3.44 & 0.05 \\
\hline \multirow{10}{*}{$\begin{array}{l}\text { Other } \\
\text { Vegetables }\end{array}$} & 7.71 & 5.00 & 0.00 & & & 3.58 & 0.35 \\
\hline & & 6.07 & 0.05 & & & 3.87 & 0.65 \\
\hline & & 6.65 & 0.20 & & & 7.69 & 0.95 \\
\hline & & 6.93 & 0.35 & & & 9.07 & 1.00 \\
\hline & & 7.67 & 0.50 & & & & \\
\hline & & 8.36 & 0.65 & \multirow{5}{*}{ Cattle Forage $^{\mathrm{c}}$} & 6.55 & 5.00 & 0.00 \\
\hline & & 9.03 & 0.80 & & & 5.85 & 0.05 \\
\hline & & 9.26 & 0.95 & & & 6.18 & 0.73 \\
\hline & & 10.93 & 1.00 & & & 9.02 & 0.95 \\
\hline & & & & & & 10.64 & 1.00 \\
\hline
\end{tabular}

${ }^{a}$ Mean $I R D_{j}$ for a crop type from Table 6.7-1, with the exception of the weighted mean calculated for cattle forage. The weighted mean was calculated as $(3 \times 5.84$ [IRD for alfalfa] $+1 \times 9.00$ [IRD for corn silage] $+1 \times 6.18$ [IRD for oat hay]) $/ 5=6.54$.

${ }^{\mathrm{b}}$ Limits determined from crop specific IRD (see Table 6.8-1).

${ }^{c}$ For 90 percent of the distribution between the minimum and maximum crop specific $I R D_{j}$ values, the probabilities for the two intervals for the distribution of cattle forage were weighted 3:1 for the range between alfalfa and oat hay $(p=0.68)$ versus the range between oat hay and corn silage $(p=0.22)$. 
Table 6.8-3. Averages and Cumulative Distributions for Daily Irrigation Rate $\left(I R D_{j} \mathrm{~mm} /\right.$ day $)$ for Upper Bound Glacial Transition Climate

\begin{tabular}{|c|c|c|c|c|c|c|c|}
\hline Crop Type & Average $^{\mathrm{a}}$ & $\begin{array}{l}\text { Upper } \\
\text { Limit of } \\
\text { Interval }^{\text {b }}\end{array}$ & $\begin{array}{l}\text { Cumulative } \\
\text { Probability }\end{array}$ & Crop Type & Average $^{\mathrm{a}}$ & $\begin{array}{l}\text { Upper } \\
\text { Limit of } \\
\text { Interval }^{b}\end{array}$ & $\begin{array}{l}\text { Cumulative } \\
\text { Probability }\end{array}$ \\
\hline \multirow{11}{*}{$\begin{array}{l}\text { Leafy } \\
\text { Vegetables }\end{array}$} & 3.81 & 3.00 & 0.00 & \multirow{8}{*}{\begin{tabular}{|l}
$\mid$ Fruits \\
\\
\\
\\
\end{tabular}} & 3.90 & 2.00 & 0.00 \\
\hline & & 3.34 & 0.05 & & & 2.51 & 0.05 \\
\hline & & 3.51 & 0.20 & & & 3.48 & 0.28 \\
\hline & & 3.86 & 0.50 & & & 4.33 & 0.51 \\
\hline & & 3.92 & 0.65 & & & 4.38 & 0.72 \\
\hline & & 4.02 & 0.80 & & & 4.79 & 0.95 \\
\hline & & 4.18 & 0.95 & & & 5.65 & 1.00 \\
\hline & & 4.93 & 1.00 & & & & \\
\hline & & & & \multirow[t]{7}{*}{ Grains } & 3.36 & 1.00 & 0.00 \\
\hline & & & & & & 1.99 & 0.05 \\
\hline & & & & & & 3.42 & 0.35 \\
\hline \multirow{9}{*}{$\begin{array}{l}\text { Other } \\
\text { Vegetables }\end{array}$} & 3.84 & 2.00 & 0.00 & & & 3.93 & 0.65 \\
\hline & & 2.73 & 0.05 & & & 4.11 & 0.95 \\
\hline & & 3.08 & 0.20 & & & 4.85 & 1.00 \\
\hline & & 3.48 & 0.35 & & & & \\
\hline & & 4.08 & 0.50 & \multirow{5}{*}{$\begin{array}{l}\text { Cattle } \\
\text { Forage }^{c}\end{array}$} & 4.14 & 3.00 & 0.00 \\
\hline & & 4.16 & 0.65 & & & 3.64 & 0.05 \\
\hline & & 4.43 & 0.80 & & & 4.01 & 0.73 \\
\hline & & 4.95 & 0.95 & & & 5.03 & 0.95 \\
\hline & & 5.84 & 1.00 & & & 5.94 & 1.00 \\
\hline
\end{tabular}

${ }^{a}$ Mean IRDj for a crop type from Table 6.7-1, with the exception of the weighted mean calculated for cattle forage. The weighted mean was calculated as $(3 \times 4.01$ [IRD for alfalfa] $+1 \times 5.03$ [IRD for corn silage] $+1 \times 3.64$ [IRD for oat hay]) $/ 5=4.14$.

${ }^{\mathrm{b}}$ Limits determined from crop specific IRD (see Table 6.8-1).

${ }^{\mathrm{C}}$ For 90 percent of the distribution between the minimum and maximum crop specific IRD values, the probabilities for the two intervals for the distribution of cattle forage were weighted $3: 1$ for the range between oat hay and alfalfa $(p=0.68)$ versus the range between corn silage and oat hay $(p=0.22)$.

Uncertainty not accounted for is due to lack of knowledge about water management practices (i.e., excessive watering or under watering during a growing season).

Variation and Uncertainty-Variation and uncertainties associated with $I R D_{j}$ are the same as those associated with $I R$ (see Section 6.5.2). Much of the variation and uncertainty in $I R$ was accounted for through selection of several representative crops (see Appendix A and Section 6.5). Variation that was not accounted for includes differences between minimum and maximum season length for each crop, and year to year variation in monthly climate variables.

Within Crop Variation in Season Length- Daily irrigation rate changes little in response to changes in season length. This is because increases or decreases in IR caused by changing the season lengths are offset in $I R D_{j}$ through division by the number of days in the season. For example, in Section 6.5.2, IR was recalculated for celery based on a 32 day increase in the growing season for present-day climate. This resulted in an increase in $I R$ from $1.50 \mathrm{~m} /$ year to $1.82 \mathrm{~m} /$ year. The concurrent increase in $I R D_{j}$ was only $0.5 \mathrm{~mm} /$ day $(6.0 \mathrm{~mm} /$ day to 
$6.5 \mathrm{~mm}$ /day). Other crops showed similar or smaller changes in $I R D_{j}$ in response to changes in season length. Additionally, season lengths were constrained by mean monthly temperatures for the two climates (i.e., temperatures below crop tolerance levels) or by growing two season crops. It was shown in Section 6.5.2 that the use of two season crops accounted for about as much of the variation in $I R$ as that produced by changing growing season lengths. Therefore, variation caused by changes in season lengths is included by the recommended distributions of $I R D_{j}$.

Yearly Variation in Climate-Year to year variation in mean monthly climate variables affect $I R D_{j}$ through $E T_{o}$ in the calculation of $I R$ (see Section 6.5.2). While daily or hourly fluctuations in $E T_{o}$ can be large, monthly means tend to be conservative from year to year (Section 6.5.2). Variation in $I R$ from yearly variation in mean monthly climate variables was not directly calculated because the data were not available. Variation from the expected monthly average $E T_{o}$ was calculated using air temperature data as a meteorological index representing variation in evaporative demands (Section 6.5.2). Monthly mean, monthly average maximum, and monthly average minimum air temperatures with standard deviations for 26 to 29 years in Amargosa Valley, Nevada (Table 6.5-5) were obtained from the Western Regional Climate Center 2002 ([DIRS 161250], 2002 [DIRS 161251], 2002 [DIRS 160537]). The coefficient of variation $(C V=S D /$ mean $)$ showed little yearly variation in the average monthly temperature parameters (Table 6.5-5). Yearly variation ranged from 3 percent to 10 percent depending on the temperature parameter and month (Table 6.5-5). Variation in $I R D_{j}$ among crops within a crop type ranged from 6 percent to 44 percent for present-day climate and from 8 percent to 28 percent for upper bound glacial transition climate (Table 6.8-1). Therefore, variation in $I R D_{j}$ that could be caused by yearly variation in mean monthly climate variables is generally encompassed by variation among crops within a crop type.

Uncertainty in Water Management Practices-Uncertainty in the distribution of $I R D_{j}$ due to lack of knowledge about water management practices (i.e., excessive irrigation or under-watering during a growing season) can be bounded similarly to $I R$, by assessing practices that would result in crop yield reductions.

Excessive Irrigation-Problems caused by excessive irrigation are discussed in Section 6.5.2. These include nutrient loss from the root zone through leaching, water loss through percolation below the root zone or runoff, oxygen deficiencies for root growth and microbial activity, denitrification, and infestation by weeds. These processes can result in loss of yield, reduced crop quality, and increased water pumping costs.

In Section 6.5.2 it was established that over watering alfalfa by about 18 percent would result in yield reduction through a variety of mechanisms, including those mentioned above. It is reasonable to conclude that an 18 percent increase in $I R D_{j}$ would have similar effects on other representative crops and pumping costs. To establish appropriate upper bounds for the distributions of $I R D_{j}$ that would include uncertainties associated with over irrigating, maximum values (within a crop type) were increased by 18 percent (Tables 6.8-2 and 6.8-3). Celery, bell peppers, tomatoes, corn, and corn silage were used for present-day climate. Celery, sweet corn, melons, corn, and corn silage were used for upper bound glacial transition climate.

Under-watering-Moisture stress occurs if irrigation water does not meet crop water requirements (see Appendix B). The level of moisture stress can vary from minor, where crop 
leaves wilt during the day but recover at night, to severe where recovery at night is not possible and leaf desiccation occurs. Reductions in both crop yield and quality can occur at various levels of water stress depending on the sensitivity of the crop. For example, grain crops tend to be more tolerant of water stress than potatoes or leafy vegetables (Robins et al. 1967 [DIRS 159939], pp. 635 and 636; Vittum and Flocker 1967 [DIRS 159941], pp. 676 and 677). It is likely that a farmer or gardener would respond to signs of under-watering by modifying their water management practices to avoid losses in quality and yield.

Water storage capacity of the root zone and crop sensitivity to soil moisture stress were considered for crops with low IRD to establish reasonable lower bounds for the distributions (see Appendix E, Section 2.6). The methods used to calculate irrigation application (Section 6.7 and Appendix E, Section 2.5) were modified to reflect under-watering conditions that would likely cause stress. The resulting percent decrease that might be tolerated was calculated (Appendix E, Section 2.6). Soil moisture was allowed to stay at a level that would impose stress for two days following each scheduled irrigation event over a 30-day time period (scheduling of irrigation events differed according to crop requirements). Two days was chosen as a likely time interval that would cause some level of crop stress without causing mortality. The resulting number of days the crop would experience stress and the percent reduction in applied water was determined (Appendix E, Section 2.6). The results of this exercise showed that small percent decreases in irrigation could cause several (non-consecutive) days of water stress in the 30 day time period (Appendix E, Table E-14). Based on this analysis, a 10 percent reduction in $I R D_{j}$ was selected to establish lower bounds for the distributions.

Spinach, onions, grapes, barley, and alfalfa were chosen for the present-day climate bounds because these crops had the lowest IRD within their crop type (Table 6.8-1). IRD for each crop was reduced by 10 percent and those values were used as the lower limits of the recommended distributions for each crop type (Table 6.8-2). The calculated minimum values were rounded down to the nearest $\mathrm{mm}$.

Spinach, squash, strawberries, winter wheat, and oats were chosen for the upper bound glacial transition climate analysis because these crops had the lowest IRD within their crop type (Table 6.8-1). IRD for each crop was reduced by 10 percent and those values were used as the lower limits of the recommended distributions for each crop type (Table 6.8-3). The calculated minimum values were rounded down to the nearest $\mathrm{mm}$.

\subsection{OVERWATERING RATE}

\subsubsection{Use in Biosphere Model}

The overwatering rate $(O W, \mathrm{~m} /$ year $)$ is the amount of irrigation water intentionally applied to soil to leach salts, and the amount of precipitation that percolates below the root zone. It is used in the surface soil submodel to calculate the radionuclide specific (i) leaching removal constant $\left(\lambda_{I i}\right)$ (Equation 6.9-1; BSC 2004 [DIRS 169460], Section 6.4.1), which is used in the calculation of radionuclide concentration in soil (Equation 6.6-1). Because soil concentrations are calculated for long-term, equilibrium conditions, one overwatering rate representative of all irrigated plants is used, rather than crop-type specific rates. 


$$
\lambda_{l i}=\frac{O W}{d \times \theta\left(1+\frac{\rho}{\theta} K d_{i}\right)}
$$

where

$$
\begin{aligned}
d= & \text { the depth of surface soil }(\mathrm{m}) \\
\theta= & \text { the volumetric water content of soil, dimensionless, } \\
\rho= & \text { the soil bulk density for surface soil }\left(\mathrm{kg} / \mathrm{m}^{3}\right), \\
K d_{i}= & \text { the surface soil solid/liquid partition coefficient for radionuclide } i\left(\left[\mathrm{~Bq} / \mathrm{kg}_{\text {solid }} /\right.\right. \\
& \left.\left.\mathrm{Bq} / \mathrm{m}^{3} \text { liquid }\right]=\mathrm{m}^{3}{ }_{\text {liquid }} / \mathrm{kg}_{\text {solid }}\right) .
\end{aligned}
$$

Depth of surface soil $(d, m)$ is either tillage depth $\left(T_{d}\right.$, Section 6.10$)$ or rooting depth $\left(Z_{r}\right.$, Section 6.12).

\subsubsection{Parameter Development}

The distribution for $O W$ was either developed from the crop leaching fraction ( $L F)$ or from deep percolation $(D P)$ of precipitation below the crop root zone, depending on which of the two values were greatest for a crop (Appendix E, Section 2.2). The leaching requirement $(L R)$ is the fraction of infiltrated water that must pass through the root zone to remove excess salts. It is a function of the salinity of irrigation water and salt tolerance of individual crops (Doorenbos and Pruitt 1977 [DIRS 103062], p. 77). LF is the actual amount of water that must be applied in addition to crop water requirements to meet the $L R$. It is determined from $E T_{c}, L R$, and effective precipitation (Appendix E, Sections 2.3 and 2.4). Deep percolation occurs when precipitation is great enough to cause the soil moisture to reach field capacity and drain below the root zone (Allen et al. 1998 [DIRS 157311], p. 156). It is calculated from storage capacity of the soil, monthly precipitation, and monthly $E T_{C}$ using soil water balance methods and information on growing season length (see Appendix E, section 2.4 for calculation methods). Deep percolation did not occur for any crops under present-day climate conditions because of low monthly precipitation and high evaporative demands. Thus, LR was used to develop the $O W$ distribution for present-day climate. For upper bound glacial transition climate, enough precipitation occurred during the winter that deep percolation occurred for some two-season and short-season crops. This resulted in use of both deep percolation and $L R$ to develop the distribution for $O W$ for upper bound glacial transition climate conditions. If $D P$ occurred, but did not meet the leaching requirement, it was accounted for by subtracting it from $W_{s}$ (seasonal crop water requirement), and $L F$ was used for $O W$.

The distributions for $O W$ were developed from 26 representative crops and a turf grass for present-day and upper bound glacial transition climates (Table 6.9-1). Seasonal crop water requirements were needed to calculate both $L R$ and $D P$ (calculation methods and examples are in Appendix E, Sections 2.2.1 to 2.3). Parameter inputs for $W_{s}$ were average monthly weather data (Section 4.1.5) and growing season lengths for present-day and upper bound glacial transition climates (Section 4.1.4). Average monthly weather data was used to calculate $E T_{o}$ in Appendix C (see Section 6.5 for relationship of $E T_{o}$ to $E T_{c}$ and $W_{s}$ ). Growing season lengths were used in Appendices D and $\mathrm{E}$ to adjust growth stage lengths and calculate $W_{s}$, respectively. Salinity of irrigation water was derived from inputs described in Section 4.1.7. 
The $O W$ means of representative crops and turf for present-day and upper bound glacial transition climate conditions were 0.079 and $0.067 \mathrm{~m} /$ year, respectively, (Table 6.9-1).

A cumulative distribution function is recommended for present-day and upper bound glacial transition climate $O W$ (Table 6.9-2). Ninety-five percent of the probability distribution is between the minimum and maximum $O W$ of representative crops (e.g., range $=0.009$ [oat hay] to 0.233 [strawberries] $\mathrm{m} /$ year for present-day climate). The distribution between the minimum and maximum crop $O W$ is divided into five equal intervals of equal probability (summing to 95 percent, Table 6.9-2). To account for variation and uncertainty beyond the range of crop specific values, an upper bound interval of five-percent probability was added to the upper end of the distributions for both climate conditions. The upper bounds are $0.275 \mathrm{~m} /$ year for present-day climate and $0.177 \mathrm{~m} /$ year for upper bound glacial transition climate (Table 6.9-2). These bounds are based on excessive irrigation and are justified in the analysis below. Because the low crop specific values for $O W$ are for crops with relatively high salinity tolerance (and therefore low $L R$ and $O W$ ), those values are used to bound the low ends of the distributions. Because there is little uncertainty regarding this low bound, addition of an interval of five-percent probability was not required for the lower ends of the $O W$ distributions. 
Table 6.9-1. Average Overwatering Rates for 26 Crops and Turf Grass for Present-Day and Upper Bound Glacial Transition Climates

\begin{tabular}{|c|c|c|c|c|c|}
\hline Crop & $\begin{array}{c}\text { Present-Day } \\
\text { Climate } \\
\text { OW }^{a} \\
\text { (m/year) }\end{array}$ & $\begin{array}{l}\text { Upper Bound } \\
\text { Glacial } \\
\text { Transition } \\
\text { Climate } \\
\text { OW }^{a} \\
\text { (m/year) } \\
\end{array}$ & Crop & $\begin{array}{c}\text { Present-Day } \\
\text { Climate } \\
\text { OW }^{a} \\
\text { (m/year) }\end{array}$ & $\begin{array}{l}\text { Upper Bound } \\
\text { Glacial } \\
\text { Transition } \\
\text { Climate } \\
\text { OW }^{a} \\
\text { (m/year) }\end{array}$ \\
\hline Alfalfa & 0.149 & 0.064 & Head lettuce & 0.080 & 0.150 \\
\hline Apples & 0.166 & 0.066 & Lettuce & 0.080 & 0.142 \\
\hline Barley & 0.015 & 0.006 & Melons & 0.058 & 0.034 \\
\hline Bell Peppers & 0.075 & 0.082 & Oat feed & 0.014 & 0.014 \\
\hline Broccoli & 0.045 & 0.098 & Oat hay & 0.009 & 0.004 \\
\hline Cabbage & 0.079 & 0.089 & Onions & 0.177 & 0.085 \\
\hline Carrots & 0.162 & 0.134 & Potatoes & 0.077 & 0.072 \\
\hline Cauliflower & 0.045 & 0.095 & Spinach & 0.039 & 0.121 \\
\hline Celery & 0.129 & 0.104 & Squash & 0.024 & 0.044 \\
\hline Feed Corn & 0.102 & 0.063 & Strawberries & 0.233 & 0.125 \\
\hline Corn silage & 0.071 & 0.059 & Sweet corn & 0.068 & 0.047 \\
\hline Cucumbers & 0.030 & 0.020 & Tomatoes & 0.042 & 0.030 \\
\hline \multirow[t]{5}{*}{ Grapes } & 0.103 & 0.038 & Turf Grass & 0.035 & 0.018 \\
\hline & & & Winter Wheat & 0.023 & 0.016 \\
\hline & & & \begin{tabular}{|r|} 
Average \\
\end{tabular} & 0.079 & 0.067 \\
\hline & & & $S D^{b}$ & 0.058 & 0.044 \\
\hline & & & $\mathrm{CV}^{\mathrm{c}}$ & 0.734 & 0.647 \\
\hline
\end{tabular}

a Overwatering rates from Tables E-5 and E-8 for present-day and upper bound glacial transition climates, respectively. See Appendix $\mathrm{E}$ for calculation methods and examples.

b Standard Deviation.

${ }^{c}$ Coefficient of variation $=\mathrm{SD} /$ mean .

Table 6.9-2. Averages and Cumulative Distributions for Overwatering Rates (OW m/year) for PresentDay and Upper Bound Glacial Transition Climates

\begin{tabular}{|c|c|c|c|c|c|}
\hline \multicolumn{3}{|c|}{ Present-Day Climate } & \multicolumn{3}{|c|}{$\begin{array}{c}\text { Upper Bound Glacial Transition } \\
\text { Climate }\end{array}$} \\
\hline Average $^{\mathbf{a}}$ & $\begin{array}{l}\text { Upper Limit } \\
\text { of Interval }\end{array}$ & $\begin{array}{l}\text { Cumulative } \\
\text { Probability }\end{array}$ & Average $^{\mathrm{a}}$ & $\begin{array}{l}\text { Upper } \\
\text { Limit of } \\
\text { Interval }\end{array}$ & $\begin{array}{l}\text { Cumulative } \\
\text { Probability }\end{array}$ \\
\hline \multirow[t]{7}{*}{0.079} & 0.009 & 0.00 & 0.067 & 0.004 & 0.00 \\
\hline & 0.030 & 0.19 & & 0.020 & 0.19 \\
\hline & 0.045 & 0.38 & & 0.047 & 0.38 \\
\hline & 0.077 & 0.57 & & 0.072 & 0.57 \\
\hline & 0.129 & 0.76 & & 0.104 & 0.76 \\
\hline & 0.233 & 0.95 & & 0.150 & 0.95 \\
\hline & 0.275 & 1.00 & & 0.177 & 1.00 \\
\hline
\end{tabular}

${ }^{a}$ Mean $O W$ of 26 representative crops and turf calculated from Table 6.9-1. 
This parameter is not used in the biosphere volcanic ash exposure scenario; therefore, changes resulting from a volcanic eruption at Yucca Mountain are not considered in this analysis.

Variation and Uncertainty-Variation in $O W$ that could arise due to differences in salinity tolerance, water requirements, or growing season lengths among crops is adequately accounted for through use of 26 crops and turf. Selection was based on an evaluation of crops currently grown in southern Nye County, Nevada and eastern Washington, national patterns of food consumption, and variation in the growing season for commonly grown and consumed crops (see Appendix A).

Overwatering rates that are based on $L R$ are dependent on seasonal crop water requirements $\left(W_{s}\right.$, Appendix E, Equations E-5 and E-6). Therefore, variation in $W_{s}$ caused by differences in minimum and maximum growing season lengths for a crop and yearly variation in climate variables that drive $E T_{o}$ could potentially influence the distribution of $O W$.

Uncertainty in the distribution of $O W$ is from lack of knowledge about which crops a farmer will choose to grow and about water management practices (i.e., excessive irrigation during a growing season). Uncertainty regarding crops is accounted for through selection of 26 crops and turf.

Variation in Minimum and Maximum Season Lengths-Ranges in minimum and maximum season lengths for crops within a crop type appear to be considerable, suggesting a potentially large influence on the distribution parameters for irrigation (Section 6.5.2). However, it was shown in Section 6.5.2 that season lengths were constrained by mean monthly temperatures for the two climates (i.e., temperatures below crop tolerance levels) or by growing two-season crops. Thus, potential variation in $I R$ due to minimum and maximum growing season lengths was encompassed by the use of two-season crops and constraints on growing season length caused by temperatures (Section 6.5.2). Therefore, any influence of this variation on the distribution of $O W$ would also be adequately accounted for through the use of two-season crops and constraints on growing season length caused by temperatures.

Yearly Variation in Climate Variables-Climate variables affect $O W$ through the effects of $E T_{o}$ on $I R$. Variation caused by mean monthly climate variables was not directly calculated because the information was not available. However, it was shown in Section 6.5.2 that variation in $I R$ caused by differences in crop water-use was greater than that caused by potential yearly variation in climate variables. It is reasonable to suggest that the influence of variation in monthly mean climate variables on the distribution of $O W$ would be accounted for in the variation among crops in $I R$ and salt tolerance. Additionally, for both climates the $C V$ for $O W$ was greater than the $C V$ for temperature data used in Section 6.5.2 (73 percent and 65 percent for present-day and upper bound glacial transition climate, respectively, versus 10 percent for yearly variation in monthly mean temperature). This suggests that the recommended distribution encompasses the variation in $O W$ that could be caused by yearly variation in mean monthly climate variables.

Uncertainty in Water Management Practices-Uncertainty in the distributions of $O W$ due to lack of knowledge about water management practices can be bounded similarly to the distributions for IR (Section 6.5.2) by assessing practices that could result in reductions in crop 
yield or water waste. Minimum values that were selected for the distributions of $O W$ would not be affected by under watering so only excessive irrigation practices are considered.

Excessive Irrigation-Problems caused by excessive irrigation are discussed in Section 6.5.2. These include loss of nutrients from the root zone through leaching, water loss through percolation below the root zone or runoff, oxygen deficiencies for root growth and microbial activity, denitrification, and infestation by weeds. These processes can result in loss of yield, reduced crop quality, and increased water pumping costs.

In Section 6.5.2 it was established that over watering alfalfa by about 18 percent would result in yield reduction through a variety of mechanisms, including those mentioned above. To establish reasonable upper bounds associated with excessive irrigation, maximum crop specific $O W$ values were increased by 18 percent for both climate conditions. Strawberries and head lettuce were used for present-day and upper bound glacial transition climates, respectively. An 18 percent increase in $O W$ for strawberries $(0.233 \mathrm{~m} /$ year $)$ resulted in an upper bound of $0.275 \mathrm{~m} /$ year for present-day climate. An 18 percent increase in $O W$ for head lettuce $(0.150 \mathrm{~m} /$ year $)$ resulted in an upper bound of $0.177 \mathrm{~m} /$ year for upper bound glacial transition climate (Table 6.9-2).

\subsection{TILLAGE DEPTH}

\subsubsection{Use in Biosphere Model}

Tillage depth $\left(T_{d}\right.$, in units of $\left.\mathrm{m}\right)$ is the depth of the soil layer where mechanical plowing or tilling occurs. Either tillage depth or rooting depth (see Section 6.12) will be used as soil surface depth in the biosphere model. In the soil submodel, soil surface depth is used to calculate the radionuclide leaching removal constant $\left(\lambda_{l i}\right)$ (Equation 6.9-1) and to estimate surface soil density (when multiplied by soil bulk density) in the calculation of the saturation activity concentration of radionuclides in surface soil per unit mass (Equation 6.10-1; BSC 2004 [DIRS 169460], Section 6.4.1):

$$
C s_{m, i}=\frac{C s_{i}}{\rho \times d}
$$

where

$$
\begin{aligned}
C s_{m, i}= & \text { activity concentration of radionuclide } i \text { in surface soil per unit mass }(\mathrm{Bq} / \mathrm{kg}), \\
C s_{i}= & \text { saturation activity concentration of radionuclide } i \text { in surface soil per unit area } \\
& \left(\mathrm{Bq} / \mathrm{m}^{2}\right), \\
\rho & =\text { bulk density for surface soil }\left(\mathrm{kg} / \mathrm{m}^{3}\right), \\
d & =\text { depth of surface soil }(\mathrm{m}) .
\end{aligned}
$$

Soil surface depth is used in a similar manner in the air, carbon-14, and external exposure biosphere submodels. In the biosphere model for the groundwater exposure scenario, radionuclide concentration in the soil is assumed to be at equilibrium (i.e., at saturated conditions that do not change over time or within the surface soil, for a given concentration of radionuclides in irrigation water). Therefore, surface soil depth has no influence on radionuclide concentration 
at equilibrium for the biosphere groundwater exposure scenario, but it does influence the time it would take to reach equilibrium conditions. For the biosphere volcanic ash exposure scenario, it is assumed that contaminated ash on agricultural fields and gardens is evenly mixed (i.e., diluted) throughout the surface soil. Therefore, deeper tillage depths will result in a decrease in radionuclide concentrations in the surface soil (and in resuspended soil deposited on plants) for the biosphere volcanic ash exposure scenario.

\subsubsection{Parameter Development}

Tillage is any mechanical manipulation of soil that is performed to prepare seed beds, control weeds, incorporate fertilizers, or mix organic residues into the soil. Conventional tillage for forage crops and vegetables is accomplished using a moldboard plow or chisel plow and is often supplemented by a disc plow. These plows are designed to till to a depth of approximately 25 to $30 \mathrm{~cm}$, which is the recommended range for conventional tillage depths (Lang et al. 1999 [DIRS 160031], p. 3; Granberry et al. 2000 [DIRS 160033], p. 8; Johnson 1999 [DIRS 160029], Chapter 8, p. 1; see Section 4.1.9 for input information). Additionally, moldboard, chisel, and disc plows that till to depths of 25 to $30 \mathrm{~cm}$ would be available to farmers in Amargosa Valley through companies such as John Deere (a common producer of agricultural equipment). However, conventional tillage practices can result in high rates of soil erosion, soil compaction, and water runoff. Conservation tillage causes less compaction and protects the soil surface from erosion. Conservation tillage methods are designed to till to depths of approximately 5 to $10 \mathrm{~cm}$ and leave at least 30 percent residue on the soil surface (Brady and Weil 1999 [DIRS 160019], pp. 579 to 587). A growing percentage of farmed area uses conservation tillage methods (Brady and Weil 1999 [DIRS 160019], pp. 579 to 587).

Based on this information, a reasonable estimate of $25 \mathrm{~cm}$, and a uniform distribution of tillage depth with a minimum of $5 \mathrm{~cm}$ and a maximum of $30 \mathrm{~cm}$ is recommended. Tillage depth is constrained at the low end by seeding depth and seedbed preparation requirements. It is unlikely that depths greater than $30 \mathrm{~cm}$ would be used due to environmental concerns such as soil loss through erosion and use of herbicides to control weeds. While recent general trends suggest an increase in conservation tillage (Brady and Weil 1999 [DIRS 160019], pp. 579 to 587) there is no information regarding central tendencies. Therefore, the recommended distribution is reasonable and encompasses uncertainty regarding use of different tillage methods. The distribution of tillage depths is based on current agricultural technology. Additionally, it is reasonable to expect that farmers in Amargosa Valley would utilize tillage practices or plows that are commonly used and available. Therefore, this parameter is consistent with present knowledge of the conditions in the region surrounding Yucca Mountain. The same distribution is recommended for both present-day and upper bound glacial transition climates because climate change will not influence tillage depth.

Deposition and redistribution of a thin layer of ash on agricultural fields expected from a volcanic eruption at Yucca Mountain (see Section 6.) would not cause long-term changes in the methods used to till agricultural fields and gardens; therefore, the distribution described above is recommended for both the biosphere groundwater and volcanic ash exposure scenarios. 


\subsection{YIELD}

\subsubsection{Use in Biosphere Model}

Yield $\left(Y_{j}, \mathrm{~kg} / \mathrm{m}^{2}\right)$ is a measure of the wet mass per unit area of the edible portion of each crop type $j$. It is used in the calculation of the uptake into foodstuffs of radionuclides deposited on the plant surface via water and dust interception (Equation 6.3-1). It represents the amount of foodstuffs into which the radionuclides are concentrated. Yield has a negative, linear effect on leaf uptake values, as any increase in yield results in a dilution, or decrease, in the concentration in foodstuffs contributed from leaf uptake.

\subsubsection{Parameter Development}

Distributions of yield were developed from measurements of commercial crops. The data used were gathered and compiled by the USDA NASS (Section 4.1.8). Data from five years (1995-1999) and up to four states (Arizona, California, Nevada, and Washington) were used (Tables 6.11-1 to 6.11-6). Data from Arizona and California were included because some representative crops are not grown commercially in Nevada and Washington in sufficient quantities to be reported. Arizona was selected because the arid climate of this state is consistent with that of the Yucca Mountain region. California was selected because it is representative of both arid (southern California) and semi-arid climate zones.

Yield is reported per growing season for vegetables, so if more than one crop is grown in a year on the same acreage, production for both crops are reported (USDA 1999 [DIRS 158643], p. D-4). For example, if a spring and fall crop of carrots are grown on 25 acres, production for carrots would be reported for 50 acres for that year. Information on crop yields from gardens was not used because little such information is available, much of the information that is available is presented in units that are useful for home gardeners (e.g., heads of lettuce per 10-foot row (Antonelli et al. 1998 [DIRS 158654], Table 2)) but not for this analysis, and the methods used to develop the data are not defined.

Yields for leafy vegetables (Table 6.11-1), fruits (Table 6.11-3), grain (Table 6.11-5), and cattle forage (Table 6.11-4) were based on all representative crops per group. Yield of corn was not included in the calculations for other vegetables (Table 6.11-2) because commercial yield of corn is measured with the husk on. Squash also was not included because production per state is not reported by the NASS. For cattle forage, yield of oat hay was represented by "other hay" because oat hay was not presented separately by NASS and because many other hays are grown in southern Nevada and eastern Washington (Tables A-2 and A-3). Yield of other hay and corn silage was based on one cutting. For alfalfa yield, if multiple cuttings are made they are included in the total production that is reported. However, NASS does not include information on how many cuttings occur per year. For this analysis, yield of alfalfa was calculated based on four cuttings per year. The number of cuttings used here for alfalfa differs from those used in the calculations of irrigation rates because alfalfa yield data comes from four states with a large variation in growing conditions. Four cuttings was selected to represent the average for all areas, based on information in Orloff and Marble 1997 ([DIRS 158655]). This is a reasonable average for present-day and upper bound glacial transition climate conditions. 
The average for each crop type is the mean yield of representative crops, with the exception of the weighted mean used for cattle forage (Table 6.11-7).

A cumulative distribution function is recommended for each crop type (Table 6.11-7). Ninety percent of the probability distribution is between the average minimum and maximum yield of representative crops within a crop type (e.g., yield for leafy vegetables ranges from 1.46 [broccoli] to $7.79 \mathrm{~kg} / \mathrm{m}^{2}$ [celery], Table $6.11-1$ ). The distribution between the average minimum and maximum yield is divided into intervals of virtually equal probability (summing to 90 percent), with the exception of cattle forage. The number of intervals is one less than the number of representative crops considered and the upper limits are average crop-specific values of yield (Table 6.11-7). The probabilities for the two intervals for the distribution of cattle forage were weighted $3: 1$ for the range between alfalfa and oat hay $(p=0.675)$ versus the range between oat hay and corn silage $(\mathrm{p}=0.225)$ (see Section 6 for justification). This results in a higher probability for selection of values that are similar to alfalfa. To account for variation and uncertainty that could result in values beyond the range of mean crop specific values, intervals of five percent probability each were added to the lower and upper ends of the distribution. The lowest and highest yield values reported within a crop type over a five year period were selected as the lower and upper bounds of the distributions (Tables 6.11-1 to 6.11-6).

The distributions presented in Table 6.11-7 are recommended for the present-day and future climates for the following reasons. Most of the uncertainty in yield per crop type is due to crop and variety selection and farming or gardening practices. Farmers and gardeners are likely to select crops and varieties of crops that are most productive for their growing conditions, and distributions of yield for a crop type therefore should not vary much due to climate change. In addition, the distributions were developed using data from a variety of crops and climatic conditions, including arid conditions representative of present-day climate (e.g., data from Arizona and parts of Nevada and California) and cooler conditions representative of future climates (e.g., data from Washington and parts of Nevada and California).

The distributions for some vegetables and fruits matched well with the limited data available for production from gardens. For example, production of broccoli (10-12 lb per 10-ft by $2-\mathrm{ft}$ row, or $2.7 \mathrm{~kg} / \mathrm{m}^{2}$, calculated as production per [10-ft row length $\times 2$-ft row spacing] $\times 1 \mathrm{~kg} / 2.2 \mathrm{lb} \times$ $\left.10.76 \mathrm{ft}^{2} / \mathrm{m}^{2}\right)$, cabbage (10-15 lb per $10-\mathrm{ft}$ by 2 -ft row, $\left.3.1 \mathrm{~kg} / \mathrm{m}^{2}\right)$, and potatoes $(20 \mathrm{lb}$ per $10-\mathrm{ft}$ by 2 -ft row, $4.1 \mathrm{~kg} / \mathrm{m}^{2}$ ) in eastern Washington gardens (Antonelli et al. 1998 [DIRS 158654], Table 2) match the distributions based on commercial production (Tables 6.9-1 to 6.9-3). However, values for carrots $\left(12 \mathrm{lb}\right.$ per $10-\mathrm{ft}$ by $1-\mathrm{ft}$ row, $\left.5.9 \mathrm{~kg} / \mathrm{m}^{2}\right)$, tomatoes $(30-50 \mathrm{lb}$ per $10-\mathrm{ft}$ by 3 -ft row, $6.5 \mathrm{~kg} / \mathrm{m}^{2}$ ), and onions ( $10 \mathrm{lb}$ per $10-\mathrm{ft}$ by $0.5-\mathrm{ft}$ row, $\left.43.5 \mathrm{~kg} / \mathrm{m}^{2}\right)$ were higher than commercial yields. Because methods of calculation are not presented, these high garden values are less reliable than those based on yields reported for thousands of acres of commercial farms.

Deposition and redistribution of a thin layer of ash expected from a volcanic eruption at Yucca Mountain (see Section 6) onto agricultural fields and gardens in northern Amargosa Valley would not cause a long-term change in the yield of crops. Therefore, the distributions of yield in Table 6.11-7 are intended for both the biosphere groundwater and volcanic ash exposure scenarios. 
Source: 1995 data from USDA 1998 ([DIRS 158648], Tables 4-14, 4-15, 4-21, 4-22, 4-33, 4-35, and 4-54), 1996 data from USDA 1999 ([DIRS 158647], Tables 4-14, 4-15, 4-21, 4-22, 4-33, 4-35, and 4-54), 1997 data from USDA 2000 ([DIRS 158646], Tables 4-14, 4-15, 4-21, 4-22, 4-33, 4-35, and 4-54), 1998 and 1999 data from USDA 2001 ([DIRS 158645], Tables 4-14, 4-15, 4-21, 4-22, 4-34, 4-36, and 4-55).

a Calculated as [1,000 Cwt Produced $\times 100 \mathrm{lbs} /$ Cwt $\times 0.4536 \mathrm{~kg} / \mathrm{lb}] /\left[1,000\right.$ Acres Harvested $\left.\times 4,047 \mathrm{~m}^{2} / \mathrm{acre}\right]=\mathrm{kg} / \mathrm{m}^{2}$. Cwt is a United States unit of weight that is equivalent to 100 pounds.

${ }^{b}$ Calculated using the STDEV function of Excel. 


\begin{tabular}{|c|c|c|c|c|c|c|c|c|c|c|c|c|c|c|c|c|c|c|}
\hline \multirow[b]{2}{*}{ Fruits } & \multirow[b]{2}{*}{ State } & \multicolumn{5}{|c|}{ Area Harvested (1,000 Acres) } & \multicolumn{5}{|c|}{ Production (1,000 Cwt) } & \multicolumn{7}{|c|}{ Yield $\left(\mathrm{kg} / \mathrm{m}^{2}\right)^{\mathrm{a}}$} \\
\hline & & 1995 & 1996 & 1997 & 1998 & 1999 & 1995 & 1996 & 1997 & 1998 & 1999 & 1995 & 1996 & 1997 & 1998 & 1999 & $\begin{array}{l}5-Y r \\
\text { Avg }\end{array}$ & $\begin{array}{c}\text { Average } \\
\text { Per } \\
\text { Crop }\end{array}$ \\
\hline \multirow[t]{2}{*}{ Cantaloupes } & $A Z$ & 16.0 & 17.7 & 17.7 & 18.5 & 19.7 & 3,040 & 4,071 & 4,514 & 4,625 & 5,319 & 2.13 & 2.58 & 2.86 & 2.80 & 3.03 & 2.68 & \\
\hline & $\mathrm{CA}$ & 59.3 & 59.0 & 62.3 & 58.0 & 61.0 & 11,860 & 12,980 & 13,083 & 12,760 & 12,810 & 2.24 & 2.47 & 2.35 & 2.47 & 2.35 & 2.38 & \\
\hline \multirow[t]{2}{*}{ Honeydew } & $A Z$ & 3.6 & 3.8 & 4.1 & 4.2 & 4.2 & 576 & 646 & 718 & 840 & 1,029 & 1.79 & 1.91 & 1.96 & 2.24 & 2.75 & 2.13 & \\
\hline & CA & 18.1 & 20.3 & 20.5 & 19.0 & 20.5 & 2,896 & 3,451 & 3,690 & 3,610 & 3,690 & 1.79 & 1.91 & 2.02 & 2.13 & 2.02 & 1.97 & \\
\hline \multirow[t]{2}{*}{ Watermelon } & $A Z$ & 7.2 & 7.3 & 7.2 & 7.6 & 7.1 & 1,800 & 2,154 & 2,232 & 2,280 & 3,025 & 2.80 & 3.31 & 3.47 & 3.36 & 4.78 & 3.54 & \\
\hline & CA & 17.2 & 17.1 & 17.0 & 15.0 & 14.7 & 6,364 & 7,524 & 7,820 & 6,750 & 6,321 & 4.15 & 4.93 & 5.16 & 5.04 & 4.82 & 4.82 & $2.92^{b}$ \\
\hline \multirow[t]{2}{*}{ Strawberries } & CA & 23.6 & 25.2 & 22.6 & 24.2 & 24.6 & 12,980 & 13,608 & 13,334 & 13,552 & 15,129 & 6.16 & 6.05 & 6.61 & 6.28 & 6.89 & 6.40 & \\
\hline & WA & 1.3 & 1.3 & 1.4 & 1.5 & 1.5 & 104 & 105 & 91 & 120 & 120 & 0.90 & 0.91 & 0.73 & 0.90 & 0.90 & 0.86 & 3.63 \\
\hline Tomatoes & CA & 38.0 & 37.4 & 34.0 & 41.0 & 44.0 & 10,260 & 10,472 & 9,860 & 9,840 & 11,440 & 3.03 & 3.14 & 3.25 & 2.69 & 2.91 & 3.00 & 3.00 \\
\hline Apples $^{c}$ & & & & & & & & & & & & & & & & & & 2.67 \\
\hline \multirow[t]{3}{*}{ Grapes $^{c}$} & & & & & & & & & & & & & & & & & & 1.51 \\
\hline & & & & & & & & & & & & & & & \multicolumn{3}{|c|}{ Average for all crops } & 2.75 \\
\hline & & & & & & & & & & & & & & & \multicolumn{3}{|c|}{ Standard deviation $^{\mathrm{d}}$} & 0.78 \\
\hline
\end{tabular}

Source: for melons, strawberries, and tomatoes: 1995 data from USDA 1998 ([DIRS 158648], Tables 4-17, 4-32, 4-61, 4-73, and 5-70), 1996 data from USDA 1999 ([DIRS 158647], Tables 4-17, 4-32, 4-61, 4-72, and 5-72), 1997 data from USDA 2000 ([DIRS 158646], Tables 4-17, 4-32, 4-61, 4-72, and 5-72), 1998 and 1999 data from USDA 2001 ([DIRS 158645], Tables 4-17, 4-33, 4-62, 4-71, and 5-76).

a Calculated as [1,000 Cwt Produced x $100 \mathrm{lbs} / \mathrm{Cwt} \times 0.4536 \mathrm{~kg} / \mathrm{lb}] /\left[1,000\right.$ acres Harvested $\left./ \times 4,047 \mathrm{~m}^{2} / \mathrm{acre}\right]=\mathrm{kg} / \mathrm{m}^{2}$. Cwt is a United States unit of weight that is equivalent to 100 pounds.

b Average of all melons.

c See Table 6.11-6.

${ }^{\mathrm{d}}$ Calculated using the STDEV function of Excel. 


\begin{tabular}{|c|c|c|c|c|c|c|c|c|c|c|c|c|c|c|c|c|c|c|}
\hline & \multirow[b]{2}{*}{ State } & \multicolumn{5}{|c|}{ Annual Yield (tons/acre) ${ }^{a}$} & \multicolumn{5}{|c|}{ Annual Yield (wet $\left.\mathrm{kg} / \mathrm{m}^{2}\right)^{\mathrm{b}}$} & \multicolumn{7}{|c|}{ Yield per Cutting $\left(\mathrm{kg} / \mathrm{m}^{2}\right)^{\mathrm{c}}$} \\
\hline & & 1995 & 1996 & 1997 & 1998 & 1999 & 1995 & 1996 & 1997 & 1998 & 1999 & 1995 & 1996 & 1997 & 1998 & 1999 & $\begin{array}{l}5-Y r \\
\text { Avg }\end{array}$ & $\begin{array}{c}\text { Avg Per } \\
\text { Crop }\end{array}$ \\
\hline \multirow[t]{4}{*}{ Alfalfa } & $\mathrm{AZ}$ & 7.8 & 8.0 & 8.2 & 8.0 & 7.9 & 5.25 & 5.38 & 5.51 & 5.38 & 5.31 & 1.31 & 1.34 & 1.38 & 1.34 & 1.33 & 1.34 & \\
\hline & CA & 6.9 & 7.0 & 7.2 & 6.6 & 6.9 & 4.64 & 4.71 & 4.84 & 4.44 & 4.64 & 1.16 & 1.18 & 1.21 & 1.11 & 1.16 & 1.16 & \\
\hline & NV & 4.5 & 4.5 & 4.2 & 4.6 & 4.1 & 3.03 & 3.03 & 2.82 & 3.09 & 2.76 & 0.76 & 0.76 & 0.71 & 0.77 & 0.69 & 0.74 & \\
\hline & WA & 5.1 & 4.7 & 4.8 & 5.0 & 4.9 & 3.43 & 3.16 & 3.23 & 3.36 & 3.30 & 0.86 & 0.79 & 0.81 & 0.84 & 0.82 & 0.82 & 1.02 \\
\hline \multirow[t]{3}{*}{ Corn Silage } & $A Z$ & 26.0 & 27.0 & 25.5 & 26.5 & 23.0 & 5.83 & 6.05 & 5.72 & 5.94 & 5.16 & 5.83 & 6.05 & 5.72 & 5.94 & 5.16 & 5.74 & \\
\hline & CA & 25.0 & 25.0 & 26.0 & 25.0 & 26.0 & 5.60 & 5.60 & 5.83 & 5.60 & 5.83 & 5.60 & 5.60 & 5.83 & 5.60 & 5.83 & 5.69 & \\
\hline & WA & 27.0 & 26.0 & 28.0 & 25.0 & 26.0 & 6.05 & 5.83 & 6.28 & 5.60 & 5.83 & 6.05 & 5.83 & 6.28 & 5.60 & 5.83 & 5.92 & 5.78 \\
\hline \multirow[t]{6}{*}{ Other Hay } & $A Z$ & 3.5 & 3.5 & 3.7 & 3.5 & 4.3 & 2.35 & 2.35 & 2.49 & 2.35 & 2.89 & 2.35 & 2.35 & 2.49 & 2.35 & 2.89 & 2.49 & \\
\hline & CA & 3.5 & 2.8 & 2.8 & 2.8 & 2.9 & 2.35 & 1.88 & 1.88 & 1.88 & 1.95 & 2.35 & 1.88 & 1.88 & 1.88 & 1.95 & 1.99 & \\
\hline & NV & 1.7 & 1.7 & 1.8 & 1.6 & 1.8 & 1.14 & 1.14 & 1.21 & 1.08 & 1.21 & 1.14 & 1.14 & 1.21 & 1.08 & 1.21 & 1.16 & \\
\hline & WA & 2.8 & 2.7 & 2.6 & 2.8 & 2.8 & 1.88 & 1.82 & 1.75 & 1.88 & 1.88 & 1.88 & 1.82 & 1.75 & 1.88 & 1.88 & 1.84 & 1.87 \\
\hline & & & & & & & & & & & & & & & \multicolumn{3}{|c|}{ Average for all states } & 2.89 \\
\hline & & & & & & & & & & & & & & & \multicolumn{3}{|c|}{ Standard deviation $^{d}$} & 2.54 \\
\hline
\end{tabular}

Source: 1995 data from USDA 1998 ([DIRS 158648], Tables 1-41, 6-3, and 6-4), 1996 data from USDA 1999 ([DIRS 158647], Tables 1-41, 6-3, and 6-4), 1997 data from USDA 2000 ([DIRS 158646], Tables 1-41, 6-3, and 6-4), 1998 and 1999 data from USDA 2001 ([DIRS 158645], Tables 1-39, 6-3, and 6-4).

${ }^{a}$ For alfalfa and other hay, data are the sum of all cuttings per year (USDA 1999 [DIRS 158643], p. D-3), reported as dry weight equivalent with a conversion factor of 3 tons green weight to 1 ton dry weight (USDA 1999 [DIRS 158643], pp. A-7 and A-8).

${ }^{\mathrm{b}}$ For alfalfa and other hay, calculated as [dry tons/acre $\times 3$ tons wet $/ 1$ ton dry $\times 907.2 \mathrm{~kg} / \mathrm{ton}$ ] $/ 4,047 \mathrm{~m}^{2} / \mathrm{acre}=$ wet $\mathrm{kg} / \mathrm{m}^{2}$; For corn silage calculated as [dry tons $/$ acre $\times 907.2 \mathrm{~kg} / \mathrm{ton}] / 4,047 \mathrm{~m}^{2} /$ acre $=$ wet $\mathrm{kg} / \mathrm{m}^{2}$.

${ }^{c}$ For alfalfa, calculated as annual yield divided by 4 cuttings per year; for corn silage and other hay calculated as annual yield divided by 1 cutting per year.

${ }^{d}$ Calculated using the STDEV function of Excel. 
Table 6.11-5. Commercial Yield of Grain

\begin{tabular}{|c|c|c|c|c|c|c|c|c|c|c|c|c|c|}
\hline \multirow[b]{2}{*}{ Grain } & \multirow[b]{2}{*}{ State } & \multicolumn{5}{|c|}{ Yield (bushels/acre) } & \multicolumn{7}{|c|}{ Yield $\left(\mathrm{kg} / \mathrm{m}^{2}\right)^{b}$} \\
\hline & & 1995 & 1996 & 1997 & 1998 & 1999 & 1995 & 1996 & 1997 & 1998 & 1999 & $\begin{array}{l}5-Y r \\
\text { Avg }\end{array}$ & $\begin{array}{l}\text { Average } \\
\text { per Crop }\end{array}$ \\
\hline \multirow[t]{4}{*}{ Barley } & AZ & 90.0 & 105.0 & 102.0 & 110.0 & 114.0 & 0.48 & 0.57 & 0.55 & 0.59 & 0.61 & 0.56 & \\
\hline & $\mathrm{CA}$ & 70.0 & 60.0 & 57.0 & 60.0 & 64.0 & 0.38 & 0.32 & 0.31 & 0.32 & 0.34 & 0.34 & \\
\hline & NV & 80.0 & 95.0 & 100.0 & 100.0 & 90.0 & 0.43 & 0.51 & 0.54 & 0.54 & 0.48 & 0.50 & \\
\hline & WA & 72.0 & 62.0 & 74.0 & 65.0 & 59.0 & 0.39 & 0.33 & 0.40 & 0.35 & 0.32 & 0.36 & 0.44 \\
\hline \multirow[t]{3}{*}{ Corn } & $A Z$ & 170.0 & 175.0 & 165.0 & 175.0 & 195.0 & 1.07 & 1.10 & 1.04 & 1.10 & 1.22 & 1.10 & \\
\hline & CA & 160.0 & 160.0 & 170.0 & 160.0 & 170.0 & 1.00 & 1.00 & 1.07 & 1.00 & 1.07 & 1.03 & \\
\hline & WA & 190.0 & 185.0 & 190.0 & 190.0 & 180.0 & 1.19 & 1.16 & 1.19 & 1.19 & 1.13 & 1.17 & 1.10 \\
\hline \multirow[t]{2}{*}{ Oats } & CA & 85.0 & 75.0 & 80.0 & 75.0 & 85.0 & 0.30 & 0.27 & 0.29 & 0.27 & 0.30 & 0.29 & \\
\hline & WA & 80.0 & 80.0 & 80.0 & 75.0 & 75.0 & 0.29 & 0.29 & 0.29 & 0.27 & 0.27 & 0.28 & 0.28 \\
\hline \multirow{6}{*}{$\begin{array}{l}\text { Winter } \\
\text { Wheat }\end{array}$} & $A Z$ & 80.0 & 95.0 & 85.0 & 90.0 & 105.0 & 0.54 & 0.64 & 0.57 & 0.60 & 0.71 & 0.61 & \\
\hline & $\mathrm{CA}$ & 61.0 & 69.0 & 70.0 & 60.0 & 78.0 & 0.41 & 0.46 & 0.47 & 0.40 & 0.52 & 0.45 & \\
\hline & NV & 100.0 & 100.0 & 100.0 & 100.0 & 95.0 & 0.67 & 0.67 & 0.67 & 0.67 & 0.64 & 0.67 & \\
\hline & WA & 62.0 & 70.0 & 66.0 & 65.0 & 58.0 & 0.42 & 0.47 & 0.44 & 0.44 & 0.39 & 0.43 & 0.54 \\
\hline & & & & & & & & & & \multicolumn{3}{|c|}{ Average for all crops } & 0.59 \\
\hline & & & & & & & & & & \multicolumn{3}{|c|}{ Standard Deviation $^{c}$} & 0.36 \\
\hline
\end{tabular}

Source: 1995 data from USDA 1998 ([DIRS 158648], Tables 1-8, 1-40, 1-50, and 1-56), 1996 data from USDA 1999 ([DIRS 158647], Tables 1-8, 1-40, 1-51, and 1-57), 1997 data from USDA 2000 ([DIRS 158646], Tables 1-8, 1-39, 1-51, and 1-57), 1998 and 1999 data from USDA 2001 ([DIRS 158645], Tables 1-8, 1-37, 1-49, and 1-55).

${ }^{\text {a }}$ Approximate net weight of a bushel of barley $=21.8 \mathrm{~kg}$; shelled corn $=25.4 \mathrm{~kg}$; oats $=14.5 \mathrm{~kg}$, and wheat $=27.2 \mathrm{~kg}$ (USDA 2001 [DIRS 158645], pp. v to vii).

b Calculated as bushels/acre $\times \mathrm{kg} / \mathrm{bushel} \div 4,047 \mathrm{~m}^{2} /$ acre.

${ }^{c}$ Calculated using the STDEV function of Excel.

Table 6.11-6. Commercial Yield of Apples and Grapes

\begin{tabular}{|c|c|c|c|c|c|c|c|c|c|c|c|c|c|}
\hline \multirow[b]{2}{*}{ Fruit } & \multirow[b]{2}{*}{ State } & \multicolumn{5}{|c|}{$\begin{array}{c}\text { Yield for Bearing Acreage } \\
\text { (apples }=\text { Ibs/acre, grapes }=\text { tons/acre) }\end{array}$} & \multicolumn{7}{|c|}{ Yield $\left(\mathrm{kg} / \mathrm{m}^{2}\right)^{\mathrm{a}}$} \\
\hline & & 1995 & 1996 & 1997 & 1998 & 1999 & 1995 & 1996 & 1997 & 1998 & 1999 & $\begin{array}{l}5-Y r \\
\text { Avg }\end{array}$ & $\begin{array}{c}\text { Average } \\
\text { per } \\
\text { Crop } \\
\end{array}$ \\
\hline \multirow[t]{3}{*}{ Apples } & $A Z$ & 2,620 & 25,000 & 12,200 & 12,100 & 8,790 & $-{ }^{b}$ & 2.80 & 1.37 & 1.36 & 0.99 & 1.63 & \\
\hline & $\mathrm{CA}$ & 24,300 & 25,000 & 25,000 & 23,200 & 25,600 & 2.72 & 2.80 & 2.80 & 2.60 & 2.87 & 2.76 & \\
\hline & WA & 31,700 & 33,500 & 29,400 & 38,400 & 29,100 & 3.55 & 3.75 & 3.30 & 4.30 & 3.26 & 3.63 & 2.67 \\
\hline \multirow[t]{3}{*}{ Grapes } & $A Z$ & 5.78 & 5.81 & 5.81 & 5.35 & 5.12 & 1.30 & 1.30 & 1.30 & 1.20 & 1.15 & 1.25 & \\
\hline & CA & 8.42 & 7.16 & 9.17 & 7.12 & 7.02 & 1.89 & 1.61 & 2.06 & 1.60 & 1.57 & 1.74 & \\
\hline & WA & 9.59 & 4.11 & 8.62 & 5.69 & 6.46 & 2.15 & 0.92 & 1.93 & 1.28 & 1.45 & 1.55 & 1.51 \\
\hline
\end{tabular}

Source: 1995 data from USDA 1998 ([DIRS 158649], Tables "Apples, Commercial: Bearing Acreage and Yield by State and United States, 1995-97" and "Grapes: Bearing Acreage and Yield by Type, State, and United States, 1995-97"), 1996 data from USDA 1999 ([DIRS 158650], Tables on pp. 8 and 40), 1997 data from USDA 2000 ([DIRS 158653], Tables on pp. 8 and 40), 1998 data from USDA 2001 ([DIRS 158651], Tables on pp. 10 and 44), 1999 data from USDA 2002 ([DIRS 158652], Tables on pp. 10 and 46). For all years, grapes = all types.

a Calculated as apples: Ibs/acre $\times 0.4536 \mathrm{~kg} / \mathrm{lb} \div 4,047 \mathrm{~m}^{2} /$ acre; grapes: tons/acre $\times 907.2 \mathrm{~kg} / \mathrm{ton} \div 4,047 \mathrm{~m}^{2} /$ acre .

${ }^{\mathrm{b}}$ Value for this year $\left(0.29 \mathrm{~kg} / \mathrm{m}^{2}\right)$ was omitted from the analysis because it was extremely low. 
Table 6.11-7. Averages and Cumulative Distributions for Yield $\left(\mathrm{kg} / \mathrm{m}^{2}\right)$

\begin{tabular}{|c|c|c|c|c|c|c|c|}
\hline Crop Type & Average $^{\mathrm{a}}$ & $\begin{array}{c}\text { Upper } \\
\text { Limit of }^{\text {Interval }} \\
\text { Int }^{\text {no }}\end{array}$ & $\begin{array}{l}\text { Cumulative } \\
\text { Probability }\end{array}$ & Crop Type & Average $^{a}$ & $\begin{array}{c}\text { Upper } \\
\text { Limit of } \\
\text { Interval }^{\text {b }}\end{array}$ & $\begin{array}{l}\text { Cumulative } \\
\text { Probability }\end{array}$ \\
\hline \multirow[t]{10}{*}{ Leafy Vegetables } & 3.30 & 1.08 & 0.00 & \multirow{8}{*}{\begin{tabular}{|l} 
Fruits \\
\end{tabular}} & 2.75 & 0.73 & 0.00 \\
\hline & & 1.46 & 0.05 & & & 1.51 & 0.05 \\
\hline & & 1.78 & 0.20 & & & 2.67 & 0.28 \\
\hline & & 2.01 & 0.35 & & & 2.92 & 0.51 \\
\hline & & 2.98 & 0.50 & & & 3.00 & 0.72 \\
\hline & & 3.25 & 0.65 & & & 3.63 & 0.95 \\
\hline & & 3.83 & 0.80 & & & 6.89 & 1.0 \\
\hline & & 7.79 & 0.95 & & & & \\
\hline & & 7.85 & 1.00 & \multirow[t]{7}{*}{ Grains } & 0.59 & 0.27 & 0.00 \\
\hline & & & & & & 0.28 & 0.05 \\
\hline \multirow[t]{10}{*}{ Other Vegetables } & 4.13 & 2.80 & 0.00 & & & 0.44 & 0.35 \\
\hline & & 3.37 & 0.05 & & & 0.54 & 0.65 \\
\hline & & 3.56 & 0.28 & & & 1.10 & 0.95 \\
\hline & & 3.64 & 0.51 & & & 1.22 & 1.00 \\
\hline & & 4.92 & 0.72 & & & & \\
\hline & & 5.15 & 0.95 & \multirow{5}{*}{$\begin{array}{l}\text { Cattle } \\
\text { Forage }^{c}\end{array}$} & 2.14 & 0.69 & 0.00 \\
\hline & & 6.61 & 1.00 & & & 1.02 & 0.05 \\
\hline & & & & & & 1.87 & 0.73 \\
\hline & & & & & & 5.78 & 0.95 \\
\hline & & & & & & 6.28 & 1.00 \\
\hline
\end{tabular}

a Mean yield for a crop type from Tables 6.11-1 to 6.11-6, with the exception of the weighted mean calculated for cattle forage. The weighted mean was calculated as $(3 \times 1.02$ [yield for alfalfa] $+1 \times 5.78$ [yield for corn silage] $+1 \times 1.87$ [yield for oat hay]) / $5=2.14$.

b Limits determined from crop specific yield (see Tables 6.11-1 to 6.11-6).

c The probabilities for the two intervals between the minimum and maximum crop specific values were weighted $3: 1$ for the range between alfalfa and oat hay $(p=0.68)$ versus the range between oat hay and corn silage $(p=0.22)$.

\subsection{ROOTING DEPTH}

\subsubsection{Use in Biosphere Model}

Mean maximum effective rooting depth $\left(Z_{r}\right)$ is the proportion of maximum rooting depth where approximately 80 to 90 percent of a plant's feeder roots occur. Either tillage depth or rooting depth will be used as soil surface depth in the biosphere model (see Section 6.10). Soil surface depth is used to calculate the radionuclide leaching removal constant $\left(\lambda_{l i}\right)$ (Equation 6.9-1) and to estimate surface soil density (when multiplied by soil bulk density) in the calculation of the saturation activity concentration of radionuclides in surface soil per unit mass (Equation 6.10-1).

In the biosphere model for the groundwater exposure scenario, radionuclide concentration in the soil is assumed to be at equilibrium (i.e., at saturated conditions that do not change over time or within the surface soil, for a given concentration of radionuclides in irrigation water). Therefore, surface soil depth has no influence on radionuclide concentration at equilibrium for the biosphere groundwater exposure scenario, but it does influence the time it would take to reach equilibrium conditions. For the biosphere volcanic ash exposure scenario, it is assumed that contaminated 
ash on agricultural fields and gardens is evenly mixed (i.e., diluted) throughout the surface soil. Therefore, deeper rooting depths will result in a decrease in radionuclide concentrations in the surface soil (and in resuspended soil deposited on plants) for the volcanic ash exposure scenario.

\subsubsection{Parameter Development}

Information on rooting depth from Allen et al. 1998 ([DIRS 157311], Table 22, pp. 163 to 165) (see Section 4.1.11 for input information) for turf and 23 of the 26 representative crops was used to develop the distribution for rooting depth. Allen et al. 1998 ([DIRS 157311]) provided one rooting depth for lettuce (did not distinguish between leaf and head lettuce), one rooting depth for field corn (did not distinguish between feed corn and corn silage), and one rooting depth for oats (did not distinguish between oat feed and oat hay). This resulted in 24 values (including turf) for development of the rooting depth distribution (see Table 6-1 for complete list of representative crops).

Allen et al. 1998 ([DIRS 157311], Table 22, pp. 163 to 165) present ranges for maximum effective rooting depths (Table 4.1-7). The smaller values for each range are recommended for irrigation scheduling because a large percentage of root biomass and activity occurs in the upper portion of the rooting zone. Effective rooting depth is less than the absolute maximum rooting depth of a mature plant because root density typically decreases near the lower part of the root zone (Jensen et al. 1990 [DIRS 160001], p. 22; Bishop and Beetham 1989 [DIRS 160038], p. 51). Generally, 80 to 90 percent of a plant's roots occur in the upper 60 to 75 percent of the root zone (Jensen et al. 1990 [DIRS 160001], p. 22). For example, even though maximum rooting depth of sweet corn could be as great as $1.2 \mathrm{~m}$, most of the root activity will occur within 0.8 to $0.9 \mathrm{~m}$. Therefore, the smaller values for rooting depth recommended by Allen et al. 1998 ([DIRS 157311], Table 22, pp. 163 to 165) represent general rooting depths that are adequate for this analysis.

The mean $Z_{r}$ of representative crops was 0.65 (Table 6.12-1).

A cumulative distribution function is recommended for $Z_{r}$ (Table 6.12-2). Ninety percent of the probability distribution is between the minimum and maximum $Z_{r}$ of representative crops (range $=0.2 \mathrm{~m}$ [strawberries] to $1.5 \mathrm{~m}$ [winter wheat]). The distribution between the minimum and maximum crop $Z_{r}$ is divided into five equal intervals of equal probability (summing to 90 percent, Table 6.12-2). To account for variation and uncertainty beyond the range of crop specific values, intervals of five-percent probability each were added to the lower and upper ends of the distribution. To avoid unreasonably low values that would not likely support a healthy plant, a minimum bound of $0.15 \mathrm{~m}$ is recommended (Table 6.12-2). The high value of $2.0 \mathrm{~m}$ for the range of $Z_{r}$ reported for alfalfa in Allen et al. 1998 ([DIRS 157311], Table 22, p. 165) is recommended as the maximum bound for the distribution (Table 6.12-2). The same distribution is recommended for present-day and future climates.

Genetic and environmental controls regulate root growth of agricultural crops. Maximum rooting depths can differ among varieties within a species, and among different crop species (Bishop and Beetham 1989 [DIRS 160038], Table 20). Important soil properties that influence root growth include texture, structure, and bulk density (Bishop and Beetham 1989 [DIRS 160038], pp. 14 to 17; Jensen et al. 1990 [DIRS 160001], p. 22). Soil moisture 
availability, temperature, aeration, and nutrient supply also regulate root growth. Use of several crops and turf accounts for uncertainties associated with choice of crop, and variation associated with differences in rooting depths among crops.

Deposition and redistribution of a thin layer of ash expected from a volcanic eruption at Yucca Mountain (see Section 6) onto agricultural fields and gardens in northern Amargosa Valley would not cause a change in growth characteristics of crops (i.e., root to shoot ratios). Therefore, the recommended distribution of rooting depth is intended for both the biosphere groundwater and volcanic ash exposure scenarios.

Table 6.12-1. Maximum Effective Rooting Depths

\begin{tabular}{|c|c|c|c|}
\hline Crop & Rooting Depth (m) & Crop & Rooting Depth (m) \\
\hline Alfalfa hay & 1.0 & Grapes & 1.0 \\
\hline Apples & 1.0 & Lettuce & 0.3 \\
\hline Barley & 1.0 & Melons & 0.8 \\
\hline Bell peppers & 0.5 & Oats & 1.0 \\
\hline Broccoli & 0.4 & Onions & 0.3 \\
\hline Cabbage & 0.5 & Potatoes & 0.4 \\
\hline Carrots & 0.5 & Spinach & 0.3 \\
\hline Cauliflower & 0.4 & Squash & 0.6 \\
\hline Celery & 0.3 & Strawberries & 0.2 \\
\hline Field corn & 1.0 & Sweet corn & 0.8 \\
\hline Cucumbers & 0.7 & Tomatoes & 0.7 \\
\hline & & Turf & 0.5 \\
\hline & & Winter wheat & 1.5 \\
\hline & & Mean & 0.65 \\
\hline & & $S D^{a}$ & 0.33 \\
\hline & & $\mathrm{CV}^{\mathrm{b}}$ & 0.50 \\
\hline
\end{tabular}

Source: Allen et al. 1998 ([DIRS 157311], Table 22, pp. 163 to 165).

a Standard deviation calculated using the STDEV function of Excel.

${ }^{b}$ Coefficient of variation (SD/mean).

Table 6.12-2. Average and Cumulative Distribution for Rooting Depth $\left(Z_{r}, \mathrm{~m}\right)$

\begin{tabular}{|c|c|c|}
\hline Average $^{\mathbf{a}}$ & $\begin{array}{c}\text { Upper Limit of } \\
\text { Interval }\end{array}$ & Cumulative Probability \\
\hline 0.65 & 0.15 & 0.00 \\
\hline & 0.20 & 0.05 \\
\hline & 0.30 & 0.23 \\
\hline & 0.50 & 0.41 \\
\hline & 0.70 & 0.59 \\
\hline & 1.00 & 0.77 \\
\hline & 1.50 & 0.95 \\
\hline & 2.00 & 1.00 \\
\hline
\end{tabular}

${ }^{a}$ Mean $Z_{r}$ of 23 representative crops and turf calculated from Table 6.12-1. 


\section{CONCLUSIONS}

\subsection{PARAMETER DISTRIBUTIONS}

This analysis report documents the development of reasonable distributions and averages for twelve agricultural parameters that are representative of environmental conditions expected under present-day and future climates. This information is summarized in Table 7.1-1 and contained in output DTN: MO0403SPAAEIBM.002. The same distributions for present-day and upper bound glacial transition climates are recommended for dry biomass, dry-to-wet-weight ratios, fraction of overhead irrigation, irrigation intensity, tillage depth, yield, and rooting depth. Separate distributions for present-day and upper bound glacial transition climates are recommended for growing time, irrigation rate - annual average, irrigation application, irrigation rate - daily, and overwatering rate. Average values are provided for irrigation rate - annual average for upper bound monsoon and lower bound glacial transition climates (Table 7.1-1).

Fraction of overhead irrigation, irrigation intensity, overwatering rate, irrigation rate - annual average, irrigation application, and irrigation rate - daily are not used in the biosphere volcanic ash exposure scenario, and therefore are only intended for the groundwater exposure scenario. The remaining distributions are intended for both the biosphere groundwater and volcanic ash exposure scenarios.

Uncertainties associated with the recommended parameter distributions are described in Sections 6., 6.1.2, 6.2.2, 6.3.2, 6.4.2, 6.5.2, 6.6.2, 6.7.2, 6.8.2, 6.9.2, 6.10.2, 6.11.2 and 6.12.2. One restriction for subsequent use of the recommended parameter distributions is that they are intended for use in the biosphere model equations presented in Section 6. If the equations used in the completed biosphere model differ from those presented here, use of these distributions must be justified or new parameter values must be developed. The distributions for irrigation parameters (irrigation rate - annual average, irrigation application, irrigation rate - daily, and overwatering rate) are restricted for use under the climate conditions described in Tables 4.1-2 and 4.1-5. The averages for irrigation rate - annual average for upper bound monsoon and lower bound glacial transition climates are restricted for use under the climate conditions in Tables 4.1-3 and 4.1-4. The remaining parameter distributions are restricted for use under more general conditions described for present-day and upper bound glacial transition climates. 
Table 7.1-1. Recommended Distributions and Averages for Agricultural and Environmental Parameters for the Biosphere Model

\begin{tabular}{|c|c|c|}
\hline $\begin{array}{l}\text { Parameter - Type of } \\
\text { Distribution } \\
\text { Crop Type }\end{array}$ & Average $^{\mathrm{a}}$ & Distribution Characteristics ${ }^{b}$ \\
\hline \multicolumn{3}{|c|}{ Dry Biomass $\left(\mathrm{kg} / \mathrm{m}^{2}\right)$ - Cumulative Distribution } \\
\hline Leafy Vegetables & 0.21 & $\begin{array}{l}(0.10 ; 0 \%),(0.13 ; 5 \%),(0.14 ; 20 \%),(0.15 ; 35 \%),(0.16 ; 50 \%),(0.18 \\
65 \%),(0.30 ; 80 \%),(0.42 ; 95 \%),(0.50 ; 100 \%)\end{array}$ \\
\hline Other Vegetables & 0.43 & $\begin{array}{l}(0.30 ; 0 \%),(0.40 ; 5 \%),(0.41 ; 28 \%),(0.43 ; 51 \%),(0.44 ; 73 \%),(0.46 \\
95 \%),(0.60 ; 100 \%)\end{array}$ \\
\hline Fruits & 0.62 & $\begin{array}{l}(0.10 ; 0 \%),(0.56 ; 5 \%),(0.60 ; 35 \%),(0.65 ; 65 \%),(0.68 ; 95 \%),(1.30 ; \\
100 \%)\end{array}$ \\
\hline Grains & 1.13 & $\begin{array}{l}(0.50 ; 0 \%),(0.61 ; 5 \%),(0.74 ; 35 \%),(1.20 ; 65 \%),(1.97 ; 95 \%),(2.20 \\
100 \%)\end{array}$ \\
\hline Cattle Forage & 0.48 & $(0.10 ; 0 \%),(0.23 ; 5 \%),(0.34 ; 73 \%),(1.38 ; 95 \%),(1.50 ; 100 \%)$ \\
\hline \multicolumn{3}{|c|}{ Dry-to-Wet-Weight Ratio (unitless) - Cumulative Distribution } \\
\hline Leafy Vegetables & 0.070 & $\begin{array}{l}(0.041 ; 0 \%),(0.054 ; 17 \%),(0.060 ; 33 \%),(0.078 ; 50 \%),(0.081 ; 67 \%) \\
(0.084 ; 83 \%),(0.093 ; 100 \%)\end{array}$ \\
\hline Other Vegetables & 0.103 & $\begin{array}{l}(0.035 ; 0 \%),(0.063 ; 17 \%),(0.078 ; 33 \%),(0.080 ; 50 \%),(0.103 ; 67 \%), \\
(0.122 ; 83 \%),(0.240 ; 100 \%)\end{array}$ \\
\hline Fruits & 0.120 & $(0.062 ; 0 \%),(0.084 ; 25 \%),(0.102 ; 50 \%),(0.155 ; 75 \%),(0.194 ; 100 \%)$ \\
\hline Grains & 0.903 & $(0.891 ; 0 \%),(0.896 ; 33 \%),(0.906 ; 67 \%),(0.918 ; 100 \%)$ \\
\hline Cattle Forage & 0.220 & $(0.182 ; 0 \%),(0.227 ; 75 \%),(0.238 ; 100 \%)$ \\
\hline \multicolumn{3}{|c|}{ Fraction of Overhead Irrigation (unitless) - Normal Distribution } \\
\hline Leafy Vegetables & 0.75 & Mean $=0.75$, Standard Deviation $=0.1$, Minimum $=0.49$, Maximum $=1.0$ \\
\hline Other Vegetables & 0.75 & Mean $=0.75$, Standard Deviation $=0.1$, Minimum $=0.49$, Maximum $=1.0$ \\
\hline Fruits & 0.50 & Mean $=0.50$, Standard Deviation $=0.1$, Minimum $=0.24$, Maximum $=1.0$ \\
\hline Grains & 0.90 & $\begin{array}{l}\text { Mean }=0.90, \text { Standard Deviation }=0.05, \text { Minimum }=0.77, \text { Maximum }= \\
1.0\end{array}$ \\
\hline Cattle Forage & 0.90 & $\begin{array}{l}\text { Mean }=0.90, \text { Standard Deviation }=0.05, \text { Minimum }=0.77, \text { Maximum }= \\
1.0\end{array}$ \\
\hline \multicolumn{3}{|c|}{ Growing Time (days) - Present-Day Climate - Fixed Value } \\
\hline Leafy Vegetables & 75 & NA \\
\hline Other Vegetables & 80 & NA \\
\hline Fruits & 160 & NA \\
\hline Grains & 200 & NA \\
\hline Cattle Forage & 75 & NA \\
\hline \multicolumn{3}{|c|}{ Growing Time (days) - Upper Bound Glacial Transition Climate - Fixed Value } \\
\hline Leafy Vegetables & 75 & NA \\
\hline Other Vegetables & 100 & NA \\
\hline Fruits & 105 & NA \\
\hline Grains & 185 & NA \\
\hline Cattle Forage & 90 & NA \\
\hline
\end{tabular}


Table 7.1-1. Recommended Distributions and Averages for Agricultural and Environmental Parameters for the Biosphere Model (Continued)

\begin{tabular}{|c|c|c|}
\hline $\begin{array}{c}\text { Parameter - Type of } \\
\text { Distribution } \\
\text { Crop Type } \\
\end{array}$ & Average $^{\mathrm{a}}$ & Distribution Characteristics ${ }^{\mathrm{b}}$ \\
\hline \multicolumn{3}{|c|}{ Average Annual Irrigation Rate $(\mathrm{m} / \mathrm{year})^{\mathrm{c}}$ - Present-Day Climate - Cumulative Distribution } \\
\hline All & 0.95 & $\begin{array}{l}(0.33 ; 0 \%),(0.40 ; 5 \%),(0.66 ; 23 \%),(0.83 ; 41 \%),(0.91 ; 59 \%),(1.34 \\
77 \%),(1.94 ; 95 \%),(2.29 ; 100 \%)\end{array}$ \\
\hline \multicolumn{3}{|c|}{$\begin{array}{l}\text { Average Annual Irrigation Rate }(\mathrm{m} / \mathrm{year})^{\mathrm{c}} \text { - Upper Bound Glacial Transition Climate - Cumulative } \\
\text { Distribution }\end{array}$} \\
\hline All & 0.50 & $\begin{array}{l}(0.14 ; 0 \%),(0.16 ; 5 \%),(0.36 ; 23 \%),(0.46 ; 41 \%),(0.54 ; 59 \%),(0.69 \\
77 \%),(0.83 ; 95 \%), 0.98 ; 100 \%)\end{array}$ \\
\hline \multicolumn{3}{|c|}{ Average Annual Irrigation Rate (m/year) $)^{\mathrm{d}}$ - Present-Day Climate - Normal Distribution } \\
\hline All & 0.95 & Mean $=0.95$, Standard Error $=0.08$, Minimum $=0.74$, Maximum $=1.16$ \\
\hline \multicolumn{3}{|c|}{ Average Annual Irrigation Rate $(\mathrm{m} / \mathrm{year})^{\mathrm{d}}$ - Upper Bound Glacial Transition Climate - Normal Distribution } \\
\hline All & 0.50 & Mean $=0.50$, Standard Error $=0.04$, Minimum $=0.40$, Maximum $=0.60$ \\
\hline \multicolumn{3}{|c|}{ Average Annual Irrigation Rate (m/year) Upper Bound Monsoon Climate } \\
\hline All & 0.52 & \\
\hline \multicolumn{3}{|c|}{ Average Annual Irrigation Rate (m/year) Lower Bound Glacial Transition Climate } \\
\hline All & 0.88 & \\
\hline \multicolumn{3}{|c|}{ Irrigation Intensity (cm/hour) - Uniform Distribution ${ }^{\mathrm{e}}$} \\
\hline All & 4.3 & Minimum $=1.0$, Maximum $=7.5$ \\
\hline \multicolumn{3}{|c|}{ Irrigation Application (mm) - Present-Day Climate - Cumulative Distribution } \\
\hline Leafy Vegetables & 14.7 & $\begin{array}{l}(6.0 ; 0 \%),(7.5 ; 5 \%),(8.4 ; 20 \%),(10.0 ; 35 \%),(10.9 ; 50 \%),(20.8 ; 65 \%), \\
(22.0 ; 80 \%),(23.5 ; 95 \%),(27.7 ; 100 \%)\end{array}$ \\
\hline Other Vegetables & 26.0 & $\begin{array}{l}(8.0 ; 0 \%),(9.1 ; 5 \%),(18.9 ; 20 \%),(19.8 ; 35 \%),(21.2 ; 50 \%),(33.3 \\
65 \%),(34.8 ; 80 \%),(44.7 ; 95 \%),(52.7 ; 100 \%)\end{array}$ \\
\hline Fruits & 33.9 & $\begin{array}{l}(5.0 ; 0 \%),(6.0 ; 5 \%),(30.3 ; 28 \%),(35.4 ; 51 \%),(48.4 ; 72 \%),(49.4 \\
95 \%),(58.3 ; 100 \%)\end{array}$ \\
\hline Grains & 56.7 & $\begin{array}{l}(43.0 ; 0 \%),(48.6 ; 5 \%),(50.1 ; 35 \%),(50.4 ; 65 \%),(77.9 ; 95 \%),(91.9 ; \\
100 \%)\end{array}$ \\
\hline Cattle Forage & 57.8 & $(50.0 ; 0 \%),(56.3 ; 5 \%),(57.6 ; 72 \%),(60.0 ; 95 \%),(71.0 ; 100 \%)$ \\
\hline \multicolumn{3}{|c|}{ Irrigation Application (mm) - Upper Bound Glacial Transition Climate - Cumulative Distribution } \\
\hline Leafy Vegetables & 14.6 & $\begin{array}{l}\text { (7.0; 0\%), (7.8; 5\%), (8.0; 20\%), (9.0; 35\%), (10.1; 50\%), (19.3; 65\%), } \\
(22.0 ; 80 \%),(26.1 ; 95 \%),(30.8 ; 100 \%)\end{array}$ \\
\hline Other Vegetables & 25.0 & $\begin{array}{l}(10.0 ; 0 \%),(11.3 ; 5 \%),(14.4 ; 20 \%),(17.7 ; 35 \%),(20.1 ; 50 \%),(34.1 ; \\
65 \%),(37.2 ; 80 \%),(40.3 ; 95 \%),(47.6 ; 100 \%)\end{array}$ \\
\hline Fruits & 34.2 & $\begin{array}{l}(6.0 ; 0 \%),(7.3 ; 5 \%),(31.4 ; 28 \%),(34.6 ; 51 \%),(43.2 ; 72 \%),(54.4 ; \\
95 \%),(64.2 ; 100 \%)\end{array}$ \\
\hline Grains & 51.3 & $\begin{array}{l}(28.0 ; 0 \%),(32.2 ; 5 \%),(46.2 ; 35 \%),(59.9 ; 65 \%),(66.7 ; 95 \%),(78.7 ; \\
100 \%)\end{array}$ \\
\hline Cattle Forage & 53.5 & $(43.0 ; 0 \%),(48.3 ; 5 \%),(52.5 ; 73 \%),(61.9 ; 95 \%),(73.0 ; 100 \%)$ \\
\hline \multicolumn{3}{|c|}{ Daily Average Irrigation Rate (mm/day) - Present-Day Climate - Cumulative Distribution } \\
\hline Leafy Vegetables & 5.41 & $\begin{array}{l}(4.00 ; 0 \%),(5.11 ; 5 \%),(5.19 ; 20 \%),(5.21 ; 35 \%),(5.38 ; 50 \%),(5.48 \\
80 \%),(6.00 ; 95 \%),(7.08 ; 100 \%)\end{array}$ \\
\hline Other Vegetables & 7.71 & $\begin{array}{l}(5.00 ; 0 \%),(6.07 ; 5 \%),(6.65 ; 20 \%),(6.93 ; 35 \%),(7.67 ; 50 \%),(8.36 \\
65 \%),(9.03 ; 80 \%),(9.26 ; 95 \%),(10.93 ; 100 \%)\end{array}$ \\
\hline Fruits & 7.41 & $\begin{array}{l}(4.00 ; 0 \%),(5.40 ; 5 \%),(7.02 ; 28 \%),(7.59 ; 51 \%),(8.38 ; 72 \%),(8.67 \\
95 \%),(10.23 ; 100 \%)\end{array}$ \\
\hline
\end{tabular}


Table 7.1-1. Recommended Distributions and Averages for Agricultural and Environmental Parameters for the Biosphere Model (Continued)

\begin{tabular}{|c|c|c|}
\hline $\begin{array}{c}\text { Parameter - Type of } \\
\text { Distribution } \\
\text { Crop Type }\end{array}$ & Average $^{\mathrm{a}}$ & Distribution Characteristics $^{\mathrm{b}}$ \\
\hline Grains & 4.64 & $\begin{array}{l}(3.00 ; 0 \%),(3.44 ; 5 \%),(3.58 ; 35 \%),(3.87 ; 65 \%),(7.69 ; 95 \%),(9.07 ; \\
100 \%)\end{array}$ \\
\hline Cattle Forage & 6.55 & $(5.00 ; 0 \%),(5.85 ; 5 \%),(6.18 ; 73 \%),(9.02 ; 95 \%),(10.64 ; 100 \%)$ \\
\hline \multicolumn{3}{|c|}{$\begin{array}{l}\text { Daily Average Irrigation Rate (mm/day) - Upper Bound Glacial Transition Climate - Cumulative } \\
\text { Distribution }\end{array}$} \\
\hline Leafy Vegetables & 3.81 & $\begin{array}{l}(3.00 ; 0 \%),(3.34 ; 5 \%),(3.51 ; 20 \%),(3.86 ; 50 \%),(3.92 ; 65 \%),(4.02 \\
80 \%),(4.18 ; 95 \%),(4.93 ; 100 \%)\end{array}$ \\
\hline Other Vegetables & 3.84 & $\begin{array}{l}(2.0 ; 0 \%),(2.73 ; 5 \%),(3.08 ; 20 \%),(3.48 ; 35 \%),(4.08 ; 50 \%),(4.16 \\
65 \%),(4.43 ; 80 \%),(4.95 ; 95 \%),(5.84 ; 100 \%)\end{array}$ \\
\hline Fruits & 3.90 & $\begin{array}{l}(2.00 ; 0 \%),(2.51 ; 5 \%),(3.48 ; 28 \%),(4.33 ; 51 \%),(4.38 ; 72 \%),(4.79 \\
95 \%),(5.65 ; 100 \%)\end{array}$ \\
\hline Grains & 3.36 & $\begin{array}{l}(1.00 ; 0 \%),(1.99 ; 5 \%),(3.42 ; 35 \%),(3.93 ; 65 \%),(4.11 ; 95 \%),(4.85 ; \\
100 \%)\end{array}$ \\
\hline Cattle Forage & 4.14 & $(3.00 ; 0 \%),(3.64 ; 5 \%),(4.01 ; 73 \%),(5.03 ; 95 \%),(5.94 ; 100 \%)$ \\
\hline \multicolumn{3}{|c|}{ Overwatering Rate (m/year) - Present-Day Climate - Cumulative Distribution } \\
\hline All & 0.079 & $\begin{array}{l}(0.009 ; 0 \%),(0.030 ; 19 \%),(0.045 ; 38 \%),(0.077 ; 57 \%),(0.129 ; 76 \%), \\
(0.233 ; 0.95),(0.275 ; 100 \%)\end{array}$ \\
\hline \multicolumn{3}{|c|}{ Overwatering Rate (m/year) - Upper Bound Glacial Transition Climate - Cumulative Distribution } \\
\hline All & 0.067 & $\begin{array}{l}(0.004 ; 0 \%),(0.020 ; 19 \%),(0.047 ; 38 \%),(0.072 ; 57 \%),(0.104 ; 76 \%), \\
(0.150 ; 0.95),(0.177 ; 100 \%)\end{array}$ \\
\hline \multicolumn{3}{|c|}{ Tillage Depth (cm) - Uniform Distribution ${ }^{\mathrm{f}}$} \\
\hline All & 25 & Minimum $=5$, Maximum $=30$ \\
\hline \multicolumn{3}{|c|}{ Yield $\left(\mathrm{kg} / \mathrm{m}^{2}\right)$ - Cumulative Distribution } \\
\hline Leafy Vegetables & 3.30 & $\begin{array}{l}(1.08 ; 0 \%),(1.46 ; 5 \%),(1.78 ; 20 \%),(2.01 ; 35 \%),(2.98 ; 50 \%),(3.25 \\
65 \%),(3.83 ; 80 \%),(7.79 ; 95 \%),(7.85 ; 100 \%)\end{array}$ \\
\hline Other Vegetables & 4.13 & $\begin{array}{l}(2.80 ; 0 \%),(3.37 ; 5 \%),(3.56 ; 28 \%),(3.64 ; 51 \%),(4.92 ; 72 \%),(5.15 \\
95 \%),(6.61 ; 100 \%)\end{array}$ \\
\hline Fruits & 2.75 & $\begin{array}{l}(0.73 ; 0 \%),(1.51 ; 5 \%),(2.67 ; 28 \%),(2.92 ; 51 \%),(3.00 ; 72 \%),(3.63 \\
95 \%),(6.89 ; 100 \%)\end{array}$ \\
\hline Grains & 0.59 & $\begin{array}{l}(0.27 ; 0 \%),(0.28 ; 5 \%),(0.44 ; 35 \%),(0.54 ; 65 \%),(1.10 ; 95 \%),(1.22 \\
100 \%)\end{array}$ \\
\hline Cattle Forage & 2.14 & $(0.69 ; 0 \%),(1.02 ; 5 \%),(1.87 ; 73 \%),(5.78 ; 95 \%),(6.28 ; 100 \%)$ \\
\hline \multicolumn{3}{|c|}{ Rooting Depth (m) - Cumulative Distribution } \\
\hline All & 0.65 & $\begin{array}{l}(0.15 ; 0 \%),(0.20 ; 5 \%),(0.30 ; 23 \%),(0.50 ; 41 \%),(0.70 ; 59 \%),(1.00 \\
77 \%),(1.50 ; 95 \%),(2.00 ; 100 \%)\end{array}$ \\
\hline
\end{tabular}

Output DTN: MO0403SPAAEIBM.002.

${ }^{a}$ Averages are calculated per crop type (i.e., Leafy Vegetables) or for 26 representative crops and turf (All) unless otherwise indicated (see notes e and f).

${ }^{b}$ Characteristics of the cumulative distribution are the upper bound of each interval and the cumulative probability associated with each interval.

${ }^{c}$ A cumulative distribution for IR is recommended for the Biosphere model if yearly variation and a wider range of uncertainty is required.

${ }^{d}$ A normal distribution is recommended for IR if values that are representative of the long-term average are required for the Biosphere model.

e The midpoint of the uniform distribution is presented instead of the average.

f The most common conventional tillage depth is presented instead of the average. 


\subsection{HOW THE APPLICABLE ACCEPTANCE CRITERIA ARE ADDRESSED}

The following information describes how this analysis addresses the acceptance criteria in the Yucca Mountain Review Plan, Final Report (NRC 2003 [DIRS 163274], Sections 2.2.1.3.13 and 2.2.1.3.14). Only those acceptance criteria that are applicable to this report (see Section 4.2) are discussed.

This analysis report is one of ten reports (Figure 1-1) that support biosphere modeling and describe how the acceptance criteria have been addressed by the biosphere model. A consideration of all ten reports is required to understand how all applicable acceptance criteria are satisfied by the biosphere model.

\section{Acceptance Criteria From Section 2.2.1.3.13.3, Redistribution of Radionuclides in Soil}

Three parameters developed in this analysis: annual average irrigation rate, overwatering rate, and tillage depth (soil surface depth), support modeling of the redistribution of radionuclides in soil.

Acceptance Criterion 1, System Description and Model Integration are Adequate:

- Subcriterion (2): Annual average irrigation rate, overwatering rate, and tillage depth are used to model the deposition and redistribution of contaminated material in soil. Annual average irrigation rate is used in the calculation of the primary radionuclide addition and removal process in the surface soil (BSC 2004 [DIRS 169460], Sections 6.4.1 and 6.5.1). Overwatering rate and tillage depth (soil surface depth) are used in the calculation of radionuclide leaching from the soil surface. Tillage depth is also used in the calculation of surface soil erosion (BSC 2004 [DIRS 169460], Sections 6.4.1 and 6.5.1). Distributions for these parameters are developed in Sections 6.5, 6.9, and 6.10. Other important aspects of redistribution of radionuclides in soil are considered in the Biosphere Model Report (BSC 2004 [DIRS 169460], Sections 6.4.1 and 6.5.1) and Soil-Related Input Parameters for the Biosphere Model (BSC 2004 [DIRS 169459]).

Acceptance Criterion 2, Data are Sufficient for Model Justification:

- Subcriterion (1): Data required to calculate annual average irrigation rates and overwatering rates included information on growing season lengths for selected crops, average monthly weather data (including precipitation), and salinity of irrigation water. These data are described and adequately justified in Sections 4.1.4, 4.1.5, and 4.1.7, respectively. Additional justification for use of analogue weather stations for future climate states is in Section 6 (Climate States), and development of growing season length from the data in Section 4.1.4 is described in Appendix D (Section 2.1). The data were used in multiple calculations to derive annual average irrigation rate and overwatering rate parameter distributions. These calculations are adequately described in Appendices C, D, and E. Synthesis of these calculations into parameters are described in Sections 6.5 and 6.9. Data used to calculate tillage depth (used in the biosphere model to determine soil surface depth) are described and adequately justified 
in Section 4.1.9. Use of plow depths to develop the tillage depth parameter is adequately described in Section 6.10.

- Subcriterion (2): Growing season data, weather data, and well water salinity data were taken from appropriate, officially recognized sources, YMP sources operating under QA programs, or reliable local Nye County sources (Sections 4.1.4, 4.1.5, and 4.1.7). The number of measurements and the number of crops considered for these data are sufficient to define the annual average irrigation rate and overwatering rate parameters as demonstrated by evaluation of uncertainties associated with those parameters (Sections 6.5.2 and 6.9.2).

Acceptance Criterion 3, Data Uncertainty is Characterized and Propagated Through the Model Abstraction:

- Subcriterion (1): Probability distributions were developed for the annual average irrigation rate, overwatering rate, and tillage depth parameters. These distributions are technically defensible and account for variation and uncertainties associated with each parameter (Sections 6.5.2, 6.9.2, and 6.10.2). The parameter distributions are adequately justified (Sections 6.5.2, 6.9.2, and 6.10.2) and parameter values are consistent with the characteristics of the RMEI (Section 4.1.5.1 and Appendix A).

- Subcriterion (2): Annual average irrigation rate and overwatering rate for the presentday climate were derived from climate data collected from the location of the RMEI (Section 4.1.5.1) for crops that can be grown in Amargosa Valley (Appendix A). Growing season information for these parameters was derived from southern Nye county and appropriate arid climate analogues for the location of the RMEI, including Arizona and southern California (Section 4.1 and Appendix D [Section 2.1.1]). Data on soil characteristics were from northern Amargosa Valley (Sections 4.1.6, 6.6.2, and Appendix E, Section 2.1.1). Tillage depths were from non-local sources but were commonly recommended, and typical plows are available to Amargosa Valley farmers (Section 6.10).

- Subcriterion (3): Factors that contribute to uncertainty in each parameter are identified in Sections 6.5.2, 6.9.2, and 6.10.2. For those factors having the greatest influence on each parameter, site specific or analogue data were used to evaluate the sensitivity of the parameters to uncertainty in those factors, and to select parameter bounds that represent reasonable uncertainty, as described in Section 6. No correlations among biosphere model input parameters are identified in this analysis.

\section{Acceptance Criteria From Section 2.2.1.3.14.3, Biosphere Characteristics}

The Acceptance Criteria from Section 2.2.1.3.14.3 apply to all parameters developed in this analysis: dry biomass, dry-to-wet-weight ratios, fraction of overhead irrigation, irrigation intensity, tillage depth, yield, and rooting depth, growing time, annual average irrigation rate, irrigation application, daily irrigation rate, and overwatering rate. 
Acceptance Criterion 1, System Description and Model Integration are Adequate:

- Subcriterion (3): Assumptions regarding climate change for parameters developed in this analysis were consistent with those used in other abstractions (Section 6.). Climate dependent parameters (growing time, annual average irrigation rate, irrigation application, daily irrigation rate, and overwatering rate) were developed in Section 6 for the three climate states modeled in other TSPA abstractions (present-day interglacial, monsoon, and glacial transition (BSC 2003 [DIRS 166296], p. 79)). These climates and their predicted occurrence at Yucca Mountain in the future are described in Future Climate Analysis (BSC 2004 [DIRS 170002], Section 6.6.2).

Acceptance Criterion 2, Data are Sufficient for Model Justification:

- Subcriterion (1): The parameters developed in this analysis are used in the plant and soil submodels of the biosphere model (BSC 2004 [DIRS 169460], Sections 6.4.1, 6.4.3, 6.5.1, and 6.5.3). The parameters are adequately described and justified in Section 6. The parameter values for the present-day climate were developed using climate data collected from the location of the RMEI (Section 4.1.5.1), and diet and living style of the RMEI were considered by selecting crops that can be grown in Amargosa Valley (Appendix A, Sections 1.1,2., and 4.). Adequate descriptions of how the data were used and interpreted are in Section 6 and Appendices C, D, and E. Adequate descriptions of how the data were synthesized into parameters are in Section 6.

- Subcriterion (2): The sufficiency of data used to develop parameter distributions is described in Sections 4.1, 6, and Appendix A. Demonstration that the parameter distributions are consistent with present knowledge of the conditions in the Yucca Mountain region is in Section 6 and Appendix A. The relationship between the parameters developed in this report and the FEPs related to biosphere characteristics modeling is shown in Table 1-1. Because the FEPs are comprised of several parameters, the determination that the parameters discussed in this report are consistent with present knowledge of conditions in the region surrounding Yucca Mountain supports a determination that the corresponding FEPs also are consistent with present knowledge of conditions in that region. However, a final determination of whether a FEP is consistent with present knowledge of conditions in the region surrounding Yucca Mountain can be made only after all of the parameters which contribute to that FEP have been evaluated for consistency with present knowledge of conditions in the region surrounding Yucca Mountain. Sensitivity and uncertainty analyses are addressed in other biosphere modeling reports listed in Figure 1-1.

Acceptance Criterion 3, Data Uncertainty is Characterized and Propagated Through the Model Abstraction:

- Subcriterion (1): The distributions and fixed values recommended in this analysis are technically defensible and adequately account for variation and uncertainties associated with each parameter (Section 6). The identification of uncertainties and variabilities, and how those uncertainties and variabilities were accounted for in the development of 
parameter bounds is described in Section 6. The consideration in this analysis of the definition of the RMEI is in Section 4.1.5.1 and in selection of crops in Appendix A.

- Subcriterion (2): The technical bases for the parameters developed in this analysis for use in the plant and soil submodels are consistent with site characterization data through use of site specific or appropriate analogue data inputs (Section 4 and Appendix A). The technical bases for the parameter values and ranges are technically defensible and provided in Section 6 and Appendices A - E.

- Subcriterion (4): Factors that contribute to uncertainty in each parameter are identified in Section 6. For those factors having the greatest influence on each parameter, site specific or analogue data were used to evaluate the sensitivity of the parameters to uncertainty in those factors, and to select parameter bounds that represent reasonable uncertainty, as described in Section 6. No correlations among biosphere model input parameters are identified in this analysis. 


\section{INPUTS AND REFERENCES}

\subsection{DOCUMENTS CITED}

Allen, R.G.; Pereira, L.S.; Raes, D.; and Smith, M. 1998. Crop Evapotranspiration, 157311 Guidelines for Computing Crop Water Requirements. FAO Irrigation and Drainage Paper 56. Rome, Italy: Food and Agriculture Organization of the United Nations. TIC: 245062.

Antonelli, A.L.; Byther, R.S.; Collman, S.J.; Thornton, R.E.; and Van Denburgh, R. 158654 1998. Home Gardens. EB0422. Pullman, Washington: Washington State University, Cooperative Extension, College of Agriculture \& Home Economics. TIC: 251823 .

Bishop, G.P. and Beetham, C.J. 1989. Biotic Transport of Radionuclides in Soils as a 160038 Result of the Action of Deep-Rooted Plant Species. ANS Report No. 780-5. Epsom, Surrey, England: Associated Nuclear Services. TIC: 253399.

Brady, N.C. and Weil, R.R. 1999. The Nature and Properties of Soils. 12th Edition. 160019 Upper Saddle River, New Jersey: Prentice-Hall. TIC: 242178.

Brouwer, C. and Heibloem, M. 1986. “Chapter 3: Effective Rainfall.” Irrigation Water Management: Irrigation Water Needs. Rome, Italy: Food and Agriculture Organization of the United Nations. Accessed August 2, 2002. TIC: 252924.

http://www.fao.org/docrep/s2022e/s2022e00.htm

BSC (Bechtel SAIC Company) 2003. Total System Performance Assessment-License Application Methods and Approach. TDR-WIS-PA-000006 REV 00 ICN 01. Las Vegas, Nevada: Bechtel SAIC Company. ACC: DOC.20031215.0001.

BSC 2004. Analysis of 1993-1997 Meteorological Data from Yucca Mountain Site 9. 167055 ANL-MGR-MM-000001 REV 00. Las Vegas, Nevada: Bechtel SAIC Company. ACC: DOC.20040126.0002.

BSC 2004. Atmospheric Dispersal and Deposition of Tephra from a Potential 170026 Volcanic Eruption at Yucca Mountain, Nevada. MDL-MGR-GS-000002 REV 01. Las Vegas, Nevada: Bechtel SAIC Company.

BSC 2004. Biosphere Model Report. MDL-MGR-MD-000001 REV 01. Las Vegas, 169460 Nevada: Bechtel SAIC Company.

BSC 2004. Disruptive Event Biosphere Dose Conversion Factor Analysis. 167287 ANL-MGR-MD-000003 REV 03. Las Vegas, Nevada: Bechtel SAIC Company.

BSC 2004. Future Climate Analysis. ANL-NBS-GS-000008 REV 01. Las Vegas, 170002 Nevada: Bechtel SAIC Company. 
BSC 2004. Nominal Performance Biosphere Dose Conversion Factor Analysis.

ANL-MGR-MD-000009 REV 03. Las Vegas, Nevada: Bechtel SAIC Company.

BSC 2004. Q-List. 000-30R-MGR0-00500-000-000 REV 00. Las Vegas, Nevada: 168361

Bechtel SAIC Company. ACC: ENG.20040721.0007.

BSC 2004. Simulation of Net Infiltration for Present-Day and Potential Future

Climates. MDL-NBS-HS-000023, Rev. 00. Las Vegas, Nevada: Bechtel SAIC

Company.

BSC 2004. Soil-Related Input Parameters for the Biosphere Model.

ANL-NBS-MD-000009 REV 02. Las Vegas, Nevada: Bechtel SAIC Company.

BSC 2004. Technical Work Plan for Biosphere Modeling and Expert Support.

TWP-NBS-MD-000004 REV 03. Las Vegas, Nevada: Bechtel SAIC Company.

ACC: DOC.20040527.0004.

Call, R.E. 1999. Arizona Master Gardener Manual. Tucson, Arizona: University of

158672

Arizona, College of Agriculture, Cooperative Extension. TIC: 252617.

Canori, G.F. and Leitner, M.M. 2003. Project Requirements Document.

166275

TER-MGR-MD-000001 REV 02. Las Vegas, Nevada: Bechtel SAIC Company.

ACC: DOC.20031222.0006.

Caprile, J.L.; Grant, J.A.; Holtz, B.A.; Kelley, K.M.; Mitcham, E.J.; Klonsky, K.M.;

and De Moura, R.L. 2001. Sample Costs to Establish an Apple Orchard and Produce Apples, Granny Smith Variety, San Joaquin Valley-North 2001. Davis, California:

University of California Cooperative Extension. TIC: 253202.

Christiansen, J.E. and Davis, J.R. 1967. "Sprinkler Irrigation Systems." In

Agronomy, Chapter 44 of Irrigation of Agricultural Lands. Madison, Wisconsin:

American Society of Agronomy. TIC: 223826.

CRWMS (Civilian Radioactive Waste Management System) M\&O (Management and

101090 Operating Contractor) 1997. Yucca Mountain Site Characterization Project Summary of Socioeconomic Data Analyses Conducted in Support of the Radiological Monitoring Program First Quarter 1996 to First Quarter 1997. Las Vegas, Nevada: CRWMS M\&O. ACC: MOL.19971117.0460.

CRWMS M\&O 1999. Environmental Baseline File for Meteorology and Air Quality. B00000000-01717-5705-00126 REV 00. Las Vegas, Nevada: CRWMS M\&O.

ACC: MOL.19990302.0186. 
CRWMS M\&O 1999. Evaluation of Soils in the Northern Amargosa Valley. 107736 B00000000-01717-5705-00084 REV 00. Las Vegas, Nevada: CRWMS M\&O. ACC: MOL.19990224.0268.

CRWMS M\&O 2000. Total System Performance Assessment for the Site 153246 Recommendation. TDR-WIS-PA-000001 REV 00 ICN 01. Las Vegas, Nevada: CRWMS M\&O. ACC: MOL.20001220.0045.

Dastane, N.G. 1978. “Chapter II. Measurement of Effective Rainfall.” Effective 159870 Rainfall in Irrigated Agriculture. Rome, Italy: Food and Agriculture Organization of the United Nations. Accessed August 19, 2002. TIC: 253117.

http://www.fao.org/docrep/x5560e/x5560e00.htm

DOE (U.S. Department of Energy) 1997. The 1997 "Biosphere” Food Consumption 100332 Survey Summary Findings and Technical Documentation. Las Vegas, Nevada: U.S. Department of Energy, Office of Civilian Radioactive Waste Management.

ACC: MOL.19981021.0301.

Dollarhide, W.E. 1999. "United States Department of Agriculture Soil Survey Data - Lathrop Wells Area." Letter from W.E. Dollarhide (USDA) to R. Aguilar (SNL), December 5, 1999, with attachments. ACC: MOL.19991217.0513.

Doorenbos, J. and Pruitt, W.O. 1977. Crop Water Requirements. FAO Irrigation and 103062 Drainage Paper 24. Rome, Italy: Food and Agriculture Organization of the United Nations. TIC: 245199.

Granberry, D.M.; Kelley, W.T.; and Boyhan, G.E. 2000. "Soil and Fertilizer 160033 Management." Commercial Production and Management of Cabbage and Leafy Greens. Bulletin 1181. Pages 8-12. Athens, Georgia: University of Georgia, College of Agricultural and Environmental Services. TIC: 253187.

Hagan, R.M.; Haise, H.R.; and Edminster, T.W. 1967. Irrigation of Agricultural 160037 Lands. Number 11 in the Series, Agronomy. Madison, Wisconsin: American Society of Agronomy. TIC: 223826.

Hansen, H. and Trimmer, W. 1997. Irrigation Runoff Control Strategies. PNW 287. 159373 Corvallis, Oregon: Pacific Northwest Extension Publication. TIC: 252843.

Hatfield, J.L. and Allen, R.G. 1996. "Evapotranspiration Estimates Under Deficient Water Supplies." Journal of Irrigation and Drainage Engineering, 122, (5), 301-308. New York, New York: American Society of Civil Engineers. TIC: 252935. 
Hay, R.K.M. 1995. "Harvest Index: A Review of its Use in Plant Breeding and Crop 160540 Physiology." Annals of Applied Biology, 126, (1), 197-216. Wellesbourne, England: Association of Applied Biologists. TIC: 252882.

Hinman, H.; Pelter, G.; Kulp, E.; Gillespie, R.; and Sorensen, E. 1997. 1997 159376

Enterprise Budgets, Potatoes, Winter Wheat, Alfalfa Hay, Grain Corn, Silage Corn and Sweet Corn Under Center Pivot Irrigation, Columbia Basin, Washington. EB1667. Pullman, Washington: Washington State University, Bulletin Office. TIC: 252852.

Horak, C. and Carns, D. 1997. Amargosa Focus Group Report. Biosphere Study. Las Vegas, Nevada: University of Nevada, Las Vegas. TIC: 241712.

IAEA (International Atomic Energy Agency) 1994. Handbook of Parameter Values 100458 for the Prediction of Radionuclide Transfer in Temperate Environments. Technical Reports Series No. 364. Vienna, Austria: International Atomic Energy Agency. TIC: 232035.

IAEA (International Atomic Energy Agency) 1996. Modelling of Radionuclide 160402 Interception and Loss Processes in Vegetation and of Transfer in Semi-Natural Ecosystems, Second Report of the VAMP Terrestrial Working Group.

IAEA-TECDOC-857. Vienna, Austria: International Atomic Energy Agency. TIC: 253017.

Jensen, M.E.; Burman, R.D.; and Allen, R.G., eds. 1990. Evapotranspiration and 160001 Irrigation Water Requirements. ASCE Manuals and Reports on Engineering Practice No. 70. New York, New York: American Society of Civil Engineers. TIC: 246697.

Johnson, J.W. 1999. "Chapter 8: Tillage.” Most Asked Agronomic Questions. 160029 Johnson, J.W. and Hudak, C., eds. Bulletin 760-88. Columbus, Ohio: Ohio State University, Department of Horticulture and Crop Sciences, OSU Extension. Accessed September 16, 2002. TIC: 253186. http://ohioline.osu.edu/b760/b760_8.html

Keller, W. and Carlson, C.W. 1967. "Forage Crops." In Agronomy, Chapter 31 of 159951 Irrigation of Agricultural Lands . Madison, Wisconsin: American Society of Agronomy. TIC: 223826.

Kennedy, W.E., Jr. and Strenge, D.L. 1992. Technical Basis for Translating 103776 Contamination Levels to Annual Total Effective Dose Equivalent. Volume 1 of Residual Radioactive Contamination from Decommissioning. NUREG/CR-5512. Washington, D.C.: U.S. Nuclear Regulatory Commission. ACC: MOL.20010721.0030. 
Klonsky, K.M. and De Moura, R.L. 2001. Sample Costs to Produce Fresh Market

Strawberries, Central Coast Region, Monterey \& Santa Cruz Counties, 2001.

ST-CC-01. Davis, California: University of California Cooperative Extension.

TIC: 252850.

Kranz, W. 2002. "Selecting Sprinkler Packages for Center Pivots." G88-870-A. Lincoln, Nebraska: University of Nebraska Cooperative Extension. Accessed June18, 2002. TIC: 252844. http://www.ianr.unl.edu/pubs/farmmgt/g870.htm

Lang, N.S.; Stevens, R.G.; Thornton, R.E.; Pan, W.L.; and Victory, S. 1999. Potato 160031 Nutrient Management for Central Washington. EB1871. Pullman, Washington: Washington State University Cooperative Extension. TIC: 253185.

LaPlante, P.A. and Poor, K. 1997. Information and Analyses to Support Selection of Critical Groups and Reference Biospheres for Yucca Mountain Exposure Scenarios. CNWRA 97-009. San Antonio, Texas: Center for Nuclear Waste Regulatory Analyses. ACC: MOL.20010721.0035.

LeStrange, S.L. Water Needs for Growing Grapes in Pahrump, Nevada. Call from 125452

LeStrange, S.L. to Sanders, J., July 28, 1997. ACC: MOL.19990331.0129.

LeStrange, S.L. Water Required for Crop Management Practices in Pahrump. Call from LeStrange, S.L. to Hafen, T., July 28, 1997. ACC: MOL.19990323.0176.

Ley, T.W. 1992. Sprinkler Irrigation-Application Rates and Depths. EB1305. Pullman, Washington: Washington State University, Cooperative Extension.

TIC: 252841.

Locke, G.L. 2001. Selected Ground-Water Data for Yucca Mountain Region, Southern Nevada and Eastern California, Through December 1999. Open-File Report 00-479. Carson City, Nevada: U.S. Geological Survey. ACC: MOL.20020206.0233.

Martin, D.L.; Gilley, J.R.; and Skaggs, R.W. 1991. “Appendix II: Evapotranspiration 101081 Equations." Managing Nitrogen for Groundwater Quality and Farm Profitability, Proceedings of a Symposium Sponsored By Division A-5 of the American Society of Agronomy, Anaheim, California, 1988 Follett, R. F.; Keeney, D. R.; Cruse, R. M., eds. Pages 333-338. Madison, Wisconsin: Soil Science Society of America.

TIC: 238376.

Martin, E.C.; Slack, D.C.; and Pegelow, E.J. 1999. Water Use in 159383

Vegetables: Carrots. Arizona Water Series No. 28. AZ1134. Tucson, Arizona: University of Arizona Cooperative Extension. TIC: 252847.

Martin, E.C.; Slack, D.C.; and Pegelow, E.J. 1999. Water Use in Vegetables: Dry Bulb Onions. Arizona Water Series No. 25. AZ1131. Tucson, Arizona: University of Arizona Cooperative Extension. TIC: 252848. 
Martin, E.C.; Slack, D.C.; and Pegelow, E.J. 1999. Water Use in

Vegetables Western Head Lettuce. Arizona Water Series No. 26. AZ1132. Tucson, Arizona: University of Arizona Cooperative Extension. TIC: 252849.

Mayberry, K.S. 2000. Sample Cost to Establish and Produce Bell Peppers, Imperial 159388 County - 2000. Circular 104-V. Davis, California: University of California Cooperative Extension. TIC: 252862.

Mayberry, K.S. 2000. Sample Cost to Establish and Produce Cantaloupes, Mid-Bed 159389 Trenched, Imperial County - 2000. Circular 104-V. Davis, California: University of California Cooperative Extension. TIC: 252861.

Mayberry, K.S. 2000. Sample Cost to Establish and Produce Iceberg Lettuce, 159386 Imperial County - 2000. Circular 104-V. Davis, California: University of California Cooperative Extension. TIC: 252863.

Mayberry, K.S. 2000. Sample Cost To Establish and Produce Watermelon, Imperial County - 2000. Circular 104-V. Davis, California: University of California Cooperative Extension. TIC: 252860.

McKinley, P.W.; Long, M.P.; and Benson, L.V. 1991. Chemical Analyses of Water from Selected Wells and Springs in the Yucca Mountain Area, Nevada and Southeastern California. Open-File Report 90-355. Denver, Colorado: U.S. Geological Survey. ACC: NNA.19901031.0004.

Mills, L.; Morris, B.; Roberts, A.; Robinson, M. L.; Hammond, B.; and Mandekic, J. 124338 n.d. Beginning Gardening in the Desert. Pahrump, Nevada: Southern Nye County Cooperative Extension. TIC: 243450.

Morris, B. and Johnson, W. 1986. Grass Selection for the Urban Mojave Desert 103033 Landscape. Fact Sheet 86-72. Reno, Nevada: University of Nevada, Cooperative Extension. TIC: 244377.

Morris, B. and Johnson, W. 1991. Maintaining Hybrid Bermudagrass for Urban 103034 Mojave Desert Landscapes. Fact Sheet 91-24. Reno, Nevada: University of Nevada, Cooperative Extension. TIC: 244378.

Napier, B.A.; Peloquin, R.A.; Strenge, D.L.; and Ramsdell, J.V. 1988. Conceptual Representation. Volume 1 of GENII - The Hanford Environmental Radiation Dosimetry Software System. PNL-6584. Richland, Washington: Pacific Northwest Laboratory. TIC: 252237. 
National Weather Service. 2003. "Delta Climate, International Station

Meteorological Climate Summary." Climate Data - Utah Historical Weather

Information. Salt Lake City, Utah: National Weather Service. Accessed March 4,

2003. TIC: 253916. http://www.wrh.noaa.gov/Saltlake/climate/ismcs.u24.html

Neitsch, S.L.; Arnold, J.G.; Kiniry, J.R.; Srinivasan, R.; and Williams, J.R. 2002.

"Land Cover/Plant Growth Database." Soil and Water Assessment Tool User's

Manual, Version 2000. Pages 356-385. College Station, Texas: Texas Water

Resources Institute. TIC: 254059.

Nobel, P.S. 1983. "Plants and Fluxes." Biophysical Plant Physiology and Ecology.

160500

Pages 461-523. New York, New York: W.H. Freeman and Company. TIC: 252952.

Nobel, P.S. 1983. "Temperature-Energy Budgets.” Biophysical Plant Physiology

and Ecology. Pages 339-386. New York, New York: W.H. Freeman and Company.

TIC: 253519.

NRC (U.S. Nuclear Regulatory Commission) 2003. Yucca Mountain Review Plan,

163274

Final Report. NUREG-1804, Rev. 2. Washington, D.C.: U.S. Nuclear Regulatory

Commission, Office of Nuclear Material Safety and Safeguards. TIC: 254568.

Orloff, S.B. 1997. "Hay Curing, Baling, and Storage." Chapter 12 of Intermountain

Alfalfa Management. Orloff, S.B.; Carlson, H.L.; and Teuber, L.R., eds. Publication 3366. Oakland, California: University of California, Division of Agriculture and Natural Resources. TIC: 251826.

Orloff, S.B. and Marble, V.L. 1997. "Harvest Management.” Chapter 11 of

Intermountain Alfalfa Management. Orloff, S.B.; Carlson, H.L.; and Teuber, L.R., eds. Publication 3366. Oakland, California: University of California, Division of Agriculture and Natural Resources. TIC: 251826.

Orloff, S.B.; Carlson, H.L.; and Hanson, B.R. 1997. "Irrigation.” Chapter 4 of Intermountain Alfalfa Management. Orloff, S.B.; Carlson, H.L.; and Teuber, L.R., eds. Publication 3366. Oakland, California: University of California, Division of Agriculture and Natural Resources. TIC: 251826.

Painter, K.; Hinman, H.R.; and Burns, J. 1995. 1995 Crop Rotation Budgets for

Eastern Whitman County, Washington. EB1437. Pullman, Washington: Washington State University, Cooperative Extension. TIC: 251820.

Prince, S.D.; Haskett, J.; Steininger, M.; Strand, H.; and Wright, R. 2001. "Net

Primary Production of U.S. Midwest Croplands from Agricultural Harvest Yield Data.” Ecological Applications, 11, (4), 1194-1205. Washington, D.C.: Ecological Society of America. TIC: 252845. 
Putnam, J.J. and Allshouse, J.E. 1999. Food Consumption, Prices, and Expenditures, 158676 1970-97. Statistical Bulletin No. 965. Washington, D.C.: U.S. Department of Agriculture, Economic Research Service. TIC: 252630.

Rasmuson, K.E. 2004. "Summary of 2004 Agricultural Activities, Businesses, and 169506 Community Services and Organizations in Amargosa Valley." Interoffice memorandum from K.E. Rasmuson (BSC) to K.R. Rautenstrauch, May 20, 2004, 0520041667, with enclosures. ACC: MOL.20040519.0033.

Robins, J.S.; Musick, J.T.; Finfrock, D.C.; and Rhoades, H.F. 1967. "Grain and Field 159939 Crops." In Agronomy, Chapter 32 of Irrigation of Agricultural Lands. Madison, Wisconsin: American Society of Agronomy. TIC: 223826.

Schmierer, J.L.; Orloff, S.B.; and Benton, R.W. 1997. "Stand Establishment." Chapter 2 of Intermountain Alfalfa Management. Orloff, S.B.; Carlson, H.L.; and Teuber, L.R.; eds. Publication 3366. Oakland, California: University of California, Division of Agriculture and Natural Resources. TIC: 251826.

Scholberg, J.; McNeal, B.L.; Jones, J.W.; Boote, K.J.; Stanley, C.D.; and Obreza, 160434 T.A. 2000. "Field-Grown Tomato, Growth and Canopy Characteristics of Field-Grown Tomato.” Agronomy Journal, 92, ([1]), 159-168.

[Madison, Wisconsin]: American Society of Agronomy. TIC: 252818.

Stahnke, G.K.; Brauen, S.E.; Byther, R.S.; Antonelli, A.L.; and Chastagner, G. 2001. Home Lawns. EB0482. Pullman, Washington: Washington State University, Cooperative Extension, College of Agriculture and Home Economics. TIC: 251822.

Tanner, C.B. 1967. "Measurement of Evapotranspiration.” In Agronomy, Chapter 29 of Irrigation of Agricultural Lands. Madison, Wisconsin: American Society of Agronomy. TIC: 223826.

Teegerstrom, T. and Clay, P. 1999. Arizona Field Crop Budgets 1999-2000, 159390 Maricopa County. Extension Bulletin \#AZ1118. Tucson, Arizona: University of Arizona, College of Agriculture and Life Sciences. TIC: 252872.

Teegerstrom, T. and Umeda, K. 2001. 2001-2002 Arizona Vegetable Crop Budgets, Central Arizona, Maricopa County. Publication AZ1261. Tucson, Arizona: University of Arizona, College of Agriculture and Life Sciences. TIC: 252874.

Teegerstrom, T.; Palumbo, J.; and Zerkoune, M. 2001. 2001-2002 Arizona Vegetable Crop Budgets, Western Arizona, Yuma County, La Paz County. Publication AZ1263. Tucson, Arizona: University of Arizona, Department of Agricultural and Resource Economics. TIC: 252873.

Till, J.E. and Meyer, H.R. 1983. Radiological Assessment, A Textbook on Environmental Dose Analysis. NUREG/CR-3332. Washington, D.C.: U.S. Nuclear Regulatory Commission. TIC: 223809. 
Uriu, K. and Magness, J.R. 1967. "Deciduous Tree Fruits and Nuts.” In Agronomy, 159169 Chapter 35 of Irrigation of Agricultural Lands. Madison, Wisconsin: American Society of Agronomy. TIC: 223826.

USDA (U.S. Department of Agriculture) 1997. Usual Planting and Harvesting Dates 169307 for U.S. Field Crops. Agricultural Handbook Number 628. Washington, D.C.: U.S. Department of Agriculture. ACC: MOL.20040511.0080.

USDA 1998. "Noncitrus Fruits and Nuts, 1997 Preliminary Summary." Fr Nt 1-3 158649 (98)a. Washington, D.C.: U.S. Department of Agriculture, National Agricultural Statistics Service. Accessed May 9, 2002. TIC: 252536.

http://usda.mannlib.cornell.edu/reports/nassr/fruit/pnf-bb/ncit0198.txt

USDA 1998. Agricultural Statistics 1998 . Washington, D.C.: U.S. Government Printing Office. TIC: 252541.

USDA 1999. 1997 Census of Agriculture, Nevada State and County Data. 158643 Volume 1, Geographic Area Series Part 28. AC97-A-28. Washington, D.C.: U.S. Department of Agriculture, National Agricultural Statistics Service. TIC: 246010.

USDA 1999. 1997 Census of Agriculture, Washington State and County Data. Volume 1, Geographic Area Series Part 47. AC97-A-47. Washington, D.C.: U.S. Department of Agriculture, National Agricultural Statistics Service. TIC: 252668.

USDA 1999. Agricultural Statistics 1999. Washington, D.C.: U.S. Government 158647 Printing Office. TIC: 252542.

USDA 1999. Noncitrus Fruits and Nuts, 1998 Preliminary Summary. Fr Nt 1-3 (99)a. 158650 Washington, D.C.: U.S. Department of Agriculture, National Agricultural Statistics Service. TIC: 252537.

USDA 2000. Agricultural Statistics 2000. Washington, D.C.: U.S. Government 158646 Printing Office. TIC: 252543.

USDA 2000. Noncitrus Fruits and Nuts, 1999 Preliminary Summary. Fr Nt 1-3 158653 (00)a. Washington, D.C.: U.S. Department of Agriculture, National Agricultural Statistics Service. TIC: 252538.

USDA 2001. Agricultural Statistics 2001. Washington, D.C.: U.S. Government 158645 Printing Office. TIC: 252544.

USDA 2001. Noncitrus Fruits and Nuts, 2000 Preliminary Summary. Fr Nt 1-3 (01)a. Washington, D.C.: U.S. Department of Agriculture, National Agricultural Statistics Service. TIC: 252539.

USDA 2002. Composition of Foods Raw, Processed, Prepared, USDA Nutrient 159272 Database for Standard Reference, Release 14. Washington, D.C.: U.S. Department of Agriculture, Agricultural Research Service, Nutrient Data Laboratory. TIC: 
252893.

USDA 2002. Nevada Agricultural Statistics 2000-2001. Nevada Agricultural 159273 Statistics Publications. Washington, D.C.: U.S. Department of Agriculture, Nevada Agricultural Statistics Service. Accessed July 24, 2002. TIC: 252859. http://www.nass.usda.gov/nv/rlsetoc.htm

USDA 2002. Noncitrus Fruits and Nuts, 2001 Preliminary Summary. Fr Nt 1-3 (02). Washington, D.C.: U.S. Department of Agriculture, National Agricultural Statistics Service. TIC: 252540 .

van Delden, A. 2001. "Cropping Systems, Yield and Growth Components of Potato 160433 and Wheat Under Organic Nitrogen Management.” Agronomy Journal, 93, 1370-1385. Madison, Wisconsin: Academic Press. TIC: 252816.

Ventura, F.; Spano, D.; Duce, P.; and Snyder, R.L. 1999. “An Evaluation of Common Evapotranspiration Equations." Irrigation Science, 18, (4), 163-170. New York, New York: Springer-Verlag. TIC: 252932.

Viets, F.G., Jr. 1967. "Nutrient Availability in Relation to Soil Water.” In Agronomy, 159952 Chapter 24 of Irrigation of Agricultural Lands. Madison, Wisconsin: American Society of Agronomy. TIC: 223826.

Vittum, M.T. and Flocker, W.J. 1967. "Vegetable Crops.” In Agronomy, Chapter 34159941 of Irrigation of Agricultural Lands. Madison, Wisconsin: American Society of Agronomy. TIC: 223826.

Washington Agricultural Statistics Service. 1999. "Usual Planting \& Harvesting Dates, Washington." 1999 Annual Bulletin. Washington, D.C.: National Agricultural Statistics Service, U.S. Department of Agriculture. Accessed February 23, 2000. TIC: 248851. http://www.nass.usda.gov/wa/annual99/plant99.htm

Washington State University Cooperative Extension. 2002. Vegetable Gardening. C146. Spokane, Washington: Washington State University Cooperative Extension. TIC: 251733.

Western Regional Climate Center. 1997. "Spokane, Washington: Normals, Means, 152233 and Extremes." Reno, Nevada: Western Regional Climate Center, Desert Research Institute. Accessed August 23, 2000. TIC: 248857. http://www.wrcc.dri.edu/cgi-bin/clilcd.pl?wa24157

Western Regional Climate Center. 2002. "Monthly Average Maximum Temperature 161250 (Degrees Fahrenheit) from 1965-2002." Amargosa Farms Garey, Nevada. Reno, Nevada: Western Regional Climate Center. Accessed December 18, 2002. TIC: 252920. http://www.wrcc.dri.edu/cgi-bin/cliMONtavt.pl?nvamar

Western Regional Climate Center. 2002. "Monthly Average Minimum Temperature (Degrees Fahrenheit) from 1965-2002.” Amargosa Farms Garey, Nevada. Reno, 
Nevada: Western Regional Climate Center. Accessed December 18, 2002.

TIC: 252920. http://www.wrcc.dri.edu/cgi-bin/cliMONtavt.pl?nvamar

Western Regional Climate Center. 2002. "Monthly Average Temperature (Degrees

160537

Fahrenheit) from 1965-2002." Amargosa Farms Garey, Nevada. Reno, Nevada:

Western Regional Climate Center. Accessed December 18, 2002. TIC: 252920.

http://www.wrcc.dri.edu/cgi-bin/cliMONtavt.pl?nvamar

Western Regional Climate Center 2003. “Average Wind Speed - MPH (1996-2002)

162302

Data, Alaska, Arizona, California, Colorado, Idaho, Montana, New Mexico, Nevada,

Oregon, Utah, Washington, and Wyoming." Reno, Nevada: Western Regional

Climate Center. Accessed February 26, 2003. TIC: 253914.

http://www.wrcc.dri.edu/htmlfiles/westwind

Western Regional Climate Center 2003. "Mean Monthly and Annual Percent of

Possible Sunshine" Mean Percent of Possible Sunshine - Western Regional Climate

Center (WRCC). Reno, Nevada: Western Regional Climate Center. Accessed March

4, 2003. TIC: 253912. http://www.wrcc.dri.edu/htmlfiles/westcomp.sun.html

Western Regional Climate Center 2003. "Nogales 6N, Arizona, NCDC 1971-2000

Monthly Normals." Reno, Nevada: Western Regional Climate Center. Accessed

March 4, 2003. TIC: 253915.

http://www.wrcc.dri.edu/cgi-bin/cliNORMNCDC2000.pl?aznoga

Western Regional Climate Center 2003. "Tucson, Arizona, Normals, Means, and

Extremes" Climate Data Summary Reno, Nevada: Western Regional Climate Center.

Accessed March 4, 2003. TIC: 253913.

http://www.wrcc.dri.edu/cgi-bin/clilcd.pl?az23160

Wolf, F. and Johnson, W.S. 1999. "Growing Seedless Grapes in Northwestern

Nevada." Fact Sheet 99-42. Reno, Nevada: University of Nevada Cooperative Extension. Accessed June 19, 2002. TIC: 252851.

www.extension.unr.edu/Plants/grapes.html

YMP (Yucca Mountain Site Characterization Project) 1999. Yucca Mountain Site

Characterization Project: Summary of Socioeconomic Data Analyses Conducted in Support of the Radiological Monitoring Program, April 1998 to April 1999.

North Las Vegas, Nevada: Yucca Mountain Site Characterization Office.

ACC: MOL.19991021.0188.

\subsection{CODES, STANDARDS, REGULATIONS, AND PROCEDURES}

10 CFR 63. Energy: Disposal of High-Level Radioactive Wastes in a Geologic

Repository at Yucca Mountain, Nevada. Readily available.

AP-2.22Q, Rev. 1, ICN 1. Classification Analyses and Maintenance of the Q-List. Washington, D.C.: U.S. Department of Energy, Office of Civilian Radioactive Waste Management. ACC: DOC.20040714.0002. 
AP-2.27Q, Rev. 1, ICN 4. Planning for Science Activities. Washington, D.C.: U.S. Department of Energy, Office of Civilian Radioactive Waste Management. ACC: DOC.20040610.0006.

AP-SIII.9Q, Rev. 1, ICN 6. Scientific Analyses. Washington, D.C.: U.S.

Department of Energy, Office of Civilian Radioactive Waste Management. ACC:

DOC.20040805.0003.

\subsection{SOURCE DATA, LISTED BY DATA TRACKING NUMBER}

LA0206AM831234.001. Eh-pH Field Measurements on Nye County EWDP Wells. 160051 Submittal date: 06/21/2002.

MO0010SPANYE00.001. Cleaned Nye County Food Consumption Frequency

Survey. Submittal date: 10/10/2000.

MO0208SPAMETHO.004. Methods of Irrigation in Amargosa Valley. Submittal date: $08 / 28 / 2002$.

MO0307SEPFEPS4.000. LA FEP List. Submittal date: 07/31/2003.

MO04019SUM9397.000. Summary of 1993-1997 Site 9 Meteorological Data.

Submittal date: 01/20/2004.

MO0407SEPFEPLA.000. LA FEP List. Submittal date: 07/20/2004.

\subsection{OUTPUT DATA, LISTED BY DATA TRACKING NUMBER}

MO0403SPAAEIBM.002. Agricultural and Environmental Parameters for the Biosphere Model. Submittal date: 3/22/04. 
APPENDIX A

SELECTION OF REPRESENTATIVE PLANTS 


\section{A. SELECTION OF REPRESENTATIVE PLANTS}

The first step in development of parameter distributions was selection of plants that are representative of the central tendency and variation within each of the five crop types and turf for the present-day climate (as represented by current conditions in Amargosa Valley [see Section 6. Climate States]) and upper bound glacial transition climate conditions (as represented by conditions in eastern Washington [see Section 6. Climate States]). The parameter values calculated for the representative plants were then used in Section 6 of this report to develop averages and distributions that incorporate variation and uncertainty due to differences among plants within crop types. The following sections summarize information on plants grown in Amargosa Valley and eastern Washington, national food consumption patterns, and other factors considered in selection of representative plants. As described in Section A1, plants selected for present-day climate conditions are also used for the upper bound monsoon climate, and those selected for the glacial transition climate are used for both upper and lower bounds.

\section{A1. COMMONLY GROWN PLANTS}

\section{A1.1 AMARGOSA VALLEY}

Field surveys and aerial photographs were used to measure acreage of crops grown in Amargosa Valley during 1996 through 1999 (CRWMS M\&O 1997 [DIRS 101090]; YMP 1999 [DIRS 158212]). Those surveys did not include gardens. Hay accounted for 91 to 93 percent of the total acreage planted per year; most (67 to 97 percent) hay was alfalfa (Table A-1). Pistachios were the next most common crop (4-5 percent of total acreage). Barley and oats were the only grains documented, and garlic and onions were the only vegetables. Fruit trees (listed as "peaches, nectarines, and pomegranates, and so forth" (CRWMS M\&O 1997 [DIRS 101090], Table 3-12])) were also recorded. In 2004, about 2,000 acres were planted in commercial agriculture, with alfalfa and other hay accounting for more than 95 percent of the total acreage (Rasmuson 2004 [DIRS 169506]). Additionally, about 1,000 acres were planted with evergreen trees.

Table A-1. Acres Planted in Amargosa Valley

\begin{tabular}{|l|r|r|r|r|}
\hline \multicolumn{1}{|c|}{ Crop $^{\mathbf{a}}$} & $\mathbf{1 9 9 6}^{\mathbf{b}}$ & $\mathbf{1 9 9 7 ^ { \mathbf { b } }}$ & $\mathbf{1 9 9 8}^{\mathbf{c}}$ & $\mathbf{1 9 9 9}^{\mathbf{c}}$ \\
\hline Alfalfa Hay & 1,747 & 1,822 & 1,278 & 1,360 \\
\hline Other Hay & 51 & 68 & 634 & 313 \\
\hline Barley & 17 & 32 & 34 & \\
\hline Oats & 45 & & & 98 \\
\hline Pistachios & 92 & 80 & 98 & 16 \\
\hline Fruit Trees & 2 & 8 & 18 & 11 \\
\hline Grapes & 8 & 10 & 10 & 0.3 \\
\hline Garlic & 5 & 5 & 0.3 & \\
\hline Onions & 5 & & & in \\
\hline a Commercial agricultural production during spring in & Radiological \\
Monitoring Program Grid cells 408, 409, 508, and 509. & \\
b Source: CRWMS M\&O 1997 ([DIRS 101090], Tables 3-12 and 3-13). \\
c Source: YMP 1999 ([DIRS 158212], Tables 10 and 11).
\end{tabular}


The 1997 U.S. Census of Agriculture (USDA 1999 [DIRS 158643]) also lists alfalfa as the most important crop in all of Nye County during 1997 (Table A-2). Other hay was second-most important, and pistachios were third. Tomatoes and numerous types of fruit trees were grown on a few farms. There were 97 farms and 10,221 acres planted in the county in 1997; all crop land was irrigated.

Table A-2. Crops Grown in Nye County, 1997

\begin{tabular}{|l|r|r|}
\hline \multicolumn{1}{|c|}{ Crop } & \multicolumn{1}{c|}{$\begin{array}{c}\text { Number of } \\
\text { Farms }\end{array}$} & \multicolumn{1}{c|}{ Acres } \\
\hline Harvested Cropland & 97 & 10,221 \\
\hline Irrigated Cropland & 97 & 10,221 \\
\hline Alfalfa Hay & 51 & 5,703 \\
\hline Small Grain Hay & 8 & 178 \\
\hline Tame Hay & 8 & 379 \\
\hline Wild Hay & 15 & 2,820 \\
\hline Vegetables, Total & 5 & 9 \\
\hline Tomatoes & 4 & 4 \\
\hline Orchards, Total & 22 & 254 \\
\hline Apples & 4 & 11 \\
\hline Apricots & 3 & 3 \\
\hline Cherries & 3 & 1 \\
\hline Grapes & 7 & 16 \\
\hline Peaches & 8 & 16 \\
\hline Pears & 3 & 5 \\
\hline Pomegranates & 3 & $D^{\mathrm{a}}$ \\
\hline Pecans & 3 & $\mathrm{D}^{\mathrm{a}}$ \\
\hline Pistachios & 9 & 181 \\
\hline Source: USDA 1999 ([DIRS 158643], Chapter 2, \\
Tables 13, 28, 29, 30, and 31). & \\
\hline D = Data not disclosed. & & \\
\hline
\end{tabular}

Thirteen residents of Amargosa Valley (representing nine households) actively involved in agriculture filled out questionnaires and were interviewed in 1997 to determine, among other things, the garden and commercial crops they grew and the reasons for growing them (Horak and Carns 1997 [DIRS 124149]). Although the results of this focus group study may not be representative of all agricultural practices in the valley, the study provides a valid list of crops commonly grown there (Horak and Carns 1997 [DIRS 124149], Tables 1 and 2 on pp. 26 and 27, respectively). Alfalfa was the most common cattle feed grown, and oats and other hays were also mentioned. Grains grown by those interviewed were barley, oats, red wheat, and corn (Horak and Carns 1997 [DIRS 124149], Table 1 and p. 15). A large variety of vegetables were listed, including commercial production of garlic, onions, and pumpkins, and garden production of potatoes, carrots, tomatoes, squash, lettuce, broccoli, cabbage, and many others. Fruit trees (type not specified), grapes, and melons were grown commercially and for personal consumption. Three participants also had pistachio trees. 
A guide for planting vegetables in Nye County lists 50 vegetables and fruits that can be grown there (Mills et al. no date [DIRS 124338]). Although this list is not comprehensive, it likely includes the easiest to grow and most commonly grown garden plants in the area.

Warm and cool season grasses can be grown in the Mojave Desert. Bermudagrass is a commonly used, drought-adapted turfgrass in southern Nevada (Morris and Johnson 1991 [DIRS 103034], p. 1) and tall fescue is the recommended cool season grass for this region (Morris and Johnson 1986 [DIRS 103033], p. 3).

\section{A1.2 EASTERN WASHINGTON}

Agriculture is an important industry in eastern Washington. There were about 280,000 acres of farmland in Spokane County and 800,000 in Whitman County (where Rosalia and St. John are located) in 1997 (Table A-3). Only about four percent and one percent of the agricultural land in each county, respectively, was irrigated (USDA 1999 [DIRS 159271]). The most important crop was winter wheat, comprising 46 percent of the total acreage planted in the two counties. Other common crops were barley (19 percent of total acreage), dry peas (10 percent), spring wheat ( 9 percent), lentils ( 8 percent), alfalfa ( 4 percent), and grass seed crops ( 3 percent). Numerous fruits and vegetables were grown on a smaller scale, especially in Spokane County. The only crops commonly irrigated were some vegetables (e.g., dry beans, sweet corn, pumpkins, tomatoes, peppers) and orchards. About 14 percent of acreage planted in alfalfa was irrigated (Table A-3).

The types of garden crops that can be grown in eastern Washington is quite varied and includes many of the same crops suggested for Nye County (Antonelli et al. 1998 [DIRS 158654]; Washington State University Cooperative Extension 2002 [DIRS 159256]).

Cool season grasses recommended for eastern Washington include tall fescue and Kentucky bluegrass. Most warm season grasses are not recommended for that region (Stahnke et al. 2001 [DIRS 158675], p. 6). 
Table A-3. Crops grown in Spokane and Whitman Counties, Washington, 1997

\begin{tabular}{|c|c|c|c|c|c|c|}
\hline \multirow[b]{2}{*}{ Selected Crops } & \multicolumn{3}{|c|}{ Spokane County ${ }^{a, b}$} & \multicolumn{3}{|c|}{ Whitman County $^{\mathrm{a}}$} \\
\hline & $\begin{array}{l}\text { Number } \\
\text { of Farms }\end{array}$ & Acres & $\begin{array}{r}\text { Irrigated } \\
\text { Acres }\end{array}$ & $\begin{array}{r}\text { Number of } \\
\text { Farms }\end{array}$ & Acres & $\begin{array}{r}\text { Irrigated } \\
\text { Acres }\end{array}$ \\
\hline Total farms & 1,133 & 280,969 & 10,044 & 852 & 801,501 & 4,805 \\
\hline Feed corn & 3 & D & $\mathrm{D}(1)$ & 4 & 101 & $D(1)$ \\
\hline Spring wheat & 145 & 21,485 & 520 & 358 & 78,603 & $\mathrm{D}(1)$ \\
\hline Winter wheat & 303 & 93,839 & 882 & 747 & 399,495 & $\mathrm{D}(2)$ \\
\hline Barley & 246 & 43,927 & 837 & 566 & 160,110 & 268 \\
\hline Canola & 8 & 1,584 & & 8 & 1,498 & \\
\hline Oats & 51 & 2,435 & $\mathrm{D}(2)$ & 12 & 203 & \\
\hline Dry edible beans & & & & 10 & 1,283 & 1,283 \\
\hline Dry edible peas & 81 & 19,596 & & 276 & 84,356 & $\mathrm{D}(1)$ \\
\hline Lentils & 80 & 25,373 & & 155 & 57,544 & \\
\hline Field/grass seed & 82 & 22,657 & $\mathrm{D}(2)$ & 45 & 4,251 & $\mathrm{D}(2)$ \\
\hline Alfalfa hay & 633 & 35,493 & 4,606 & 134 & 6,644 & 1,438 \\
\hline Small grain hay & 110 & 3,495 & 138 & 42 & D & $\mathrm{D}(2)$ \\
\hline Tame hay & 184 & 8,390 & 538 & 102 & 2981 & $\mathrm{D}(1)$ \\
\hline Wild hay & 109 & 4,183 & & 47 & 1,552 & \\
\hline Corn Silage & 4 & 128 & 128 & & & \\
\hline Vegetables-Total & 37 & 449 & 408 & 33 & 5,792 & \\
\hline Carrots & 6 & 34 & $\mathrm{D}(3)$ & & & \\
\hline Green peas & 4 & $\mathrm{D}$ & $\mathrm{D}(3)$ & 31 & 5,589 & \\
\hline Lettuce & 3 & 1 & 1 & & & \\
\hline Sweet peppers & 3 & 7 & 7 & & & \\
\hline Pumpkins & 17 & 139 & 119 & & & \\
\hline Squash & 10 & 58 & $\mathrm{D}(6)$ & & & \\
\hline Sweet corn & 15 & 152 & 150 & & & \\
\hline Tomatoes & 11 & 5 & 5 & & & \\
\hline Orchards - Total & 48 & 367 & 192 & 9 & 25 & 19 \\
\hline Apples & 44 & 227 & - & 9 & 19 & - \\
\hline Apricots & 14 & 11 & - & & & - \\
\hline Cherries & 29 & 50 & -- & 4 & D & - \\
\hline Peaches & 17 & 42 & & & & \\
\hline Pears & 16 & 24 & - & 4 & 2 & - \\
\hline Nursery Crops & 69 & 378 & - & 14 & 980 & - \\
\hline
\end{tabular}

Source: USDA 1999 [DIRS 159271], Tables 13, 26, 27, 28, 29, 30, 31, and 33.

a Blanks indicate not grown or irrigated, dash indicates not reported, D indicates data withheld to avoid reporting for individual farms (number in parentheses is the number of farms irrigating a crop).

b Other crops listed for Spokane County include snap beans, cucumbers and pickles, garlic, herbs, dry onions, potatoes, grapes, plums, blackberries, raspberries, strawberries, and floriculture and nursery products. 


\section{A2. FOOD CONSUMPTION}

A U.S. Department of Agriculture report (Putnam and Allshouse 1999 [DIRS 158676]) on United States food consumption patterns was examined to identify plants commonly eaten (Table A-4). Consumption estimates were derived from measurements of national food production (minus non-consumptive uses such as exports, farm use, industrial use) divided by population size; therefore, they are estimates of the upper bounds of national rates of consumption of commercially produced foods. However, because the same methods were used for all products within a food type, they are valid for general comparisons of nationwide consumption patterns within food types (Putnam and Allshouse 1999 [DIRS 158676], pp. 2 to 4). Crops not grown in southern Nevada or eastern Washington (e.g., bananas, citrus, rice) were omitted from this analysis (Table A-4).

Table A-4. Per-Capita Food Consumption

\begin{tabular}{|c|c|c|c|}
\hline $\begin{array}{c}\text { Crop Type } \\
\text { Crop }^{\text {a,b }} \\
\end{array}$ & $\begin{array}{c}\text { Consumption } \\
\text { (Ib/person) }\end{array}$ & $\begin{array}{l}\text { Crop Type } \\
\text { Crop }^{\text {a,b }} \\
\end{array}$ & $\begin{array}{c}\text { Consumption } \\
\text { (Ib/person) }\end{array}$ \\
\hline Leafy Vegetables & & Fruits and Nuts & \\
\hline Lettuce-Head & 24.3 & Melons & 30.4 \\
\hline Cabbage & 10.2 & Tomatoes & 18.9 \\
\hline Lettuce-Leaf & 6.1 & Apples & 18.5 \\
\hline Celery & 6.0 & Grapes & 8.0 \\
\hline Broccoli & 5.2 & Peaches & 5.7 \\
\hline Cauliflower & 1.6 & Strawberries & 4.2 \\
\hline Asparagus & 0.7 & Pears & 3.5 \\
\hline Spinach & 0.6 & Plums \& Prunes & 1.5 \\
\hline Other Vegetables & & Tree Nuts & 2.2 \\
\hline Potatoes & 47.9 & Grains & \\
\hline Onions & 17.9 & Wheat Flour & 149.7 \\
\hline Carrots & 12.5 & Corn Products & 23.1 \\
\hline Sweet Corn & 8.1 & Oat Products & 6.5 \\
\hline Bell Peppers & 7.2 & Barley Products & 0.7 \\
\hline Cucumbers & 6.3 & & \\
\hline Garlic & 2.1 & & \\
\hline Snap Beans & 1.4 & & \\
\hline
\end{tabular}

Source: Putnam and Allshouse 1999 ([DIRS 158676], 1997 data from Tables 2, 16, 17, 27,32 , and 34).

a Only crops with $>0.5$ pounds consumed are listed.

b Crops not likely to be grown in southern Nevada or eastern Washington are not listed, including citrus, avocados, bananas, mangoes, pineapples, papayas, rice. 
Per capita consumption of head lettuce during 1997 was more than twice that of other leafy vegetables. Consumption of potatoes far exceeded consumption of other vegetables, including other root vegetables, corn, and other vegetables. Melons were consumed more than other fruits, followed by tomatoes, apples, and grapes. Wheat consumption was much greater than corn products and other grains (Table A-4).

Food consumption information was examined only to identify commonly eaten plants in the United States, not to predict food consumption patterns of the population in the town of Amargosa Valley. Food consumption patterns used in the biosphere model were developed from a survey of people in Amargosa Valley (DOE 1997 [DIRS 100332]; DTN: MO0010SPANYE00.001 [DIRS 154976]). There is only limited information from that survey that can be used to identify commonly eaten, locally grown plants in Amargosa Valley because people surveyed were asked how often they ate any of a group of plants, but were not asked to identify specific plants. The only exception was a question asked toward the end of the survey requesting respondents to list "any other locally-produced food, such as tomatoes, or anything I did not already mention" (DOE 1997 [DIRS 100332], p. B-10). Previously mentioned fruits and vegetables included leafy vegetables ("such as cabbage, asparagus, lettuce, spinach, broccoli, or herbs"), root vegetables ("such as potatoes, garlic, beets, turnips, carrots, or onions"), grains, and fruits ("such as grapes, raisins, berries, plums, melons, or peaches") (DOE 1997 [DIRS 100332], pp. B-3 to B-6). Therefore, responses to the question are not valid for identifying commonly eaten locally produced leafy vegetables, root vegetables, or fruits. The most common responses to the question by Nye County residents were squash, tomatoes, peppers, cucumbers, zucchini, corn, and radishes (DTN: MO0010SPANYE00.001 [DIRS 154976]).

\section{A3. REPRESENTATIVE CROP VALUE PARAMETERS}

Of the parameters required for each crop type, irrigation rate probably is the most important contributor to variation in BDCFs because it appears in the numerator for calculations of soil concentrations (which is used in pathways for root uptake, external exposure, and inhalation exposure) and water-to-plant deposition rates. Irrigation rates among garden and agricultural crops for a specified location are influenced primarily by planting date and growing season, because those two parameters control how long and during what time of year plants must be irrigated. To evaluate variation in irrigation rate among plants within a crop type, growing seasons for commonly grown and consumed plants were plotted (Figures A-1 and A-2). Data on growing season are discussed in Appendix D, and presented in Tables D-1 and D-2. Plant growth form (i.e., morphology differences within a crop type) also was considered in selection of representative crops to ensure that the range in biomass and dry-to-wet-weight ratios within crop types was represented by crops selected.

Lettuce and most other commonly consumed leafy vegetables are small annuals that are planted in the spring. In southern Nevada, many leafy vegetables can also be grown in the fall (Figure A-1), but the growing season for celery is too long for spring and fall production in eastern Washington (Figure A-2). Asparagus is the only perennial leafy vegetable and has a very different growth form from other plants in this category. 
Most root and other vegetables are planted in mid to late spring and have only one growing season per year. The exceptions are onions (two seasons in southern Nevada) and carrots (two seasons in both areas). Growth form varies substantially within this group.

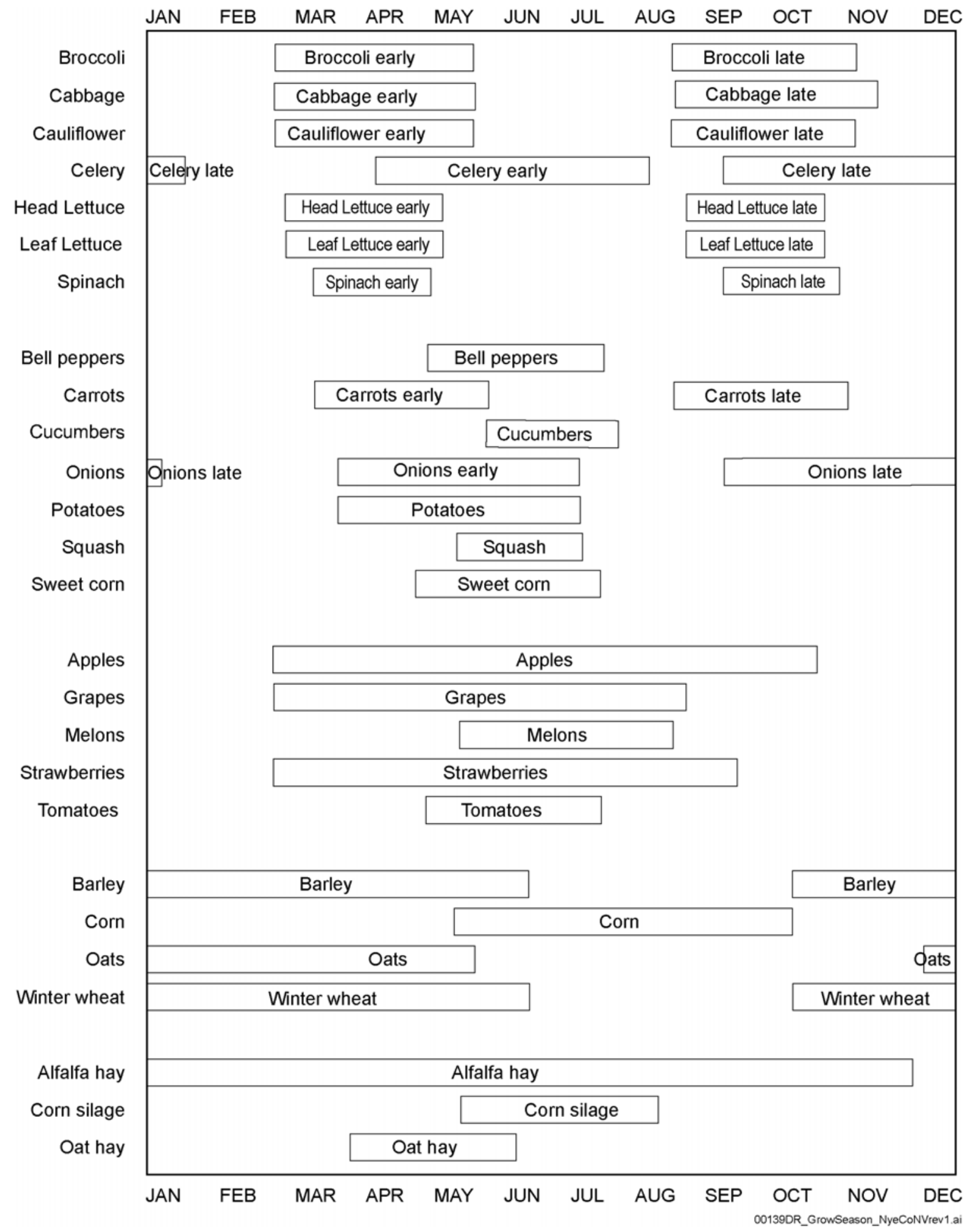

Figure A-1. Growing Season Lengths for Representative Crops under Present-Day Climate Conditions 


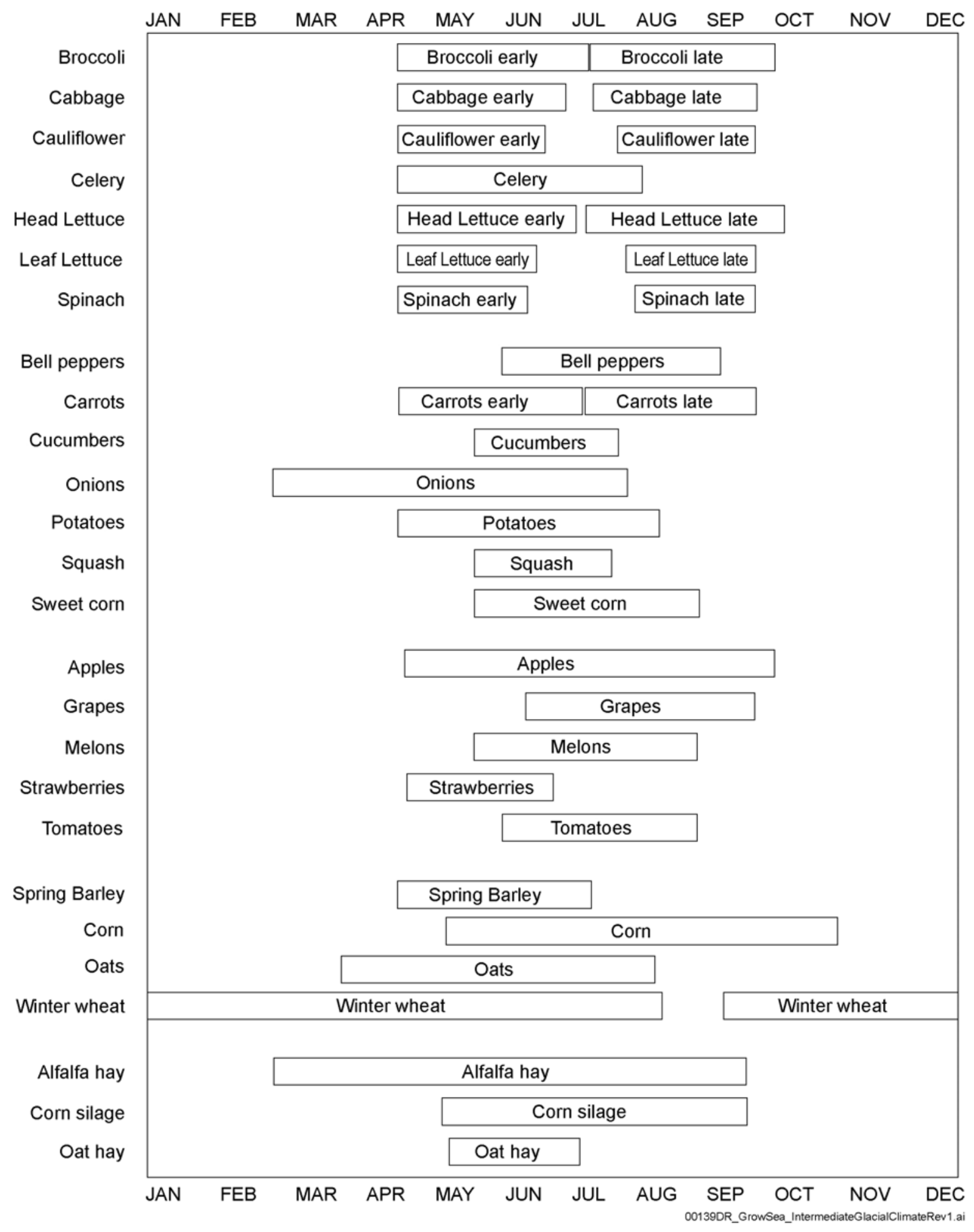

Figure A-2. Growing Season Lengths for Representative Crops under Upper Bound Glacial Transition Climate Conditions 
Fruits are a very diverse group. Melons and tomatoes are late spring or summer annuals. Other commonly consumed fruits are perennials, including orchard fruits (e.g., apples), vining grapes, and prostrate strawberries.

Wheat and barley are grown during winter in Nye County, but barley often is grown as a spring crop in Washington. Feed corn and oats are spring-summer crops in both locations.

Alfalfa hay is a perennial plant, and the common annual hays in Nye County (e.g., oats) generally are spring crops. Corn silage is planted in the spring.

\section{A4. PLANT SELECTION}

Based on the above information, three to seven plants were selected per crop type. The primary selection criterion was whether crops are grown in Nye County and eastern Washington. Once this was determined, the potential range of variation in crop type was considered. Information on crops commonly eaten in the United States was used to support the selection. Therefore, representative crops selected are those likely to be grown in the two regions of interest; representative of the range of variation in the crop type, but without having extreme values, and commonly eaten in the United States. Because the same crops can be grown in both climates considered, the same representative crops were selected for both conditions. However, different grasses were selected to represent home irrigation rates. Evergreen tree farms were observed in Amargosa Valley in 2004 (Rasmuson 2004 [DIRS 169506]) but were not included in the selection process because irrigation rates for evergreens are within the range established by low water-use vegetables (squash) and high water-use field crops (alfalfa). Additionally, the trees were drip irrigated, making them unimportant with respect to radionuclide deposition from irrigation water on leaves.

Leafy vegetables-Seven locally grown leafy vegetables (Mills et al. no date [DIRS 124338]; Antonelli et al. 1998 [DIRS 158654]; (Horak and Carns 1997 [DIRS 124149], p. 5, Table 2 on p. 27) that were also commonly consumed (Table A-4) were selected: broccoli, cabbage, cauliflower, celery, head lettuce, leaf lettuce, and spinach. Asparagus was not selected because its growth form is not typical of leafy vegetables, its growing season length is extreme compared to other leafy vegetables, and it is not frequently consumed.

Other vegetables-Seven locally grown other vegetables were selected: bell peppers, carrots, cucumbers, onions, potatoes, squash, and sweet corn (Horak and Carns 1997 [DIRS 124149], p. 5, Table 2 on p. 27; Mills et al. no date [DIRS 124338]). Six of these are the most commonly eaten other vegetables (Table A-4). The seventh, squash, was chosen instead of other commonly eaten vegetables (garlic and snap beans) because it was commonly mentioned in the food consumption survey for Amargosa Valley (DTN: MO0010SPANYE00.001 [DIRS 154976]). Peppers, cucumbers, and sweet corn were also commonly mentioned in the food consumption survey for Amargosa Valley (DTN: MO0010SPANYE00.001 [DIRS 154976]).

Fruits-Five locally grown fruits were selected: melons, tomatoes, apples, grapes, and strawberries (Horak and Carns 1997 [DIRS 124149], p. 5, Table 2 on p. 27; Mills et al. no date [DIRS 124338]). Peaches, plums, and pears, were not selected because they are similar to apples. Pistachios and other nuts were not selected because another tree (apples) was selected 
that has higher water use requirements (Allen et al. 1998 [DIRS 157311], Tables 11 and 12, pp. 104 to 108 and pp. 110 to 114). Tomatoes were commonly mentioned in the food consumption survey for Amargosa Valley (DTN: MO0010SPANYE00.001 [DIRS 154976]).

Grains-Wheat and barley were selected because they are the two most commonly grown grains in eastern Washington and were also grown in Nye County. Oats and feed corn were also selected because they are grown in both locations, although in small amounts. This selection includes both winter and spring/summer grains (Figures A-1 and A-2).

Cattle forage-Alfalfa was selected because it is the dominant crop in Amargosa Valley (Tables A-1 and A-2) and is the most common feed crop in eastern Washington (Table A-3). Oats and corn silage were also selected to include spring/summer hay and silage.

To account for irrigation around homes and for landscapes, two turf grasses were selected. The recommended warm season grass, bermudagrass, was selected as representative for calculation of turf irrigation rates in southern Nevada (Morris and Johnson 1986 [DIRS 103033], 1991 [DIRS 103034]). The cool season grass, tall fescue, was selected for eastern Washington, because warm season grasses generally are not grown there (Stahnke et al. 2001 [DIRS 158675]). 


\section{APPENDIX B}

\section{JUSTIFICATION OF METHODS USED FOR CALCULATING IRRIGATION PARAMETERS}




\section{B. JUSTIFICATION OF METHODS USED FOR CALCULATING IRRIGATION PARAMETERS}

This appendix contains a description of the relationship between photosynthesis and transpiration in terrestrial plants and how that relationship influences plant water use. Factors affecting water balance of a vegetated field are also discussed. This appendix also contains justification for use of FAO methodologies in Allen et al. (1998 [DIRS 157311]) for calculating evapotranspiration (ET) and irrigation parameters. Six commonly used methods for calculating ET are evaluated.

\section{B1. BACKGROUND INFORMATION}

Plant water use-Photosynthesis is the process by which light energy is used to drive the synthesis of organic compounds in plants. The photosynthetic process requires atmospheric carbon dioxide $\left(\mathrm{CO}_{2}\right)$. To gain $\mathrm{CO}_{2}$ for photosynthesis, plants must lose water to the atmosphere. Carbon dioxide diffuses through small pores in the leaf surface (stomata) to intercellular spaces of the leaf, and to the photosynthetic cells (Figure B-1). Concurrently, water moves in the opposite direction, from wet cell membranes inside the leaf through open stomata to the atmosphere, a process called transpiration (Figure B-1). Because water and $\mathrm{CO}_{2}$ share the same diffusional pathway through the stomata, there is an inevitable cost of water for $\mathrm{CO}_{2}$ gain.

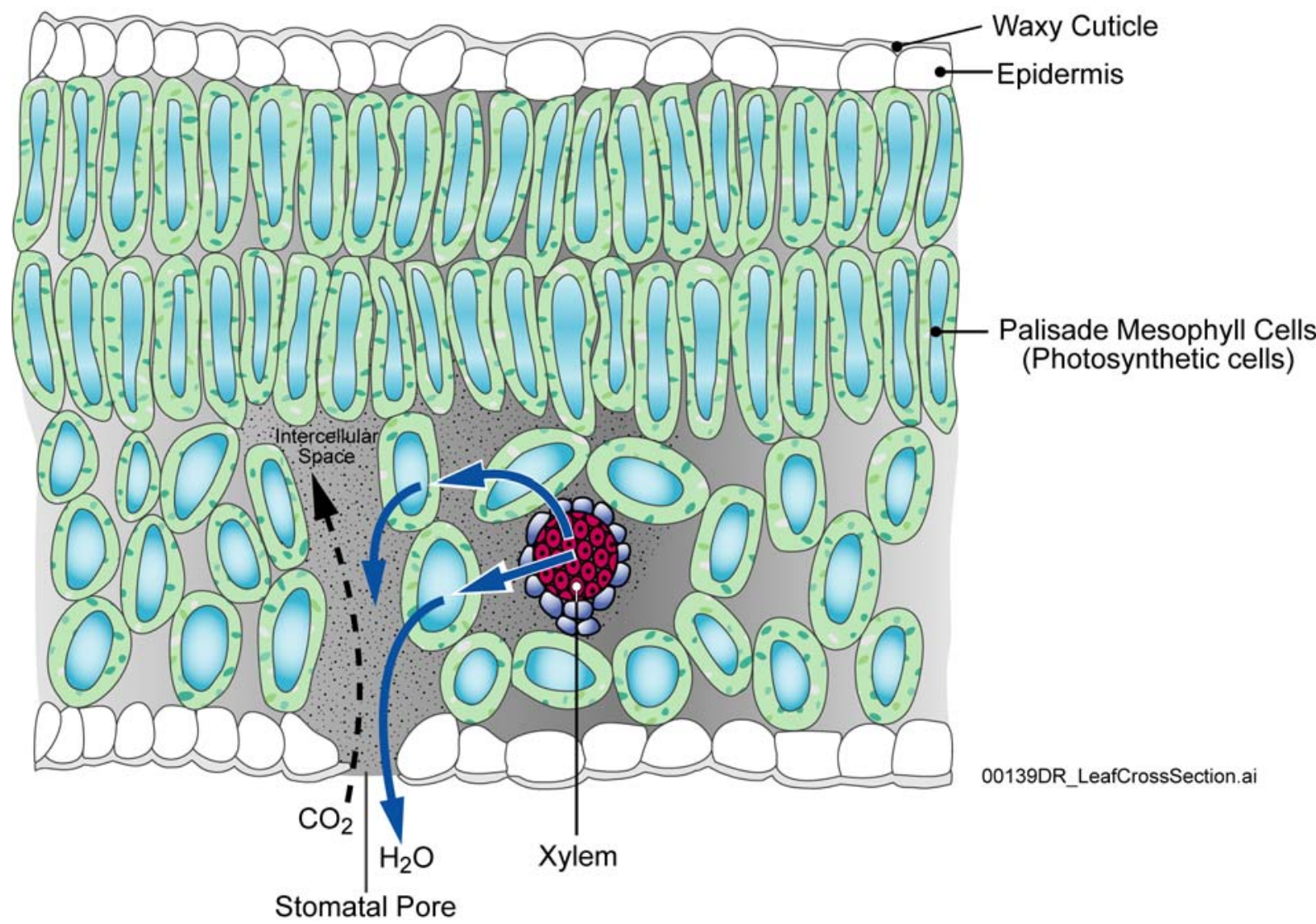

Figure B-1. Leaf Cross Section Showing Diffusional Pathway for Carbon Dioxide $\left(\mathrm{CO}_{2}\right)$ and Water $\left(\mathrm{H}_{2} \mathrm{O}\right)$ 
Water moves from the soil, through the plant, to the atmosphere down an increasingly negative water potential gradient (Figure B-2). Water potential is a thermodynamic parameter that describes the energy status of water in the soil-plant-atmosphere system (Brady and Weil 1999 [DIRS 160019], pp. 178 and 179). The soil acts as a water reservoir with texture determining the water holding capacity. Soils with high clay and silt content hold water more tightly than sandy soils. Water enters the plant through the roots and moves in a column of high tensile water through specialized cells called xylem, and into the atmosphere through open stomata. Water flow through the soil-plant-atmosphere system represents important processes in the overall hydrologic cycle.

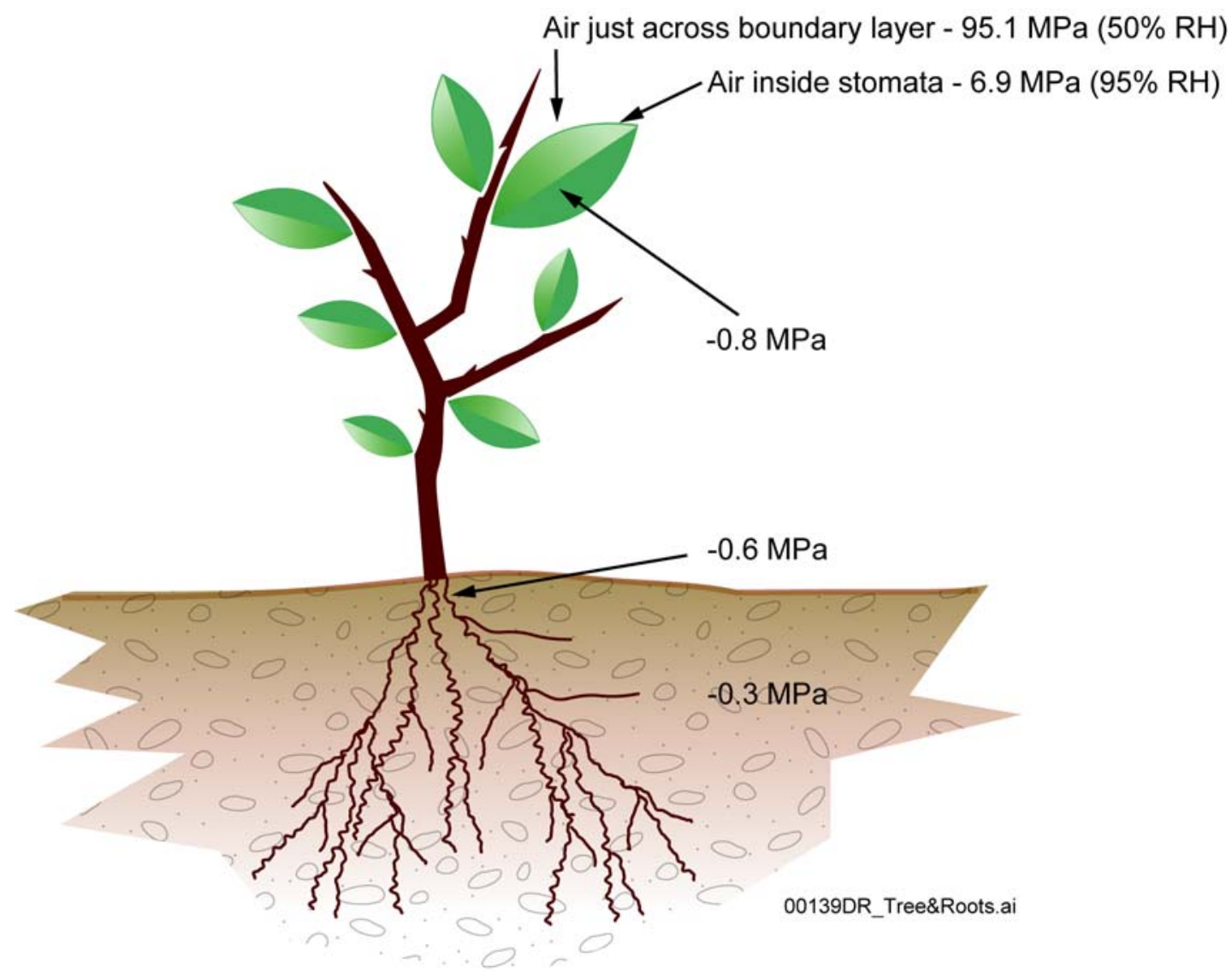

NOTE: Water moves through the system along a gradient of increasingly negative water potentials.

Figure B-2. Water Potential (MPa) In Various Components of the Soil-Plant-Atmosphere System

When soil moisture is limiting, plants can reduce water loss through stomatal closure. However, stomatal closure also results in reducing the supply of $\mathrm{CO}_{2}$, which ultimately reduces plant productivity. In arid regions, approximately 400 to 700 units of water are lost for every unit of dry matter produced by a plant (Brady and Weil 1999 [DIRS 160019], pp. 227 to 228). This is because the diffusion gradient for water from inside the leaf to the atmosphere is orders of magnitude steeper than that for $\mathrm{CO}_{2}$ diffusion into the leaf. Water is required for photosynthesis and other metabolic processes; however, 95 - 99 percent of the water that passes through a plant is lost through transpiration (Nobel 1983 [DIRS 160500], p. 506). Thus, transpiration is an accurate estimate of water uptake by plant roots (Nobel 1983 [DIRS 160500], p. 506). Water is 
also lost from the soil and other surfaces (i.e., plant litter), through the process of direct evaporation. Direct evaporation from the soil generally occurs in the upper 0.15 to $0.20 \mathrm{~m}$ of the soil profile (Figure B-3). Evapotranspiration (ET) is the combined water loss through plant transpiration and direct evaporation.

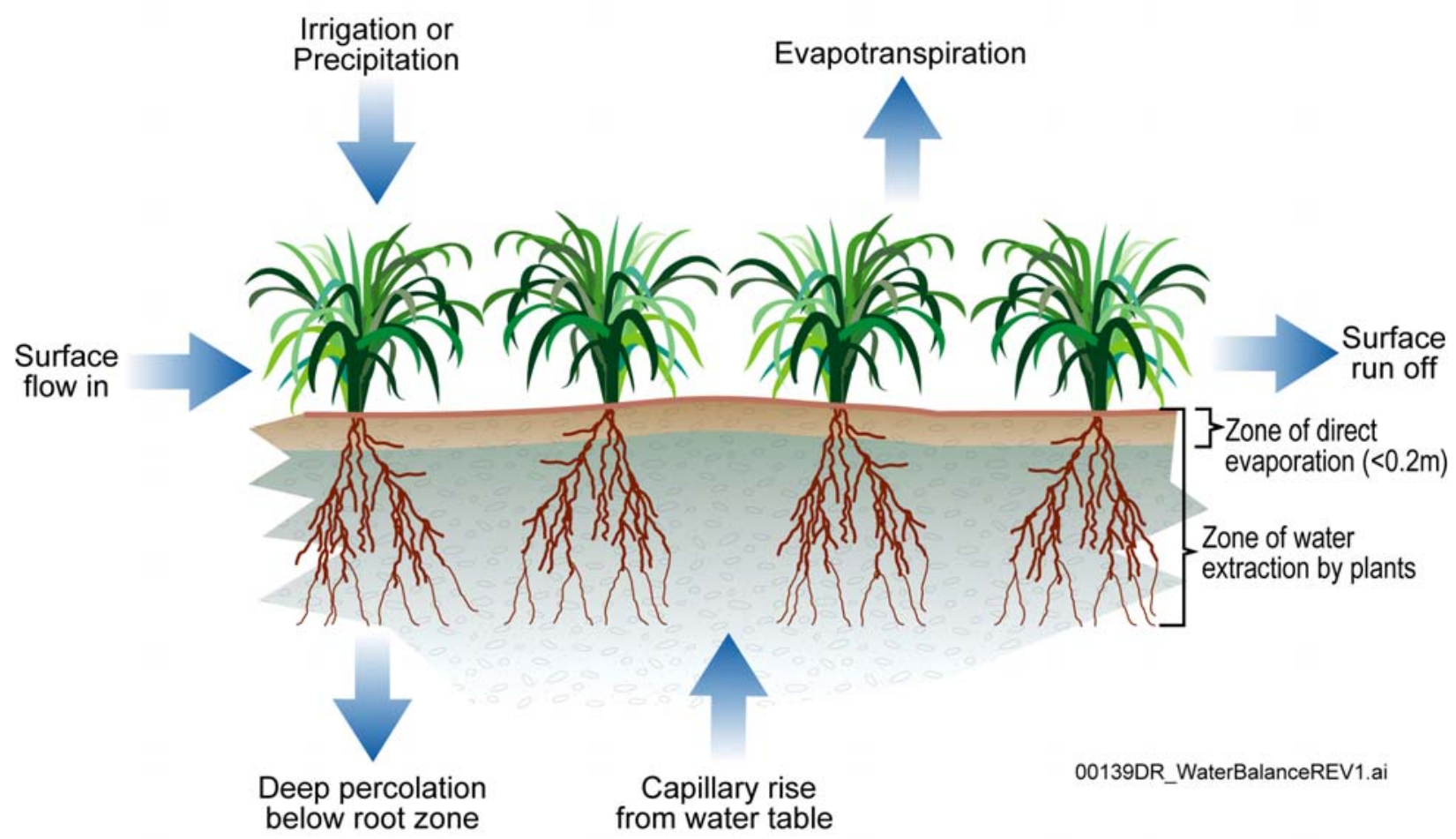

Figure B-3. Water Balance of a Cropped Field

Plant water availability depends on soil texture, soil water potential, soil hydraulic conductivity, rooting depth, and species specific ability to extract moisture from the soil. When the rate of water absorption through the roots equals or exceeds ET, internal plant water balance is maintained, and carbon gain is not affected. If ET exceeds water absorption for a period of time, internal water deficits occur and plants wilt. Short-term water deficits can occur under periods of high air temperatures and low humidity. However, if soil moisture is available, plants can recover. As soil moisture is depleted, it becomes more difficult for plants to extract water, resulting in lower plant water potentials and reduced carbon gain. Without additional water, plants will permanently wilt. Therefore, in agricultural situations, irrigation water must be applied to a crop in time to prevent water stress from occurring if reduction in crop yield is to be avoided.

Water balance of a cropped field-To prevent crop water stress, water entering a plot of vegetated land must equal that leaving. Water enters the system through precipitation, irrigation, surface and subsurface flow in, and capillary rise from the water table (Allen et al. 1998 [DIRS 157311], p. 12) (Figure B-3). Water leaves the system through ET, runoff, subsurface flow out, and percolation below the root zone (Figure B-3). 
Fluxes such as subsurface flow on or off a vegetated plot of land, or capillary rise from a water table are difficult to measure and are usually ignored. Thus, methods for assessing the appropriate amount of irrigation water required to avoid crop water stress rely on estimates of crop evapotranspiration $\left(E T_{C}\right)$, precipitation, and the storage capacity of the soil within the crop rooting zone.

Commonly, ET of a grass or alfalfa reference surface $\left(E T_{o}\right)$ is calculated and used with a crop specific coefficient $\left(K_{c}\right)$ to estimate $E T_{c}$ (Doorenbos and Pruitt 1977 [DIRS 103062], p. 37; Allen et al. 1998 [DIRS 157311], p. 89; Jensen et al. 1990 [DIRS 160001], p.114). Climatic influences on $E T$ are incorporated into $E T_{o}$ and crop specific influences on $E T$ are reflected in $K_{c}$ values. The FAO first published a procedure using the $K_{c} E T_{o}$ approach for calculating $E T_{C}$ (Doorenbos and Pruitt 1977 [DIRS 103062]). Four alternative methods for calculating $E T_{o}$ were suggested. Since this publication, advances in research and understanding of crop water requirements revealed the need to revise and update the calculation procedures (Allen et al. 1998 [DIRS 157311], pp. 15 to 18). Improvements were identified and incorporated in the FAO Irrigation and Drainage Paper 56, Crop Evapotranspiration (Allen et al. 1998 [DIRS 157311], pp. 15 to 18). The methods for calculating crop water requirements and irrigation supply requirements presented in Allen et al. (1998 [DIRS 157311]) and Doorenbos and Pruitt (1977 [DIRS 103062]) were used in this analysis report.

\section{B2. JUSTIFICATION FOR USE OF FAO METHODS}

There is a long history of the study of ET that dates back to the late 1800s (Jensen et al. 1990 [DIRS 160001], p.4). One of the advancements in estimating ET occurred when Penman developed an equation to estimate evaporation from a free water surface using energy balance and mass transfer concepts (Allen et al. 1998 [DIRS 157311], pp. 18 and 19). This free water surface was originally proposed as a reference surface. However, differences in aerodynamics, water vapor diffusion, and radiation characteristics between open water and a vegetated surface made relating ET to free water evaporation difficult (Allen et al. 1998 [DIRS 157311], p. 23). The approach was later modified by Penman to apply to leaf surfaces, and then by Monteith to apply to whole plant canopies (Equation B-1). The Penman-Monteith equation (Allen et al. 1998 [DIRS 157311], Equation 3, p. 19) used net radiation balance, ambient temperature, vapor pressure deficit, conductance at the soil or canopy surface, and leaf or canopy conductance to characterize the rate of water loss from a vegetated surface:

$$
E T=\frac{\Delta\left(R_{n}-G\right)+\rho_{a} c_{p} \frac{\left(e_{s}-e_{a}\right)}{r_{a}}}{\lambda\left(\Delta+\gamma\left[1+\frac{r_{s}}{r_{a}}\right]\right)}
$$

where

$$
\begin{array}{ll}
E T & =\text { evapotranspiration }(\mathrm{mm} / \text { day }), \\
R_{n} & =\text { net radiation energy }\left(\mathrm{MJ} \mathrm{m}^{-2} \text { day }^{-1}\right), \\
G & =\text { soil heat flux }\left(\mathrm{MJ} \mathrm{m}^{-2} \text { day }^{-1}\right), \\
\rho_{a} & =\text { density of air }\left(\mathrm{kg} \mathrm{m}^{-3}\right),
\end{array}
$$




$$
\begin{array}{ll}
c_{p} & =\text { specific heat of air }\left(\mathrm{MJ} \mathrm{kg}{ }^{-1}{ }^{\circ} \mathrm{C}^{-1}\right), \\
e_{s}-e_{a} & =\text { vapor pressure deficit }(\mathrm{kPa}), \\
\Delta & =\text { slope of saturation vapor pressure curve }\left(\mathrm{kPa}^{\circ} \mathrm{C}^{-1}\right), \\
\lambda & =\text { latent heat of vaporization }\left(\mathrm{MJ} \mathrm{kg}^{-1}\right), \\
\gamma & =\text { psychrometric constant }\left(\mathrm{kPa}^{\circ} \mathrm{C}^{-1}\right), \\
\mathrm{r}_{\mathrm{s}} \text { and } \mathrm{r}_{\mathrm{a}} & =\text { (bulk) surface and aerodynamic resistances }\left(\mathrm{s} \mathrm{m}^{-1}\right) .
\end{array}
$$

A variety of modifications to the Penman-Monteith equation have been developed to provide ease of calculation, or to provide methods for ET calculation when the data required for the Penman-Monteith are not available. Several of these methods for calculating $E T_{o}$ can provide reasonable predictions of ET for specific environmental circumstances. Several methods for estimating $E T_{o}$ have been evaluated in various comparative studies (see Jensen et al. 1990 [DIRS 160001], pp. 164 to 265; Martin et al. 1991 [DIRS 101081]; Ventura et al. 1999 [DIRS 159871] for examples). In a comprehensive evaluation of 20 different methods for estimating $E T_{o}$, Jensen et al. (1990 [DIRS 160001], pp. 164 to 265) compared calculated $E T_{o}$ values to measured ET in 11 variable climate locations.

Published evaluations of six commonly used methods are described below to show that the selected FAO methods (presented in Appendices C, D, and E) lessen the uncertainties in irrigation parameters compared to the alternatives.

\section{B2.1 THORNTHWAITE FORMULA}

The Thornthwaite formula, based on air temperature, is one of the simplest approaches for calculating potential ET (Martin et al. 1991 [DIRS 101081]):

$$
P E=1.6 \frac{(10 T)^{a}}{I}
$$

where

$$
\begin{aligned}
& P E=\text { potential evapotranspiration }(\mathrm{mm}) \\
& T=\text { mean monthly temperature }\left({ }^{\circ} \mathrm{C}\right) \\
& I \quad=\text { heat index, constant for a site, function of long term mean temperatures, } \\
& a \quad=\text { an empirical derived value that is function of } \mathrm{I} .
\end{aligned}
$$

However, it has limited applicability and its recommended use is restricted to climates similar to that of the east-central region of the United States (Martin et al. 1991 [DIRS 101081]; Jensen et al. 1990 [DIRS 160001], pp. 225 to 235). Jensen et al. 1990 ([DIRS 160001], pp. 225 to 235) showed that the Thornthwaite formula consistently underestimated ET at arid locations and was one of the poorest methods in estimating $E T_{o}$ when compared to measured $E T$. Therefore, the Thornthwaite formula was considered inadequate for this analysis. 


\section{B2.2 BLANEY-CRIDDLE}

The Blaney-Criddle method (Equation B-3), also based on air temperature, was modified in Doorenbos and Pruitt 1977 ([DIRS 103062], p. 3) to develop a grass reference method for estimating $E T_{o}$ :

$$
E T_{o}=k_{1}+k_{2}(p T / 100)
$$

where

$$
\begin{array}{ll}
E T_{o} & =\text { daily ET for a grass reference crop (mm/day), } \\
T & =\text { average air temperature }\left({ }^{\circ} \mathrm{C}\right) \\
p & =\text { percent of annual sunlight, } \\
k_{1} \text { and } k_{2} & =\text { adjustment coefficients for the FAO method (dimensionless). }
\end{array}
$$

Jensen et al. 1990 ([DIRS 160001], p. 235) showed that this method tended to overestimate $E T_{o}$ by 15 to 25 percent in humid climates, but provided good estimates in arid climates when compared to measured data. Martin et al. 1991 ([DIRS 101081], p. 333) suggested that the modified Blaney-Criddle (Equation B-3) should only be considered an approximate method for determining $E T_{o}$ for irrigation scheduling, and that other methods were preferable if appropriate atmospheric data were available. Therefore, the Blaney-Criddle method was not selected for this analysis.

\section{B2.3 JENSEN-HAISE}

The Jensen-Haise equation is an energy balance approach used to predict $E T_{o}$ for an alfalfa reference surface (Martin et al. 1991 [DIRS 101081], Equation 2, p. 334; Jensen et al. 1990 [DIRS 160001], p. 166):

$$
E T_{o}=C_{T}\left(T-T_{x}\right) R_{s} / 1486
$$

where

$$
\begin{aligned}
C_{T}= & 1 /\left(\mathrm{C}_{1}+\mathrm{C}_{2} \mathrm{C}_{\mathrm{H}}\right), \\
C_{1}= & 68-3.6(\text { elevation in feet }) / 1,000 \\
C_{2}= & 13,{ }^{\circ} \mathrm{F}(\text { a constant }), \\
C_{H}= & 50 /\left(e_{2}-e_{1}\right), \text { mbars } \\
T_{X}= & 27.5-0.25\left(e_{2}-e_{1}\right)-\text { elevation } / 1,000, \\
e_{2}= & \text { saturated vapor pressure (mbars) at the mean maximum air temperature for the } \\
& \text { hottest month, } \\
e_{1}= & \text { Saturated vapor pressure (mbars) at the mean minimum air temperature for the } \\
& \text { hottest month, } \\
R_{S}= & \text { Incoming solar radiation, langleys } / \text { day } \\
T= & \text { Average monthly air temperature, }{ }^{\circ} \mathrm{F} .
\end{aligned}
$$


This equation uses air temperature, incoming solar radiation, and air humidity to calculate $E T_{o}$. Elevation and latitude are used to correct for local conditions. It is more reliable for arid climates than Blaney-Criddle because of the inclusion of solar radiation and adjustments for local conditions (Martin et al. 1991 [DIRS 101081]). It was less reliable in semiarid to subhumid climates where it tended to underestimate $E T_{o}$ when compared to measured data (Jensen et al. 1990 [DIRS 160001], p. 235).

Use of a grass reference surface as opposed to the alfalfa reference surface used in Jensen-Haise was preferred in this analysis because published $K_{c}$ values for a grass reference were available for all of the representative crops. Additionally, because the Jensen-Haise method tended to underestimate $E T_{o}$ in semi-arid and sub-humid climates, it would likely underestimate $E T_{o}$ for the future climates (upper bound monsoon, lower bound glacial transition and upper bound glacial transition climates) required for this analysis.

\section{B2.4 PRIESTLEY-TAYLOR}

The Priestley-Taylor method is a simplification of the Penman-Montieth equation with the absence of an advection term for sensible heat energy (Jensen et al. 1990 [DIRS 160001], Equation 6.35, p. 100):

$$
E T_{0}=\alpha \frac{\Delta}{\Delta+\gamma}\left(R_{n}-G\right)
$$

where

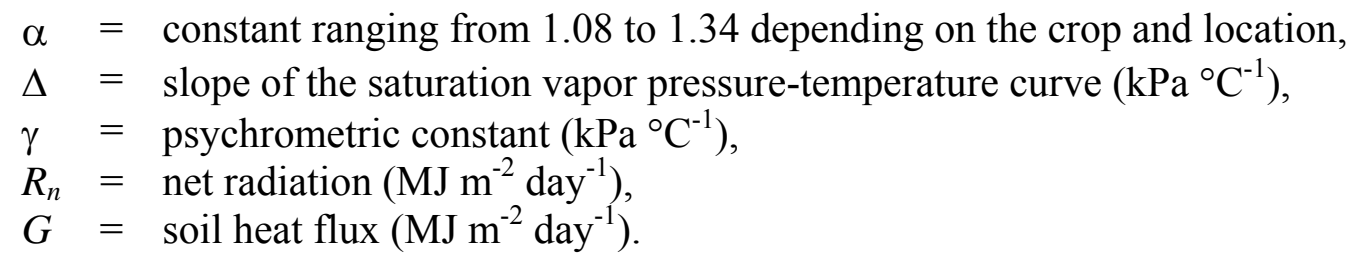

The equation was developed to predict $E T_{o}$ for a grass reference under humid conditions with a wet grass surface (Jensen et al. 1990 [DIRS 160001], p. 100). Hatfield and Allen (1996 [DIRS 159872]) compared the results of the Priestley-Taylor method and the Penman-Montieth equation (Equation B-1) with measured ET under arid conditions. They found the Penman-Montieth model tracked actual ET for cotton, grain sorghum, and grass forage better and more consistently throughout the growing season than the Priestley-Taylor method. When compared to measured ET, the Priestley-Taylor method produced reasonably good estimates in humid locations; however, it substantially underestimated seasonal ET in arid climates (Jensen et al. 1990 [DIRS 160001], p. 235) making it inappropriate for this analysis.

\section{B2.5 FAO CORRECTED PENMAN}

The FAO corrected Penman equation (Equation B-6) was modified from the original Penman-Montieth equation (Equation B-1) by Doorenbos and Pruitt (1977 [DIRS 103062]) to estimate $E T_{o}$ for a grass reference surface. A more sensitive wind function, an adjustment factor 
for local weather conditions $(c)$, and an assumption that soil heat flux $(G)$ equals 0 for daily time frames were added to the original Penman:

$$
E T_{o}=c\left[\frac{\Delta}{\Delta+\gamma}\left(R_{n}-G\right)+\frac{\gamma}{\Delta+\gamma} 2.7 W_{f}\left(e_{z}^{o}-e_{z}\right)\right]
$$

where

$$
\begin{array}{ll}
c & =\text { adjustment factor to compensate for local climate conditions } \\
& \text { (dimensionless), } \\
= & \text { slope of the saturation vapor pressure-temperature curve }\left(\mathrm{kPa}^{\circ} \mathrm{C}^{-1}\right), \\
\Delta & =\text { psychrometric constant }\left(\mathrm{kPa}^{\circ} \mathrm{C}^{-1}\right), \\
\gamma & =\text { net radiation }\left(\mathrm{MJ} \mathrm{m}^{-2} \operatorname{day}^{-1}\right), \\
R_{n} & \text { soil heat flux }\left(\mathrm{MJ} \mathrm{m}^{-2} \mathrm{day}^{-1}\right), \\
G & =\text { temperature related weighting factor (dimensionless), } \\
W_{f} & =\text { difference between the saturation vapor pressure at mean air temperature } \\
e^{o}{ }_{z}-e_{z}= & \text { and the mean actual vapor pressure of the air }(\mathrm{kPa}) .
\end{array}
$$

The Penman-Monteith and FAO corrected Penman equations (Equations B-1 and B-6) were fairly well correlated with measured ET data in 10 of 11 sites studied by Jensen et al. (1990 [DIRS 160001], p. 234). However, the FAO corrected Penman equation consistently overestimated $E T_{o}$ under both humid and arid conditions (Jensen et al. (1990 [DIRS 160001], p. 234; Allen et al. 1998 [DIRS 157311], p. 17).

The variable results of these and other validation studies prompted the FAO to elicit scientists and specialists to establish recommendations for an $E T_{o}$ formula that was generally applicable under a wide variety of conditions without the need for extensive local calibrations (see Allen et al. 1998 [DIRS 157311], pp. v, 17, and 18). The consultations and recommendations resulted in revised methodologies that are published by the FAO in Allen et al. (1998 [DIRS 157311]). The FAO Penman-Monteith method is currently recommended as the standard for calculating $E T_{o}$ (Allen et al. 1998 [DIRS 157311]). Based on this recommendation and the results of studies by Jensen et al. (1990 [DIRS 160001]), Martin et al. (1991 [DIRS 101081]), and Hatfield and Allen (1996 [DIRS 159872]), it was determined that the FAO methodologies in Allen et al. (1998 [DIRS 157311]) would reduce the uncertainties in irrigation parameters compared to other methods, and produce valid, reasonable parameter values. The FAO PenmanMonteith equation (Equation C-1) and FAO methodologies are presented in Appendices C, D, and $\mathrm{E}$. 
APPENDIX C

METHODS FOR CALCULATING REFERENCE EVAPOTRANSPIRATION 


\section{METHODS FOR CALCULATING REFERENCE EVAPOTRANSPIRATION}

\section{C1. INTRODUCTION}

Reference evapotranspiration $\left(E T_{o}\right)$ was calculated for a grass reference surface and represents the effects of climate on crop ET. The reference surface as defined by Allen et al. (1998 [DIRS 157311], p. 15) is a "hypothetical grass reference crop with an assumed crop height of $0.12 \mathrm{~m}$, a fixed surface resistance of $70 \mathrm{~s} \mathrm{~m}^{-1}$ and an albedo of $0.23 \%$. It is considered to be of uniform height, actively growing, completely shading the ground, with an adequate water supply.

Meteorological factors that drive evapotranspiration include solar radiation, air temperature, air humidity, and wind speed. Climatological and physical parameters required to derive monthly mean $E T_{o}$ were either measured directly or derived from standard meteorological data. Weather data inputs are described in Section 4.1.5 (Tables 4.1-2, 4.1-3, 4.1-4, and 4.1-5). Monthly mean $E T_{o}$ was calculated for present-day, upper bound monsoon, lower bound glacial transition, and upper bound glacial transition climate conditions. Altitude and latitude of the YMP meteorological monitoring Site 9 were used in calculations for all climate conditions.

The FAO Penman-Monteith equation was used to calculate ETo (Allen et al. 1998 [DIRS 157311], Equation 6, p. 24):

$$
E T_{o}=\frac{0.408 \Delta\left(R_{n}-G\right)+\gamma \frac{900}{T+273} u_{2}\left(e_{s}-e_{a}\right)}{\Delta+\gamma\left(1+0.34 u_{2}\right)}
$$

where

$$
\begin{array}{ll}
E T_{o} & =\text { reference evapotranspiration }(\mathrm{mm} / \mathrm{day}), \\
R_{n} & =\text { net radiation at the crop surface }\left(\mathrm{MJ} \mathrm{m}^{-2} \text { day }{ }^{-1}\right), \\
G & =\text { soil heat flux density }\left(\mathrm{MJ} \mathrm{m}^{-2} \text { day }^{-1}\right), \\
T & =\text { mean daily air temperature at } 2 \mathrm{~m} \text { height }\left({ }^{\circ} \mathrm{C}\right), \\
u_{2} & =\text { wind speed at } 2 \mathrm{~m} \text { height }\left(\mathrm{m} \mathrm{s}^{-1}\right), \\
e_{s} & =\text { saturation vapor pressure }(\mathrm{kPa}), \\
e_{a} & =\text { actual vapor pressure }(\mathrm{kPa}) \\
e_{s}-e_{a} & =\text { saturation vapor pressure deficit }(\mathrm{kPa}), \\
\Delta & =\text { slope vapor pressure curve }\left(\mathrm{kPa}^{\circ} \mathrm{C}^{-1}\right), \\
\gamma & =\text { psychrometric constant }\left(\mathrm{kPa}^{\circ} \mathrm{C}^{-1}\right) .
\end{array}
$$

Justification for use of this equation is in Appendix B. The step-by-step methods to calculate $E T_{o}$ are described and example calculations are provided below.

\section{C2. CALCULATIONS}

Several calculations related to humidity and radiation parameters are required to generate the variables used in Equation C-1. 


\section{C2.1 HUMIDITY}

Atmospheric humidity is an important driver of transpiration from plant leaves. The air in the intercellular spaces of a leaf (Appendix B, Figure B-1) is nearly saturated with water vapor. As the air outside the leaf dries, the leaf to air water vapor gradient increases, increasing the rate of water loss through the stomata (Appendix B, Figure B-2). With increasing evaporative demands the plant will begin to close stomata to prevent water loss. However, stomatal closure also results in reduced concentrations of $\mathrm{CO}_{2}$ for use in photosynthesis (see Appendix B for additional background). Similarly, when atmospheric humidity is high, the leaf-to-air water vapor gradient decreases. This results in lower evaporative demand, allowing stomates to remain open without high rates of water loss.

Three atmospheric parameters were generated from meteorological data and used directly in the calculation of $E T_{o}$. These include the slope of the saturation vapor pressure curve $(\Delta)$, the psychrometric constant $(\gamma)$, and the vapor pressure deficit $\left(e_{s}-e_{a}\right)$.

\section{C2.1.1 Slope of Saturation Vapor Pressure Curve $(\Delta)$}

$\Delta$ is the slope of the relationship between the saturation vapor pressure of the air and air temperature. Vapor pressure is the component of total atmospheric pressure exerted by the motion of water vapor molecules. Saturation vapor pressure is the vapor pressure the air would have if it were saturated with water vapor molecules at a given temperature. As temperature increases, the storage capacity of the air increases, which results in higher saturation vapor pressure. $\Delta$ is calculated from mean monthly air temperature $\left({ }^{\circ} \mathrm{C}\right)$ according to the following equation (Allen et al. 1998 [DIRS 157311], Equation 13, p. 37):

$$
\Delta=4098\left[\frac{0.6108 \exp \left(\frac{17.27 T}{T+237.3}\right)}{(T+237.3)^{2}}\right]
$$

where

$$
\begin{aligned}
& \exp (\mathrm{x})=2.7183 \text { (base of natural logarithm) raised to the power }(\mathrm{x}) \text {, } \\
& \mathrm{T}=\text { mean monthly air temperature }\left({ }^{\circ} \mathrm{C}\right) \text {. }
\end{aligned}
$$

\section{Example:}

For January present-day climate conditions, $T=7.0{ }^{\circ} \mathrm{C}$ (see Table 4.1-2).

$$
\Delta=4098\left[\frac{0.6108 \exp \left(\frac{17.27 \times 7.0}{7.0+237.3}\right)}{(7.0+237.3)^{2}}\right]=4098\left[\frac{0.6108 \times 1.6379}{59,682.49}\right]=0.069 \mathrm{kPa}^{\circ} \mathrm{C}^{-1}
$$


Monthly mean $\Delta$ values for present-day, upper bound monsoon, lower bound glacial transition, and upper bound glacial transition climate conditions are in Tables C-1, C-2, C-3, and C-4 respectively.

Table C-1. Atmospheric Parameters for Present-Day Climate Conditions

\begin{tabular}{|c|c|c|c|c|c|c|c|}
\hline Month & $\mathrm{T}_{\text {dew }}\left({ }^{\circ} \mathrm{C}\right)$ & $\mathbf{e}_{T \max }^{\mathbf{o}}(\mathbf{k P a})$ & $\mathrm{e}^{0}{ }_{T \min }(\mathrm{kPa})$ & $e_{s}(\mathrm{kPa})$ & $\Delta\left(\mathrm{kPa}^{\circ} \mathrm{C}^{-1}\right)$ & $e_{a}(k P a)$ & $e_{s}-e_{a}(k P a)$ \\
\hline January & 1.1 & 1.547 & 0.661 & 1.104 & 0.069 & 0.661 & 0.443 \\
\hline February & 2.0 & 1.877 & 0.758 & 1.317 & 0.080 & 0.706 & 0.612 \\
\hline March & 2.8 & 2.564 & 0.922 & 1.743 & 0.101 & 0.747 & 0.996 \\
\hline April & 5.0 & 3.093 & 1.073 & 2.083 & 0.121 & 0.872 & 1.211 \\
\hline May & 9.9 & 4.268 & 1.488 & 2.878 & 0.162 & 1.220 & 1.658 \\
\hline June & 13.8 & 5.717 & 1.913 & 3.815 & 0.212 & 1.578 & 2.237 \\
\hline July & 18.1 & 7.067 & 2.502 & 4.785 & 0.258 & 2.077 & 2.708 \\
\hline August & 18.0 & 6.954 & 2.487 & 4.721 & 0.249 & 2.064 & 2.656 \\
\hline September & 13.8 & 5.260 & 1.913 & 3.587 & 0.193 & 1.578 & 2.009 \\
\hline October & 6.7 & 3.342 & 1.203 & 2.273 & 0.128 & 0.981 & 1.291 \\
\hline November & 2.7 & 2.103 & 0.796 & 1.450 & 0.085 & 0.742 & 0.708 \\
\hline December & 0.8 & 1.588 & 0.647 & 1.118 & 0.068 & 0.647 & 0.470 \\
\hline
\end{tabular}

$\mathrm{T}_{\text {dew }}=$ dewpoint temperature (Equation C-5).

$\mathrm{e}^{\mathrm{o}} \mathrm{Tmax}_{\mathrm{T}}=$ saturation vapor pressure at the maximum monthly air temperature (Equation C-3).

$\mathrm{e}^{\mathrm{O}}{ }_{\mathrm{T} \min }=$ saturation vapor pressure at the maximum monthly air temperature (Equation C-3).

$\mathrm{e}_{\mathrm{s}}=$ saturation vapor pressure (Equation C-4).

$\Delta=$ the slope of the saturation vapor pressure curve (Equation C-2).

$\mathrm{e}_{\mathrm{a}}=$ actual vapor pressure (Equation C-6).

$e_{s}-e_{a}=$ vapor pressure deficit (Equation C-8).

Table C-2. Atmospheric Parameters for Upper Bound Monsoon Climate Conditions

\begin{tabular}{|c|c|c|c|c|c|c|c|}
\hline Month & $\mathrm{T}_{\text {dew }}\left({ }^{\circ} \mathrm{C}\right)$ & $\mathrm{e}_{T \max }^{\mathbf{o}}(\mathrm{kPa})$ & $\mathrm{e}_{T \min }^{\mathbf{o}}(\mathrm{kPa})$ & $e_{s}(\mathrm{kPa})$ & $\Delta\left(\mathrm{kPa}^{\circ} \mathrm{C}^{-1}\right)$ & $e_{a}(k P a)$ & $e_{s}-e_{a}(k P a)$ \\
\hline January & -3.7 & 2.028 & 0.500 & 1.264 & 0.071 & 0.464 & 0.800 \\
\hline February & -2.2 & 2.267 & 0.559 & 1.413 & 0.078 & 0.519 & 0.894 \\
\hline March & 0.1 & 2.617 & 0.662 & 1.640 & 0.090 & 0.616 & 1.024 \\
\hline April & 2.6 & 3.307 & 0.788 & 2.047 & 0.108 & 0.734 & 1.313 \\
\hline May & 6.3 & 4.270 & 1.025 & 2.648 & 0.135 & 0.957 & 1.691 \\
\hline June & 11.4 & 5.745 & 1.439 & 3.592 & 0.178 & 1.347 & 2.245 \\
\hline July & 16.5 & 5.486 & 2.000 & 3.743 & 0.199 & 1.877 & 1.866 \\
\hline August & 16.2 & 5.157 & 1.958 & 3.558 & 0.192 & 1.838 & 1.720 \\
\hline September & 12.2 & 4.845 & 1.514 & 3.180 & 0.168 & 1.418 & 1.762 \\
\hline October & 5.4 & 3.743 & 0.961 & 2.352 & 0.124 & 0.896 & 1.456 \\
\hline November & -0.7 & 2.644 & 0.626 & 1.635 & 0.088 & 0.582 & 1.053 \\
\hline December & -3.4 & 2.071 & 0.512 & 1.292 & 0.072 & 0.476 & 0.816 \\
\hline
\end{tabular}

$\mathrm{T}_{\text {dew }}=$ dewpoint temperature (Equation C-5).

$\mathrm{e}^{\mathrm{o}} \mathrm{Tmax}_{\max }=$ saturation vapor pressure at the maximum monthly air temperature (Equation C-3).

$e^{0}{ }_{T \min }=$ saturation vapor pressure at the maximum monthly air temperature (Equation $\mathrm{C}-3$ ).

$\mathrm{e}_{\mathrm{s}}=$ saturation vapor pressure (Equation C-4).

$\Delta=$ the slope of the saturation vapor pressure curve (Equation C-2).

$\mathrm{e}_{\mathrm{a}}=$ actual vapor pressure (Equation C-6).

$e_{s}-e_{a}=$ vapor pressure deficit (Equation C-8). 
Table C-3. Atmospheric Parameters for Lower Bound Glacial Transition Climate Conditions

\begin{tabular}{|c|c|c|c|c|c|c|}
\hline Month & $\mathrm{e}^{\mathrm{o}}{ }_{\operatorname{Tmax}}(\mathrm{kPa})$ & $\mathrm{e}_{\text {Tmin }}^{\mathbf{o}}(\mathrm{kPa})$ & $e_{s}(k P a)$ & $\Delta\left(\mathrm{kPa}{ }^{\circ} \mathrm{C}^{-1}\right)$ & $e_{a}(k P a)$ & $e_{s}-e_{a}(k P a)$ \\
\hline January & 0.807 & 0.286 & 0.546 & 0.036 & 0.326 & 0.221 \\
\hline February & 0.979 & 0.355 & 0.667 & 0.044 & 0.371 & 0.296 \\
\hline March & 1.372 & 0.478 & 0.925 & 0.058 & 0.404 & 0.521 \\
\hline April & 2.035 & 0.689 & 1.362 & 0.081 & 0.541 & 0.822 \\
\hline May & 2.867 & 0.942 & 1.904 & 0.108 & 0.662 & 1.242 \\
\hline June & 3.980 & 1.228 & 2.604 & 0.140 & 0.689 & 1.915 \\
\hline July & 5.452 & 1.705 & 3.579 & 0.186 & 1.057 & 2.522 \\
\hline August & 5.125 & 1.587 & 3.356 & 0.175 & 0.907 & 2.449 \\
\hline Sept & 3.854 & 1.097 & 2.476 & 0.132 & 0.746 & 1.730 \\
\hline October & 2.338 & 0.717 & 1.528 & 0.088 & 0.587 & 0.941 \\
\hline November & 1.274 & 0.421 & 0.848 & 0.053 & 0.458 & 0.390 \\
\hline December & 0.907 & 0.326 & 0.616 & 0.041 & 0.371 & 0.245 \\
\hline
\end{tabular}

$\mathrm{e}^{\mathrm{o}}{ }_{\text {Tmax }}=$ saturation vapor pressure at the maximum monthly air temperature (Equation $\mathrm{C}-3$ ).

$\mathrm{e}^{\mathrm{O}}{ }_{\mathrm{Tmin}}=$ saturation vapor pressure at the maximum monthly air temperature (Equation $\mathrm{C}-3$ ).

$\mathrm{e}_{\mathrm{s}}=$ saturation vapor pressure (Equation C-4).

$\Delta=$ the slope of the saturation vapor pressure curve (Equation C-2).

$\mathrm{e}_{\mathrm{a}}=$ actual vapor pressure (Equation C-6).

$e_{s}-e_{a}=$ vapor pressure deficit (Equation $C-8$ ).

Table C-4. Atmospheric Parameters for Upper Bound Glacial Transition Climate Conditions

\begin{tabular}{|c|c|c|c|c|c|c|}
\hline Month & $\mathrm{e}_{\operatorname{Tmax}}^{\mathrm{o}}(\mathrm{kPa})$ & $\mathrm{e}^{\mathrm{o}}{ }_{\operatorname{Tmin}}(\mathrm{kPa})$ & $e_{s}(\mathrm{kPa})$ & $\Delta\left(\mathrm{kPa}^{\circ} \mathrm{C}^{-1}\right)$ & $e_{a}(k P a)$ & $e_{s}-e_{a}(k P a)$ \\
\hline January & 0.641 & 0.384 & 0.512 & 0.037 & 0.418 & 0.094 \\
\hline February & 0.859 & 0.476 & 0.667 & 0.047 & 0.498 & 0.169 \\
\hline March & 1.127 & 0.554 & 0.840 & 0.056 & 0.529 & 0.312 \\
\hline April & 1.587 & 0.681 & 1.134 & 0.072 & 0.611 & 0.523 \\
\hline May & 2.167 & 0.903 & 1.535 & 0.093 & 0.781 & 0.754 \\
\hline June & 2.934 & 1.192 & 2.063 & 0.120 & 0.975 & 1.088 \\
\hline July & 3.867 & 1.444 & 2.655 & 0.148 & 1.011 & 1.645 \\
\hline August & 3.793 & 1.439 & 2.616 & 0.146 & 0.984 & 1.632 \\
\hline Sept & 2.680 & 1.049 & 1.864 & 0.109 & 0.828 & 1.036 \\
\hline October & 1.681 & 0.717 & 1.199 & 0.075 & 0.695 & 0.504 \\
\hline November & 0.886 & 0.536 & 0.711 & 0.050 & 0.570 & 0.141 \\
\hline December & 0.657 & 0.399 & 0.528 & 0.038 & 0.448 & 0.080 \\
\hline
\end{tabular}

$\mathrm{e}^{\mathrm{o}}{ }_{\mathrm{Tmax}}=$ saturation vapor pressure at the maximum monthly air temperature (Equation $\mathrm{C}-3$ ).

$\mathrm{e}^{\mathrm{o}} \mathrm{Tmin}_{\mathrm{min}}=$ saturation vapor pressure at the maximum monthly air temperature (Equation C-3).

$\mathrm{e}_{\mathrm{s}}=$ saturation vapor pressure (Equation C-4).

$\Delta=$ the slope of the saturation vapor pressure curve (Equation C-2).

$\mathrm{e}_{\mathrm{a}}=$ actual vapor pressure (Equation $\mathrm{C}-7$ ).

$\mathrm{e}_{\mathrm{s}}-\mathrm{e}_{\mathrm{a}}=$ vapor pressure deficit (Equation C-8). 


\section{C2.1.2 Psychrometric Constant $(\gamma)$}

The psychrometric constant represents a balance between the heat required to evaporate water into an air stream from the wick of a wet bulb thermometer (wet wick with thermometer beneath it) and the air's potential to absorb the water and carry it away. The constant is dependent on atmospheric pressure, latent heat of vaporization (energy required for evaporation), the specific heat of air at a constant pressure (quantity of energy required to raise the temperature of a given amount of air by one degree at constant pressure), and the ratio of molecular weight of water vapor to dry air. Values for $\gamma$ at different altitudes are provided in Allen et al. (1998 [DIRS 157311], Table 2.2, p. 214). The weather station altitude of $838 \mathrm{~m}$ for the Yucca Mountain meteorological monitoring Site 9 (data for present-day climatic conditions) corresponds to a table value for $\gamma$ of $0.061 \mathrm{kPa}^{\circ} \mathrm{C}^{-1}$. This value was used in the calculations of $E T_{o}$ for present-day, upper bound monsoon, lower bound glacial transition, and upper bound glacial transition climates.

\section{C2.1.3 Vapor Pressure Deficit $\left(e_{s}-e_{a}\right)$}

The vapor pressure deficit $\left(e_{s}-e_{a}\right)$ is the difference between the saturation vapor pressure $\left(e_{s}\right)$ and the actual vapor pressure $\left(e_{a}\right)$ of the air. Essentially, it is the amount of water vapor that the air could still hold before becoming saturated and represents the evaporative power of the air. The air becomes dryer as the vapor pressure deficit increases.

Mean $\mathrm{e}_{\mathrm{s}}$ is calculated from mean monthly maximum $\left(T_{\max }\right)$ and minimum $\left(T_{\min }\right)$ air temperatures (see Tables 4.1-2, 4.1-3, 4.1-4, and 4.1-5 for temperature data). The relationship of $e_{s}$ to temperature is given by the following (Allen et al. 1998 [DIRS 157311], Equations 11 and 12, p. 36):

$$
e^{o}(T)=0.6108 \exp \left[\frac{17.27 T}{T+237.3}\right]
$$

where

$$
\begin{aligned}
& e^{o}(T)=\text { saturation vapor pressure at temperature } T(\mathrm{kPa}), \\
& T=\text { air temperature }\left({ }^{\circ} \mathrm{C}\right), \\
& \exp (\mathrm{x})=2.7183 \text { (base of natural logarithm) raised to the power }(\mathrm{x}),
\end{aligned}
$$

and

$$
e_{s}=\frac{e^{o}\left(T_{\max }\right)+e^{o}\left(T_{\min }\right)}{2}
$$

Example: For January present-day climate conditions, $T_{\max }=13.5^{\circ} \mathrm{C}$ and $T_{\min }=1.1{ }^{\circ} \mathrm{C}$ (Table 4.1-2).

$e^{o}\left(T_{\max }\right)=0.6108 \exp \left[\frac{17.27(13.5)}{13.5+237.3}\right]=0.6108 \exp 0.929=1.547 \mathrm{kPa}$ 


$$
\begin{gathered}
e^{o}\left(T_{\min }\right)=0.6108 \exp \left[\frac{17.27(1.1)}{1.1+237.3}\right]=0.6108 \exp 0.0797=0.661 \mathrm{kPa} \\
e_{s}=\frac{1.547+0.661}{2}=1.104 \mathrm{kPa}
\end{gathered}
$$

Monthly $e^{o}\left(T_{\max }\right), e^{o}\left(T_{\min }\right)$, and $e_{s}$ for present-day, upper bound monsoon, lower bound glacial transition, and upper bound glacial transition climate conditions are in Tables C-1, C-2, C-3, and C-4, respectively.

Actual vapor pressure $\left(\mathrm{e}_{\mathrm{a}}\right)$ can be calculated from relative humidity $(R H)$, the dewpoint temperature $\left(T_{\text {dew }}\right)$, or psychrometric data. No air humidity data were available for the upper bound monsoon climate and so $T_{\text {dew }}$ was calculated from $T_{\min }$ using equation C-5 (see below). Monthly mean $T_{\text {dew }}$ was available from the Delta, Utah weather station (lower bound glacial transition climate analogue). Monthly mean $T_{\text {dew }}$ was used in equation C-6 to calculate $\mathrm{e}_{\mathrm{a}}$ for the upper bound monsoon and lower bound glacial transition climates (see below). Monthly mean maximum and minimum $R H$ values were available for both present-day and upper bound glacial transition climates. However, examination of $R H$ values for the present-day climate indicated that these values were not representative of the expected conditions of the reference area for which $E T_{o}$ was calculated (see Allen et al. 1998 [DIRS 157311], Annex 6, pp. 257 to 262). Under reference area conditions, $R H_{\max }$ is expected to approach 90 - 100 percent. For the present-day climate, mean $R H_{\max }$ ranged from a low of 23.9 percent in July to a high of 62.2 percent in January (Sections 4.1.3.1, Table 4.1-2). Use of such low $R H$ values would result in overestimation of $E T_{o}$, which would translate into overestimation of crop irrigation requirements. Allen et al. (1998 [DIRS 157311], p. 36 and Annex 6, pp. 257 to 262) recommended use of $T_{\text {dew }}$ calculated from daily minimum temperature rather than using unreliable or unrepresentative $R H$ values, or when no humidity data is available. Therefore, instead of using $R H_{\max }$ to calculate $e_{a}$ for the present-day climate and in the absence of humidity data for the upper bound monsoon climate, $T_{\text {dew }}$ was estimated from $T_{\min }$ (Allen et al. 1998 [DIRS 157311], Equation 6-6, p. 261):

$$
T_{\text {dew }}=T_{\min }-K_{o}
$$

Where $K_{o}$ is a correction factor $\left({ }^{\circ} \mathrm{C}\right)$. Values selected for $K_{o}$ were $0{ }^{\circ} \mathrm{C}$ for January, $1{ }^{\circ} \mathrm{C}$ for February, $3{ }^{\circ} \mathrm{C}$ for March through October, $1{ }^{\circ} \mathrm{C}$ for November, and $0{ }^{\circ} \mathrm{C}$ for December for present-day climate, and $K_{o}=1{ }^{\circ} \mathrm{C}$ for all months for upper bound monsoon climate. Different values for $K_{o}$ were used for present-day climate because the extreme aridity could cause the minimum temperature to be significantly greater than the dewpoint temperature in spring through fall months. Smaller differences between minimum temperature and dewpoint were expected during the same time period for the moister monsoon climate. The monsoon climate has warmer (more evaporative) winter seasons than present-day climate making the $1{ }^{\circ} \mathrm{C}$ adjustment appropriate for December and January. These adjustments increased values of $T_{\text {dew }}$ to reflect the higher humidity anticipated under reference conditions. The adjusted $T_{d e w}$ was used in the following equation to calculate $e_{a}$ for the present-day and upper bound monsoon climates (Allen et al. 1998 [DIRS 157311], Equation 14, p. 37): 


$$
e_{a}=e^{o}\left(T_{\text {dew }}\right)=0.6108 \exp \left[\frac{17.27 T_{\text {dew }}}{T_{\text {dew }}+237.3}\right]
$$

Example: For January present-day climate $T_{\min }=1.1{ }^{\circ} \mathrm{C}$ (Section 4.1.5.1, Table 4.1-2) and $T_{\text {dew }}=1.1^{\circ} \mathrm{C}$ (Equation C-5).

$$
e_{a}=0.6108 \exp \left[\frac{17.27 \times 1.1}{1.1+237.3}\right]=0.6108 \exp (0.0797)=0.661 \mathrm{kPa}
$$

Because $R H_{\max }$ from the upper bound glacial transition climate data set approached 90 percent for most months (Section 4.1.5.4, Table 4.1-5) no correction was needed. Therefore, $R H_{\text {min }}$, $R H_{\max }, T_{\min }$, and $T_{\max }$ were used to calculate $e_{a}$ (Allen et al. 1998 [DIRS 157311], Equation 17, p. 38):

$$
e_{a}=\frac{e^{o}\left(T_{\min }\right) \frac{R H_{\text {max }}}{100}+e^{o}\left(T_{\max }\right) \frac{R H_{\text {min }}}{100}}{2}
$$

Example: For January upper bound glacial transition climate $R H_{\min }=79$ percent and $R H_{\max }=$ 86 percent (Section 4.1.5.4, Table 4.1-5), $e^{o}\left(T_{\min }\right)=0.384$ and $e^{o}\left(T_{\max }\right)=0.641$ (from Table C-4).

$$
e_{a}=\frac{0.384(.86)+0.641(.79)}{2}=\frac{0.330+0.506}{2}=0.418 \mathrm{kPa}
$$

Monthly $e_{a}$ values for present-day, upper bound monsoon, lower bound glacial transition, and upper bound glacial transition climates are in Tables C-1,C-2, C-3, and C-4 respectively.

Using mean $e_{s}$ and $e_{a}$ calculated for January present-day climate conditions, the vapor pressure deficit is:

$$
\left(e_{s}-e_{a}\right)=1.104-0.661=0.443 \mathrm{kPa}
$$

Monthly $\left(e_{s}-e_{a}\right)$ values for present-day, upper bound monsoon, lower bound glacial transition, and upper bound glacial transition climates are in Tables C-1, C-2, C-3, and C-4, respectively.

\section{C2.2 RADIATION}

Net radiant energy is one of the main factors controlling the energy balance of a vegetated soil surface. Heat energy for ET is principally supplied by solar radiation, which can reach the plant canopy as direct sunlight, or sunlight scattered by molecules and particles in the atmosphere. Both direct and scattered sunlight can be reflected by surroundings to the plant canopy. Net radiation $\left(R_{n}\right)$ represents the balance between energy absorbed, reflected, and emitted by the earth's surface and is used directly in the calculation of $E T_{o}$. Extraterrestrial radiation $\left(R_{a}\right)$, solar radiation $\left(R_{S}\right)$, relative sunshine duration $(n / N)$, clear sky radiation $\left(R_{s o}\right)$, net shortwave radiation $\left(R_{n s}\right)$, and net longwave radiation $\left(R_{n l}\right)$ are required either directly or indirectly in calculating $R_{n}$. 


\section{C2.2.1 Extraterrestrial Radiation $\left(\boldsymbol{R}_{a}\right)$}

Extraterrestrial radiation is the solar radiation received at the top of the earth's atmosphere on a horizontal surface. It is a function of latitude, date, and time of day. Allen et al. (1998 [DIRS 157311], Annex 2, Table 2.6, p. 219) provide $R_{a}$ values for the 15th day of each month for different latitudes. These values provide an estimate of $R_{a}$ that deviates from the monthly average by less than 1 percent. Because the latitude will not change among climate conditions, latitude for the weather station representing present-day climate was used and $R_{a}$ was the same for all climate conditions.

Example: Weather station latitude for the present-day climate was $36^{\circ} 40^{\prime} 38^{\prime \prime}$ (Table 4.1-2). From Table 2.6 (Allen et al. 1998 [DIRS 157311], p. 219), $R_{a}$ for January at the station latitude is $17.5 \mathrm{MJ} \mathrm{m}^{-2}$ day $^{-1}$.

Monthly $R_{a}$ averages are in Tables C-5, C-6, C7, and C8.

Table C-5. Radiation Parameters, Soil Heat Flux, and Wind Speed for Present-Day Climate Conditions

\begin{tabular}{|c|c|c|c|c|c|c|c|c|}
\hline Month & $\begin{array}{c}R_{\mathrm{a}} \\
\left(\mathrm{MJ} \mathrm{m}^{-2}\right. \\
\left.\text { day }^{-1}\right)\end{array}$ & $\begin{array}{c}R_{\mathbf{S}} \\
\left(\mathrm{MJ} \mathrm{m}^{-2}\right. \\
\left.\text { day }^{-1}\right)\end{array}$ & $\begin{array}{c}\mathbf{R}_{\mathrm{so}} \\
\left(\mathrm{MJ} \mathrm{m}^{-2}\right. \\
\left.\text { day }^{-1}\right)\end{array}$ & $\begin{array}{c}R_{\mathrm{ns}} \\
\left(\mathrm{MJ} \mathrm{m}^{-2}\right. \\
\left.\text { day }^{-1}\right)\end{array}$ & $\begin{array}{c}R_{\mathrm{nl}} \\
\left(\mathrm{MJ} \mathrm{m}^{-2}\right. \\
\left.\text { day }^{-1}\right)\end{array}$ & $\begin{array}{c}R_{\mathbf{n}} \\
\left(\mathrm{MJ} \mathrm{m}^{-2}\right. \\
\left.\text { day }^{-1}\right)\end{array}$ & $\begin{array}{c}G \\
\begin{array}{c}G \\
\left(M^{-2} m^{-2}\right. \\
\left.\text { day }^{-1}\right)\end{array}\end{array}$ & $\begin{array}{c}\mathrm{u}_{2} \\
\left(\mathrm{~m} \mathrm{~s}^{-1}\right)\end{array}$ \\
\hline January & 17.5 & 9.6 & 13.4 & 7.4 & 4.2 & 3.2 & 0.19 & 2.9 \\
\hline February & 22.6 & 13.9 & 17.3 & 10.7 & 5.1 & 5.6 & 0.46 & 3.2 \\
\hline March & 29.0 & 19.5 & 22.2 & 15.0 & 6.1 & 8.9 & 0.50 & 3.3 \\
\hline April & 35.7 & 24.6 & 27.4 & 18.9 & 6.2 & 12.7 & 0.60 & 3.5 \\
\hline May & 40.0 & 27.5 & 30.7 & 21.2 & 5.9 & 15.2 & 0.74 & 3.4 \\
\hline June & 41.7 & 30.0 & 32.0 & 23.1 & 5.9 & 17.2 & 0.64 & 3.7 \\
\hline July & 40.8 & 29.6 & 31.3 & 22.8 & 5.3 & 17.4 & 0.22 & 3.4 \\
\hline August & 37.4 & 27.0 & 28.7 & 20.8 & 5.3 & 15.5 & -0.41 & 3.5 \\
\hline Sept & 31.5 & 22.8 & 24.2 & 17.6 & 5.9 & 11.6 & -0.90 & 3.3 \\
\hline October & 24.6 & 17.4 & 18.9 & 13.4 & 6.4 & 7.0 & -1.04 & 3.1 \\
\hline November & 18.7 & 11.9 & 14.3 & 9.2 & 5.4 & 3.7 & -0.76 & 3.0 \\
\hline December & 16.1 & 9.6 & 12.3 & 7.4 & 4.8 & 2.5 & -0.25 & 3.0 \\
\hline
\end{tabular}

$\mathrm{R}_{\mathrm{a}}=$ extraterrestrial radiation (from Allen et al. [1998 DIRS 157311], Annex 2, Table 2.6, p. 219).

$\mathrm{R}_{\mathrm{s}}=$ solar radiation (from Table 4.1-2).

$\mathrm{R}_{\mathrm{so}}=$ clear sky radiation (Equation $\mathrm{C}-10$ ).

$\mathrm{R}_{\mathrm{ns}}=$ net solar radiation (Equation C-11).

$\mathrm{R}_{\mathrm{nl}}=$ net longwave radiation (Equation $\mathrm{C}-12$ ).

$\mathrm{R}_{\mathrm{n}}=$ net radiation (Equation $\mathrm{C}-13$ ).

$\mathrm{G}=$ solar heat flux (Equation $\mathrm{C}-14$ ).

$\mathrm{u}_{2}=$ wind speed (from Table 4.1-2) corrected for height according to Equation C-15. 
Table C-6. Radiation Parameters, Soil Heat Flux, and Wind Speed for Upper Bound Monsoon Climate Conditions

\begin{tabular}{|c|c|c|c|c|c|c|c|c|c|}
\hline Month & $\begin{array}{c}\mathrm{R}_{\mathrm{a}} \\
\left(\mathrm{MJ} \mathrm{m}^{-2}\right. \\
\left.\text { day }^{-1}\right)\end{array}$ & $n / N$ & $\begin{array}{c}\mathrm{R}_{\mathrm{s}} \\
\left(\mathrm{MJ} \mathrm{m}^{-2}\right. \\
\left.\text { day }^{-1}\right)\end{array}$ & $\begin{array}{c}R_{\text {so }} \\
\left(\mathrm{MJ} \mathrm{m}^{-2}\right. \\
\left.\text { day }^{-1}\right)\end{array}$ & $\begin{array}{c}R_{n s} \\
\left(M^{-2} \mathrm{~m}^{-2}\right. \\
\left.\text { day }^{-1}\right)\end{array}$ & $\begin{array}{c}R_{n l} \\
\left(\mathrm{MJ} \mathrm{m}^{-2}\right. \\
\left.\text { day }^{-1}\right)\end{array}$ & $\begin{array}{c}R_{n} \\
\left(\mathrm{MJ} \mathrm{m}^{-2}\right. \\
\left.\text { day }^{-1}\right)\end{array}$ & $\begin{array}{c}\text { G } \\
\left(\mathrm{MJ} \mathrm{m}^{-2}\right. \\
\left.\text { day }^{-1}\right)\end{array}$ & $\begin{array}{c}\mathrm{u}_{2} \\
\left(\mathrm{~m} \mathrm{~s}^{-1}\right)\end{array}$ \\
\hline January & 17.5 & 0.80 & 11.4 & 13.4 & 8.8 & 6.0 & 2.8 & 0.09 & 1.5 \\
\hline February & 22.6 & 0.82 & 14.9 & 17.3 & 11.5 & 6.1 & 5.4 & 0.28 & 2.2 \\
\hline March & 29.0 & 0.86 & 19.7 & 22.2 & 15.2 & 6.3 & 8.9 & 0.38 & 2.2 \\
\hline April & 35.7 & 0.92 & 25.3 & 27.4 & 19.5 & 6.7 & 12.8 & 0.51 & 2.2 \\
\hline May & 40.0 & 0.93 & 28.6 & 30.7 & 22.0 & 6.6 & 15.4 & 0.65 & 2.3 \\
\hline June & 41.7 & 0.93 & 29.8 & 32.0 & 23.0 & 6.2 & 16.7 & 0.51 & 2.2 \\
\hline July & 40.8 & 0.78 & 26.1 & 31.3 & 20.1 & 4.5 & 15.6 & 0.10 & 1.7 \\
\hline August & 37.4 & 0.80 & 24.3 & 28.7 & 18.7 & 4.7 & 14.1 & -0.23 & 1.5 \\
\hline Sept & 31.5 & 0.87 & 21.6 & 24.2 & 16.6 & 5.6 & 11.0 & -0.58 & 1.7 \\
\hline October & 24.6 & 0.88 & 17.0 & 18.9 & 13.1 & 6.3 & 6.8 & -0.81 & 1.8 \\
\hline November & 18.7 & 0.85 & 12.6 & 14.3 & 9.7 & 6.3 & 3.4 & -0.65 & 1.4 \\
\hline December & 16.1 & 0.79 & 10.4 & 12.3 & 8.0 & 5.9 & 2.1 & -0.26 & 1.7 \\
\hline
\end{tabular}

$\mathrm{R}_{\mathrm{a}}=$ extraterrestrial radiation (from Allen et al. [1998 DIRS 157311], Annex 2, Table 2.6, p. 219).

$\mathrm{n} / \mathrm{N}=$ percent of possible sunshine converted to decimal value (from Table 4.1-3).

$\mathrm{R}_{\mathrm{s}}=$ solar radiation (from Equation $\mathrm{C}-9$ ).

$\mathrm{R}_{\mathrm{so}}=$ clear sky radiation (Equation $\mathrm{C}-10$ ).

$\mathrm{R}_{\mathrm{ns}}=$ net solar radiation (Equation $\mathrm{C}-11$ ).

$\mathrm{R}_{\mathrm{nl}}=$ net longwave radiation (Equation $\mathrm{C}-12$ ).

$\mathrm{R}_{\mathrm{n}}=$ net radiation (Equation $\mathrm{C}-13$ ).

$\mathrm{G}=$ solar heat flux (Equation $\mathrm{C}-14)$.

$\mathrm{u}_{2}=$ wind speed (from Table 4.1-3) corrected for height according to Equation C-15. 
Table C-7. Radiation Parameters, Soil Heat Flux, and Wind Speed for Lower Bound Glacial Transition Climate Conditions

\begin{tabular}{|c|c|c|c|c|c|c|c|c|c|}
\hline Month & $\begin{array}{c}R_{a} \\
\left(M^{-2} ~ m^{-2}\right. \\
\left.\operatorname{day}^{-1}\right)\end{array}$ & $\mathrm{n} / \mathrm{N}$ & $\begin{array}{c}R_{s} \\
\left(M^{-2} ~ m^{-2}\right. \\
\left.\text { day }^{-1}\right)\end{array}$ & $\begin{array}{c}R_{\text {so }} \\
\left(\mathrm{MJ} \mathrm{m}^{-2}\right. \\
\left.\text { day }^{-1}\right)\end{array}$ & $\begin{array}{c}R_{n s} \\
\left(\mathrm{MJ} \mathrm{m}^{-2}\right. \\
\left.\text { day }^{-1}\right)\end{array}$ & $\begin{array}{c}R_{n l} \\
\left(\mathrm{MJ} \mathrm{m}^{-2}\right. \\
\left.\operatorname{day}^{-1}\right)\end{array}$ & $\begin{array}{c}R_{n} \\
\left(\mathrm{MJ} \mathrm{m}^{-2}\right. \\
\left.\mathrm{day}^{-1}\right)\end{array}$ & $\begin{array}{c}\text { G } \\
\begin{array}{c}\left(\mathrm{MJ} \mathrm{m}^{-2}\right. \\
\left.\mathrm{day}^{-1}\right)\end{array}\end{array}$ & $\begin{array}{c}\mathrm{u}_{2} \\
\left(\mathrm{~m} \mathrm{~s}^{-1}\right)\end{array}$ \\
\hline January & 17.5 & 0.58 & 9.45 & 13.4 & 7.3 & 4.1 & 3.2 & 0.08 & 3.6 \\
\hline February & 22.6 & 0.64 & 12.88 & 17.3 & 9.9 & 4.5 & 5.4 & 0.51 & 3.5 \\
\hline March & 29.0 & 0.63 & 16.39 & 22.2 & 12.6 & 4.7 & 7.9 & 0.70 & 3.8 \\
\hline April & 35.7 & 0.69 & 21.24 & 27.4 & 16.4 & 5.2 & 11.1 & 0.74 & 3.8 \\
\hline May & 40.0 & 0.73 & 24.6 & 30.7 & 18.9 & 5.6 & 13.3 & 0.68 & 4.1 \\
\hline June & 41.7 & 0.82 & 27.52 & 32.0 & 21.2 & 6.6 & 14.6 & 0.70 & 4.1 \\
\hline July & 40.8 & 0.77 & 25.91 & 31.3 & 19.9 & 5.9 & 14.1 & 0.29 & 4.0 \\
\hline August & 37.4 & 0.79 & 24.12 & 28.7 & 18.6 & 6.2 & 12.4 & -0.45 & 3.7 \\
\hline Sept & 31.5 & 0.80 & 20.48 & 24.2 & 15.8 & 6.2 & 9.6 & -0.88 & 3.3 \\
\hline October & 24.6 & 0.76 & 15.50 & 18.9 & 11.9 & 5.7 & 6.2 & -1.09 & 3.5 \\
\hline November & 18.7 & 0.62 & 10.47 & 14.3 & 8.1 & 4.5 & 3.6 & -0.88 & 3.1 \\
\hline December & 16.1 & 0.60 & 8.86 & 12.3 & 6.8 & 4.2 & 2.6 & -0.41 & 3.3 \\
\hline
\end{tabular}

$\mathrm{R}_{\mathrm{a}}=$ extraterrestrial radiation (from Allen et al. 1998 [DIRS 157311], Annex 2, Table 2.6, p. 219).

$\mathrm{n} / \mathrm{N}=$ percent of possible sunshine converted to decimal value (from Table 4.1-4).

$\mathrm{R}_{\mathrm{s}}=$ solar radiation (from Equation C-9).

$\mathrm{R}_{\mathrm{so}}=$ clear sky radiation (Equation $\mathrm{C}-10$ ).

$\mathrm{R}_{\mathrm{ns}}=$ net solar radiation (Equation $\mathrm{C}-11$ ).

$\mathrm{R}_{\mathrm{nl}}=$ net longwave radiation (Equation $\mathrm{C}-12$ ).

$\mathrm{R}_{\mathrm{n}}=$ net radiation (Equation $\mathrm{C}-13$ ).

$\mathrm{G}=$ solar heat flux (Equation $\mathrm{C}-14)$.

$\mathrm{u}_{2}=$ wind speed (from Table 4.1-4), with corrections for measurement height using Equation C-15. 
Table C-8. Radiation Parameters, Soil Heat Flux, and Wind Speed for Upper Bound Glacial Transition Climate Conditions

\begin{tabular}{|c|c|c|c|c|c|c|c|c|c|}
\hline Month & $\begin{array}{c}R_{\mathrm{a}} \\
\left(\mathrm{MJ} \mathrm{m}^{-2}\right. \\
\left.\text { day }^{-1}\right)\end{array}$ & $n / N$ & $\begin{array}{c}R_{\mathbf{S}} \\
\left(\mathrm{MJ} \mathrm{m}^{-2}\right. \\
\left.\text { day }^{-1}\right) \\
\end{array}$ & $\begin{array}{c}R_{\text {so }} \\
\left(\mathrm{MJ} \mathrm{m}^{-2}\right. \\
\left.\text { day }^{-1}\right)\end{array}$ & $\begin{array}{c}R_{\mathrm{ns}} \\
\left(\mathrm{MJ} \mathrm{m}^{-2}\right. \\
\left.\text { day }^{-1}\right) \\
\end{array}$ & $\begin{array}{c}R_{\mathrm{nl}} \\
\left(\mathrm{MJ} \mathrm{m}^{-2}\right. \\
\left.\text { day }^{-1}\right)\end{array}$ & $\begin{array}{c}R_{n} \\
\left(M^{-2} m^{-2}\right. \\
\left.\text { day }^{-1}\right)\end{array}$ & $\begin{array}{c}\text { G } \\
\left(M^{M J ~ m}{ }^{-2}\right. \\
\left.\text { day }^{-1}\right)\end{array}$ & $\begin{array}{c}\mathrm{u}_{2} \\
\left(\mathrm{~m} \mathrm{~s}^{-1}\right)\end{array}$ \\
\hline January & 17.5 & 0.28 & 6.8 & 13.4 & 5.3 & 2.2 & 3.1 & 0.21 & 2.9 \\
\hline February & 22.6 & 0.41 & 10.3 & 17.3 & 7.9 & 3.0 & 4.9 & 0.45 & 3.1 \\
\hline March & 29.0 & 0.55 & 15.2 & 22.2 & 11.7 & 4.0 & 7.8 & 0.49 & 3.2 \\
\hline April & 35.7 & 0.61 & 19.8 & 27.4 & 15.3 & 4.4 & 10.8 & 0.59 & 3.4 \\
\hline May & 40.0 & 0.65 & 23.0 & 30.7 & 17.7 & 4.7 & 13.0 & 0.63 & 3.1 \\
\hline June & 41.7 & 0.67 & 24.4 & 32.0 & 18.8 & 4.8 & 14.0 & 0.58 & 3.1 \\
\hline July & 40.8 & 0.80 & 26.5 & 31.3 & 20.4 & 5.8 & 14.6 & 0.25 & 2.8 \\
\hline August & 37.4 & 0.78 & 23.9 & 28.7 & 18.4 & 5.7 & 12.7 & -0.39 & 2.8 \\
\hline Sept & 31.5 & 0.72 & 19.2 & 24.2 & 14.8 & 5.2 & 9.6 & -0.82 & 2.8 \\
\hline October & 24.6 & 0.55 & 12.9 & 18.9 & 9.9 & 4.0 & 6.0 & -0.93 & 2.8 \\
\hline November & 18.7 & 0.29 & 7.4 & 14.3 & 5.7 & 2.3 & 3.4 & -0.76 & 2.9 \\
\hline December & 16.1 & 0.23 & 5.9 & 12.3 & 4.5 & 1.9 & 2.6 & -0.31 & 2.9 \\
\hline
\end{tabular}

$\mathrm{R}_{\mathrm{a}}=$ extraterrestrial radiation (from Allen et al. 1998 [DIRS 157311], Annex 2, Table 2.6, p. 219).

$\mathrm{n} / \mathrm{N}=$ percent of possible sunshine (from Table 4.1-5).

$\mathrm{R}_{\mathrm{s}}=$ solar radiation (from Equation C-9).

$\mathrm{R}_{\mathrm{so}}=$ clear sky radiation (Equation $\mathrm{C}-10$ ).

$\mathrm{R}_{\mathrm{ns}}=$ net solar radiation (Equation $\mathrm{C}-11$ ).

$\mathrm{R}_{\mathrm{nl}}=$ net longwave radiation (Equation C-12).

$\mathrm{R}_{\mathrm{n}}=$ net radiation (Equation $\mathrm{C}-13$ ).

$\mathrm{G}=$ solar heat flux (Equation C-14).

$\mathrm{u}_{2}=$ wind speed (from Table 4.1-5), with corrections for measurement height using Equation C-15.

\section{C2.2.2 Solar Radiation $\left(\boldsymbol{R}_{s}\right)$}

Solar radiation $\left(R_{s}\right)$ was measured at the YMP meteorological monitoring Site 9 for the presentday climate (Section 4.1.5, Table 4.1-2). However, it was not measured at the Nogales, Delta, or Spokane weather stations, (analogues for upper bound monsoon, lower bound glacial transition, and upper bound glacial transition climates), and was therefore calculated according to Allen et al. (1998 [DIRS 157311], Equation 35, p. 50). This equation uses the Angstrom formula to relate $\mathrm{R}_{\mathrm{s}}$ to relative sunshine duration and $R_{a}$ :

$$
R_{s}=\left(a_{s}+b_{s} \frac{n}{N}\right) R_{a}
$$

where

$$
\begin{array}{ll}
\mathrm{n} / \mathrm{N} & =\text { relative sunshine duration (percent of possible sunshine), } \\
\mathrm{a}_{\mathrm{s}} & =\text { fraction of extraterrestrial radiation reaching the earth on overcast days }(\mathrm{n}=0), \\
\mathrm{a}_{\mathrm{s}}+\mathrm{b}_{\mathrm{s}} & =\text { fraction of extraterrestrial radiation reaching the earth on clear days }(\mathrm{n}=\mathrm{N}), \\
\mathrm{R}_{\mathrm{a}} & =\text { extraterrestrial radiation }\left(\mathrm{MJ} \mathrm{m}^{-2} \text { day }^{-1}\right) .
\end{array}
$$

The Angstrom values $a_{s}$ and $b_{s}$ vary with atmospheric conditions such as dust and humidity, and with solar declination. However, no site specific calibration for these variables were available. 
Therefore the values of $a_{s}=0.25$ and $b_{s}=0.50$ recommended by Allen et al. (1998 [DIRS 157311], p. 50) were used in the calculations of $R_{s}$ for upper bound monsoon, lower bound glacial transition, and upper bound glacial transition climates. Values for percent of possible sunshine $(\mathrm{n} / \mathrm{N})$ from Tables 4.1-3, 4.1-4, and 4.1-5 were converted to decimal values for calculations of $\mathrm{R}_{\mathrm{s}}$.

Example: January $R_{a}$ for upper bound glacial transition climate $=17.5$ (from Table C-8), and $n / N=0.28$ (converted from percent to decimal for calculation, Table 4.1-5).

$$
R_{s}=(0.25+0.50(0.28)) \times 17.5=6.8 \mathrm{MJ} \mathrm{m}^{-2} \text { day }^{-1}
$$

Monthly $R_{s}$ values for present-day and future climates are in Tables C-5, C-6, C-7, and C-8.

\section{2.2.3 Clear Sky Radiation $\left(R_{s o}\right)$}

Clear sky radiation $\left(R_{S O}\right)$ is the radiation that would hit a flat surface under cloudless conditions (Allen et al. 1998 [DIRS 157311], Equation 37, p. 51):

$$
R_{s o}=\left(0.75+2 \times 10^{-5} Z\right) R_{a}
$$

where

$$
Z=\text { station elevation above sea level ( } \mathrm{m} \text {, note that this is the same for all climates). }
$$

Example: Station elevation for the present-day climate $=838 \mathrm{~m}$ and $R_{a}$ for January $=17.5$ (from Table C-5).

$$
R_{\text {so }}=\left(0.75+2 \times 10^{-5} \times 838\right) 17.5=13.4 \mathrm{MJ} \mathrm{m}^{-2} \text { day }^{-1}
$$

Clear sky radiation is required to calculate net longwave radiation $\left(R_{n l}\right)$, which is used directly in the calculation of $R_{n}$. Mean monthly $R_{s o}$ values are in Tables C-5, C-6, C-7, and C-8.

\section{C2.2.4 Net Solar (shortwave) Radiation $\left(R_{n s}\right)$}

Net solar radiation incorporates albedo (shortwave radiation reflected from the canopy of the grass reference crop) into incoming solar radiation and is used directly in the calculation of $R_{n}$ (Allen et al. 1998 [DIRS 157311], Equation 38, p. 51):

$$
R_{n s}=(1-\alpha) R_{s}
$$

where:

$$
\alpha=\text { albedo of grass reference crop }=0.23 \text { (Allen et al. } 1998 \text { [DIRS 157311], p. 51). }
$$

Example: For January present-day climate $\mathrm{R}_{\mathrm{s}}=9.6 \mathrm{MJ} \mathrm{m}^{-2}$ day $^{-1}$ (from Table C-5).

$$
R_{n s}=(1-0.23) 9.6=7.4 \mathrm{MJ} \mathrm{m}^{-2} \text { day }^{-1}
$$


Mean monthly $R_{n s}$ values are in Tables C-5, C-6, C-7, and C-8.

\section{C2.2.5 Net Longwave Radiation $\left(\boldsymbol{R}_{n l}\right)$}

Net loss of radiant energy $\left(R_{n l}\right)$ occurs primarily through thermal or longwave radiation. The Stefan-Boltzmann law predicts that black body radiation emission (radiation emitted by a perfect radiator) is proportional to surface temperature raised to the fourth power (Nobel 1983 [DIRS 159953], p. 347). Plants are virtually black body absorbers and emitters to longwave radiation. However, radiant energy is also absorbed and emitted by water vapor, carbon dioxide, ozone and clouds, which affects the outgoing energy flux. Because of this, the Stefan-Boltzmann law is corrected for humidity and cloudiness in the calculation of net outgoing longwave radiation $\left(\mathrm{R}_{\mathrm{nl}}\right.$, Allen et al. 1998 [DIRS 157311], Equation 39, p. 52):

$$
R_{n l}=\sigma\left[\frac{T_{\max }, K^{4}+T_{\min }, K^{4}}{2}\right]\left(0.34-0.14 \sqrt{e_{a}}\right)\left[1.35 \frac{R_{s}}{R_{s o}}-0.35\right]
$$

where

$$
\begin{aligned}
\sigma & =\text { Stefan-Boltzmann constant }\left(4.90310^{-9} \mathrm{MJ} \mathrm{K}^{-4} \mathrm{~m}^{-2} \text { day }{ }^{-1}\right), \\
T_{\max }, K= & \text { maximum absolute temperature during the } 24 \text {-hour period }\left(K={ }^{\circ} \mathrm{C}+273.16\right), \\
T_{\min }, K= & \text { minimum absolute temperature during the } 24 \text {-hour period }\left(K={ }^{0} \mathrm{C}+273.16\right), \\
e_{a}= & \text { actual vapor pressure }(\mathrm{kPa}), \\
R_{S} / R_{S O}= & \text { relative shortwave radiation (limited to } \leq 1.0), \\
R_{S}= & \text { measured (present-day climate) or calculated (future climate) solar radiation } \\
& \left(\mathrm{MJ} \mathrm{m}^{-2} \text { day- }{ }^{-1}\right), \\
R_{S O}= & \text { calculated clear-sky radiation }\left(\mathrm{MJ} \mathrm{m}^{-2} \mathrm{day}^{-1}\right) .
\end{aligned}
$$

Example: For January present-day climate $T_{\max }=13.5{ }^{\circ} \mathrm{C}$ and $T_{\min }=1.1{ }^{\circ} \mathrm{C}$ (Section 4.1.5, Table 4.1-2), $\mathrm{e}_{\mathrm{a}}=0.661$ (Table C-1), $R_{s}=9.6 \mathrm{MJ} \mathrm{m}^{-2}$ day $^{-1}, R_{s o}=13.4 \mathrm{MJ} \mathrm{m}^{-2}$ day $^{-1}$ (Table C-5).

Allen et al. (1998 [DIRS 157311], Table 2.8, p. 221) provides values for $\sigma T_{\max }, \mathrm{K}^{4}$ based on air temperatures $\left({ }^{\circ} \mathrm{C}\right)$. For $T_{\max }=13.5{ }^{\circ} \mathrm{C}$ the value for $\sigma T_{\max }, \mathrm{K}^{4}=33.11$. For $T_{\min }=1.1{ }^{\circ} \mathrm{C}$ the value for $\sigma T_{\min }, \mathrm{K}^{4}=27.70$.

$$
\begin{gathered}
R_{n l}=\left[\frac{33.11+27.70}{2}\right](0.34-0.14 \sqrt{.661})\left[1.35\left(\frac{9.6}{13.4}\right)-0.35\right] \\
=30.42 \times 0.226 \times 0.616=4.2 \mathrm{MJ} \mathrm{m}^{-2} \text { day }^{-1}
\end{gathered}
$$

Mean monthly $R_{n l}$ values are in Tables C-5, C-6, C-7, and C-8. 


\section{C2.2.6 Net Radiation $\left(R_{n}\right)$}

Net Radiation is the balance between net shortwave radiation (both incoming and reflected) and net loss of longwave radiation (Allen et al. 1998 [DIRS 157311], Equation 40, p. 53):

$$
R_{n}=R_{n s}-R_{n l}
$$

Example: For January present-day climate $R_{n s}=7.4$ and $R_{n l}=4.2$ (from Table C-5).

$$
R_{n}=7.4-4.2=3.2 \mathrm{MJ} \mathrm{m}^{-2} \text { day }^{-1}
$$

Mean monthly $R_{n}$ values are in Tables C-5, C-6, C-7, and C-8.

\section{C2.3 SOIL HEAT FLUX}

Soil heat flux $(G)$ can be derived for monthly periods assuming a constant soil heat capacity of $2.1 \mathrm{MJ} \mathrm{m}^{3}{ }^{\circ} \mathrm{C}^{-1}$ and that, over long time periods, soil temperature at a depth of $2 \mathrm{~m}$ changes approximately with average air temperature (Allen et al. 1998 [DIRS 157311], Equation 43, p. 54)

$$
G_{\text {month }, i}=0.07\left(T_{\text {month }, i+1}-T_{\text {month }, i-1}\right)
$$

Example: For January present-day climate, $\mathrm{T}_{\text {month, } \mathrm{i}+1}=9.6{ }^{\circ} \mathrm{C}$ and $\mathrm{T}_{\text {month, } \mathrm{i}-1}=6.9{ }^{\circ} \mathrm{C}$ (Table 4.12).

$$
G_{\text {january }}=0.07(9.6-6.9)=0.19
$$

Monthly values for $\mathrm{G}$ are in Tables C-5, C-6, C-7, and C-8, respectively.

\section{C2.4 WIND SPEED $\left(u_{2}\right)$}

Wind speed $\left(u_{2}\right)$ data were collected at the weather stations for present-day, upper bound monsoon, and upper bound glacial transition climates. Wind speed for lower bound glacial transition climate was taken from Milford, Utah, the closest weather station to Delta, Utah (lower bound glacial transition climate analogue). Standard anemometer height in agrometeorology is 2 $\mathrm{m}$ above the ground surface (Allen et al. 1998 [DIRS 157311], p. 55). Anemometer height at the weather stations used in this analysis was $10 \mathrm{~m}$. Because wind speed increases with height above the soil surface, a logarithmic wind profile function is required to adjust wind speeds placed at heights other than the standard $2 \mathrm{~m}$. Therefore, the following correction was made for wind speed (Allen et al. 1998 [DIRS 157311], Equation 47, p. 56):

$$
u_{2}=u_{z} \frac{4.87}{\ln (67.8 z-5.24)}
$$

where 


$$
\begin{aligned}
& u_{z}=\text { wind speed measured at } \mathrm{z} \mathrm{m} \text { above ground surface }\left(\mathrm{m} \mathrm{s}^{-1}\right), \\
& z=\text { height of measurement above ground surface }(\mathrm{m})
\end{aligned}
$$

Example: For January upper bound glacial transition climate, $\mathrm{u}_{10}=3.9 \mathrm{~m} \mathrm{~s}^{-1}$ (Table 4.1-5).

$$
u_{2}=3.9 \frac{4.87}{\ln (67.8 * 10-5.24)}=2.9 \mathrm{~m} \mathrm{~s}^{-1}
$$

Mean monthly values for $u_{2}$ are in Tables C-5, C-6, C-7, and C-8.

\section{C2.5 REFERENCE EVAPOTRANSPIRATION}

Using the humidity, radiation, soil heat flux, and wind speed values generated in this appendix for January present-day climate, mean monthly $E T_{o}$ for January can be calculated using Equation C-1.

Example: For January present-day climate conditions,

$$
\begin{aligned}
& \Delta=0.069 \\
& R n=3.2 \\
& G=0.19 \\
& \gamma=0.061 \\
& T=7.0 \\
& u_{2}=2.9 \\
& \left(e_{s}-e_{a}\right)=0.443
\end{aligned}
$$

$$
E T_{o}=\frac{0.408 * 0.069(3.2-0.19)+0.061 \frac{900}{7.0+273} 2.9(0.443)}{0.069+0.061(1+0.34 * 2.9)}=1.77 \mathrm{~mm} / \text { day }
$$

Mean monthly $E T_{o}$ for present-day, upper bound monsoon, lower bound glacial transition, and upper bound glacial transition climates are in Table C-9. 
Table C-9. Mean Monthly Reference Evapotranspiration for Present-Day, Upper Bound Monsoon, Lower Bound Glacial Transition, and Upper Bound Glacial Transition Climate Conditions

\begin{tabular}{|c|c|c|c|c|}
\hline Month & $\begin{array}{c}\text { Present-Day } \\
\text { Climate } E T_{o}^{a} \\
(\mathrm{~mm} / \text { day })\end{array}$ & $\begin{array}{c}\text { Upper Bound } \\
\text { Monsoon Climate } E T_{o}{ }^{a} \\
(\mathrm{~mm} / \text { day })\end{array}$ & $\begin{array}{l}\text { Lower Bound Glacial } \\
\text { Transition Climate } \\
E T_{o}^{\mathrm{a}} \text { (mm/day) }\end{array}$ & $\begin{array}{l}\text { Upper Bound } \\
\text { Glacial } \\
\text { Transition } \\
\text { Climate } E T_{o}^{a} \\
\text { (mm/day) }\end{array}$ \\
\hline January & 1.77 & 1.92 & 1.21 & 0.62 \\
\hline February & 2.64 & 2.96 & 1.67 & 1.10 \\
\hline March & 4.24 & 3.82 & 2.85 & 1.99 \\
\hline April & 5.51 & 5.10 & 4.30 & 3.18 \\
\hline May & 6.86 & 6.32 & 6.01 & 4.21 \\
\hline June & 8.38 & 7.36 & 7.96 & 5.31 \\
\hline July & 8.89 & 6.25 & 8.82 & 6.51 \\
\hline August & 8.62 & 5.64 & 8.26 & 6.15 \\
\hline September & 6.84 & 5.08 & 6.27 & 4.44 \\
\hline October & 4.67 & 3.99 & 4.05 & 2.50 \\
\hline November & 2.72 & 2.45 & 1.90 & 0.97 \\
\hline December & 1.85 & 2.00 & 1.25 & 0.58 \\
\hline
\end{tabular}

${ }^{a}$ Mean reference evapotranspiration (ETo) calculated according to Equation $\mathrm{C}-1$. Climate data used in the calculations are from Section 4, Tables 4.1-2 to 4.1-5. 


\section{APPENDIX D}

\section{METHODS FOR DERIVING CROP COEFFICIENTS AND CROP EVAPOTRANSPIRATION}




\section{METHODS FOR DERIVING CROP COEFFICIENTS AND CROP EVAPOTRANSPIRATION}

The single crop coefficient $\left(K_{c}\right)$ approach described by Allen et al. (1998 [DIRS 157311], pp. 103 to 134) was used to calculate crop evapotranspiration $\left(E T_{c}\right)$, which is required for calculation of the irrigation parameters. This appendix describes methods for deriving growing season lengths for the crops used in this analysis and the methods from Allen et al. 1(998 [DIRS 157311], pp. 103 to 134) used to calculate $K_{c}$ and $E T_{c}$.

\section{D1. INTRODUCTION}

A grass reference evapotranspiration ( $E T_{o}$, Appendix $\left.C\right)$ and crop specific coefficients are used to calculate $E T_{c}$ (Allen et al. 1998 [DIRS 157311], Equation 58, p. 103):

$$
E T_{C}=E T_{o} * K_{C}
$$

$E T_{o}$ incorporates the effects of local climatic conditions on $E T_{c}$, and $K_{c}$ integrates the effects of four primary crop characteristics that differ from the reference grass (crop height, albedo, canopy resistance, and evaporation from soil). Changes in crop characteristics (i.e., leaf area, stomatal conductance, phenological stages) over the growing season also affect $K_{c}$, and so growth stage information is used in deriving crop specific values. Locally determined values for $K_{c}$ were not available for this analysis so values published in Allen et al. (1998 [DIRS 157311], Table 12, pp. 110 to 114) were used for the 26 representative crops and turf. Relative humidity and wind speed were used to correct the published $K_{c}$ values to correspond with local conditions according to Allen et al. (1998 [DIRS 157311], pp. 121 to 127). Methods and example calculations are provided below.

\section{D2. METHODS}

Crop coefficients were derived for the 26 representative crops and turf grass by: 1) using the growth stage lengths and $K_{c}$ values from Allen et al. (1998 [DIRS 157311], Table 11, pp. 104 to 108, and Table 12, pp. 110 to 114), 2) developing season lengths from appropriate local or regional data sources to correct growth stage lengths, and 3) correcting $K_{c}$ values under non-standard climatic conditions. Once $K_{c}$ values were corrected, average monthly values were calculated to correspond with average monthly $E T_{o}$.

\section{D2.1 GROWING SEASON LENGTHS}

\section{D2.1.1 Present-Day Climate}

The season lengths developed in this section apply to both present-day climate and upper bound monsoon climate states.

Fruits and vegetables-As described and justified in Section 4.1.4, information from the University of Nevada and University of Arizona Cooperative Extensions were used to determine planting dates (Mills et al. no date [DIRS 124338]) and season lengths (Call 1999 [DIRS 158672]) for most representative fruits and vegetables. Use of data from these sources resulted in growing seasons that are consistent with current knowledge of the conditions in the 
region surrounding Yucca Mountain. Planting dates, which can vary across arid climate zones, were selected for southern Nevada. Season lengths are constrained by crop specific developmental processes that result in approximate times to maturity and are general for most climate zones; therefore, use of Arizona as a natural analogue for season length is appropriate. Planting dates and season lengths for each crop were calculated as the midpoint of ranges (Table D-1). Harvest date was calculated by adding the number of days in the season to the selected planting date (Table D-1). Except for sweet corn, two planting seasons were included for all vegetables that Mills et al. no (date [DIRS 124338]) show can be planted in spring and fall in southern Nye County. Mills et al. (no date [DIRS 124338]) show that sweet corn can be planted from mid-April through mid-May and from mid through late June. Because the season length of sweet corn is 63 to 100 days (Table D-1), an April-May crop could not be harvested before the second crop is planted in June.

Apples and strawberries-As described in Section 4.1.4, information from Allen et al. (1998 [DIRS 157311], Table 11, p. 107) was used to determine the onset of growth and season lengths for apples and strawberries. Allen et al. (1998 [DIRS 157311], Table 11, p. 107) lists a planting time of March and a total growing season of 240 days for orchard fruit trees in California. This is corroborated by Caprile et al. (2001 [DIRS 159938]) with reference to irrigating apples from April through September in the San Joaquin Valley, California. In the category of "Grapes and Berries", a planting time of March and growing season of 205 days is suggested (Allen et al. 1998 [DIRS 157311], Table 11, p. 107). Based on this information, March 1 was selected for onset of growth for both apples and strawberries (Table D-1). A growing season length of 240 days and harvest date of October 27 were selected for apples. A growing season length of 205 days and harvest date of September 22 were selected for strawberries (Table D-1).

Grapes-As described in Section 4.1.4, information from the founder of the Pahrump Valley Vineyards was used for initiation of growth and season length for grapes. Grapes in southern Nye County bloom in late March to early April and are harvested late August to early September (LeStrange 1997 [DIRS 125452]). This is corroborated by the planting period (March) and growing season length (205 days) suggested by Allen et al. (1998 [DIRS 157311], Table 11, p. 107,) for grapes grown in California. Based on this information, a growth initiation date of March 1 and a harvest date of August 31 were selected for grapes (Table D-1).

Barley, winter wheat, oat hay, and alfalfa-As described in Section 4.1.4, information from a local farmer was used to determine planting and harvest dates for barley, winter wheat, oat hay, and alfalfa. According to this source, one crop of winter wheat, barley, and oats can be produced per year in Amargosa Valley (LeStrange 1997 [DIRS 125429]). Winter wheat and barley are planted in October and harvested in June, and oats are planted in March or April and harvested in June (LeStrange 1997 [DIRS 125429]). According to Allen et al. (1998 [DIRS 157311], Table 11, p. 106), cereal oats in desert climates are planted in December and have a growing season of 160 days. Based on this information, a planting date of October 16 (mid-month) and a harvest date of June 16 (mid-month) were chosen for winter wheat and barley. A planting date of March 31 (mid-point between March 1 and April 30) and harvest date of June 14 (mid-month) were chosen for oat hay (Table D-1). A planting date of December 16 (mid-month) and a harvest date of May 25 were selected for oats (Table D-1). 
In southern Nye County, approximately six to seven alfalfa cuttings can occur per year with the first cutting around mid to late April and the last cutting mid to late November (LeStrange 1997 [DIRS 125429]). Irrigation generally begins in early February and ends in December when alfalfa goes dormant (LeStrange 1997 [DIRS 125429]). Allen et al. 1998 [DIRS 157311] suggested a planting month of January with a 60-day growing period for the first cutting of alfalfa in California. Given this, the suggested six cuttings per year with dormancy beginning in December (LeStrange 1997 [DIRS 125429]) can be achieved with initial growth starting January 1, the first cutting 60 days later on March 2, and the second through sixth cuttings occurring 55 days apart. Based on this information, January 1 was chosen for growth initiation, with cuttings on March 2, April 26, June 20, August 14, October 8, and December 2 (Table D-1). The average time between cuttings is 56 days.

Table D-1. Growing Season - Present-Day and Upper Bound Monsoon Climates

\begin{tabular}{|c|c|c|c|c|c|c|c|c|c|}
\hline \multirow[b]{2}{*}{ Crop } & \multicolumn{4}{|c|}{ Start of Season ${ }^{a}$} & \multicolumn{5}{|c|}{ Season Length (days) ${ }^{b}$} \\
\hline & Start & End & $\mathrm{Mid}^{\mathrm{c}}$ & Julian $^{\mathrm{d}}$ & Min & Max & Mid & Harvest $^{\mathrm{e}}$ & Julian \\
\hline Broccoli early & $09-\mathrm{Feb}$ & 20-Mar & 1-Mar & 60 & 60 & 100 & 80 & 20-May & 140 \\
\hline Broccoli late & 01-Aug & 20-Sep & 26-Aug & 238 & 60 & 100 & 80 & 14-Nov & 318 \\
\hline Cabbage early & 09-Feb & 20-Mar & 1-Mar & 60 & 70 & 100 & 85 & 25-May & 145 \\
\hline Cabbage late & 01-Aug & 20-Sep & 26-Aug & 238 & 70 & 100 & 85 & 19-Nov & 323 \\
\hline Cauliflower early & $09-F e b$ & 20-Mar & 1-Mar & 60 & 70 & 90 & 80 & 20-May & 140 \\
\hline Cauliflower late & 01-Aug & 20-Sep & 26-Aug & 238 & 70 & 90 & 80 & 14-Nov & 318 \\
\hline Celery early & 01-Apr & 20-Apr & 11-Apr & 101 & 125 & 125 & 125 & 14-Aug & 226 \\
\hline Celery late & 01-Sep & 30-Sep & 16-Sep & 259 & 125 & 125 & 125 & 19-Jan & 19 \\
\hline Head lettuce early & $09-\mathrm{Feb}$ & 31-Mar & 6-Mar & 65 & 40 & 80 & 60 & 5-May & 125 \\
\hline Head lettuce late & 10-Aug & 20-Sep & 31-Aug & 243 & 40 & 80 & 60 & 30-Oct & 303 \\
\hline Leaf lettuce early & 09-Feb & 31-Mar & 6-Mar & 65 & 40 & 80 & 60 & 5-May & 125 \\
\hline Leaf lettuce late & 10-Aug & 20-Sep & 31-Aug & 243 & 40 & 80 & 60 & 30-Oct & 303 \\
\hline Spinach early & 09-Feb & 20-Apr & 16-Mar & 75 & 40 & 60 & 50 & 5-May & 125 \\
\hline Spinach late & 01-Sep & 30-Sep & 16-Sep & 259 & 40 & 60 & 50 & 5-Nov & 309 \\
\hline Bell peppers & 10-Apr & 31-May & 6-May & 126 & 70 & 85 & 78 & 23-Jul & 204 \\
\hline Carrots early & $09-\mathrm{Feb}$ & 20-Apr & 16-Mar & 75 & 70 & 80 & 75 & 30-May & 150 \\
\hline Carrots late & 01-Aug & 20-Sep & 26-Aug & 238 & 70 & 80 & 75 & 9-Nov & 313 \\
\hline Cucumbers & 01-Apr & 31-Jul & 1-Jun & 152 & 50 & 70 & 60 & 31-Jul & 212 \\
\hline Onions early & 01-Mar & 20-Apr & 26-Mar & 85 & 100 & 120 & 110 & 14-Jul & 195 \\
\hline Onions late & 01-Sep & 30-Sep & 16-Sep & 259 & 100 & 120 & 110 & 4-Jan & 4 \\
\hline Potatoes & 01-Mar & 20-Apr & 26-Mar & 85 & 100 & 120 & 110 & 14-Jul & 195 \\
\hline Squash & 10-Apr & 20-Jun & 16-May & 136 & 50 & 65 & 58 & 13-Jul & 194 \\
\hline Sweet corn & 10-Apr & 20-May & 30-Apr & 120 & 63 & 100 & 82 & 21-Jul & 202 \\
\hline Apples & & & 1-Mar & 60 & & & 240 & 27-Oct & 300 \\
\hline Grapes & & & 1-Mar & 60 & & & 183 & 31-Aug & 243 \\
\hline Melons & 10-Apr & 20-Jun & 16-May & 136 & 70 & 130 & 100 & 24-Aug & 236 \\
\hline Strawberries & & & 1-Mar & 60 & & & 205 & 22-Sept & 265 \\
\hline Tomatoes & 10-Apr & 31-May & 6-May & 126 & 55 & 105 & 80 & 25-Jul & 206 \\
\hline
\end{tabular}


Table D-1. Growing Season - Present-Day and Upper Bound Monsoon Climates (Continued)

\begin{tabular}{|c|c|c|c|c|c|c|c|c|c|}
\hline \multirow[b]{2}{*}{ Crop } & \multicolumn{4}{|c|}{ Start of Season ${ }^{a}$} & \multicolumn{5}{|c|}{ Season Length (days) $^{b}$} \\
\hline & Start & End & Mid $^{\mathrm{c}}$ & Julian $^{\mathrm{d}}$ & Min & Max & Mid & Harvest $^{\mathrm{e}}$ & Julian \\
\hline Barley & $01-$ Oct & 31-Oct & 16-Oct & 289 & 213 & 272 & 243 & 16-Jun & 167 \\
\hline Feed Corn & 01-May & 30-May & 16-May & 136 & & & 154 & 17-Oct & 290 \\
\hline Oats & 01-Dec & 31-Dec & 16-Dec & 350 & & & 160 & 25-May & 145 \\
\hline Winter wheat & $01-$ Oct & 31-Oct & 16-Oct & 289 & 213 & 272 & 243 & 16-Jun & 167 \\
\hline Corn silage & 01-May & 30-May & 16-May & 136 & & & 93 & 17-Aug & 229 \\
\hline Oat hay & 01-Mar & 30-Apr & 31-Mar & 90 & 75 & 75 & 75 & 14-Jun & 165 \\
\hline
\end{tabular}

${ }^{a}$ Sources: Mills et al. no date [DIRS 124338], except corn and corn silage (USDA 2002 [DIRS 159273], pp. 16 and 17) apples and strawberries (Allen et al. 1998 [DIRS 157311], Table 11, pp. 104-108), grapes, barley, oats, winter wheat, alfalfa, and oat hay (LeStrange 1997 [DIRS 125452], 1997 [DIRS 125429]).

b Sources: Call (1999 [DIRS 158672], Table 10.10 for celery, spinach, and carrots and crop-specific information on pp. 71-125 of Chapter 10 for others), except corn and corn silage (USDA 2002 [DIRS 159273], pp. 16 and 17) apples and strawberries (Allen et al. 1998 [DIRS 157311], Table 11, pp. 104-108) grapes, barley, oats, winter wheat, alfalfa, and oat hay (LeStrange 1997 [DIRS 125452], 1997 [DIRS 125429]) (see Section 4.1.4).

${ }^{c}$ Midpoint of start of season.

${ }^{d}$ Date is expressed in Julian format, excluding year, and represents the midpoint of the start of the season.

e Calculated as midpoint of start of season plus median season length, except apples, grapes, strawberries, winter wheat, barley, grain corn, oats, winter wheat, corn silage and oat hay.

Feed corn and corn silage-As described in Section 4.1.4, information from Nevada Agricultural Statistics 2000-2001 (USDA 2002 [DIRS 159273], pp. 16 and 17) was used to determine planting and harvest dates for feed corn and corn silage. According to this source, corn is planted during May and June, silage is harvested in August through October, and feed corn is harvested in October and November. Because this source describes growing seasons for all of Nevada, the first months listed for planting and harvest were chosen for this analysis to conform with the likely planting and harvesting times in southern Nye County, Nevada. May 16 (mid-month) was selected as the planting date for corn silage and feed corn (Table D-1). August 17 (mid-month) and October 17 (mid-month) were selected as harvest dates for corn silage and feed corn, respectively (Table D-1).

\section{D2.1.2 Upper Bound Glacial Transition Climate}

The season lengths developed in this section apply to both lower bound future and upper bound glacial transition climate states.

As described and justified in Section 4.1.4, information from the Washington State University Cooperative Extension and Washington Agricultural Statistics Service were used to determine planting dates (Washington State University Cooperative Extension 2002 [DIRS 159256]; Painter et al. 1995 [DIRS 158674]; Washington Agricultural Statistics Service 1999 [DIRS 152232]) and season lengths (Antonelli et al. 1998 [DIRS 158654]; Painter et al. 1995 [DIRS 158674]; Washington Agricultural Statistics Service 1999 [DIRS 152232]) for most representative fruits, vegetables, and field crops. Planting date and season length for early season and single season crops were calculated as the midpoint of ranges, and harvest date was calculated by adding the number of days in the season to the selected planting date (Table D-2). Two seasons were included for all vegetables having a season length less than the number of days between first harvest and October 1, the expected date that temperatures become too cold for vegetable growth in eastern Washington (Antonelli 1998 [DIRS 158654], Figure 3, p. 4). For 
example, a second season for celery was not included because the time between the first harvest (August 11) and October 1 is less than the 110-day season length for celery. An exception to this method was made for broccoli, because the early and late seasons overlapped by only five days. To accommodate, the late-season length was moved back by six days, which is within the range of season length for this crop (Table D-2).

Table D-2. Growing Season - Upper and Lower Bound Glacial Transition Climates

\begin{tabular}{|c|c|c|c|c|c|c|c|c|c|}
\hline \multirow[b]{2}{*}{ Crop } & \multicolumn{4}{|c|}{ Start of Season ${ }^{a}$} & \multicolumn{5}{|c|}{ Season Length (days) } \\
\hline & Start & End & Mid $^{\mathrm{c}}$ & Julian $^{\mathrm{d}}$ & Min & Max & Mid & Harvest $\mathrm{e}^{\mathrm{e}}$ & Julian \\
\hline Broccoli early & 15-Apr & 01-May & 23-Apr & 113 & 65 & 100 & 83 & 15-Jul & 196 \\
\hline Broccoli late & & & 16-Jul & 197 & 65 & 100 & 83 & 7-Oct & 280 \\
\hline Cabbage early & 15-Apr & 01-May & 23-Apr & 113 & 60 & 90 & 75 & 7-Jul & 188 \\
\hline Cabbage late & & & 18-Jul & 199 & & & 75 & 1-Oct & 274 \\
\hline Cauliflower early & 15-Apr & 01-May & 23-Apr & 113 & 50 & 75 & 63 & 25-Jun & 176 \\
\hline Cauliflower late & & & 30-Jul & 211 & 50 & 75 & 63 & 1-Oct & 274 \\
\hline Celery & 15-Apr & 01-May & 23-Apr & 113 & 100 & 120 & 110 & 11-Aug & 223 \\
\hline Head lettuce early & 15-Apr & 01-May & 23-Apr & 113 & 75 & 80 & 78 & 10-Jul & 191 \\
\hline Head lettuce late & & & 15-Jul & 196 & 75 & 80 & 78 & 1-Oct & 274 \\
\hline Leaf lettuce early & 15-Apr & 01-May & 23-Apr & 113 & 55 & 60 & 58 & 20-Jun & 171 \\
\hline Leaf lettuce late & & & 4-Aug & 196 & 55 & 60 & 58 & 11-Sep & 254 \\
\hline Spinach early & 15-Apr & 01-May & 23-Apr & 113 & 50 & 60 & 55 & 17-Jun & 168 \\
\hline Spinach late & & & 7-Aug & 219 & 50 & 60 & 55 & 1-Oct & 274 \\
\hline Bell peppers & 01-Jun & 15-Jun & 8-Jun & 159 & 90 & 110 & 100 & 16-Sep & 259 \\
\hline Carrots early & 15-Apr & 01-May & 23-Apr & 113 & 70 & 90 & 80 & 12-Jul & 193 \\
\hline Carrots late & & & 13-Jul & 194 & 70 & 90 & 80 & 1-Oct & 274 \\
\hline Cucumbers & 15-May & 01-Jun & 24-May & 144 & 60 & 75 & 68 & 31-Jul & 212 \\
\hline Onions & 01-Mar & 01-Mar & 1-Mar & 60 & 130 & 180 & 155 & 3-Aug & 215 \\
\hline Potatoes & 15-Apr & 01-May & 23-Apr & 113 & 90 & 140 & 115 & 16-Aug & 228 \\
\hline Squash & 15-May & 01-Jun & 24-May & 144 & 60 & 70 & 65 & 28-Jul & 209 \\
\hline Sweet corn & 15-May & 01-Jun & 24-May & 144 & 70 & 140 & 105 & 6-Sep & 249 \\
\hline Apples & 05-Apr & 10-May & 22-Apr & 112 & & & 166 & $5-O c t$ & 278 \\
\hline Grapes & 25-May & 10-Jul & 17-Jun & 168 & & & 105 & 30-Sep & 273 \\
\hline Melons & 15-May & 01-Jun & 24-May & 144 & 90 & 115 & 103 & 4-Sep & 247 \\
\hline Strawberries & 10-Apr & 15-May & 27-Apr & 117 & & & 64 & 30-Jun & 181 \\
\hline Tomatoes & 01-Jun & 15-Jun & 8-Jun & 159 & 65 & 110 & 88 & 4-Sep & 247 \\
\hline Spring barley & 01-Apr & 30-Apr & 16-Apr & 106 & & & 91 & 16-Jul & 197 \\
\hline Feed Corn & 15-Apr & 5-Jun & 11-May & 131 & & & 178 & 5-Nov & 309 \\
\hline Oats & 5-Mar & 20-Apr & 28-Mar & 87 & & & 141 & 16-Aug & 228 \\
\hline Winter wheat & 01-Sep & 30-Sep & 16-Sep & 259 & & & 334 & 16-Aug & 228 \\
\hline
\end{tabular}


Table D-2. Growing Season - Upper and Lower Bound Glacial Transition Climates (Continued)

\begin{tabular}{|c|c|c|c|c|c|c|c|c|c|}
\hline \multirow[b]{2}{*}{ Crop } & \multicolumn{4}{|c|}{ Start of Season ${ }^{a}$} & \multicolumn{5}{|c|}{ Season Length (days) ${ }^{b}$} \\
\hline & Start & End & $\mathrm{Mid}^{\mathrm{c}}$ & Julian $^{d}$ & Min & Max & Mid & Harvest $^{\mathrm{e}}$ & Julian \\
\hline Alfalfa hay & & & 1-Mar & 60 & & & 211 & 28-Sept & 271 \\
\hline Corn silage & $15 \mathrm{Apr}$ & 5 Jun & 11 May & 131 & & & 137 & 25-Sep & 268 \\
\hline Oat hay & & & 15-May & 135 & & & 57 & 11-Jul & 192 \\
\hline
\end{tabular}

a Sources: Early season and single season annual vegetables and fruits-Washington State University Cooperative Extension (2002 [DIRS 159256], p. 2) with celery assigned the same dates as other leafy vegetables; late season annual vegetables-calculated as October 1, which is about expected date of first killing frost (Antonelli et al. 1998 [DIRS 158654], Figure 3) minus median season length; winter wheat-Painter et al. (1995 [DIRS 158674], Table A1); spring barley-Painter et al. (1995 [DIRS 158674], Table A4); apples, grapes, strawberries, grain corn, oats, corn silage, and oat hay-Washington Agricultural Statistics Service (1999 [DIRS 152232], with oat hay = other hay); alfalfa - Schmierer et al. (1997 [DIRS 160479], pp. 9 to 18), Orloff and Marble (1997 [DIRS 158655], pp. 106 to 107).

b Sources: Antonelli et al. (1998 [DIRS 158654], Table 2), except apples, grapes, strawberries, wheat, barley, and oat hay, which were calculated as days from midpoint of season start to harvest ${ }^{\mathrm{e}}$.

c Midpoint of start of season.

d Date is expressed in Julian format, excluding year, and represents the midpoint of start of season.

e Calculated as midpoint of season start plus median season length, except winter wheat-Painter et al. (1995 [DIRS 158674], Table A1); spring barley-Painter et al. (1995 [DIRS 158674], Table A4); apples, grapes, strawberries, grain corn, oats, corn silage, and oat hay-Washington Agricultural Statistics Service (1999 [DIRS 152232]) midpoint of most active harvest dates, with oat hay = other hay.

As described and justified in Section 4.1.4, information from Intermountain Alfalfa Management (Orloff and Marble 1997 [DIRS 158655], pp. 106 to 107; Schmierer et al. 1997 [DIRS 160479], pp. 9 to 18) was used to determine dates for growth initiation, the last harvest, and cutting schedules for alfalfa. For conditions similar to those in eastern Washington, three- to four-cut schedules are common for alfalfa (Orloff and Marble 1997 [DIRS 158655], pp. 106 to 107) with a three-cut schedule recommended if at least one cutting is used for beef cattle or horses. A three-cut schedule was chosen for this analysis. Initiation of spring growth or planting is recommended when temperatures are $-3{ }^{\circ} \mathrm{C}$ to $-4{ }^{\circ} \mathrm{C}$ (Schmierer et al. 1997 [DIRS 160479], pp. 9 to 18; Allen et al. 1998 [DIRS 157311], Table 11, p. 107). The last harvest of the growing season should occur four to six weeks before the first killing frost (Schmierer et al. 1997 [DIRS 160479], pp. 9 to 18). Using mean monthly temperature data for Spokane (Table 4.1-5) this corresponds approximately to a growing period of March 1 (mean minimum temperatures $1.33{ }^{\circ} \mathrm{C}$ ) through September 28 (assuming first killing frost occurs the first week in November). Allen et al. (1998 DIRS 157311], Table 11, p. 107) recommended 75 days for the first cutting cycle in Idaho (similar climate to Spokane, but drier). The recommended interval between the first and second cuttings, or second and third cuttings, was 30-50 days in Schmierer et al. (1997 [DIRS 160479], pp. 9 to 18). Based on this information, March 1 and September 28 were chosen for growth initiation and the last cutting date, respectively (Table D-2). Using a three-cut schedule with the initial cut after 75 days of growth, the remaining intervals between the second and third cuts are 68 days (Table D-2). A three-cut schedule was chosen with the first cutting on May 15 (75 days from growth initiation), the second cutting on July 22 (68 days), and the third cutting on September 28 (Table D-2). 


\section{D2.2 GROWTH STAGE LENGTHS}

Allen et al. (1998 [DIRS 157311], pp. 103 to 108) divided crop development into four growth stages (initial, development, mid-season, and late season) that are related to leaf area index (ground area covered by crop canopy) and developmental stages. The initial stage begins at the planting date and ends when the crop has reached approximately 10 percent ground cover. The development stage runs from 10 percent cover to effective full cover, which, for many crops, occurs when flowering is initiated. The mid-season stage begins when the crop has reached effective full cover and ends at the start of maturity. The late season stage runs from maturity to harvest or senescence. The stages are crop specific and the lengths are affected by local climatic factors.

Growth stages and total growing season lengths from Allen et al. (1998 [DIRS 157311], Table 11. pp. 104 to 108) were selected for present-day and future climates based on regional information. Growth stage information selected for present-day climate was also used for upper bound monsoon climate. Growth stage information selected for the glacial transition climate was used for both lower and upper bounds. For the present-day climate, growth stages for California, California Desert, Semi Arid, or Arid Region were selected depending upon availability (Table D-3). When both California Desert and Arid Region were options, the region with planting dates and season lengths most similar to those identified for the local conditions were selected (see Table D-1). For the glacial transition climate, growth stage lengths for the

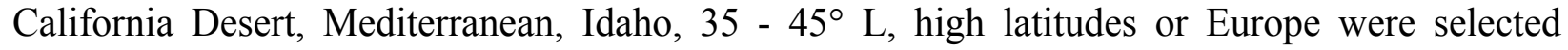
depending on which more accurately reflected data for Spokane conditions (Table D-4).

Growing season lengths developed for each crop for all climates (Tables D-1 and D-2) were used to adjust growth stage lengths from Allen et al. (1998 [DIRS 157311], Table 11, pp. 104 to 108) to local conditions. This was done by determining the ratio of the published stage length to the total growing time. This ratio was multiplied by the length of the growing season determined for local conditions and rounded to the nearest whole day. Occasionally, rounding resulted in stage lengths that were either a day too long or too short to sum to the total growing season length. If the sum of the days of stage lengths did not equal the total number of days in the growing season, the stage length days were adjusted to sum to the growing season length. Adjusted stages for present-day climate were also used for upper bound monsoon, and those for glacial transition climate were used for both lower and upper bounds.

Example: For the present-day climate early lettuce crop the published growth stage lengths and total growing time were (Allen et al. 1998 [DIRS 157311], Table 11, pp. 104 to 108):

Initial stage $=25$ days

Development stage $=35$ days

Mid-season stage $=30$ days

Late stage $=10$ days

Total $=100$ days 
The season length for the early lettuce crop for present-day climate conditions was 60 days (from Table D-1). The adjusted stage lengths were:

Initial stage $=25 / 100 \times 60=15$ days

Development stage $=34 / 100 \times 60=21$ days

Mid-season stage $=30 / 100 \times 60=18$ days

Late stage $=10 / 100 \times 60=6$ days

Published and adjusted crop growth stage lengths are in Tables D-3 and D-4, respectively.

Table D-3. Length (days) of Four Crop Growth Stages and Total Growing Season for Present-Day and Upper Bound Monsoon Climate Conditions

\begin{tabular}{|c|c|c|c|c|c|c|}
\hline Crop & Initial & Dev & Mid & Late & $\begin{array}{l}\text { Season } \\
\text { Length }\end{array}$ & Region $^{a}$ \\
\hline \multicolumn{7}{|l|}{ Leaf Lettuce early } \\
\hline Stage Length ${ }^{\mathrm{b}}$ & 25 & 35 & 30 & 10 & 100 & Arid Region \\
\hline Adjusted Stage Length ${ }^{c}$ & 15 & 21 & 18 & 6 & 60 & \\
\hline \multicolumn{7}{|l|}{ Leaf Lettuce late } \\
\hline Stage Length & 25 & 35 & 30 & 10 & 100 & Arid Region \\
\hline Adjusted Stage Length & 15 & 21 & 18 & 6 & 60 & \\
\hline \multicolumn{7}{|l|}{ Head Lettuce early } \\
\hline Stage Length & 25 & 35 & 30 & 10 & 100 & Arid Region \\
\hline Adjusted Stage Length & 15 & 21 & 18 & 6 & 60 & \\
\hline \multicolumn{7}{|l|}{ Head Lettuce late } \\
\hline Stage Length & 25 & 35 & 30 & 10 & 100 & Arid Region \\
\hline Adjusted Stage Length & 15 & 21 & 18 & 6 & 60 & \\
\hline \multicolumn{7}{|l|}{ Cabbage early } \\
\hline Stage Length & 40 & 60 & 50 & 15 & 165 & California Desert \\
\hline Adjusted Stage Length & 20 & 31 & 26 & 8 & 85 & \\
\hline \multicolumn{7}{|l|}{ Cabbage late } \\
\hline Stage Length & 40 & 60 & 50 & 15 & 165 & California Desert \\
\hline Adjusted Stage Length & 20 & 31 & 26 & 8 & 85 & \\
\hline \multicolumn{7}{|l|}{ Celery early } \\
\hline Stage Length & 30 & 55 & 105 & 20 & 210 & Semi Arid \\
\hline Adjusted Stage Length & 18 & 33 & 62 & 12 & 125 & \\
\hline \multicolumn{7}{|l|}{ Celery late } \\
\hline Stage Length & 25 & 40 & 95 & 20 & 180 & Semi Arid \\
\hline Adjusted Stage Length & 17 & 28 & 66 & 14 & 125 & \\
\hline \multicolumn{7}{|l|}{ Broccoli early } \\
\hline Stage Length & 35 & 45 & 40 & 15 & 135 & California Desert \\
\hline Adjusted Stage Length & 21 & 26 & 24 & 9 & 80 & \\
\hline
\end{tabular}


Table D-3. Length (Days) of Four Crop Growth Stages and Total Growing Season for Present-Day and Upper Bound Monsoon Climate Conditions (Continued)

\begin{tabular}{|c|c|c|c|c|c|c|}
\hline Crop & Initial & Dev & Mid & Late & $\begin{array}{l}\text { Season } \\
\text { Length }\end{array}$ & Region $^{a}$ \\
\hline \multicolumn{7}{|l|}{ Broccoli late } \\
\hline Stage Length & 35 & 45 & 40 & 15 & 135 & California Desert \\
\hline Adjusted Stage Length & 21 & 26 & 24 & 9 & 80 & \\
\hline \multicolumn{7}{|l|}{ Cauliflower early } \\
\hline Stage Length & 35 & 50 & 40 & 15 & 140 & California Desert \\
\hline Adjusted Stage Length & 20 & 29 & 23 & 8 & 80 & \\
\hline \multicolumn{7}{|l|}{ Cauliflower late } \\
\hline Stage Length & 35 & 50 & 40 & 15 & 140 & California Desert \\
\hline Adjusted Stage Length & 20 & 29 & 23 & 8 & 80 & \\
\hline \multicolumn{7}{|l|}{ Spinach early } \\
\hline Stage Length & 20 & 30 & 40 & 10 & 100 & Arid Region \\
\hline Adjusted Stage Length & 10 & 15 & 20 & 5 & 50 & \\
\hline \multicolumn{7}{|l|}{ Spinach late } \\
\hline Stage Length & 20 & 30 & 40 & 10 & 100 & Arid Region \\
\hline Adjusted Stage Length & 10 & 15 & 20 & 5 & 50 & \\
\hline \multicolumn{7}{|l|}{ Potatoes } \\
\hline Stage Length & 30 & 35 & 50 & 25 & 140 & California Desert \\
\hline Adjusted Stage Length & 24 & 27 & 39 & 20 & 110 & \\
\hline \multicolumn{7}{|l|}{ Onions early } \\
\hline Stage Length & 20 & 35 & 110 & 45 & 210 & Arid Region; CA \\
\hline Adjusted Stage Length & 10 & 18 & 58 & 24 & 110 & \\
\hline \multicolumn{7}{|l|}{ Onions late } \\
\hline Stage Length & 20 & 35 & 110 & 45 & 210 & Arid Region; CA \\
\hline Adjusted Stage Length & 10 & 18 & 58 & 24 & 110 & \\
\hline \multicolumn{7}{|l|}{ Carrots early } \\
\hline Stage Length & 30 & 50 & 90 & 30 & 200 & California Desert \\
\hline Adjusted Stage Length & 11 & 19 & 34 & 11 & 75 & \\
\hline \multicolumn{7}{|l|}{ Carrots late } \\
\hline Stage Length & 30 & 50 & 90 & 30 & 200 & California Desert \\
\hline Adjusted Stage Length & 11 & 19 & 34 & 11 & 75 & \\
\hline \multicolumn{7}{|l|}{ Sweet corn } \\
\hline Stage Length & 20 & 40 & 70 & 10 & 140 & California Desert \\
\hline Adjusted Stage Length & 12 & 23 & 41 & 6 & 82 & \\
\hline \multicolumn{7}{|l|}{ Bell peppers } \\
\hline Stage Length & 30 & 40 & 110 & 30 & 210 & Arid Region \\
\hline Adjusted Stage Length & 11 & 15 & 41 & 11 & 78 & \\
\hline \multicolumn{7}{|l|}{ Cucumbers } \\
\hline Stage Length & 20 & 30 & 40 & 15 & 105 & Arid Region \\
\hline Adjusted Stage Length & 11 & 17 & 23 & 9 & 60 & \\
\hline \multicolumn{7}{|l|}{ Zucchini Squash } \\
\hline Stage Length & 25 & 35 & 25 & 15 & 100 & Arid Region \\
\hline Adjusted Stage Length & 15 & 20 & 14 & 9 & 58 & \\
\hline
\end{tabular}


Table D-3. Length (Days) of Four Crop Growth Stages and Total Growing Season for Present-Day and Upper Bound Monsoon Climate Conditions (Continued)

\begin{tabular}{|c|c|c|c|c|c|c|}
\hline Crop & Initial & Dev & Mid & Late & $\begin{array}{l}\text { Season } \\
\text { Length }\end{array}$ & Region $^{a}$ \\
\hline \multicolumn{7}{|l|}{ Melons } \\
\hline Stage Length & 15 & 40 & 65 & 15 & 135 & California Desert \\
\hline Adjusted Stage Length & 11 & 30 & 48 & 11 & 100 & \\
\hline \multicolumn{7}{|l|}{ Tomatoes } \\
\hline Stage Length & 35 & 40 & 50 & 30 & 155 & California \\
\hline Adjusted Stage Length & 18 & 21 & 26 & 15 & 80 & \\
\hline \multicolumn{7}{|l|}{ Apples } \\
\hline Stage Length & 30 & 50 & 130 & 30 & 240 & California \\
\hline Adjusted Stage Length & 30 & 50 & 130 & 30 & 240 & \\
\hline \multicolumn{7}{|l|}{ Wine Grapes } \\
\hline Stage Length & 20 & 50 & 75 & 60 & 205 & California \\
\hline Adjusted Stage Length & 18 & 45 & 67 & 53 & 183 & \\
\hline \multicolumn{7}{|l|}{ Strawberries } \\
\hline Stage Length & 20 & 50 & 75 & 60 & 205 & California \\
\hline Adjusted Stage Length & 20 & 50 & 75 & 60 & 205 & \\
\hline \multicolumn{7}{|l|}{ Winter Wheat } \\
\hline Stage Length & 20 & 60 & 70 & 30 & 180 & California \\
\hline Adjusted Stage Length & 27 & 81 & 94 & 41 & 243 & \\
\hline \multicolumn{7}{|l|}{ Barley } \\
\hline Stage Length & 20 & 50 & 60 & 30 & 160 & California Desert \\
\hline Adjusted Stage Length & 30 & 76 & 91 & 46 & 243 & \\
\hline \multicolumn{7}{|l|}{ Corn-feed } \\
\hline Stage Length & 25 & 40 & 45 & 30 & 140 & Arid Region \\
\hline Adjusted Stage Length & 27 & 44 & 50 & 33 & 154 & \\
\hline \multicolumn{7}{|l|}{ Oats } \\
\hline Stage Length & 20 & 50 & 60 & 30 & 160 & California \\
\hline Adjusted Stage Length & 20 & 50 & 60 & 30 & 160 & \\
\hline \multicolumn{7}{|l|}{ Alfalfa hay (1st cutting) } \\
\hline Stage Length & 10 & 20 & 20 & 10 & 60 & California \\
\hline Adjusted Stage Length & 10 & 20 & 20 & 10 & 60 & \\
\hline \multicolumn{7}{|l|}{ Alfalfa hay (2nd cutting) } \\
\hline Stage Length & 5 & 10 & 10 & 5 & 30 & California \\
\hline Adjusted Stage Length & 9 & 18 & 18 & 10 & 55 & \\
\hline \multicolumn{7}{|l|}{ Alfalfa hay (3rd cutting) } \\
\hline Stage Length & 5 & 10 & 10 & 5 & 30 & California \\
\hline Adjusted Stage Length & 9 & 18 & 18 & 10 & 55 & \\
\hline \multicolumn{7}{|l|}{ Alfalfa hay (4th cutting) } \\
\hline Stage Length & 5 & 10 & 10 & 5 & 30 & California \\
\hline Adjusted Stage Length & 9 & 18 & 18 & 10 & 55 & \\
\hline \multicolumn{7}{|l|}{ Alfalfa hay (5th cutting) } \\
\hline Stage Length & 5 & 10 & 10 & 5 & 30 & California \\
\hline Adjusted Stage Length & 9 & 18 & 18 & 10 & 55 & \\
\hline
\end{tabular}


Table D-3. Length (Days) of Four Crop Growth Stages and Total Growing Season for Present-Day and Upper Bound Monsoon Climate Conditions (Continued)

\begin{tabular}{|c|c|c|c|c|c|c|}
\hline Crop & Initial & Dev & Mid & Late & $\begin{array}{l}\text { Season } \\
\text { Length }\end{array}$ & Region $^{\mathrm{a}}$ \\
\hline \multicolumn{7}{|l|}{ Alfalfa hay (6th cutting) } \\
\hline Stage Length & 5 & 10 & 10 & 5 & 30 & California \\
\hline Adjusted Stage Length & 9 & 18 & 18 & 10 & 55 & \\
\hline \multicolumn{7}{|l|}{ Corn silage } \\
\hline Stage Length & 25 & 40 & 45 & 30 & 140 & Arid Region \\
\hline Adjusted Stage Length & 17 & 26 & 30 & 20 & 93 & \\
\hline \multicolumn{7}{|l|}{ Oat hay } \\
\hline Stage Length & 20 & 50 & 60 & 30 & 160 & California Desert \\
\hline Adjusted Stage Length & 9 & 24 & 28 & 14 & 75 & \\
\hline
\end{tabular}

${ }^{a}$ Geographic region from which growth stage and season lengths were determined (Source: Allen et al. 1998 [DIRS 157311], Table 11, pp. 104 to108).

b Source: Allen et al. (1998 [DIRS 157311], Table 11, pp. 104 to 108).

${ }^{\mathrm{C}}$ Stage lengths adjusted from Allen et al. (1998 ([DIRS 157311]) according to Appendix D, Section 2.2).

Note: Initial $=$ initial crop growth stage, $\mathrm{Dev}=$ development stage, $\mathrm{Mid}=$ mid-season stage, and Late $=$ late season stage.

Table D-4. Length (Days) of Crop Growth Stages and Total Growing Season for Lower and Upper Bound Glacial Transition Climate Conditions

\begin{tabular}{|c|c|c|c|c|c|c|}
\hline Crop & Initial & Dev & Mid & Late & $\begin{array}{l}\text { Season } \\
\text { Length }\end{array}$ & Region $^{a}$ \\
\hline \multicolumn{7}{|l|}{ Leaf Lettuce early } \\
\hline Stage Length $^{\mathrm{b}}$ & 20 & 30 & 15 & 10 & 75 & Mediterranean \\
\hline Adjusted Stage Length ${ }^{c}$ & 15 & 23 & 12 & 8 & 58 & \\
\hline \multicolumn{7}{|l|}{ Leaf Lettuce late } \\
\hline Stage Length & 20 & 30 & 15 & 10 & 75 & Mediterranean \\
\hline Adjusted Stage Length & 15 & 23 & 12 & 8 & 58 & \\
\hline \multicolumn{7}{|l|}{ Head Lettuce early } \\
\hline Stage Length & 20 & 30 & 15 & 10 & 75 & Mediterranean \\
\hline Adjusted Stage Length & 21 & 31 & 16 & 10 & 78 & \\
\hline \multicolumn{7}{|l|}{ Head Lettuce late } \\
\hline Stage Length & 20 & 30 & 15 & 10 & 75 & Mediterranean \\
\hline Adjusted Stage Length & 21 & 31 & 16 & 10 & 78 & \\
\hline \multicolumn{7}{|l|}{ Cabbage early } \\
\hline Stage Length & 40 & 60 & 50 & 15 & 165 & California Desert \\
\hline Adjusted Stage Length & 18 & 27 & 23 & 7 & 75 & \\
\hline \multicolumn{7}{|l|}{ Cabbage late } \\
\hline Stage Length & 40 & 60 & 50 & 15 & 165 & California Desert \\
\hline Adjusted Stage Length & 18 & 27 & 23 & 7 & 75 & \\
\hline \multicolumn{7}{|l|}{ Celery } \\
\hline Stage Length & 25 & 40 & 45 & 15 & 125 & Mediterranean \\
\hline Adjusted Stage Length & 22 & 35 & 40 & 13 & 110 & \\
\hline
\end{tabular}


Table D-4. Length (Days) of Crop Growth Stages and Total Growing Season for Lower and Upper Bound Glacial Transition Climate Conditions (Continued)

\begin{tabular}{|c|c|c|c|c|c|c|}
\hline Crop & Initial & Dev & Mid & Late & $\begin{array}{l}\text { Season } \\
\text { Length }\end{array}$ & Region $^{a}$ \\
\hline \multicolumn{7}{|l|}{ Broccoli early } \\
\hline Stage Length & 35 & 45 & 40 & 15 & 135 & California Desert \\
\hline Adjusted Stage Length & 21 & 28 & 25 & 9 & 83 & \\
\hline \multicolumn{7}{|l|}{ Broccoli late } \\
\hline Stage Length & 35 & 45 & 40 & 15 & 135 & California Desert \\
\hline Adjusted Stage Length & 21 & 28 & 25 & 9 & 83 & \\
\hline \multicolumn{7}{|l|}{ Cauliflower early } \\
\hline Stage Length & 35 & 50 & 40 & 15 & 140 & California Desert \\
\hline Adjusted Stage Length & 16 & 22 & 18 & 7 & 63 & \\
\hline \multicolumn{7}{|l|}{ Cauliflower late } \\
\hline Stage Length & 35 & 50 & 40 & 15 & 140 & California Desert \\
\hline Adjusted Stage Length & 16 & 22 & 18 & 7 & 63 & \\
\hline \multicolumn{7}{|l|}{ Spinach early } \\
\hline Stage Length & 20 & 20 & 20 & 5 & 65 & Mediterranean \\
\hline Adjusted Stage Length & 17 & 17 & 17 & 4 & 55 & \\
\hline \multicolumn{7}{|l|}{ Spinach late } \\
\hline Stage Length & 20 & 20 & 20 & 5 & 65 & Mediterranean \\
\hline Adjusted Stage Length & 17 & 17 & 17 & 4 & 55 & \\
\hline \multicolumn{7}{|l|}{ Potatoes } \\
\hline Stage Length & 45 & 30 & 70 & 20 & 165 & Idaho \\
\hline Adjusted Stage Length & 31 & 21 & 49 & 14 & 115 & \\
\hline \multicolumn{7}{|l|}{ Onions } \\
\hline Stage Length & 15 & 25 & 70 & 40 & 150 & Mediterranean \\
\hline Adjusted Stage Length & 16 & 26 & 72 & 41 & 155 & \\
\hline \multicolumn{7}{|l|}{ Carrots early } \\
\hline Stage Length & 30 & 40 & 60 & 20 & 150 & Mediterranean \\
\hline Adjusted Stage Length & 16 & 21 & 32 & 11 & 80 & \\
\hline \multicolumn{7}{|l|}{ Carrots late } \\
\hline Stage Length & 30 & 40 & 60 & 20 & 150 & Mediterranean \\
\hline Adjusted Stage Length & 16 & 21 & 32 & 11 & 80 & \\
\hline \multicolumn{7}{|l|}{ Sweet corn } \\
\hline Stage Length & 20 & 25 & 25 & 10 & 80 & Mediterranean \\
\hline Adjusted Stage Length & 26 & 33 & 33 & 13 & 105 & \\
\hline \multicolumn{7}{|l|}{ Bell peppers } \\
\hline Stage Length & 30 & 35 & 40 & 20 & 125 & Europe and Med. \\
\hline Adjusted Stage Length & 24 & 28 & 32 & 16 & 100 & \\
\hline \multicolumn{7}{|l|}{ Cucumbers } \\
\hline Stage Length & 20 & 30 & 40 & 15 & 105 & Arid Region \\
\hline Adjusted Stage Length & 13 & 19 & 26 & 10 & 68 & \\
\hline \multicolumn{7}{|l|}{ Squash } \\
\hline Stage Length & 20 & 30 & 25 & 15 & 90 & Med; Europe \\
\hline Adjusted Stage Length & 14 & 22 & 18 & 11 & 65 & \\
\hline
\end{tabular}


Table D-4. Length (Days) of Crop Growth Stages and Total Growing Season for Lower and Upper Bound Glacial Transition Climate Conditions (Continued)

\begin{tabular}{|c|c|c|c|c|c|c|}
\hline Crop & Initial & Dev & Mid & Late & $\begin{array}{l}\text { Season } \\
\text { Length }\end{array}$ & Region $^{a}$ \\
\hline \multicolumn{7}{|l|}{ Melons } \\
\hline Stage Length & 25 & 35 & 40 & 20 & 120 & Mediterranean \\
\hline Adjusted Stage Length & 22 & 30 & 34 & 17 & 103 & \\
\hline \multicolumn{7}{|l|}{ Tomatoes } \\
\hline Stage Length & 30 & 40 & 45 & 30 & 145 & Mediterranean \\
\hline Adjusted Stage Length & 18 & 24 & 28 & 18 & 88 & \\
\hline \multicolumn{7}{|l|}{ Apples } \\
\hline Stage Length & 20 & 70 & 90 & 30 & 210 & High Latitudes \\
\hline Adjusted Stage Length & 16 & 55 & 71 & 24 & 166 & \\
\hline \multicolumn{7}{|l|}{ Wine Grapes } \\
\hline Stage Length & 20 & 50 & 90 & 20 & 180 & High Latitudes \\
\hline Adjusted Stage Length & 12 & 30 & 52 & 11 & 105 & \\
\hline \multicolumn{7}{|l|}{ Strawberries } \\
\hline Stage Length & 20 & 50 & 90 & 20 & 180 & High Latitudes \\
\hline Adjusted Stage Length & 7 & 18 & 32 & 7 & 64 & \\
\hline \multicolumn{7}{|l|}{ Winter wheat } \\
\hline Stage Length & 30 & 140 & 40 & 30 & 240 & Mediterranean \\
\hline Adjusted Stage Length & 42 & 195 & 55 & 42 & 334 & \\
\hline \multicolumn{7}{|l|}{ Barley } \\
\hline Stage Length & 20 & 25 & 60 & 30 & 135 & $35-45^{\circ} \mathrm{L}$ \\
\hline Adjusted Stage Length & 14 & 17 & 40 & 20 & 91 & \\
\hline \multicolumn{7}{|l|}{ Feed corn } \\
\hline Stage Length & 30 & 40 & 50 & 50 & 170 & Idaho \\
\hline Adjusted Stage Length & 32 & 42 & 52 & 52 & 178 & \\
\hline \multicolumn{7}{|l|}{ Oat Feed } \\
\hline Stage Length & 20 & 25 & 60 & 30 & 135 & $35-45^{\circ} \mathrm{L}$ \\
\hline Adjusted Stage Length & 21 & 26 & 63 & 31 & 141 & \\
\hline \multicolumn{7}{|l|}{ Alfalfa hay (1st cutting) } \\
\hline Stage Length & 10 & 30 & 25 & 10 & 75 & Idaho \\
\hline Adjusted Stage Length & 10 & 30 & 25 & 10 & 75 & \\
\hline \multicolumn{7}{|l|}{ Alfalfa hay (2nd cutting) } \\
\hline Stage Length & 5 & 20 & 10 & 10 & 45 & Idaho \\
\hline Adjusted Stage Length & 8 & 30 & 15 & 15 & 68 & \\
\hline \multicolumn{7}{|l|}{ Alfalfa hay (3rd cutting) } \\
\hline Stage Length & 5 & 20 & 10 & 10 & 45 & Idaho \\
\hline Adjusted Stage Length & 8 & 30 & 15 & 15 & 68 & \\
\hline \multicolumn{7}{|l|}{ Corn silage } \\
\hline Stage Length & 30 & 40 & 50 & 50 & 170 & Idaho \\
\hline Adjusted Stage Length & 24 & 32 & 40 & 41 & 137 & \\
\hline
\end{tabular}


Table D-4. Length (Days) of Crop Growth Stages and Total Growing Season for Lower and Upper Bound Glacial Transition Climate Conditions (Continued)

\begin{tabular}{|l|c|c|c|c|c|c|}
\hline \multicolumn{1}{|c|}{ Crop } & Initial & Dev & Mid & Late & $\begin{array}{c}\text { Season } \\
\text { Length }\end{array}$ & Region $^{\text {a }}$ \\
\hline Oat hay & 20 & 25 & 60 & 30 & 135 & $35-45^{\circ} \mathrm{L}$ \\
\hline Stage Length & 9 & 10 & 26 & 12 & 57 & \\
\hline Adjusted Stage Length & 9
\end{tabular}

${ }^{a}$ Geographic region from which growth stage and season lengths were determined (Source: Allen et al. 1998 [DIRS 157311], Table 11, pp. 104 to 108).

b Source: Allen et al. (1998 [DIRS 157311], Table 11, pp 104 to 108).

C Stage lengths adjusted from Allen et al. (1998 [DIRS 157311]) according to Appendix D, Section 2.2.

NOTE: Initial = initial crop growth stage, $\mathrm{Dev}=$ development stage, Mid $=$ mid-season stage, and Late $=$ late season stage.

\section{D3. $\mathrm{K}_{\mathrm{C}}$ CORRECTIONS}

Allen et al. (1998 [DIRS 157311], Table 12, pp. 110 to 114) published $K_{c}$ values for initial $\left(K_{c \text { ini }}\right)$, mid-season $\left(K_{c}\right.$ mid $)$, and end of the late season $\left(K_{c}\right.$ end $)$ growth stages for several crops. The values were developed for non-stressed, well-managed crops in subhumid climates (minimum relative humidity, $\left[R H_{\min }\right] \approx 45$ percent, wind speed $\left[u_{2}\right] \approx 2 \mathrm{~m} / \mathrm{s}$ ). When $R H_{\min }$ and $u_{2}$ ( $2 \mathrm{~m}$ above the surface) were different from the assumptions, the following recommended corrections for $K_{c}$ mid and $K_{c}$ end were used (Allen et al. 1998 [DIRS 157311], Equations 62 and 65 , pp. 121 and 125 , respectively):

$$
\begin{aligned}
& K_{c_{\text {mid }}}=K_{c_{\text {mid }(T a b)}}+\left[0.04\left(u_{2}-2\right)-0.004\left(R H_{\min }-45\right)\right]\left(\frac{h}{3}\right)^{0.3} \\
& K_{\text {cend }}=K_{c \text { end (Tab) }}+\left[0.04\left(u_{2}-2\right)-0.004\left(R H_{\text {min }}-45\right)\right]\left(\frac{h}{3}\right)^{0.3}
\end{aligned}
$$

where:

$K_{c \text { mid (Tab) }}$ or $K_{c \text { end (Tab) }}=K_{c \text { mid }}$ value (Equation D-2) or $K_{c}$ end value (Equation D-3) from Table 12 (Allen et al. 1998 [DIRS 157311], pp. 110 to 114),

$R H_{\min }=$ mean minimum $R H(\%)$ during the mid-season (Equation D-2) or late season (Equation D-3) growth stages,

$u_{2}=$ mean daily wind speed $\left(\mathrm{m} \mathrm{s}^{-1}\right)$ at $2 \mathrm{~m}$ during the mid-season (Equation D-2) or late season (Equation D-3) growth stages,

$h=$ mean plant height (m) during the mid-season (Equation D-2) or late season (Equation D-3) growth stages.

The following limitations to $R H, u_{2}$, and $h$ apply to Equations D-2 and D-3:

20 percent $\leq R H_{\min } \leq 80$ percent, 
$1 \mathrm{~m} \mathrm{~s}^{-1} \leq u_{2} \leq 6 \mathrm{~m} \mathrm{~s}^{-1}$, and

$0.1 \mathrm{~m} \leq h \leq 10 \mathrm{~m}$.

Additionally, Equation D-3 is only applied when $K_{c}$ end values from Table 12 (Allen et al. 1998 [DIRS 157311], pp. 110 to 114) exceed 0.45. This is because a $K_{c}$ end value of 0.45 or less indicates that the crop is allowed to senesce and dry in the field. In this case, $R H_{\min }$ and $u_{2}$ have little effect on $K_{c}$ end and no adjustment is necessary. Because the $K_{c}$ adjustments are based on site specific relative humidity and wind speed, adjustments were required for all climate states considered for annual average irrigation rate calculations.

For the present-day climate mean daily $u_{2}$ was greater than $2 \mathrm{~m} \mathrm{~s}^{-1}$ and less than $6 \mathrm{~m} \mathrm{~s}^{-1}$ for all months (Appendix C, Table C-5). $R H_{\min }$ was less than 45 percent for all months and less than 20 percent March through October (Section 4.15, Table 4.1-2). To meet the requirements for Equations D-2 and D-3 for March through October and still adjust approximately for local conditions, 20 percent was substituted for the recorded $R H_{\text {min. }}$. Adjustments for $K_{c}$ mid and $K_{c}$ end were required for all crops except grapes, oats, oat hay, feed corn, barley, and winter wheat which had $K_{c}$ end values less than 0.45 (Allen et al. 1998 [DIRS 157311], Table 12, pp. 110 to 114).

Minimum relative humidity was not available for the upper bound monsoon or lower bound glacial transition climates. To estimate $R H_{\text {min }}$ the following equation was used from Allen et al. (1998 [DIRS 157311], Equation 10, p. 35):

$$
R H=100 \frac{e_{a}}{e^{o}(T)}
$$

where

$$
\mathrm{T}=\mathrm{T}_{\max }
$$

Estimated $\mathrm{RH}_{\min }$ values for upper bound monsoon and lower bound glacial transition climates are in Table D-5.

Table D-5. Estimated Minimum Relative Humidity for Upper Bound Monsoon and Lower Bound Glacial Transition Climates

\begin{tabular}{|l|c|c|}
\hline \multicolumn{1}{|c|}{ Month } & $\begin{array}{c}\text { Upper Bound Monsoon Climate } \\
\mathbf{R H}_{\text {min }}(\mathbf{( \% )}\end{array}$ & $\begin{array}{c}\text { 'awer Bound Glacial } \\
\text { Transition Climate }^{\mathbf{2}}\end{array}$ \\
\hline January & 22.9 & 40.4 \\
\hline February & 22.9 & 37.9 \\
\hline March & 23.5 & 29.4 \\
\hline April & 22.2 & 26.6 \\
\hline May & 22.4 & 23.1 \\
\hline June & 23.4 & 17.1 \\
\hline July & 34.2 & 19.4 \\
\hline
\end{tabular}


Table D-5. Estimated Minimum Relative Humidity for Upper Bound Monsoon and Lower Bound Glacial Transition Climates (Continued)

\begin{tabular}{|c|c|c|}
\hline Month & $\begin{array}{l}\text { Upper Bound Monsoon Climate } \\
\qquad \mathbf{R H}_{\min }(\%)^{\mathrm{a}}\end{array}$ & $\begin{array}{c}\text { Lower Bound Glacial } \\
\text { Transition Climate } \\
\mathbf{R H}_{\min }(\%)^{\mathbf{a}}\end{array}$ \\
\hline August & 35.6 & 17.7 \\
\hline September & 29.3 & 19.4 \\
\hline October & 23.9 & 25.1 \\
\hline November & 22.0 & 35.9 \\
\hline December & 23.0 & 40.9 \\
\hline
\end{tabular}

For the upper bound monsoon climate, mean daily $u_{2}$ was greater than $2 \mathrm{~m} \mathrm{~s}^{-1}$ February through June and less than $6 \mathrm{~m} \mathrm{~s}^{-1}$ for all months (Table C-6). $R H_{\text {min }}$ was less than 45 percent and greater than 20 percent for all months (Table D-5). Therefore, the requirements of Equations D-2 and D-3 were met for all months. Adjustments for $K_{c \text { mid }}$ and $K_{c \text { end }}$ were required for all crops except grapes, oat hay, oat feed, feed corn, barley, and winter wheat which had $K_{c}$ end values less than 0.45 (Allen et al. 1998 [DIRS 157311], Table 12, pp. 110 to 114).

For the lower bound glacial transition climate, mean daily $u_{2}$ was greater than $2 \mathrm{~m} \mathrm{~s}^{-1}$ and less than $6 \mathrm{~m} \mathrm{~s}^{-1}$ for all months (Section 4.1.5, Table 4.1-4, and Appendix C Table C-7). $R H_{\min }$ was less than 45 percent for all months and less than 20 percent June through September (Table D-5). To meet the requirements for Equations D-2 and D-3 for June through September and still adjust approximately for local conditions, 20 percent was substituted for the recorded $R H_{\min }$. Adjustments for $K_{c}$ mid and $K_{c}$ end were required for all crops except grapes, oats, oat hay, feed corn, barley, and winter wheat which had $K_{c}$ end values less than 0.45 (Allen et al. 1998 [DIRS 157311], Table 12, pp. 110 to 114).

For the upper bound glacial transition climate, mean daily $u_{2}$ was greater than $2 \mathrm{~m} \mathrm{~s}^{-1}$ and less than $6 \mathrm{~m} \mathrm{~s}^{-1}$ for all months (Table C-8). $R H_{\text {min }}$ was less than 45 percent May through September and was 20 percent or greater for all months (Section 4.1.5, Table 4.1-5). Therefore, the requirements of Equations D-2 and D-3 were met for all months. Adjustments for $K_{c}$ mid and $K_{c}$ end were required for all crops except grapes, oat hay, oat feed, feed corn, barley, and winter wheat which had $K_{c}$ end values less than 0.45 (Allen et al. 1998 [DIRS 157311], Table 12, pp. 110 to 114$)$.

The adjustments to $K_{c \text { mid }}$ and $K_{c}$ end required mean plant height during the mid- and late season growing stages. Because the mid-season stage begins at effective full cover, it was reasonable to assume that plants had reached their maximum height at this time. No local data exists for crop heights so the maximum crop heights published in Allen et al. (1998 [DIRS 157311], Table 12, pp. 110 to 114) were used in the calculations, with the exception of wine grapes (see Tables D-6 through D-9). Those heights are listed in Tables D-6 through D-9. 
Example: The $K_{c}$ mid calculation for early leaf lettuce (present-day climate) requires the following:

$K_{c \text { mid }}=1.0$ (Allen et al. 1998 [DIRS 157311], Table 12, p. 110),

Stage length $=18$ days (Table D-3),

Stage $\operatorname{month}(\mathrm{s})=$ April $=18$ days $($ Table D-1 $)$

$R H_{\min }=13.7$ percent (Table $4.1-2$, required adjustment $=20$ percent $)$,

$u_{2}=3.5 \mathrm{~m} \mathrm{~s}^{-1}$ (Table C-5),

$h=0.3 \mathrm{~m}$ (Allen et al. 1998 [DIRS 157311], Table 12, p. 110, and Table D-6).

$$
K_{c \text { mid }}=1.0+[0.04(3.5-2)-0.004(20-45)]\left(\frac{0.3}{3}\right)^{0.3}=1.1
$$

The following inputs are required for $K_{c}$ end. The late stage growing period occurs in April and May. Values for both months must be considered.

$K_{c \text { end }}=0.95$ (Allen et al. 1998 [DIRS 157311], Table 12, p. 110),

Stage length $=6$ days $($ Table D-3),

Stage $\operatorname{month}(\mathrm{s})=$ April $=1$ day; May $=5$ days $($ Table D-1 $)$,

$R H_{\min }=$ April $=13.7$ percent; May $=14.1$ percent $($ Table $4.1-2$, required adjustment $=20$ percent),

$u_{2}=$ April $=3.5 \mathrm{~m} \mathrm{~s}^{-1} ;$ May $=3.4 \mathrm{~m} \mathrm{~s}^{-1}($ Table C-5),

$h=0.3 \mathrm{~m}$ (Allen et al. 1998 [DIRS 157311], Table 12, p. 110, and Table D-6).

Mean $R H_{\text {min }}=20$ percent

$$
\begin{gathered}
\text { Mean } u_{2}=\left(\frac{1}{6} \times 3.5\right)+\left(\frac{5}{6} \times 3.4\right)=3.4 \mathrm{~m} \mathrm{~s}^{-1} \\
K_{\text {cend }}=0.95+[0.04(3.4-2)-0.004(20-45)]\left(\frac{0.3}{3}\right)^{0.3}=1.08
\end{gathered}
$$

Adjusted $K_{c}$ values and maximum crop heights are in Tables D-6 through D-9. 
Table D-6. Adjusted Crop Coefficients $\left(\mathrm{K}_{\mathrm{c}}\right)$ and Maximum Crop Height for Early and Late Season Crops for Present-Day Climate Conditions

\begin{tabular}{|c|c|c|c|c|}
\hline Crop & $K_{c} \mathrm{ini}^{\mathrm{a}}$ & $K_{c \text { mid }}{ }^{b}$ & $K_{c}$ end $^{c}$ & Maximum Crop Height (m) \\
\hline Leaf Lettuce early & 0.70 & 1.08 & 1.03 & 0.3 \\
\hline Leaf Lettuce late & 0.70 & 1.07 & 1.02 & 0.3 \\
\hline Head Lettuce early & 0.70 & 1.08 & 1.03 & 0.3 \\
\hline Head Lettuce late & 0.70 & 1.07 & 1.02 & 0.3 \\
\hline Cabbage early & 0.70 & 1.14 & 1.04 & 0.4 \\
\hline Cabbage late & 0.70 & 1.12 & 1.02 & 0.4 \\
\hline Celery early & 0.70 & 1.15 & 1.10 & 0.6 \\
\hline Celery late & 0.70 & 1.12 & 1.04 & 0.6 \\
\hline Broccoli early & 0.70 & 1.13 & 1.03 & 0.3 \\
\hline Broccoli late & 0.70 & 1.12 & 1.01 & 0.3 \\
\hline Cauliflower early & 0.70 & 1.14 & 1.04 & 0.4 \\
\hline Cauliflower late & 0.70 & 1.13 & 1.02 & 0.4 \\
\hline Spinach early & 0.70 & 1.08 & 1.03 & 0.3 \\
\hline Spinach late & 0.70 & 1.07 & 1.01 & 0.3 \\
\hline Potatoes & 0.50 & 1.25 & 0.85 & 0.6 \\
\hline Onions early & 0.70 & 1.14 & 0.84 & 0.4 \\
\hline Onions late & 0.70 & 1.12 & 0.80 & 0.4 \\
\hline Carrots early & 0.70 & 1.13 & 1.03 & 0.3 \\
\hline Carrots late & 0.70 & 1.12 & 1.01 & 0.3 \\
\hline Sweet corn & 0.30 & 1.28 & 1.18 & 1.5 \\
\hline Bell peppers & 0.60 & 1.16 & 1.00 & 0.7 \\
\hline Cucumbers & 0.60 & 1.08 & 0.83 & 0.3 \\
\hline Squash & 0.50 & 1.03 & 0.83 & 0.3 \\
\hline Melons & 0.50 & 1.14 & 0.84 & 0.4 \\
\hline Tomatoes $^{\mathrm{e}}$ & 0.60 & 1.25 & 0.90 & 0.6 \\
\hline Apples & 0.60 & 1.12 & 0.91 & 4.0 \\
\hline Wine Grapes & 0.30 & 0.83 & 0.45 & 1.5 \\
\hline Strawberries & 0.40 & 0.92 & 0.82 & 0.2 \\
\hline Winter wheat & 0.70 & 1.25 & 0.25 & 1.0 \\
\hline Barley & 0.30 & 1.25 & 0.25 & 1.0 \\
\hline Feed Corn ${ }^{f}$ & 0.30 & 1.34 & 0.35 & 2.0 \\
\hline Oats & 0.30 & 1.26 & 0.25 & 1.0 \\
\hline Alfalfa hay ( $1^{\text {st }}$ cutting) & 0.40 & 1.28 & 1.23 & 0.7 \\
\hline Alfalfa hay ( $2^{\text {nd }}$ cutting) & 0.40 & 1.30 & 1.25 & 0.7 \\
\hline Alfalfa hay ( $3^{\text {rd }}$ cutting) & 0.40 & 1.30 & 1.26 & 0.7 \\
\hline Alfalfa hay ( $4^{\text {th }}$ cutting) & 0.40 & 1.30 & 1.25 & 0.7 \\
\hline Alfalfa hay ( $5^{\text {th }}$ cutting) & 0.40 & 1.30 & 1.24 & 0.7 \\
\hline
\end{tabular}


Table D-6. Adjusted Crop Coefficients $\left(\mathrm{K}_{\mathrm{c}}\right)$ and Maximum Crop Height for Early and Late Season Crops for Present-Day Climate Conditions (Continued)

\begin{tabular}{|c|c|c|c|c|}
\hline Crop & $K_{c}$ ini $^{\mathrm{a}}$ & $K_{c \text { mid }}{ }^{b}$ & $K_{c}$ end $^{\mathrm{c}}$ & Maximum Crop Height $(m)^{d}$ \\
\hline Alfalfa hay ( $6^{\text {th }}$ cutting $)$ & 0.40 & 1.28 & 1.23 & 0.7 \\
\hline Oat hay & 0.30 & 1.26 & 0.25 & 1.0 \\
\hline Corn silage $^{g}$ & 0.30 & 1.34 & 0.74 & 2.0 \\
\hline
\end{tabular}

${ }^{\text {a }} K_{c}$ values for the initial growth stage. Source: Allen et al. (1998 [DIRS 157311], Table 12, pp. 110 to 114).

${ }^{\mathrm{b}} K_{c}$ values for the mid-season growth stage adjusted from Allen et al. (1998 [DIRS 157311], Equation 62 , p. 121) according to Equation D-2.

${ }^{\mathrm{C}} \mathrm{K} C$ values for the end of the late season growth stage adjusted from Allen et al. (1998 [DIRS 157311], Equation 65, p. 125) according to Equation D-3.

d Source: Allen et al. (1998 [DIRS 157311], Table 12, pp. 110 to 114).

e Midpoint of the range for $\mathrm{K}_{\mathrm{c} \text { end }}(0.8)$ was used.

${ }^{f} K_{c}$ end for dry harvest was used.

${ }^{g} K_{c \text { end }}$ for wet harvest was used.

Table D-7. Adjusted Crop Coefficients $\left(K_{c}\right)$ and Maximum Crop Height for Early and Late Season Crops for Upper Bound Monsoon Climate Conditions

\begin{tabular}{|c|c|c|c|c|}
\hline Crop & $K_{c i n i}{ }^{a}$ & $K_{c \text { mid }}^{b}$ & $K_{c}$ end ${ }^{c}$ & Maximum Crop Height $(\mathrm{m})^{\mathrm{d}}$ \\
\hline Leaf Lettuce early & 0.70 & 1.05 & 1.00 & 0.3 \\
\hline Leaf Lettuce late & 0.70 & 1.04 & 0.99 & 0.3 \\
\hline Head Lettuce early & 0.70 & 1.05 & 1.00 & 0.3 \\
\hline Head Lettuce late & 0.70 & 1.04 & 0.99 & 0.3 \\
\hline Cabbage early & 0.70 & 1.11 & 1.01 & 0.4 \\
\hline Cabbage late & 0.70 & 1.09 & 0.99 & 0.4 \\
\hline Celery early & 0.70 & 1.09 & 1.01 & 0.6 \\
\hline Celery late & 0.70 & 1.09 & 1.04 & 0.6 \\
\hline Broccoli early & 0.70 & 1.10 & 1.00 & 0.3 \\
\hline Broccoli late & 0.70 & 1.09 & 0.98 & 0.3 \\
\hline Cauliflower early & 0.70 & 1.05 & 1.01 & 0.4 \\
\hline Cauliflower late & 0.70 & 1.09 & 0.99 & 0.4 \\
\hline Spinach early & 0.70 & 1.05 & 1.00 & 0.3 \\
\hline Spinach late & 0.70 & 1.04 & 0.98 & 0.3 \\
\hline Potatoes & 0.50 & 1.21 & 0.78 & 0.6 \\
\hline Onions early & 0.70 & 1.10 & 0.78 & 0.4 \\
\hline Onions late & 0.70 & 1.09 & 0.79 & 0.4 \\
\hline Carrots early & 0.70 & 1.10 & 1.00 & 0.3 \\
\hline Carrots late & 0.70 & 1.09 & 0.99 & 0.3 \\
\hline Sweet corn & 0.30 & 1.21 & 1.08 & 1.5 \\
\hline Bell peppers & 0.60 & 1.10 & 0.92 & 0.7 \\
\hline Cucumbers & 0.60 & 1.02 & 0.77 & 0.3 \\
\hline Squash & 0.50 & 0.99 & 0.77 & 0.3 \\
\hline Melons & 0.50 & 1.07 & 0.76 & 0.4 \\
\hline Tomatoes $^{\mathrm{e}}$ & 0.60 & 1.19 & 0.82 & 0.6 \\
\hline
\end{tabular}


Table D-7. Adjusted Crop Coefficients $\left(K_{c}\right)$ and Maximum Crop Height for Early and Late Season Crops for Upper Bound Monsoon Climate Conditions (Continued)

\begin{tabular}{|c|c|c|c|c|}
\hline Crop & $K_{c \text { ini }}{ }^{a}$ & $K_{c \text { mid }}{ }^{b}$ & $K_{c}$ end $^{\mathrm{c}}$ & Maximum Crop Height $(m)^{d}$ \\
\hline Apples & 0.60 & 1.01 & 0.83 & 4.0 \\
\hline Wine Grapes & 0.30 & 0.77 & 0.45 & 1.5 \\
\hline Strawberries & 0.40 & 0.88 & 0.76 & 0.2 \\
\hline Winter wheat & 0.70 & 1.22 & 0.25 & 1.0 \\
\hline Barley & 0.30 & 1.22 & 0.25 & 1.0 \\
\hline Feed Corn ${ }^{f}$ & 0.30 & 1.23 & 0.35 & 2.0 \\
\hline Oats & 0.30 & 1.22 & 0.25 & 1.0 \\
\hline Alfalfa hay $\left(1^{\text {st }}\right.$ cutting $)$ & 0.40 & 1.26 & 1.21 & 0.7 \\
\hline Alfalfa hay $\left(2^{\text {nd }}\right.$ cutting $)$ & 0.40 & 1.26 & 1.21 & 0.7 \\
\hline Alfalfa hay (3rd cutting) & 0.40 & 1.26 & 1.18 & 0.7 \\
\hline Alfalfa hay (4th cutting) & 0.40 & 1.22 & 1.16 & 0.7 \\
\hline Alfalfa hay (5th cutting) & 0.40 & 1.23 & 1.20 & 0.7 \\
\hline Alfalfa hay (6th cutting) & 0.40 & 1.24 & 1.20 & 0.7 \\
\hline Oat hay & 0.30 & 1.22 & 0.25 & 1.0 \\
\hline Corn silage $\mathrm{e}^{\mathrm{g}}$ & 0.30 & 1.24 & 0.62 & 2.0 \\
\hline
\end{tabular}

${ }^{a} K_{c}$ values for the initial growth stage. Source: Allen et al. (1998 [DIRS 157311], Table 12, pp. 110 to 114).

${ }^{b} K_{c}$ values for the mid-season growth stage adjusted from Allen et al. 1998 ([DIRS 157311], Equation 62, p. 121) according to Equation D-2.

${ }^{c} K_{c}$ values for the end of the late season growth stage adjusted from Allen et al. (1998 [DIRS 157311], Equation 65, p. 125) according to Equation D-3.

d Source: Allen et al. 1998 ([DIRS 157311], Table 12, pp. 110 to 114).

e Midpoint of the range for Kc end (0.8) was used.

${ }^{f} K_{c}$ end for dry harvest was used.

${ }^{g} K_{c}$ end for wet harvest was used.

Table D-8. Adjusted Crop Coefficients $\left(K_{c}\right)$ and Maximum Crop Height for Early and Late Season Crops for Lower Bound Glacial Transition Climate Conditions

\begin{tabular}{|l|c|c|c|c|}
\hline \multicolumn{1}{|c|}{ Crop } & $\boldsymbol{K}_{\boldsymbol{c} \text { ini }}{ }^{\mathrm{a}}$ & $\boldsymbol{K}_{\boldsymbol{c} \text { } \text { mid }^{\mathbf{b}}}$ & $\boldsymbol{K}_{\boldsymbol{c} \text { end }}{ }^{\mathbf{c}}$ & ${\text { Maximum Crop Height }(\mathbf{m})^{\mathbf{d}}}$ \\
\hline Leaf Lettuce early & 0.70 & 1.09 & 1.04 & 0.3 \\
\hline Leaf Lettuce late & 0.70 & 1.08 & 1.03 & 0.3 \\
\hline Head Lettuce early & 0.70 & 1.09 & 1.04 & 0.3 \\
\hline Head Lettuce late & 0.70 & 1.08 & 1.03 & 0.3 \\
\hline Cabbage early & 0.70 & 1.15 & 1.05 & 0.4 \\
\hline Cabbage late & 0.70 & 1.13 & 1.03 & 0.4 \\
\hline Spinach early & 0.70 & 1.09 & 1.04 & 0.3 \\
\hline Spinach late & 0.70 & 1.08 & 1.02 & 0.3 \\
\hline Celery & 0.70 & 1.16 & 1.10 & 0.6 \\
\hline Broccoli early & 0.70 & 1.14 & 1.04 & 0.3 \\
\hline Broccoli late & 0.70 & 1.13 & 1.02 & 0.3 \\
\hline Cauliflower early & 0.70 & 1.15 & 1.05 & 0.4 \\
\hline Cauliflower late & 0.70 & 1.13 & 1.03 & 0.4 \\
\hline Potatoes & 0.50 & 1.26 & 0.85 & 0.6 \\
\hline Onions & 0.70 & 1.14 & 0.85 & 0.4 \\
\hline Carrots early & 0.70 & 1.14 & 1.04 & 0.3 \\
\hline
\end{tabular}


Table D-8. Adjusted Crop Coefficients $\left(K_{c}\right)$ and Maximum Crop Height for Early and Late Season Crops for Lower Bound Glacial Transition Climate Conditions (Continued)

\begin{tabular}{|c|c|c|c|c|}
\hline Crop & $K_{c i n i}{ }^{a}$ & $K_{c \text { mid }}{ }^{b}$ & $K_{c}$ end ${ }^{c}$ & Maximum Crop Height $(m)^{d}$ \\
\hline Carrots late & 0.70 & 1.13 & 1.03 & 0.3 \\
\hline Sweet Corn & 0.30 & 1.29 & 1.18 & 1.5 \\
\hline Bell peppers & 0.60 & 1.16 & 1.00 & 0.7 \\
\hline Cucumbers & 0.60 & 1.09 & 0.84 & 0.3 \\
\hline Squash & 0.50 & 1.04 & 0.84 & 0.3 \\
\hline Melons & 0.50 & 1.14 & 0.84 & 0.4 \\
\hline Tomatoes $^{\mathrm{e}}$ & 0.60 & 1.26 & 0.90 & 0.6 \\
\hline Alfalfa hay (1st cutting) & 0.40 & 1.30 & 1.26 & 0.7 \\
\hline Alfalfa hay (2nd cutting) & 0.40 & 1.32 & 1.27 & 0.7 \\
\hline Alfalfa hay (3rd cutting) & 0.40 & 1.30 & 1.25 & 0.7 \\
\hline Apples & 0.45 & 1.14 & 0.86 & 4.0 \\
\hline Wine Grapes & 0.30 & 0.84 & 0.45 & 1.75 \\
\hline Strawberries & 0.40 & 0.93 & 0.83 & 0.2 \\
\hline Winter wheat & 0.40 & 1.28 & 0.25 & 1.0 \\
\hline Barley & 0.30 & 1.28 & 0.25 & 1.0 \\
\hline Oats & 0.30 & 1.28 & 0.25 & 1.0 \\
\hline Feed Corn ${ }^{f}$ & 0.30 & 1.35 & 0.35 & 2.0 \\
\hline Corn silage $^{g}$ & 0.30 & 1.36 & 0.74 & 2.0 \\
\hline Oat hay & 0.30 & 1.28 & 0.25 & 1.0 \\
\hline
\end{tabular}

${ }^{a} K_{c}$ values for the initial growth stage. Source: Allen et al. (1998 [DIRS 157311], Table 12, pp. 110 to 114).

b $K_{c}$ values for the mid-season growth stage adjusted from Allen et al. (1998 [DIRS 157311], Equation 62, p. 121) according to Equation D-2.

${ }^{c} K c$ values for the end of the late season growth stage adjusted from Allen et al. (1998 [DIRS 157311], Equation 65, p. 125) according to Equation D-3.

d Source: Allen et al. (1998 [DIRS 157311], Table 12, pp. 110 to 114).

e Midpoint of the range for $\mathrm{K}_{\mathrm{c} \text { end }}$ was used.

${ }^{f} K_{c}$ end for dry harvest was used.

${ }^{g} K_{c}$ end for wet harvest was used.

Table D-9. Adjusted Crop Coefficients $\left(K_{c}\right)$ and Maximum Crop Height for Early and Late Season Crops for Upper Bound Glacial Transition Climate Conditions

\begin{tabular}{|l|c|c|c|c|}
\hline \multicolumn{1}{|c|}{ Crop } & $\boldsymbol{K}_{\boldsymbol{c} \text { ini }}{ }^{\mathbf{a}}$ & $\boldsymbol{K}_{\boldsymbol{c} \text { mid }}{ }^{\mathbf{b}}$ & $\boldsymbol{K}_{\boldsymbol{c} \text { end }}{ }^{\mathbf{c}}$ & ${\text { Maximum Crop Height }(\mathbf{m})^{\mathbf{d}}}$ \\
\hline Leaf Lettuce early & 0.70 & 1.04 & 0.99 & 0.3 \\
\hline Leaf Lettuce late & 0.70 & 1.05 & 0.99 & 0.3 \\
\hline Head Lettuce early & 0.70 & 1.04 & 1.00 & 0.3 \\
\hline Head Lettuce late & 0.70 & 1.04 & 0.99 & 0.3 \\
\hline Cabbage early & 0.70 & 1.09 & 1.00 & 0.4 \\
\hline Cabbage late & 0.70 & 1.09 & 0.99 & 0.4 \\
\hline Spinach early & 0.70 & 1.04 & 0.99 & 0.3 \\
\hline Spinach late & 0.70 & 1.04 & 0.98 & 0.3 \\
\hline Celery & 0.70 & 1.11 & 1.06 & 0.6 \\
\hline Broccoli early & 0.70 & 1.09 & 1.00 & 0.3 \\
\hline Broccoli late & 0.70 & 1.09 & 0.96 & 0.3 \\
\hline
\end{tabular}


Table D-9. Adjusted Crop Coefficients $\left(K_{c}\right)$ and Maximum Crop Height for Early and Late Season Crops for Upper Bound Glacial Transition Climate Conditions (Continued)

\begin{tabular}{|c|c|c|c|c|}
\hline Crop & $K_{c \text { ini }}{ }^{a}$ & $K_{c \text { mid }}{ }^{b}$ & $K_{c}$ end $^{\mathrm{c}}$ & Maximum Crop Height $(m)^{d}$ \\
\hline Cauliflower early & 0.70 & 1.09 & 0.99 & 0.4 \\
\hline Cauliflower late & 0.70 & 1.09 & 0.99 & 0.4 \\
\hline Potatoes & 0.50 & 1.21 & 0.81 & 0.6 \\
\hline Onions & 0.70 & 1.09 & 0.80 & 0.4 \\
\hline Carrots early & 0.70 & 1.09 & 1.00 & 0.3 \\
\hline Carrots late & 0.70 & 1.09 & 0.99 & 0.3 \\
\hline Sweet Corn & 0.30 & 1.24 & 1.13 & 1.5 \\
\hline Bell peppers & 0.60 & 1.11 & 0.95 & 0.7 \\
\hline Cucumbers & 0.60 & 1.05 & 0.80 & 0.3 \\
\hline Squash & 0.50 & 1.00 & 0.80 & 0.3 \\
\hline Melons & 0.50 & 1.10 & 0.80 & 0.4 \\
\hline Tomatoes $^{\mathrm{e}}$ & 0.60 & 1.21 & 0.86 & 0.6 \\
\hline Alfalfa hay $\left(1^{\text {st }}\right.$ cutting $)$ & 0.40 & 1.24 & 1.19 & 0.7 \\
\hline Alfalfa hay (2nd cutting) & 0.40 & 1.26 & 1.21 & 0.7 \\
\hline Alfalfa hay (3rd cutting) & 0.40 & 1.25 & 1.20 & 0.7 \\
\hline Apples & 0.45 & 1.05 & 0.77 & 4.0 \\
\hline Wine Grapes & 0.30 & 0.78 & 0.45 & 1.75 \\
\hline Strawberries & 0.40 & 0.89 & 0.80 & 0.2 \\
\hline Winter wheat & 0.40 & 1.20 & 0.25 & 1.0 \\
\hline Barley & 0.30 & 1.20 & 0.25 & 1.0 \\
\hline Oats & 0.30 & 1.21 & 0.25 & 1.0 \\
\hline Feed Corn ${ }^{f}$ & 0.30 & 1.28 & 0.35 & 2.0 \\
\hline Corn silage $^{g}$ & 0.30 & 1.29 & 0.67 & 2.0 \\
\hline Oat hay & 0.30 & 1.21 & 0.25 & 1.0 \\
\hline
\end{tabular}

${ }^{a} K_{c}$ values for the initial growth stage. Source: Allen et al. (1998 [DIRS 157311], Table 12, pp. 110 to 114).

${ }^{b} K_{c}$ values for the mid-season growth stage adjusted from Allen et al. (1998 [DIRS 157311], Equation 62, p. 121) according to Equation D-2.

${ }^{c} K_{c}$ values for the end of the late season growth stage adjusted from Allen et al. (1998 [DIRS 157311], Equation 65, p. 125) according to Equation D-3.

d Source: Allen et al. (1998 [DIRS 157311], Table 12, pp. 110 to 114).

e Midpoint of the range for $\mathrm{K}_{\mathrm{c} \text { end }}$ was used.

f $K_{c}$ end for dry harvest was used.

${ }^{g} K_{c}$ end for wet harvest was used. 


\section{D4. AVERAGE MONTHLY $K_{C}$ VALUES}

For $K_{c}$ values for different growth stages to correspond with mean monthly $E T_{o}$, it was necessary to calculate mean monthly $K_{c}$ for each crop. This was done by first identifying the months in which the four growth stages occurred using planting dates in Tables D-1 and D-2 and growth stage lengths in Tables D-3 and D-4. Months with overlapping growth stages were noted and the number of days in the month for each growth stage was recorded. $K_{c}$ curves were constructed according to Allen et al. (1998 [DIRS 157311], Figure 36, p. 132) to aide in determination of mean monthly values (Figure D-1). If the development or late stages were split across a month, the following equation was used to calculate $K_{c}$ for the day of the growth stage that ended the month:

$$
K_{c i}=K_{c \text { prev }}+\left[\frac{i-\sum\left(L_{\text {prev }}\right)}{L_{\text {stage }}}\right]\left(K_{c \text { next }}-K_{\text {c prev }}\right)
$$

where

$$
\begin{array}{ll}
i & =\text { day within the growing season, } \\
K_{c i} & =\mathrm{K}_{\mathrm{c}} \text { crop coefficient on day } \mathrm{i}, \\
K_{c \text { prev }} & =\mathrm{K}_{\mathrm{c}} \text { for the previous growth stage, } \\
\mathrm{L}_{\text {stage }} & =\text { length of stage under consideration (days), } \\
\sum\left(\mathrm{L}_{\text {prev }}\right) & =\text { sum of the lengths of all previous stages (days). }
\end{array}
$$

Example: The crop coefficient curve for lettuce (present-day climate) is shown in Figure D-1. The following inputs were required to calculate the monthly $K_{c}$ values.

Planting date $=$ March $6($ Julian Day 65, Table D-1 $)$.

Stage length (days): Initial $=15$, Developmental $=21, \operatorname{Mid}=18$, Late $=6$, Total $=60$.

End of stage (Julian day): Initial $=80$, Developmental $=101, \mathrm{Mid}=119$, Late $=125$.

$K_{c}$ for stages: Initial $=0.7, \mathrm{Mid}=1.08, \mathrm{End}=1.03$.

Growing days per stage in March: Initial $=15$, Developmental $=10$, Total $=25$.

Growing days per stage in April: Developmental $=11, \operatorname{Mid}=18$, Late $=1$, Total $=30$.

Growing days per stage in May: Late $=5$, Total $=5$

$K_{c i}$ (Equation D-5) was required for March 31 (Julian Day 90) because the development stage overlapped March and April, and for April 30 (Julian Day 120) because the late stage overlapped April and May.

$$
K_{c(90)}=0.70+\left[\frac{(90-65)-15}{21}\right](1.08-0.70)=0.88
$$




$$
K_{c(120)}=1.08+\left[\frac{(120-65)-(15+21+18)}{6}\right](1.03-1.08)=1.07
$$

The mean $K_{c}$ month values were calculated by multiplying the number of days in the growth stage by the corresponding $K_{c}$ to get a weighted average:

$$
\begin{gathered}
K_{c \text { March }}=\frac{15}{25} 0.70+\frac{10}{25}\left(\frac{0.70+0.88}{2}\right)=0.74 \\
K_{\text {cApril }}=\frac{11}{30}\left(\frac{0.88+1.08}{2}\right)+\frac{18}{30} 1.08+\frac{1}{30}\left(\frac{1.08+1.07}{2}\right)=1.05 \\
K_{\text {cMay }}=\frac{5}{5}\left(\frac{1.07+1.03}{2}\right)=1.05
\end{gathered}
$$

Mean monthly $K_{c}$ values are in Tables D-10, D-11, D-12, and D-13.

\section{Lettuce early - Current climate}

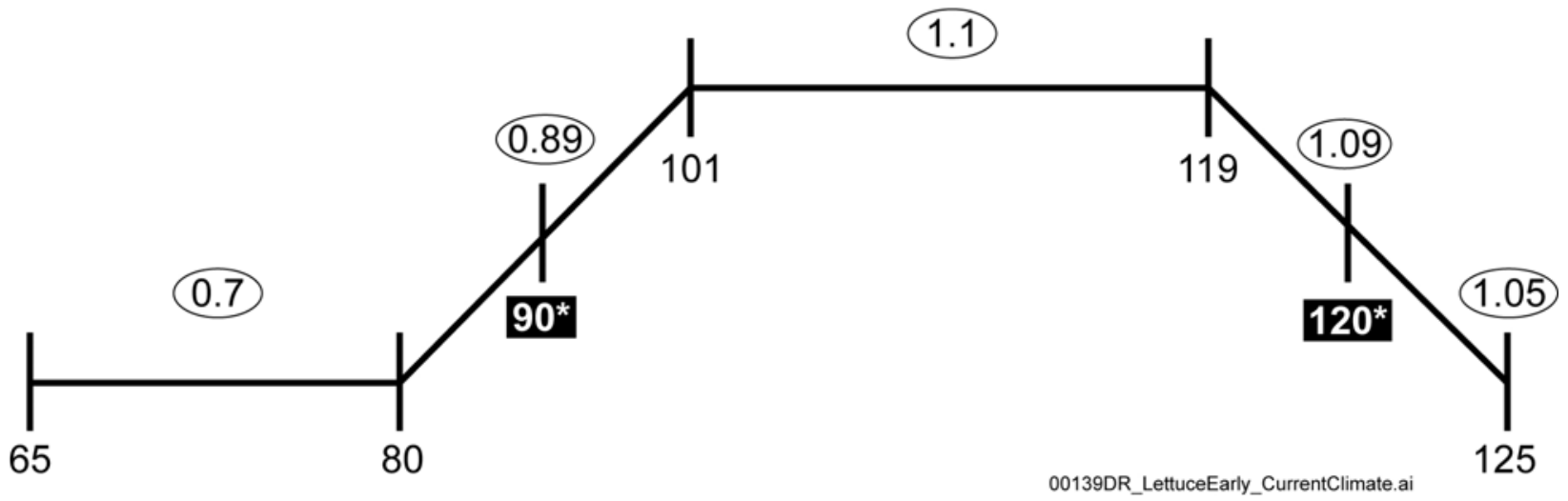

NOTE: $\quad$ Circled numbers are crop coefficients. Numbers are dates expressed in Julian format, excluding year (JD). Initial stage = JD 65 through 80, development stage = JD 81 through 101, midseason stage = JD 102 through 119, and the late stage = JD 120 through 125. 90* and 120* are the last Julian Days of March and April for which calculation of $\mathrm{K}_{\mathrm{ci}}$ was required in order to calculate monthly means (see text).

Figure D-1. Crop Coefficient Curve for Early Lettuce under Present-Day Climate Conditions 


\section{D5. CALCULATION OF CROP EVAPOTRANSPIRATION}

Mean daily $E T_{o}$ for each month (Appendix C, Table C-9) and $K_{c}$ (Tables D-10 through D-13) were used in Equation D-1 to generate mean monthly crop evapotranspiration $\left(E T_{C}\right)$ for the 26 crops and turf grass for all climates (Tables D-10 through D-13). Mean daily $E T_{c}$ values for each month were multiplied by the number of growing days per month to get total mean monthly $E T_{c}$ (Tables D-10 through D-13). These monthly values were used to generate seasonal irrigation requirements (Appendix $\mathrm{E}$ ), which were used to calculate annual average irrigation rate $(I R)$, daily average irrigation rate $\left(I R D_{j}\right)$, irrigation application $\left(I A_{j}\right)$, and overwatering rate $(O W)$ (see Section 6 and Appendix E).

Example: Monthly mean $E T_{o}$, monthly mean $K_{c}$, and number of growing season days in each month were required for calculating mean daily and monthly $E T_{c}$. $E T_{c}$ daily is $K_{c}$ multiplied by

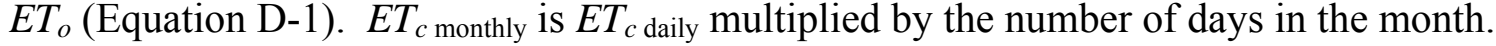

Example calculation:

$\begin{array}{llll} & \text { March } & \text { April } & \text { May } \\ K_{c} & 0.74 & 1.05 & 1.05 \\ E T_{o} & 4.24 & 5.51 & 6.86 \\ \text { Days } & 25 & 30 & 5 \\ E T_{\text {cdaily }}=K_{c}{ }^{*} E T_{o} & 0.74^{*} 4.24=3.14 & 1.05^{*} 5.51=5.78 & 1.05^{*} 6.86=7.20 \\ E T_{\text {cmonthly }}=E T_{\text {cdaily }}{ }^{*} \text { Days } & 3.14^{*} 25=78.5 & 5.78^{*} 30=173.40 & 7.20^{*} 5=36.00\end{array}$

It should be noted that the values presented in the appendix tables are rounded. Calculations were done using more precise values from the original data sources, resulting in small differences between the examples and the data reported in the tables in some cases. 
Table D-10. Mean Monthly Crop Coefficients $\left(K_{c}\right)$, Reference Evapotranspiration $\left(E T_{o}\right)$, and Crop Evapotranspiration $\left(E T_{c}\right)$ for Present-Day Climate Conditions

\begin{tabular}{|c|c|c|c|c|c|c|c|c|c|c|c|c|}
\hline Crop & Jan & Feb & Mar & Apr & May & June & July & Aug & Sept & Oct & Nov & Dec \\
\hline Leaf Lettuce early $-\mathrm{K}_{\mathrm{c}}{ }^{\mathrm{a}}$ & & & 0.74 & 1.04 & 1.05 & & & & & & & \\
\hline$E T_{0}(\mathrm{~mm} / \mathrm{day})^{\mathrm{b}}$ & & & 4.24 & 5.51 & 6.86 & & & & & & & \\
\hline $\mathrm{ET}_{\mathrm{c}}(\mathrm{mm} / \mathrm{day})^{\mathrm{c}}$ & & & 3.12 & 5.75 & 7.21 & & & & & & & \\
\hline Monthly $\mathrm{ET}_{\mathrm{c}}(\mathrm{mm} / \mathrm{month})^{\mathrm{d}}$ & & & 77.95 & 172.47 & 36.05 & & & & & & & \\
\hline Leaf Lettuce late $-K_{c}$ & & & & & & & & & 0.77 & 1.06 & & \\
\hline $\mathrm{Et}_{\mathrm{o}}$ (mm/day) & & & & & & & & & 6.84 & 4.67 & & \\
\hline $\mathrm{Et}_{\mathrm{c}}$ (mm/day) & & & & & & & & & 5.24 & 4.94 & & \\
\hline $\mathrm{Et}_{\mathrm{c}}(\mathrm{mm} / \mathrm{month})$ & & & & & & & & & 157.21 & 148.27 & & \\
\hline Head Lettuce early $-K_{c}$ & & & 0.74 & 1.04 & 1.05 & & & & & & & \\
\hline$E T_{0}(\mathrm{~mm} /$ day $)$ & & & 4.24 & 5.51 & 6.86 & & & & & & & \\
\hline $\mathrm{ET}_{\mathrm{c}}(\mathrm{mm} /$ day $)$ & & & 3.12 & 5.75 & 7.21 & & & & & & & \\
\hline Monthly $\mathrm{ET}_{\mathrm{c}}$ (mm/month) & & & 77.95 & 172.47 & 36.05 & & & & & & & \\
\hline Head Lettuce late $-\mathrm{K}_{\mathrm{c}}$ & & & & & & & & & 0.77 & 1.06 & & \\
\hline $\mathrm{Et}_{\mathrm{o}}(\mathrm{mm} / \mathrm{day})$ & & & & & & & & & 6.84 & 4.67 & & \\
\hline $\mathrm{Et}_{\mathrm{c}}$ (mm/day) & & & & & & & & & 5.24 & 4.94 & & \\
\hline $\mathrm{Et}_{\mathrm{c}}(\mathrm{mm} / \mathrm{month})$ & & & & & & & & & 157.21 & 148.27 & & \\
\hline Cabbage early - $\mathrm{K}_{\mathrm{c}}$ & & & 0.72 & 1.03 & 1.12 & & & & & & & \\
\hline $\mathrm{Et}_{\mathrm{o}}$ (mm/day) & & & 4.24 & 5.51 & 6.86 & & & & & & & \\
\hline $\mathrm{Et}_{\mathrm{c}}$ (mm/day) & & & 3.06 & 5.69 & 7.69 & & & & & & & \\
\hline $\mathrm{Et}_{\mathrm{c}}(\mathrm{mm} / \mathrm{month})$ & & & 91.92 & 170.70 & 192.26 & & & & & & & \\
\hline Cabbage late $-\mathrm{K}_{\mathrm{c}}$ & & & & & & & & 0.70 & 0.75 & 1.07 & 1.10 & \\
\hline $\mathrm{Et}_{\mathrm{o}}$ (mm/day) & & & & & & & & 8.62 & 6.84 & 4.67 & 2.72 & \\
\hline $\mathrm{Et}_{\mathrm{c}}$ (mm/day) & & & & & & & & 6.03 & 5.14 & 4.96 & 3.00 & \\
\hline $\mathrm{Et}_{\mathrm{c}}(\mathrm{mm} / \mathrm{month})$ & & & & & & & & 30.17 & 154.09 & 154.82 & 56.96 & \\
\hline
\end{tabular}


Table D-10. Mean Monthly Crop Coefficients $\left(K_{c}\right)$, Reference Evapotranspiration $\left(E T_{o}\right)$, and Crop Evapotranspiration $\left(E T_{c}\right)$ for PresentDay Climate Conditions (Continued)

\begin{tabular}{|c|c|c|c|c|c|c|c|c|c|c|c|c|}
\hline Crop & Jan & Feb & Mar & Apr & May & June & July & Aug & Sept & Oct & Nov & Dec \\
\hline Celery early - $\mathrm{K}_{\mathrm{c}}$ & & & & 0.70 & 0.92 & 1.15 & 1.15 & 1.13 & & & & \\
\hline $\mathrm{Et}_{\mathrm{o}}$ (mm/day) & & & & 5.51 & 6.86 & 8.38 & 8.89 & 8.62 & & & & \\
\hline $\mathrm{Et}_{\mathrm{c}}(\mathrm{mm} / \mathrm{day})$ & & & & 3.86 & 6.34 & 9.63 & 10.22 & 9.72 & & & & \\
\hline $\mathrm{Et}_{\mathrm{c}}$ (mm/month) & & & & 73.29 & 196.68 & 289.00 & 316.67 & 136.09 & & & & \\
\hline Celery late $-\mathrm{K}_{\mathrm{c}}$ & 1.09 & & & & & & & & 0.70 & 0.89 & 1.12 & 1.12 \\
\hline $\mathrm{Et}_{\mathrm{o}}$ (mm/day) & 1.77 & & & & & & & & 6.84 & 4.67 & 2.72 & 1.85 \\
\hline $\mathrm{Et}_{\mathrm{c}}$ (mm/day) & 1.93 & & & & & & & & 4.78 & 4.16 & 3.04 & 2.07 \\
\hline $\mathrm{Et}_{\mathrm{c}}(\mathrm{mm} / \mathrm{month})$ & 36.60 & & & & & & & & 66.99 & 128.88 & 91.30 & 64.20 \\
\hline Broccoli early - $K_{c}$ & & & 0.72 & 1.05 & 1.11 & & & & & & & \\
\hline $\mathrm{Et}_{\mathrm{o}}(\mathrm{mm} / \mathrm{day})$ & & & 4.24 & 5.51 & 6.86 & & & & & & & \\
\hline $\mathrm{Et}_{\mathrm{c}}$ (mm/day) & & & 3.06 & 5.78 & 7.60 & & & & & & & \\
\hline $\mathrm{Et}_{\mathrm{c}}$ (mm/month) & & & 91.78 & 173.52 & 151.96 & & & & & & & \\
\hline Broccoli late $-K_{c}$ & & & & & & & & 0.70 & 0.75 & 1.08 & 1.09 & \\
\hline $\mathrm{Et}_{\mathrm{o}}$ (mm/day) & & & & & & & & 8.62 & 6.84 & 4.67 & 2.72 & \\
\hline $\mathrm{Et}_{\mathrm{c}}$ (mm/day) & & & & & & & & 6.03 & 5.15 & 5.06 & 2.95 & \\
\hline $\mathrm{Et}_{\mathrm{c}}(\mathrm{mm} / \mathrm{month})$ & & & & & & & & 30.17 & 154.40 & 156.98 & 41.35 & \\
\hline Cauliflower early - $\mathrm{K}_{\mathrm{c}}$ & & & 0.73 & 1.05 & 1.11 & & & & & & & \\
\hline $\mathrm{Et}_{\mathrm{o}}$ (mm/day) & & & 4.24 & 5.51 & 6.86 & & & & & & & \\
\hline $\mathrm{Et}_{\mathrm{c}}$ (mm/day) & & & 3.07 & 5.80 & 7.65 & & & & & & & \\
\hline $\mathrm{Et}_{\mathrm{c}}$ (mm/month) & & & 92.24 & 173.93 & 152.94 & & & & & & & \\
\hline Cauliflower late $-\mathrm{K}_{\mathrm{c}}$ & & & & & & & & 0.70 & 0.76 & 1.08 & 1.09 & \\
\hline $\mathrm{Et}_{\mathrm{o}}$ (mm/day) & & & & & & & & 8.62 & 6.84 & 4.67 & 2.72 & \\
\hline $\mathrm{Et}_{\mathrm{c}}$ (mm/day) & & & & & & & & 6.03 & 5.18 & 5.07 & 2.97 & \\
\hline $\mathrm{Et}_{\mathrm{c}}(\mathrm{mm} / \mathrm{month})$ & & & & & & & & 30.17 & 155.28 & 157.32 & 41.58 & \\
\hline
\end{tabular}


Table D-10. Mean Monthly Crop Coefficients $\left(K_{c}\right)$, Reference Evapotranspiration $\left(E T_{o}\right)$, and Crop Evapotranspiration $\left(E T_{c}\right)$ for PresentDay Climate Conditions (Continued)

\begin{tabular}{|c|c|c|c|c|c|c|c|c|c|c|c|c|}
\hline Crop & Jan & Feb & Mar & Apr & May & June & July & Aug & Sept & Oct & Nov & Dec \\
\hline Spinach early $-\mathrm{K}_{\mathrm{c}}$ & & & 0.72 & 1.04 & 1.05 & & & & & & & \\
\hline $\mathrm{Et}_{\mathrm{o}}$ (mm/day) & & & 4.24 & 5.51 & 6.86 & & & & & & & \\
\hline $\mathrm{Et}_{\mathrm{c}}$ (mm/day) & & & 3.05 & 5.72 & 7.24 & & & & & & & \\
\hline $\mathrm{Et}_{\mathrm{c}}$ (mm/month) & & & 45.81 & 171.54 & 36.19 & & & & & & & \\
\hline Spinach late $-K_{c}$ & & & & & & & & & 0.71 & 1.02 & 1.04 & \\
\hline $\mathrm{Et}_{\mathrm{o}}(\mathrm{mm} / \mathrm{day})$ & & & & & & & & & 6.84 & 4.67 & 2.72 & \\
\hline $\mathrm{Et}_{\mathrm{c}}(\mathrm{mm} / \mathrm{day})$ & & & & & & & & & 4.88 & 4.79 & 2.84 & \\
\hline $\mathrm{Et}_{\mathrm{c}}$ (mm/month) & & & & & & & & & 68.35 & 148.45 & 14.18 & \\
\hline Potatoes $-\mathrm{K}_{\mathrm{c}}$ & & & 0.50 & 0.56 & 1.14 & 1.24 & 0.94 & & & & & \\
\hline $\mathrm{Et}_{\mathrm{o}}(\mathrm{mm} /$ day $)$ & & & 4.23 & 5.51 & 6.86 & 8.38 & 8.89 & & & & & \\
\hline $\mathrm{Et}_{\mathrm{c}}$ (mm/day) & & & 2.12 & 3.06 & 7.80 & 10.39 & 8.36 & & & & & \\
\hline $\mathrm{Et}_{\mathrm{c}}$ (mm/month) & & & 10.59 & 91.88 & 241.65 & 311.60 & 116.99 & & & & & \\
\hline Onions early $-\mathrm{K}_{\mathrm{c}}$ & & & 0.70 & 0.93 & 1.14 & 1.12 & 0.92 & & & & & \\
\hline $\mathrm{Et}_{\mathrm{o}}(\mathrm{mm} /$ day $)$ & & & 4.24 & 5.51 & 6.86 & 8.38 & 8.89 & & & & & \\
\hline $\mathrm{Et}_{\mathrm{c}}(\mathrm{mm} / \mathrm{day})$ & & & 2.96 & 5.14 & 7.81 & 9.37 & 8.22 & & & & & \\
\hline $\mathrm{Et}_{\mathrm{c}}$ (mm/month) & & & 14.82 & 154.26 & 242.10 & 281.04 & 115.13 & & & & & \\
\hline Onions late $-\mathrm{K}_{\mathrm{c}}$ & 0.83 & & & & & & & & 0.71 & 1.05 & 1.12 & 1.04 \\
\hline $\mathrm{Et}_{\mathrm{o}}(\mathrm{mm} / \mathrm{day})$ & 1.77 & & & & & & & & 6.84 & 4.67 & 2.72 & 1.85 \\
\hline $\mathrm{Et}_{\mathrm{c}}(\mathrm{mm} /$ day $)$ & 1.47 & & & & & & & & 4.88 & 4.89 & 3.04 & 1.92 \\
\hline $\mathrm{Et}_{\mathrm{c}}$ (mm/month) & 5.88 & & & & & & & & 68.27 & 151.62 & 91.36 & 59.37 \\
\hline Carrots early - $\mathrm{K}_{\mathrm{c}}$ & & & 0.71 & 1.04 & 1.11 & & & & & & & \\
\hline $\mathrm{Et}_{\mathrm{o}}(\mathrm{mm} / \mathrm{day})$ & & & 4.24 & 5.51 & 6.86 & & & & & & & \\
\hline $\mathrm{Et}_{\mathrm{c}}(\mathrm{mm} /$ day $)$ & & & 3.02 & 5.75 & 7.62 & & & & & & & \\
\hline $\mathrm{Et}_{\mathrm{c}}$ (mm/month) & & & 45.24 & 172.64 & 288.78 & & & & & & & \\
\hline
\end{tabular}


Table D-10. Mean Monthly Crop Coefficients $\left(K_{c}\right)$, Reference Evapotranspiration $\left(E T_{o}\right)$, and Crop Evapotranspiration $\left(E T_{c}\right)$ for PresentDay Climate Conditions (Continued)

\begin{tabular}{|c|c|c|c|c|c|c|c|c|c|c|c|c|}
\hline Crop & Jan & Feb & Mar & Apr & May & June & July & Aug & Sept & Oct & Nov & Dec \\
\hline Carrots late $-\mathrm{K}_{\mathrm{c}}$ & & & & & & & & 0.70 & 0.90 & 1.12 & 1.06 & \\
\hline $\mathrm{Et}_{\mathrm{o}}$ (mm/day) & & & & & & & & 8.62 & 6.84 & 4.67 & 2.72 & \\
\hline $\mathrm{Et}_{\mathrm{c}}(\mathrm{mm} / \mathrm{day})$ & & & & & & & & 6.03 & 6.18 & 5.25 & 2.88 & \\
\hline $\mathrm{Et}_{\mathrm{c}}$ (mm/month) & & & & & & & & 30.17 & 185.52 & 162.70 & 25.92 & \\
\hline Sweet Corn - $K_{c}$ & & & & & 0.55 & 1.27 & 1.27 & & & & & \\
\hline $\mathrm{Et}_{\mathrm{o}}$ (mm/day) & & & & & 6.86 & 8.38 & 8.89 & & & & & \\
\hline $\mathrm{Et}_{\mathrm{c}}$ (mm/day) & & & & & 3.76 & 10.66 & 11.26 & & & & & \\
\hline $\mathrm{Et}_{\mathrm{c}}(\mathrm{mm} /$ month) & & & & & 116.70 & 319.60 & 236.48 & & & & & \\
\hline Bell Peppers - $\mathrm{K}_{\mathrm{c}}$ & & & & & 0.75 & 1.15 & 1.12 & & & & & \\
\hline $\mathrm{Et}_{\mathrm{o}}$ (mm/day) & & & & & 6.86 & 8.38 & 8.89 & & & & & \\
\hline $\mathrm{Et}_{\mathrm{c}}$ (mm/day) & & & & & 5.12 & 9.68 & 9.94 & & & & & \\
\hline $\mathrm{Et}_{\mathrm{c}}$ (mm/month) & & & & & 127.84 & 290.52 & 228.66 & & & & & \\
\hline Cucumbers - $\mathrm{K}_{\mathrm{c}}$ & & & & & & 0.76 & 1.04 & & & & & \\
\hline $\mathrm{Et}_{\mathrm{o}}(\mathrm{mm} / \mathrm{day})$ & & & & & & 8.39 & 8.89 & & & & & \\
\hline $\mathrm{Et}_{\mathrm{c}}$ (mm/day) & & & & & & 6.34 & 9.26 & & & & & \\
\hline $\mathrm{Et}_{\mathrm{c}}$ (mm/month) & & & & & & 183.98 & 287.03 & & & & & \\
\hline Squash - $\mathrm{K}_{\mathrm{c}}$ & & & & & 0.50 & 0.85 & 0.96 & & & & & \\
\hline $\mathrm{Et}_{\mathrm{o}}$ (mm/day) & & & & & 6.86 & 8.38 & 8.89 & & & & & \\
\hline $\mathrm{Et}_{\mathrm{c}}(\mathrm{mm} /$ day $)$ & & & & & 3.43 & 7.16 & 8.54 & & & & & \\
\hline $\mathrm{Et}_{\mathrm{c}}$ (mm/month) & & & & & 51.47 & 214.98 & 111.08 & & & & & \\
\hline Melons - $\mathrm{K}_{\mathrm{c}}$ & & & & & 0.51 & 0.75 & 1.15 & 1.07 & & & & \\
\hline $\mathrm{Et}_{\mathrm{o}}$ (mm/day) & & & & & 6.86 & 8.38 & 8.89 & 8.62 & & & & \\
\hline $\mathrm{Et}_{\mathrm{c}}(\mathrm{mm} /$ day $)$ & & & & & 3.51 & 6.29 & 10.18 & 9.27 & & & & \\
\hline $\mathrm{Et}_{\mathrm{c}}$ (mm/month) & & & & & 52.65 & 188.74 & 315.65 & 222.37 & & & & \\
\hline
\end{tabular}


Table D-10. Mean Monthly Crop Coefficients $\left(K_{c}\right)$, Reference Evapotranspiration $\left(E T_{o}\right)$, and Crop Evapotranspiration $\left(E T_{c}\right)$ for PresentDay Climate Conditions (Continued)

\begin{tabular}{|c|c|c|c|c|c|c|c|c|c|c|c|c|}
\hline Crop & Jan & Feb & Mar & Apr & May & June & July & Aug & Sept & Oct & Nov & Dec \\
\hline Tomatoes - $\mathrm{K}_{\mathrm{c}}$ & & & & & 0.63 & 1.15 & 1.14 & & & & & \\
\hline $\mathrm{Et}_{\mathrm{o}}$ (mm/day) & & & & & 6.86 & 8.38 & 8.89 & & & & & \\
\hline $\mathrm{Et}_{\mathrm{c}}$ (mm/day) & & & & & 4.32 & 9.63 & 10.17 & & & & & \\
\hline $\mathrm{Et}_{\mathrm{c}}$ (mm/month) & & & & & 108.14 & 289.02 & 254.18 & & & & & \\
\hline Apples - $\mathrm{K}_{\mathrm{c}}$ & & & 0.60 & 0.76 & 1.06 & 1.12 & 1.12 & 1.12 & 1.12 & 1.00 & & \\
\hline $\mathrm{Et}_{\mathrm{o}}$ (mm/day) & & & 4.24 & 5.51 & 6.86 & 8.38 & 8.89 & 8.62 & 6.84 & 4.67 & & \\
\hline $\mathrm{Et}_{\mathrm{c}}(\mathrm{mm} /$ day $)$ & & & 2.54 & 4.17 & 7.24 & 9.42 & 9.98 & 9.68 & 7.67 & 4.70 & & \\
\hline $\mathrm{Et}_{\mathrm{c}}(\mathrm{mm} /$ month) & & & 76.24 & 125.05 & 224.50 & 282.45 & 309.44 & 300.04 & 230.02 & 126.89 & & \\
\hline Grapes - $\mathrm{K}_{\mathrm{c}}$ & & & 0.33 & 0.62 & 0.83 & 0.83 & 0.77 & 0.56 & & & & \\
\hline $\mathrm{Et}_{\mathrm{o}}$ (mm/day) & & & 4.24 & 5.51 & 6.86 & 8.38 & 8.89 & 8.62 & & & & \\
\hline $\mathrm{Et}_{\mathrm{c}}(\mathrm{mm} / \mathrm{day})$ & & & 1.39 & 3.41 & 5.69 & 6.97 & 6.89 & 4.84 & & & & \\
\hline $\mathrm{Et}_{\mathrm{c}}(\mathrm{mm} /$ month$)$ & & & 41.72 & 102.21 & 176.42 & 209.05 & 213.56 & 150.03 & & & & \\
\hline Strawberries - $\mathrm{K}_{\mathrm{c}}$ & & & 0.57 & 0.66 & 0.90 & 0.92 & 0.92 & 0.88 & 0.84 & & & \\
\hline $\mathrm{Et}_{\mathrm{o}}(\mathrm{mm} /$ day $)$ & & & 4.24 & 5.51 & 6.86 & 8.38 & 8.89 & 8.62 & 6.84 & & & \\
\hline $\mathrm{Et}_{\mathrm{c}}$ (mm/day) & & & 2.41 & 3.64 & 6.21 & 7.72 & 8.14 & 7.61 & 5.73 & & & \\
\hline $\mathrm{Et}_{\mathrm{c}}(\mathrm{mm} / \mathrm{month})$ & & & 72.18 & 109.14 & 192.39 & 231.73 & 252.24 & 235.98 & 126.04 & & & \\
\hline Winter wheat $-\mathrm{K}_{\mathrm{c}}$ & 1.14 & 1.25 & 1.25 & 1.25 & 1.01 & 0.45 & & & & 0.70 & 0.74 & 0.93 \\
\hline $\mathrm{Et}_{\mathrm{o}}(\mathrm{mm} / \mathrm{day})$ & 1.77 & 2.64 & 4.24 & 5.51 & 6.86 & 8.38 & & & & 4.67 & 2.72 & 1.85 \\
\hline $\mathrm{Et}_{\mathrm{c}}$ (mm/day) & 2.02 & 3.31 & 5.31 & 6.91 & 6.91 & 3.74 & & & & 3.27 & 2.00 & 1.72 \\
\hline $\mathrm{Et}_{\mathrm{c}}$ (mm/month) & 62.60 & 92.78 & 164.72 & 207.29 & 214.36 & 59.84 & & & & 49.08 & 60.11 & 53.30 \\
\hline Barley $-\mathrm{K}_{\mathrm{c}}$ & 1.07 & 1.25 & 1.25 & 1.25 & 0.94 & 0.42 & & & & 0.30 & 0.35 & 0.68 \\
\hline $\mathrm{Et}_{\mathrm{o}}$ (mm/day) & 1.77 & 2.64 & 4.24 & 5.51 & 6.86 & 8.38 & & & & 4.67 & 2.72 & 1.85 \\
\hline $\mathrm{Et}_{\mathrm{c}}(\mathrm{mm} /$ day $)$ & 1.89 & 3.31 & 5.31 & 6.90 & 6.43 & 3.56 & & & & 1.40 & 0.94 & 1.26 \\
\hline $\mathrm{Et}_{\mathrm{c}}$ (mm/month) & 58.74 & 92.69 & 164.54 & 207.07 & 199.26 & 56.95 & & & & 21.03 & 28.30 & 39.14 \\
\hline
\end{tabular}


Table D-10. Mean Monthly Crop Coefficients $\left(K_{c}\right)$, Reference Evapotranspiration $\left(E T_{o}\right)$, and Crop Evapotranspiration $\left(E T_{c}\right)$ for PresentDay Climate Conditions (Continued)

\begin{tabular}{|c|c|c|c|c|c|c|c|c|c|c|c|c|}
\hline Crop & Jan & Feb & Mar & Apr & May & June & July & Aug & Sept & Oct & Nov & Dec \\
\hline Feed Corn - Kc & & & & & 0.30 & 0.43 & 1.08 & 1.34 & 1.21 & 0.60 & & \\
\hline $\mathrm{Et}_{\mathrm{o}}$ (mm/day) & & & & & 6.86 & 8.38 & 8.89 & 8.62 & 6.84 & 4.67 & & \\
\hline $\mathrm{Et}_{\mathrm{c}}(\mathrm{mm} / \mathrm{day})$ & & & & & 2.06 & 3.59 & 9.62 & 11.55 & 8.28 & 2.83 & & \\
\hline $\mathrm{Et}_{\mathrm{c}}(\mathrm{mm} / \mathrm{month})$ & & & & & 30.88 & 107.57 & 298.18 & 357.96 & 248.45 & 48.06 & & \\
\hline Oat Feed - Kc & 0.51 & 1.06 & 1.26 & 1.25 & 0.67 & & & & & & & 0.30 \\
\hline $\mathrm{Et}_{\mathrm{o}}$ (mm/day) & 1.76 & 2.64 & 4.24 & 5.51 & 6.86 & & & & & & & 1.85 \\
\hline $\mathrm{Et}_{\mathrm{c}}(\mathrm{mm} /$ day $)$ & 0.90 & 2.81 & 5.34 & 6.86 & 4.60 & & & & & & & 0.56 \\
\hline $\mathrm{Et}_{\mathrm{c}}$ (mm/month) & 27.93 & 78.60 & 165.47 & 205.92 & 115.11 & & & & & & & 8.32 \\
\hline Alfalfa hay (1st) - $K_{c}$ & 0.69 & 1.26 & 1.20 & & & & & & & & & \\
\hline $\mathrm{Et}_{\mathrm{o}}(\mathrm{mm} / \mathrm{day})$ & 1.77 & 2.64 & 4.24 & & & & & & & & & \\
\hline $\mathrm{Et}_{\mathrm{c}}$ (mm/day) & 1.22 & 3.33 & 5.10 & & & & & & & & & \\
\hline $\mathrm{Et}_{\mathrm{c}}(\mathrm{mm} / \mathrm{month})$ & 36.73 & 93.34 & 10.19 & & & & & & & & & \\
\hline Alfalfa hay (2nd) $-K_{c}$ & & & 0.74 & 1.29 & & & & & & & & \\
\hline $\mathrm{Et}_{\mathrm{o}}(\mathrm{mm} / \mathrm{day})$ & & & 4.24 & 5.51 & & & & & & & & \\
\hline $\mathrm{Et}_{\mathrm{c}}(\mathrm{mm} / \mathrm{day})$ & & & 3.14 & 7.12 & & & & & & & & \\
\hline $\mathrm{Et}_{\mathrm{c}}$ (mm/month) & & & 91.21 & 185.25 & & & & & & & & \\
\hline Alfalfa hay $(3 r d)-K_{c}$ & & & & 0.40 & 0.90 & 1.29 & & & & & & \\
\hline $\mathrm{Et}_{\mathrm{o}}(\mathrm{mm} / \mathrm{day})$ & & & & 5.51 & 6.86 & 8.38 & & & & & & \\
\hline $\mathrm{Et}_{\mathrm{c}}(\mathrm{mm} /$ day $)$ & & & & 2.20 & 6.15 & 10.84 & & & & & & \\
\hline $\mathrm{Et}_{\mathrm{c}}$ (mm/month) & & & & 8.81 & 190.69 & 216.90 & & & & & & \\
\hline Alfalfa hay (4th) $-K_{c}$ & & & & & & 0.40 & 1.07 & 1.28 & & & & \\
\hline $\mathrm{Et}_{\mathrm{o}}(\mathrm{mm} / \mathrm{day})$ & & & & & & 8.38 & 8.99 & 8.62 & & & & \\
\hline $\mathrm{Et}_{\mathrm{c}}(\mathrm{mm} /$ day $)$ & & & & & & 3.38 & 9.49 & 11.07 & & & & \\
\hline $\mathrm{Et}_{\mathrm{c}}(\mathrm{mm} / \mathrm{month})$ & & & & & & 33.75 & 294.22 & 154.96 & & & & \\
\hline
\end{tabular}


Table D-10. Mean Monthly Crop Coefficients $\left(K_{c}\right)$, Reference Evapotranspiration $\left(E T_{o}\right)$, and Crop Evapotranspiration $\left(E T_{c}\right)$ for PresentDay Climate Conditions (Continued)

\begin{tabular}{|c|c|c|c|c|c|c|c|c|c|c|c|c|}
\hline Crop & Jan & Feb & Mar & Apr & May & June & July & Aug & Sept & Oct & Nov & Dec \\
\hline Alfalfa hay (5th) - $K_{c}$ & & & & & & & & 0.49 & 1.21 & 1.26 & & \\
\hline $\mathrm{Et}_{\mathrm{o}}$ (mm/day) & & & & & & & & 8.62 & 6.84 & 4.67 & & \\
\hline $\mathrm{Et}_{\mathrm{c}}(\mathrm{mm} / \mathrm{day})$ & & & & & & & & 4.26 & 8.30 & 5.87 & & \\
\hline $\mathrm{Et}_{\mathrm{c}}(\mathrm{mm} / \mathrm{month})$ & & & & & & & & 72.38 & 248.93 & 46.99 & & \\
\hline Alfalfa hay $(6$ th $)-K_{c}$ & & & & & & & & & & 0.61 & 1.26 & 1.23 \\
\hline $\mathrm{Et}_{\mathrm{o}}$ (mm/day) & & & & & & & & & & 4.67 & 2.72 & 1.85 \\
\hline $\mathrm{Et}_{\mathrm{c}}(\mathrm{mm} / \mathrm{day})$ & & & & & & & & & & 2.84 & 3.43 & 2.28 \\
\hline $\mathrm{Et}_{\mathrm{c}}(\mathrm{mm} / \mathrm{month})$ & & & & & & & & & & 65.44 & 103.00 & 4.57 \\
\hline Corn silage - Kc & & & & & 0.30 & 0.85 & 1.33 & 0.99 & & & & \\
\hline $\mathrm{Et}_{\mathrm{o}}$ (mm/day) & & & & & 6.86 & 8.28 & 8.89 & 8.62 & & & & \\
\hline $\mathrm{Et}_{\mathrm{c}}(\mathrm{mm} /$ day $)$ & & & & & 2.06 & 7.16 & 11.85 & 8.58 & & & & \\
\hline $\mathrm{Et}_{\mathrm{c}}$ (mm/month) & & & & & 30.88 & 214.70 & 367.47 & 145.79 & & & & \\
\hline Oat hay $-\mathrm{K}_{\mathrm{c}}$ & & & & 0.60 & 1.26 & 0.76 & & & & & & \\
\hline $\mathrm{Et}_{\mathrm{o}}$ (mm/day) & & & & 5.51 & 6.86 & 8.38 & & & & & & \\
\hline $\mathrm{Et}_{\mathrm{c}}$ (mm/day) & & & & 3.28 & 8.63 & 6.34 & & & & & & \\
\hline $\mathrm{Et}_{\mathrm{c}}$ (mm/month) & & & & 98.32 & 267.53 & 88.84 & & & & & & \\
\hline Bermuda $^{\mathrm{e}}-\mathrm{K}_{\mathrm{c}}$ & 0.85 & 0.85 & 0.85 & 0.85 & 0.85 & 0.85 & 0.85 & 0.85 & 0.85 & 0.85 & 0.85 & 0.85 \\
\hline $\mathrm{Et}_{\mathrm{o}}$ (mm/day) & 1.77 & 2.64 & 4.24 & 5.51 & 6.86 & 8.38 & 8.89 & 8.62 & 6.84 & 4.67 & 2.72 & 1.85 \\
\hline $\mathrm{Et}_{\mathrm{c}}(\mathrm{mm} / \mathrm{day})$ & 1.50 & 2.24 & 3.60 & 4.68 & 5.83 & 7.13 & 7.56 & 7.33 & 5.81 & 3.97 & 2.31 & 1.57 \\
\hline $\mathrm{Et}_{\mathrm{c}}$ (mm/month) & 46.61 & 62.87 & 111.60 & 140.44 & 180.83 & 213.84 & 234.27 & 227.15 & 174.31 & 123.17 & 69.33 & 48.75 \\
\hline
\end{tabular}

${ }^{a}$ Mean monthly $K_{c}$ values calculated according to Appendix D, Section 4.

bean monthly $E T_{o}$ values from Appendix C, Table C-9.

${ }^{c}$ Mean daily $E T_{c}$ calculated using Equation D-1.

d Mean monthly $E T_{c}$ calculated from mean daily $E T_{c}$ and the number of growing days per month (Appendix $\mathrm{D}$, Section 5 ).

e Bermudagrass was selected for present-day and upper bound monsoon climates because it is a warm season grass. 
Table D-11. Mean Monthly Crop Coefficients $\left(K_{c}\right)$, Reference Evapotranspiration $\left(E T_{o}\right)$, and Crop Evapotranspiration $\left(E T_{c}\right)$ for Upper Bound Monsoon Climate Conditions

\begin{tabular}{|c|c|c|c|c|c|c|c|c|c|c|c|c|}
\hline Crop & Jan & Feb & Mar & Apr & May & June & July & Aug & Sept & Oct & Nov & Dec \\
\hline Leaf Lettuce early - $\mathrm{K}_{\mathrm{c}}{ }^{\mathrm{a}}$ & & & 0.73 & 1.02 & 1.02 & & & & & & & \\
\hline $\mathrm{ET}_{\mathrm{o}}(\mathrm{mm} / \mathrm{day})^{\mathrm{b}}$ & & & 3.82 & 5.10 & 6.32 & & & & & & & \\
\hline $\mathrm{ET}_{\mathrm{c}}(\mathrm{mm} / \text { day })^{\mathrm{c}}$ & & & 2.80 & 5.18 & 6.45 & & & & & & & \\
\hline Monthly $\mathrm{ET}_{\mathrm{C}}(\mathrm{mm} / \text { month })^{\mathrm{d}}$ & & & 69.99 & 155.43 & 32.27 & & & & & & & \\
\hline Leaf Lettuce late $-\mathrm{K}_{\mathrm{c}}$ & & & & & & & & & 0.76 & 1.02 & & \\
\hline $\mathrm{Et}_{\mathrm{o}}(\mathrm{mm} / \mathrm{day})$ & & & & & & & & & 5.08 & 3.99 & & \\
\hline $\mathrm{Et}_{\mathrm{c}}(\mathrm{mm} /$ day $)$ & & & & & & & & & 3.87 & 4.09 & & \\
\hline $\mathrm{Et}_{\mathrm{c}}$ (mm/month) & & & & & & & & & 115.97 & 122.66 & & \\
\hline Head Lettuce early - $\mathrm{K}_{\mathrm{c}}$ & & & 0.73 & 1.02 & 1.02 & & & & & & & \\
\hline $\mathrm{ET}_{\mathrm{o}}$ (mm/day) & & & 3.82 & 5.10 & 6.32 & & & & & & & \\
\hline $\mathrm{ET}_{\mathrm{c}}(\mathrm{mm} / \mathrm{day})$ & & & 2.80 & 5.18 & 6.45 & & & & & & & \\
\hline Monthly $\mathrm{ET}_{\mathrm{c}}$ (mm/month) & & & 69.99 & 155.30 & 32.27 & & & & & & & \\
\hline Head Lettuce late $-K_{c}$ & & & & & & & & & 0.76 & 1.02 & & \\
\hline $\mathrm{Et}_{\mathrm{o}}$ (mm/day) & & & & & & & & & 5.08 & 3.99 & & \\
\hline $\mathrm{Et}_{\mathrm{c}}(\mathrm{mm} /$ day $)$ & & & & & & & & & 3.87 & 4.09 & & \\
\hline $\mathrm{Et}_{\mathrm{c}}(\mathrm{mm} / \mathrm{month})$ & & & & & & & & & 115.97 & 122.66 & & \\
\hline Cabbage early - Kc & & & 0.72 & 1.01 & 1.09 & & & & & & & \\
\hline Eto (mm/day) & & & 3.82 & 5.10 & 6.32 & & & & & & & \\
\hline Etc (mm/day) & & & 2.76 & 5.15 & 6.88 & & & & & & & \\
\hline Etc (mm/month) & & & 82.67 & 154.37 & 172.08 & & & & & & & \\
\hline Cabbage late - Kc & & & & & & & & 0.70 & 0.75 & 1.04 & 1.07 & \\
\hline Eto (mm/day) & & & & & & & & 5.64 & 5.08 & 3.99 & 2.45 & \\
\hline Etc (mm/day) & & & & & & & & 3.95 & 3.80 & 4.15 & 2.62 & \\
\hline Etc (mm/month) & & & & & & & & 19.73 & 113.95 & 128.52 & 49.72 & \\
\hline
\end{tabular}


Table D-11. Mean Monthly Crop Coefficients $\left(K_{c}\right)$, Reference Evapotranspiration $\left(E T_{o}\right)$, and Crop Evapotranspiration $\left(E T_{c}\right)$ for Upper Bound Monsoon Climate Conditions (Continued)

\begin{tabular}{|c|c|c|c|c|c|c|c|c|c|c|c|c|}
\hline Crop & Jan & Feb & Mar & Apr & May & June & July & Aug & Sept & Oct & Nov & Dec \\
\hline Celery early - $\mathrm{K}_{\mathrm{c}}$ & & & & 0.70 & 0.89 & 1.09 & 1.09 & 1.06 & & & & \\
\hline $\mathrm{Et}_{\mathrm{o}}$ (mm/day) & & & & 5.10 & 6.32 & 7.36 & 6.25 & 5.64 & & & & \\
\hline $\mathrm{Et}_{\mathrm{c}}$ (mm/day) & & & & 3.57 & 5.65 & 8.01 & 6.80 & 5.95 & & & & \\
\hline $\mathrm{Et}_{\mathrm{c}}$ (mm/month) & & & & 67.82 & 175.09 & 240.16 & 210.95 & 83.26 & & & & \\
\hline Celery late $-\mathrm{K}_{\mathrm{c}}$ & 1.08 & & & & & & & & 0.70 & 0.88 & 1.09 & 1.09 \\
\hline $\mathrm{Et}_{\mathrm{o}}(\mathrm{mm} /$ day $)$ & 1.92 & & & & & & & & 5.08 & 3.99 & 2.45 & 2.00 \\
\hline $\mathrm{Et}_{\mathrm{c}}$ (mm/day) & 2.07 & & & & & & & & 3.56 & 3.51 & 2.68 & 2.19 \\
\hline $\mathrm{Et}_{\mathrm{c}}$ (mm/month) & 39.31 & & & & & & & & 49.82 & 108.67 & 80.38 & 67.93 \\
\hline Broccoli early $-\mathrm{K}_{\mathrm{c}}$ & & & 0.72 & 1.03 & 1.08 & & & & & & & \\
\hline $\mathrm{Et}_{\mathrm{o}}$ (mm/day) & & & 3.82 & 5.10 & 6.32 & & & & & & & \\
\hline $\mathrm{Et}_{\mathrm{c}}(\mathrm{mm} / \mathrm{day})$ & & & 2.75 & 5.23 & 6.81 & & & & & & & \\
\hline $\mathrm{Et}_{\mathrm{c}}(\mathrm{mm} /$ month$)$ & & & 82.55 & 156.97 & 136.24 & & & & & & & \\
\hline Broccoli late $-\mathrm{K}_{\mathrm{c}}$ & & & & & & & & 0.70 & 0.75 & 1.05 & 1.05 & \\
\hline $\mathrm{Et}_{\mathrm{o}}(\mathrm{mm} /$ day $)$ & & & & & & & & 5.64 & 5.08 & 3.99 & 2.45 & \\
\hline $\mathrm{Et}_{\mathrm{c}}$ (mm/day) & & & & & & & & 3.95 & 3.81 & 4.21 & 2.58 & \\
\hline $\mathrm{Et}_{\mathrm{c}}(\mathrm{mm} / \mathrm{month})$ & & & & & & & & 19.73 & 114.18 & 130.36 & 36.15 & \\
\hline Cauliflower early $-\mathrm{K}_{\mathrm{c}}$ & & & 0.72 & 1.03 & 1.08 & & & & & & & \\
\hline $\mathrm{Et}_{\mathrm{o}}(\mathrm{mm} /$ day $)$ & & & 3.82 & 5.10 & 6.32 & & & & & & & \\
\hline $\mathrm{Et}_{\mathrm{c}}$ (mm/day) & & & 2.76 & 5.24 & 6.84 & & & & & & & \\
\hline $\mathrm{Et}_{\mathrm{c}}$ (mm/month) & & & 82.94 & 157.08 & 136.83 & & & & & & & \\
\hline Cauliflower late $-\mathrm{K}_{\mathrm{c}}$ & & & & & & & & 0.70 & 0.75 & 1.05 & 1.06 & \\
\hline $\mathrm{Et}_{\mathrm{o}}$ (mm/day) & & & & & & & & 5.64 & 5.08 & 3.99 & 2.45 & \\
\hline $\mathrm{Et}_{\mathrm{c}}(\mathrm{mm} /$ day $)$ & & & & & & & & 3.95 & 3.82 & 4.20 & 2.59 & \\
\hline $\mathrm{Et}_{\mathrm{c}}(\mathrm{mm} / \mathrm{month})$ & & & & & & & & 19.73 & 114.74 & 130.35 & 36.27 & \\
\hline
\end{tabular}


Table D-11. Mean Monthly Crop Coefficients $\left(K_{c}\right)$, Reference Evapotranspiration $\left(E T_{o}\right)$, and Crop Evapotranspiration $\left(E T_{c}\right)$ for Upper Bound Monsoon Climate Conditions (Continued)

\begin{tabular}{|c|c|c|c|c|c|c|c|c|c|c|c|c|}
\hline Crop & Jan & Feb & Mar & Apr & May & June & July & Aug & Sept & Oct & Nov & Dec \\
\hline Spinach early $-\mathrm{K}_{\mathrm{c}}$ & & & 0.72 & 1.01 & 1.03 & & & & & & & \\
\hline $\mathrm{Et}_{\mathrm{o}}$ (mm/day) & & & 3.82 & 5.10 & 6.32 & & & & & & & \\
\hline $\mathrm{Et}_{\mathrm{c}}$ (mm/day) & & & 2.75 & 5.15 & 6.48 & & & & & & & \\
\hline $\mathrm{Et}_{\mathrm{c}}$ (mm/month) & & & 41.20 & 154.64 & 32.40 & & & & & & & \\
\hline Spinach late $-\mathrm{K}_{\mathrm{C}}$ & & & & & & & & & 0.71 & 0.99 & 1.01 & \\
\hline $\mathrm{Et}_{\mathrm{o}}$ (mm/day) & & & & & & & & & 5.08 & 3.99 & 2.45 & \\
\hline $\mathrm{Et}_{\mathrm{c}}(\mathrm{mm} / \mathrm{day})$ & & & & & & & & & 3.62 & 3.97 & 2.48 & \\
\hline $\mathrm{Et}_{\mathrm{c}}$ (mm/month) & & & & & & & & & 50.73 & 123.11 & 12.39 & \\
\hline Potatoes $-\mathrm{K}_{\mathrm{c}}$ & & & 0.50 & 0.55 & 1.10 & 1.20 & 0.92 & & & & & \\
\hline $\mathrm{Et}_{\mathrm{o}}(\mathrm{mm} /$ day $)$ & & & 3.82 & 5.10 & 6.32 & 7.36 & 6.25 & & & & & \\
\hline $\mathrm{Et}_{\mathrm{c}}$ (mm/day) & & & 1.91 & 2.82 & 6.96 & 8.81 & 5.73 & & & & & \\
\hline $\mathrm{Et}_{\mathrm{c}}$ (mm/month) & & & 9.54 & 84.57 & 215.82 & 264.39 & 80.19 & & & & & \\
\hline Onions early $-\mathrm{K}_{\mathrm{c}}$ & & & 0.70 & 0.92 & 1.10 & 1.08 & 0.88 & & & & & \\
\hline $\mathrm{Et}_{\mathrm{o}}(\mathrm{mm} /$ day $)$ & & & 3.82 & 5.10 & 6.32 & 7.36 & 6.25 & & & & & \\
\hline $\mathrm{Et}_{\mathrm{c}}(\mathrm{mm} / \mathrm{day})$ & & & 2.67 & 4.67 & 6.98 & 7.96 & 5.48 & & & & & \\
\hline $\mathrm{Et}_{\mathrm{c}}$ (mm/month) & & & 13.36 & 140.05 & 216.32 & 238.86 & 76.72 & & & & & \\
\hline Onions late $-\mathrm{K}_{\mathrm{c}}$ & .82 & & & & & & & & 0.71 & 1.55 & 1.09 & 1.01 \\
\hline $\mathrm{Et}_{\mathrm{o}}(\mathrm{mm} / \mathrm{day})$ & 1.92 & & & & & & & & 5.08 & 3.99 & 2.45 & 2.00 \\
\hline $\mathrm{Et}_{\mathrm{c}}(\mathrm{mm} /$ day $)$ & 1.57 & & & & & & & & 3.62 & 6.20 & 2.67 & 2.02 \\
\hline $\mathrm{Et}_{\mathrm{c}}$ (mm/month) & 6.28 & & & & & & & & 50.70 & 192.07 & 80.04 & 62.65 \\
\hline Carrots early - $\mathrm{K}_{\mathrm{c}}$ & & & 0.71 & 1.02 & 1.08 & & & & & & & \\
\hline $\mathrm{Et}_{\mathrm{o}}(\mathrm{mm} / \mathrm{day})$ & & & 3.82 & 5.10 & 6.32 & & & & & & & \\
\hline $\mathrm{Et}_{\mathrm{c}}(\mathrm{mm} /$ day $)$ & & & 2.72 & 5.21 & 6.84 & & & & & & & \\
\hline $\mathrm{Et}_{\mathrm{c}}$ (mm/month) & & & 40.73 & 156.25 & 205.17 & & & & & & & \\
\hline
\end{tabular}


Table D-11. Mean Monthly Crop Coefficients $\left(K_{c}\right)$, Reference Evapotranspiration $\left(E T_{o}\right)$, and Crop Evapotranspiration $\left(E T_{c}\right)$ for Upper Bound Monsoon Climate Conditions (Continued)

\begin{tabular}{|c|c|c|c|c|c|c|c|c|c|c|c|c|}
\hline Crop & Jan & Feb & Mar & Apr & May & June & July & Aug & Sept & Oct & Nov & Dec \\
\hline Carrots late $-\mathrm{K}_{\mathrm{c}}$ & & & & & & & & 0.70 & 0.89 & 1.09 & 1.03 & \\
\hline $\mathrm{Et}_{\mathrm{o}}$ (mm/day) & & & & & & & & 5.64 & 5.08 & 3.99 & 2.45 & \\
\hline $\mathrm{Et}_{\mathrm{c}}(\mathrm{mm} /$ day $)$ & & & & & & & & 3.95 & 4.51 & 4.34 & 2.51 & \\
\hline $\mathrm{Et}_{\mathrm{c}}(\mathrm{mm} / \mathrm{month})$ & & & & & & & & 19.73 & 135.26 & 134.44 & 22.63 & \\
\hline Sweet Corn - $K_{c}$ & & & & & 0.53 & 1.20 & 1.19 & & & & & \\
\hline $\mathrm{Et}_{\mathrm{o}}(\mathrm{mm} / \mathrm{day})$ & & & & & 6.32 & 7.36 & 6.25 & & & & & \\
\hline $\mathrm{Et}_{\mathrm{c}}(\mathrm{mm} / \mathrm{day})$ & & & & & 6.01 & 7.96 & 8.82 & & & & & \\
\hline $\mathrm{Et}_{\mathrm{c}}$ (mm/month) & & & & & 186.31 & 238.8 & 185.22 & & & & & \\
\hline Bell Peppers - $K_{C}$ & & & & & 0.73 & 1.10 & 1.06 & & & & & \\
\hline $\mathrm{Et}_{\mathrm{o}}$ (mm/day) & & & & & 6.32 & 7.36 & 6.25 & & & & & \\
\hline $\mathrm{Et}_{\mathrm{c}}$ (mm/day) & & & & & 4.62 & 8.09 & 6.61 & & & & & \\
\hline $\mathrm{Et}_{\mathrm{c}}$ (mm/month) & & & & & 115.39 & 242.69 & 152.07 & & & & & \\
\hline Cucumbers - $\mathrm{K}_{\mathrm{c}}$ & & & & & & 0.74 & 0.98 & & & & & \\
\hline $\mathrm{Et}_{\mathrm{o}}$ (mm/day) & & & & & & 7.36 & 6.25 & & & & & \\
\hline $\mathrm{Et}_{\mathrm{c}}(\mathrm{mm} / \mathrm{day})$ & & & & & & 5.42 & 6.14 & & & & & \\
\hline $\mathrm{Et}_{\mathrm{c}}$ (mm/month) & & & & & & 157.21 & 190.25 & & & & & \\
\hline Squash - $\mathrm{K}_{\mathrm{c}}$ & & & & & 0.50 & 0.83 & 0.91 & & & & & \\
\hline $\mathrm{Et}_{\mathrm{o}}$ (mm/day) & & & & & 6.32 & 7.36 & 6.25 & & & & & \\
\hline $\mathrm{Et}_{\mathrm{c}}$ (mm/day) & & & & & 3.16 & 6.08 & 5.70 & & & & & \\
\hline $\mathrm{Et}_{\mathrm{c}}$ (mm/month) & & & & & 47.37 & 182.32 & 74.14 & & & & & \\
\hline Melons - $\mathrm{K}_{\mathrm{c}}$ & & & & & 0.51 & 0.71 & 1.07 & 1.00 & & & & \\
\hline $\mathrm{Et}_{\mathrm{o}}$ (mm/day) & & & & & 6.32 & 7.36 & 6.25 & 5.64 & & & & \\
\hline $\mathrm{Et}_{\mathrm{c}}$ (mm/day) & & & & & 3.22 & 5.25 & 6.69 & 5.63 & & & & \\
\hline $\mathrm{Et}_{\mathrm{c}}$ (mm/month) & & & & & 48.33 & 157.46 & 207.47 & 135.17 & & & & \\
\hline
\end{tabular}


Table D-11. Mean Monthly Crop Coefficients $\left(K_{c}\right)$, Reference Evapotranspiration $\left(E T_{o}\right)$, and Crop Evapotranspiration $\left(E T_{c}\right)$ for Upper Bound Monsoon Climate Conditions (Continued)

\begin{tabular}{|c|c|c|c|c|c|c|c|c|c|c|c|c|}
\hline Crop & Jan & Feb & Mar & Apr & May & June & July & Aug & Sept & Oct & Nov & Dec \\
\hline Tomatoes - $\mathrm{K}_{\mathrm{c}}$ & & & & & 0.63 & 1.10 & 1.08 & & & & & \\
\hline $\mathrm{Et}_{\mathrm{o}}$ (mm/day) & & & & & 6.32 & 7.36 & 6.25 & & & & & \\
\hline $\mathrm{Et}_{\mathrm{c}}$ (mm/day) & & & & & 3.96 & 8.11 & 6.77 & & & & & \\
\hline $\mathrm{Et}_{\mathrm{c}}(\mathrm{mm} / \mathrm{month})$ & & & & & 99.12 & 243.19 & 169.16 & & & & & \\
\hline Apples - $\mathrm{K}_{\mathrm{c}}$ & & & 0.60 & 0.72 & 0.96 & 1.01 & 1.01 & 1.01 & 1.01 & 0.91 & & \\
\hline $\mathrm{Et}_{\mathrm{o}}$ (mm/day) & & & 3.82 & 5.10 & 6.32 & 7.36 & 6.25 & 5.64 & 5.08 & 3.99 & & \\
\hline $\mathrm{Et}_{\mathrm{c}}$ (mm/day) & & & 2.29 & 3.68 & 6.04 & 7.42 & 6.30 & 5.68 & 5.12 & 3.64 & & \\
\hline $\mathrm{Et}_{\mathrm{c}}(\mathrm{mm} / \mathrm{month})$ & & & 68.72 & 110.48 & 187.14 & 222.55 & 195.45 & 176.21 & 153.66 & 98.22 & & \\
\hline Grapes - $\mathrm{K}_{\mathrm{c}}$ & & & 0.33 & 0.58 & 0.77 & 0.77 & 0.73 & 0.54 & & & & \\
\hline $\mathrm{Et}_{\mathrm{o}}$ (mm/day) & & & 3.82 & 5.10 & 6.32 & 7.36 & 6.25 & 5.64 & & & & \\
\hline $\mathrm{Et}_{\mathrm{c}}$ (mm/day) & & & 1.24 & 2.98 & 4.88 & 5.69 & 4.54 & 3.07 & & & & \\
\hline $\mathrm{Et}_{\mathrm{c}}$ (mm/month) & & & 37.25 & 89.32 & 151.17 & 170.72 & 140.69 & 95.16 & & & & \\
\hline Strawberries - $\mathrm{K}_{\mathrm{c}}$ & & & 0.57 & 0.64 & 0.87 & 0.88 & 0.68 & 0.84 & 0.79 & & & \\
\hline $\mathrm{Et}_{\mathrm{o}}(\mathrm{mm} / \mathrm{day})$ & & & 3.82 & 5.10 & 6.32 & 7.36 & 6.25 & 5.64 & 5.08 & & & \\
\hline $\mathrm{Et}_{\mathrm{c}}$ (mm/day) & & & 2.16 & 3.27 & 5.49 & 6.51 & 4.25 & 4.73 & 4.00 & & & \\
\hline $\mathrm{Et}_{\mathrm{c}}(\mathrm{mm} / \mathrm{month})$ & & & 64.78 & 98.22 & 170.15 & 195.22 & 131.67 & 146.67 & 87.91 & & & \\
\hline Winter wheat $-\mathrm{K}_{\mathrm{c}}$ & 1.11 & 1.22 & 1.22 & 1.22 & 0.98 & 0.44 & & & & 0.70 & 0.73 & 0.91 \\
\hline $\mathrm{Et}_{\mathrm{o}}(\mathrm{mm} / \mathrm{day})$ & 1.92 & 2.96 & 3.82 & 5.10 & 6.32 & 7.36 & & & & 3.99 & 2.45 & 2.00 \\
\hline $\mathrm{Et}_{\mathrm{c}}(\mathrm{mm} / \mathrm{day})$ & 2.14 & 3.61 & 4.66 & 6.22 & 6.20 & 3.23 & & & & 2.79 & 1.80 & 1.83 \\
\hline $\mathrm{Et}_{\mathrm{c}}$ (mm/month) & 66.46 & 100.94 & 144.36 & 186.52 & 192.15 & 51.69 & & & & 41.92 & 53.96 & 56.80 \\
\hline Barley - $\mathrm{K}_{\mathrm{c}}$ & 1.04 & 1.22 & 1.22 & 1.22 & 0.91 & 0.42 & & & & 0.30 & 0.35 & 0.67 \\
\hline $\mathrm{Et}_{\mathrm{o}}$ (mm/day) & 1.92 & 2.96 & 3.82 & 5.10 & 6.32 & 7.36 & & & & 3.99 & 2.45 & 2.00 \\
\hline $\mathrm{Et}_{\mathrm{c}}(\mathrm{mm} / \mathrm{day})$ & 2.01 & 3.60 & 4.66 & 6.21 & 5.77 & 3.08 & & & & 1.20 & 0.85 & 1.34 \\
\hline $\mathrm{Et}_{\mathrm{c}}(\mathrm{mm} / \mathrm{month})$ & 62.27 & 100.91 & 144.31 & 186.45 & 178.86 & 49.26 & & & & 17.96 & 25.36 & 41.52 \\
\hline
\end{tabular}


Table D-11. Mean Monthly Crop Coefficients $\left(K_{c}\right)$, Reference Evapotranspiration $\left(E T_{o}\right)$, and Crop Evapotranspiration $\left(E T_{c}\right)$ for Upper Bound Monsoon Climate Conditions (Continued)

\begin{tabular}{|c|c|c|c|c|c|c|c|c|c|c|c|c|}
\hline Crop & Jan & Feb & Mar & Apr & May & June & July & Aug & Sept & Oct & Nov & Dec \\
\hline Feed Corn - Kc & & & & & 0.30 & 0.41 & 1.00 & 1.23 & 1.11 & 0.58 & & \\
\hline $\mathrm{Et}_{\mathrm{o}}(\mathrm{mm} / \mathrm{day})$ & & & & & 6.32 & 7.36 & 6.25 & 5.64 & 5.08 & 3.99 & & \\
\hline $\mathrm{Et}_{\mathrm{c}}(\mathrm{mm} / \mathrm{day})$ & & & & & 1.89 & 3.04 & 6.23 & 6.91 & 5.65 & 2.30 & & \\
\hline $\mathrm{Et}_{\mathrm{c}}$ (mm/month) & & & & & 28.42 & 91.26 & 193.01 & 214.07 & 169.58 & 39.05 & & \\
\hline Oat Feed - Kc & 0.50 & 1.03 & 1.22 & 1.21 & 0.65 & & & & & & & 0.30 \\
\hline $\mathrm{Et}_{\mathrm{o}}(\mathrm{mm} / \mathrm{day})$ & 1.92 & 2.96 & 3.82 & 5.10 & 6.32 & & & & & & & 2.00 \\
\hline $\mathrm{Et}_{\mathrm{c}}(\mathrm{mm} / \mathrm{day})$ & 0.96 & 3.05 & 4.66 & 6.15 & 4.13 & & & & & & & 0.60 \\
\hline $\mathrm{Et}_{\mathrm{c}}$ (mm/month) & 29.86 & 85.27 & 144.32 & 184.40 & 103.26 & & & & & & & 9.01 \\
\hline Alfalfa hay (1st) - $K_{c}$ & 0.69 & 1.25 & 1.19 & & & & & & & & & \\
\hline $\mathrm{Et}_{\mathrm{o}}$ (mm/day) & 1.92 & 2.96 & 3.82 & & & & & & & & & \\
\hline $\mathrm{Et}_{\mathrm{c}}(\mathrm{mm} / \mathrm{day})$ & 1.32 & 3.69 & 4.55 & & & & & & & & & \\
\hline $\mathrm{Et}_{\mathrm{c}}$ (mm/month) & 39.69 & 103.40 & 9.10 & & & & & & & & & \\
\hline Alfalfa hay $(2 n d)-K_{c}$ & & & 0.71 & 1.26 & & & & & & & & \\
\hline $\mathrm{Et}_{\mathrm{o}}(\mathrm{mm} / \mathrm{day})$ & & & 3.82 & 5.10 & & & & & & & & \\
\hline $\mathrm{Et}_{\mathrm{c}}(\mathrm{mm} /$ day $)$ & & & 2.71 & 6.40 & & & & & & & & \\
\hline $\mathrm{Et}_{\mathrm{c}}$ (mm/month) & & & 75.76 & 172.76 & & & & & & & & \\
\hline Alfalfa hay $(3 r d)-K_{c}$ & & & & 0.40 & 0.87 & 1.24 & & & & & & \\
\hline $\mathrm{Et}_{\mathrm{o}}$ (mm/day) & & & & 5.01 & 6.32 & 7.36 & & & & & & \\
\hline $\mathrm{Et}_{\mathrm{c}}(\mathrm{mm} / \mathrm{day})$ & & & & 2.04 & 5.52 & 9.15 & & & & & & \\
\hline $\mathrm{Et}_{\mathrm{c}}$ (mm/month) & & & & 8.16 & 171.16 & 183.04 & & & & & & \\
\hline Alfalfa hay (4th) - $K_{c}$ & & & & & & 0.47 & 1.39 & 1.20 & & & & \\
\hline $\mathrm{Et}_{\mathrm{o}}$ (mm/day) & & & & & & 7.36 & 6.25 & 5.64 & & & & \\
\hline $\mathrm{Et}_{\mathrm{c}}$ (mm/day) & & & & & & 3.48 & 8.72 & 6.76 & & & & \\
\hline $\mathrm{Et}_{\mathrm{c}}$ (mm/month) & & & & & & 34.78 & 270.18 & 94.58 & & & & \\
\hline
\end{tabular}


Table D-11. Mean Monthly Crop Coefficients $\left(K_{c}\right)$, Reference Evapotranspiration $\left(E T_{o}\right)$, and Crop Evapotranspiration $\left(E T_{c}\right)$ for Upper Bound Monsoon Climate Conditions (Continued)

\begin{tabular}{|c|c|c|c|c|c|c|c|c|c|c|c|c|}
\hline Crop & Jan & Feb & Mar & Apr & May & June & July & Aug & Sept & Oct & Nov & Dec \\
\hline Alfalfa hay (5th) - $K_{c}$ & & & & & & & & 0.49 & 1.01 & 1.21 & & \\
\hline $\mathrm{Et}_{\mathrm{o}}(\mathrm{mm} /$ day $)$ & & & & & & & & 5.64 & 5.08 & 3.99 & & \\
\hline $\mathrm{Et}_{\mathrm{c}}$ (mm/day) & & & & & & & & 2.76 & 5.15 & 4.84 & & \\
\hline $\mathrm{Et}_{\mathrm{c}}(\mathrm{mm} / \mathrm{month})$ & & & & & & & & 46.84 & 51.54 & 96.85 & & \\
\hline Alfalfa hay (6th) $-K_{c}$ & & & & & & & & & & 0.60 & 1.23 & 1.20 \\
\hline $\mathrm{Et}_{\mathrm{o}}$ (mm/day) & & & & & & & & & & 3.99 & 2.45 & 2.00 \\
\hline $\mathrm{Et}_{\mathrm{c}}$ (mm/day) & & & & & & & & & & 2.40 & 3.00 & 2.40 \\
\hline $\mathrm{Et}_{\mathrm{c}}$ (mm/month) & & & & & & & & & & 55.09 & 90.13 & 4.81 \\
\hline Corn silage - Kc & & & & & 0.30 & 0.85 & 1.23 & 0.87 & & & & \\
\hline $\mathrm{Et}_{\mathrm{o}}$ (mm/day) & & & & & 6.32 & 7.36 & 6.25 & 5.64 & & & & \\
\hline $\mathrm{Et}_{\mathrm{c}}$ (mm/day) & & & & & 1.89 & 6.22 & 7.67 & 4.88 & & & & \\
\hline $\mathrm{Et}_{\mathrm{c}}(\mathrm{mm} / \mathrm{month})$ & & & & & 28.42 & 186.59 & 237.85 & 78.02 & & & & \\
\hline Oat Hay $-K_{c}$ & & & & 0.58 & 1.22 & 0.74 & & & & & & \\
\hline$E t_{o}$ (mm/day) & & & & 5.10 & 6.32 & 7.36 & & & & & & \\
\hline $\mathrm{Et}_{\mathrm{c}}(\mathrm{mm} / \mathrm{day})$ & & & & 2.97 & 7.70 & 5.42 & & & & & & \\
\hline $\mathrm{Et}_{\mathrm{c}}(\mathrm{mm} / \mathrm{month})$ & & & & 89.14 & 238.57 & 75.90 & & & & & & \\
\hline Bermuda $^{\mathrm{e}}-\mathrm{K}_{\mathrm{c}}$ & 0.85 & 0.85 & 0.85 & 0.85 & 0.85 & 0.85 & 0.85 & 0.85 & 0.85 & 0.85 & 0.85 & 0.85 \\
\hline $\mathrm{Et}_{\mathrm{o}}$ (mm/day) & 1.92 & 2.96 & 3.82 & 5.10 & 6.32 & 7.36 & 6.25 & 5.64 & 5.08 & 3.99 & 2.45 & 2.00 \\
\hline$E_{\mathrm{c}}(\mathrm{mm} /$ day $)$ & 1.64 & 2.51 & 3.25 & 4.33 & 5.37 & 6.25 & 5.31 & 4.79 & 4.32 & 3.39 & 2.08 & 1.70 \\
\hline $\mathrm{Et}_{\mathrm{c}}$ (mm/month) & 50.71 & 70.35 & 100.60 & 129.97 & 166.43 & 187.57 & 164.73 & 148.52 & 129.62 & 105.19 & 62.43 & 52.76 \\
\hline
\end{tabular}

${ }^{a}$ Mean monthly $K_{c}$ values calculated according to Appendix D, Section 4.

${ }^{b}$ Mean monthly $E T_{0}$ values from Appendix C, Table C-9.

${ }^{c}$ Mean daily $E T_{c}$ calculated using Equation D-1.

d Mean monthly $E T_{c}$ calculated from mean daily $E T_{c}$ and the number of growing days per month (Appendix D, Section 5 ).

e Bermudagrass was selected for upper bound monsoon climate because it is a warm season grass. 
Table D-12. Mean Monthly Crop Coefficients $\left(K_{c}\right)$, Reference Evapotranspiration $\left(E T_{o}\right)$, and Crop Evapotranspiration $\left(E T_{c}\right)$ for Lower Bound Glacial Transition Climate Conditions

\begin{tabular}{|c|c|c|c|c|c|c|c|c|c|c|c|c|}
\hline Crop & Jan & Feb & Mar & Apr & May & Jun & Jul & Aug & Sep & Oct & Nov & Dec \\
\hline Leaf Lettuce early $-\mathrm{K}_{\mathrm{c}}{ }^{\mathrm{a}}$ & & & & 0.70 & 0.85 & 1.08 & & & & & & \\
\hline $\mathrm{ET}_{\mathrm{o}}(\mathrm{mm} / \mathrm{day})^{\mathrm{b}}$ & & & & 4.30 & 6.01 & 7.96 & & & & & & \\
\hline $\mathrm{ET}_{\mathrm{c}}(\mathrm{mm} / \mathrm{day})^{\mathrm{c}}$ & & & & 3.01 & 5.08 & 8.62 & & & & & & \\
\hline Monthly $\mathrm{ET}_{\mathrm{c}}(\mathrm{mm} / \mathrm{month})^{\mathrm{d}}$ & & & & 21.07 & 157.59 & 172.44 & & & & & & \\
\hline Leaf Lettuce late $-\mathrm{K}_{\mathrm{c}}$ & & & & & & & 0.70 & 0.95 & 1.06 & & & \\
\hline $\mathrm{ET}_{\mathrm{o}}$ (mm/day) & & & & & & & 8.82 & 8.26 & 6.27 & & & \\
\hline $\mathrm{ET}_{\mathrm{C}}(\mathrm{mm} /$ day $)$ & & & & & & & 6.18 & 7.87 & 6.66 & & & \\
\hline Monthly $\mathrm{ET}_{\mathrm{c}}$ (mm/month) & & & & & & & 98.86 & 243.84 & 73.23 & & & \\
\hline Head Lettuce early - $\mathrm{K}_{\mathrm{c}}$ & & & & 0.70 & 0.76 & 1.05 & 1.07 & & & & & \\
\hline $\mathrm{ET}_{\mathrm{o}}(\mathrm{mm} / \mathrm{day})$ & & & & 4.30 & 6.01 & 7.96 & 8.82 & & & & & \\
\hline $\mathrm{ET}_{\mathrm{C}}$ (mm/day) & & & & 3.01 & 4.56 & 8.37 & 9.41 & & & & & \\
\hline Monthly $\mathrm{ET}_{\mathrm{c}}$ (mm/month) & & & & 21.07 & 141.43 & 251.15 & 94.09 & & & & & \\
\hline Head Lettuce late - $\mathrm{K}_{\mathrm{c}}$ & & & & & & & 0.70 & 0.83 & 1.06 & 1.03 & & \\
\hline $\mathrm{ET}_{\mathrm{o}}$ (mm/day) & & & & & & & 8.82 & 8.26 & 6.27 & 4.05 & & \\
\hline $\mathrm{ET}_{\mathrm{C}}$ (mm/day) & & & & & & & 6.17 & 6.88 & 6.67 & 4.16 & & \\
\hline Monthly $\mathrm{ET}_{\mathrm{c}}$ (mm/month) & & & & & & & 98.78 & 213.14 & 200.23 & 4.16 & & \\
\hline Cabbage early $-\mathrm{K}_{\mathrm{c}}$ & & & & 0.70 & 0.81 & 1.14 & 1.10 & & & & & \\
\hline $\mathrm{ET}_{\mathrm{o}}$ (mm/day) & & & & 4.30 & 6.01 & 7.96 & 8.82 & & & & & \\
\hline $\mathrm{ET}_{\mathrm{c}}(\mathrm{mm} /$ day $)$ & & & & 3.01 & 4.86 & 9.06 & 9.70 & & & & & \\
\hline Monthly $\mathrm{ET}_{\mathrm{C}}$ (mm/month) & & & & 21.07 & 150.52 & 271.73 & 67.92 & & & & & \\
\hline Cabbage late $-\mathrm{K}_{\mathrm{c}}$ & & & & & & & 0.70 & 0.87 & 1.12 & 1.04 & & \\
\hline $\mathrm{ET}_{\mathrm{o}}$ (mm/day) & & & & & & & 8.82 & 8.26 & 6.27 & 4.05 & & \\
\hline $\mathrm{ET}_{\mathrm{c}}(\mathrm{mm} / \mathrm{day})$ & & & & & & & 6.17 & 7.23 & 7.05 & 4.21 & & \\
\hline Monthly ETc (mm/month) & & & & & & & 80.26 & 224.04 & 211.49 & 4.21 & & \\
\hline
\end{tabular}


Table D-12. Mean Monthly Crop Coefficients $(K C)$, Reference Evapotranspiration (ETo), and Crop Evapotranspiration (ETC) for Lower Bound Glacial Transition Climate Conditions (Continued)

\begin{tabular}{|c|c|c|c|c|c|c|c|c|c|c|c|c|}
\hline Crop & Jan & Feb & Mar & Apr & May & Jun & Jul & Aug & Sep & Oct & Nov & Dec \\
\hline Celery - $\mathrm{K}_{\mathrm{c}}$ & & & & 0.70 & 0.75 & 1.08 & 1.16 & 1.13 & & & & \\
\hline$E T_{o}$ (mm/day) & & & & 4.30 & 6.01 & 7.96 & 8.82 & 8.26 & & & & \\
\hline$E T_{c}(\mathrm{~mm} /$ day $)$ & & & & 3.01 & 4.53 & 8.62 & 10.25 & 9.32 & & & & \\
\hline Monthly $\mathrm{ET}_{\mathrm{c}}$ (mm/month) & & & & 21.07 & 140.58 & 258.58 & 317.71 & 102.57 & & & & \\
\hline Broccoli early - $K_{c}$ & & & & 0.70 & 0.77 & 1.11 & 1.11 & & & & & \\
\hline $\mathrm{ET}_{\mathrm{o}}$ (mm/day) & & & & 4.30 & 6.01 & 7.96 & 8.82 & & & & & \\
\hline $\mathrm{ET}_{\mathrm{c}}(\mathrm{mm} / \mathrm{day})$ & & & & 3.01 & 4.65 & 8.84 & 9.81 & & & & & \\
\hline Monthly $\mathrm{ET}_{\mathrm{c}}$ (mm/month) & & & & 21.07 & 144.14 & 265.22 & 147.10 & & & & & \\
\hline Broccoli late $-\mathrm{K}_{\mathrm{c}}$ & & & & & & & 0.70 & 0.85 & 1.12 & 1.06 & & \\
\hline $\mathrm{ET}_{\mathrm{o}}(\mathrm{mm} /$ day $)$ & & & & & & & 8.82 & 8.26 & 6.27 & 4.05 & & \\
\hline$E T_{c}(\mathrm{~mm} /$ day $)$ & & & & & & & 6.17 & 7.05 & 7.04 & 4.30 & & \\
\hline Monthly $\mathrm{ET}_{\mathrm{c}}$ (mm/month) & & & & & & & 92.61 & 218.55 & 211.30 & 30.11 & & \\
\hline Cauliflower early - $\mathrm{K}_{\mathrm{c}}$ & & & & 0.70 & 0.86 & 1.14 & & & & & & \\
\hline $\mathrm{ET}_{\mathrm{o}}(\mathrm{mm} /$ day $)$ & & & & 4.30 & 6.01 & 7.96 & & & & & & \\
\hline $\mathrm{ET}_{\mathrm{c}}$ (mm/day) & & & & 3.01 & 5.17 & 9.05 & & & & & & \\
\hline Monthly $\mathrm{ET}_{\mathrm{c}}$ (mm/month) & & & & 21.07 & 160.27 & 226.37 & & & & & & \\
\hline Cauliflower late $-\mathrm{K}_{\mathrm{c}}$ & & & & & & & 0.70 & 0.78 & 1.10 & 1.04 & & \\
\hline $\mathrm{ET}_{\mathrm{o}}(\mathrm{mm} / \mathrm{day})$ & & & & & & & 8.82 & 8.26 & 6.27 & 4.05 & & \\
\hline$E T_{c}(\mathrm{~mm} /$ day $)$ & & & & & & & 6.17 & 6.45 & 6.91 & 4.21 & & \\
\hline Monthly $\mathrm{ET}_{\mathrm{c}}$ (mm/month) & & & & & & & 6.17 & 200.06 & 207.42 & 4.21 & & \\
\hline Spinach early $-\mathrm{K}_{\mathrm{c}}$ & & & & 0.70 & 0.86 & 1.09 & & & & & & \\
\hline $\mathrm{ET}_{\mathrm{o}}(\mathrm{mm} / \mathrm{day})$ & & & & 4.30 & 6.01 & 7.96 & & & & & & \\
\hline $\mathrm{ET}_{\mathrm{c}}(\mathrm{mm} / \mathrm{day})$ & & & & 3.01 & 5.16 & 8.64 & & & & & & \\
\hline Monthly $\mathrm{ET}_{\mathrm{c}}$ (mm/month) & & & & 21.07 & 159.82 & 146.92 & & & & & & \\
\hline Spinach late $-\mathrm{K}_{\mathrm{c}}$ & & & & & & & & 0.72 & 1.04 & 1.03 & & \\
\hline $\mathrm{ET}_{\circ}(\mathrm{mm} /$ day $)$ & & & & & & & & 8.26 & 6.27 & 4.05 & & \\
\hline $\mathrm{ET}_{\mathrm{c}}$ (mm/day) & & & & & & & & 5.97 & 6.51 & 4.18 & & \\
\hline
\end{tabular}


Table D-12. Mean Monthly Crop Coefficients $(K C)$, Reference Evapotranspiration (ETo), and Crop Evapotranspiration (ETC) for Lower Bound Glacial Transition Climate Conditions (Continued)

\begin{tabular}{|c|c|c|c|c|c|c|c|c|c|c|c|c|}
\hline Crop & Jan & Feb & Mar & Apr & May & Jun & Jul & Aug & Sep & Oct & Nov & Dec \\
\hline Monthly $\mathrm{ET}_{\mathrm{c}}$ (mm/month) & & & & & & & & 143.24 & 195.16 & 4.18 & & \\
\hline Potatoes - $\mathrm{K}_{\mathrm{c}}$ & & & & 0.50 & 0.53 & 1.14 & 1.26 & 1.08 & & & & \\
\hline $\mathrm{ET}_{\mathrm{o}}(\mathrm{mm} /$ day $)$ & & & & 4.30 & 6.01 & 7.96 & 8.82 & 8.26 & & & & \\
\hline $\mathrm{ET}_{\mathrm{c}}$ (mm/day) & & & & 2.15 & 3.18 & 9.10 & 11.13 & 8.95 & & & & \\
\hline Monthly $\mathrm{ET}_{\mathrm{c}}$ (mm/month) & & & & 15.05 & 98.50 & 273.08 & 345.09 & 143.15 & & & & \\
\hline Onions - $\mathrm{K}_{\mathrm{c}}$ & & & 0.76 & 1.10 & 1.14 & 1.14 & 0.98 & 0.86 & & & & \\
\hline $\mathrm{ET}_{0}(\mathrm{~mm} /$ day $)$ & & & 2.85 & 4.30 & 6.01 & 7.96 & 8.82 & 8.26 & & & & \\
\hline $\mathrm{ET}_{\mathrm{c}}(\mathrm{mm} / \mathrm{day})$ & & & 2.16 & 4.75 & 6.86 & 9.05 & 8.65 & 7.10 & & & & \\
\hline Monthly $\mathrm{ET}_{\mathrm{c}}$ (mm/month) & & & 64.94 & 142.52 & 212.81 & 271.37 & 268.25 & 21.29 & & & & \\
\hline Carrots early - $\mathrm{K}_{\mathrm{c}}$ & & & & 0.70 & 0.86 & 1.14 & 1.10 & & & & & \\
\hline $\mathrm{ET}_{\mathrm{o}}(\mathrm{mm} /$ day $)$ & & & & 4.30 & 6.01 & 7.96 & 8.82 & & & & & \\
\hline $\mathrm{ET}_{\mathrm{C}}$ (mm/day) & & & & 3.01 & 5.19 & 9.10 & 9.67 & & & & & \\
\hline Monthly $\mathrm{ET}_{\mathrm{c}}$ (mm/month) & & & & 21.07 & 161.02 & 272.91 & 116.00 & & & & & \\
\hline Carrots late $-\mathrm{K}_{\mathrm{c}}$ & & & & & & & 0.70 & 1.01 & 1.11 & 1.03 & & \\
\hline $\mathrm{ET}_{\mathrm{o}}$ (mm/day) & & & & & & & 8.82 & 8.26 & 6.27 & 4.05 & & \\
\hline $\mathrm{ET}_{\mathrm{C}}$ (mm/day) & & & & & & & 6.19 & 8.34 & 6.98 & 4.17 & & \\
\hline Monthly $\mathrm{ET}_{\mathrm{c}}$ (mm/month) & & & & & & & 111.49 & 258.66 & 209.45 & 4.17 & & \\
\hline Sweet corn $-K_{c}$ & & & & & 0.30 & 0.36 & 1.05 & 1.28 & 1.21 & & & \\
\hline $\mathrm{ET}_{\mathrm{o}}(\mathrm{mm} / \mathrm{day})$ & & & & & 5.39 & 6.96 & 7.83 & 7.39 & 5.77 & & & \\
\hline $\mathrm{ET}_{\mathrm{c}}(\mathrm{mm} /$ day $)$ & & & & & 6.01 & 7.96 & 8.82 & 8.26 & 6.27 & & & \\
\hline Monthly $\mathrm{ET}_{\mathrm{C}}$ (mm/month) & & & & & 42.07 & 238.80 & 273.42 & 256.06 & 37.62 & & & \\
\hline Bell peppers - $\mathrm{K}_{\mathrm{c}}$ & & & & & & 0.60 & 0.87 & 1.16 & 1.08 & & & \\
\hline $\mathrm{ET}_{\mathrm{o}}(\mathrm{mm} /$ day $)$ & & & & & & 7.96 & 8.82 & 8.26 & 6.27 & & & \\
\hline $\mathrm{ET}_{\mathrm{c}}(\mathrm{mm} /$ day $)$ & & & & & & 4.78 & 7.67 & 9.57 & 6.76 & & & \\
\hline Monthly $\mathrm{ET}_{\mathrm{C}}$ (mm/month) & & & & & & 105.07 & 237.88 & 296.52 & 108.17 & & & \\
\hline Cucumbers - $\mathrm{K}_{\mathrm{c}}$ & & & & & 0.60 & 0.84 & 1.05 & & & & & \\
\hline $\mathrm{ET}_{\mathrm{o}}(\mathrm{mm} /$ day $)$ & & & & & 6.01 & 7.96 & 8.82 & & & & & \\
\hline $\mathrm{ET}_{\mathrm{c}}(\mathrm{mm} /$ day $)$ & & & & & 3.61 & 6.66 & 9.27 & & & & & \\
\hline Monthly $\mathrm{ET}_{\mathrm{c}}$ (mm/month) & & & & & 25.24 & 199.95 & 287.25 & & & & & \\
\hline
\end{tabular}


Table D-12. Mean Monthly Crop Coefficients $(K C)$, Reference Evapotranspiration (ETo), and Crop Evapotranspiration (ETC) for Lower Bound Glacial Transition Climate Conditions (Continued)

\begin{tabular}{|c|c|c|c|c|c|c|c|c|c|c|c|c|}
\hline Crop & Jan & Feb & Mar & Apr & May & Jun & Jul & Aug & Sep & Oct & Nov & Dec \\
\hline Squash $-\mathrm{K}_{\mathrm{c}}$ & & & & & 0.50 & 0.72 & 1.00 & & & & & \\
\hline $\mathrm{ET}_{\mathrm{o}}$ (mm/day) & & & & & 6.01 & 7.96 & 8.82 & & & & & \\
\hline $\mathrm{ET}_{\mathrm{C}}$ (mm/day) & & & & & 3.00 & 5.70 & 8.83 & & & & & \\
\hline Monthly $\mathrm{ET}_{\mathrm{c}}$ (mm/month) & & & & & 21.04 & 171.04 & 247.28 & & & & & \\
\hline Melons - $\mathrm{K}_{\mathrm{c}}$ & & & & & 0.50 & 0.58 & 1.07 & 1.10 & 0.88 & & & \\
\hline $\mathrm{ET}_{\mathrm{o}}(\mathrm{mm} /$ day $)$ & & & & & 6.01 & 7.96 & 8.82 & 8.26 & 6.27 & & & \\
\hline $\mathrm{ET}_{\mathrm{C}}(\mathrm{mm} / \mathrm{day})$ & & & & & 3.00 & 4.62 & 9.41 & 9.05 & 5.50 & & & \\
\hline Monthly $\mathrm{ET}_{\mathrm{c}}$ (mm/month) & & & & & 21.04 & 138.65 & 291.67 & 280.67 & 27.00 & & & \\
\hline Tomatoes - $\mathrm{K}_{\mathrm{c}}$ & & & & & & 0.61 & 1.08 & 1.19 & 0.94 & & & \\
\hline $\mathrm{ET}_{\mathrm{o}}$ (mm/day) & & & & & & 7.96 & 8.82 & 8.26 & 6.27 & & & \\
\hline $\mathrm{ET}_{\mathrm{c}}$ (mm/day) & & & & & & 4.86 & 9.52 & 9.87 & 5.91 & & & \\
\hline Monthly $\mathrm{ET}_{\mathrm{c}}$ (mm/month) & & & & & & 106.81 & 295.27 & 305.82 & 23.63 & & & \\
\hline Corn silage $-\mathrm{K}_{\mathrm{c}}$ & & & & & 0.30 & 0.67 & 1.34 & 1.29 & 0.93 & & & \\
\hline $\mathrm{ET}_{\mathrm{o}}$ (mm/day) & & & & & 6.01 & 7.96 & 8.82 & 8.26 & 6.27 & & & \\
\hline $\mathrm{ET}_{\mathrm{c}}(\mathrm{mm} /$ day $)$ & & & & & 1.80 & 5.35 & 11.79 & 10.68 & 5.82 & & & \\
\hline Monthly $\mathrm{ET}_{\mathrm{c}}$ (mm/month) & & & & & 36.06 & 160.37 & 365.35 & 331.19 & 145.41 & & & \\
\hline Feed Corn - $\mathrm{K}_{\mathrm{c}}$ & & & & & 0.30 & 0.43 & 1.11 & 1.35 & 1.26 & 0.74 & 0.40 & \\
\hline $\mathrm{ET}_{\mathrm{o}}(\mathrm{mm} / \mathrm{day})$ & & & & & 6.01 & 7.96 & 8.82 & 8.26 & 6.27 & 4.05 & 1.90 & \\
\hline $\mathrm{ET}_{\mathrm{c}}(\mathrm{mm} /$ day $)$ & & & & & 1.80 & 3.46 & 9.83 & 11.12 & 7.93 & 3.01 & 0.76 & \\
\hline Monthly $\mathrm{ET}_{\mathrm{c}}$ (mm/month) & & & & & 36.06 & 103.76 & 304.78 & 344.68 & 237.82 & 93.24 & 3.78 & \\
\hline Oat Feed - $\mathrm{K}_{\mathrm{c}}$ & & & 0.30 & 0.39 & 1.16 & 1.28 & 1.16 & 0.52 & & & & \\
\hline $\mathrm{ET}_{\mathrm{o}}(\mathrm{mm} /$ day $)$ & & & 2.85 & 4.30 & 6.01 & 7.96 & 8.82 & 8.26 & & & & \\
\hline $\mathrm{ET}_{\mathrm{c}}$ (mm/day) & & & 0.86 & 1.68 & 6.98 & 10.19 & 10.22 & 4.26 & & & & \\
\hline Monthly $\mathrm{ET}_{\mathrm{c}}$ (mm/month) & & & 2.66 & 50.37 & 216.25 & 305.63 & 316.97 & 68.16 & & & & \\
\hline Alfalfa (1 ${ }^{\text {st }}$ cutting) $-\mathrm{K}_{\mathrm{c}}$ & & & 0.60 & 1.25 & 1.28 & & & & & & & \\
\hline $\mathrm{ET}_{\mathrm{o}}(\mathrm{mm} / \mathrm{day})$ & & & 2.85 & 4.30 & 6.01 & & & & & & & \\
\hline $\mathrm{ET}_{\mathrm{c}}$ (mm/day) & & & 1.71 & 5.36 & 7.72 & & & & & & & \\
\hline Monthly $\mathrm{ET}_{\mathrm{c}}$ (mm/month) & & & 51.23 & 160.78 & 115.78 & & & & & & & \\
\hline Alfalfa $\left(2^{\text {nd }}\right.$ cutting $)-\mathrm{K}_{\mathrm{c}}$ & & & & & 0.46 & 1.07 & 1.30 & & & & & \\
\hline $\mathrm{ET}_{\mathrm{o}}$ (mm/day) & & & & & 6.01 & 7.96 & 8.82 & & & & & \\
\hline
\end{tabular}


Table D-12. Mean Monthly Crop Coefficients $(K C)$, Reference Evapotranspiration (ETo), and Crop Evapotranspiration (ETC) for Lower Bound Glacial Transition Climate Conditions (Continued)

\begin{tabular}{|c|c|c|c|c|c|c|c|c|c|c|c|c|}
\hline Crop & Jan & Feb & Mar & Apr & May & Jun & Jul & Aug & Sep & Oct & Nov & Dec \\
\hline $\mathrm{ET}_{\mathrm{c}}$ (mm/day) & & & & & 2.77 & 8.53 & 11.47 & & & & & \\
\hline Monthly $\mathrm{ET}_{\mathrm{c}}$ (mm/month) & & & & & 44.35 & 255.88 & 252.41 & & & & & \\
\hline Alfalfa ( $3^{\text {rd }}$ cutting) $-\mathrm{K}_{\mathrm{c}}$ & & & & & & & 0.40 & 0.89 & 1.29 & & & \\
\hline $\mathrm{ET}_{\mathrm{o}}(\mathrm{mm} / \mathrm{day})$ & & & & & & & 8.82 & 8.26 & 6.27 & & & \\
\hline $\mathrm{ET}_{\mathrm{c}}$ (mm/day) & & & & & & & 3.54 & 7.38 & 8.06 & & & \\
\hline Monthly $\mathrm{ET}_{\mathrm{c}}$ (mm/month) & & & & & & & 31.88 & 228.64 & 225.78 & & & \\
\hline Apples - $\mathrm{K}_{\mathrm{c}}$ & & & & 0.45 & 0.56 & 0.92 & 1.13 & 1.14 & 1.07 & 0.89 & & \\
\hline $\mathrm{ET}_{\mathrm{o}}$ (mm/day) & & & & 4.30 & 6.01 & 7.96 & 8.82 & 8.26 & 6.27 & 4.05 & & \\
\hline $\mathrm{ET}_{\mathrm{c}}(\mathrm{mm} / \mathrm{day})$ & & & & 1.94 & 3.34 & 7.35 & 10.01 & 9.38 & 6.69 & 3.61 & & \\
\hline Monthly $\mathrm{ET}_{\mathrm{c}}$ (mm/month) & & & & 15.48 & 103.66 & 220.59 & 310.29 & 290.80 & 200.77 & 18.05 & & \\
\hline Grapes - $\mathrm{K}_{\mathrm{c}}$ & & & & & & & 0.30 & 0.60 & 0.84 & 0.77 & & \\
\hline $\mathrm{ET}_{\mathrm{o}}(\mathrm{mm} / \mathrm{day})$ & & & & & & & 7.96 & 8.82 & 8.26 & 6.27 & & \\
\hline $\mathrm{ET}_{\mathrm{c}}$ (mm/day) & & & & & & & 2.39 & 5.25 & 6.92 & 4.81 & & \\
\hline Monthly $\mathrm{ET}_{\mathrm{c}}$ (mm/month) & & & & & & & 31.12 & 162.70 & 214.59 & 144.25 & & \\
\hline Strawberries - $\mathrm{K}_{\mathrm{c}}$ & & & & 0.40 & 0.71 & 0.92 & & & & & & \\
\hline $\mathrm{ET}_{\mathrm{o}}$ (mm/day) & & & & 4.30 & 6.01 & 7.96 & & & & & & \\
\hline $\mathrm{ET}_{\mathrm{c}}$ (mm/day) & & & & 1.72 & 4.26 & 7.32 & & & & & & \\
\hline Monthly $\mathrm{ET}_{\mathrm{C}}$ (mm/month) & & & & 5.16 & 131.92 & 219.49 & & & & & & \\
\hline Winter wheat $-\mathrm{K}_{\mathrm{c}}$ & 0.76 & 0.89 & 1.02 & 1.16 & 1.27 & 1.28 & 1.01 & 0.45 & 0.40 & 0.40 & 0.48 & 0.62 \\
\hline $\mathrm{ET}_{0}$ (mm/day) & 1.21 & 1.67 & 2.85 & 4.30 & 6.01 & 7.96 & 8.82 & 8.26 & 6.27 & 4.05 & 1.90 & 1.25 \\
\hline $\mathrm{ET}_{\mathrm{C}}(\mathrm{mm} /$ day $)$ & 0.92 & 1.45 & 2.92 & 5.00 & 7.64 & 10.18 & 8.93 & 3.68 & 2.51 & 1.62 & 0.91 & 0.77 \\
\hline Monthly $\mathrm{ET}_{\mathrm{c}}$ (mm/month) & 28.45 & 41.69 & 90.53 & 149.93 & 236.74 & 305.54 & 276.76 & 58.96 & 35.11 & 50.30 & 27.43 & 23.98 \\
\hline Barley $-\mathrm{K}_{\mathrm{c}}$ & & & & 0.30 & 1.01 & 1.27 & 0.66 & & & & & \\
\hline $\mathrm{ET}_{\mathrm{o}}$ (mm/day) & & & & 4.30 & 6.01 & 7.96 & 8.82 & & & & & \\
\hline $\mathrm{ET}_{\mathrm{C}}(\mathrm{mm} /$ day $)$ & & & & 1.29 & 6.08 & 10.08 & 5.84 & & & & & \\
\hline Monthly $\mathrm{ET}_{\mathrm{c}}$ (mm/month) & & & & 18.06 & 188.41 & 302.38 & 93.42 & & & & & \\
\hline Oat Hay $-\mathrm{K}_{\mathrm{c}}$ & & & & & 0.45 & 1.27 & 0.72 & & & & & \\
\hline $\mathrm{ET}_{\mathrm{o}}$ (mm/day) & & & & & 6.01 & 7.96 & 8.82 & & & & & \\
\hline $\mathrm{ET}_{\mathrm{c}}(\mathrm{mm} /$ day $)$ & & & & & 2.71 & 10.09 & 6.38 & & & & & \\
\hline Monthly $\mathrm{ET}_{\mathrm{c}}$ (mm/month) & & & & & 43.33 & 302.67 & 70.22 & & & & & \\
\hline
\end{tabular}


Table D-12. Mean Monthly Crop Coefficients $(K C)$, Reference Evapotranspiration (ETo), and Crop Evapotranspiration (ETC) for Lower Bound Glacial Transition Climate Conditions (Continued)

\begin{tabular}{|c|c|c|c|c|c|c|c|c|c|c|c|c|}
\hline Crop & Jan & Feb & Mar & Apr & May & Jun & Jul & Aug & Sep & Oct & Nov & Dec \\
\hline Fescue $^{\mathrm{e}}-\mathrm{K}_{\mathrm{c}}$ & & & & 0.95 & 0.95 & 0.95 & 0.95 & 0.95 & 0.95 & 0.95 & & \\
\hline $\mathrm{ET}_{\mathrm{o}}(\mathrm{mm} /$ day $)$ & & & & 4.30 & 6.01 & 7.96 & 8.82 & 8.26 & 6.27 & 4.05 & & \\
\hline $\mathrm{ET}_{\mathrm{c}}$ (mm/day) & & & & 4.08 & 5.71 & 7.56 & 8.38 & 7.85 & 5.96 & 3.85 & & \\
\hline Monthly $\mathrm{ET}_{\mathrm{c}}$ (mm/month) & & & & 122.55 & 176.99 & 226.86 & 259.75 & 243.26 & 178.70 & 119.27 & & \\
\hline
\end{tabular}

${ }^{a}$ Mean monthly $K_{c}$ values calculated according to Appendix D, Section 4.

${ }^{\mathrm{b}}$ Mean monthly $E T_{o}$ values from Appendix C, Table C-9.

${ }^{c}$ Mean daily $E T_{c}$ calculated using Equation D-1.

${ }^{d}$ Mean monthly $E T_{c}$ calculated from mean daily $E T_{c}$ and the number of growing days per month (Appendix $D$, Section 5 ).

e Fescue was selected for lower bound glacial transition climate because it is a cool season grass. 
Table D-13. Mean Monthly Crop Coefficients $\left(K_{c}\right)$, Reference Evapotranspiration $\left(E T_{o}\right)$, and Crop Evapotranspiration $\left(E T_{c}\right)$ for Upper Bound Glacial Transition Climate Conditions

\begin{tabular}{|c|c|c|c|c|c|c|c|c|c|c|c|c|}
\hline Crop & Jan & Feb & Mar & Apr & May & Jun & Jul & Aug & Sep & Oct & Nov & Dec \\
\hline Leaf Lettuce early $-\mathrm{K}_{\mathrm{c}}{ }^{\mathrm{a}}$ & & & & 0.70 & 0.83 & 1.03 & & & & & & \\
\hline $\mathrm{ET}_{\mathrm{o}}(\mathrm{mm} / \mathrm{day})^{\mathrm{b}}$ & & & & 3.18 & 4.21 & 5.31 & & & & & & \\
\hline $\mathrm{ET}_{\mathrm{C}}(\mathrm{mm} / \mathrm{day})^{\mathrm{c}}$ & & & & 2.23 & 3.48 & 5.47 & & & & & & \\
\hline Monthly $\mathrm{ET}_{\mathrm{c}}(\mathrm{mm} / \mathrm{month})^{\mathrm{d}}$ & & & & 15.58 & 107.82 & 109.40 & & & & & & \\
\hline Leaf Lettuce late $-\mathrm{K}_{\mathrm{c}}$ & & & & & & & 0.70 & 0.93 & 1.03 & & & \\
\hline $\mathrm{ET}_{\mathrm{o}}$ (mm/day) & & & & & & & 6.50 & 6.15 & 4.44 & & & \\
\hline $\mathrm{ET}_{\mathrm{c}}(\mathrm{mm} /$ day $)$ & & & & & & & 4.55 & 5.72 & 4.55 & & & \\
\hline Monthly $\mathrm{ET}_{\mathrm{c}}$ (mm/month) & & & & & & & 72.80 & 177.17 & 50.09 & & & \\
\hline Head Lettuce early - $K_{c}$ & & & & 0.70 & 0.75 & 1.00 & 1.02 & & & & & \\
\hline $\mathrm{ET}_{\mathrm{o}}$ (mm/day) & & & & 3.18 & 4.21 & 5.31 & 6.50 & & & & & \\
\hline $\mathrm{ET}_{\mathrm{C}}$ (mm/day) & & & & 2.23 & 3.16 & 5.33 & 6.63 & & & & & \\
\hline Monthly $\mathrm{ET}_{\mathrm{c}}$ (mm/month) & & & & 15.58 & 98.03 & 159.98 & 66.31 & & & & & \\
\hline Head Lettuce late $-\mathrm{K}_{\mathrm{c}}$ & & & & & & & 0.70 & 0.82 & 1.03 & 0.99 & & \\
\hline $\mathrm{ET}_{\mathrm{o}}$ (mm/day) & & & & & & & 6.50 & 6.15 & 4.44 & 2.50 & & \\
\hline $\mathrm{ET}_{\mathrm{C}}(\mathrm{mm} / \mathrm{day})$ & & & & & & & 4.55 & 5.04 & 4.56 & 2.47 & & \\
\hline Monthly $\mathrm{ET}_{\mathrm{c}}$ (mm/month) & & & & & & & 72.80 & 156.13 & 136.72 & 2.47 & & \\
\hline Cabbage early $-\mathrm{K}_{\mathrm{C}}$ & & & & 0.70 & 0.79 & 1.08 & 1.05 & & & & & \\
\hline $\mathrm{ET}_{\mathrm{o}}(\mathrm{mm} /$ day $)$ & & & & 3.18 & 4.21 & 5.31 & 6.50 & & & & & \\
\hline $\mathrm{ET}_{\mathrm{c}}$ (mm/day) & & & & 2.23 & 3.34 & 5.74 & 6.82 & & & & & \\
\hline Monthly $\mathrm{ET}_{\mathrm{c}}$ (mm/month) & & & & 15.58 & 103.63 & 172.33 & 47.74 & & & & & \\
\hline Cabbage late $-\mathrm{K}_{\mathrm{c}}$ & & & & & & & 0.70 & 0.86 & 1.08 & 0.99 & & \\
\hline $\mathrm{ET}_{\mathrm{o}}$ (mm/day) & & & & & & & 6.50 & 6.15 & 4.44 & 2.50 & & \\
\hline $\mathrm{ET}_{\mathrm{c}}(\mathrm{mm} /$ day $)$ & & & & & & & 4.55 & 5.28 & 4.81 & 2.49 & & \\
\hline Monthly ETc (mm/month) & & & & & & & 59.15 & 163.60 & 144.16 & 2.49 & & \\
\hline
\end{tabular}


Table D-13. Mean Monthly Crop Coefficients $\left(K_{c}\right)$, Reference Evapotranspiration $\left(E T_{o}\right)$, and Crop Evapotranspiration $\left(E T_{c}\right)$ for Upper Bound Glacial Transition Climate Conditions (Continued)

\begin{tabular}{|c|c|c|c|c|c|c|c|c|c|c|c|c|}
\hline Crop & Jan & Feb & Mar & Apr & May & Jun & Jul & Aug & Sep & Oct & Nov & Dec \\
\hline Celery - $\mathrm{K}_{\mathrm{c}}$ & & & & 0.70 & 0.75 & 1.04 & 1.11 & 1.08 & & & & \\
\hline$E T_{0}$ (mm/day) & & & & 3.18 & 4.21 & 5.31 & 6.50 & 6.15 & & & & \\
\hline $\mathrm{ET}_{\mathrm{c}}(\mathrm{mm} / \mathrm{day})$ & & & & 2.23 & 3.15 & 5.51 & 7.20 & 6.65 & & & & \\
\hline Monthly $\mathrm{ET}_{\mathrm{c}}(\mathrm{mm} / \mathrm{month})$ & & & & 15.58 & 97.64 & 165.37 & 223.28 & 73.16 & & & & \\
\hline Broccoli early $-\mathrm{K}_{\mathrm{c}}$ & & & & 0.70 & 0.77 & 1.06 & 1.06 & & & & & \\
\hline$E T_{o}$ (mm/day) & & & & 3.18 & 4.21 & 5.31 & 6.50 & & & & & \\
\hline$E T_{c}(\mathrm{~mm} /$ day $)$ & & & & 2.23 & 3.22 & 5.65 & 6.92 & & & & & \\
\hline Monthly $\mathrm{ET}_{\mathrm{c}}$ (mm/month) & & & & 15.58 & 99.88 & 169.53 & 103.82 & & & & & \\
\hline Broccoli late $-\mathrm{K}_{\mathrm{c}}$ & & & & & & & 0.70 & 0.84 & 1.09 & 1.01 & & \\
\hline $\mathrm{ET}_{\mathrm{o}}(\mathrm{mm} /$ day $)$ & & & & & & & 6.50 & 6.15 & 4.44 & 2.50 & & \\
\hline$E T_{c}(\mathrm{~mm} /$ day $)$ & & & & & & & 4.55 & 5.16 & 4.82 & 2.53 & & \\
\hline Monthly $\mathrm{ET}_{\mathrm{c}}$ (mm/month) & & & & & & & 68.25 & 160.09 & 144.53 & 17.72 & & \\
\hline Cauliflower early - $\mathrm{K}_{\mathrm{c}}$ & & & & 0.70 & 0.85 & 1.08 & & & & & & \\
\hline $\mathrm{ET}_{\mathrm{o}}(\mathrm{mm} / \mathrm{day})$ & & & & 3.18 & 4.21 & 5.31 & & & & & & \\
\hline $\mathrm{ET}_{\mathrm{c}}(\mathrm{mm} / \mathrm{day})$ & & & & 2.23 & 3.54 & 5.73 & & & & & & \\
\hline Monthly $\mathrm{ET}_{\mathrm{C}}$ (mm/month) & & & & 15.58 & 109.59 & 143.33 & & & & & & \\
\hline Cauliflower late $-\mathrm{K}_{\mathrm{c}}$ & & & & & & & 0.70 & 0.77 & 1.06 & 0.99 & & \\
\hline $\mathrm{ET}_{\mathrm{o}}$ (mm/day) & & & & & & & 6.50 & 6.15 & 4.44 & 2.50 & & \\
\hline $\mathrm{ET}_{\mathrm{c}}(\mathrm{mm} / \mathrm{day})$ & & & & & & & 4.55 & 4.76 & 4.71 & 2.49 & & \\
\hline Monthly $\mathrm{ET}_{\mathrm{c}}(\mathrm{mm} / \mathrm{month})$ & & & & & & & 4.55 & 147.46 & 141.38 & 2.49 & & \\
\hline Spinach early $-\mathrm{K}_{\mathrm{c}}$ & & & & 0.70 & 0.84 & 1.03 & & & & & & \\
\hline $\mathrm{ET}_{\mathrm{o}}(\mathrm{mm} / \mathrm{day})$ & & & & 3.18 & 4.21 & 5.31 & & & & & & \\
\hline $\mathrm{ET}_{\mathrm{c}}(\mathrm{mm} /$ day $)$ & & & & 2.23 & 3.52 & 5.48 & & & & & & \\
\hline Monthly $\mathrm{ET}_{\mathrm{c}}$ (mm/month) & & & & 15.58 & 109.16 & 93.21 & & & & & & \\
\hline Spinach late $-\mathrm{K}_{\mathrm{c}}$ & & & & & & & & 0.72 & 1.00 & 0.99 & & \\
\hline $\mathrm{ET}_{\circ}(\mathrm{mm} /$ day $)$ & & & & & & & & 6.15 & 4.44 & 2.50 & & \\
\hline $\mathrm{ET}_{\mathrm{C}}(\mathrm{mm} / \mathrm{day})$ & & & & & & & & 4.43 & 4.45 & 2.47 & & \\
\hline Monthly $\mathrm{ET}_{\mathrm{c}}$ (mm/month) & & & & & & & & 106.32 & 133.57 & 2.47 & & \\
\hline
\end{tabular}


Table D-13. Mean Monthly Crop Coefficients $\left(K_{c}\right)$, Reference Evapotranspiration $\left(E T_{o}\right)$, and Crop Evapotranspiration $\left(E T_{c}\right)$ for Upper Bound Glacial Transition Climate Conditions (Continued)

\begin{tabular}{|c|c|c|c|c|c|c|c|c|c|c|c|c|}
\hline Crop & Jan & Feb & Mar & Apr & May & Jun & Jul & Aug & Sep & Oct & Nov & Dec \\
\hline Potatoes - $\mathrm{K}_{\mathrm{c}}$ & & & & 0.50 & 0.53 & 1.10 & 1.21 & 1.03 & & & & \\
\hline $\mathrm{ET}_{\mathrm{o}}$ (mm/day) & & & & 3.18 & 4.21 & 5.31 & 6.50 & 6.15 & & & & \\
\hline $\mathrm{ET}_{\mathrm{c}}$ (mm/day) & & & & 1.59 & 2.22 & 5.83 & 7.85 & 6.36 & & & & \\
\hline Monthly $\mathrm{ET}_{\mathrm{c}}$ (mm/month) & & & & 11.13 & 68.73 & 174.85 & 243.35 & 101.79 & & & & \\
\hline Onions - $\mathrm{K}_{\mathrm{c}}$ & & & 0.75 & 1.05 & 1.09 & 1.08 & 0.93 & 0.81 & & & & \\
\hline $\mathrm{ET}_{\mathrm{o}}$ (mm/day) & & & 1.99 & 3.18 & 4.21 & 5.31 & 6.50 & 6.15 & & & & \\
\hline $\mathrm{ET}_{\mathrm{c}}$ (mm/day) & & & 1.50 & 3.35 & 4.58 & 5.74 & 6.05 & 5.00 & & & & \\
\hline Monthly $\mathrm{ET}_{\mathrm{c}}$ (mm/month) & & & 44.90 & 100.59 & 141.89 & 172.29 & 187.62 & 15.00 & & & & \\
\hline Carrots early - $\mathrm{K}_{\mathrm{c}}$ & & & & 0.70 & 0.84 & 1.09 & 1.05 & & & & & \\
\hline $\mathrm{ET}_{\mathrm{o}}$ (mm/day) & & & & 3.18 & 4.21 & 5.31 & 6.50 & & & & & \\
\hline $\mathrm{ET}_{\mathrm{c}}(\mathrm{mm} /$ day $)$ & & & & 2.23 & 3.56 & 5.79 & 6.82 & & & & & \\
\hline Monthly $\mathrm{ET}_{\mathrm{c}}$ (mm/month) & & & & 15.58 & 110.25 & 173.66 & 81.81 & & & & & \\
\hline Carrots late $-\mathrm{K}_{\mathrm{c}}$ & & & & & & & 0.70 & 0.98 & 1.08 & 0.99 & & \\
\hline $\mathrm{ET}_{\mathrm{o}}$ (mm/day) & & & & & & & 6.50 & 6.15 & 4.44 & 2.50 & & \\
\hline $\mathrm{ET}_{\mathrm{c}}$ (mm/day) & & & & & & & 4.56 & 6.05 & 4.78 & 2.48 & & \\
\hline Monthly $\mathrm{ET}_{\mathrm{c}}$ (mm/month) & & & & & & & 82.14 & 187.55 & 143.37 & 2.48 & & \\
\hline Sweet corn - $K_{c}$ & & & & & 0.30 & 0.36 & 1.02 & 1.23 & 1.15 & & & \\
\hline $\mathrm{ET}_{\mathrm{o}}(\mathrm{mm} / \mathrm{day})$ & & & & & 4.21 & 5.31 & 6.50 & 6.15 & 4.44 & & & \\
\hline $\mathrm{ET}_{\mathrm{c}}(\mathrm{mm} /$ day $)$ & & & & & 1.26 & 1.90 & 6.61 & 7.58 & 5.12 & & & \\
\hline Monthly $\mathrm{ET}_{\mathrm{c}}$ (mm/month) & & & & & 8.84 & 56.93 & 204.83 & 234.86 & 30.74 & & & \\
\hline Bell peppers - $\mathrm{K}_{\mathrm{c}}$ & & & & & & 0.60 & 0.85 & 1.11 & 1.03 & & & \\
\hline $\mathrm{ET}_{\mathrm{o}}(\mathrm{mm} /$ day $)$ & & & & & & 5.31 & 6.50 & 6.15 & 4.44 & & & \\
\hline $\mathrm{ET}_{\mathrm{c}}(\mathrm{mm} /$ day $)$ & & & & & & 3.19 & 5.52 & 6.85 & 4.58 & & & \\
\hline Monthly $\mathrm{ET}_{\mathrm{C}}$ (mm/month) & & & & & & 70.09 & 171.08 & 212.50 & 73.30 & & & \\
\hline Cucumbers - $\mathrm{K}_{\mathrm{c}}$ & & & & & 0.60 & 0.82 & 1.01 & & & & & \\
\hline $\mathrm{ET}_{\mathrm{o}}(\mathrm{mm} / \mathrm{day})$ & & & & & 4.21 & 5.31 & 6.50 & & & & & \\
\hline $\mathrm{ET}_{\mathrm{c}}(\mathrm{mm} /$ day $)$ & & & & & 2.53 & 4.34 & 6.55 & & & & & \\
\hline Monthly $\mathrm{ET}_{\mathrm{c}}$ (mm/month) & & & & & 17.68 & 130.09 & 203.15 & & & & & \\
\hline
\end{tabular}


Table D-13. Mean Monthly Crop Coefficients $\left(K_{c}\right)$, Reference Evapotranspiration $\left(E T_{o}\right)$, and Crop Evapotranspiration $\left(E T_{c}\right)$ for Upper Bound Glacial Transition Climate Conditions (Continued)

\begin{tabular}{|c|c|c|c|c|c|c|c|c|c|c|c|c|}
\hline Crop & Jan & Feb & Mar & Apr & May & Jun & Jul & Aug & Sep & Oct & Nov & Dec \\
\hline Squash - $\mathrm{K}_{\mathrm{c}}$ & & & & & 0.50 & 0.70 & 0.96 & & & & & \\
\hline $\mathrm{ET}_{\mathrm{o}}$ (mm/day) & & & & & 4.21 & 5.31 & 6.50 & & & & & \\
\hline $\mathrm{ET}_{\mathrm{c}}$ (mm/day) & & & & & 2.10 & 3.72 & 6.24 & & & & & \\
\hline Monthly $\mathrm{ET}_{\mathrm{c}}$ (mm/month) & & & & & 14.74 & 111.48 & 174.79 & & & & & \\
\hline Melons - $\mathrm{K}_{\mathrm{c}}$ & & & & & 0.50 & 0.58 & 1.03 & 1.06 & 0.84 & & & \\
\hline $\mathrm{ET}_{\mathrm{o}}$ (mm/day) & & & & & 4.21 & 5.31 & 6.50 & 6.15 & 4.44 & & & \\
\hline $\mathrm{ET}_{\mathrm{c}}$ (mm/day) & & & & & 2.10 & 3.06 & 6.70 & 6.49 & 3.71 & & & \\
\hline Monthly $\mathrm{ET}_{\mathrm{c}}$ (mm/month) & & & & & 14.74 & 91.69 & 207.85 & 201.33 & 14.87 & & & \\
\hline Tomatoes $-\mathrm{K}_{\mathrm{c}}$ & & & & & & 0.61 & 1.05 & 1.15 & 0.90 & & & \\
\hline $\mathrm{ET}_{\mathrm{o}}$ (mm/day) & & & & & & 5.31 & 6.50 & 6.15 & 4.44 & & & \\
\hline $\mathrm{ET}_{\mathrm{c}}(\mathrm{mm} /$ day $)$ & & & & & & 3.24 & 6.81 & 7.07 & 3.99 & & & \\
\hline Monthly $\mathrm{ET}_{\mathrm{c}}$ (mm/month) & & & & & & 71.17 & 211.02 & 219.18 & 15.94 & & & \\
\hline Corn silage $-\mathrm{K}_{\mathrm{c}}$ & & & & & 0.30 & 0.65 & 1.27 & 1.23 & 0.86 & & & \\
\hline $\mathrm{ET}_{\mathrm{o}}$ (mm/day) & & & & & 4.21 & 5.31 & 6.50 & 6.15 & 4.44 & & & \\
\hline $\mathrm{ET}_{\mathrm{c}}$ (mm/day) & & & & & 1.26 & 3.44 & 8.26 & 7.54 & 3.83 & & & \\
\hline Monthly $\mathrm{ET}_{\mathrm{c}}$ (mm/month) & & & & & 25.26 & 103.23 & 256.03 & 233.89 & 95.73 & & & \\
\hline Feed Corn - $\mathrm{K}_{\mathrm{c}}$ & & & & & 0.30 & 0.43 & 1.07 & 1.28 & 1.21 & 0.72 & 0.39 & \\
\hline$E T_{0}(\mathrm{~mm} /$ day $)$ & & & & & 4.21 & 5.31 & 6.50 & 6.15 & 4.44 & 2.50 & 0.98 & \\
\hline $\mathrm{ET}_{\mathrm{c}}(\mathrm{mm} / \mathrm{day})$ & & & & & 1.26 & 2.26 & 6.93 & 7.90 & 5.36 & 1.79 & 0.39 & \\
\hline Monthly $\mathrm{ET}_{\mathrm{c}}$ (mm/month) & & & & & 25.26 & 67.92 & 214.68 & 244.57 & 160.68 & 55.63 & 1.93 & \\
\hline Oat Feed - $K_{c}$ & & & 0.30 & 0.38 & 1.10 & 1.21 & 1.10 & 0.50 & & & & \\
\hline $\mathrm{ET}_{\mathrm{o}}$ (mm/day) & & & 1.99 & 3.18 & 4.21 & 5.31 & 6.50 & 6.15 & & & & \\
\hline $\mathrm{ET}_{\mathrm{c}}(\mathrm{mm} /$ day $)$ & & & 0.60 & 1.22 & 4.62 & 6.41 & 7.12 & 3.06 & & & & \\
\hline Monthly $\mathrm{ET}_{\mathrm{c}}$ (mm/month) & & & 1.79 & 36.62 & 143.26 & 192.45 & 220.83 & 48.93 & & & & \\
\hline Alfalfa ( $1^{\text {st }}$ cutting $)-K_{c}$ & & & 0.59 & 1.19 & 1.22 & & & & & & & \\
\hline $\mathrm{ET}_{\mathrm{o}}$ (mm/day) & & & 1.99 & 3.18 & 4.21 & & & & & & & \\
\hline $\mathrm{ET}_{\mathrm{c}}(\mathrm{mm} /$ day $)$ & & & 1.17 & 3.79 & 5.15 & & & & & & & \\
\hline Monthly $\mathrm{ET}_{\mathrm{c}}$ (mm/month) & & & 35.01 & 113.78 & 77.25 & & & & & & & \\
\hline
\end{tabular}


Table D-13. Mean Monthly Crop Coefficients $\left(K_{c}\right)$, Reference Evapotranspiration $\left(E T_{o}\right)$, and Crop Evapotranspiration $\left(E T_{c}\right)$ for Upper Bound Glacial Transition Climate Conditions (Continued)

\begin{tabular}{|c|c|c|c|c|c|c|c|c|c|c|c|c|}
\hline Crop & Jan & Feb & Mar & Apr & May & Jun & Jul & Aug & Sep & Oct & Nov & Dec \\
\hline Alfalfa ( $2^{\text {nd }}$ cutting) $-\mathrm{K}_{\mathrm{c}}$ & & & & & 0.46 & 1.03 & 1.24 & & & & & \\
\hline $\mathrm{ET}_{\mathrm{o}}(\mathrm{mm} / \mathrm{day})$ & & & & & 4.21 & 5.31 & 6.50 & & & & & \\
\hline $\mathrm{ET}_{\mathrm{C}}$ (mm/day) & & & & & 1.92 & 5.45 & 8.08 & & & & & \\
\hline Monthly $\mathrm{ET}_{\mathrm{c}}$ (mm/month) & & & & & 30.80 & 163.62 & 177.75 & & & & & \\
\hline Alfalfa ( $3^{\text {rd }}$ cutting) $-K_{c}$ & & & & & & & 0.40 & 0.87 & 1.24 & & & \\
\hline $\mathrm{ET}_{\mathrm{o}}(\mathrm{mm} /$ day $)$ & & & & & & & 6.50 & 6.15 & 4.44 & & & \\
\hline $\mathrm{ET}_{\mathrm{c}}$ (mm/day) & & & & & & & 2.61 & 5.33 & 5.49 & & & \\
\hline Monthly $\mathrm{ET}_{\mathrm{c}}$ (mm/month) & & & & & & & 23.49 & 165.16 & 153.81 & & & \\
\hline Apples - $\mathrm{K}_{\mathrm{c}}$ & & & & 0.45 & 0.54 & 0.87 & 1.05 & 1.05 & 0.98 & 0.80 & & \\
\hline $\mathrm{ET}_{\mathrm{o}}(\mathrm{mm} /$ day $)$ & & & & 3.18 & 4.21 & 5.31 & 6.50 & 6.15 & 4.44 & 2.50 & & \\
\hline $\mathrm{ET}_{\mathrm{c}}$ (mm/day) & & & & 1.43 & 2.29 & 4.61 & 6.85 & 6.49 & 4.37 & 2.00 & & \\
\hline Monthly $\mathrm{ET}_{\mathrm{c}}$ (mm/month) & & & & 11.45 & 71.00 & 138.27 & 212.43 & 201.13 & 130.98 & 9.99 & & \\
\hline Grapes - $\mathrm{K}_{\mathrm{c}}$ & & & & & & & 0.30 & 0.56 & 0.78 & 0.72 & & \\
\hline $\mathrm{ET}_{\mathrm{o}}(\mathrm{mm} /$ day $)$ & & & & & & & 5.31 & 6.50 & 6.15 & 4.44 & & \\
\hline $\mathrm{ET}_{\mathrm{c}}(\mathrm{mm} /$ day $)$ & & & & & & & 1.60 & 3.65 & 4.78 & 3.19 & & \\
\hline Monthly $\mathrm{ET}_{\mathrm{C}}$ (mm/month) & & & & & & & 20.75 & 113.22 & 148.25 & 95.58 & & \\
\hline Strawberries - $\mathrm{K}_{\mathrm{c}}$ & & & & 0.40 & 0.69 & 0.88 & & & & & & \\
\hline $\mathrm{ET}_{\mathrm{o}}(\mathrm{mm} /$ day $)$ & & & & 3.18 & 4.21 & 5.31 & & & & & & \\
\hline $\mathrm{ET}_{\mathrm{c}}(\mathrm{mm} /$ day $)$ & & & & 1.27 & 2.89 & 4.69 & & & & & & \\
\hline Monthly $\mathrm{ET}_{\mathrm{c}}$ (mm/month) & & & & 3.82 & 89.65 & 140.62 & & & & & & \\
\hline Winter wheat - $\mathrm{K}_{\mathrm{C}}$ & 0.73 & 0.85 & 0.97 & 1.10 & 1.20 & 1.20 & 0.96 & 0.43 & 0.40 & 0.40 & 0.47 & 0.60 \\
\hline $\mathrm{ET}_{\mathrm{o}}$ (mm/day) & 0.62 & 1.10 & 1.99 & 3.18 & 4.21 & 5.31 & 6.50 & 6.15 & 4.44 & 2.50 & 0.98 & 0.58 \\
\hline $\mathrm{ET}_{\mathrm{c}}$ (mm/day) & 0.45 & 0.93 & 1.93 & 3.49 & 5.04 & 6.40 & 6.22 & 2.66 & 1.78 & 1.00 & 0.46 & 0.35 \\
\hline Monthly $\mathrm{ET}_{\mathrm{c}}$ (mm/month) & 14.00 & 26.17 & 59.93 & 104.69 & 156.17 & 191.90 & 192.80 & 42.49 & 24.86 & 31.05 & 13.94 & 10.79 \\
\hline Barley - $\mathrm{K}_{\mathrm{c}}$ & & & & 0.30 & 0.96 & 1.19 & 0.63 & & & & & \\
\hline $\mathrm{ET}_{\mathrm{o}}(\mathrm{mm} /$ day $)$ & & & & 3.18 & 4.21 & 5.31 & 6.50 & & & & & \\
\hline $\mathrm{ET}_{\mathrm{c}}$ (mm/day) & & & & 0.95 & 4.02 & 6.32 & 4.10 & & & & & \\
\hline Monthly $\mathrm{ET}_{\mathrm{c}}$ (mm/month) & & & & 13.36 & 124.74 & 189.69 & 65.67 & & & & & \\
\hline
\end{tabular}


Table D-13. Mean Monthly Crop Coefficients $\left(K_{c}\right)$, Reference Evapotranspiration $\left(E T_{o}\right)$, and Crop Evapotranspiration $\left(E T_{c}\right)$ for Upper Bound Glacial Transition Climate Conditions (Continued)

\begin{tabular}{|c|c|c|c|c|c|c|c|c|c|c|c|c|}
\hline Crop & Jan & Feb & Mar & Apr & May & Jun & Jul & Aug & Sep & Oct & Nov & Dec \\
\hline Oat Hay - $K_{c}$ & & & & & 0.44 & 1.19 & 0.69 & & & & & \\
\hline $\mathrm{ET}_{\mathrm{o}}$ (mm/day) & & & & & 4.21 & 5.31 & 6.50 & & & & & \\
\hline $\mathrm{ET}_{\mathrm{c}}(\mathrm{mm} /$ day $)$ & & & & & 1.85 & 6.33 & 4.48 & & & & & \\
\hline Monthly $\mathrm{ET}_{\mathrm{c}}$ (mm/month) & & & & & 29.57 & 189.98 & 49.25 & & & & & \\
\hline Fescue $^{\mathrm{e}}-\mathrm{K}_{\mathrm{c}}$ & & & & 0.95 & 0.95 & 0.95 & 0.95 & 0.95 & 0.95 & 0.95 & & \\
\hline $\mathrm{ET}_{\mathrm{o}}(\mathrm{mm} / \mathrm{day})$ & & & & 3.18 & 4.21 & 5.31 & 6.50 & 6.15 & 4.44 & 2.50 & & \\
\hline $\mathrm{ET}_{\mathrm{C}}(\mathrm{mm} /$ day $)$ & & & & 3.02 & 4.00 & 5.04 & 6.18 & 5.84 & 4.22 & 2.38 & & \\
\hline Monthly $\mathrm{ET}_{\mathrm{c}}$ (mm/month) & & & & 90.63 & 123.99 & 151.34 & 191.43 & 181.12 & 126.54 & 73.63 & & \\
\hline
\end{tabular}

${ }^{a}$ Mean monthly $K_{c}$ values calculated according to Appendix D, Section 4.

${ }^{b}$ Mean monthly $E T_{o}$ values from Appendix C, Table C-9.

${ }^{c}$ Mean daily $E T_{c}$ calculated using Equation $\mathrm{D}-1$.

${ }^{d}$ Mean monthly $E T_{c}$ calculated from mean daily $E T_{c}$ and the number of growing days per month (Appendix D, Section 5 ).

e Fescue was selected for upper bound glacial transition climate because it is a cool season grass. 


\section{INTENTIONALLY LEFT BLANK}




\begin{abstract}
APPENDIX E
METHODS FOR DERIVING SEASONAL WATER REQUIREMENTS, LEACHING REQUIREMENTS, DEEP PERCOLATION, AND IRRIGATION APPLICATION AMOUNTS
\end{abstract}




\section{E. METHODS FOR DERIVING SEASONAL WATER REQUIREMENTS, LEACHING REQUIREMENTS, DEEP PERCOLATION, AND IRRIGATION APPLICATION AMOUNTS}

\section{E1. INTRODUCTION}

Seasonal water requirements $\left(W_{s}\right)$ and net irrigation requirements $(\mathrm{In})$ are related variables and are used to determine several parameters including annual average irrigation rate (IR), daily average irrigation rate $\left(I R D_{j}\right)$, irrigation application $\left(\mathrm{IA}_{\mathrm{j}}\right)$ and overwatering rate $(O W)$. Seasonal water requirements were derived from water lost from the soil-plant system (monthly $E T_{c}$ ), water added to the system (monthly effective precipitation $[P e]$, and leaching requirements $[L R]$ ). In addition to $E T_{c}, P e$, and $L R$, determination of $I n$ requires information on stored soil moisture at the beginning of the growing season $(W b)$, and groundwater contribution to the water requirement $(G e)$.

A Leaching Fraction ( $L F$, the actual amount of water that must be added to leach salts below the crop root zone in addition to water needed to balance $E T_{c}$ ) was determined from $W_{s}$ for each crop. This was compared to deep percolation of precipitation below the root zone $(D P)$ and the greater of the two values was used as the overwatering rate $(O W)$. Depending on whether $L R$ was met by precipitation or irrigation, either $W_{s}$ or $I n$ was used to calculate annual average irrigation rate $(I R)$, and daily average irrigation rate $\left(I R D_{j}\right)$. Seasonal crop evapotranspiration $\left(E T_{c}\right)$, deep percolation below the root zone $(D P)$, stored soil moisture in the rooting zone $(W b)$, and leaching requirements $(L R)$ were needed to estimate $\mathrm{W}_{\mathrm{s}}, I n$, irrigation application $\left(I A_{j}\right)$, and overwatering rate $(O W)$ (see Section 6).

Methods for deriving $E T_{c}$ are in Appendix D. Methods for deriving $W_{s}, I n, I A_{j}, I R, I R D_{j}$, and $O W$ are described below.

\section{E2. METHODS}

\section{E2.1 EFFECTIVE PRECIPITATION}

Not all precipitation is available for plant use. Precipitation that collects on the soil surface can be lost to evaporation and surface flow can be lost as runoff. Some of the rainfall that percolates through the soil can be lost below the root zone (Doorenbos and Pruitt 1977 [DIRS 103062]). The portion of rainfall that percolates through the soil and remains in the root zone is available for plant use $(P e)$. Thus, $P e$ is the total rainfall minus the losses that occur from the system.

There are several methods for direct measurement of Pe (Brouwer and Heibloem 1986 [DIRS 159869], Section 4.2) however none of those methods were employed under the climate conditions in this analysis. Empirically developed formulae also exist, but are specific to the conditions under which they were developed, and in most cases their use elsewhere is not recommended (Dastane 1978 [DIRS 159870], Sections 2.2 and 2.3). Doorenbos and Pruitt (1977 [DIRS 103062], pp. 74 and 75) use the evaporation/precipitation ratio method developed by the USDA 1969, from Doorenbos and Pruitt (1977 [DIRS 103062], p. 74) to estimate Pe. This method was included in an evaluation of 12 direct and empirical methods for estimating $P e$ 
(Dastane 1978 [DIRS 159870], Section 2.4). It was rated as satisfactory for preliminary planning purposes with medium accuracy and low relative cost. This compared to four other empirical methods, two of which were rated low for accuracy, one medium, and one low to high. Only direct measurement methods were given high and very high accuracy ratings. Based on this information and the lack of direct measurements of $P e$, the evaporation/ precipitation ratio method was selected for use in this analysis.

The evaporation/precipitation ratio method requires mean monthly rainfall measurements (Section 4, Tables 4.1-2, 4.1-3, 4.1-4, and 4.1-5), mean monthly $E T_{c}$ (Appendix D, Tables D-10 through D-13), and the net depth of water that could be effectively stored over the root zone (Doorenbos and Pruitt 1977 [DIRS 103062], p. 74).

\section{E2.1.1 Soil Water Availability (TAW)}

The concept of total available water in the root zone (TAW) discussed by Allen et al. (1998 [DIRS 157311], pp. 161 and 162) was used to estimate the net depth of water that could be effectively stored over the root zone for the 26 crops and turf in a sandy loam soil. A sandy loam soil was chosen because the common soils in northern Amargosa Valley (Arizo, Corbilt, Sanwell, Shamock, Yermo) are sandy to sandy loam, well drained, and have a moderate to rapid permeability (CRWMS M\&O 1999 [DIRS 107736], Figure 1 and pp. C-1, C-2, C-25, C-27, $\mathrm{C}-39$, and C40). After rainfall or irrigation, the hydraulic gradient in the soil causes some of the water to rapidly drain downward until field capacity is reached. Field capacity is the amount of water left in the soil after this downward movement becomes negligible (Jensen et al. 1990 [DIRS 160001], p. 20; Allen et al. 1998 [DIRS 157311], p. 161). As crops deplete water from the rooting zone, soil water potentials become more negative, making it increasingly difficult for crops to extract soil moisture. With no additional water input, the soil will continue to dry out and plants will begin to wilt to conserve moisture during the day (Jensen et al. 1990 [DIRS 160001], p. 21). When soil water potentials become so negative that water can no longer be extracted by plants, the permanent wilting point is reached (Jensen et al. 1990 [DIRS 160001], p. 21; Allen et al. 1998 [DIRS 157311], p. 161). At the permanent wilting point, water remains in the soil, but is held too tightly by matric and osmotic forces to allow absorption by plant roots. $T A W$ can be estimated from the difference between field capacity and the permanent wilting point (Allen et al. 1998 [DIRS 157311], Equation 82, p. 162):

$$
T A W=1000\left(\theta_{F C}-\theta_{W P}\right) Z_{r}
$$

where

$$
\begin{aligned}
& \theta_{\mathrm{FC}}=\text { soil water content at field capacity }\left(\mathrm{m}^{3} \mathrm{~m}^{-3}\right), \\
& \theta_{\mathrm{WP}}=\text { soil water content at the wilting point }\left(\mathrm{m}^{3} \mathrm{~m}^{-3}\right), \\
& Z_{r}=\text { rooting depth }(\mathrm{m}) .
\end{aligned}
$$


For a sandy loam soil, typical ranges for $\theta_{F C}$ and $\theta_{W P}$ are $0.18-0.28 \mathrm{~m}^{3} \mathrm{~m}^{-3}$ and $0.06-0.16 \mathrm{~m}^{3}$ $\mathrm{m}^{-3}$, respectively (Allen et al. 1998 [DIRS 157311], Table 19, p. 144). The midpoint of each range was chosen for this analysis $\left(\theta_{F C}=0.23\right.$ and $\left.\theta_{W P}=0.11\right)$.

Mean monthly rooting depths required for TAW were calculated by taking the maximum effective rooting depths $\left(Z_{r \max }\right.$, Table E-1) for the 26 crops and turf from Allen et al. (1998 [DIRS 157311], Table 22, pp. 163 through 165), and using minimum root depths $\left(Z_{r \text { min }}\right)$ of 0.15 for plants with $Z_{r \max }$ of 0.3 to $0.5 \mathrm{~m}$ and $0.20 \mathrm{~m}$ for plants with $Z_{r \text { max }}>0.5 \mathrm{~m}$ in the following equation (Allen et al. 1998 [DIRS 157311], Equation 8-3, p. 279):

$$
Z_{r i}=Z_{r \text { min }}+\left(Z_{r \text { max }}-Z_{r \text { min }}\right) \frac{J-J_{\text {start }}}{J_{\text {max }}-J_{\text {start }}} \text { for } \mathrm{J}_{\text {start }} \leq \mathrm{J} \leq \mathrm{J}_{\max }
$$

where

$$
\begin{aligned}
& Z_{r i}=\text { effective depth of the root zone on day } \mathrm{i}(\mathrm{m}), \\
& J_{\text {start }}=\text { Day of year that } Z_{\mathrm{ri}} \text { increases beyond } Z_{\mathrm{r} \text { min }}, \\
& J_{\max }=\text { Day of year that maximum rooting depth is attained. }
\end{aligned}
$$

For annual plants, $Z_{r i}$ was set equal to $Z_{r \text { min }}$ for days 1 through 5 of the initial growth stage (see Tables D-1 and D-2 for timing of growth seasons and Tables D-3 and D-4 for stage lengths). $Z_{r i}$ was calculated according to Equation E-2 for day 6 through the last day of the development stage. $Z_{r i}$ was set equal to $Z_{r \text { max }}$ for the mid-season and late growth stages. Monthly means were calculated from the daily values generated from Equation E-2 for each annual crop and used in Equation E-1 to calculate mean monthly TAW.

Example: Using early lettuce and present-day climate conditions:

planting day $=65$

$J_{\text {start }}=71$

$J_{\max }=101$

$Z_{r \min }=0.15$

$Z_{r \max }=0.30$

Using equation E-1:

TAW for $Z_{r \min }=1000 *(0.23-0.11) * 0.15=18 \mathrm{~mm}$

TAW for $Z_{r \max }=1000 *(0.23-0.11) * 0.30=36.0 \mathrm{~mm}$ 
Example calculations for $\mathrm{Z}_{\mathrm{ri}}$ using Equation E-2:

\begin{tabular}{|c|c|c|}
\hline Julian day ${ }^{a}$ & Rooting depth $\left(Z_{\mathrm{ri}}\right)$ & Monthly Mean \\
\hline $65-70$ & 0.15 & \\
\hline 71 & $0.15+(0.3-0.15)^{*}(71-71) /(101-71)=0.15$ & \\
\hline 72 & $0.15+(0.3-0.15)^{*}(72-71) /(101-71)=0.155$ & \\
\hline 73 & $0.15+(0.3-0.15)^{*}(73-71) /(101-71)=0.16$ & \\
\hline 74 & $0.15+(0.3-0.15)^{*}(74-71) /(101-71)=0.165$ & \\
\hline 75 & $0.15+(0.3-0.15)^{*}(75-71) /(101-71)=0.17$ & \\
\hline 76 & $0.15+(0.3-0.15)^{*}(76-71) /(101-71)=0.175$ & \\
\hline 77 & $0.15+(0.3-0.15)^{\star}(77-71) /(101-71)=0.18$ & \\
\hline 78 & $0.15+(0.3-0.15)^{*}(78-71) /(101-71)=0.185$ & \\
\hline 79 & $0.15+(0.3-0.15)^{*}(79-71) /(101-71)=0.19$ & \\
\hline 80 & $0.15+(0.3-0.15)^{*}(80-71) /(101-71)=0.195$ & \\
\hline 81 & $0.15+(0.3-0.15)^{*}(81-71) /(101-71)=0.2$ & \\
\hline 82 & $0.15+(0.3-0.15)^{*}(82-71) /(101-71)=0.205$ & \\
\hline 83 & $0.15+(0.3-0.15)^{\star}(83-71) /(101-71)=0.21$ & \\
\hline 84 & $0.15+(0.3-0.15)^{*}(84-71) /(101-71)=0.215$ & \\
\hline 85 & $0.15+(0.3-0.15)^{*}(85-71) /(101-71)=0.22$ & \\
\hline 86 & $0.15+(0.3-0.15)^{*}(86-71) /(101-71)=0.225$ & \\
\hline 87 & $0.15+(0.3-0.15)^{*}(87-71) /(101-71)=0.23$ & \\
\hline 88 & $0.15+(0.3-0.15)^{*}(88-71) /(101-71)=0.235$ & \\
\hline 89 & $0.15+(0.3-0.15)^{*}(89-71) /(101-71)=0.24$ & \\
\hline 90 & $0.15+(0.3-0.15)^{*}(90-71) /(101-71)=0.245$ & 0.188 \\
\hline 91 & $0.15+(0.3-0.15)^{\star}(91-71) /(101-71)=0.25$ & \\
\hline 92 & $0.15+(0.3-0.15)^{*}(92-71) /(101-71)=0.255$ & \\
\hline 93 & $0.15+(0.3-0.15)^{*}(93-71) /(101-71)=0.26$ & \\
\hline 94 & $0.15+(0.3-0.15)^{*}(94-71) /(101-71)=0.265$ & \\
\hline 95 & $0.15+(0.3-0.15)^{*}(95-71) /(101-71)=0.27$ & \\
\hline 96 & $0.15+(0.3-0.15)^{*}(96-71) /(101-71)=0.275$ & \\
\hline 97 & $0.15+(0.3-0.15)^{*}(97-71) /(101-71)=0.28$ & \\
\hline 98 & $0.15+(0.3-0.15)^{*}(98-71) /(101-71)=0.285$ & \\
\hline 99 & $0.15+(0.3-0.15)^{*}(99-71) /(101-71)=0.29$ & \\
\hline 100 & $0.15+(0.3-0.15)^{*}(100-71) /(101-71)=0.295$ & \\
\hline 101 & $0.15+(0.3-0.15)^{*}(101-71) /(101-71)=0.3$ & 0.291 \\
\hline $102-120$ & 0.3 & 0.3 \\
\hline
\end{tabular}

aDate is expressed in Julian format, excluding year.

It was assumed that perennial crops were established for this analysis, and so maximum rooting depths were used for each month to calculate $T A W$. Equation E-2 was used to calculate monthly rooting depths for the first cutting of alfalfa. $Z_{r} \max$ was used for subsequent cuttings. Mean monthly rooting depths and effective storage $(T A W)$ for each crop are listed in Tables E-2 and E-3. 
Table E-1. Minimum and Maximum Rooting Depths for 26 Crops and Turf

\begin{tabular}{|c|c|c|}
\hline Crop & $\begin{array}{l}\text { Minimum Rooting } \\
\text { Depth }(\mathrm{m})^{\mathrm{a}}\end{array}$ & $\begin{array}{l}\text { Maximum Rooting } \\
\text { Depth }(\mathrm{m})^{\mathrm{b}}\end{array}$ \\
\hline Lettuce & 0.15 & 0.3 \\
\hline Cabbage & 0.15 & 0.5 \\
\hline Celery & 0.15 & 0.3 \\
\hline Broccoli & 0.15 & 0.4 \\
\hline Cauliflower & 0.15 & 0.4 \\
\hline Spinach & 0.15 & 0.3 \\
\hline Potatoes & 0.15 & 0.4 \\
\hline Onions & 0.15 & 0.3 \\
\hline Carrots & 0.15 & 0.5 \\
\hline Sweet corn & 0.20 & 0.8 \\
\hline Bell peppers & 0.15 & 0.5 \\
\hline Cucumbers & 0.20 & 0.7 \\
\hline Squash & 0.20 & 0.6 \\
\hline Melons & 0.20 & 0.8 \\
\hline Tomatoes & 0.20 & 0.7 \\
\hline Alfalfa hay & 0.20 & 1.0 \\
\hline Oat hay & 0.20 & 1.0 \\
\hline Apples & 0.20 & 1.0 \\
\hline Grapes & 0.20 & 1.0 \\
\hline Strawberries & 0.15 & 0.2 \\
\hline Winter wheat & 0.20 & 1.5 \\
\hline Barley & 0.20 & 1.0 \\
\hline Feed Corn & 0.20 & 1.0 \\
\hline Corn silage & 0.20 & 1.0 \\
\hline Oats & 0.20 & 1.0 \\
\hline Bermuda & 0.15 & 0.5 \\
\hline Fescue & 0.15 & 0.5 \\
\hline \multicolumn{2}{|c|}{$\begin{array}{l}\text { a Source for minimum rooting depth: } \\
\text { [DIRS 157311], p. 279). } \\
\text { b Source for maximum rooting depth: } \\
\text { [DIRS 157311], Table 22, pp. 163-165). }\end{array}$} & $\begin{array}{l}\text { Allen et al. (1998 } \\
\text { Allen et al. (1998 }\end{array}$ \\
\hline
\end{tabular}


Table E-2. Mean Monthly Rooting Depths ( $\mathrm{m}$ ), Effective Storage Depths ( $\mathrm{mm}$ ), and Effective Precipitation (mm) for 26 Crops and Turf for Present-Day and Upper Bound Monsoon Climate Conditions

\begin{tabular}{|c|c|c|c|c|c|c|c|c|c|c|c|c|}
\hline Crop & Jan & Feb & Mar & Apr & May & Jun & Jul & Aug & Sept & Oct & Nov & Dec \\
\hline \multicolumn{13}{|l|}{ Leaf Lettuce early } \\
\hline Rooting depth ${ }^{\mathrm{a}}$ & & & 0.19 & 0.29 & 0.30 & & & & & & & \\
\hline Effective storage ${ }^{b}$ & & & 22.6 & 34.9 & 36.0 & & & & & & & \\
\hline Effective precip. ${ }^{c}$ & & & 6.9 & 0 & 0 & & & & & & & \\
\hline Effective precip. ${ }^{d}$ & & & 13.9 & 8.6 & 6.9 & & & & & & & \\
\hline \multicolumn{13}{|l|}{ Leaf Lettuce late } \\
\hline Rooting depth & & & & & & & & & 0.20 & 0.30 & & \\
\hline Effective storage & & & & & & & & & 24.0 & 36.0 & & \\
\hline Effective precip. & & & & & & & & & 7.7 & 0 & & \\
\hline Effective precip. & & & & & & & & & 23.1 & 31.8 & & \\
\hline \multicolumn{13}{|c|}{ Head Lettuce early } \\
\hline Rooting depth & & & 0.19 & 0.29 & 0.30 & & & & & & & \\
\hline Effective storage & & & 22.6 & 34.9 & 36.0 & & & & & & & \\
\hline Effective precip. & & & 6.9 & 0 & 0 & & & & & & & \\
\hline Effective precip. & & & 13.9 & 8.6 & 6.9 & & & & & & & \\
\hline \multicolumn{13}{|l|}{ Head Lettuce late } \\
\hline Rooting depth & & & & & & & & & 0.20 & 0.30 & & \\
\hline Effective storage & & & & & & & & & 24.0 & 36.0 & & \\
\hline Effective precip. & & & & & & & & & 7.70 & 0 & & \\
\hline Effective precip. & & & & & & & & & 23.1 & 31.8 & & \\
\hline \multicolumn{13}{|l|}{ Cabbage early } \\
\hline Rooting depth & & & 0.23 & 0.44 & 0.50 & & & & & & & \\
\hline Effective storage & & & 27.3 & 53.5 & 60.0 & & & & & & & \\
\hline Effective precip. & & & 6.9 & 0 & 0 & & & & & & & \\
\hline Effective precip. & & & 13.9 & 9.3 & 8.1 & & & & & & & \\
\hline \multicolumn{13}{|l|}{ Cabbage late } \\
\hline Rooting depth & & & & & & & & 0.15 & 0.26 & 0.47 & 0.50 & \\
\hline Effective storage & & & & & & & & 18.0 & 31.5 & 56.7 & 60.0 & \\
\hline Effective precip. & & & & & & & & 0 & 7.7 & 0 & 0 & \\
\hline Effective precip. & & & & & & & & 19.7 & 25.8 & 34.4 & 16.5 & \\
\hline \multicolumn{13}{|l|}{ Celery early } \\
\hline Rooting depth & & & & 0.17 & 0.25 & 0.30 & 0.30 & 0.30 & & & & \\
\hline Effective storage & & & & 19.9 & 29.6 & 36.0 & 36.0 & 36.0 & & & & \\
\hline Effective precip. & & & & 0 & 0 & 0 & 0 & 0 & & & & \\
\hline Effective precip. & & & & 6.6 & 8.1 & 11.2 & 78.3 & 59.3 & & & & \\
\hline
\end{tabular}


Table E-2. Mean Monthly Rooting Depths ( $\mathrm{m}$ ), Effective Storage Depths ( $\mathrm{mm}$ ), and Effective Precipitation (mm) for 26 Crops and Turf for Present-Day and Upper Bound Monsoon Climate Conditions (Continued)

\begin{tabular}{|c|c|c|c|c|c|c|c|c|c|c|c|c|}
\hline Crop & Jan & Feb & Mar & Apr & May & Jun & Jul & Aug & Sept & Oct & Nov & Dec \\
\hline \multicolumn{13}{|l|}{ Celery late } \\
\hline Rooting depth & 0.30 & & & & & & & & 0.16 & 0.24 & 0.30 & 0.30 \\
\hline Effective storage & 36.0 & & & & & & & & 19.2 & 29.1 & 36.0 & 36.0 \\
\hline Effective precip. & 13.8 & & & & & & & & 6.6 & 0 & 0 & 7.7 \\
\hline Effective precip. & 21.5 & & & & & & & & 18.2 & 27.0 & 15.5 & 23.2 \\
\hline \multicolumn{13}{|l|}{ Broccoli early } \\
\hline Rooting depth & & & 0.21 & 0.37 & 0.40 & & & & & & & \\
\hline Effective storage & & & 25.3 & 44.7 & 48.0 & & & & & & & \\
\hline Effective precip. & & & 6.9 & 0 & 0 & & & & & & & \\
\hline Effective precip. ${ }^{d}$ & & & 13.9 & 9.3 & 8.1 & & & & & & & \\
\hline \multicolumn{13}{|l|}{ Broccoli late } \\
\hline Rooting depth & & & & & & & & 0.15 & 0.24 & 0.39 & 0.40 & \\
\hline Effective storage & & & & & & & & 18.0 & 28.3 & 46.6 & 48.0 & \\
\hline Effective precip. & & & & & & & & 0 & 7.7 & 0 & 0 & \\
\hline Effective precip. & & & & & & & & 19.7 & 23.1 & 34.4 & 14.9 & \\
\hline \multicolumn{13}{|l|}{ Cauliflower early } \\
\hline Rooting depth & & & 0.21 & 0.37 & 0.40 & & & & & & & \\
\hline Effective storage & & & 25.1 & 44.4 & 48.0 & & & & & & & \\
\hline Effective precip. & & & 6.9 & 0 & 0 & & & & & & & \\
\hline Effective precip. & & & 13.9 & 10.2 & 8.1 & & & & & & & \\
\hline \multicolumn{13}{|l|}{ Cauliflower late } \\
\hline Rooting depth & & & & & & & & 0.15 & 0.23 & 0.39 & 0.40 & \\
\hline Effective storage & & & & & & & & 18.0 & 28.0 & 46.2 & 48.0 & \\
\hline Effective precip. & & & & & & & & 0 & 7.7 & 0 & 0 & \\
\hline Effective precip. & & & & & & & & 19.7 & 23.1 & 39.1 & 15.9 & \\
\hline \multicolumn{13}{|l|}{ Spinach early } \\
\hline Rooting depth & & & 0.17 & 0.28 & 0.30 & & & & & & & \\
\hline Effective storage & & & 20.8 & 34.3 & 36.0 & & & & & & & \\
\hline Effective precip. & & & 5.8 & 0 & 0 & & & & & & & \\
\hline Effective precip. & & & 12.4 & 8.6 & 6.9 & & & & & & & \\
\hline \multicolumn{13}{|l|}{ Spinach late } \\
\hline Rooting depth & & & & & & & & & 0.17 & 0.28 & 0.30 & \\
\hline Effective storage & & & & & & & & & 20.4 & 34.3 & 36.0 & \\
\hline Effective precip. & & & & & & & & & 6.6 & 0 & 0 & \\
\hline Effective precip. & & & & & & & & & 18.2 & 31.8 & 13.8 & \\
\hline
\end{tabular}


Table E-2. Mean Monthly Rooting Depths (m), Effective Storage Depths ( $\mathrm{mm}$ ), and Effective Precipitation ( $\mathrm{mm}$ ) for 26 Crops and Turf for Present-Day and Upper Bound Monsoon Climate Conditions (Continued)

\begin{tabular}{|c|c|c|c|c|c|c|c|c|c|c|c|c|}
\hline Crop & Jan & Feb & Mar & April & May & June & July & Aug & Sept & Oct & Nov & Dec \\
\hline \multicolumn{13}{|l|}{ Potatoes } \\
\hline Rooting depth & & & 0.15 & 0.23 & 0.38 & 0.40 & 0.40 & & & & & \\
\hline Effective storage & & & 18.0 & 27.4 & 45.7 & 48.0 & 48.0 & & & & & \\
\hline Effective precip. & & & 5.8 & 0 & 0 & 0 & 0 & & & & & \\
\hline Effective precip. & & & 9.5 & 6.9 & 8.1 & 12.1 & 64.2 & & & & & \\
\hline \multicolumn{13}{|l|}{ Onions early } \\
\hline Rooting depth & & & 0.15 & 0.24 & 0.30 & 0.30 & 0.30 & & & & & \\
\hline Effective storage & & & 18.0 & 29.1 & 36.0 & 36.0 & 36.0 & & & & & \\
\hline Effective precip. & & & 5.8 & 0 & 0 & 0 & 0 & & & & & \\
\hline Effective precip. & & & 11.7 & 7.7 & 8.1 & 11.2 & 59.3 & & & & & \\
\hline \multicolumn{13}{|l|}{ Onions late } \\
\hline Rooting depth & 0.30 & & & & & & & & 0.17 & 0.28 & 0.30 & 0.30 \\
\hline Effective storage & 36.0 & & & & & & & & 20.1 & 33.9 & 36.0 & 36.0 \\
\hline Effective precip. & 5.8 & & & & & & & & 6.6 & 0 & 0 & 6.9 \\
\hline Effective precip. & 6.3 & & & & & & & & 18.2 & 37.8 & 15.5 & 23.2 \\
\hline \multicolumn{13}{|l|}{ Carrots early } \\
\hline Rooting depth & & & 0.19 & 0.45 & 0.50 & & & & & & & \\
\hline Effective storage & & & 23.2 & 53.9 & 60.0 & & & & & & & \\
\hline Effective precip. & & & 6.2 & 0 & 0 & & & & & & & \\
\hline Effective precip. & & & 13.1 & 9.3 & 8.1 & & & & & & & \\
\hline \multicolumn{13}{|l|}{ Carrots late } \\
\hline Rooting depth & & & & & & & & 0.15 & 0.35 & 0.50 & 0.50 & \\
\hline Effective storage & & & & & & & & 18.0 & 42.5 & 60.0 & 60.0 & \\
\hline Effective precip. & & & & & & & & 0 & 9.46 & 0 & 0 & \\
\hline Effective precip. & & & & & & & & 19.7 & 25.8 & 35.9 & 15.5 & \\
\hline \multicolumn{13}{|l|}{ Sweet corn } \\
\hline Rooting depth & & & & & 0.42 & 0.80 & 0.80 & & & & & \\
\hline Effective storage & & & & & 50.4 & 96.0 & 96.0 & & & & & \\
\hline Effective precip. & & & & & 0 & 0 & 0 & & & & & \\
\hline Effective precip. & & & & & 8.1 & 13.3 & 87.7 & & & & & \\
\hline \multicolumn{13}{|l|}{ Bell Peppers } \\
\hline Rooting depth & & & & & 0.28 & 0.50 & 0.50 & & & & & \\
\hline Effective storage & & & & & 34.0 & 59.9 & 60.0 & & & & & \\
\hline Effective precip. & & & & & 0 & 0 & 0 & & & & & \\
\hline Effective precip. & & & & & 8.1 & 12.6 & 78.6 & & & & & \\
\hline
\end{tabular}


Table E-2. Mean Monthly Rooting Depths (m), Effective Storage Depths ( $\mathrm{mm}$ ), and Effective Precipitation (mm) for 26 Crops and Turf for Present-Day and Upper Bound Monsoon Climate Conditions (Continued)

\begin{tabular}{|c|c|c|c|c|c|c|c|c|c|c|c|c|}
\hline Crop & Jan & Feb & Mar & April & May & Jun & July & Aug & Sept & Oct & Nov & Dec \\
\hline \multicolumn{13}{|l|}{ Cucumbers } \\
\hline Rooting depth & & & & & & 0.42 & 0.70 & & & & & \\
\hline Effective storage & & & & & & 49.9 & 84.0 & & & & & \\
\hline Effective precip. & & & & & & 0 & 0 & & & & & \\
\hline Effective precip. & & & & & & 9.3 & 91.0 & & & & & \\
\hline \multicolumn{13}{|l|}{ Squash } \\
\hline Rooting depth & & & & & 0.24 & 0.51 & 0.60 & & & & & \\
\hline Effective storage & & & & & 29.0 & 61.5 & 72.0 & & & & & \\
\hline Effective precip. & & & & & 0 & 0 & 0 & & & & & \\
\hline Effective precip. & & & & & 6.2 & 10.7 & 69.0 & & & & & \\
\hline \multicolumn{13}{|l|}{ Melons } \\
\hline Rooting depth & & & & & 0.25 & 0.60 & 0.80 & 0.80 & & & & \\
\hline Effective storage & & & & & 30.2 & 72.7 & 96.0 & 96.0 & & & & \\
\hline Effective precip. & & & & & 0 & 0 & 0 & 0 & & & & \\
\hline Effective precip. & & & & & 6.2 & 10.0 & 92.8 & 77.5 & & & & \\
\hline \multicolumn{13}{|l|}{ Tomatoes } \\
\hline Rooting depth & & & & & 0.32 & 0.70 & 0.70 & & & & & \\
\hline Effective storage & & & & & 37.8 & 84.0 & 84.0 & & & & & \\
\hline Effective precip. & & & & & 0 & 0 & 0 & & & & & \\
\hline Effective precip. & & & & & 7.7 & 13.0 & 86.0 & & & & & \\
\hline \multicolumn{13}{|l|}{ Apples } \\
\hline Rooting depth & & & 1.00 & 1.00 & 1.00 & 1.00 & 1.00 & 1.00 & 1.00 & 1.00 & & \\
\hline Effective storage & & & 120.0 & 120.0 & 120.0 & 120.0 & 120.0 & 120.0 & 120.0 & 120.0 & & \\
\hline Effective precip. & & & 9.4 & 0 & 0 & 0 & 0 & 0 & 9.1 & 0 & & \\
\hline Effective precip. & & & 18.7 & 9.4 & 8.1 & 12.5 & 94.6 & 89.4 & 32.2 & 36.4 & & \\
\hline \multicolumn{13}{|l|}{ Grapes } \\
\hline Rooting depth & & & 1.00 & 1.00 & 1.00 & 1.00 & 1.00 & 1.00 & & & & \\
\hline Effective storage & & & 120.0 & 120.0 & 120.0 & 120.0 & 120.0 & 120.0 & & & & \\
\hline Effective precip. & & & 8.3 & 0 & 0 & 0 & 0 & 0 & & & & \\
\hline Effective precip. & & & 18.7 & 10.4 & 8.1 & 13.5 & 94.6 & 75.9 & & & & \\
\hline \multicolumn{13}{|l|}{ Strawberries } \\
\hline Rooting depth & & & 0.20 & 0.20 & 0.20 & 0.20 & 0.20 & 0.20 & 0.20 & & & \\
\hline Effective storage & & & 24.0 & 24.0 & 24.0 & 24.0 & 24.0 & 24.0 & 24.0 & & & \\
\hline Effective precip. & & & 6.9 & 0 & 0 & 0 & 0 & 0 & 7.7 & & & \\
\hline Effective precip. & & & 13.1 & 6.9 & 8.1 & 10.0 & 66.2 & 66.2 & 21.6 & & & \\
\hline
\end{tabular}


Table E-2. Mean Monthly Rooting Depths (m), Effective Storage Depths ( $\mathrm{mm}$ ), and Effective Precipitation (mm) for 26 Crops and Turf for Present-Day and Upper Bound Monsoon Climate Conditions (Continued)

\begin{tabular}{|c|c|c|c|c|c|c|c|c|c|c|c|c|}
\hline Crop & Jan & Feb & Mar & April & May & Jun & July & Aug & Sept & Oct & Nov & Dec \\
\hline \multicolumn{13}{|l|}{ Winter Wheat } \\
\hline Rooting depth & 1.30 & 1.50 & 1.50 & 1.50 & 1.50 & 1.50 & & & & 0.24 & 0.51 & 0.90 \\
\hline Effective storage & 155.5 & 180.0 & 180.0 & 180.0 & 180.0 & 180.0 & & & & 28.6 & 61.5 & 108.1 \\
\hline Effective precip. & 18.0 & 9.6 & 11.7 & 0 & 0 & 0 & & & & 0 & 0 & 8.2 \\
\hline Effective precip. & 28.9 & 20.3 & 22.5 & 11.8 & 8.1 & 8.6 & & & & 24.6 & 16.5 & 25.5 \\
\hline \multicolumn{13}{|l|}{ Barley } \\
\hline Rooting depth & 0.89 & 1.00 & 1.00 & 1.00 & 1.00 & 1.00 & & & & 0.22 & 0.39 & 0.64 \\
\hline Effective storage & 106.5 & 120.0 & 120.0 & 120.0 & 120.0 & 120.0 & & & & 26.9 & 47.0 & 76.8 \\
\hline Effective precip. & 17.3 & 9.4 & 11.4 & 0 & 0 & 0 & & & & 0 & 0 & 8.0 \\
\hline Effective precip. & 26.0 & 19.8 & 21.8 & 11.4 & 8.1 & 8.3 & & & & 18.0 & 16.3 & 26.0 \\
\hline \multicolumn{13}{|l|}{ Alfalfa $1^{\text {st }}$ cutting } \\
\hline Rooting depth & 0.53 & 1.00 & 1.00 & & & & & & & & & \\
\hline Effective storage & 64.0 & 120.0 & 120.0 & & & & & & & & & \\
\hline Effective precip. & 15.5 & 9.4 & 8.3 & & & & & & & & & \\
\hline Effective precip. & 24.2 & 19.8 & 9.1 & & & & & & & & & \\
\hline \multicolumn{13}{|c|}{ Alfalfa 2 nd cutting } \\
\hline Rooting depth & & & 1.00 & 1.00 & & & & & & & & \\
\hline Effective storage & & & 120.0 & 120.0 & & & & & & & & \\
\hline Effective precip. & & & 9.4 & 0 & & & & & & & & \\
\hline Effective precip. & & & 18.7 & 11.4 & & & & & & & & \\
\hline \multicolumn{13}{|l|}{ Alfalfa 3 rd cutting } \\
\hline Rooting depth & & & & 1.00 & 1.00 & 1.00 & & & & & & \\
\hline Effective storage & & & & 120.0 & 120.0 & 120.0 & & & & & & \\
\hline Effective precip. & & & & 0 & 0 & 0 & & & & & & \\
\hline Effective precip. & & & & 4.1 & 8.1 & 11.4 & & & & & & \\
\hline \multicolumn{13}{|l|}{ Alfalfa 4th cutting } \\
\hline Rooting depth & & & & & & 1.00 & 1.00 & 1.00 & & & & \\
\hline Effective storage & & & & & & 120.0 & 120.0 & 120.0 & & & & \\
\hline Effective precip. & & & & & & 0 & 0 & 0 & & & & \\
\hline Effective precip. & & & & & & 20.6 & 89.4 & 31.0 & & & & \\
\hline \multicolumn{13}{|l|}{ Alfalfa 5th cutting } \\
\hline Rooting depth & & & & & & & & 1.00 & 1.00 & 1.00 & & \\
\hline Effective storage & & & & & & & & 120.0 & 120.0 & 120.0 & & \\
\hline Effective precip. & & & & & & & & 0 & 9.1 & 0 & & \\
\hline Effective precip. & & & & & & & & 31.4 & 89.4 & 26.0 & & \\
\hline
\end{tabular}


Table E-2. Mean Monthly Rooting Depths (m), Effective Storage Depths (mm), and Effective Precipitation $(\mathrm{mm})$ for 26 Crops and Turf for Present-Day and Upper Bound Monsoon Climate Conditions (Continued)

\begin{tabular}{|l|l|l|l|l|l|l|l|l|l|r|r|r|}
\hline \multicolumn{1}{|c|}{ Crop } & Jan & Feb & Mar & April & May & Jun & July & Aug & Sept & Oct & Nov & Dec \\
\hline Alfalfa 6th cutting & & & & & & & & & & & & \\
\hline Rooting depth & & & & & & & & & & 1.00 & 1.00 & 1.00 \\
\hline Effective storage & & & & & & & & & & 120.0 & 120.0 & 120.0 \\
\hline Effective precip. & & & & & & & & & & 0 & 0 & 4.6 \\
\hline Effective precip. & & & & & & & & & & 33.3 & 18.7 & 25.0 \\
\hline
\end{tabular}

Oat hay

\begin{tabular}{|l|r|r|r|r|r|r|r|r|r|r|r|r|}
\hline Rooting depth & & & & 0.50 & 1.00 & 1.00 & & & & & & \\
\hline Effective storage & & & & 59.6 & 120.0 & 120.0 & & & & & & \\
\hline Effective precip. & & & & 0 & 0 & 0 & & & & & & \\
\hline Effective precip. & & & & 8.7 & 8.1 & 9.4 & & & & & & \\
\hline Bermudagrass & & \\
\hline Rooting depth & 0.50 & 0.50 & 0.50 & 0.50 & 0.50 & 0.50 & 0.50 & 0.50 & 0.50 & 0.50 & 0.50 & 0.50 \\
\hline Effective storage & 60.0 & 60.0 & 60.0 & 60.0 & 60.0 & 60.0 & 60.0 & 60.0 & 60.0 & 60.0 & 60.0 & 60.0 \\
\hline Effective precip. & 16.5 & 8.7 & 8.7 & 0 & 0 & 0 & 0 & 0 & 10.7 & 0 & 0 & 7.8 \\
\hline Effective precip. & 23.2 & 15.5 & 16.3 & 7.7 & 8.1 & 8.5 & 82.7 & 78.4 & 27.9 & 34.0 & 15.5 & 23.2 \\
\hline
\end{tabular}

\section{Feed Corn}

\begin{tabular}{|c|c|c|c|c|c|c|c|c|c|c|c|}
\hline Rooting depth & & & & & 0.24 & 0.50 & 0.87 & 1.00 & 1.00 & 1.00 & \\
\hline Effective storage & & & & & 28.4 & 60.2 & 104.5 & 120.0 & 120.0 & 120.0 & \\
\hline Effective precip. & & & & & 0 & 0 & 0 & 0 & 9.1 & 0 & \\
\hline Effective precip. & & & & & 6.9 & 10.7 & 92.8 & 99.8 & 33.3 & 33.3 & \\
\hline \multicolumn{12}{|l|}{ Corn silage } \\
\hline Rooting depth & & & & & 0.26 & 0.73 & 1.00 & 1.00 & & & \\
\hline Effective storage & & & & & 31.8 & 87.3 & 120.0 & 120.0 & & & \\
\hline Effective precip. & & & & & 0 & 0 & 0 & 0 & & & \\
\hline Effective precip. & & & & & 6.9 & 11.2 & 106.1 & 71.8 & & & \\
\hline \multicolumn{12}{|l|}{ Oat feed } \\
\hline Rooting depth & 0.51 & 0.80 & 1.00 & 1.00 & 1.00 & & & & & & 0.24 \\
\hline Effective storage & 61.5 & 96.1 & 120.0 & 120.0 & 120.0 & & & & & & 28.8 \\
\hline Effective precip. & 15.5 & 9.2 & 11.4 & 0 & 0 & & & & & & 6.2 \\
\hline Effective precip. & 23.3 & 18.4 & 21.8 & 11.4 & 8.1 & & & & & & 9.0 \\
\hline
\end{tabular}

${ }^{a}$ Mean monthly rooting depth calculated according to Equation E-2.

${ }^{\mathrm{b}}$ Mean monthly effective storage depth for sandy loam soil calculated from Equation E-1.

${ }^{c}$ Mean monthly effective precipitation for present-day climate calculated according to Appendix E, Section 2.1.2.

${ }^{d}$ Mean monthly effective precipitation for upper bound monsoon climate calculated according to Appendix $E$, Section 2.1.2 
Table E-3. Mean Monthly Rooting Depths, Effective Storage Depths, and Effective Precipitation for 26 Crops and Turf for Upper and Lower Bound Glacial Transition Climate Conditions

\begin{tabular}{|c|c|c|c|c|c|c|c|c|c|c|c|c|}
\hline Crop & Jan & Feb & Mar & Apr & May & Jun & Jul & Aug & Sept & Oct & Nov & Dec \\
\hline Rooting depth $^{a}$ & & & & 0.15 & 0.23 & 0.30 & & & & & & \\
\hline Effective storage ${ }^{b}$ & & & & 18.2 & 27.8 & 36.0 & & & & & & \\
\hline Effective precip. ${ }^{c}$ & & & & 11.7 & 21.6 & 24.1 & & & & & & \\
\hline Effective precip. ${ }^{d}$ & & & & 11.7 & 16.2 & 9.5 & & & & & & \\
\hline \multicolumn{13}{|l|}{ Leaf Lettuce late } \\
\hline Rooting depth & & & & & & & 0.17 & 0.27 & 0.30 & & & \\
\hline Effective storage & & & & & & & 19.9 & 31.8 & 36.0 & & & \\
\hline Effective precip. & & & & & & & 6.6 & 9.5 & 6.9 & & & \\
\hline Effective precip. & & & & & & & 0 & 10.7 & 7.7 & & & \\
\hline \multicolumn{13}{|c|}{ Head Lettuce early } \\
\hline Rooting depth & & & & 0.15 & 0.21 & 0.29 & 0.30 & & & & & \\
\hline Effective storage & & & & 18.1 & 24.7 & 34.8 & 36.0 & & & & & \\
\hline Effective precip. & & & & 11.7 & 21.6 & 26.7 & 7.7 & & & & & \\
\hline Effective precip. & & & & 11.7 & 16.2 & 11.2 & 0 & & & & & \\
\hline \multicolumn{13}{|l|}{ Head Lettuce late } \\
\hline Rooting depth & & & & & & & 0.16 & 0.23 & 0.30 & 0.30 & & \\
\hline Effective storage & & & & & & & 19.3 & 28.2 & 36.0 & 36.0 & & \\
\hline Effective precip. & & & & & & & 6.6 & 7.7 & 8.6 & 2.5 & & \\
\hline Effective precip. & & & & & & & 0 & 9.4 & 9.5 & 4.2 & & \\
\hline \multicolumn{13}{|l|}{ Cabbage early } \\
\hline Rooting depth & & & & 0.15 & 0.30 & 0.49 & 0.50 & & & & & \\
\hline Effective storage & & & & 18.2 & 36.3 & 59.2 & 60.0 & & & & & \\
\hline Effective precip. & & & & 11.7 & 24.1 & 31.0 & 7.8 & & & & & \\
\hline Effective precip. & & & & 11.7 & 18.1 & 12.6 & 0 & & & & & \\
\hline \multicolumn{13}{|l|}{ Cabbage late } \\
\hline Rooting depth & & & & & & & 0.17 & 0.36 & 0.50 & 0.50 & & \\
\hline Effective storage & & & & & & & 20.3 & 42.8 & 60.0 & 60.0 & & \\
\hline Effective precip. & & & & & & & 5.8 & 9.5 & 9.7 & 2.5 & & \\
\hline Effective precip. & & & & & & & 0 & 10.3 & 10.4 & 4.2 & & \\
\hline \multicolumn{13}{|l|}{ Celery } \\
\hline Rooting depth & & & & 0.15 & 0.20 & 0.28 & 0.30 & 0.30 & & & & \\
\hline Effective storage & & & & 18.0 & 24.0 & 34.0 & 36.0 & 36.0 & & & & \\
\hline Effective precip. & & & & 11.7 & 21.6 & 27.5 & 10.3 & 7.7 & & & & \\
\hline Effective precip. & & & & 11.7 & 16.2 & 11.2 & 0 & 7.7 & & & & \\
\hline \multicolumn{13}{|l|}{ Broccoli early } \\
\hline Rooting depth & & & & 0.15 & 0.25 & 0.39 & 0.40 & & & & & \\
\hline Effective storage & & & & 18.1 & 29.9 & 46.7 & 48.0 & & & & & \\
\hline Effective precip. & & & & 11.7 & 21.6 & 29.8 & 8.4 & & & & & \\
\hline Effective precip. & & & & 11.7 & 16.2 & 12.1 & 0 & & & & & \\
\hline
\end{tabular}


Table E-3. Mean Monthly Rooting Depths, Effective Storage Depths, and Effective Precipitation for 26 Crops and Turf for Upper and Lower Bound Glacial Transition Climate Conditions (Continued)

\begin{tabular}{|c|c|c|c|c|c|c|c|c|c|c|c|c|}
\hline Crop & Jan & Feb & Mar & Apr & May & Jun & Jul & Aug & Sept & Oct & Nov & Dec \\
\hline \multicolumn{13}{|l|}{ Broccoli late } \\
\hline Rooting depth & & & & & & & 0.17 & 0.30 & 0.40 & 0.40 & & \\
\hline Effective storage & & & & & & & 20.1 & 35.4 & 48.0 & 48.0 & & \\
\hline Effective precip. & & & & & & & 6.6 & 8.6 & 9.3 & 14.9 & & \\
\hline Effective precip. & & & & & & & 0 & 10.3 & 10.2 & 14.9 & & \\
\hline \multicolumn{13}{|l|}{ Cauliflower late } \\
\hline Rooting depth & & & & & & 0.15 & 0.24 & 0.40 & 0.40 & & & \\
\hline Effective storage & & & & & & 18.0 & 28.3 & 47.5 & 48.0 & & & \\
\hline Effective precip. & & & & & & 4.6 & 7.7 & 9.3 & 2.5 & & & \\
\hline Effective precip. & & & & & & 0 & 8.5 & 10.2 & 4.2 & & & \\
\hline \multicolumn{13}{|l|}{ Spinach early } \\
\hline Rooting depth & & & & 0.15 & 0.24 & 0.30 & & & & & & \\
\hline Effective storage & & & & 18.1 & 28.7 & 36.0 & & & & & & \\
\hline Effective precip. & & & & 11.7 & 21.6 & 24.1 & & & & & & \\
\hline Effective precip. & & & & 11.7 & 16.2 & 8.6 & & & & & & \\
\hline \multicolumn{13}{|l|}{ Spinach late } \\
\hline Rooting depth & & & & & & & & 0.19 & 0.29 & 0.30 & & \\
\hline Effective storage & & & & & & & & 22.6 & 35.0 & 36.0 & & \\
\hline Effective precip. & & & & & & & & 6.9 & 8.6 & 2.5 & & \\
\hline Effective precip. & & & & & & & & 7.7 & 9.5 & 4.2 & & \\
\hline \multicolumn{13}{|l|}{ Potatoes } \\
\hline Rooting depth & & & & 0.15 & 0.24 & 0.38 & 0.40 & 0.40 & & & & \\
\hline Effective storage & & & & 18.0 & 29.1 & 46.0 & 48.0 & 48.0 & & & & \\
\hline Effective precip. & & & & 11.1 & 20.8 & 29.8 & 12.1 & 8.4 & & & & \\
\hline Effective precip. & & & & 11.7 & 14.6 & 12.1 & 0 & 9.3 & & & & \\
\hline \multicolumn{13}{|l|}{ Onions } \\
\hline Rooting depth & & & 0.19 & 0.29 & 0.30 & 0.30 & 0.30 & 0.30 & & & & \\
\hline Effective storage & & & 23.0 & 34.9 & 36.0 & 36.0 & 36.0 & 36.0 & & & & \\
\hline Effective precip. & & & 19.2 & 16.3 & 26.7 & 27.5 & 9.5 & 6.9 & & & & \\
\hline Effective precip. & & & 13.9 & 18.1 & 21.3 & 11.2 & 0 & 6.9 & & & & \\
\hline \multicolumn{13}{|l|}{ Carrots early } \\
\hline Rooting depth & & & & 0.15 & 0.34 & 0.50 & 0.50 & & & & & \\
\hline Effective storage & & & & 18.2 & 41.0 & 60.0 & 60.0 & & & & & \\
\hline Effective precip. & & & & 11.7 & 24.1 & 31.0 & 8.7 & & & & & \\
\hline Effective precip. & & & & 11.7 & 18.1 & 12.6 & 0 & & & & & \\
\hline \multicolumn{13}{|l|}{ Carrots late } \\
\hline Rooting depth & & & & & & & 0.20 & 0.43 & 0.50 & 0.50 & & \\
\hline Effective storage & & & & & & & 23.9 & 52.0 & 60.0 & 60.0 & & \\
\hline Effective precip. & & & & & & & 6.9 & 10.2 & 9.7 & 2.5 & & \\
\hline Effective precip. & & & & & & & 0 & 10.7 & 10.4 & 4.2 & & \\
\hline
\end{tabular}


Table E-3. Mean Monthly Rooting Depths, Effective Storage Depths, and Effective Precipitation for 26 Crops and Turf for Upper and Lower Bound Glacial Transition Climate Conditions (Continued)

\begin{tabular}{|c|c|c|c|c|c|c|c|c|c|c|c|c|}
\hline Crop & Jan & Feb & Mar & Apr & May & Jun & Jul & Aug & Sept & Oct & Nov & Dec \\
\hline \multicolumn{13}{|l|}{ Sweet corn } \\
\hline Rooting depth & & & & & 0.20 & 0.39 & 0.72 & 0.80 & 0.80 & & & \\
\hline Effective storage & & & & & 24.0 & 46.8 & 86.4 & 96.0 & 96.0 & & & \\
\hline Effective precip. & & & & & 8.8 & 23.2 & 11.0 & 12.2 & 8.2 & & & \\
\hline Effective precip. & & & & & 13.1 & 12.1 & 0 & 10.7 & 8.2 & & & \\
\hline \multicolumn{13}{|l|}{ Bell Peppers } \\
\hline Rooting depth & & & & & & 0.20 & 0.39 & 0.50 & 0.50 & & & \\
\hline Effective storage & & & & & & 23.6 & 47.2 & 60.0 & 60.0 & & & \\
\hline Effective precip. & & & & & & 20.8 & 10.2 & 11.6 & 8.7 & & & \\
\hline Effective precip. & & & & & & 6.9 & 0 & 10.7 & 8.7 & & & \\
\hline \multicolumn{13}{|l|}{ Cucumbers } \\
\hline Rooting depth & & & & & 0.20 & 0.51 & 0.70 & & & & & \\
\hline Effective storage & & & & & 24.3 & 60.9 & 84.0 & & & & & \\
\hline Effective precip. & & & & & 17.7 & 29.1 & 11.0 & & & & & \\
\hline Effective precip. & & & & & 12.3 & 10.7 & 0 & & & & & \\
\hline \multicolumn{13}{|l|}{ Squash } \\
\hline Rooting depth & & & & & 0.20 & 0.42 & 0.60 & & & & & \\
\hline Effective storage & & & & & 24.2 & 50.3 & 72.0 & & & & & \\
\hline Effective precip. & & & & & 14.7 & 26.0 & 11.0 & & & & & \\
\hline Effective precip. & & & & & 12.3 & 10.2 & 0 & & & & & \\
\hline \multicolumn{13}{|l|}{ Melons } \\
\hline Rooting depth & & & & & 0.20 & 0.42 & 0.76 & 0.80 & 0.80 & & & \\
\hline Effective storage & & & & & 24.2 & 49.8 & 90.7 & 96.0 & 96.0 & & & \\
\hline Effective precip. & & & & & 14.7 & 26.0 & 11.2 & 11.2 & 8.2 & & & \\
\hline Effective precip. & & & & & 12.3 & 9.3 & 0 & 10.7 & 8.2 & & & \\
\hline \multicolumn{13}{|l|}{ Tomatoes } \\
\hline Rooting depth & & & & & & 0.29 & 0.61 & 0.70 & 0.70 & & & \\
\hline Effective storage & & & & & & 34.3 & 73.8 & 84.0 & 84.0 & & & \\
\hline Effective precip. & & & & & & 23.2 & 11.0 & 12.0 & 8.0 & & & \\
\hline Effective precip. & & & & & & 7.7 & 0 & 10.7 & 8.0 & & & \\
\hline \multicolumn{13}{|l|}{ Apples } \\
\hline Rooting depth & & & & 1.00 & 1.00 & 1.00 & 1.00 & 1.00 & 1.00 & 1.00 & & \\
\hline Effective storage & & & & 120.0 & 120.0 & 120.0 & 120.0 & 120.0 & 120.0 & 120.0 & & \\
\hline Effective precip. & & & & 11.4 & 28.1 & 32.2 & 11.4 & 11.4 & 10.4 & 10.0 & & \\
\hline Effective precip. & & & & 16.6 & 19.8 & 12.5 & 0 & 10.7 & 10.4 & 16.6 & & \\
\hline \multicolumn{13}{|l|}{ Grapes } \\
\hline Rooting depth & & & & & & 1.00 & 1.00 & 1.00 & 1.00 & & & \\
\hline Effective storage & & & & & & 120.0 & 120.0 & 120.0 & 120.0 & & & \\
\hline Effective precip. & & & & & & 20.8 & 10.4 & 10.4 & 9.4 & & & \\
\hline Effective precip. & & & & & & 8.3 & 0 & 10.7 & 10.4 & & & \\
\hline
\end{tabular}


Table E-3. Mean Monthly Rooting Depths, Effective Storage Depths, and Effective Precipitation for 26 Crops and Turf for Upper and Lower Bound Glacial Transition Climate Conditions (Continued)

\begin{tabular}{|c|c|c|c|c|c|c|c|c|c|c|c|c|}
\hline Crop & Jan & Feb & Mar & Apr & May & Jun & Jul & Aug & Sept & Oct & Nov & Dec \\
\hline \multicolumn{13}{|l|}{ Strawberries } \\
\hline Rooting depth & & & & 0.20 & 0.20 & 0.20 & & & & & & \\
\hline Effective storage & & & & 24.0 & 24.0 & 24.0 & & & & & & \\
\hline Effective precip. & & & & 3.8 & 21.6 & 23.9 & & & & & & \\
\hline Effective precip. & & & & 5.2 & 15.4 & 9.2 & & & & & & \\
\hline \multicolumn{13}{|l|}{ Winter Wheat } \\
\hline Rooting depth & 0.85 & 1.02 & 1.18 & 1.36 & 1.49 & 1.50 & 1.50 & 1.50 & 0.21 & 0.34 & 0.51 & 0.68 \\
\hline Effective storage & 102.3 & 122.3 & 142.2 & 162.8 & 178.8 & 180.0 & 180.0 & 180.0 & 25.7 & 40.2 & 60.8 & 81.4 \\
\hline Effective precip. & 14.0 & 25.0 & 26.5 & 20.3 & 33.2 & 35.3 & 11.8 & 8.6 & 6.2 & 13.8 & 13.9 & 10.8 \\
\hline Effective precip. & 8.2 & 8.3 & 20.1 & 20.1 & 21.3 & 12.7 & 0 & 8.6 & 6.2 & 14.6 & 7.8 & 8.0 \\
\hline \multicolumn{13}{|l|}{ Barley } \\
\hline Rooting depth & & & & 0.28 & 0.86 & 1.00 & 1.00 & & & & & \\
\hline Effective storage & & & & 33.9 & 103.2 & 120.0 & 120.0 & & & & & \\
\hline Effective precip. & & & & 13.4 & 30.6 & 34.3 & 9.4 & & & & & \\
\hline Effective precip. & & & & 13.8 & 21.3 & 12.7 & 0 & & & & & \\
\hline \multicolumn{13}{|l|}{ Alfalfa $1^{\text {st }}$ cutting } \\
\hline Rooting depth & & & 0.44 & 0.96 & 1.00 & & & & & & & \\
\hline Effective storage & & & 52.2 & 115.8 & 120.0 & & & & & & & \\
\hline Effective precip. & & & 22.3 & 20.8 & 28.1 & & & & & & & \\
\hline Effective precip. & & & 15.8 & 20.1 & 20.8 & & & & & & & \\
\hline \multicolumn{13}{|l|}{ Alfalfa $2^{\text {nd }}$ cutting } \\
\hline Rooting depth & & & & & 1.00 & 1.00 & 1.00 & & & & & \\
\hline Effective storage & & & & & 120.0 & 120.0 & 120.0 & & & & & \\
\hline Effective precip. & & & & & 25.0 & 33.3 & 11.4 & & & & & \\
\hline Effective precip. & & & & & 17.7 & 12.7 & 0 & & & & & \\
\hline \multicolumn{13}{|l|}{ Alfalfa 3 rd cutting } \\
\hline Rooting depth & & & & & & & 1.00 & 1.00 & 1.00 & & & \\
\hline Effective storage & & & & & & & 120.0 & 120.0 & 120.0 & & & \\
\hline Effective precip. & & & & & & & 8.3 & 11.4 & 10.4 & & & \\
\hline Effective precip. & & & & & & & 0 & 10.7 & 10.4 & & & \\
\hline \multicolumn{13}{|l|}{ Oat hay } \\
\hline Rooting depth & & & & & 0.41 & 1.00 & 1.00 & & & & & \\
\hline Effective storage & & & & & 49.4 & 120.0 & 120.0 & & & & & \\
\hline Effective precip. & & & & & 22.3 & 34.3 & 8.3 & & & & & \\
\hline Effective precip. & & & & & 15.8 & 12.7 & 0 & & & & & \\
\hline \multicolumn{13}{|l|}{ Fescue } \\
\hline Rooting depth & & & & 0.50 & 0.50 & 0.50 & 0.50 & 0.50 & 0.50 & 0.50 & & \\
\hline Effective storage & & & & 60.0 & 60.0 & 60.0 & 60.0 & 60.0 & 60.0 & 60.0 & & \\
\hline
\end{tabular}


Table E-3. Mean Monthly Rooting Depths, Effective Storage Depths, and Effective Precipitation for 26 Crops and Turf for Upper and Lower Bound Glacial Transition Climate Conditions (Continued)

\begin{tabular}{|l|l|l|l|l|l|l|l|l|l|l|l|l|}
\hline \multicolumn{1}{|c|}{ Crop } & Jan & Feb & Mar & Apr & May & Jun & Jul & Aug & Sept & Oct & Nov & Dec \\
\hline Effective precip. & & & & 18.4 & 29.1 & 30.1 & 10.7 & 10.7 & 9.7 & 17.5 & & \\
\hline Effective precip. & & & & 19.4 & 21.3 & 12.7 & 0 & 10.7 & 10.4 & 19.4 & & \\
\hline Feed Corn & & & & & & & & & & & & \\
\hline Rooting depth & & & & & 0.26 & 0.54 & 0.90 & 1.00 & 1.00 & 1.00 & 1.00 & \\
\hline Effective storage & & & & & 31.4 & 65.6 & 107.4 & 120.0 & 120.0 & 120.0 & 120.0 & \\
\hline Effective precip. & & & & & 20.6 & 26.2 & 12.2 & 13.5 & 10.4 & 17.7 & 1.9 & \\
\hline Effective precip. & & & & & 13.8 & 8.7 & 0 & 10.7 & 10.4 & 19.8 & 3.8 & \\
\hline Corn silage & & & & & & & & & & & & \\
\hline Rooting depth & & & & & 0.28 & 0.67 & 0.99 & 1.00 & 1.00 & & & \\
\hline Effective storage & & & & & 34.1 & 80.6 & 2119.1 & 120.0 & 120.0 & & & \\
\hline Effective precip. & & & & & 20.6 & 28.0 & 13.5 & 12.5 & 9.4 & & & \\
\hline Effective precip. & & & & & 13.8 & 10.0 & 0 & 10.7 & 10.4 & & & \\
\hline Oat feed & & & & & & & & & & & \\
\hline Rooting depth & & 0.20 & 0.42 & 0.94 & 1.00 & 1.00 & 1.00 & & & & \\
\hline Effective storage & & & 24.0 & 50.8 & 113.1 & 120.0 & 120.0 & 120.0 & & & & \\
\hline Effective precip. & & 1.8 & 14.9 & 32.2 & 34.3 & 12.5 & 8.3 & & & & \\
\hline Effective precip. & & & 2.6 & 15.8 & 21.3 & 12.7 & 0 & 9.4 & & & & \\
\hline
\end{tabular}

${ }^{a}$ Mean monthly rooting depth calculated according to Equation E-2.

b Mean monthly effective storage depth for sandy loam soil calculated from Equation E-1.

${ }^{\mathrm{C}}$ Mean monthly effective precipitation for upper bound glacial transition climate calculated according to Appendix E, Section 2.1.2.

d Mean monthly effective precipitation for lower bound glacial transition climate calculated according to Appendix E, Section 2.1.2.

\section{E2.1.2 Evapotranspiration/Precipitation Ratio Method for Estimating Effective Precipitation}

Pe was derived using methods from Doorenbos and Pruitt (1977 [DIRS 103062], Table 34, p. 75) using mean monthly precipitation (Section 4, Tables 4.1-2 through 4.1-5), mean monthly $E T_{c}$ (Tables D-10 through D-13), and effective storage in the root zone (TAW, Tables E-2 and E-3). For direct use of Table 34 (reproduced below in Table E-4), Doorenbos and Pruitt assumed an effective root zone storage of $75 \mathrm{~mm}$. This was rarely the case for the representative crops and so the correction factors for storage were used (Doorenbos and Pruitt 1977 [DIRS 103062], p. 75, see example below). The mean monthly precipitation values in Table 34 (Doorenbos and Pruitt 1977 [DIRS 103062], p. 75) were listed in $12.5 \mathrm{~mm}$ increments, and mean monthly $E T_{c}$ in $25 \mathrm{~mm}$ increments. The closest table values to the calculated mean monthly precipitation and $E T_{c}$ were used. If mean monthly precipitation was less than $8 \mathrm{~mm}, P e$ was set equal to zero (recommended by Dastane 1978 [DIRS 159870], Section 2.1). If the adjusted table Pe values were greater than the monthly mean $E T_{c}$, effective precipitation was set equal to mean monthly $E T_{c}$ because precipitation in excess of what is used by the crop cannot be considered effective. 
Example: Using early lettuce in March for present-day climate conditions, mean monthly precipitation $=11.7 \mathrm{~mm}\left(\right.$ Section 4 , Table 4.1-2), mean monthly $E T_{c}=77.95 \mathrm{~mm}$ (Table D-10), and effective storage $=22.6 \mathrm{~mm}$ (Table E-2).

From Table E-4 below, the closest mean monthly precipitation and $E T_{c}$ values were $12.5 \mathrm{~mm}$ and $75 \mathrm{~mm}$, respectively. These values correspond to an average monthly $P e$ of $9 \mathrm{~mm}$ (Table E-4). The correction factor for effective storage of $22.6 \mathrm{~mm}$ was 0.77 (Table E-4). Thus, effective precipitation for lettuce in March was $9 \times 0.77=6.93 \mathrm{~mm}$.

Table E-4. Average Monthly Effective Precipitation Determined From Mean Monthly Precipitation and Average Monthly Crop Evapotranspiration

\begin{tabular}{|c|c|c|c|c|c|c|c|c|c|c|}
\hline \multicolumn{11}{|c|}{ Monthly mean precipitation (mm) } \\
\hline & & 12.5 & 25.0 & 37.5 & 50 & 62.5 & 75.0 & 87.5 & 100.0 & 112.5 \\
\hline \multicolumn{11}{|c|}{ Average monthly effective precipitation (mm) } \\
\hline \multirow{10}{*}{$\begin{array}{l}\text { Average } \\
\text { monthly } \\
E T_{c} \\
(\mathrm{~mm})\end{array}$} & 25 & 8 & 16 & 24 & & & & & & \\
\hline & 50 & 8 & 17 & 25 & 32 & 39 & 46 & & & \\
\hline & 75 & 9 & 18 & 27 & 34 & 41 & 48 & 56 & 62 & 69 \\
\hline & 100 & 9 & 19 & 28 & 35 & 43 & 52 & 59 & 66 & 73 \\
\hline & 125 & 10 & 20 & 30 & 37 & 46 & 54 & 62 & 70 & 76 \\
\hline & 150 & 10 & 21 & 31 & 39 & 49 & 57 & 66 & 74 & 81 \\
\hline & 175 & 11 & 23 & 32 & 42 & 52 & 61 & 69 & 78 & 86 \\
\hline & 200 & 11 & 24 & 33 & 44 & 54 & 64 & 73 & 82 & 91 \\
\hline & 225 & 12 & 25 & 35 & 47 & 57 & 68 & 78 & 87 & 96 \\
\hline & 250 & 13 & 25 & 38 & 50 & 61 & 72 & 84 & 92 & 102 \\
\hline \multicolumn{11}{|c|}{ Correction factors for soil water storage depths that are not equal to $75 \mathrm{~mm}$. } \\
\hline $\begin{array}{l}\text { Effective } \\
\text { storage }\end{array}$ & 20 & 25 & 37.5 & 50 & 62.5 & 75 & 100 & 125 & 150 & 175 \\
\hline $\begin{array}{l}\text { Storage } \\
\text { factor }\end{array}$ & .73 & .77 & .86 & .93 & .97 & 1.00 & 1.02 & 1.04 & 1.06 & 1.07 \\
\hline
\end{tabular}

NOTE: Partial Table Redrawn from Doorenbos and Pruitt (1977 [DIRS 103062], Table 34, p. 75).

Mean monthly $P e$ for the present-day, lower bound monsoon, lower bound glacial transition, and upper bound glacial transition climate conditions are in Tables E-2 and E-3. Seasonal totals for $P e$ are in Tables E-5, E-6, E-7, and E-8. 
Table E-5. Seasonal Water Inputs and Requirements for 26 Crops and Turf for Present-Day Climate Conditions

\begin{tabular}{|c|c|c|c|c|c|c|c|c|c|}
\hline Crop & $P e(\mathrm{~mm})^{\mathrm{a}}$ & $W b(\mathrm{~mm})^{b}$ & $D P(\mathrm{~mm})^{\mathrm{c}}$ & OW (mm) & $L R^{\mathrm{d}}$ & $L F(\mathrm{~mm})^{\mathrm{e}}$ & $E T_{c}(\mathrm{~mm})^{\mathrm{f}}$ & $W_{s}(\mathrm{~mm})^{\mathrm{g}}$ & $\ln (\mathrm{mm})^{h}$ \\
\hline Leaf Lettuce early & 6.9 & 0 & 0 & 38.71 & 0.12 & 38.71 & 286.47 & 318.25 & 318.25 \\
\hline Leaf Lettuce late & 7.7 & 0 & 0 & 41.23 & 0.12 & 41.23 & 305.48 & 339.01 & 339.01 \\
\hline Head Lettuce early & 6.9 & 0 & 0 & 38.71 & 0.12 & 38.71 & 286.47 & 318.25 & 318.25 \\
\hline Head Lettuce late & 7.7 & 0 & 0 & 41.23 & 0.12 & 41.23 & 305.48 & 339.01 & 339.01 \\
\hline Cabbage early & 6.9 & 0 & 0 & 42.05 & 0.09 & 42.05 & 454.88 & 490.00 & 490.00 \\
\hline Cabbage late & 7.7 & 0 & 0 & 36.45 & 0.09 & 36.45 & 396.04 & 424.80 & 424.80 \\
\hline Celery early & 0 & 0 & 0 & 94.97 & 0.09 & 94.97 & 1011.73 & 1106.71 & 1106.71 \\
\hline Celery late & 28.1 & 0 & 0 & 33.78 & 0.09 & 33.78 & 388.00 & 393.68 & 393.68 \\
\hline Broccoli early & 6.9 & 0 & 0 & 23.43 & 0.05 & 23.43 & 417.25 & 433.75 & 433.75 \\
\hline Broccoli late & 7.7 & 0 & 0 & 21.42 & 0.05 & 21.42 & 383.00 & 396.62 & 396.62 \\
\hline Cauliflower early & 6.9 & 0 & 0 & 23.53 & 0.05 & 23.53 & 419.12 & 435.72 & 435.72 \\
\hline Cauliflower late & 7.7 & 0 & 0 & 21.50 & 0.05 & 21.50 & 384.35 & 398.16 & 398.16 \\
\hline Spinach early & 5.8 & 0 & 0 & 20.60 & 0.08 & 20.60 & 253.55 & 268.31 & 268.31 \\
\hline Spinach late & 6.6 & 0 & 0 & 18.66 & 0.08 & 18.66 & 231.00 & 243.07 & 243.07 \\
\hline Potatoes & 5.8 & 0 & 0 & 76.94 & 0.09 & 76.94 & 772.70 & 843.80 & 843.80 \\
\hline Onions early & 5.8 & 0 & 0 & 122.64 & 0.13 & 122.64 & 807.35 & 924.16 & 924.16 \\
\hline Onions late & 19.2 & 0 & 0 & 54.65 & 0.13 & 54.65 & 376.49 & 411.82 & 411.82 \\
\hline Carrots early & 6.2 & 0 & 0 & 85.32 & 0.16 & 85.32 & 446.65 & 525.81 & 525.81 \\
\hline Carrots late & 9.5 & 0 & 0 & 76.48 & 0.16 & 76.48 & 404.31 & 471.33 & 471.33 \\
\hline Sweet corn & 0 & 0 & 0 & 67.50 & 0.09 & 67.50 & 672.78 & 740.28 & 740.28 \\
\hline Bell Peppers & 0 & 0 & 0 & 75.29 & 0.10 & 75.29 & 647.02 & 722.30 & 722.30 \\
\hline Cucumbers & 0 & 0 & 0 & 30.47 & 0.06 & 30.47 & 471.01 & 501.48 & 501.48 \\
\hline Squash & 0 & 0 & 0 & 24.42 & 0.06 & 24.42 & 377.53 & 401.95 & 401.95 \\
\hline Melons & 0 & 0 & 0 & 58.17 & 0.07 & 58.17 & 779.41 & 837.58 & 837.58 \\
\hline Tomatoes & 0 & 0 & 0 & 42.14 & 0.06 & 42.14 & 651.35 & 693.49 & 693.49 \\
\hline Apples & 18.5 & 0 & 0 & 166.17 & 0.09 & 166.17 & 1674.63 & 1822.34 & 1822.34 \\
\hline
\end{tabular}


Table E-5. Seasonal Water Inputs and Requirements for 26 Crops and Turf for Present-Day Climate Conditions (Continued)

\begin{tabular}{|c|c|c|c|c|c|c|c|c|c|}
\hline Crop & $P e(\mathrm{~mm})^{\mathrm{a}}$ & $W b(\mathrm{~mm})^{b}$ & $D P(\mathrm{~mm})^{\mathrm{c}}$ & $O W(\mathrm{~mm})$ & $L R^{\mathrm{d}}$ & $L F(\mathrm{~mm})^{\mathrm{e}}$ & $E T_{c}(\mathrm{~mm})^{\mathrm{f}}$ & $W_{s}(\mathrm{~mm})^{\mathrm{g}}$ & $\ln (\mathrm{mm})^{h}$ \\
\hline Grapes & 8.3 & 0 & 0 & 102.94 & 0.10 & 102.94 & 892.98 & 987.60 & 987.60 \\
\hline Strawberries & 14.6 & 0 & 0 & 233.42 & 0.16 & 233.42 & 1219.70 & 1438.48 & 1438.48 \\
\hline Winter Wheat & 47.5 & 0 & 0 & 23.22 & 0.02 & 23.22 & 964.1 & 939.80 & 939.80 \\
\hline Barley & 46.1 & 0 & 0 & 15.44 & 0.02 & 15.44 & 867.74 & 837.04 & 837.04 \\
\hline Alfalfa 1st & 33.2 & 0 & 0 & 8.90 & 0.08 & 8.90 & 140.26 & 115.96 & 115.96 \\
\hline Alfalfa 2nd & 9.4 & 0 & 0 & 22.21 & 0.08 & 22.21 & 276.46 & 289.30 & 289.30 \\
\hline Alfalfa 3rd & 0 & 0 & 0 & 34.63 & 0.08 & 34.63 & 416.40 & 451.02 & 451.02 \\
\hline Alfalfa 4th & 0 & 0 & 0 & 39.40 & 0.08 & 39.40 & 482.94 & 513.24 & 513.24 \\
\hline Alfalfa 5th & 9.1 & 0 & 0 & 29.87 & 0.08 & 29.87 & 368.30 & 389.07 & 389.07 \\
\hline Alfalfa 6th & 4.6 & 0 & 0 & 14.01 & 0.08 & 14.01 & 173.00 & 182.44 & 182.44 \\
\hline Oats feed & 42.3 & 0 & 0 & 14.16 & 0.02 & 14.16 & 601.37 & 573.23 & 573.23 \\
\hline Bermuda & 50.8 & 0 & 0 & 34.66 & 0.02 & 34.66 & 1633.18 & 1617.03 & 1617.03 \\
\hline Feed Corn & 9.1 & 0 & 0 & 101.57 & 0.09 & 101.57 & 1091.10 & 1183.57 & 1183.57 \\
\hline Corn silage & 0 & 0 & 0 & 71.23 & 0.09 & 71.23 & 758.84 & 830.08 & 830.08 \\
\hline Oats hay & 0 & 0 & 0 & 8.55 & 0.02 & 8.55 & 454.68 & 463.23 & 463.23 \\
\hline
\end{tabular}

a Effective precipitation calculated according to Appendix E, Section 2.1.2.

${ }^{b}$ Water stored in the root zone prior to planting (annuals) or onset of growth (perennials) calculated according to methods in Appendix E, Section 2.2.1.

c Deep percolation of soil moisture below the root zone calculated according to methods in Appendix E, Section 2.2.1.

d Leaching requirement calculated according to Equation E-4.

e Leaching fraction calculated according to Appendix E, Section 2.4, Equation E-6.

$f$ Crop evapotranspiration. Values from Appendix D, Table D-10, were summed over the growing season.

g Seasonal water requirement calculated from Equation E-5.

Net irrigation requirement calculated from Equation E-8. 
Table E-6. Seasonal Water Inputs and Requirements for 26 Crops and Turf for Upper Bound Monsoon Climate Conditions

\begin{tabular}{|c|c|c|c|c|c|c|c|c|c|}
\hline Crop & $\operatorname{Pe}(\mathrm{mm})^{\mathrm{a}}$ & $W b(\mathrm{~mm})^{b}$ & $D P(\mathrm{~mm})^{\mathrm{c}}$ & $O W(\mathrm{~mm})$ & $L R^{\mathrm{d}}$ & $L F(\mathrm{~mm})^{\mathrm{e}}$ & $E T_{c}(\mathrm{~mm})^{\mathrm{f}}$ & $W_{s}(\mathrm{~mm})^{\mathrm{g}}$ & In $(\mathrm{mm})^{h}$ \\
\hline Leaf Lettuce early & 29.3 & 36.0 & 0 & 31.62 & 0.12 & 31.62 & 257.69 & 259.97 & 223.97 \\
\hline Leaf Lettuce late & 54.9 & 36.0 & 112.15 & 112.15 & 0.12 & 25.44 & 238.64 & 209.15 & 147.72 \\
\hline Head Lettuce early & 29.3 & 47.3 & 0 & 31.60 & 0.12 & 31.60 & 257.56 & 259.82 & 212.50 \\
\hline Head Lettuce late & 54.9 & 36.0 & 112.15 & 112.15 & 0.12 & 25.44 & 238.64 & 209.15 & 147.72 \\
\hline Cabbage early & 31.2 & 46.6 & 0 & 35.47 & 0.09 & 35.47 & 409.12 & 413.30 & 366.65 \\
\hline Cabbage late & 96.4 & 60.0 & 51.61 & 51.61 & 0.09 & 20.23 & 311.92 & 235.72 & 155.49 \\
\hline Celery early & 163.5 & 22.3 & 0 & 57.62 & 0.09 & 57.62 & 777.27 & 671.41 & 649.08 \\
\hline Celery late & 105.4 & 36.0 & 125.58 & 125.58 & 0.09 & 22.60 & 346.11 & 263.30 & 204.71 \\
\hline Broccoli early & 31.3 & 47.0 & 0 & 19.67 & 0.05 & 19.67 & 375.77 & 364.15 & 317.12 \\
\hline Broccoli late & 92.1 & 48.0 & 71.70 & 71.70 & 0.05 & 11.89 & 300.42 & 220.20 & 160.31 \\
\hline Cauliflower early & 32.2 & 47.0 & 0 & 19.68 & 0.05 & 19.68 & 376.84 & 364.30 & 317.27 \\
\hline Cauliflower late & 97.7 & 48.0 & 74.61 & 74.61 & 0.05 & 11.61 & 301.09 & 215.00 & 155.39 \\
\hline Spinach early & 27.9 & 36.0 & 0 & 16.66 & 0.08 & 16.66 & 228.24 & 217.01 & 181.01 \\
\hline Spinach late & 63.8 & 36.0 & 125.58 & 125.58 & 0.08 & 10.18 & 186.23 & 132.58 & 86.40 \\
\hline Potatoes & 100.9 & 48.0 & 148.05 & 148.05 & 0.09 & 55.55 & 654.52 & 609.21 & 505.66 \\
\hline Onions early & 98.0 & 31.3 & 0 & 89.86 & 0.13 & 89.86 & 685.31 & 677.15 & 645.83 \\
\hline Onions late & 101.1 & 36.0 & 120.12 & 120.12 & 0.13 & 44.48 & 391.73 & 335.14 & 254.67 \\
\hline Carrots early & 30.5 & 51.5 & 0 & 71.98 & 0.16 & 71.98 & 402.15 & 443.61 & 392.12 \\
\hline Carrots late & 96.9 & 60.0 & 48.70 & 48.70 & 0.16 & 41.67 & 312.06 & 256.79 & 155.12 \\
\hline Sweet corn & 109.1 & 96.0 & 40.90 & 50.29 & 0.09 & 50.29 & 610.33 & 551.51 & 455.51 \\
\hline Bell Peppers & 99.3 & 60.0 & 102.22 & 102.22 & 0.10 & 47.81 & 510.15 & 458.65 & 350.85 \\
\hline Cucumbers & 100.3 & 84.0 & 200.19 & 200.19 & 0.06 & 15.99 & 347.46 & 263.15 & 163.16 \\
\hline Squash & 85.83 & 72.0 & 91.17 & 91.17 & 0.06 & 14.10 & 303.83 & 232.10 & 146.00 \\
\hline Melons & 186.5 & 96.0 & 0 & 27.01 & 0.07 & 27.01 & 548.43 & 388.94 & 292.94 \\
\hline Tomatoes & 106.7 & 84.0 & 100.36 & 100.36 & 0.06 & 26.18 & 511.47 & 430.92 & 320.73 \\
\hline Apples & 301.4 & 0 & 0 & 91.41 & 0.09 & 91.41 & 1212.43 & 1002.43 & 1002.43 \\
\hline
\end{tabular}


Table E-6. Seasonal Water Inputs and Requirements for 26 Crops and Turf for Upper Bound Monsoon Climate Conditions (Continued)

\begin{tabular}{|c|c|c|c|c|c|c|c|c|c|}
\hline Crop & $P e(\mathrm{~mm})^{\mathrm{a}}$ & $W b(\mathrm{~mm})^{b}$ & $D P(\mathrm{~mm})^{\mathrm{c}}$ & $O W(\mathrm{~mm})$ & $L R^{\mathrm{d}}$ & $L F(\mathrm{~mm})^{\mathrm{e}}$ & $E T_{c}(\mathrm{~mm})^{\mathrm{f}}$ & $W_{s}(\mathrm{~mm})^{\mathrm{g}}$ & $\ln (\mathrm{mm})^{h}$ \\
\hline Grapes & 221.3 & 0 & 0 & 53.87 & 0.10 & 53.87 & 684.32 & 516.86 & 516.86 \\
\hline Strawberries & 192.2 & 24.0 & 0 & 136.06 & 0.16 & 136.06 & 894.62 & 838.53 & 814.53 \\
\hline Winter Wheat & 166.8 & 180.0 & 0 & 18.45 & 0.02 & 18.45 & 894.81 & 746.75 & 566.75 \\
\hline Barley & 155.8 & 120.0 & 0 & 12.24 & 0.02 & 12.24 & 806.92 & 663.39 & 543.39 \\
\hline Alfalfa 1st & 53.1 & 15.3 & 0 & 8.24 & 0.08 & 8.24 & 152.19 & 107.32 & 91.96 \\
\hline Alfalfa 2nd & 30.2 & 0 & 0 & 18.16 & 0.08 & 18.16 & 248.52 & 236.52 & 236.52 \\
\hline Alfalfa 3rd & 23.6 & 0 & 0 & 27.83 & 0.08 & 27.83 & 362.35 & 362.45 & 362.45 \\
\hline Alfalfa 4th & 141.2 & 0 & 0 & 20.30 & 0.08 & 20.30 & 399.54 & 264.42 & 264.42 \\
\hline Alfalfa 5th & 146.8 & 0 & 0 & 5.63 & 0.08 & 5.63 & 195.24 & 73.38 & 73.38 \\
\hline Alfalfa 6th & 77.0 & 0 & 0 & 7.75 & 0.08 & 7.75 & 150.03 & 100.97 & 100.97 \\
\hline Oat hay & 26.2 & 120.0 & 61.57 & 61.57 & 0.02 & 7.09 & 403.61 & 384.49 & 257.39 \\
\hline Bermuda & 341.1 & 0 & 0 & 22.51 & 0.02 & 22.51 & 1368.87 & 1050.32 & 1050.32 \\
\hline Feed Corn & 276.8 & 59.3 & 0 & 43.05 & 0.09 & 43.05 & 735.40 & 501.63 & 442.30 \\
\hline Corn silage & 195.9 & 59.3 & 0 & 31.44 & 0.09 & 31.44 & 530.88 & 366.38 & 307.06 \\
\hline Oat feed & 92.0 & 120.0 & 27.71 & 27.71 & 0.02 & 11.76 & 556.12 & 475.82 & 344.06 \\
\hline
\end{tabular}

a Effective precipitation calculated according to Appendix E, Section 2.1.2.

${ }^{b}$ Water stored in the root zone prior to planting (annuals) or onset of growth (perennials) calculated according to methods in Appendix E, Section 2.2.1.

c Deep percolation of soil moisture below the root zone calculated according to methods in Appendix E, Section 2.2.1.

d Leaching requirement calculated according to Equation E-4.

e Leaching fraction calculated according to Appendix E, Section 2.4, Equation E-6.

$f$ Crop evapotranspiration. Values from Appendix D, Table D-11, were summed over the growing season.

g Seasonal water requirement calculated from Equation E-5.

Net irrigation requirement calculated from Equations E-7 and E-8. 
Table E-7. Seasonal Water Inputs and Requirements for 26 Crops and Turf for Lower Bound Glacial Transition Climate Conditions

\begin{tabular}{|c|c|c|c|c|c|c|c|c|c|}
\hline Crop & $P e(\mathrm{~mm})^{\mathrm{a}}$ & $W b(\mathrm{~mm})^{\mathrm{b}}$ & $D P(\mathrm{~mm})^{\mathrm{c}}$ & $O W(\mathrm{~mm})$ & $L R^{\mathrm{d}}$ & $L F(\mathrm{~mm})^{\mathrm{e}}$ & $E T_{c}(\mathrm{~mm})^{\mathrm{f}}$ & $W_{s}(\mathrm{~mm})^{\mathrm{g}}$ & $\ln (\mathrm{mm})^{h}$ \\
\hline Leaf Lettuce early & 37.3 & 5.3 & 0 & 43.45 & 0.12 & 43.45 & 351.10 & 357.24 & 351.94 \\
\hline Leaf Lettuce late & 18.4 & 0 & 0 & 55.04 & 0.12 & 55.04 & 415.93 & 452.53 & 452.53 \\
\hline Head Lettuce early & 39.0 & 5.3 & 0 & 64.90 & 0.12 & 64.90 & 507.74 & 533.62 & 528.33 \\
\hline Head Lettuce late & 23.0 & 0 & 0 & 68.31 & 0.12 & 68.31 & 516.32 & 561.58 & 561.58 \\
\hline Cabbage early & 42.4 & 5.3 & 0 & 44.01 & 0.09 & 44.01 & 511.24 & 512.90 & 507.61 \\
\hline Cabbage late & 24.9 & 0 & 0 & 46.47 & 0.09 & 46.47 & 520.01 & 541.55 & 541.55 \\
\hline Celery & 46.8 & 5.3 & 0 & 74.51 & 0.09 & 74.51 & 840.51 & 868.25 & 862.95 \\
\hline Broccoli early & 39.9 & 5.3 & 0 & 30.69 & 0.05 & 30.69 & 577.53 & 568.29 & 562.99 \\
\hline Broccoli late & 35.4 & 0 & 0 & 29.52 & 0.05 & 29.52 & 552.57 & 546.66 & 546.66 \\
\hline Cauliflower early & 40.9 & 5.3 & 0 & 20.94 & 0.05 & 20.94 & 407.71 & 387.75 & 382.46 \\
\hline Cauliflower late & 22.9 & 0 & 0 & 22.55 & 0.05 & 22.55 & 417.86 & 417.50 & 417.5 \\
\hline Spinach early & 36.4 & 5.3 & 0 & 24.23 & 0.08 & 24.23 & 327.81 & 315.59 & 310.30 \\
\hline Spinach late & 21.3 & 0 & 0 & 26.71 & 0.08 & 26.71 & 342.59 & 347.97 & 347.97 \\
\hline Potatoes & 47.7 & 5.3 & 0 & 82.99 & 0.09 & 82.99 & 874.87 & 910.17 & 904.88 \\
\hline Onions & 71.3 & 0 & 0 & 139.23 & 0.13 & 139.23 & 981.20 & 1049.15 & 1049.15 \\
\hline Carrots early & 42.4 & 5.3 & 0 & 102.40 & 0.16 & 102.40 & 570.99 & 631.04 & 625.75 \\
\hline Carrots late & 25.3 & 0 & 0 & 108.18 & 0.16 & 108.18 & 583.78 & 666.68 & 666.68 \\
\hline Sweet corn & 44.0 & 6.9 & 0 & 80.66 & 0.09 & 80.66 & 847.97 & 884.59 & 877.71 \\
\hline Bell Peppers & 26.4 & 8.4 & 0 & 83.93 & 0.10 & 83.93 & 747.64 & 805.20 & 796.78 \\
\hline Cucumbers & 23.0 & 8.8 & 0 & 31.67 & 0.06 & 31.67 & 512.44 & 521.14 & 512.29 \\
\hline Squash & 22.6 & 8.8 & 0 & 26.97 & 0.06 & 26.97 & 439.36 & 443.77 & 434.93 \\
\hline Melons & 40.5 & 8.8 & 0 & 53.26 & 0.06 & 53.26 & 754.02 & 766.79 & 757.95 \\
\hline Tomatoes & 26.4 & 8.4 & 0 & 45.62 & 0.06 & 45.62 & 731.54 & 750.72 & 742.30 \\
\hline Apples & 86.6 & 0 & 0 & 107.66 & 0.09 & 107.66 & 1159.64 & 1180.68 & 1180.68 \\
\hline Grapes & 29.4 & 0 & 0 & 60.88 & 0.10 & 60.88 & 552.66 & 584.12 & 584.12 \\
\hline Strawberries & 29.8 & 0 & 0 & 63.30 & 0.16 & 63.30 & 356.58 & 390.07 & 390.07 \\
\hline
\end{tabular}




\begin{tabular}{|c|c|c|c|c|c|c|c|c|c|}
\hline Crop & $P e(\mathrm{~mm})^{\mathrm{a}}$ & $W b(\mathrm{~mm})^{\mathrm{b}}$ & $D P(\mathrm{~mm})^{\mathrm{c}}$ & $O W(\mathrm{~mm})$ & $L R^{\mathrm{d}}$ & $L F(\mathrm{~mm})^{\mathrm{e}}$ & $E T_{c}(\mathrm{~mm})^{f}$ & $W_{s}(\mathrm{~mm})^{g}$ & $\ln (\mathrm{mm})^{h}$ \\
\hline Winter Wheat & 135.8 & 0 & 0 & 30.13 & 0.02 & 30.13 & 1325.42 & 1219.73 & 1219.73 \\
\hline Barley & 47.8 & 4.7 & 0 & 10.42 & 0.02 & 10.42 & 602.27 & 564.93 & 560.25 \\
\hline Alfalfa 1st cutting & 56.7 & 0 & 0 & 22.54 & 0.08 & 22.54 & 327.78 & 293.62 & 293.62 \\
\hline Alfalfa 2nd cutting & 30.4 & 0 & 0 & 43.43 & 0.08 & 43.43 & 552.64 & 565.69 & 565.69 \\
\hline Alfalfa 3rd cutting & 21.1 & 0 & 0 & 38.68 & 0.08 & 38.68 & 486.31 & 503.89 & 503.89 \\
\hline Oat Hay & 28.5 & 7.9 & 0 & 7.29 & 0.02 & 7.29 & 416.23 & 395.00 & 387.14 \\
\hline Fescue & 93.9 & 0 & 0 & 27.02 & 0.02 & 27.02 & 1327.38 & 1260.50 & 1260.50 \\
\hline Feed Corn & 67.1 & 7.1 & 0 & 99.22 & 0.09 & 99.22 & 1124.12 & 1156.21 & 1149.08 \\
\hline Corn silage & 44.9 & 7.1 & 0 & 93.26 & 0.09 & 93.26 & 1038.39 & 1086.80 & 1079.70 \\
\hline Oat Feed & 61.7 & 5.9 & 0 & 22.76 & 0.02 & 22.76 & 959.95 & 920.97 & 915.07 \\
\hline
\end{tabular}

${ }^{a}$ Effective precipitation calculated according to Appendix E, Section 2.1.2.

b Water stored in the root zone prior to planting (annuals) or onset of growth (perennials) calculated according to methods in Appendix E, Section 2.2.1.

c Deep percolation of soil moisture below the root zone calculated according to methods in Appendix E, Section 2.2.1.

Leaching requirement calculated according to Equation E-4

(T) Leaching fraction calculated according to Appendix E, Section 2.4, Equation E-6.

f Crop evapotranspiration. Values from Appendix D, Table D-12, were summed over the growing season.

g Seasonal water requirement calculated from Equation E-5.

${ }^{\mathrm{h}}$ Net irrigation requirement calculated from Equations E-7 and E-8. 
Table E-8. Seasonal Water Inputs and Requirements for 26 Crops and Turf for Upper Bound Glacial Transition Climate Conditions

\begin{tabular}{|c|c|c|c|c|c|c|c|c|c|}
\hline Crop & $P e(\mathrm{~mm})^{\mathrm{a}}$ & $W b(\mathrm{~mm})^{\mathrm{b}}$ & $D P(\mathrm{~mm})^{\mathrm{c}}$ & $O W(\mathrm{~mm})$ & $L R^{\mathrm{d}}$ & $L F(\mathrm{~mm})^{\mathrm{e}}$ & $E T_{c}(\mathrm{~mm})^{\mathrm{f}}$ & $W_{s}(\mathrm{~mm})^{g}$ & $\ln (\mathrm{mm})^{h}$ \\
\hline Leaf Lettuce early & 57.3 & 36.0 & 103.47 & 103.47 & 0.12 & 24.30 & 232.80 & 199.78 & 139.48 \\
\hline Leaf Lettuce late & 22.9 & 0.0 & 0.0 & 38.39 & 0.12 & 38.39 & 300.11 & 315.59 & 315.59 \\
\hline Head Lettuce early & 67.6 & 36.0 & 102.81 & 102.81 & 0.12 & 37.70 & 339.90 & 309.96 & 236.26 \\
\hline Head Lettuce late & 25.3 & 0.0 & 0.0 & 47.46 & 0.12 & 47.46 & 368.11 & 390.24 & 390.24 \\
\hline Cabbage early & 74.6 & 60.0 & 56.81 & 56.81 & 0.09 & 24.85 & 339.29 & 289.58 & 204.73 \\
\hline Cabbage late & 27.5 & 0.0 & 0.0 & 32.10 & 0.09 & 32.10 & 369.40 & 374.01 & 374.01 \\
\hline Celery & 78.8 & 36.0 & 104.37 & 104.37 & 0.09 & 46.58 & 575.03 & 542.79 & 460.21 \\
\hline Broccoli early & 71.4 & 48.0 & 78.08 & 78.08 & 0.05 & 18.12 & 388.82 & 335.57 & 269.45 \\
\hline Broccoli late & 39.4 & 0.0 & 0.0 & 20.05 & 0.05 & 20.05 & 390.60 & 371.30 & 371.30 \\
\hline Cauliflower early & 64.6 & 48.0 & 79.81 & 79.81 & 0.05 & 11.64 & 268.50 & 215.55 & 155.91 \\
\hline Cauliflower late & 24.0 & 0.0 & 0.0 & 15.52 & 0.05 & 15.52 & 295.88 & 287.36 & 287.36 \\
\hline Spinach early & 57.3 & 36.0 & 102.81 & 102.81 & 0.08 & 13.36 & 217.97 & 173.98 & 124.63 \\
\hline Spinach late & 18.0 & 0.0 & 0.0 & 18.66 & 0.08 & 18.66 & 242.36 & 243.01 & 243.01 \\
\hline Potatoes & 82.1 & 48.0 & 72.16 & 72.16 & 0.09 & 51.94 & 599.84 & 569.65 & 469.70 \\
\hline Onions & 106.1 & 36.0 & 65.3 & 85.11 & 0.13 & 85.11 & 662.30 & 641.30 & 540.05 \\
\hline Carrots early & 75.5 & 60.0 & 56.81 & 59.23 & 0.16 & 59.23 & 381.30 & 365.00 & 248.19 \\
\hline Carrots late & 29.3 & 0.0 & 0.0 & 74.81 & 0.16 & 74.81 & 415.54 & 461.01 & 461.01 \\
\hline Sweet corn & 63.5 & 0.0 & 0.0 & 47.43 & 0.09 & 47.43 & 536.20 & 520.14 & 520.14 \\
\hline Bell Peppers & 50.4 & 60.0 & 82.39 & 82.39 & 0.10 & 55.34 & 526.97 & 530.92 & 415.58 \\
\hline Cucumbers & 57.8 & 84.0 & 20.25 & 20.25 & 0.06 & 18.96 & 350.92 & 312.10 & 209.14 \\
\hline Squash & 51.8 & 72.0 & 43.72 & 43.72 & 0.06 & 16.12 & 301.01 & 265.36 & 177.23 \\
\hline Melons & 71.4 & 0.0 & 0 & 34.27 & 0.07 & 34.27 & 530.47 & 493.36 & 493.36 \\
\hline Tomatoes & 54.2 & 84.0 & 28.26 & 29.96 & 0.06 & 29.96 & 517.32 & 493.06 & 380.81 \\
\hline Apples & 115.0 & 0.0 & 0 & 66.24 & 0.09 & 66.24 & 775.22 & 726.42 & 726.42 \\
\hline Grapes & 50.9 & 0.0 & 0 & 38.04 & 0.10 & 38.04 & 377.81 & 364.93 & 364.93 \\
\hline Strawberries & 49.2 & 24.0 & 125.09 & 125.09 & 0.16 & 35.80 & 234.08 & 220.64 & 160.84 \\
\hline
\end{tabular}


Table E-8. Seasonal Water Inputs and Requirements for 26 Crops and Turf for Upper Bound Glacial Transition Climate Conditions (Continued)

\begin{tabular}{|c|c|c|c|c|c|c|c|c|c|}
\hline Crop & $P e(\mathrm{~mm})^{\mathrm{a}}$ & $W b(\mathrm{~mm})^{b}$ & $D P(\mathrm{~mm})^{\mathrm{c}}$ & OW (mm) & $L R^{\mathrm{d}}$ & $L F(\mathrm{~mm})^{\mathrm{e}}$ & $E T_{c}(\mathrm{~mm})^{\mathrm{f}}$ & $W_{s}(\mathrm{~mm})^{\mathrm{g}}$ & $\ln (\mathrm{mm})^{h}$ \\
\hline Winter Wheat & 219.3 & 0.0 & 0 & 16.45 & 0.02 & 16.45 & 868.80 & 666.01 & 666.01 \\
\hline Barley & 87.6 & 0.0 & 0 & 5.75 & 0.02 & 5.75 & 393.45 & 311.57 & 311.57 \\
\hline Alfalfa 1st cutting & 71.2 & 0.0 & 0 & 12.88 & 0.08 & 12.88 & 226.05 & 167.72 & 167.72 \\
\hline Alfalfa 2nd cutting & 69.7 & 0.0 & 0 & 25.15 & 0.08 & 25.15 & 372.16 & 327.64 & 327.64 \\
\hline Alfalfa 3rd cutting & 30.2 & 0.0 & 0 & 25.97 & 0.08 & 25.97 & 342.47 & 338.28 & 338.28 \\
\hline Oat hay & 65.0 & 0.0 & 0 & 3.83 & 0.02 & 3.83 & 268.80 & 207.67 & 207.67 \\
\hline Fescue & 126.1 & 0.0 & 0 & 17.80 & 0.02 & 17.80 & 938.66 & 830.36 & 830.36 \\
\hline Feed Corn & 102.6 & 0.0 & 0 & 62.71 & 0.09 & 62.71 & 770.67 & 730.78 & 730.78 \\
\hline Corn silage & 84.0 & 0.0 & 0 & 59.15 & 0.13 & 59.15 & 714.15 & 689.30 & 689.30 \\
\hline Oat feed & 104.0 & 0.0 & 0 & 13.67 & 0.02 & 13.67 & 643.87 & 553.52 & 553.52 \\
\hline
\end{tabular}

${ }^{a}$ Effective precipitation calculated according to Appendix E, Section 2.1.2.

${ }^{b}$ Water stored in the root zone prior to planting (annuals) or onset of growth (perennials) calculated according to methods in Appendix E, Section 2.2.1.

${ }^{c}$ Deep percolation of soil moisture below the root zone calculated according to methods in Appendix E, Section 2.2.1.

d Leaching requirement calculated according to Equation E-4.

(1) Leaching fraction calculated according to Appendix E, Section 2.4, Equation E-6.

f Crop evapotranspiration. Values from Appendix D, Table D-13, were summed over the growing season.

g Seasonal water requirement calculated from Equation E-5.

${ }^{\mathrm{h}}$ Net irrigation requirement calculated from Equations $\mathrm{E}-7$ and $\mathrm{E}-8$. 


\section{E2.2 STORED SOIL MOISTURE (WB), LEACHING REQUIREMENT (LR), AND DEEP PERCOLATION (DP)}

Soil moisture can be stored in the root zone if precipitation is greater than $E T_{c}$ when a crop is actively growing, or if precipitation is greater than evaporation from the soil surface when no crop is present. It is dependant on the water holding capacity of the soil and depth of the root zone. Deep percolation $(D P)$ occurs after a rain or irrigation event that causes soil moisture in the root zone to reach and exceed field capacity. Field capacity is the amount of water held against gravitational forces when downward drainage following a rain or irrigation event has markedly decreased. Soil moisture stored in the root zone and $D P$ were derived using soil water balance calculations across months. The soil water balance is based on water holding capacity of the soil in the root zone and the portion of that water that can be used by the crop (TAW), total evaporable water from the soil surface (TEW, Allen et al. 1998 [DIRS 157311], p. 144), Pe, and $E T_{c}$.

\section{E2.2.1 Stored Soil Moisture and Deep Percolation}

TEW is the amount of water $(\mathrm{mm})$ that can be depleted from the upper soil layers through direct evaporation during a complete drying cycle (Allen et al. 1998 [DIRS 157311], Equation 73, p. 144):

$$
T E W=1000\left(\theta_{F C}-0.5 \theta_{W P}\right) Z_{e}
$$

where

$$
\begin{aligned}
& \theta_{F C}=\text { soil water content at field capacity }\left(\mathrm{m}^{3} \mathrm{~m}^{-3}\right), \\
& \theta_{W P}=\text { soil water content at wilting point }\left(\mathrm{m}^{3} \mathrm{~m}^{-3}\right),
\end{aligned}
$$

$Z_{e}$ is the depth of the soil surface layer $(\mathrm{m})$ that is subject to drying through the process of evaporation.

In the absence of site specific data, Allen et al. (1998 [DIRS 157311]) recommended a range of 0.10 to $0.50 \mathrm{~m}$ for $Z_{e}$, and provided typical values for $T E W$ for a sandy loam soil which ranged from 15 - $20 \mathrm{~mm}$ (Allen et al. 1998 [DIRS 157311], Table 19, p. 144). The midpoint of this range $(17.5 \mathrm{~mm})$ was selected for the analysis.

Moisture can be stored in the soil when precipitation is greater than $E T_{c}$ from a cropped surface or when precipitation is greater than TEW from a fallow field. Percolation below the root zone can only occur when the soil water content in the root zone exceeds $\theta_{F C}$.

Annual Crops-The following guidelines were used for annual crops:

- Early and late season crops were planted on the same land

- The land was fallow outside of the growing season 
- Of the monthly precipitation that entered the system outside of the growing season, TEW was evaporated, the rest percolated into the soil

- Of the monthly precipitation that entered the system during the growing season, $E T_{c}$ was evaporated, the rest percolated into the soil

- TAW was the maximum amount of water that could be stored in the root zone and used by plants

- Deep percolation occurred when precipitation outside of the growing season exceeded $\theta_{F C}-T E W$ or when precipitation during the growing season exceeded $\theta_{F C}-E T_{c}$.

Example: For upper bound glacial transition climate conditions, the growing seasons for early and late head lettuce were April 23 - July 10 and July 15 - Oct 1, respectively (Appendix D, Table D-2). During this time monthly $E T_{c}$ (see Table D-13) exceeded precipitation so no moisture was stored over the growing seasons. The soil plot was fallow Oct. 2 - April 23. The maximum amount of plant available water that can be stored in the lettuce root zone (TAW) was $36 \mathrm{~mm}$ (Table E-3), TEW was $17.5 \mathrm{~mm}$, and $\theta_{\mathrm{FC}}$ of the root zone was $69 \mathrm{~mm}\left(\theta_{\mathrm{FC}}\right.$ of the root zone $=1000 \times \theta_{\mathrm{FC}} \times Z_{\mathrm{r}}$, from equation E-1). Table E-9 shows monthly precipitation inputs, water available for percolation into the soil, water stored in the root zone, percolation below the root zone, and stored soil water at the time of planting. The calculations start in October with the assumption that there is no soil moisture left the month of harvest: October water balance $=$ precipitation $(25.2 \mathrm{~mm})-T E W(17.5 \mathrm{~mm})=7.7 \mathrm{~mm}$. The $\theta_{F C}$ of the soil in the root zone was $69 \mathrm{~mm}$, therefore, $7.7 \mathrm{~mm}$ of water was stored in the root zone, but no percolation below the root zone occurred in October.

November $_{\text {water balance }}=$ precipitation $(54.6 \mathrm{~mm})+$ water stored in October $(7.7 \mathrm{~mm})-\mathrm{TEW}$ $(17.5 \mathrm{~mm})=44.8 \mathrm{~mm}$. $44.8 \mathrm{~mm}$ of water was stored in the root zone; no water percolated below the root zone.

December $_{\text {water balance }}=$ precipitation $(61.5 \mathrm{~mm})+$ water stored in November $(44.8 \mathrm{~mm})-\mathrm{TEW}$ $(17.5 \mathrm{~mm})=88.8 \mathrm{~mm}$. Of this amount, $69 \mathrm{~mm}$ was stored in the root zone and $19.8 \mathrm{~mm}$ percolated below the root zone.

Calculations for January, February, and March were the same as those for November and December (Table E-9). Cumulative DP for October through March was $93.2 \mathrm{~mm}$.

In April, there were 22 days before planting the early season crop. Therefore, $T E W=(17.5 / 30) \mathrm{x}$ $23=13.4 \mathrm{~mm}$ and precipitation $=(30.0 / 30) \times 23=23.0 \mathrm{~mm}$. The water balance equals precipitation $(23.0 \mathrm{~mm})+$ water stored in March $(69 \mathrm{~mm})-T E W(13.4 \mathrm{~mm})=78.6 \mathrm{~mm}$. Of this amount, $69 \mathrm{~mm}$ was stored in the root zone and 9.6 percolated below the root zone. Not all of the water at field capacity can be used by the crop (see Section 2.1.1 above). For upper bound glacial transition climate conditions when soil water in the rooting zone reached $\theta_{\mathrm{FC}}$ it was necessary to use Equation 3 to estimate $T A W$ to determine $W b$. For this example, $T A W=W b=$ $36 \mathrm{~mm}$ and cumulative $D P=103.0 \mathrm{~mm}$. 
Table E-9. Monthly Stored Water and Deep Percolation Totals (mm)

\begin{tabular}{|l|r|r|r|r|r|r|r|r|r|r|r|r|}
\hline & Jan & Feb & Mar & Apr & May & Jun & Jul & Aug & Sep & Oct & Nov & Dec \\
\hline Lettuce & & & & & & & & & & & & \\
\hline Monthly Precip (mm) & 50.3 & 37.8 & 37.8 & 23.0 & & & & & & 25.2 & 54.6 & 61.5 \\
\hline $\begin{array}{l}\text { Monthly Precipitation + } \\
\text { stored moisture from } \\
\text { previous month - } \\
\text { Evaporation } \\
\text { i.e., Percolation) }\end{array}$ & 101.8 & 89.3 & 89.3 & 78.6 & & & & & & 7.7 & 44.8 & 88.8 \\
\hline $\begin{array}{l}\text { Water Stored in Root } \\
\text { Zone }\end{array}$ & 69.0 & 69.0 & 69.0 & & & & & & & 7.7 & 44.8 & 69.0 \\
\hline $\begin{array}{l}\text { Cumulative Percolation } \\
\text { Below Root Zone (DP) }\end{array}$ & 52.6 & 72.9 & 93.2 & 102.8 & & & & & & 0 & 0 & 19.8 \\
\hline $\begin{array}{l}\text { Stored Water at the } \\
\text { time of Planting (Wb) }\end{array}$ & & & & 36 & & & & & & & & \\
\hline
\end{tabular}

For present-day and lower bound glacial transition climate conditions, water was rarely stored in the root zone at the beginning of the planting season. Because $\theta_{\mathrm{FC}}$ was never reached, $W b$ was simply the water stored in the root zone prior to planting (it was not necessary to calculate TAW to determine $W b)$.

Water stored in the root zone and cumulative DP are in Tables E-5, E-6, E-7, and E-8.

Perennial Crops - The same methods used to calculate $W b$ and $D P$ for annual crops were used for perennial crops with the following exception:

During low growth and dormant periods, perennials were assumed to continue to loose water at low rates. To reflect this, initial $K_{c}$ values were used to calculate monthly mean $E T_{c}$ for non-growing periods (see Appendix $\mathrm{D}$ for information regarding $K_{c}$ and $E T_{c}$ calculations). This $E T_{c}$ was used instead of $T E W$ to calculate the water balance for perennials during non-growing periods.

Water stored in the in the root zone at the onset of active growth and cumulative $D P$ for perennials are in Tables E-5, E-6, E-7, and E-8.

\section{E2.3 LEACHING REQUIREMENT (LR)}

Salt build up in agricultural soils can occur when crops are irrigated with water containing significant quantities of soluble salts. In a well-drained soil, addition of enough water to cause drainage below the root zone can eliminate salt build up that can be harmful to plants. If downward drainage is insufficient, salts that are left in the soil can precipitate in the root zone and increase soil salinity as evaporation occurs. Soil salinity is measured by the electrical conductivity $(E C)$ of the saturated soil solution. The leaching requirement $(L R)$ is the fraction of infiltrated water that must pass through the root zone to remove excess salts. It is a function of the salinity of the irrigation water, and crop tolerance to salts. For a sandy loam to clay loam soil 
in arid to semi-arid environments, $L R$ can be calculated according the following equation (Doorenbos and Pruitt 1977 [DIRS 103062], pp. 77 and 78 ):

$$
L R=\frac{E C_{w}}{5 E C_{e}-E C_{w}} \times \frac{1}{L E}
$$

where

$$
\begin{aligned}
& E C_{w}=\text { electrical conductivity of the irrigation water (mmhos/cm), } \\
& E C_{e}=\text { crop salt tolerance under acceptable yield reduction (mmhos } / \mathrm{cm} \text { ), } \\
& L E=\text { leaching efficiency which varies with soil type (dimensionless). }
\end{aligned}
$$

As described in Section 4.1.7, an $E C_{w}$ of $0.50 \mathrm{dS} / \mathrm{m}$ was selected for this analysis.

Crop salt tolerance values with no reduction in yield were taken from Doorenbos and Pruitt (1977 [DIRS 103062], Table 36, p. 78) for $\mathrm{EC}_{\mathrm{e}}$ (Table E-10). There were no $E C_{e}$ values available for celery, cauliflower, squash, oats, or fescue so values for similar crops in the same crop type were chosen for each. The value for cabbage was used for celery, broccoli was used for cauliflower, cucumber was used for squash, winter wheat for oats, and bermudagrass for tall fescue (Table E-10).

Table E-10. Crop Salt Tolerance Levels $\left(E C_{e}, \mathrm{mmhos} / \mathrm{cm}\right)$ that Result in No Yield Reduction for 26 Crops and Turf

\begin{tabular}{|l|l|l|l|}
\hline \multicolumn{1}{|c|}{ Crop } & \multicolumn{1}{|c|}{$E C_{e}{ }^{\mathrm{a}}$} & \multicolumn{1}{c|}{$E C_{\mathrm{e}}{ }^{\mathrm{a}}$} \\
\hline Lettuce & 1.3 & Melons & 2.2 \\
\hline Cabbage & 1.8 & Tomatoes & 2.5 \\
\hline Celery & 1.8 & Alfalfa hay & 2.0 \\
\hline Broccoli & 2.8 & Oats & 6.0 \\
\hline Cauliflower & 2.8 & Barley & 8.0 \\
\hline Spinach & 2.0 & Apples & 1.7 \\
\hline Potatoes & 1.7 & Grapes & 1.5 \\
\hline Onions & 1.2 & Strawberries & 1.0 \\
\hline Carrots & 1.0 & Winter wheat & 6.0 \\
\hline Sweet corn & 1.7 & Feed Corn & 1.8 \\
\hline Bell peppers & 1.5 & Corn silage & 1.8 \\
\hline Cucumbers & 2.5 & Oat hay & 6.0 \\
\hline Squash & 2.5 & Bermuda & 6.9 \\
\hline & & Fescue & 6.9 \\
\hline
\end{tabular}

Source: Doorenbos and Pruitt (1977 [DIRS 103062], Table 36, p. 78).

a Electrical conductivity. 
The common soils in northern Amargosa Valley (Arizo, Corbilt, Sanwell, Shamock, Yermo) are sandy to sandy loam so an $L E$ of 0.7 for a medium textured soil (Doorenbos and Pruitt 1977 [DIRS 103062], p. 79) was used for LR calculations.

Example: Using early lettuce, $E C_{e}=1.3 \mathrm{mmhos} / \mathrm{cm}$ (Table E-10), $E C_{w}=0.50 \mathrm{mmhos} / \mathrm{cm}$, and $L E=0.7$.

$$
L R=\frac{0.50}{5 \times 1.3-0.50} \times \frac{1}{0.7}=0.12
$$

For the lettuce crop, about 12 percent of the total water entering the soil must pass through and out of the root zone.

The LRs for the 26 crops and turf grass are in Tables E-5, E-6, E-7, and E-8.

\section{E2.4 SEASONAL WATER REQUIREMENTS $\left(W_{S}\right)$, NET IRRIGATION REQUIREMENTS (IN), LEACHING FRACTION ( $L F)$, AND OVERWATERING RATE $(O W)$}

Seasonal water requirements $\left(W_{s}\right)$ were estimated using the following equation from Doorenbos and Pruitt (1977 [DIRS 103062], p. 79):

$$
W_{s}=\frac{E T_{c}-P e}{1-L R}
$$

where

$$
\begin{aligned}
& E T_{C}=\text { monthly mean crop evapotranspiration summed over the growing season }(\mathrm{mm}), \\
& P e=\text { monthly mean effective precipitation summed over the growing season }(\mathrm{mm}), \\
& L R=\text { leaching requirement (unitless). }
\end{aligned}
$$

Example: For early lettuce and present-day climate conditions, seasonal $E T_{c}=286.5 \mathrm{~mm}$ (Table E-5), seasonal $P e=6.9 \mathrm{~mm}$ (Table E-5), and $L R=0.12$ (Table E-5).

$$
W_{s}=\left(\frac{286.5-6.9}{1-0.1216}\right)=318.3 \mathrm{~mm}
$$

The $W_{s}$ values for the 26 crops and turf are in Tables E-5, E-6, E-7, and E-8.

Once $L R$ and $W_{s}$ were determined, it was necessary to evaluate whether seasonal precipitation resulted in cumulative $D P$ that was greater than $L R$. This directly impacts the net irrigation requirement $(I n)$ and the overwatering rate $(O W)$. If precipitation results in cumulative $D P$ that equals or exceeds $L R$, then additional irrigation water for leaching calculated into $W_{s}$ is not required. The overwatering rate $(O W)$, which is defined as the "average amount of groundwater or precipitation that percolates through the root zone and leaches salts and radionuclides out of 
that zone" (Section 1), is equal to $D P$ or the Leaching Fraction $(L F)$, depending on which is greater.

Leaching Fraction, which is the amount of water that percolates below the root zone, can be determined from:

$$
L F=W_{s}-\left(E T_{c}-P e\right)
$$

Example: From the previous example for lettuce and present-day climate conditions, $W_{s}=$ $318.3 \mathrm{~mm}, \mathrm{ET}_{\mathrm{c}}=286.5$, and $P e=6.9$.

$L F=318.3 \mathrm{~mm}-(286.5 \mathrm{~mm}-6.9 \mathrm{~mm})=38.7 \mathrm{~mm}$.

The cumulative $D P$ for early lettuce was 0 . Therefore, $L F$ was the value selected for lettuce that would be included in development of the distribution for $O W$ and was included in the net irrigation requirement (In). Because of the aridity of present-day and lower bound glacial transition climate conditions, $D P$ never occurred, making $L R$ a necessary inclusion to all net irrigation calculations. Additionally, for present-day climate, $L F$ for each crop and turf was used to generate the distribution of $O W$ (see Section 6.9).

For upper bound monsoon and upper bound glacial transition climate conditions, $D P$ often exceeded $L F$ (Tables E-6 and E-8, respectively). Under these circumstances, $L R$ was not needed to meet the net irrigation requirements and Equation E-7 was used to calculate $I n$. For crops that didn't require additional water to meet $L R, D P$ was used to generate the distribution of $O W$.

In a few cases, $D P$ occurred but did not meet the crop $L R$. Under these circumstances, $L R$ was included in the calculation for In (Equation E-8) and DP was subtracted from the total to compensate for the extra water in the system. Leaching Fraction was used to generate the distribution of $O W$.

One of the following equations from Doorenbos and Pruitt (1977 [DIRS 103062], p. 70) were used to calculate net irrigation requirements (In) depending on whether $D P$ was greater or less than $L F$ :

For $D P>L F: \quad$ In $=\sum_{i=1}^{n} E T_{c \text { monthly }}-\left(\sum_{i=1}^{n} P_{e}+G e+W b\right)$

For $D P<L F: \quad I n=W_{s}-(G e+W b)$

where

$E T_{c}=$ monthly mean crop evapotranspiration summed over the growing season $(\mathrm{mm})$,

$P e=$ monthly mean effective precipitation summed over the growing season $(\mathrm{mm})$,

$G e=$ groundwater contribution to the water requirement ( $\mathrm{mm}$, direct plant use),

$W b=$ stored soil moisture in the root system $(\mathrm{mm})$. 
Groundwater contribution $(\mathrm{Ge})$ to the water requirement was set to zero for all calculations. Data collected by the USGS from Well AD-2 located in the Amargosa Valley showed that depth to groundwater was about $99 \mathrm{~m}$ (325 feet, Locke 2001 [DIRS 159957], Figure 1, p. 3 and Figure 4, p. 35). This depth remained relatively constant from 1987 through 1999 (Locke 2001 [DIRS 159957], Figure 4, p. 35). Groundwater contribution from a water table that is more than about $1 \mathrm{~m}$ below the bottom of a crop rooting zone is generally considered negligible (Allen et al. 1998 [DIRS 157311], p. 171). Therefore a water table as deep as $99 \mathrm{~m}$ would not contribute to crop water requirements.

Net seasonal irrigation requirements (Tables E-5, E-6, E-7, and E-8) were used to calculate annual average irrigation rates (IR, Section 6.5) for present-day, upper bound monsoon, lower bound glacial transition, and upper bound glacial transition climates. Net seasonal irrigation requirements for present-day and upper bound glacial transition climates (Tables E-5 and E-8) were used to calculate daily average irrigation rates $\left(I R D_{j}\right.$, Section 6.8).

\section{E2.5 IRRIGATION APPLICATION $\left(I A_{J}\right)$}

Average amount of water applied per irrigation event during the 30 days prior to harvest for each crop type was needed to develop the distribution for irrigation application $\left(I A_{j}\right.$, Section 6.7) for present-day and upper bound glacial transition climates. Irrigation application rates for each crop were calculated using a soil water balance approach and the soil moisture threshold at which crop stress was expected to occur.

\section{E2.5.1 Readily Available Water (RAW)}

As described in Section 2.1.1, field capacity, permanent wilting point, and crop specific rooting depth were used to estimate the total available water $(T A W)$ in the rooting zone. In theory, water is available to plants until the wilting point is reached. However, decreases in hydraulic conductivity as the soil dries decreases the rate at which plant roots can extract water from the soil. Thus, crop water uptake is reduced long before soil moisture is extracted to the wilting point (Allen et al. 1998 [DIRS 157311], p. 162). Crops will begin to experience stress at the soil moisture threshold at which root absorption and transport of water are less than transpiration demands. Readily available soil water $(R A W)$ is expressed as the fraction of $T A W$ that can be extracted from the root zone before crop water stress occurs (Allen et al. 1998 [DIRS 157311], Equation 83, p. 162):

$$
R A W=p T A W
$$

where

$p$ is a crop specific average fraction of TAW that can be depleted from the root zone before moisture stress occurs.

Values for $p$ from Allen et al. (1998 [DIRS 157311], Table 22, pp. 163 to 165), TAW at maximum root depth, and $R A W$ for each crop are in Table E-11. 
Table E-11. Maximum Rooting Depths and Soil Moisture Parameters for 26 Crops and Turf

\begin{tabular}{|c|c|c|c|c|}
\hline Crop & $\begin{array}{l}\text { Maximum Rooting } \\
\text { Depth }(\mathrm{m})^{\mathrm{a}}\end{array}$ & $\operatorname{TAW}(\mathrm{mm})^{\mathrm{b}}$ & $p^{c}$ & $R A W(\mathrm{~mm})^{\mathrm{d}}$ \\
\hline Lettuce early & 0.3 & 36 & 0.30 & 10.8 \\
\hline Lettuce late & 0.3 & 36 & 0.30 & 10.8 \\
\hline Cabbage early & 0.5 & 60 & 0.45 & 27.0 \\
\hline Cabbage late & 0.5 & 60 & 0.45 & 27.0 \\
\hline Celery early & 0.3 & 36 & 0.20 & 7.2 \\
\hline Celery late & 0.3 & 36 & 0.20 & 7.2 \\
\hline Broccoli early & 0.4 & 48 & 0.45 & 21.6 \\
\hline Broccoli late & 0.4 & 48 & 0.45 & 21.6 \\
\hline Cauliflower early & 0.4 & 48 & 0.45 & 21.6 \\
\hline Cauliflower late & 0.4 & 48 & 0.45 & 21.6 \\
\hline Spinach early & 0.3 & 36 & 0.20 & 7.2 \\
\hline Spinach late & 0.3 & 36 & 0.20 & 7.2 \\
\hline Potatoes & 0.4 & 48 & 0.35 & 16.8 \\
\hline Onions early & 0.3 & 36 & 0.30 & 10.8 \\
\hline Onions late & 0.3 & 36 & 0.30 & 10.8 \\
\hline Carrots early & 0.5 & 60 & 0.35 & 21.0 \\
\hline Carrots late & 0.5 & 60 & 0.35 & 21.0 \\
\hline Sweet corn & 0.8 & 96 & 0.50 & 48.0 \\
\hline Bell peppers & 0.5 & 60 & 0.30 & 18.0 \\
\hline Cucumbers & 0.7 & 84 & 0.50 & 42.0 \\
\hline Squash & 0.6 & 72 & 0.50 & 36.0 \\
\hline Melons & 0.8 & 96 & 0.40 & 38.4 \\
\hline Tomatoes & 0.7 & 84 & 0.40 & 33.6 \\
\hline Alfalfa hay & 1.0 & 120 & 0.55 & 66.0 \\
\hline Oats & 1.0 & 120 & 0.55 & 66.0 \\
\hline Feed Corn & 1.0 & 120 & 0.55 & 66.0 \\
\hline Corn silage & 1.0 & 120 & 0.55 & 66.0 \\
\hline Apples & 1.0 & 120 & 0.50 & 60.0 \\
\hline Grapes & 1.0 & 120 & 0.45 & 54.0 \\
\hline Strawberries & 0.2 & 24 & 0.20 & 4.8 \\
\hline Winter wheat & 1.5 & 180 & 0.55 & 99.0 \\
\hline Barley & 1.0 & 120 & 0.55 & 66.0 \\
\hline Fescue & 0.5 & 60 & 0.40 & 24.0 \\
\hline Bermudagrass & 0.5 & 60 & 0.50 & 30.0 \\
\hline
\end{tabular}

a Source: Allen et al. (1998 [DIRS157311], Table 22, pp. 163 to 165, minimum range values).

b Total available soil moisture in the root zone calculated from Equation E-1.

c Soil water depletion fraction, Source: Allen et al. (1998 [DIRS 157311], Table 22, pp. 163 to 165).

${ }^{d}$ Readily available soil moisture in the root zone calculated from Equation E-9. 


\section{E2.5.2 Soil Water Balance Approach}

Irrigation application for each crop was determined by calculating a simplified soil water balance over the 30 days prior to harvest using the following parameters:

- $T A W$ at maximum root depth (Table E-11)

- $R A W($ Table E-11)

- Average daily $E T_{c}$ per month for 30 days prior to harvest (calculated from Tables D-10 and D-13)

- Irrigation requirement (In) for 30 days prior to harvest (calculated from Equations E-7 and E-8, and Tables E-5 and E-8)

- Average daily effective precipitation $\left(P_{d}\right)$ for 30 days prior to harvest (calculated from Tables E-2 and E-3).

$R A W$ is the fraction of TAW that can be extracted from the soil before moisture stress occurs. Therefore, irrigation water should be applied when $R A W$ is depleted. TAW - RAW was used as the threshold at which irrigation water should be applied to avoid onset of crop stress. If the amount of irrigation exceeds field capacity of the soil in the root zone, percolation below the root zone will occur. Excessive watering could cause nutrient leaching, changes in nutrient availability due to microbial responses to wet soil conditions, and water waste. Therefore, to avoid exceeding field capacity, irrigation was calculated such that TAW would not be exceeded in the root zone. Average daily $E T_{c}$ was used to estimate daily water loss from the soil system, and average daily effective precipitation was used as water input to the soil system.

The following guidelines were observed:

- Soil moisture at the beginning of the 30 day period was set equal to $T A W$ for a given crop

- When $R A W$ was depleted (within $+/-4 \mathrm{~mm}$ ), irrigation water was applied the following morning to increase soil moisture to TAW

- Daily $E T_{C}$ was subtracted at the end of the day

- Average daily precipitation was added to the balance at the end of each day.

Thus, the soil water balance at the end of each day $\left(S W B_{d}\right)$ was calculated as:

$$
S W B_{d}=I r r+P_{d}-E T_{c} \text {, with } S W B_{d} \leq T A W
$$


where

$I r r=$ the irrigation water applied in the morning (when applicable) $(\mathrm{mm})$,

$P_{d}=$ the average daily effective precipitation input $(\mathrm{mm})$,

$E T_{c}=$ the average daily crop evapotranspiration calculated for 30 days prior to harvest (mm/day).

Equation E-10 was derived from Allen et al. (1998 [DIRS 157311], Equation 85, p. 170).

Example: Using early lettuce and present-day climate conditions the following parameters were determined from the appropriate Tables:

The last Julian day of the growing season $=125=$ May 5 (Table D-1). Therefore, for the last 30 days of the growing season, 25 days were in April and 5 days were in May.

Effective precipitation for April and May $=0$ (Table E-2). Therefore, mean daily effective precipitation for the last 30 days of the growing season was equal to 0 .

Mean daily $E T_{c}$ for April $=5.75 \mathrm{~mm} /$ day $($ Table D-10).

Mean daily $E T_{c}$ for May $=7.21 \mathrm{~mm} /$ day (Table D-10).

Irrigation requirement for 25 days in April $=143.72 \mathrm{~mm}(5.75 \times 25)$.

Irrigation requirement for 5 days in May $=36.05 \mathrm{~mm}(7.21 \times 5)$.

TAW at maximum root depth $=36$ (Table E-11).

$R A W=10.8$ (Table E-11).

The water balance calculations (Equation E-10) for the 30 days prior to harvest for early lettuce are illustrated in Table E-12 using the values above. Irrigation water was added when $R A W$ was depleted. This occurred on days $1,3,5,7,9,11,13,15,17,19,21,23,25,26,27,28,29$, and 30. Irrigation events occurred on the days following $R A W$ depletion for days 1 through 25 . Because of high daily $E T_{c}$ on days 25 through 30, irrigation was applied prior to $R A W$ depletion so that soil moisture would not go below $R A W$ on a daily basis. Enough water was added so that soil moisture equaled, but did not exceed TAW.

Table E-12. Water Balance Calculations Over the Thirty-Day Time Period Prior to Harvest for Early Season Lettuce and Present-Day Climate Conditions

\begin{tabular}{|l|l|l|l|l|l|}
\hline Day & \multicolumn{1}{|c|}{$\boldsymbol{T A W}^{\mathrm{a}}$} & \multicolumn{1}{|c|}{$\boldsymbol{E}_{\boldsymbol{c}}{ }^{\boldsymbol{c}}$} & \multicolumn{1}{c|}{$\boldsymbol{P}_{\boldsymbol{d}}{ }^{\mathbf{}}$} & \multicolumn{1}{|c|}{ Irrigation } & \multicolumn{1}{c|}{ Balance } \\
\hline 1 & 36 & 5.75 & 0 & $36.0-25.2=10.8$ & $25.2+10.8-5.75=30.25$ \\
\hline 2 & 36 & 5.75 & 0 & & $30.25-5.75=24.5$ \\
\hline 3 & 36 & 5.75 & 0 & $36-24.5=11.5$ & $24.5+11.5-5.75=30.25$ \\
\hline 4 & 36 & 5.75 & 0 & & $30.25-5.75=24.5$ \\
\hline 5 & 36 & 5.75 & 0 & $36-24.5=11.5$ & $24.5+11.5-5.75=30.25$ \\
\hline 6 & 36 & 5.75 & 0 & & $30.25-5.75=24.5$ \\
\hline 7 & 36 & 5.75 & 0 & $36-24.5=11.5$ & $24.5+11.5-5.75=30.25$ \\
\hline 8 & 36 & 5.75 & 0 & & $30.25-5.75=24.5$ \\
\hline 9 & 36 & 5.75 & 0 & $36-24.5=11.5$ & $24.5+11.5-5.75=30.25$ \\
\hline
\end{tabular}


Table E-12. Water Balance Calculations Over the Thirty-Day Time Period Prior to Harvest for Early Season Lettuce and Present-Day Climate Conditions (Continued)

\begin{tabular}{|l|l|l|l|l|l|}
\hline Day & \multicolumn{1}{|c|}{$\boldsymbol{T A W}^{\mathrm{a}}$} & \multicolumn{1}{|c|}{$\boldsymbol{E}_{\boldsymbol{c}}{ }^{\boldsymbol{}}$} & \multicolumn{1}{c|}{$\boldsymbol{P}_{\boldsymbol{d}}{ }^{\mathbf{}}$} & \multicolumn{1}{|c|}{ Irrigation } & \multicolumn{1}{c|}{ Balance } \\
\hline 10 & 36 & 5.75 & 0 & & $30.25-5.75=24.5$ \\
\hline 11 & 36 & 5.75 & 0 & $36-24.5=11.5$ & $24.5+11.5-5.75=30.25$ \\
\hline 12 & 36 & 5.75 & 0 & & $30.25-5.75=24.5$ \\
\hline 13 & 36 & 5.75 & 0 & $36-24.5=11.5$ & $24.5+11.5-5.75=30.25$ \\
\hline 14 & 36 & 5.75 & 0 & & $30.25-5.75=24.5$ \\
\hline 15 & 36 & 5.75 & 0 & $36-24.5=11.5$ & $24.5+11.5-5.75=30.2$ \\
\hline 16 & 36 & 5.75 & 0 & & $30.25-5.75=24.5$ \\
\hline 17 & 36 & 5.75 & 0 & $36-24.5=11.5$ & $24.5+11.5-5.75=30.2$ \\
\hline 18 & 36 & 5.75 & 0 & & $30.25-5.75=24.5$ \\
\hline 19 & 36 & 5.75 & 0 & $36-24.5=11.5$ & $24.5+11.5-5.75=30.2$ \\
\hline 20 & 36 & 5.75 & 0 & & $30.25-5.75=24.5$ \\
\hline 21 & 36 & 5.75 & 0 & $36-24.5=11.5$ & $24.5+11.5-5.75=30.2$ \\
\hline 22 & 36 & 5.75 & 0 & & $30.25-5.75=24.5$ \\
\hline 23 & 36 & 5.75 & 0 & $36-24.5=11.5$ & $24.5+11.5-5.75=30.2$ \\
\hline 24 & 36 & 5.75 & 0 & & $30.25-5.75=24.5$ \\
\hline 25 & 36 & 5.75 & 0 & $36-24.5=11.5$ & $24.5+11.5-5.75=30.2$ \\
\hline 26 & 36 & 7.21 & 0 & $36-30.2=5.8$ & $30.2+5.8-7.21=28.8$ \\
\hline 27 & 36 & 7.21 & 0 & $36-28.8=7.2$ & $28.8+7.2-7.21=28.8$ \\
\hline 28 & 36 & 7.21 & 0 & $36-28.8=7.2$ & $28.8+7.2-7.21=28.8$ \\
\hline 29 & 36 & 7.21 & 0 & $36-28.8=7.2$ & $28.8+7.2-7.21=28.8$ \\
\hline 30 & 36 & 7.21 & 0 & $36-28.8=7.2$ & $28.8+7.2-7.21=28.8$ \\
\hline
\end{tabular}

a TAW (total available water) at maximum root depth for early season lettuce under present-day climate conditions (Table E-11).

${ }^{b}$ Mean daily $E T_{c}$ (crop evapotranspiration) for the last 30 days of the growing season for early season lettuce under present-day climate conditions (Table D-10).

c Mean daily effective precipitation (Table E-2).

Mean irrigation application amounts for each crop for present-day and upper bound glacial transition climate conditions are in Tables E-13 and E-14, respectively.

\section{E2.6 CROP MOISTURE STRESS}

In order to quantify uncertainty in irrigation management practices that could affect the distributions of irrigation parameters, the soil moisture balance method described above in Section 2.5 was used to determine the percent reduction in irrigation water that would be required to cause crop water stress. It was concluded that under-watering would likely result in visible crop stress that would signal the farmer or gardener to make adjustments in order to avoid loss in yield (Sections 6.5, 6.7, 6.8, and 6.9).

\section{E2.6.1 Under-Watering}

To avoid crop water stress, irrigation water should be applied when $R A W$ is depleted (Allen et al. 1998 [DIRS 157311], p. 171). Because most crop species are fairly sensitive to stress caused from lack of water, it was concluded that withholding water for 2 days after depletion of $R A W$ at each irrigation event would cause visible signs of stress. The water balance calculations for the 
last 30 days prior to harvest were altered by withholding irrigation for 2 days after depletion of $R A W$ at each irrigation event. After 2 days, enough irrigation water was added to bring soil moisture to TAW. The resulting percent decrease in irrigation water and the number of days the crop experienced water stress were calculated. The percent decrease per crop was determined for present-day and upper bound glacial transition climate conditions. The results of this analysis indicated that small percent decreases in irrigation resulted in several (nonconsecutive) days of water stress (Tables E-16 and E-17). Based on this analysis, a 10 percent reduction was used to assess the lower ends of the distributions for the irrigation parameters to determine whether adjustments were necessary (Sections 6.5, 6.7, 6.8, and 6.9).

Example: Using early lettuce and present-day climate conditions the following parameters were determined from the appropriate Tables:

The last Julian day of the growing season $=125=$ May 5 (Table D-1). Therefore, for the last 30 days of the growing season, 25 days were in April and 5 days were in May.

Effective precipitation for April and May $=0$ (Table E-2). Therefore, mean daily effective precipitation for the last 30 days of the growing season was equal to 0 .

Mean daily $E T_{c}$ for April $=5.75 \mathrm{~mm} /$ day $($ Table D-10).

Mean daily $E T_{c}$ for May $=7.21 \mathrm{~mm} /$ day (Table D-10).

Irrigation requirement for 25 days in April $=143.75 \mathrm{~mm}(5.75 \times 25)$.

Irrigation requirement for 5 days in May $=36.10 \mathrm{~mm}(7.21 \times 5)$.

TAW at maximum root depth $=36$ (Table E-11).

$R A W=10.8$ (Table E-11).

The water balance calculations with water withheld to cause water stress for the 30 days prior to harvest for early lettuce are illustrated in Table E-15 using the above values. Irrigation water was added two days after depletion of RAW (i.e., when soil water balance was at or just below $36 \mathrm{~mm}-10.8 \mathrm{~mm}=25.2 \mathrm{~mm}$ at the end of the day). Enough water was added so that soil moisture was equal to but did not exceed TAW. Irrigation events occurred on days 1, 5, 9, 13, 17, 21, 25, and 29. The total amount of irrigation for the 30-day period decreased from $183 \mathrm{~mm}$ to $176 \mathrm{~mm}$ (a 3.9 percent decrease) and the crop experienced some degree of water-stress for 15 days.

Table E-13. Irrigation Application for Crops under Present-Day Climate Conditions

\begin{tabular}{|l|c|c|c|}
\hline \multicolumn{1}{|c|}{ Crop } & $\begin{array}{c}\text { Irrigation } \\
\text { Application } \\
(\mathbf{m m})\end{array}$ & $\begin{array}{c}\text { Number of } \\
\text { Applications }^{\mathbf{b}}\end{array}$ & $\begin{array}{c}\text { 30-day Total } \\
(\mathbf{m m})\end{array}$ \\
\hline Leaf Lettuce early & 10.19 & 18 & 183.36 \\
\hline Leaf Lettuce late & 9.87 & 15 & 148.10 \\
\hline Head Lettuce early & 12.00 & 15 & 179.95 \\
\hline Head Lettuce late & 9.87 & 15 & 148.10 \\
\hline Cabbage early & 24.56 & 9 & 221.03 \\
\hline Cabbage late & 22.47 & 5 & 112.36 \\
\hline Celery early & 9.98 & 30 & 299.53 \\
\hline Celery late & 6.84 & 7 & 47.89 \\
\hline
\end{tabular}


Table E-13. Irrigation Application for Crops under Present-Day Climate Conditions (Continued)

\begin{tabular}{|c|c|c|c|}
\hline Crop & $\begin{array}{c}\text { Irrigation } \\
\text { Application } \\
(\mathrm{mm})\end{array}$ & $\begin{array}{c}\text { Number of } \\
\text { Applications }^{b}\end{array}$ & $\begin{array}{c}\text { 30-day Total } \\
(\mathrm{mm})\end{array}$ \\
\hline Broccoli early & 23.35 & 9 & 210.11 \\
\hline Broccoli late & 20.61 & 7 & 123.64 \\
\hline Cauliflower early & 21.12 & 10 & 211.20 \\
\hline Cauliflower late & 20.55 & 6 & 123.30 \\
\hline Spinach early & 5.97 & 30 & 179.23 \\
\hline Spinach late & 8.94 & 15 & 134.04 \\
\hline Potatoes & 18.89 & 15 & 283.29 \\
\hline Onions early & 8.84 & 30 & 265.08 \\
\hline Onions late & 9.26 & 6 & 55.55 \\
\hline Carrots early & 22.90 & 10 & 229.05 \\
\hline Carrots late & 19.49 & 7 & 136.42 \\
\hline Sweet corn & 44.68 & 7 & 312.79 \\
\hline Bell Peppers & 19.77 & 15 & 296.56 \\
\hline Cucumbers & 34.76 & 8 & 278.07 \\
\hline Squash & 33.30 & 7 & 233.1 \\
\hline Melons & 35.43 & 8 & 283.48 \\
\hline Tomatoes & 30.26 & 10 & 302.57 \\
\hline Apples & 49.39 & 3 & 148.18 \\
\hline Grapes & 48.38 & 3 & 145.15 \\
\hline Strawberries & 6.04 & 30 & 181.22 \\
\hline Winter Wheat & 77.93 & 2 & 155.86 \\
\hline Barley & 48.62 & 3 & 145.87 \\
\hline Alfalfa hay $1^{\text {st }}$ cutting & 46.53 & 2 & 93.06 \\
\hline Alfalfa hay $2^{\text {nd }}$ cutting & 65.84 & 3 & 197.52 \\
\hline Alfalfa hay $3^{\text {rd }}$ cutting & 66.36 & 4 & 265.43 \\
\hline Alfalfa hay $4^{\text {th }}$ cutting & 60.56 & 5 & 302.78 \\
\hline Alfalfa hay $5^{\text {th }}$ cutting & 55.56 & 4 & 222.23 \\
\hline Alfalfa hay $6^{\text {th }}$ cutting & 50.88 & 2 & 101.75 \\
\hline Oat Feed & 49.96 & 3 & 149.88 \\
\hline Feed Corn & 50.39 & 3 & 151.18 \\
\hline Corn silage & 60.01 & 5 & 300.03 \\
\hline Oat hay & 56.32 & 4 & 225.29 \\
\hline
\end{tabular}

a Average amount of water applied per irrigation event for 30 days prior to harvest.

b Number of irrigation events for 30 days prior to harvest.

c Total irrigation requirement for 30 days prior to harvest. 
Table E-14. Irrigation Application for Crops under Upper Bound Glacial Transition Climate Conditions

\begin{tabular}{|c|c|c|c|}
\hline Crop & $\begin{array}{l}\text { Irrigation Application }^{\mathrm{a}} \\
(\mathrm{mm})\end{array}$ & $\begin{array}{c}\text { Number of } \\
\text { Applications }\end{array}$ & $\begin{array}{l}\text { 30-day Total } \\
(\mathrm{mm})\end{array}$ \\
\hline Leaf Lettuce early & 10.1 & 12 & 121.2 \\
\hline Leaf Lettuce late & 10.0 & 15 & 150.3 \\
\hline Head Lettuce early & 9.5 & 16 & 152.7 \\
\hline Head Lettuce late & 8.4 & 15 & 126.2 \\
\hline Cabbage early & 25.7 & 6 & 154.5 \\
\hline Cabbage late & 26.5 & 5 & 132.4 \\
\hline Celery & 8.0 & 25 & 200.9 \\
\hline Broccoli early & 18.9 & 9 & 169.7 \\
\hline Broccoli late & 19.7 & 6 & 118.1 \\
\hline Cauliflower early & 22.2 & 6 & 133.1 \\
\hline Cauliflower late & 21.7 & 6 & 130.1 \\
\hline Spinach early & 7.3 & 16 & 116.2 \\
\hline Spinach late & 8.2 & 15 & 123.0 \\
\hline Potatoes & 14.4 & 14 & 201.9 \\
\hline Onions & 11.3 & 15 & 169.3 \\
\hline Carrots early & 18.2 & 9 & 164.2 \\
\hline Carrots late & 22.0 & 6 & 131.7 \\
\hline Sweet corn & 40.3 & 5 & 201.6 \\
\hline Bell Peppers & 17.7 & 9 & 159.2 \\
\hline Cucumbers & 37.2 & 5 & 186.0 \\
\hline Squash & 34.1 & 5 & 170.6 \\
\hline Melons & 34.6 & 5 & 173.1 \\
\hline Tomatoes & 31.4 & 6 & 188.6 \\
\hline Apples & 54.4 & 2 & 108.9 \\
\hline Grapes & 43.2 & 2 & 86.4 \\
\hline Strawberries & 7.3 & 16 & 116.7 \\
\hline Winter Wheat & 59.9 & 2 & 119.8 \\
\hline Barley & 66.7 & 2 & 133.3 \\
\hline Alfalfa $1^{\text {st }}$ cutting & 55.0 & 2 & 110.0 \\
\hline Alfalfa $2^{\text {nd }}$ cutting & 51.1 & 4 & 204.4 \\
\hline Alfalfa $3^{\text {rd }}$ cutting & 51.3 & 3 & 153.9 \\
\hline Oat Feed & 48.3 & 3 & 144.9 \\
\hline Feed Corn & 32.2 & 1 & 32.2 \\
\hline Corn silage & 61.9 & 2 & 123.7 \\
\hline Oat hay & 46.2 & 3 & 138.7 \\
\hline
\end{tabular}

${ }^{a}$ Average amount of water applied per irrigation event for 30 days prior to harvest.

b Number of irrigation events for 30 days prior to harvest.

${ }^{c}$ Total irrigation requirement for 30 days prior to harvest. 
Table E-15. Water Balance Calculations Over the Thirty-Day Time Period Prior to Harvest with Water Withheld to Cause Crop Water-Stress

\begin{tabular}{|c|c|c|c|c|c|}
\hline Day & TAW & $E T C$ & $\mathrm{Pe}$ & Irrigation & current balance \\
\hline 1 & 36 & 5.75 & 0 & $36-25.2=10.8$ & $25.2+10.8-5.75=30.2$ \\
\hline 2 & 36 & 5.75 & 0 & & $30.2-5.75=24.5$ \\
\hline 3 & 36 & 5.75 & 0 & & $24.5-5.75=18.6$ \\
\hline 4 & 36 & 5.75 & 0 & & $18.6-5.75=12.9$ \\
\hline 5 & 36 & 5.75 & 0 & $36-12.9=23.1$ & $12.9+23.1-5.75=30.2$ \\
\hline 6 & 36 & 5.75 & 0 & & $30.2-5.75=24.4$ \\
\hline 7 & 36 & 5.75 & 0 & & $24.4-5.75=18.6$ \\
\hline 8 & 36 & 5.75 & 0 & & $18.6-5.75=12.9$ \\
\hline 9 & 36 & 5.75 & 0 & $36-12.9=23.1$ & $12.9+23.1-5.75=30.2$ \\
\hline 10 & 36 & 5.75 & 0 & & $30.2-5.75=24.4$ \\
\hline 11 & 36 & 5.75 & 0 & & $24.4-5.75=18.6$ \\
\hline 12 & 36 & 5.75 & 0 & & $18.6-5.75=12.9$ \\
\hline 13 & 36 & 5.75 & 0 & $36-12.9=23.1$ & $12.9+23.1-5.75=30.2$ \\
\hline 14 & 36 & 5.75 & 0 & & $30.2-5.75=24.4$ \\
\hline 15 & 36 & 5.75 & 0 & & $24.4-5.75=18.6$ \\
\hline 16 & 36 & 5.75 & 0 & & $18.6-5.75=12.9$ \\
\hline 17 & 36 & 5.75 & 0 & $36-12.9=23.1$ & $12.9+23.1-5.75=30.2$ \\
\hline 18 & 36 & 5.75 & 0 & & $30.2-5.75=24.4$ \\
\hline 19 & 36 & 5.75 & 0 & & $24.4-5.75=18.6$ \\
\hline 20 & 36 & 5.75 & 0 & & $18.6-5.75=12.9$ \\
\hline 21 & 36 & 5.75 & 0 & $36-12.9=23.1$ & $12.9+23.1-5.75=30.2$ \\
\hline 22 & 36 & 5.75 & 0 & & $30.2-5.75=24.4$ \\
\hline 23 & 36 & 5.75 & 0 & & $24.4-5.75=18.6$ \\
\hline 24 & 36 & 5.75 & 0 & & $18.6-5.75=12.9$ \\
\hline 25 & 36 & 5.75 & 0 & $36-12.9=23.1$ & $12.9+23.1-5.75=30.2$ \\
\hline 26 & 36 & 7.21 & 0 & & $30.2-7.21=23.0$ \\
\hline 27 & 36 & 7.21 & 0 & & $23 \cdot 0-7 \cdot 21=15.8$ \\
\hline 28 & 36 & 7.21 & 0 & & $15.8-7.21=8.6$ \\
\hline 29 & 36 & 7.21 & 0 & $36-8.6=27.4$ & $8.6+27.4-7.21=28.8$ \\
\hline 30 & 36 & 7.21 & 0 & & $28.8-7.21=21.6$ \\
\hline
\end{tabular}

Mean percent decreases in irrigation application amounts for each crop under present-day and upper bound glacial transition climates are in Tables E-16 and E-17, respectively.

Table E-16. Reduction in Irrigation Requirement with Crop Stress for Present-Day Climate Conditions

\begin{tabular}{|l|r|r|r|r|}
\hline \multicolumn{1}{|c|}{ Crop } & $\begin{array}{c}\text { 30-day Irrigation } \\
\text { Requirement }^{\mathbf{a}} \mathbf{( \mathbf { m m } )}\end{array}$ & $\begin{array}{c}\text { 30-day Reduced }_{\text {Irrigation }^{\mathbf{b}} \mathbf{( \mathbf { m m } )}} \\
\text { Alfalfa 1st cutting }^{\text {\% Reduction }}{ }^{\mathbf{c}}\end{array}$ & $\begin{array}{c}\text { Number of } \\
\text { days stressed }\end{array}$ \\
\hline Alfalfa 2nd cutting & 93.1 & 86.0 & 7.6 & 4 \\
\hline Alfalfa 3rd cutting & 197.5 & 186.5 & 5.6 & 6 \\
\hline Alfalfa 4th cutting & 265.4 & 256.0 & 3.6 & 7 \\
\hline
\end{tabular}


Table E-16. Reduction in Irrigation Requirement with Crop Stress for Present-Day Climate Conditions (Continued)

\begin{tabular}{|c|c|c|c|c|}
\hline Crop & $\begin{array}{c}\text { 30-day Irrigation } \\
\text { Requirement }^{\mathrm{a}}(\mathrm{mm})\end{array}$ & $\begin{array}{l}\text { 30-day Reduced } \\
\text { Irrigation }^{b}(\mathrm{~mm})\end{array}$ & \% Reduction ${ }^{c}$ & $\begin{array}{c}\text { Number of } \\
\text { days stressed }\end{array}$ \\
\hline Alfalfa 5th cutting & 222.2 & 210.9 & 5.1 & 6 \\
\hline Alfalfa 6th cutting & 101.8 & 97.0 & 4.7 & 4 \\
\hline Bell Peppers & 296.6 & 289.8 & 2.3 & 15 \\
\hline Bermuda & 226.9 & 212.9 & 6.2 & 12 \\
\hline Broccoli early & 210.1 & 200.6 & 4.5 & 12 \\
\hline Broccoli late & 123.6 & 118.5 & 4.1 & 10 \\
\hline Cabbage early & 221.0 & 211.2 & 4.5 & 12 \\
\hline Cabbage late & 112.4 & 108.9 & 3.1 & 8 \\
\hline Carrots early & 229.1 & 211.6 & 7.6 & 12 \\
\hline Carrots late & 136.4 & 130.5 & 4.4 & 10 \\
\hline Cauliflower early & 211.2 & 201.9 & 4.4 & 14 \\
\hline Cauliflower late & 123.3 & 118.7 & 3.7 & 10 \\
\hline Celery early & 299.5 & 277.6 & 7.3 & 20 \\
\hline Celery late & 47.9 & 45.1 & 5.8 & 10 \\
\hline Feed Corn & 151.2 & 146.9 & 2.8 & 6 \\
\hline Corn-silage & 300.0 & 288.7 & 3.8 & 8 \\
\hline Cucumbers & 278.1 & 264.2 & 5.0 & 10 \\
\hline Head Lettuce early & 180.0 & 168.9 & 6.1 & 16 \\
\hline Head Lettuce late & 148.1 & 144.4 & 2.5 & 15 \\
\hline Leaf Lettuce early & 183.4 & 176.2 & 3.9 & 15 \\
\hline Leaf Lettuce late & 148.1 & 144.4 & 2.5 & 15 \\
\hline Melons & 283.5 & 266.3 & 6.1 & 10 \\
\hline Oat Feed & 149.9 & 141.8 & 5.4 & 4 \\
\hline Oat hay & 225.3 & 219.7 & 2.9 & 6 \\
\hline Onions early & 265.1 & 251.1 & 5.3 & 20 \\
\hline Onions late & 55.6 & 53.4 & 3.8 & 8 \\
\hline Potatoes & 283.3 & 266.6 & 5.9 & 18 \\
\hline Spinach early & 179.2 & 164.6 & 8.2 & 20 \\
\hline Spinach late & 134.0 & 132.1 & 1.4 & 15 \\
\hline Tomatoes & 302.6 & 285.1 & 5.8 & 12 \\
\hline Squash & 233.1 & 223.4 & 4.1 & 10 \\
\hline Apples & 148.2 & 139.1 & 6.1 & 5 \\
\hline Grapes & 145.2 & 136.9 & 5.7 & 6 \\
\hline Strawberries & 181.2 & 169.7 & 6.4 & 20 \\
\hline Barley & 145.9 & 139.0 & 4.7 & 4 \\
\hline Winter Wheat & 155.9 & 148.8 & 4.5 & 4 \\
\hline
\end{tabular}

${ }^{a}$ Irrigation requirement with no moisture stress calculated according to Appendix E, Section 2.6.1.

${ }^{b}$ Irrigation reduced by withholding irrigation for two days after RAW is depleted (calculated according to Appendix E, Section 2.6.1).

c Percent reduction from column 2 to column 3 . 
Table E-17. Reduction in Irrigation Requirement with Crop Stress for Upper Bound Glacial Transition Climate Conditions

\begin{tabular}{|c|c|c|c|c|}
\hline Crop & $\begin{array}{c}\text { 30-day Irrigation } \\
\text { Requirement (mm) }\end{array}$ & $\begin{array}{l}\text { 30-day Reduced Irrigation } \\
\text { Requirement (mm) }^{\mathbf{b}}\end{array}$ & $\%$ Reduction $^{c}$ & $\begin{array}{c}\text { Number of days } \\
\text { stressed }\end{array}$ \\
\hline Alfalfa 1st cutting & 110.0 & 94.1 & 14.4 & 3 \\
\hline Alfalfa 2 nd cutting & 204.4 & 170.1 & 16.8 & 8 \\
\hline Alfalfa 3 rd cutting & 153.9 & 142.7 & 7.2 & 4 \\
\hline Apples & 108.9 & 104.2 & 4.3 & 2 \\
\hline Bell Peppers & 159.2 & 142.9 & 10.2 & 11 \\
\hline Fescue & 174.9 & 164.0 & 6.3 & 10 \\
\hline Broccoli early & 169.7 & 164.7 & 2.9 & 8 \\
\hline Broccoli late & 118.1 & 116.3 & 1.5 & 6 \\
\hline Cabbage early & 154.3 & 141.9 & 8.0 & 7 \\
\hline Cabbage late & 132.4 & 125.8 & 5.2 & 8 \\
\hline Carrots early & 164.2 & 159.0 & 3.1 & 7 \\
\hline Carrots late & 131.7 & 128.0 & 2.8 & 6 \\
\hline Cauliflower early & 133.1 & 121.3 & 8.9 & 8 \\
\hline Cauliflower late & 130.1 & 127.2 & 2.2 & 10 \\
\hline Celery & 200.9 & 169.7 & 15.5 & 16 \\
\hline Feed Corn & 32.2 & 31.0 & 3.8 & 4 \\
\hline Corn silage & 123.7 & 119.3 & 3.6 & 1 \\
\hline Cucumbers & 186.0 & 166.0 & 10.8 & 9 \\
\hline Head Lettuce early & 152.7 & 125.1 & 18.0 & 14 \\
\hline Head Lettuce late & 126.2 & 117.5 & 6.9 & 12 \\
\hline Leaf Lettuce early & 121.2 & 118.0 & 2.6 & 10 \\
\hline Leaf Lettuce late & 150.4 & 139.5 & 7.2 & 14 \\
\hline Melons & 173.1 & 161.0 & 7.0 & 9 \\
\hline Oat Feed & 144.9 & 138.7 & 4.3 & 2 \\
\hline Oat hay & 138.7 & 133.2 & 4.0 & 41 \\
\hline Onions & 169.3 & 165.8 & 2.1 & 13 \\
\hline Potatoes & 201.9 & 188.2 & 6.7 & 12 \\
\hline Spinach early & 116.2 & 109.4 & 5.9 & 13 \\
\hline Spinach late & 123.0 & 119.5 & 2.9 & 14 \\
\hline Sweet Corn & 201.6 & 191.8 & 4.9 & 8 \\
\hline Tomatoes & 188.6 & 180.6 & 4.2 & 6 \\
\hline Squash & 170.6 & 147.7 & 13.4 & 8 \\
\hline Grapes & 86.2 & 82.8 & 4.2 & 1 \\
\hline Strawberries & 116.8 & 113.7 & 2.6 & 14 \\
\hline Barley & 133.3 & 128.2 & 3.9 & 1 \\
\hline Winter Wheat & 119.8 & 99.0 & 17.4 & 8 \\
\hline
\end{tabular}

${ }^{a}$ Irrigation requirement with no moisture stress calculated according to Appendix E, Section 2.6.1.

${ }^{\mathrm{b}}$ Irrigation reduced by withholding irrigation for two days after RAW is depleted (calculated according to Appendix E, Section 2.6.1).

${ }^{c}$ Percent reduction from column 2 to column 3. 